\title{
U.S. Efforts in Support of Examinations at Fukushima Daiichi - 2018 Evaluations
}

Nuclear Engineering Division 


\section{Ãbout Ãrgonne Nationai Laboratory}

Argonne is a U.S. Department of Energy laboratory managed by UChicago Argonne, LLC under contract DE-AC02-06CH11357. The Laboratory's main facility is outside Chicago, at 9700 South Cass Avenue, Argonne, Illinois 60439. For information about Argonne and its pioneering science and technology programs, see www.anl.gov.

\section{DOCUMENT AVAILABILITY}

Online Access: U.S. Department of Energy (DOE) reports produced after 1991 and a growing number of pre-1991 documents are available free via DOE's SciTech Connect (http://www.osti.gov/scitech/)

Reports not in digital format may be purchased by the public from the

National Technical Information Service (NTIS):

U.S. Department of Commerce

National Technical Information Service 5301 Shawnee Rd

Alexandria, VA 22312

www.ntis.gov

Phone: (800) 553-NTIS (6847) or (703) 605-6000

Fax: (703) 605-6900

Email: orders@ntis.gov

Reports not in digital format are available to DOE and DOE contractors from the

Office of Scientific and Technical Information (OSTI):

U.S. Department of Energy

Office of Scientific and Technical Information

P.O. Box 62

Oak Ridge, TN 37831-0062

www.osti.gov

Phone: (865) 576-8401

Fax: (865) 576-5728

Email: reports@osti.gov

Disclaimer

This report was prepared as an account of work sponsored by an agency of the United States Government. Neither the United States Government nor any agency thereof, nor UChicago Argonne, LLC, nor any of their employees or officers, makes any warranty, express or implied, or assumes any legal liability or responsibility for the accuracy, completeness, or usefulness of any information, apparatus, product, or process disclosed, or represents that its use would not infringe privately owned rights. Reference herein to any specific commercial product, process, or service by trade name, tradeprivately mark, manufacturer, or otherwise, does not necessarily constitute or imply its endorsement, recommendation, or favoring by the United States Government or any agency thereof. The views and opinions of document authors expressed herein do not necessarily state or reflect those of the United States Government or any agency thereof, Argonne National Laboratory, or UChicago Argonne, LLC. 


\section{U.S. Efforts in Support of Examinations at Fukushima Daiichi - 2018 Evaluations}

Prepared for:

U. S. Department of Energy - Office of Nuclear Energy

Report Contributors:

P. Amway, ${ }^{1,2}$ N. Andrews, ${ }^{3}$ S. Basu, ${ }^{4}$ R. Bunt, ${ }^{2,5}$ M. Corradini, ${ }^{6}$ P. Ellison, ${ }^{2,7}$

M. Farmer, ${ }^{8}$ J. Gabor, ${ }^{9}$ R. Gauntt, ${ }^{3}$ T. Hara, ${ }^{10}$ P. Humrickhouse, ${ }^{11}$

K. Klass, ${ }^{2,12}$ S. Kraft, ${ }^{13}$ R. Linthicum, ${ }^{14}$ W. Luangdilok, ${ }^{15}$ R. Lutz, ${ }^{16}$ D. Luxat, ${ }^{9}$

S. Mizokami, ${ }^{10}$ D. Osborn, ${ }^{3}$ C. Paik, ${ }^{15}$ M. Plys, ${ }^{15}$ J. Rempe, ${ }^{17}$ K. Robb, ${ }^{18}$

R. Wachowiak, ${ }^{19}$ T. Washiya, ${ }^{20}$ B. Williamson ${ }^{2,21}$

Contributor Organizations:

${ }^{1}$ Exelon Corporation, ${ }^{2}$ BWR Owners Group, ${ }^{3}$ Sandia National Laboratories,

${ }^{4}$ McGill Engineering Associates, ${ }^{5}$ Southern Nuclear, ${ }^{6}$ University of Wisconsin, ${ }^{7}$ GE-Hitachi, ${ }^{8}$ Argonne National Laboratory, ${ }^{9}$ Jensen Hughes, ${ }^{10}$ Tokyo Electric Power Company Holdings, ${ }^{11}$ Idaho National Laboratory, ${ }^{12}$ Talen Energy,

${ }^{13}$ Nuclear Energy Institute, ${ }^{14}$ PWR Owners Group, ${ }^{15}$ Fauske and Associates LLC, ${ }^{16}$ Lutz Nuclear Consulting, ${ }^{17}$ Rempe and Associates LLC, ${ }^{18}$ Oak Ridge National Laboratory, ${ }^{19}$ Electric Power Research Institute, ${ }^{20}$ Japan Atomic Energy Agency, ${ }^{21}$ Tennessee Valley Authority

Edited by: J.Rempe 



\section{ABSTRACT}

Much is still not known about the end-state of core materials in each unit that was operating on March 11, 2011 at the Fukushima Daiichi Nuclear Power Station [Daiichi]. Clearly, the accident signatures for each of these units differed. Some of this uncertainty about debris end-state can be attributed to a lack of information related to cooling system operation and cooling water injection during the events. There is also uncertainty in our understanding of phenomena affecting: a) in-vessel core damage progression during severe accidents in boiling water reactors (BWRs) [compared with Pressurized Water Reactors (PWRs)], and $b$ ) accident progression after vessel failure (ex-vessel progression) for BWRs and PWRs. These uncertainties arise due to limited full scale prototypic data. Similar to what occurred after the accident at Three Mile Island Unit 2, these Daiichi units offer the international community a means to reduce such uncertainties by obtaining prototypic data from multiple full-scale BWR severe accidents.

Information obtained from Daiichi is being used to inform Decontamination and Decommissioning activities, improving the ability of the Tokyo Electric Power Company Holdings, Incorporated (TEPCO Holdings) to characterize potential hazards and to ensure the safety of workers involved with cleanup activities. This document, which has been updated to include Fiscal Year 2018 (FY2018) information, summarizes results from U.S. efforts to use information obtained by TEPCO Holdings to enhance the safety of existing and future nuclear power plant designs. This effort, which was initiated in 2014 by the Department of Energy Office of Nuclear Energy (DOE-NE), consists of a group of U.S. experts in Light Water Reactor safety and plant operations that have identified examination needs and are evaluating TEPCO Holdings information from Daiichi that address these needs. Each year, annual reports include examples demonstrating that significant safety insights are being obtained in the areas of special emphasis. For FY2018, the areas emphasized by the expert panel include component performance, radionuclide surveys and sampling, debris end-state location, combustible gas effects, and plant operations and maintenance. In addition to reducing uncertainties related to severe accident modeling progression, these insights are being used to update guidance for severe accident prevention, mitigation, and emergency planning. Furthermore, reduced uncertainties in modeling the events at Daiichi will improve the realism of reactor safety evaluations and inform future D\&D activities by improving the capability for characterizing potential hazards to workers involved with cleanup activities.

The FY2018 differs from prior reports in that the main report primarily emphasizes results from new information obtained from the affected units at Daiichi. For example, the main report highlights recent examinations that imply vessel failure occurred at multiple locations and hold-up on ex-vessel structures. In addition, the main report highlights insights that can be gained by focused evaluations of plant data and possible credit that may be given for instrumentation performance during severe accident conditions. Detailed results from prior years have been moved to appendices. This report contains an appendix with a list of examination needs that is updated by U.S. experts after they review recently obtained information from examinations at Daiichi. Additional details for higher priority, near-term, examination activities are provided. This report also includes an appendix with a description of an updated website that has been reformatted to better assist U.S. experts by providing information in an archived retrievable location. 
ANL-18/24 


\section{ACKNOWLEDGEMENTS}

Successful preparation of this report required input and support from several individuals and organizations. Financial support for present and former national laboratory panel participants was provided by the U.S. Department of Energy Office of Nuclear Energy. In addition, there were substantial in-kind contributions made by various industry organizations that supported technical experts to participate in this multi-year effort; these organizations included AREVA, the Boiling Water Reactor Owners Group, the Electric Power Research Institute, Exelon Corporation, GE-Hitachi, the Institute of Nuclear Power Operations, Jensen Hughes, the Nuclear Energy Institute, the Pressurized Water Reactors Owners Group, Southern Nuclear, the Tennessee Valley Authority, and Westinghouse. Finally, the U.S. Nuclear Regulatory Commission and the Tokyo Electric Power Company Holdings, Incorporated provided technical experts to participate in the panel meetings. In particular, Mr. Takashi Hara, Dr. Shinya Mizokami, and Mr. Daichi Yamada from TEPCO Holdings attended, as well as Mr. Donald Marksberry, Dr. Sudamay Basu (since retired), Dr. Richard Lee from the U.S. NRC Office of Nuclear Regulatory Research, Mr. Richard Wachowiak from the Electric Power Research Institute, Mr. Steven Kraft from the Nuclear Energy Institute, and Mr. Damian Peko and Dr. John Kelly (now retired) from the U.S. Department of Energy. These individuals facilitated the overall process by providing key clarifications in various areas as the meetings progressed. These efforts are greatly appreciated. 
ANL-18/24 


\section{CONTENTS}

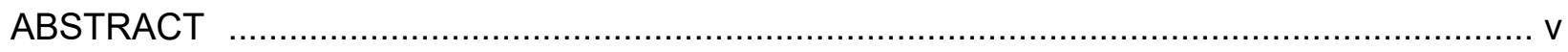

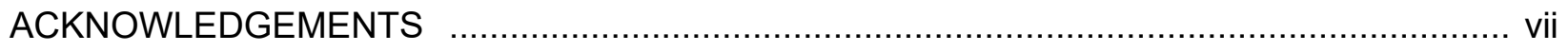

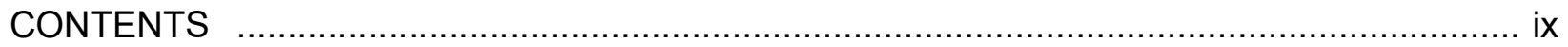

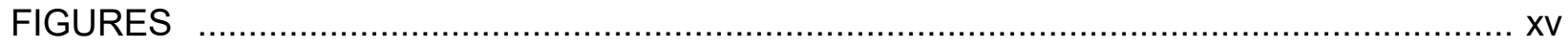

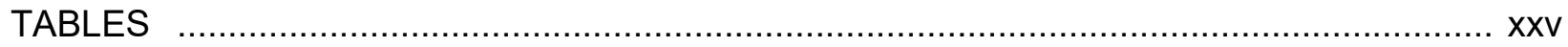

ACRONYMS AND ABBREVIATIONS ................................................................

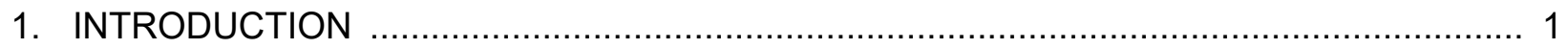

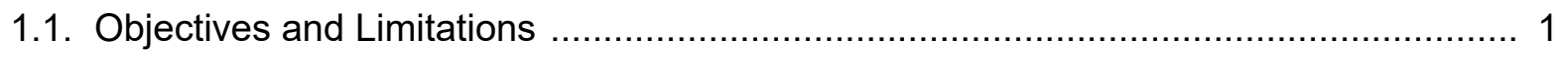

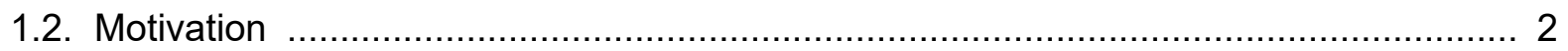

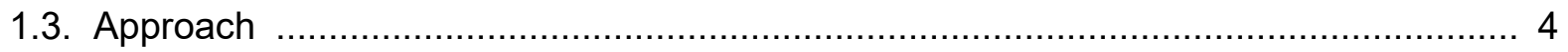

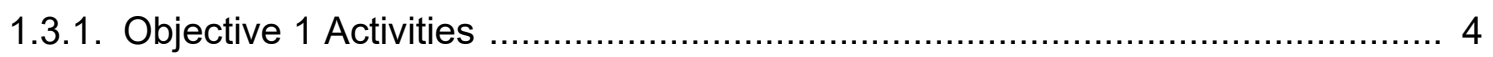

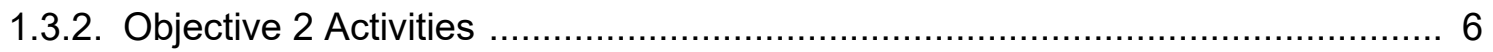

1.3.3. Other Considerations .................................................................... 7

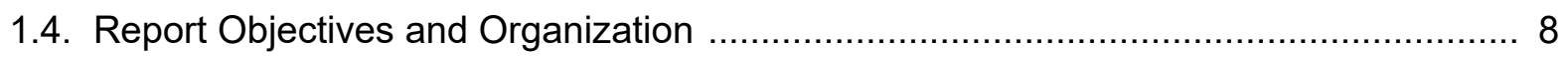

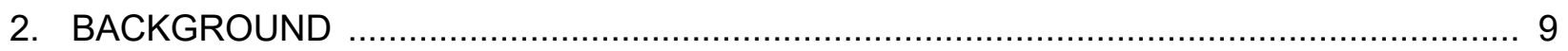

2.1. TMI-2 Post-Accident Evaluations …................................................................ 9

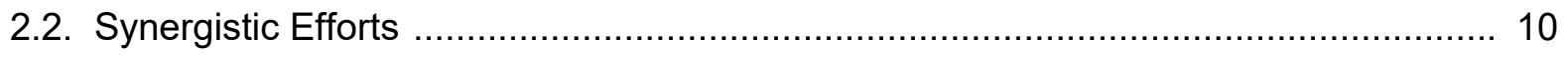

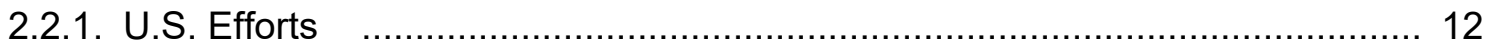

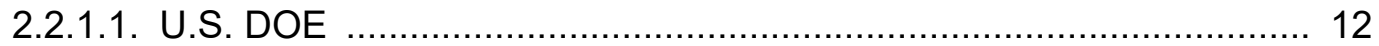

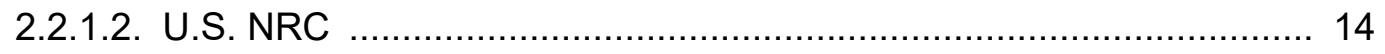

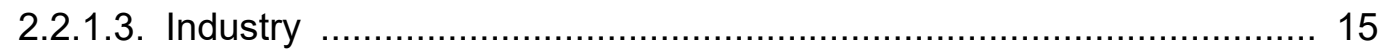

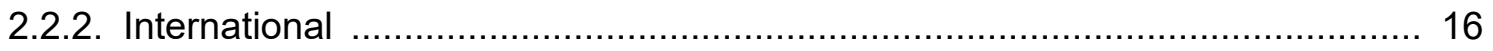

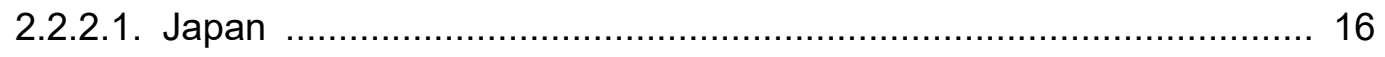

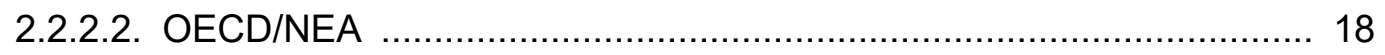

2.2.2.3. European Union (EU) ….................................................... 20

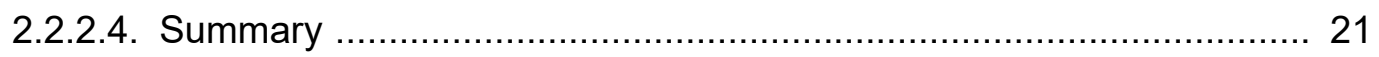

2.3. Decontamination \& Decommissioning Activities ........................................... 21

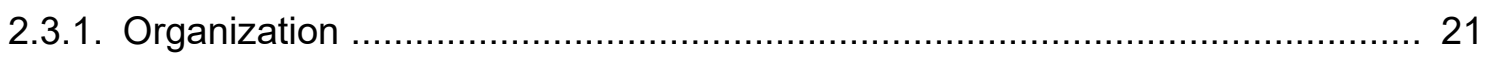

2.3.2. Strategic Plan ............................................................................... 22

2.3.3. Mid-and-Long-Term D\&D Roadmap Activities and Schedule ....................... 24

2.3.4. Phase 2 D\&D Activities ................................................................... 26

2.3.4.1. Fuel Debris Retrieval Methods ................................................ 26

2.3.4.2. Debris End-state Location and Radionuclide Distribution ................ 27

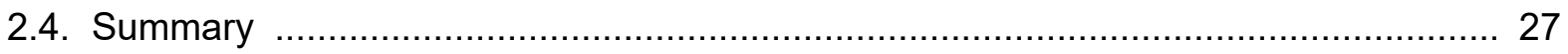




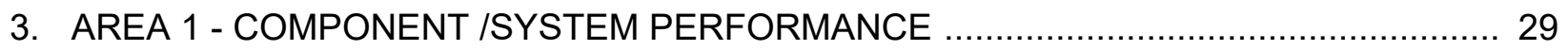

3.1. Key Questions for Reactor Safety and D\&D ................................................... 29

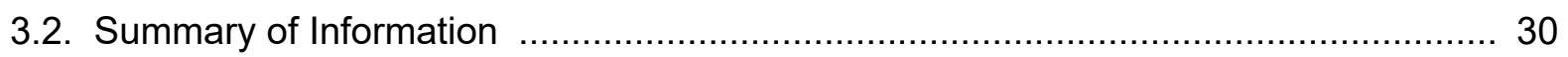

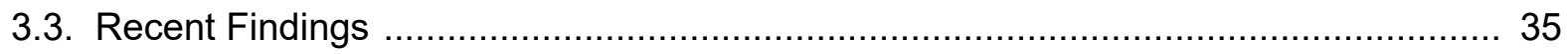

3.3.1. Containment Examinations ................................................................. 35

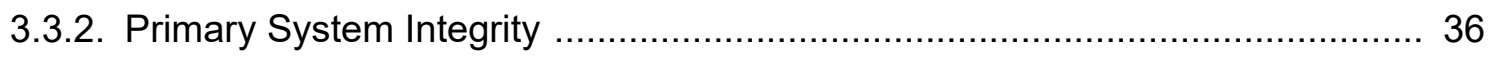

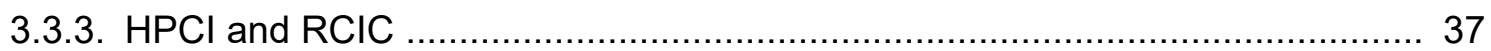

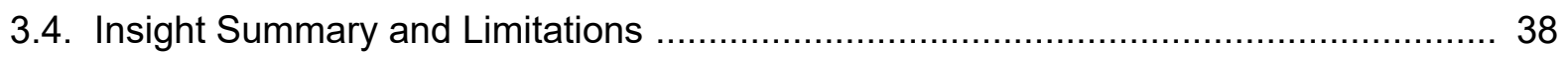

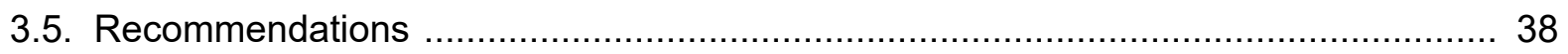

3.6. Suggestions for Additional Information .............................................................. 40

4. AREA 2 - DOSE SURVEYS AND ISOTOPIC SAMPLING ……................................. 43

4.1. Key Questions for Reactor Safety and D\&D ....................................................... 43

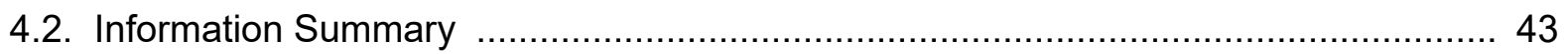

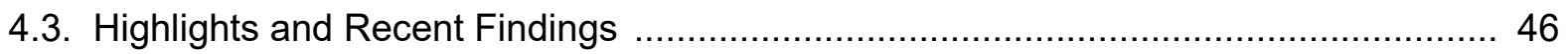

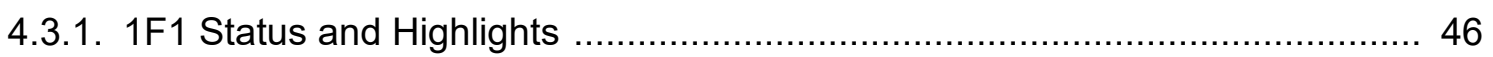

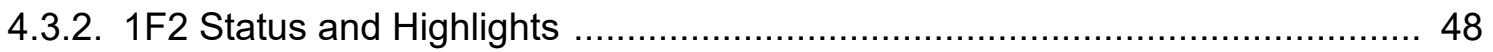

4.3.3. 1F3 Status and Highlights ................................................................ 50

4.3.4. Evaluation of Samples from Examinations within the PCV ......................... 51

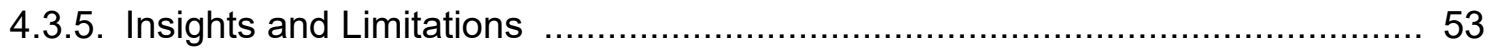

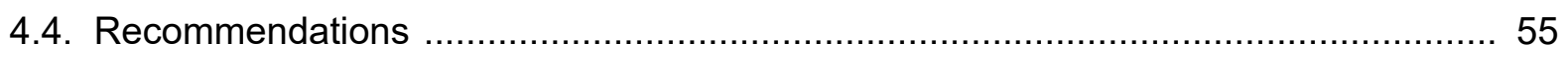

4.5. Suggestions for Additional Information ......................................................... 57

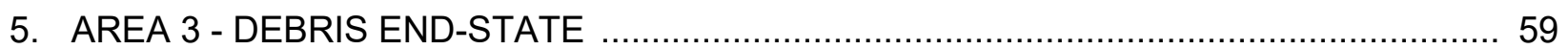

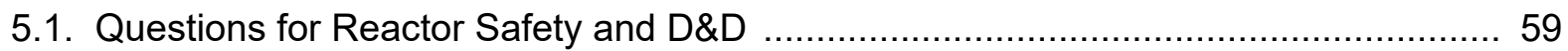

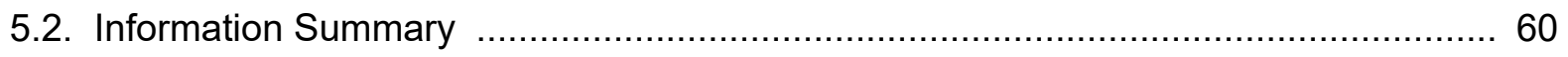

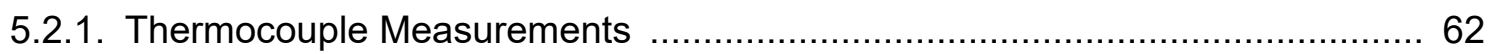

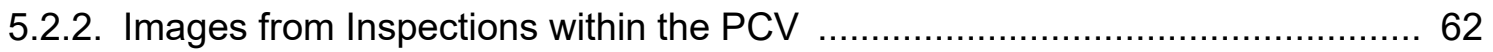

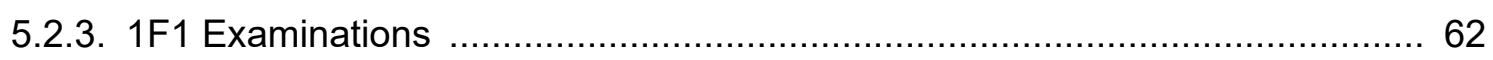

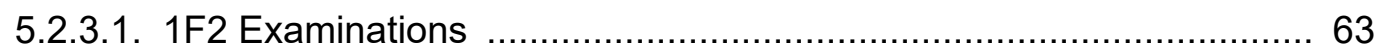

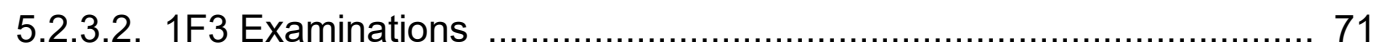

5.2.3.3. Modeling Implications from Examinations within the PCV ............... 73

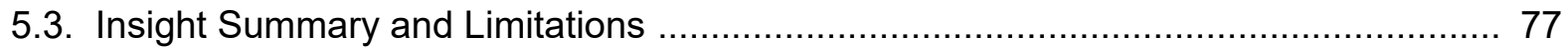

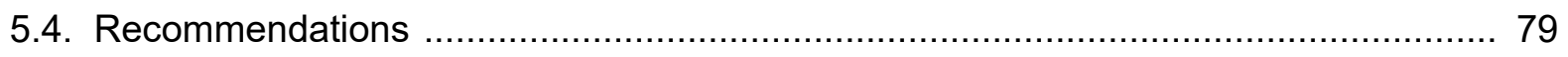

5.5. Suggestions for Additional Information .......................................................... 80

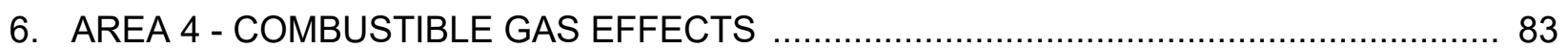

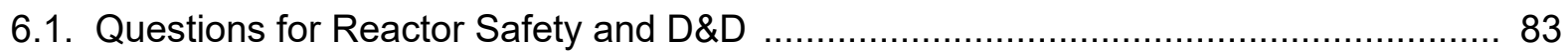

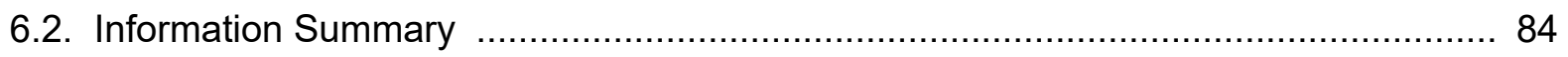

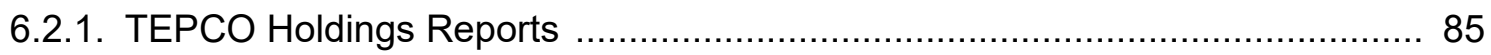

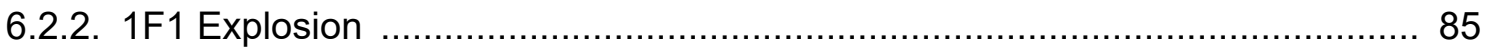




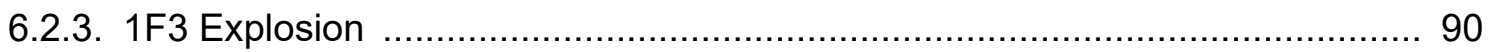

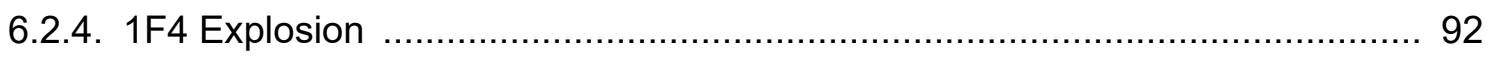

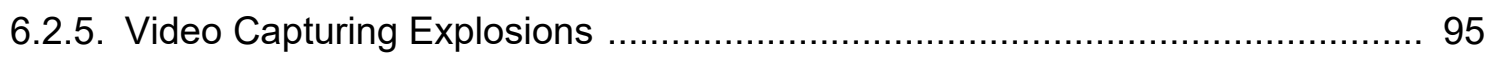

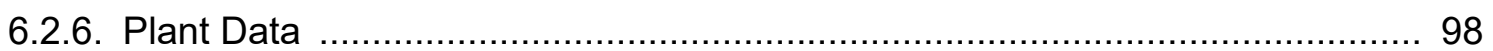

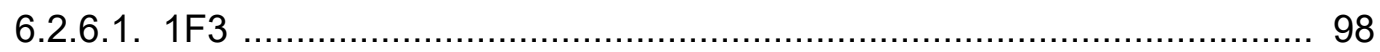

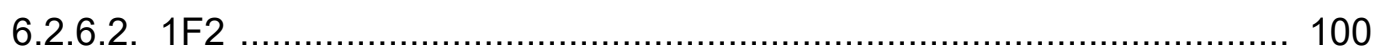

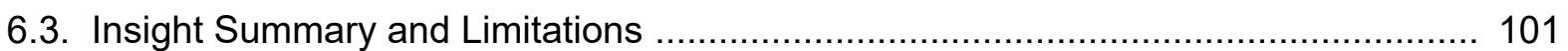

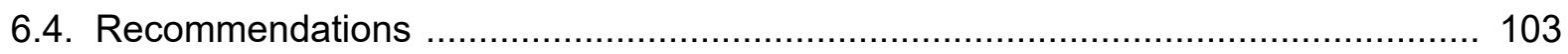

6.5. Suggestions for Additional Information .......................................................... 107

7. AREA 5 - OPERATIONS AND MAINTENANCE

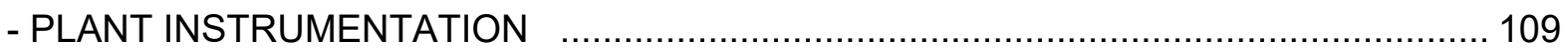

7.1. Questions for Reactor Safety, Plant Operations, and D\&D ................................ 109

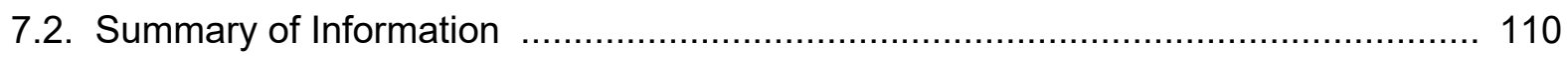

7.2.1. Instrumentation Characteristics and Location ....................................... 110

7.2.2. Evaluation Approach ................................................................. 112

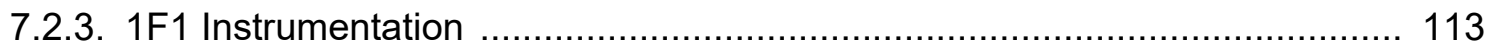

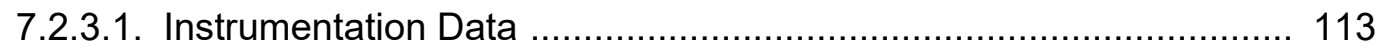

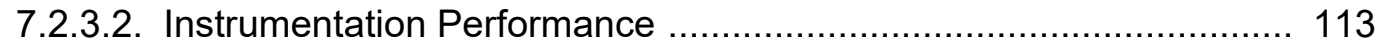

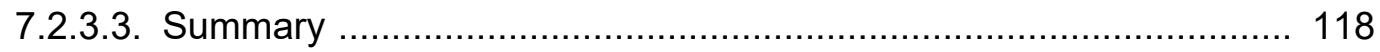

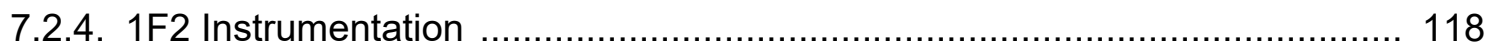

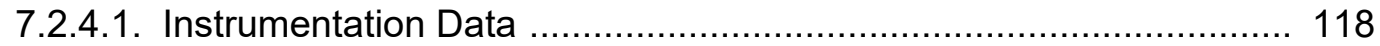

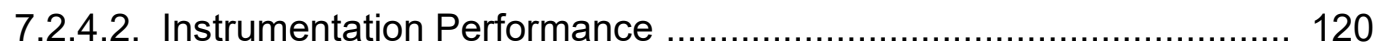

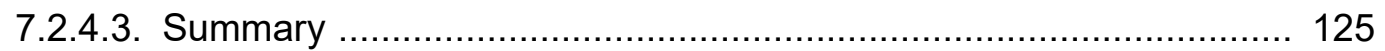

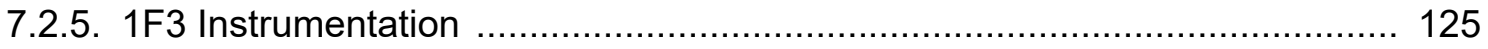

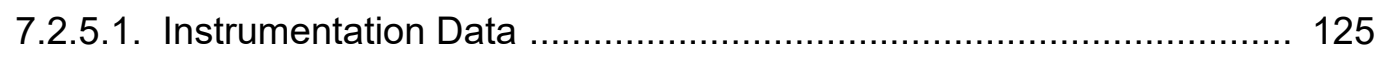

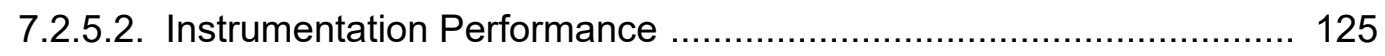

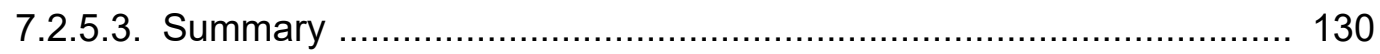

7.3. Environmental Conditions Predicted by Systems Analysis Codes ....................... 130

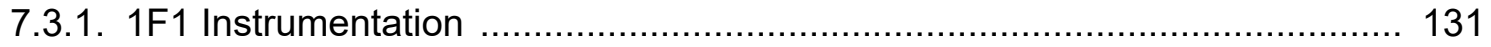

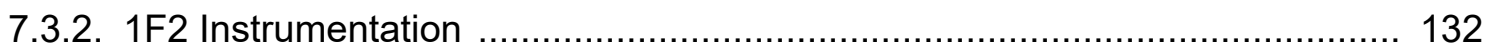

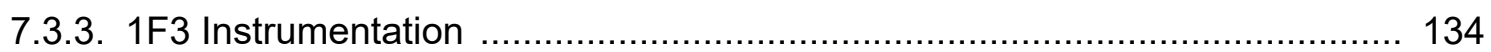

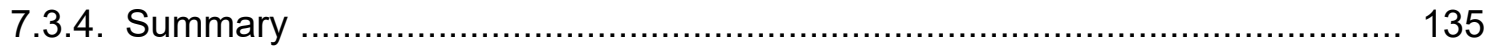

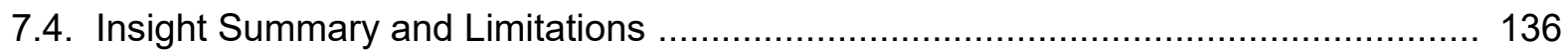

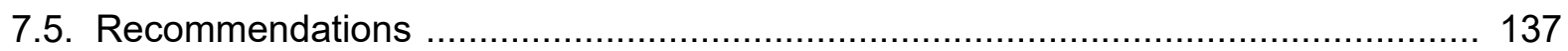

7.6. Suggestions for Additional Information ......................................................... 137

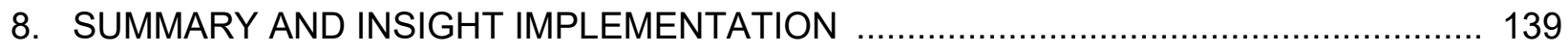

8.1. Evaluations and Recommendations ........................................................... 139

8.2. Implementation Activities for Forensics Insights ............................................. 143 
8.2.1. Industry Accident Management Guidance 143

8.2.2. Code Modeling Enhancements ........................................................... 147

8.2.2.1. Vessel Failure and Ex-vessel Debris Heat Transfer ...................... 148

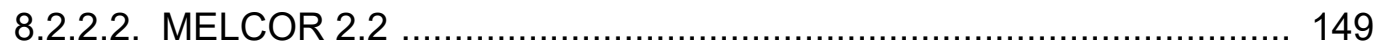

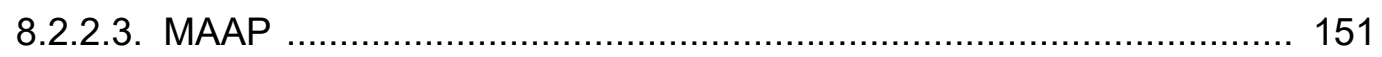

8.2.2.4. Possible Future Code Applications and Enhancements ................. 155

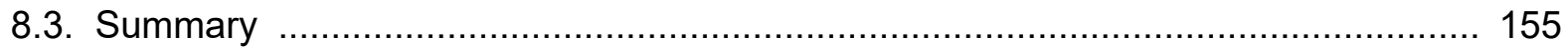

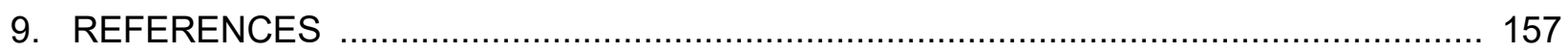

APPENDIX A. FY2018 Meeting Agenda and Attendee List .......................................... A-1

A.1. November 1-2, 2017 Meeting Agenda ………................................ A-1

A.2. November 1-2, 2017 Attendees ........................................................ A-3

APPENDIX B. Website to Support Forensics Evaluations ……….................................. B-1

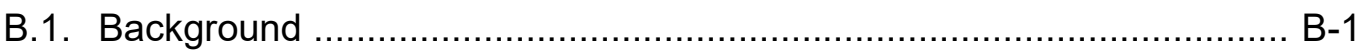

B.2. Website Design .......................................................................... B-1

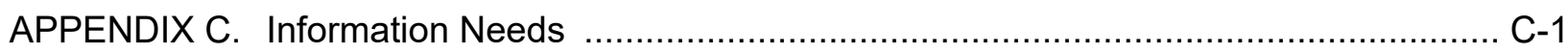

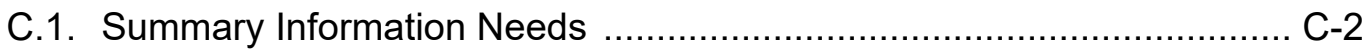

C.2. Detailed Information Needs ………………………………...... C-19

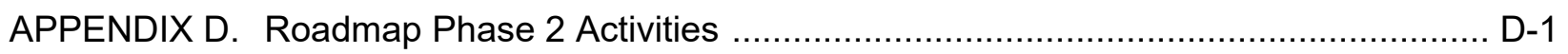

APPENDIXE. AREA 1 - COMPONENT/SYSTEM PERFORMANCE PREVIOUSLY

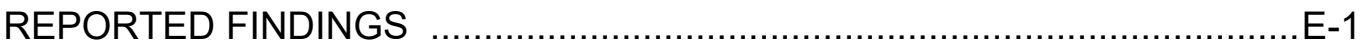

E.1. Examinations Outside of the Primary Containment ……………….... E-1

E.1.1. 1F1 Drywell Head Shield Plug Relocation ............................. E-1

E.1.1.1. High Rate of Gas Production Inside PCV ................ E-2

E.1.1.2. Vacuum Condition Created by Hydrogen Deflagration .... E-5

E.1.2. Reactor Building Closed Cooling Water System ..................... E-5

E.1.3. Spent Fuel Pools and Shared Spent Fuel Storage Building ...... E-7

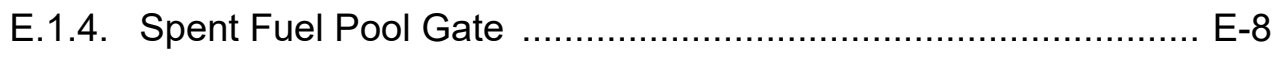

E.2. Containment Examinations .......................................................... E-9

E.2.1. Leakage Locations ............................................................ E-9

E.2.2. Code Modeling Enhancements .......................................... E-11

E.3. Primary System Integrity and Water Injection ................................. E-12

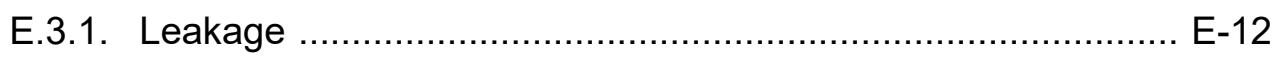

E.3.2. Fire Engine Injection .................................................... E-13

APPENDIX F. AREA 2 - DOSE SURVEYS AND ISOTOPIC SAMPLING

PREVIOUSLY REPORTED FINDINGS $\mathrm{F}-1$ 
F.1. Post-accident Evaluations of Reactor Building Contamination $\mathrm{F}-1$

F.1.1. 1F1 Reactor Building Contamination $\mathrm{F}-1$

F.1.2. 1F2 Reactor Building Contamination ................................ F-3

F.1.3. 1F3 Reactor Building Contamination ................................ F-6

F.2. Containment Radiation Data Obtained during Event Progression ......... F-8

F.2.1. Overview of Available Radiation Measurements ................... F-8

F.2.2. Insights and Limitations ............................................... F-10

F.3. Post-Accident Examinations within the Containment ....................... F-11

F.3.1. 1F1 Examinations .......................................................... F-11

F.3.2. 1F2 Examinations ...................................................... F-13

F.3.3. 1F3 Examinations ................................................. F-13

F.4. Other Radiological Measurements ........................................... F-13

F.4.1. Insights from Examinations of Concrete Samples ................. F-13

F.4.2. Insights from Examinations of Soil Samples ...................... F-14

F.4.3. Insights based on Initial Burnup ...................................... F-15

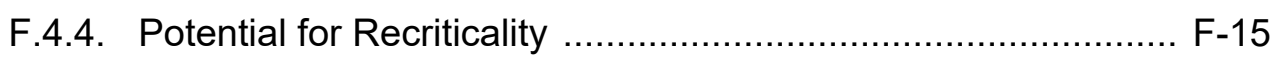

F.4.5. Limitations ................................................................. F-15

APPENDIX G. AREA 3 - DEBRIS END-STATE

PREVIOUSLY REPORTED FINDINGS ......................................... G-1

G.1. Thermocouple Measurements ............................................ G-1

G.2. Images from Inspections within the PCV ...................................... G-5

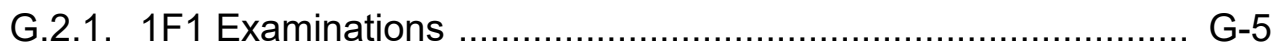

G.3. Images within the Reactor Building ....................................... G-8

G.4. Muon Tomography Examinations ....................................... G-9

G.4.1. 1F1 Examinations ............................................. G-9

G.4.2. 1F2 Examinations ...................................................... G-9

G.4.3. 1F3 Examinations ........................................... G-12

G.5. Gas Cleanup System Measurements ...................................... G-13

G.6. Deposits from Leaking Penetrations ............................................. G-15

G.7. Contamination of the RCW System ....................................... G-16

APPENDIX H. AREA 5 - EVALUATIONS OF REGARDING INSTRUMENTATION

PERFORMANCE AT 1F1, 1F2, AND1F3 ............................................

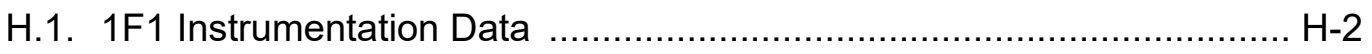

H.2. 1F2 Instrumentation Data ............................................... H-11

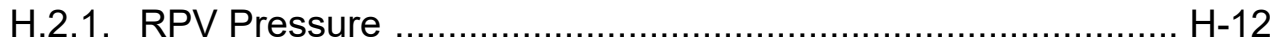

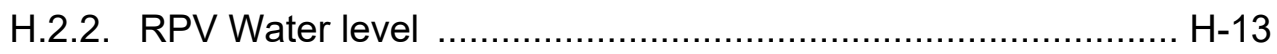

$\mathrm{H} .2 .3$. Drywell Pressure .................................................... $\mathrm{H}-14$

H.2.4. Suppression Pool Temperature ................................... H-15 
H.2.5. Indication of Hydrogen without Using Monitors $\mathrm{H}-18$

H.2.6. Indication of Vessel Breach .......................................... H-20

H.2.7. DW Radiation ........................................................ H-21

H.2.8. RPV Metal Temperatures ........................................... H-21

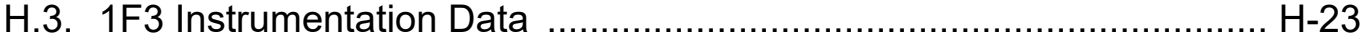

H.3.1. RPV Water Level ...................................................... H-23

H.3.2. RPV Pressure .......................................................... H-25

H.3.3. DW and SC Pressure ............................................... H-26

H.3.4. Indication of Vessel Breach .......................................... H-27

H.3.5. DW Radiation .......................................................... H-28

H.3.6. RPV Metal Temperatures ........................................ H-29 


\section{FIGURES}

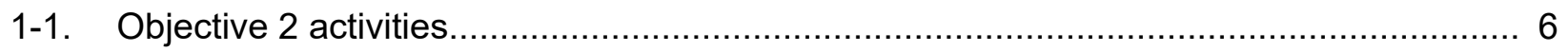

2-1. TMl-2 video examinations revealed locations where damage to core barrel and nozzles was more severe. (Courtesy of FirstEnergy) ........................................ 9

2-2. LWRS RST pathway tasks and relationship to forensic information from

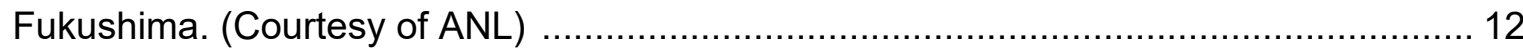

2-3. Roles and responsibilities of organizations involved in decommissioning Daiichi.

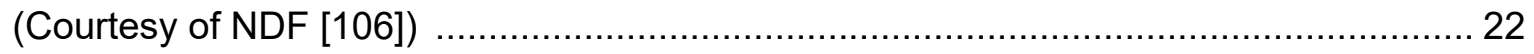

2-4. Risk associated with various D\&D sources at Daiichi. (Courtesy of NDF [106]) ............ 23

2-5. Roadmap phase definition; red pointer designates current status. (Courtesy of

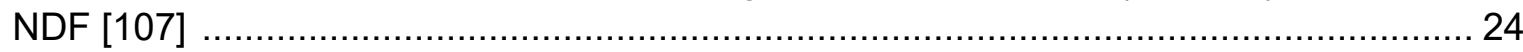

2-6. Summary schedule showing main decommissioning works, steps, and milestones. (Courtesy of Inter-Ministerial Council for Contaminated Water and Decommissioning Issues [108]) .................................................................. 25

2-7. Debris retrieval methods under evaluation. (Courtesy of NDF [106])......................... 26

2-8. Logic tree identifying activities to understand location, amount, and properties of fuel debris and distribution of FPs. (Courtesy of NDF [107])

2-9. Status of 1F1 through 1F3 including fuel debris location estimates. (Courtesy of NDF [106])

3-1. Photographs and radiation surveys (in $\mathrm{mSv} / \mathrm{hr}$ ) near $1 \mathrm{~F} 2 \mathrm{X}-6$ penetration (values measured in 13 locations). (Courtesy of TEPCO Holdings $[11,13]$ ) ................ 37

4-1. 1F1 status. (Courtesy of TEPCO Holdings [108]) .............................................. 46

4-2. Approach for 1F1 RB dose measurements. (Courtesy of TEPCO Holdings [147])

4-3. 1F1 dose measurements near the shield plug. (Courtesy of TEPCO Holdings [147])

4-4. 1F1 investigations using the PMORPH Scorpion robot; dose rate measurements taken in March 2017. (Courtesy of TEPCO $[148,149]$ )

4-5. 1F2 status. (Courtesy of TEPCO Holdings [108]) ............................................ 49

4-6. 1F2 reactor building with open blowout panel. (Courtesy of TEPCO Holdings [151])

4-7. Dose revisions calculated during subsequent analysis of 1F2 entry. (Courtesy

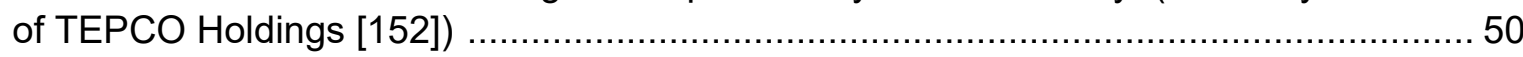

4-8. 1F3 status. (Courtesy of TEPCO Holdings [108]) ............................................ 51

4-9. Sampling location and gamma dose analysis results of the sediment within 1F1. (Courtesy of TEPCO Holdings $[154,154]$ )

4-10. SEM 1F2 TIP pipe sample (left); EDS of the same sample (right). (Courtesy of TEPCO Holdings [153])

4-11. 1F2 (top) and 1F3 (below) sampling methods used during the recent entries into the containments of both reactors. (Courtesy of TEPCO Holdings [153]) 
5-1. Evidence of damage to thermocouple cabling inside the PCV for 1F3.

(Courtesy of TEPCO Holdings [174])

5-2. Access path through the $\mathrm{X}-6$ penetration in 1F2 allowing initial examinations

along the CRD exchange rail. (Courtesy of TEPCO Holdings [176])

5-3. Photograph of CRD exchange rail surface near the CRD platform showing the presence of black material. (Courtesy of TEPCO Holdings [176])

5-4. Combined images from entry into 1F2 pedestal region, indicating findings.

(Courtesy of TEPCO Holdings [177])

5-5. Image of 1F5 pedestal region, included for reference. (Courtesy of TEPCO

Holdings [177])

5-6. Access path through the $\mathrm{X}-6$ penetration in $1 \mathrm{~F} 2$ for the second examination

along the CRD exchange rail and below into the pedestal. (Courtesy of

TEPCO Holdings [139])

5-7. Photographs of vertical structures inside 1F2 pedestal. (Courtesy of TEPCO

Holdings [143])

5-8. Photographs of horizontal surfaces inside the pedestal for 1F2. (Courtesy of TEPCO Holdings [143])

5-9. Fuel assembly design showing top tie-plate features. (Courtesy of TEPCO Holdings [143]) 67

5-10. Photograph of the top platform showing damage inflicted by relocating core debris. (Courtesy of TEPCO Holdings [139])

5-11. Photograph of lower head showing core debris adhering to TIP guide tube and PIP and LPRM cables in the region where platform grating has failed.

(Courtesy of TEPCO Holdings [139])

5-12. Mid-level platform conditions. (Courtesy of TEPCO Holdings [139]).

5-13. View of core debris on the floor of the pedestal region. (Courtesy of

TEPCO Holdings [139])

5-14. Details of core debris surface characteristics for 1F2. (Courtesy of TEPCO

Holdings [139])

5-15. Area explored by the "Little Sunfish" submersible robot within the 1F3 PCV.

(Courtesy of TEPCO Holdings [181])

5-16. Image of relocated CRD rail on the 1F3 platform with no grating; obtained on July 19, 2017. (Courtesy of TEPCO Holdings [181])

5-17. Image of relocated material adhered to remaining 1F3 CRD housing and cable structures; obtained on July 21, 2017. (Courtesy of TEPCO Holdings [182])

5-18. Image of material that had relocated beneath the 1F3 platform into the pedestal area; obtained on July 22, 2017. (Courtesy of TEPCO Holdings [183])

5-19. 3-D reconstruction of structures located in the pedestal region for $1 \mathrm{~F} 3$.

(Courtesy of TEPCO Holdings [140]) 73

5-20. 3-D reconstruction of core debris distribution in the pedestal region of 1F3.

(Courtesy of TEPCO Holdings [140]) 
5-21. Steam superheat solution for case in which $\mathrm{F}_{\mathrm{BVS}-\mathrm{C}}=0$ and $\mathrm{T}_{\text {sat }}=100^{\circ} \mathrm{C}$ as a function of fraction of core debris retained on BVS. (Courtesy of ANL) ……….....76

5-22. Corresponding PCV pressure increase. (Courtesy of ANL) ...................................... 77

6-1. 1F1 reactor building damage following explosion. (Courtesy of TEPCO Holdings [187]) 86

6-2. Dislocation of 1F1 drywell head shield plugs. (Courtesy of TEPCO Holdings [192])

6-3. 1F3 reactor building damage following explosion. (Courtesy of TEPCO Holdings [188])

6-4. Damaged areas on 1F3 reactor building floor plan. (Courtesy of TEPCO Holdings [188])

6-5. Damaged areas on $1 \mathrm{~F} 3$ reactor building floor. (Courtesy of TEPCO Holdings [16])

6-6. 1F4 reactor building damage following explosion. (Courtesy of TEPCO Holdings [187])

6-7. Inferred leakage paths; flow paths differ from 1 F1 and 1 F3 due to system configuration. (Courtesy of TEPCO Holdings [190]

6-8. Hydrogen transport path from 1F3 to 1F4. (Courtesy of TEPCO Holdings [189]) 93

6-9. 1F4 SGTS radiation measurement results. (Courtesy of TEPCO Holdings [189])......... 94

6-10. Field investigation of the 1F4 $4^{\text {th }}$ floor. (Courtesy of TEPCO Holdings [189]) ................ 94

6-11. Images of 1F3 explosions at 1-second intervals. (Courtesy of FCT [193]) .................... 95

6-12. Images of $1 \mathrm{~F} 3$ explosions during an appearance of a flash fire. (Courtesy of FCT [193]) 96

6-13. Sonic frequency analysis of $1 \mathrm{~F} 3$ reactor building explosion video. Acoustic wave examination shows a large peak replicated three times at approximately 2 second intervals; discussions with FCT indicate that video had no sound detection capabilities (Courtesy of SNL, [197, 198])

6-14. Images of $1 \mathrm{~F} 1$ explosion compared with $1 \mathrm{~F} 3$ explosion. (Courtesy of FCT [193])

6-15. 1F3 PCV pressure - Rapid drop in PCV pressure coincides well with the timing of 1F3 explosion at 11:01 am March 14, 2011. (Courtesy of TEPCO Holdings [199])

6-16. Timing of $1 \mathrm{~F} 2 \mathrm{RCIC}$ failure and $1 \mathrm{~F} 3$ explosion. (Courtesy of $\mathrm{FAl}$ ) 101

6-17. $1 \mathrm{~F} 2 \mathrm{PCV}$ pressure trend - Rapid increase in PCV pressure coincides well with the second RPV pressure spike following the injection with fire trucks at 20:00, March 14, 2011. (Courtesy of TEPCO Holdings [201]) 102

6-18. MAAP $1 \mathrm{~F} 3$ modeling uncertainty evaluation: refueling floor hydrogen build-up at time of $1 \mathrm{~F} 3$ reactor building explosion. (Courtesy of EPRI [60]) 103

6-19. MAAP 1F3 modeling uncertainty evaluation: fourth floor hydrogen build-up at time of $1 \mathrm{~F} 3$ reactor building explosion. (Courtesy of EPRI [60]) 104 
6-20. Process used to obtain ballpark estimate of the latest vessel failure time.

(Courtesy of FAl [202])

7-1. Water level instrument diagram. (Courtesy of TEPCO Holdings [42])

7-2. Approximate location for reported RPV vessel temperatures. (Courtesy of TEPCO Holdings [208])

7-3. Approximate location for reported PCV and SC temperatures. (Courtesy of TEPCO Holdings [208])

7-4. Available 1F1 pressure and water level data until noon on March 12, 2011.

(Data courtesy of TEPCO Holdings [9])

7-5. 1F1 pressure and water level data until July 28, 2011. (Data courtesy of TEPCO Holdings [9])

7-6. 1F1 temperature data through March 31, 2011. (Data courtesy of TEPCO Holdings [9])

7-7. 1F1 temperature data through September 6, 2011. (Data courtesy of TEPCO

Holdings [9])

7-8. 1F2 pressure and water level data through March 16, 2011. (Data courtesy of TEPCO Holdings [9])

7-9. 1F2 pressure data through March 14, 2011. (Data courtesy of TEPCO Holdings [9])

7-10. 1F2 radiation measurement data through March 31, 2011. (Data courtesy of TEPCO Holdings [9])

7-11. 1F2 temperature data through March 31, 2011. (Data courtesy of TEPCO Holdings [9])

7-12. 1F2 temperatures through September 6, 2011. (Data courtesy of TEPCO Holdings [9])

7-13. Estimated range for corrected water level for 1F2 (Courtesy of TEPCO [42])

7-14. 1F3 pressure and water level data through March 15, 2011. (Data courtesy of TEPCO Holdings [9])

7-15. Enlarged view of 1F3 RPV pressure data on through 16:48 on March 13, 2011. (Data courtesy of TEPCO Holdings [9])

7-16. Enlarged view of 1F3 pressure data March 14-22, 2011. (Data courtesy of TEPCO Holdings [9])

7-17. 1F3 DW and SC radiation data through March 22, 2011. (Data courtesy of TEPCO Holdings [9])

7-18. 1F3 temperature data through March 31, 2011. (Data courtesy of TEPCO Holdings [9])

7-19. MELCOR estimates for pressure and water levels at selected 1F1 locations [ $t=0.0$ corresponds to 14:46 on March 11, 2011; RPV water level of 0 corresponds to TAF]. (Courtesy of SNL)

7-20. MELCOR estimates for saturation temperatures at selected $1 \mathrm{~F} 1$ locations [ $\mathrm{t}=0.0$ corresponds to 14:46 on March 11, 2011]. (Courtesy of SNL) 132 
7-21. MELCOR estimates for pressure and water levels at selected 1F2 locations [ $t=0.0$ corresponds to $14: 46$ on March 11, 2011; RPV water level of 0 corresponds to TAF]. (Courtesy of SNL)

7-22. MELCOR estimates for temperatures at selected 1F2 locations [ $t=0.0$ corresponds to $14: 46$ on March 11, 2011]. (Courtesy of SNL)

7-23. MELCOR estimates for pressure and water levels at selected 1F3 locations [ $t=0.0$ corresponds to $14: 46$ on March 11, 2011; RPV water level of 0 corresponds to TAF]. (Courtesy of SNL)

7-24. MELCOR estimates for saturation temperatures at selected $1 \mathrm{~F} 3$ locations $\mathrm{t}=0.0$ corresponds to $14: 46$ on March 11, 201]. (Courtesy of SNL) ....

B-1. Representative view of the website with filters applied. (Courtesy of INL).

D-1. Near-term measures and R\&D plan for waste management. (Courtesy of NDF [106])

D-2. Processes to improve understanding of conditions within each reactor.

(Courtesy of NDF [106])

D-3. Processes for debris retrieval and characterization technology development. (Courtesy of NDF [106])

D-4. Processes for developing technologies for investigation inside the PCV. (Courtesy of NDF [106])

D-5. Processes for developing technologies for in-depth investigation inside the PCV. (Courtesy of NDF [106])

D-6. Processes for developing technologies for investigation inside the RPV. (Courtesy of NDF [106])

D-7. Processes for advancing debris and internal structure retrieval technologies. (Courtesy of NDF [106])

D-8. Processes for advancing fundamental debris and internal structure retrieval technologies (Courtesy of NDF [106])

D-9. Processes for developing sampling technologies for retrieving debris and internal structures (Courtesy of NDF [106])

D-10. Processes for developing methods for evaluating RPV and PCV seismic performance. (Courtesy of NDF [106])

D-11. Processes for developing criticality control technologies. (Courtesy of NDF [106])

D-12. Processes for developing technologies to repair leakage sections in PCV. (Courtesy of NDF [106])

D-13. Processes for full-scale test of PCV leakage repair technologies. (Courtesy of NDF [106])

D-14. Processes for developing technologies for containing, transporting, and storing fuel debris. (Courtesy of NDF [106])

D-15. Processes for R\&D of processing and storage of solid waste. (Courtesy of NDF [106]) 
E-1. Physical characteristics, photographs, and 3D images based on photographs showing the displacement of the 1F1 drywell head shield plugs. (Courtesy of TEPCO Holdings [237, 239])

E-2. Predicted steam production from melt jet fragmentation during relocation into the sumps for MAAP and MELCOR pour conditions. (Courtesy of ANL [241])

E-3. Plan view of $1 \mathrm{~F} 1$ showing sump locations in pedestal and drywell regions. (Courtesy of TEPCO Holdings [19])

E-4. 1F1 containment pressure versus time. (Courtesy of TEPCO Holdings [243]) ............. E-6

E-5. 1F1 RCW surge tank. (Courtesy of TEPCO Holdings [245])................................... E-6

E-6. Visual examinations within $1 \mathrm{~F} 1 \mathrm{X}-100 \mathrm{~B}$ penetration. (Courtesy of TEPCO Holdings [11])

E-7. 1F3 radiation survey (value in $\mathrm{mSv} / \mathrm{hr}$ measured on November 16-17, 2013 at $5 \mathrm{~m}$ above the floor at points shown on red grid) and photograph taken on March 16, 2011. (Courtesy of TEPCO Holdings [11,13])

E-8. Containment pressure/temperature curve with available 1F1 and 1F2 information. (Graphic courtesy of Nuclear Energy Institute [84] as modified by Jensen Hughes)

E-9. Improved MAAP nodalization. (Courtesy of Jensen Hughes, [26]) ............................ E-12

F-1. Impairment of 1F1 vacuum breaker line expansion joint. (Courtesy of TEPCO Holdings [155])

$\mathrm{F}-2$. 1F1 reactor building first floor dose rate measurements (in $\mathrm{mSv} / \mathrm{hr}$; taken above floor elevation measured on February 14, 2013) illustrating elevated radiological contamination of RCW (circled area). (Courtesy of TEPCO Holdings [156])

F-3. Leakage out of the sand cushion drain pipes at 1F1. (Courtesy of TEPCO Holdings [157])

F-4. Torus room radiation level readings from entry into $1 \mathrm{~F} 1$ reactor building measured on May 30, 2014 (in mSv/hr; taken above floor elevation). (Courtesy of TEPCO Holdings [158])

F-5. 1F1 reactor building TIP room dose rate measurements (in $\mathrm{mSv} / \mathrm{hr}$; taken above floor elevation between September 24 through October 2, 2015). (Courtesy of TEPCO [159])

F-6. Typical TIP room illustration. (Courtesy of TEPCO Holdings [160])... $\mathrm{F}-4$

F-7. Torus room radiation level readings from entry into 1F2 reactor building (in $\mathrm{mSv} / \mathrm{hr}$; taken above floor elevation in April 2011). (Courtesy of TEPCO Holdings [137])

F-8. 1F2 reactor building refueling floor visual and dose rate information (in $\mathrm{mSv} /$ hr; taken above floor elevation on February 27, 2012 and June 13, 2012). (Courtesy of TEPCO Holdings [161]) F-5

F-9. Air dose rates in 1F2 TIP room (in $\mathrm{mSv} / \mathrm{hr}$; taken above floor elevation on March 22, 2013). (Courtesy of TEPCO Holdings [137]) F-6 
$\mathrm{F}-10$. Torus room radiation level readings from entry into $1 \mathrm{~F} 3$ reactor building (in $\mathrm{mSv} / \mathrm{hr}$; taken above floor elevation on April 25, 2011). (Courtesy of TEPCO Holdings [137])

F-11. Liquid-phase leakage from 1F3 equipment hatch. (Courtesy of TEPCO Holdings [155])

F-12. Robot image leading to 1F3 TIP room. (Courtesy of TEPCO Holdings [165]) ............. F-8

F-13. 1F CAM data. (Data courtesy of TEPCO Holdings [9]) ....................................... F-9

F-14. 1F2 DW and WW CAMS readings starting from 14:46 on March 11, 2011. (Courtesy of Jensen Hughes based on information in [97])

F-15. PCV dose measurements on and below the grated floor outside the pedestal region of 1F1, taken in March 2017. (Courtesy of TEPCO Holdings [168])

$\mathrm{F}-16$. PCV dose measurements on the grated floor outside the pedestal region of 1F1, taken in April 2015. (Courtesy of TEPCO Holdings [168])

F-17. Cs-134/Cs-137 ratios of paint-covered 1F2 concrete. (Courtesy of TEPCO Holdings [19])

F-18. Generalized BWR power distribution (left) and burnup distribution (right) on an assembly by assembly basis, red represents higher power and higher burnup. (Courtesy of SNL [172])

$\mathrm{F}-19$. 2D spatial distribution of the Cs-134 to Cs-137 activity ratios in $1 \mathrm{~F} 3$. (Courtesy of SNL [172])

F-20. Gamma dose rate measurements at the main gain, indicating timings of coincident neutron dose rate. (Courtesy of TEPCO Holdings [40])

G-1. RPV temperature measurements for 1F1 following the accident. (Courtesy of TEPCO Holdings [11]

G-2. RPV temperature measurements for 1F2 following the accident. (Courtesy of TEPCO Holdings [11])

G-3. RPV temperature measurements for 1F3 following the accident. (Courtesy of TEPCO Holdings [11])

G-4. Relationship between HVH temperature and water injection from the feedwater system. (Courtesy of TEPCO Holdings [18])

G-5. Location of X-100B in $1 \mathrm{~F} 1 \mathrm{PCV}$ and pathways of robotic examinations completed on April 10, 2015. (Courtesy of TEPCO Holdings [271])

G-6. Illustration of CCD camera access through X-100B penetration. (Courtesy of TEPCO Holdings [18])

G-7. Views of sediment surface covering the drywell floor at the X-100B location. (Courtesy of TEPCO Holdings [18])

G-8. Approximate location of $\mathrm{X}-100 \mathrm{~B}$ penetration relative to predictions of core debris spreading in 1F1. (Courtesy of TEPCO Holdings and ORNL $[58,271]$ )

G-9. Photographs of structures outside the pedestal doorway in 1F1. (Courtesy of TEPCO Holdings [168])

G-10. Comparison of photographs of wall splatter material observed in $\mathrm{MCCl}$ tests with prototypic reactor material and material observed in 1F1. (Courtesy of ANL[273] and TEPCO Holdings[168]) 
G-11. MELTSPREAD predictions of liner heatup due to heat transfer from impinging melt for $1 \mathrm{~F} 1$ based on a MAAP low pressure (LP) scenario [56] (left) and MELCOR[55] (right) melt pour conditions. (Courtesy of ORNL [58])

G-12. Images of $1 F 1$ obtained using muon tomography with scintillation detectors (The lower left image is measured; the other two images were calculated. Dashed lines show location of identified geometrical features). (Courtesy of TEPCO Holdings [15])

G-13. Images of 1F2 obtained using muon tomography with scintillation detectors. (Courtesy of TEPCO Holdings [18])

G-14. Muon tomography scan of the lower head of the 1F2 RPV (Scan 4).

Data points near the upper (green) line indicate the presence of high density debris (between 2.0 and $6.0 \mathrm{~g} / \mathrm{cc}$ ). The presence of high density debris was only found in the muon tomography ray that passed through the lower head. (Courtesy of TEPCO Holdings [179])

G-15. MELCOR modeling of molten pools and particulate debris within the lower plenum, particulate and molten debris mases are dependent on the accident transient. (Courtesy SNL [8])

G-16. Comparison of muon tomography images obtained for 1F2 and 1F3 using scintillation detectors. (Courtesy of TEPCO Holdings [185])

G-17. Expected long-term noncondensable-combustible gas production from ablation within the $1 \mathrm{~F} 1$ sump if debris had not been quenched and stabilized.

(Courtesy of ANL [36])

G-18. Depiction of HPCl pump steam supply penetration showing location of deposit with high dose rate. (Courtesy of TEPCO Holdings [16])

G-19. Photographs of leakage location and sediment. (Courtesy of TEPCO Holdings [16])

G-20. Illustration of 1F1 RCW system showing contamination levels within the system. (Courtesy of TEPCO Holdings [176])

$\mathrm{H}-1$. 1F1 RPV pressure and wide range (WR) and narrow range (NR) water levels. (Data courtesy of TEPCO Holdings [9])

H-2. 1F1 WR trend on March 11, 2011. (Data courtesy of TEPCO Holdings [9]) $\mathrm{H}-3$

H-3. 1F1 pressure and water level (March 11, 2011). (Data courtesy of TEPCO Holdings [9])

$\mathrm{H}-4$. 1F1 pressure and water level during the first 19 hours (March 11-12, 2011). (Data courtesy of TEPCO Holdings [9]) $. \mathrm{H}-4$

$\mathrm{H}-5$. 1F1 pressure, water level, and injection from 19 to 105 hours. (Data courtesy of TEPCO Holdings [9])

H-6. 1F1 pressure, water level, and injection from 273 to 345 hours. (Data courtesy of TEPCO Holdings [9])

H-7. 1F1 pressure, water level, and injection with SRV and FW temperatures from 273 to 345 hours. (Data courtesy of TEPCO Holdings [9]) . $\mathrm{H}-7$

$\mathrm{H}-8$. 1F1 pressure, water level, and injection out to 439 hours. (Data courtesy of TEPCO Holdings [9]) $. \mathrm{H}-8$ 
H-9. 1F1 pressure, water level, and injection out to 126 days. (Data courtesy of TEPCO Holdings [9])

$\mathrm{H}$-10. $1 \mathrm{~F} 1$ temperature data. (Data courtesy of TEPCO Holdings [9])

$\mathrm{H}-11$. $1 \mathrm{~F} 1$ temperature data out through early 2012. (Data courtesy of TEPCO Holdings [9])

$\mathrm{H}$-12. $1 \mathrm{~F} 2 \mathrm{RPV}, \mathrm{DW}$, and SC data from March 11 through14, 2011 (annotated for RPV pressure evaluation). (Data courtesy of TEPCO Holdings [9])

H-13. 1F2 RPV pressure on March 14, 2011. (Data courtesy of TEPCO Holdings [9])

$\mathrm{H}-14$. 1F2 water level and DW radiation data on March 14, 2011. (Data courtesy of TEPCO Holdings [9])

$\mathrm{H}-15$. 1F2 RPV and containment data March 11 through 14, 2011 annotated for DW pressure evaluation. (Data courtesy of TEPCO Holdings [9])

$\mathrm{H}-16$. 1F2 RPV and containment data March 11 through 14, 2011. (Data courtesy of TEPCO Holdings [9])

$\mathrm{H}-17$. 1F2 RPV and containment data March 13 through 14, 2011. (Data courtesy of TEPCO Holdings [9])

$\mathrm{H}$-18. Closer look at the first two peaks in 1F2 DW pressure (March 14 through 15, 2011). (Data courtesy of TEPCO Holdings [9])

H-19. 1F2 RPV, DW, and SC data from March 14 through 15, 2011. (Data courtesy of TEPCO Holdings [9])

H-20. 1F2 RPV, DW, and SC data on March 14 through 15, 2011 annotated for DW and SC pressure evaluations. (Data courtesy of TEPCO Holdings [9])

$\mathrm{H}-21$. 1F2 RPV, DW, and SC data on March 15, 2011 indicating loss of primary system and vessel breach. (Data courtesy of TEPCO Holdings [9])

$\mathrm{H}-22$. $1 \mathrm{~F} 2$ pressure and radiation data from March 16 through 30, 2011. (Data courtesy of TEPCO Holdings [9])

$\mathrm{H}-23$. 1F2 radiation data (red) plotted on Browns Ferry Nuclear plant decay curve (Decay plot courtesy of TVA [276]; Data courtesy of TEPCO Holdings [9])

$\mathrm{H}$-24. 1F2 RPV metal temperatures. (Data courtesy of TEPCO Holdings [9]) $\mathrm{H}-22$

$\mathrm{H}-25$. 1F RPV pressure and water level (March 11 through 12, 2011). (Data courtesy of TEPCO Holdings [9])

$\mathrm{H}-26$. 1F3 RPV pressure and water level and DW and SC pressure (March 12 through 13, 2011). (Data courtesy of TEPCO Holdings [9]) $\mathrm{H}-24$

$\mathrm{H}-27$. Corrected $1 \mathrm{~F} 3 \mathrm{WR}$ readings. (Data courtesy of TEPCO Holdings [9, 201]). $\mathrm{H}-24$

H-28. 1F3 RPV pressure on March 11-12, 2011. (Data courtesy of TEPCO Holdings [9])

H-29. $1 F 3$ RPV pressure and water level and DW and SC pressure (March 12 through 13, 2011). (Data courtesy of TEPCO Holdings [9])

H-30. 1F3 data from 9:00 to 13:00 on March 13, 2011. (Data courtesy of TEPCO Holdings [9]) 
H-31. 1F3 data from 18:00 on March 13, 2011 through 02:00 on March 14, 2011. (Data courtesy of TEPCO Holdings [9])

$\mathrm{H}$-32. 1F3 pressure and radiation data (March 14, 2011). (Data courtesy of TEPCO Holdings [9])

H-33. 1F3 pressure, water level, and radiation data (March 14, 2011). (Data courtesy of TEPCO Holdings [9])

H-34. 1F3 pressure and radiation data (March 19 through 22, 2011). (Data courtesy of TEPCO Holdings [9]) 30

$\mathrm{H}-35$. 1F3 radiation data (red) plotted on Browns Ferry Nuclear plant decay curve (Decay curve courtesy of TVA [276]; Data courtesy of TEPCO Holdings [9])

H-36. 1F3 RPV temperature and injection data (August 22 through September 26, 2011). (Data courtesy of TEPCO Holdings [9]) 


\section{TABLES}

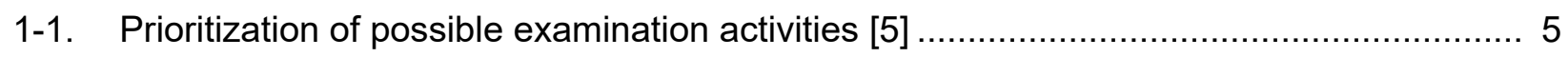

2-1. Synergistic activities of special interest ............................................................ 11

2-2. Major milestones in the Mid-and-Long Term Roadmap (based on information

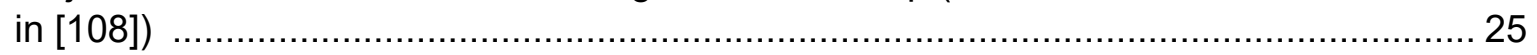

3-1. Area 1 information needs from the reactor building ............................................ 31

3-2. Area 1 information needs from the PCV ........................................................... 32

3-3. Area 1 information needs from the RPV .......................................................... 33

3-4. Results from component and system examinations ............................................ 34

3-5. Summary of examination dates and progression ............................................ 36

4-1. Area 2 information needs from the reactor building .......................................... 44

4-2. Area 2 information needs from the PCV .......................................................... 44

4-3. Area 2 information needs from the RPV ............................................................. 45

4-4. Locations of elevated dose rate inside reactor buildings......................................... 54

$5-1$. Area 3 information needs from the reactor building .........................................6 60

5-2. Area 3 information needs from the PCV ....................................................... 61

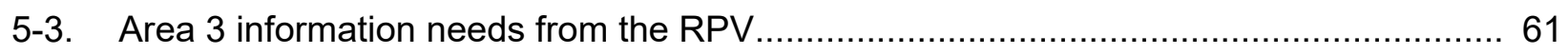

6-1. Area 4 information needs from the reactor building ........................................ 84

6-2. Area 4 information needs from the PCV ............................................................... 85

6-3. Ballpark estimate of required hydrogen generation............................................. 106

6-4. Ballpark estimate of required latest vessel failure time for MAAP5 analysis of

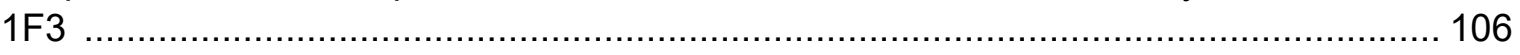

6-5. Ballpark estimate of required latest vessel failure time for MELCOR analysis

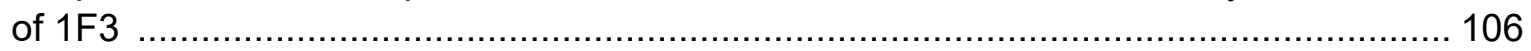

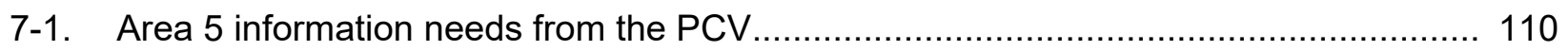

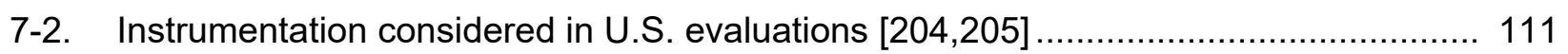

7-3. Summary of survivability insights ............................................................ 136

8-1. Evaluation areas and types of evaluated examination information ........................... 139

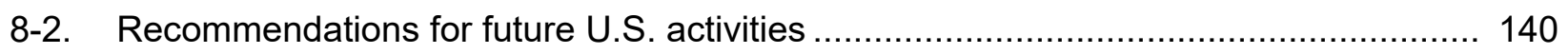

8-3. Suggestions for additional examinations ..................................................... 142

C-1. Information needs from the reactor building ....................................................... C-2

C-2. Information needs from the primary containment vessel................................. C-10

C-3. Information needs from the reactor pressure vessel ...................................... C-17

C-4. Detailed information need for RB-9b and RB-10 ........................................... C-19

C-5. Detailed information need for RB-15 ......................................................... C-20

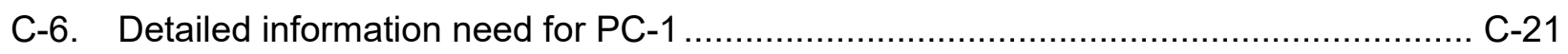

C-7. Detailed information need for PC-3a ......................................................... C-22

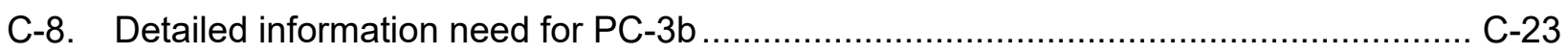

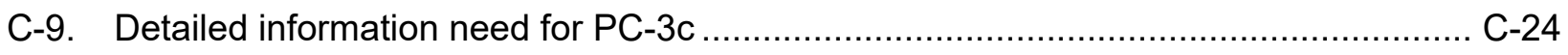


C-10. Detailed information need for PC-3d .............................................................. C-25

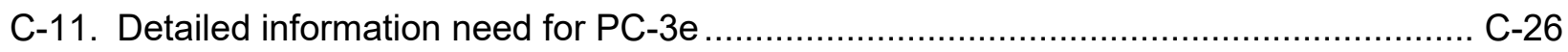

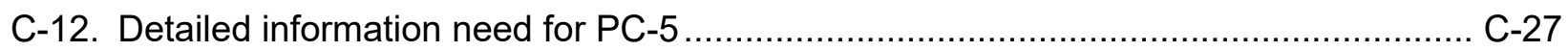

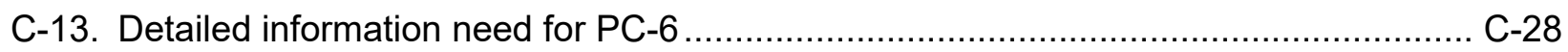

C-14. Detailed information need for PC-17, PC-18, PC-19, and PC-20 ............................ C-29

$\mathrm{C}-15$. Composition data from analysis of two concrete samples at $1 \mathrm{~F}$ site.[225]................. C-30

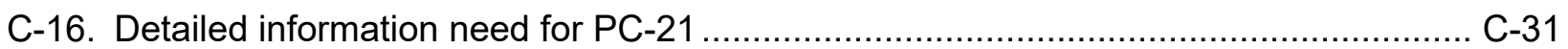

C-17. Detailed information need for RPV-1b.......................................................... C-32

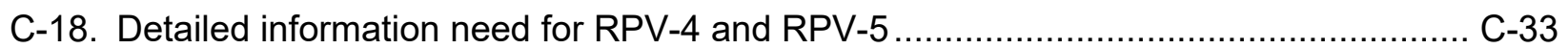

$\mathrm{E}-1$. Rough estimate of the relocation behavior of the shield plugs induced by the

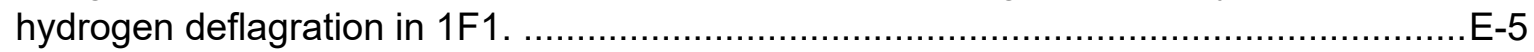

F-1. Back-calculated cesium activity ratios found in 1F1 and 1F2 samples.[19] ............... F-14

G-1. Concentrations (Vol\%) of $\mathrm{H}_{2}, \mathrm{CO}$, and $\mathrm{CO}_{2}$ in the $\mathrm{PCV}$ atmospheres of $1 \mathrm{~F} 1$ and 1F2 measured several months after the accidents [274] .............................. G-13

G-2. Expected atmospheric concentration of $\mathrm{MCCl}$ gases in the $1 \mathrm{~F} 1$ containment atmosphere if $\mathrm{MCCl}$ was not terminated.[36]

$\mathrm{H}-1$. Typical SRV setpoint pressures.[275] 


\section{ACRONYMS AND ABBREVIATIONS}

$\mathrm{AC}$

ADS

$\mathrm{AE}$

AFW

AM

ANL

ATF

BAF

BDBEE

BFN

BSAF

BVS

BWR

BWROG

CAM

CCI

CFD

CLADS

CR

CRD

CNWG

CRIEPI

CS

CST

CSNI

Daiichi

DC

$\mathrm{D} \& \mathrm{D}$ or $\mathrm{DD}$

DOE

DOE-EM

DOE-NE

dP

DW or $\mathrm{D} / \mathrm{W}$

EDS

ELAP

ENSREG

EPG

Alternating Current

Automatic Depressurization System

Accident Evaluation

Auxiliary Feed Water

Accident Management and Prevention

Argonne National Laboratory

Accident Tolerant Fuel

Bottom of Active Fuel

Beyond Design Basis External Events

Browns Ferry Nuclear Plant

Benchmark Study of the Accident at the Fukushima Daiichi Nuclear Power Plant

Below Vessel Structure

Boiling Water Reactor

Boiling Water Reactor Owners Group

Containment Air Monitor

Core Concrete Interactions

Computational Fluid Dynamics

Collaborative Laboratories for Advanced Decommissioning Science

Control Rod

Control Rod Drive

Civil Nuclear Energy Research and Development Working Group

Central Research Institute of Electric Power Industry

Core Spray

Condensate Storage Tank

Committee on the Safety of Nuclear Installations

Fukushima Daiichi Nuclear Power Station

Direct Current

Decontamination and Decommissioning

Department Of Energy

Department of Energy Office of Environmental Management

Department of Energy Office of Nuclear Energy

Differential Pressure

DryWell

Energy-Dispersive X-ray Spectroscopy

Extended Loss of AC Power

European Nuclear Safety Regulators Group

Emergency Planning Guideline 


\begin{tabular}{|c|c|}
\hline EPRI & Electric Power Research Institute \\
\hline EU & European Union \\
\hline FAI & Fauske and Associates, LLC \\
\hline FCT & Fukushima Central Television Company, LTD \\
\hline FDW & FeeDWater \\
\hline FE-SEM & Field Emission Scanning Electron Microscopy \\
\hline FLEX & Diverse and Flexible Mitigation Capability (for accident mitigation) \\
\hline FP & Fire Protection \\
\hline FP & Fission Product \\
\hline FY & Fiscal Year \\
\hline FZ & Fuel Zone \\
\hline GEH & GE-Hitachi Nuclear Energy, Limited \\
\hline GPU & General Public Utilities \\
\hline GRS & Gesellschaft für Anlagen- und Reaktorsicherheit \\
\hline HPCI & High Pressure Coolant Injection \\
\hline IAE & Institute of Applied Energy \\
\hline IAEA & International Atomic Energy Agency \\
\hline IC & Isolation Condenser \\
\hline ICP-MS & Inductively Coupled Plasma Mass Spectrometry \\
\hline INL & Idaho National Laboratory \\
\hline INPO & Institute of Nuclear Power Operations \\
\hline IRID & International Research Institute for Nuclear Decommissioning \\
\hline IRM & Intermediate Range Monitor \\
\hline JAEA & Japan Atomic Energy Agency \\
\hline LIBS & Laser Induced Breakdown Spectroscopy \\
\hline LP & Low Pressure \\
\hline LPRM & Local Power Range Monitor \\
\hline LWR & Light Water Reactor \\
\hline LWRS & Light Water Reactor Sustainability \\
\hline MAAP & Modular Accident Analysis Program \\
\hline MCCI & Molten Core Concrete Interactions \\
\hline MDRIR & Minimum Debris Retention Injection Rate \\
\hline MELCOR & Methods for Estimation of Leakages and Consequences of Releases \\
\hline METI & Ministry of Economy, Trade and Industry \\
\hline MEXT & Ministry of Education, Culture, Sports, Science and Technology \\
\hline MHI & Mitsubishi Heavy Industry \\
\hline MSIV & Main Steam Isolation Valve \\
\hline MSL & Main Steam Line \\
\hline NAcPs & National Action Plans \\
\hline
\end{tabular}




\begin{tabular}{|c|c|}
\hline NDF & Nuclear Damage Compensation and Decommissioning Facilitation Corporation \\
\hline NEA & Nuclear Energy Agency \\
\hline NEI & Nuclear Energy Institute \\
\hline NPS & Nuclear Power Station \\
\hline NR & Narrow Range \\
\hline NRA & Nuclear Regulatory Authority (Japan) \\
\hline NRC & Nuclear Regulatory Commission \\
\hline NSC & Nuclear Science Committee \\
\hline NTTF & Near Term Task Force \\
\hline NUGENIA & NUclear GENeration II \& III Association \\
\hline OECD & Organization for Economic Cooperation and Development \\
\hline ORNL & Oak Ridge National Laboratory \\
\hline PCPL & Primary Containment Pressure Limit \\
\hline PCV & Primary Containment Vessel \\
\hline PIP & Position Indicator Probe \\
\hline PLR & Primary Loop Recirculation \\
\hline PM & Plant Maintenance \\
\hline PORV & Pilot-Operated Relief Valve \\
\hline PreADES & Preparatory Studies for Fuel Debris Analysis \\
\hline PRA & Probabilistic Risk Assessments \\
\hline PWR & Pressurized Water Reactor \\
\hline PWROG & Pressurized Water Reactor Owners Group \\
\hline $\mathrm{R} \& \mathrm{D}$ & Research and Development \\
\hline $\mathrm{RB}$ or $\mathrm{R} / \mathrm{B}$ & Reactor Building \\
\hline $\mathrm{RCIC}$ & Reactor Core Isolation Cooling \\
\hline RCW or RBCCW & Reactor Building Closed Cooling Water System \\
\hline $\mathrm{RN}$ & RadioNuclide \\
\hline RPV & Reactor Pressure Vessel \\
\hline RST & Reactor Safety Technologies \\
\hline SAG & Severe Accidence Guidance or Severe Accident Guideline \\
\hline SAMG & Severe Accident Management Guideline \\
\hline SAREF & SAfety REsearch opportunities post-Fukushima \\
\hline SARNET & Severe Accident Research NETwork \\
\hline SAWA & Severe Accident Water Addition \\
\hline SBO & Station BlackOut \\
\hline $\mathrm{SC}$ or $\mathrm{S} / \mathrm{C}$ & Suppression Chamber \\
\hline SEG & Senior Expert Group \\
\hline SFP & Spent Fuel Pool \\
\hline SGTS & Standby Gas Treatment System \\
\hline
\end{tabular}




\begin{tabular}{|c|c|}
\hline SLC & Standby Liquid Cooling \\
\hline SNL & Sandia National Laboratories \\
\hline SRM & Source Range Monitor \\
\hline SRV & Safety Relief Valve \\
\hline $\mathrm{SSC}$ & Structures, Systems, and Components \\
\hline TAF & Top of Active Fuel \\
\hline TAG & Technical Advisory Group (for TMI-2 defueling and cleanup) \\
\hline TAMU & Texas A\&M University \\
\hline TBD & To Be Determined \\
\hline TBR & Technical Basis Report \\
\hline TC & Thermocouple \\
\hline TCOFF & $\begin{array}{l}\text { Thermodynamic Characterization Of Fuel debris and Fission products based on } \\
\text { Scenario Analysis for Severe Accident Progression at Fukushima-Daiichi NPS }\end{array}$ \\
\hline TEPCO Holdings & Tokyo Electric Power Company Holdings, Inc. \\
\hline TIP & Traversing In-core Probe \\
\hline TMI-2 & Three Mile Island Unit 2 \\
\hline $\mathrm{TSC}$ & Technical Support Center \\
\hline TSG & Technical Support Guidance \\
\hline TVA & Tennessee Valley Authority \\
\hline UI & Unresolved Issues \\
\hline U.S. & United States \\
\hline UW & University of Wisconsin \\
\hline VIP & Vessel and Internals Program \\
\hline WR & Wide Range \\
\hline $\mathrm{WW}$ or $\mathrm{W} / \mathrm{W}$ & Wetwell \\
\hline XRD & X-Ray Diffraction \\
\hline XRF & X-Ray Florescence \\
\hline $1 \mathrm{~F} 1$ & Fukushima Daiichi Unit 1 \\
\hline $1 \mathrm{~F} 2$ & Fukushima Daiichi Unit 2 \\
\hline $1 F 3$ & Fukushima Daiichi Unit 3 \\
\hline $1 \mathrm{~F} 4$ & Fukushima Daiichi Unit 4 \\
\hline
\end{tabular}




\section{U.S. Efforts in Support of Examinations at Fukushima Daiichi - 2018 Evaluations}

\section{INTRODUCTION}

The Great East Japan Earthquake of magnitude 9.0 and subsequent tsunami that occurred on March 11, 2011 led to a multi-unit severe accident at the Fukushima Daiichi Nuclear Power Station [Daiichi]. Much is still not known about the end-state of core materials in each unit that was operating on that date. Some of this uncertainty can be attributed to a lack of information related to cooling system operation and cooling water injection during the events. There is also uncertainty in our understanding of phenomena affecting: a) in-vessel core damage progression during severe accidents in boiling water reactors (BWRs) [compared with Pressurized Water Reactors (PWRs)], and b) accident progression after vessel failure (ex-vessel progression) for BWRs and PWRs. These uncertainties arise due to limited full scale prototypic data. Similar to what occurred after the accident at Three Mile Island Unit 2 (TMI-2),[1] these Daiichi units offer the international community a means to obtain prototypic severe accident data from multiple full-scale BWR cores related to fuel heatup, cladding and other metallic structure oxidation and associated hydrogen production, fission product release and transport, and fuel/structure interactions from relocating fuel materials. In addition, these units may offer data related to the effects of salt water addition, vessel failure, containment failure, and ex-vessel core/concrete interactions (CCI). As documented in this report, much of the information obtained from these units is already being used to reduce uncertainties in BWR severe accident progression and also offers the potential for safety enhancements for BWRs, PWRs, and future nuclear power plant designs. Furthermore, evaluations show that reduced uncertainties in modeling the events at Daiichi improves the realism of reactor safety evaluations and accident mitigation guidance and informs future Decontamination and Decommissioning (D\&D) activities by improving the capability for characterizing potential hazards to workers involved with cleanup activities.

\subsection{Objectives and Limitations}

The Department of Energy Office of Nuclear Energy (DOE-NE) is sponsoring U.S. efforts to participate in the Daiichi Forensics Evaluations with the following objectives:

- Objective 1: Develop consensus U.S. input for high priority time-sequenced examination tasks and supporting research activities that can be completed with minimal disruption of Tokyo Electric Power Company Holdings, Incorporated, (TEPCO Holdings) D\&D plans for Daiichi.

- Objective 2: Evaluate obtained information to:

- Gain a better understanding related to events that occurred in each unit at Daiichi

- Gain insights to reduce uncertainties in predicting phenomena and equipment performance during severe accidents

- Provide insights beneficial to TEPCO Holdings D\&D activities

- Confirm and, if needed, improve guidance for severe accident prevention, mitigation, and emergency planning

- Update and/or refine Objective 1 information requests.

- Objective 3: Facilitate implementation of Japan-led international research efforts to support D\&D. 
There are several potential safety benefits from this U.S. effort. In fact, as discussed in [2 through 5], the U.S. has already gained significant safety benefit from information obtained from Daiichi. Although there are many potential benefits from this U.S. effort, it is also important to recognize its limitations. As discussed below, other organizations have activities underway to address these limitations.

First, other organizations within the U.S. have the role of implementing institutional measures to ensure prevention of severe accidents. For example, as discussed in Section 2.2.1.2, the U.S. Nuclear Regulatory Commission (U.S. NRC) established the Fukushima Near Term Task Force (NTTF) and Japan Lessons Learned activities to ensure that appropriate near-term regulatory actions were taken in areas where additional efforts were required, such as the re-evaluation of hazards associated with flooding and seismic events. This has been completed in the U.S., and many of the assessments are complete now, too. Training of plant and agency personnel, which was also required by the Commission, is underway.

Second, within the U.S., the industry leads the implementation of safety measures in response to insights from Fukushima. For example, as discussed in Section 2.2.1.3, industry has implemented the diverse and flexible coping strategies or FLEX program to address concerns related to events associated with extended loss of AC power (ELAP) conditions. In addition, both the PWR Owners Group (PWROG) and BWR Owners Group (BWROG) have implemented updates to their severe ancient guidance (SAG) to address insights from the forensic effort. These guidelines will continue to be enhanced as further insights are gained form the ongoing work related to the Fukushima Accident. With a limited number of exceptions, ${ }^{*}$ updated SAG is being implemented world-wide.

Third, it is beyond the scope of the U.S. DOE Forensics Effort to develop an international program. However, it is recognized that information gained from Daiichi is of benefit to global nuclear reactor safety. Ultimately, a long-term international framework, led by Japanese organizations, may be appropriate for supporting post-accident examinations at Daiichi. As discussed in Section 2.2.2, organizations within Japan are initiating such international efforts. The U.S. Forensics Effort provides a means for U.S. experts to contribute to and benefit from such international efforts.

\subsection{Motivation}

Data, models, and insights from post-accident inspections at Daiichi inform many aspects of reactor safety, including severe accident modeling and simulation tools, severe accident management guidelines, plant staff training, and new or revised safety requirements in response to Fukushima. To increase the benefit from post-accident examinations that support D\&D endeavors, this effort is needed to: (a) identify data needs to ensure that key information is not lost; (b) identify examination techniques, sample types, and evaluations to address each information need; and (c) when necessary, help finance acquisition of the required data and conduct of the analyses. Results from this effort are beneficial to the U.S. and to Japan.

For the U.S., this effort provides access to prototypic data from three units with distinctively different accident signatures. U.S. experts are interested in examination information with respect to:

- Component Performance and System Survivability Assessments - Examinations provide key information related to the performance of structures, systems, and components at each unit. For example, many improvements were made to plant instrumentation after the TMI-2 accident.[6]

\footnotetext{
* Updated Severe Accident Management Guidelines (SAMGs) have not been implemented for Nordic BWRs and BWRs in India.
} 
Similarly, the events at Daiichi provide information to better ensure that operators are able to assess the status of the plant and the effects of mitigating actions that may be taken.

- Enhancements to Accident Progression and Source Term Models - Similar to the processes that occurred with TMI-2 examinations, knowledge gained from examinations at Daiichi is being used to reduce uncertainties in systems analysis codes, such as the Modular Accident Analysis Program (MAAP) code[7] and the Methods for Estimation of Leakages and Consequences of Releases (MELCOR) code.[8] These codes are used both domestically and internationally to evaluate the safety of operating plants, as well as new nuclear reactor designs.

- $\quad$ Accident Management Strategies and Plant Staff Training - As uncertainties in predicting BWR and PWR accident progression and associated source terms are reduced, strategies for mitigating severe accidents can be improved. Knowledge gained from Daiichi has and will continue to be factored into accident management guidance and staff training to prevent or reduce the consequences of future accidents.

- $\quad$ Preserving Severe Accident Capabilities - Examinations provide exciting and important research opportunities that can serve as a springboard for rekindling much needed expertise within the younger generation of U.S. nuclear engineers regarding Light Water Reactor (LWR) severe accident behavior.

For Japan, U.S. involvement provides an independent evaluation of inputs to D\&D activities. Such evaluations are useful because of U.S. experience with respect to:

- $\quad$ Plant Operations - The U.S. has over 20 operating BWRs, and personnel with considerable experience with respect to BWR operations.

- Reactor Safety - Experts involved in this U.S. effort lead development of U.S. severe accident codes and large-scale U.S. experimental programs.

- $\quad$ TMI-2 Post-Accident Examinations and Cleanup - Several U.S. experts participating in this program were also involved in TMI-2 post-accident evaluations. To facilitate exchange of this information, the U.S. DOE collaborated with the U.S. NRC to host a U.S.-Japan TMI-2 Knowledge Transfer and Relevance to Fukushima meeting in FY2017 to promote exchange of relevant information to cognizant organizations within Japan.

Unique U.S. expertise provides TEPCO Holdings an independent assessment of their progress reports, the adequacy of severe accident analysis code models for evaluations to support their D\&D plans, and the adequacy of available examination information and proposed plans for additional examinations. In the latter case, U.S. input focuses on the desired amount of information, the resolution of data required from sampling, and the cost versus the benefit of obtaining such information. As discussed in Section 2.1, the U.S. devoted significant funding for extraction of radioactive samples of core debris from the TMI-2 vessel and evaluating these samples in hot cells. These efforts provided insights about the chemical composition and porosity of core debris. Although such evaluations from the core region improved our understanding of melt progression, it is less clear that results from relocated core debris samples obtain from the lower head were as beneficial. Conversely, additional samples to characterize the interface between relocated debris and the vessel head could help reduce uncertainties in characterizing heat transfer from relocated debris and the potential for vessel failure. Such insights are useful to Japan.

Because of the benefit to global nuclear reactor safety, it is recognized that an international framework is ultimately needed to support post-accident examinations. Japanese organizations should lead this international framework. Nevertheless, the U.S. has a vested interest in these examinations. The U.S. has the largest number of operating nuclear power plants in the world; there are also a significant number of reac- 
tors operating around the world based on U.S. plant designs. Hence, U.S. organizations - both industry and government-are major beneficiaries from any improvements in LWR severe accident knowledge just as Japan was a major beneficiary from their participation in prior international TMI-2 programs. U.S. collaborative work with the international community in establishing this framework to support our Japanese colleagues is beneficial to the U.S. and Japan, but also offers the potential to advance reactor safety across the global nuclear energy community.

\subsection{Approach}

The approach developed to ensure that objectives outlined in Section 1.1 are achieved relies on expert panel meetings. Over 30 experts from industry, universities, and national laboratories participate in this process. Experts from the U.S. NRC, the U.S. DOE, and TEPCO Holdings also attend and inform participants during these meetings.

\subsubsection{Objective 1 Activities}

To complete Objective 1, expert panel meetings initially focused on developing a report during FY2015 with a prioritized initial list of information of interest to U.S. stakeholders.[5] In this report, special attention was devoted to identifying why such information is important and how it will be used to benefit the U.S. nuclear enterprise.

During initial meetings to complete Objective 1, U.S. experts agreed upon several significant findings:

- Information obtained from the affected reactors at Daiichi offers a unique means to obtain full-scale, prototypic data for enhancing reactor safety (e.g., improved severe accident guidance, possible plant modifications, improved simulation codes for staff training, etc.).

- Insights gained from collecting and comparing similar observations and data from each of the three units are valuable because the accident progression at each unit was unique in many respects.

- This information is important for BWRs and PWRs; i.e., many insights gained from this information are not only applicable to BWRs, but also could have significant safety impacts on PWRs.

- Some information is required for all identified items to obtain a complete picture of the events. It is only meaningful to prioritize data needs with respect to the 'cost' and 'logical sequence' for obtaining such information.

- Information from other units at Daiichi and other plants, such as Daini, also provide valuable insights for forensics, repair, maintenance, and field applications. Critical information from these plants can be more easily obtained at lower cost and with less radiation exposure to personnel.

- D\&D plans (or activities already completed) address much of the information identified by the U.S. expert panel.

- Maximum benefits from this information requires: reviews by cognizant experts, posting for easy-to-use access, interactions with TEPCO Holdings for added requests and understanding of information available, and interactions with code assessments.

- Ultimately, an international framework should be established to benefit from information obtained during D\&D efforts at Daiichi.

- Important information and data are already available, and more is being gathered at the current time. U.S. forensics evaluation tasks should be initiated as soon as possible. 
Most of the information needs identified by the expert panel are related to the affected units at Daiichi Units 1 through $4(1 \mathrm{~F} 1,1 \mathrm{~F} 2,1 \mathrm{~F} 3$, and $1 \mathrm{~F} 4) .^{\dagger}$ Although details varied, U.S. experts generally identified needs required to answer fundamental questions related to how the accident progressed in each unit, to understand equipment and component survivability, and to benchmark severe accident progression and dose assessment codes. These needs are organized in tables per location [e.g., the reactor building (RB), the primary containment vessel (PCV), and the reactor pressure vessel (RPV)]. These tables also identify applicable units for each need and other relevant factors (e.g., how information should be obtained, why it is needed, its expected use or benefits, when it should be obtained, and the estimated level of effort).

Table 1-1 summarizes, at a high level, the activities identified by the expert panel for addressing information needs from the affected units at Daiichi. As indicated above, the expert panel concluded that some information is needed from all locations to obtain a complete picture of the entire accident progression in each unit. Therefore, experts concluded that information needs were best prioritized with respect to cost and the logical sequence for obtaining such information. For each location, Table 1-1 groups the desired examination information by method and specifies the priority of the information need by the number of asterisks in each box. Results indicate that the expert panel typically placed the most emphasis upon information obtained from visual examinations, such as videos and photographs, and near-term proximity exams, such as dose surveys. Experts agreed that such information was the easiest to obtain and could provide critical information related to whether additional examinations were required.

Table 1-1. Prioritization of possible examination activities [5]

\begin{tabular}{|c|c|c|c|c|}
\hline \multirow{2}{*}{ Region } & \multicolumn{4}{|c|}{ Examination Information Classification $^{\mathbf{a}, \mathbf{b}}$} \\
\hline & Visual & Near-Proximity & Destructive & Analytical \\
\hline \multicolumn{5}{|c|}{ Reactor Building (RB) } \\
\hline Reactor Core Isolation Cooling (RCIC) & $* * * *$ & $* * *$ & $* *$ & \\
\hline High Pressure Coolant Injection (HPCI) & $* * * *$ & & $* * *$ & \\
\hline Building & $* * * *$ & $* * *$ & $* *$ & * \\
\hline \multicolumn{5}{|c|}{ Primary Containment Vessel (PCV) } \\
\hline $\begin{array}{l}\text { Main Steam Isolation Valves (MSIVs) and Safety } \\
\text { Relief Valves (SRVs) }\end{array}$ & $* * * *$ & & $* * *$ & \\
\hline Drywell (DW) Area & $* * * *$ & $* * *$ & $* *$ & $*$ \\
\hline Suppression Chamber (SC) & $* * * *$ & $* * *$ & & \\
\hline Pedestal / RPV-lower head & $* * * *$ & & $* * *$ & ** \\
\hline Instrumentation & & $* * * *$ & $* * *$ & \\
\hline \multicolumn{5}{|c|}{ Reactor Pressure Vessel (RPV) } \\
\hline Upper Vessel Penetrations & $* * * *$ & & $* * *$ & ** \\
\hline Upper Internals & $* * * *$ & $* * *$ & $* *$ & $*$ \\
\hline Core Regions \& Shroud & $* * * *$ & & $* * *$ & $* *$ \\
\hline Lower Plenum & $* * * *$ & & $* * *$ & $* *$ \\
\hline
\end{tabular}

a. Examination Classification Examples:

Visual- Videos, Photographs, etc.

Near-Proximity- Radionuclide Surveys, Seismic Integrity Inspections, Bolt Tension Inspections, and Instrumentation Calibration Evaluations

Destructive- System or Component Disassembly, Sampling, etc.

Analytical- Chemical Analysis, Metallurgical Analysis, Gamma Scanning, etc.

b. Prioritization based on number of asterisks, e.g., more asterisks designate a higher priority on this information.

\footnotetext{
${ }^{\dagger}$ Because of the hydrogen explosion damage observed at Unit 4 (1F4), this unit is also of interest.
} 
Another important conclusion is that much information is already available. As discussed in Section 1.3.2, Objective 2 activities evaluate available information and make additional requests, if required.

\subsubsection{Objective 2 Activities}

Activities used to complete the second objective are shown in Figure 1-1. As shown in this figure, activities and products completed by U.S. organizations focus on Phase 2 Activities associated with the Mid-and-Long-Term Roadmap for D\&D (the blue box; see Section 2.3). As indicated by the gray box, severe accident and plant operations experts from U.S. industry, universities, and national laboratories evaluate plant examination information obtained from Daiichi. Since its origin, the forensics effort has striven to include a broad spectrum of U.S. stakeholder input. Objective 2 activities are also informed by experts from the U.S. NRC, U.S. DOE, and TEPCO Holdings that participate in expert panel meetings.

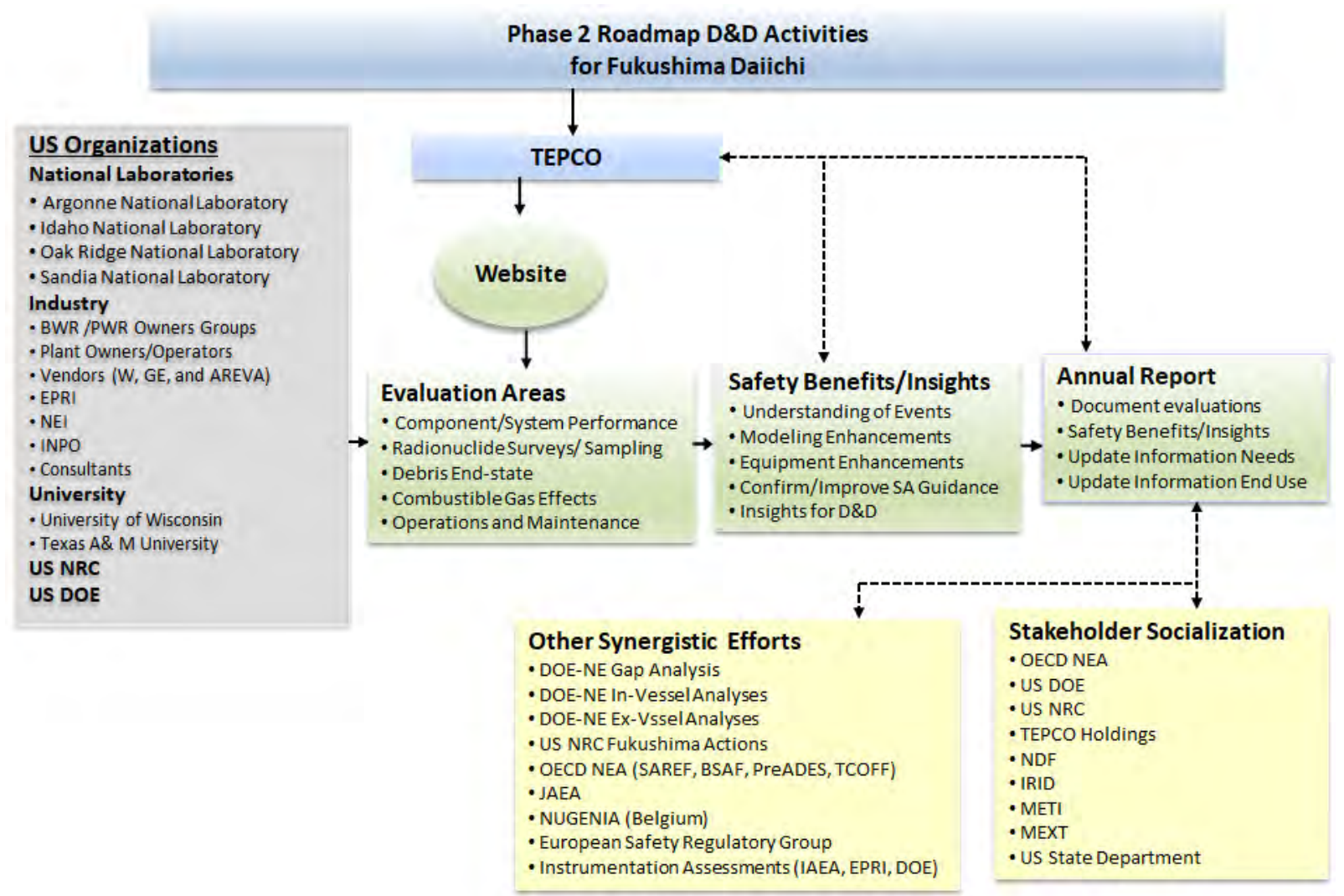

Figure 1-1. Objective 2 activities.

Activities and products completed by U.S. organizations are shown in green. Severe accident and plant operations experts evaluated information from five higher priority topic areas identified by the panel. These areas are:

- Component/System Performance

- Radiological Sampling and Surveys

- Core Debris End-state 
- Combustible Gas Effect

- Operations and Maintenance ${ }^{* *}$

The expert panel agreed to add the fifth area, "Plant Operations and Maintenance," in FY2018 This area covers a range of topics of interest to industry, starting with the instrumentation survivability information obtained from examinations at Daiichi.

The primary source of information used in U.S. Forensics Effort evaluations is the TEPCO Holdings website.[9] Presentations provided by representatives from TEPCO Holdings,[10 through 21], industry[22-25], and topic area leads[e.g., 26 through 36]. TEPCO Holdings reports documenting unconfirmed and unresolved issues also received special attention in the forensics effort.[37 through 42] The website created by the Institute of Applied Energy (IAE)[43] is also an important reference for this effort. In addition, a website has been developed by this program to archive key references used by U.S. experts to complete these evaluations.

As previously discussed, these evaluations lead to several types of safety benefits and insights:

- Increased understanding of the events that occurred at each of the affected units at Daiichi

- Enhanced severe accident analysis models (reduced severe accident modeling uncertainties)

- Increased understanding of equipment performance during severe accidents

- Confirmed / improved guidance and training for severe accident prevention, mitigation, and emergency planning

- Additional insights beneficial to future D\&D activities

As shown in Figure 1-1, U.S. experts prepare an annual report documenting results from these evaluations and updates related to the U.S. information needs. For each area, prioritized questions of interest are identified; available information is reviewed; and insights gained from evaluating this information are provided. Where appropriate, information needs are updated, and a complete list of information needs that includes these updates is developed. Additional details, such as the benefits, use, and suggested methods for obtaining higher priority, near-term examination activities are also provided.

\subsubsection{Other Considerations}

In completing Objective 2 activities, there are other considerations (shown in yellow boxes in Figure 1-1). These other considerations are important aspects of this forensics effort. The first consideration relates to other synergistic efforts that are discussed in Section 2.2. These other efforts, including those funded by DOE, those completed by NRC, and those organized by other agencies and other organizations, are considered in these U.S. activities. In addition, as discussed in Section 2.2, results from this U.S. effort support several aspects of these synergistic efforts. The second consideration relates to interactions with other stakeholders to garner support for forensics activities. For example, copies of reports issued in prior years were provided to external stakeholders.

\footnotetext{
* This fourth area was added in FY2016.

** This fifth area was added in FY2018.
} 


\subsection{Report Objectives and Organization}

This report summarizes efforts by U.S. experts to evaluate available examination data to address information needs in higher priority areas of interest. The balance of this report is organized as follows. Section 2 provides background information related to prior efforts to obtain similar information from the TMI-2 PWR and provides an overview of other synergistic efforts of interest to this Forensics Effort. Section 2 also reviews the organization and schedule for D\&D activities within Japan. Sections 3 through 7 primarily summarize insights from recent efforts to evaluate information in the areas of component /system degradation, dose surveys / isotopic surveys and sampling, debris end-state, combustible gas effects, and operations and maintenance. Each of these sections identifies key questions of interest and insights gained from the information evaluated. Limitations associated with the insights and recommendations related to future DOE program activities and examination information are also provided. Section 8 of this report summarizes key insights and recommendations from this effort. In addition, Section 8 identifies how insights and recommendations from this effort are being implemented. References are listed in Section 9. Appendices to this document provide more detailed information. Specifically, Appendix A provides lists of attendees and agendas from the U.S. Forensics Effort expert meetings held during FY2018. Appendix B provides a description of the U.S. Forensics website used to archive noteworthy references relied upon in this effort. Appendix C provides updated tables with detailed information needs developed by U.S. experts and additional details for high priority, nearer term examination activities. Appendix D contains recent schedules produced by the Japanese Government that detail planned D\&D activities. Appendices E through $\mathrm{H}$ provide supplemental information for Sections 3 through 7 of this report. 


\section{BACKGROUND}

As part of this project, experts review important aspects of the TMI-2 evaluation process, synergistic activities underway by other U.S. and international organizations, and D\&D plans by Japanese organizations. These reviews ensure that current efforts are cognizant of lessons learned from past inspection programs, avoid duplication with other synergistic activities, and are coordinated with on-going D\&D plans.

\subsection{TMI-2 Post-Accident Evaluations}

Post-accident insights related to what occurred at TMI-2 required an integrated set of information that included post-accident videos, examinations of core debris and vessel structure samples, instrumentation data, calculation results from 'best-estimate' severe accident analysis tools, separate effects laboratory test results, and in some cases, data from large integral tests. [1,6,44,45] Video examinations and ultrasonic scanning surveys were initially used to determine the shape, dimensions, and mass of materials remaining in the reactor vessel and the damage sustained by internal support structures and penetrations (see Figure 2-1). Several types of samples were removed from the reactor pressure vessel, including fuel, cladding, control rods, fuel support structures, and in-core instrumentation nozzles. Samples from within the primary coolant system and the reactor containment building were also obtained. Analyses to interpret and integrate these information sources were crucial because insufficient data were available from any single source to uniquely quantify information required for D\&D and develop a consistent understanding of the TMI-2 accident scenario.
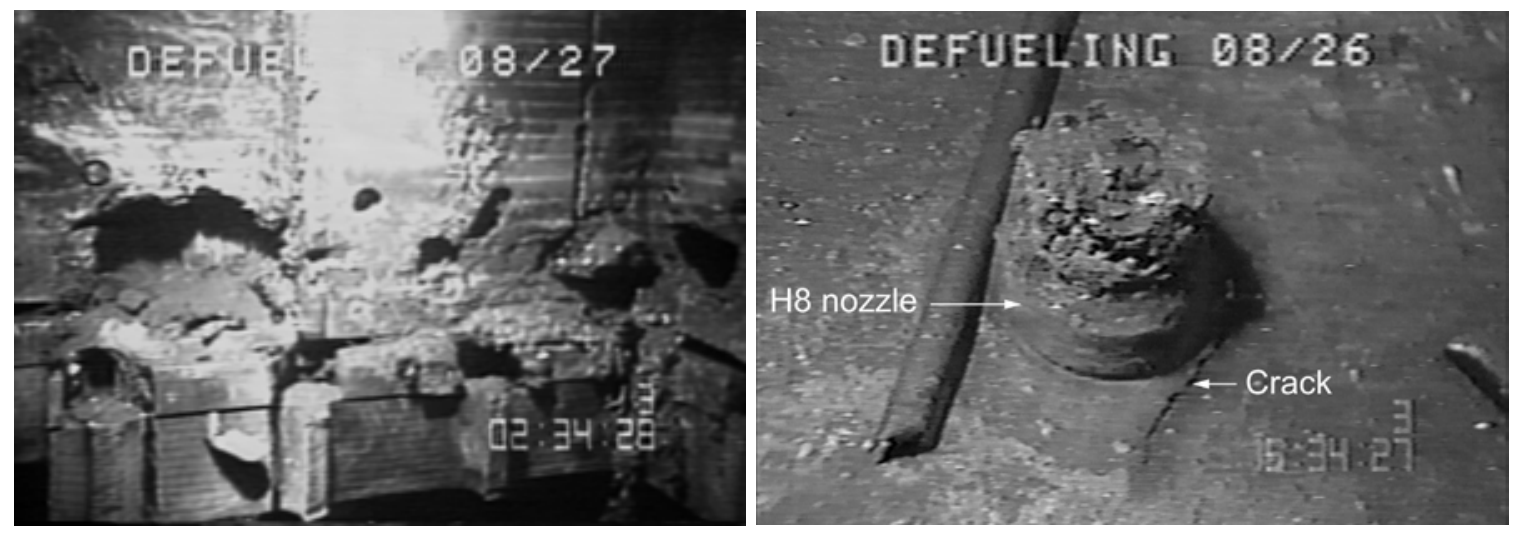

Figure 2-1. TMI-2 video examinations revealed locations where damage to core barrel and nozzles was more severe. (Courtesy of FirstEnergy)

A systematic investigation of the cost versus the benefits of specific TMI-2 inspection information is not available. Such an investigation could provide insights related to the desired number and type of sample measurements, better characterization of hazards associated with D\&D activities, the feasibility of advanced sample extraction techniques, and the benefit of separate effects testing. In addition, such evaluations might identify useful information not obtained from TMI-2 that should be obtained from Daiichi. Nevertheless, U.S. experts applied available TMI-2 experience to identify information needs from Daiichi. For example, information needs developed by U.S. experts focus on visual information that could provide important insights at a lower cost (see Section 1.3.1). Clearly, such information from within the TMI-2 vessel and the containment offer important insights at a lower cost than insights gained from post-accident examinations of radioactive samples. 
Although examination information did not reduce regulatory oversight, it enabled General Public Utilities (GPU) to address several technical issues required for TMI-2 defueling, including:

- Core Debris Condition - Initial examination and sampling activities provided evidence that large portions of the core exceeded clad oxidation and melting temperatures, that significant fuel liquefaction and melting occurred, and that large fractions of core material (up to 20,000 kg) relocated.[46] Evaluations also found that fission product retention was significant within samples of core materials. Such information caused TMI-2 cleanup plans and equipment to be revised.

- Recriticality - As documented in [47,48], the allowable fuel mass limit was increased from 70 to $140 \mathrm{~kg}$ for defueling and long-term storage condition evaluations. This limit was developed using more realistic assumptions based on data obtained from debris samples, video inspections, and other defueling data that were unavailable at the time of the original 1985 analysis. The data provided a better understanding of the accident scenario and the actual debris configuration and composition, permitting refined and more realistic modeling. Calculation results, in conjunction with available information from examinations showing that the fuel was oxidized and mixed with structural material, were used to select which parameters to monitor during defueling and shipping.

- Pyrophoricity - The TMI-2 Technical Advisory Group (TAG) raised concerns about possible pyrophoric reactions from cutting and removal of debris containing metallic Zircaloy, uranium/zirconium alloy, and zirconium hydride. As documented in [48,49], theoretical evaluations, prior experience, and separate effect tests were completed to show that conditions to cause such reactions were limited; and examination information was used to confirm that such conditions were not present at TMI-2.

- Hydrogen Generation - There were concerns about radiolytic hydrogen generation associated with debris defueling, transportation, and storage. Examination information related to debris composition and oxidation [48] was used to demonstrate that the off-gas system would preclude formation of combustible gas concentrations.

- Fission Product Gas Release - There were concerns that chipping of the fuel could lead to release of gaseous fission products. As documented in [46,48,50], knowledge of the fuel compositions and fission product retention alleviated such concerns.

- Plant growth within the RPV - It had not been anticipated that conditions within the reactor vessel would allow plant growth (e.g., radiation levels were high). Decayed plant material stopped cleanup operations because visibility was significantly reduced.[51] Underwater cameras within the vessel were unusable. Hydrogen peroxide was injected into the water to remove decayed plant material. Concerns about adverse effects, such as chemical reactions or recriticality, associated with injecting this hydrogen peroxide were addressed using examination information.

In summary, examination information was essential for TMI-2 cleanup efforts. The importance of this experience was emphasized during the workshop, TMI-2 Knowledge Transfer and Relevance to Fukushima Meeting (See Appendix E of [3]).

\subsection{Synergistic Efforts}

As part of their post-Fukushima actions, the U.S. NRC, the U.S. DOE, and industry continue to support several efforts in the severe accident area. Furthermore, several international activities have been initiated. To minimize duplication, it is important to remain cognizant of such activities. Table 2-1 lists synergistic activities of special interest to the U.S. Forensics Efforts. This section highlights activities sponsored by U.S. and international organizations. Japan's D\&D activities are summarized in Section 2.3. 
Table 2-1. Synergistic activities of special interest ${ }^{\mathrm{a}}$

\begin{tabular}{|c|c|c|}
\hline Country & Organization(s) & Activity/Objective \\
\hline \multirow[t]{5}{*}{ U.S. } & \multirow[t]{3}{*}{ DOE } & $\begin{array}{l}\text { Severe Accident Analyses; Perform MAAP analyses to confirm SAGs (and SAWA / SAWM } \\
\text { strategies). Perform 'MELCOR/MAAP crosswalk' to identify differences in predictions for } \\
\text { in-vessel and ex-vessel evaluations and root cause for observed differences. Develop software } \\
\text { for Technical Support Center staff. }\end{array}$ \\
\hline & & $\begin{array}{l}\text { Accident Tolerant Component Performance; Conduct analysis and experiments on hard- } \\
\text { ware-related issues, including systems, structures and components with the potential to prevent } \\
\text { core degradation or mitigate the effects of severe events }\end{array}$ \\
\hline & & $\begin{array}{l}\text { Passive Plant Safety Assessments; Conduct analysis to evaluate synergistic effects of accident } \\
\text { tolerant fuel, extended operation of emergency core cooling equipment, and novel containment } \\
\text { heat sink approaches on extending plant coping time during a severe accident }\end{array}$ \\
\hline & NRC & $\begin{array}{l}\text { MAAP/MELCOR, ASTEC/MELCOR, and MELCOR/SAMPSON crosswalk analyses, partici- } \\
\text { pation in DOE, CNWG and OECD activities, and support regulatory decisions using MELCOR } \\
\text { analyses benchmarked against evaluations of affected units at Daiichi. }\end{array}$ \\
\hline & Industry & $\begin{array}{l}\text { Performing PWR and BWR MAAP analyses to confirm SAGs, participating in MAAP/MEL- } \\
\text { COR crosswalk, participating in OECD and DOE activities (e.g., BSAF, Forensics, etc.); Imple- } \\
\text { menting actions to address potential vulnerabilities associated with operating nuclear power } \\
\text { plants and associated facilities. }\end{array}$ \\
\hline \multirow[t]{2}{*}{ Japan } & $\begin{array}{l}\text { NDF, IAE, IRID, } \\
\text { JAEA, TEPCO Hold- } \\
\text { ings }\end{array}$ & D\&D Activities; Complete D\&D of affected reactors at Daiichi (see Section 2.3) \\
\hline & $\begin{array}{l}\text { JAEA, MHI, CRIEPI, } \\
\text { Universities }\end{array}$ & $\begin{array}{l}\text { Gap Analysis; Identifies gaps in knowledge about the performance of existing safety systems } \\
\text { and the need to develop new materials, components, and systems with enhanced performance. }\end{array}$ \\
\hline $\begin{array}{l}\text { U.S. - } \\
\text { Japan }\end{array}$ & $\begin{array}{l}\text { U.S.: DOE and NRC } \\
\text { JAPAN: JAEA, NRA, } \\
\text { METI, MEXT, NDF, }\end{array}$ & $\begin{array}{l}\text { CNWG; Collaborative activities related to wide range of research, including examinations, } \\
\text { instrumentation, analyses, and workshops, such as the TMI-2 Knowledge Transfer and Rele- } \\
\text { vance to Fukushima Meeting held in Idaho Falls, ID during October } 2016 .\end{array}$ \\
\hline \multirow[t]{2}{*}{ EU } & $\begin{array}{l}\text { NUGENIA (includes } \\
\text { SARNET) }\end{array}$ & $\begin{array}{l}\text { Prioritization Evaluations; Prioritize R\&D topics and use ranking results to 'harmonize' and } \\
\text { 'reorient' existing R\&D program as well as justify new research topics. }\end{array}$ \\
\hline & ENSREG & $\begin{array}{l}\text { Stress Tests; Complete reassessments of the safety margins in EU nuclear power plants. Evalu- } \\
\text { ations consider 'extraordinary' external events, such as earthquakes and floods, and conse- } \\
\text { quences of other initiating events }\end{array}$ \\
\hline \multirow[t]{4}{*}{$\begin{array}{l}\text { OECD - } \\
\text { NEA }\end{array}$} & $\begin{array}{l}\text { NEA Senior Expert } \\
\text { Group on SAREF }\end{array}$ & $\begin{array}{l}\text { Senior group of technical and regulatory experts formed to identify activities and research } \\
\text { opportunities to address safety research gaps and advance safety knowledge related to the } \\
\text { Fukushima Daiichi nuclear accident and to support safe and timely decommissioning in Japan. } \\
\text { As an outgrowth, several near-term follow-on projects are underway or proposed. }\end{array}$ \\
\hline & PreADES & $\begin{array}{l}\text { Proposed near-term follow-on SAREF project that will include: fuel debris characterization } \\
\text { (analytical, experimental); evaluation of radiation doses during fuel debris retrieval operations; } \\
\text { and discussion on future long-term projects (fuel debris sampling) }\end{array}$ \\
\hline & BSAF & $\begin{array}{l}\text { Improve severe accident codes by analyzing the accident progression and status of 1F1, 1F2, } \\
\text { and 1F3 using a common information database. Phase I analyses covered the first six days of } \\
\text { the accidents and focused on thermal-hydraulics and estimating distribution and composition of } \\
\text { degraded core materials. Phase II analyses extended to the first three weeks of the accident and } \\
\text { focused on fission product releases and transport within the PCV, the RB, and offsite. Results } \\
\text { support D\&D at Daiichi and identification of data needs for code validation. }\end{array}$ \\
\hline & TCOFF & $\begin{array}{l}\text { Follow-on project to perform a detailed thermodynamic characterization for predicting the sta- } \\
\text { tus of fuel debris and fission products within } 1 \mathrm{~F} 1,1 \mathrm{~F} 2 \text { and } 1 \mathrm{~F} 3 \text {. }\end{array}$ \\
\hline
\end{tabular}

a. See acronym list. 


\subsubsection{U.S. Efforts}

As discussed below, synergistic activities performed by the U.S. DOE, the U.S. NRC, and the U.S. industry are of interest to and informed by the U.S. DOE Forensics Effort.

\subsubsection{U.S. DOE}

After the initial response to the events at Daiichi, the U.S. DOE funded high priority safety research activities with the goals of gaining a more thorough understanding of the events that occurred at Daiichi, to identify and reduce in-vessel and ex-vessel severe accident modeling uncertainties, especially with respect to BWR phenomena, and to inform industry efforts in refining guidance to prevent significant core damage and to mitigate source term release during a severe accident. The selected activities were prioritized based on results of a technology gap evaluation completed by U.S. experts in LWR operations and safety with representatives from industry, DOE-NE staff, the national laboratories, and universities.[52, 53] Evaluation results emphasized that information from the damaged Fukushima reactors provides the potential for key insights that could be used to help address virtually all the identified gaps. Information obtained from these units not only offers the potential to fill these gaps and reduce uncertainties in severe accident progression, but may also inform potential safety enhancements. Figure 2-2 identifies current DOE-funded tasks (in yellow) within the Reactor Safety Technologies (RST) pathway of the Light Water Reactor Sustainability (LWRS) program and their relationship to information obtained from the affected reactors at Fukushima. As described in [54], remaining tasks fall into two activity groups: severe accident analyses and accident tolerant component performance.

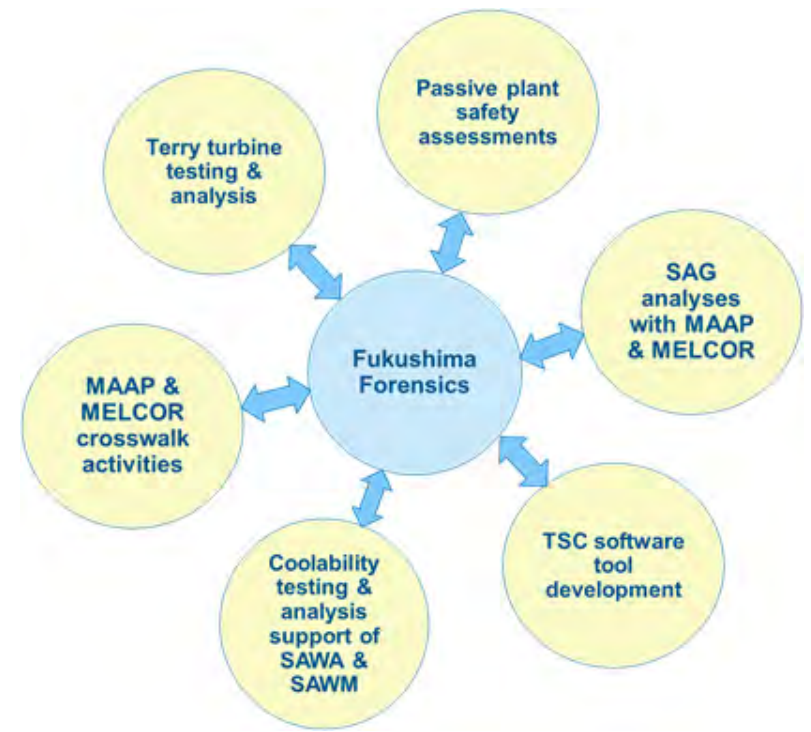

Figure 2-2. LWRS RST pathway tasks and relationship to forensic information from Fukushima. (Courtesy of ANL)

\section{- Severe Accident Analyses}

As discussed below, information obtained from the affected reactors at Daiichi affect all RST severe accident analyses tasks [e.g., MAAP \& MELCOR crosswalk tasks, coolability testing \& analysis in sup- 
port of severe accident water addition (SAWA) strategies, severe accident management guidance evaluations, and technical support center (TSC) software tool development].

Analyses of events occurring in the affected units at Daiichi indicated notable differences in predictions obtained from the industry-developed MAAP and the U.S. NRC-developed MELCOR systems analysis codes.[55 through 57] A cross-walk activity between the MAAP and MELCOR development teams was then completed to determine the principal modeling differences between the two codes that led to such differences in predicting in-vessel core melt progression phenomena. Results indicate that the principal phenomenological uncertainty relates to the extent that degraded core materials are permeable to gas flow. Namely, impermeable debris (assumed in MAAP) gradually accumulates as a large high temperature in-core melt mass similar to that formed during the TMI-2 accident, while permeable debris (assumed in MELCOR) steadily relocates to the lower head and collects as a debris bed. These in-vessel modeling differences lead to significant differences in subsequent severe accident phenomena, such as hydrogen production, the timing and location of vessel failure, and ex-vessel melt spreading phenomena.[58,59] The DOE and the Electric Power Research Institute (EPRI) continue to conduct analyses using existing computer models to provide information and insights into severe accident progression.[60] Results from these analyses aid in post-Fukushima enhancements to BWR and PWR SAG to confirm strategies, such as severe accident water addition (SAWA) and Severe Accident Water Management (SAWM), and for training operators on this guidance. In the case of ex-vessel analyses, an on-going core debris coolability test program is being used to gather additional data for validating, and enhancing if needed, severe accident codes.

\section{- Accident Tolerant Component Performance}

Results from the gap analyses [52] also emphasize the need to better characterize the performance of several hardware components and safety systems during severe accidents. To address this, the U.S. DOE has worked with industry to develop models and launch a test program to better determine the actual operating envelope for BWR Reactor Core Isolation Cooling (RCIC) and PWR Auxiliary Feed Water (AFW) Terry $^{\mathrm{TM}}$ turbine systems under severe accident conditions. The workscope of this activity could be expanded to investigate the performance of other equipment, such as BWR Safety Relief Valves (SRVs) and PWR Pilot-Operated Relief Valves (PORVs) under severe accident conditions. Insights from examinations at the affected units at Daiichi will also provide important information regarding the performance of BWR systems and components.

This area has been expanded to investigate passive plant component cooling concepts, such as the synergistic effects of extended RCIC/AFW pump performance coupled with Accident Tolerant Fuel (ATF) and/or DW head cooling to increase plant coping time during a severe accident. Analyses with codes, such as MELCOR and MAAP, can be used to quantify the benefit of proposed new components or strategies, such as ATF, extended operation of emergency core cooling equipment, and novel containment heat sink approaches to extending plant coping time during a severe accident. In some cases, these evaluations will require new models and /or data. Hence, it is also important that insights from forensics evaluations be incorporated into these codes to reduce uncertainties in accident progression phenomena and improve assessments of proposed new options. 


\subsubsection{U.S. NRC}

NRC Long-Term Response. In their initial response to the events at Fukushima, the NRC initiated an intensive 90-day effort to document insights (as they were known at that time) and make recommendations for enhancing the plant capability to respond to Beyond Design Basis External Events (BDBEE).[61] Results from this effort are documented in a report that contained twelve high level recommendations with each having several unique individual recommendations. To address these recommendations, the NRC Commissioners could require safety enhancements through an Order if there was not adequate protection of the health and safety of the public or the Commissioners could direct the NRC staff to initiate rulemaking to require safety enhancements. In the latter case, proposed safety enhancements must be shown to be cost beneficial using established processes.[62, 63]

The Commission issued Orders EA-12-049 (Mitigation Strategies; Emergency Equipment), EA-12-050 (Hardened Vents), and EA-12-051 (Spent Fuel Instrumentation), as well as a request for information letter to licensees to re-confirm resistance to beyond design basis seismic and flooding events.[64, $65,66,67$, respectively]

Subsequently, the NRC staff issued Order EA-13-109[68] to replace and improve requirements in EA-12-050 (ensuring that hardened vents would remain functional after core damage occurred and ensuring that plant personnel could operate the vents under those conditions). In August 2015, the Commission directed the staff to cease rulemaking activities related to EA-13-109; although the other requirements of the Order stands.[69] As of June 2018 [70], 25 of the 30 reactors covered by the Order have met the requirements of the Order's first phase (upgrade the venting capabilities from the containment wetwell), and 11 of 30 have met the requirements of the second phase (install a reliable, severe accident capable drywell vent, or develop a reliable containment venting strategy).

Other post-Fukushima regulatory actions, included those outlined in EA-12-049 and EA-12-051, will be provided for in rulemaking. As of June 2018 [70], all plants have obtained their additional onsite portable equipment. The U.S. nuclear industry has also established and stocked two offsite response centers. The vast majority of the plants have satisfied the requirements of the emergency equipment. NRC staff have inspected the compliance of 49 sites with EA-12-049. Every operating U.S. reactor has met the requirements for the Order pertaining to spent fuel pool instrumentation.

Initially, recommendations related to SAG were planned to also be addressed in rulemaking. However, in [71], the Commission directed the staff to remove requirements imposing SAMGs from this rulemaking. Rather, the Commission instructed the staff to revise their Reactor Oversight Process, such that the staff would periodically review industry's voluntary implementation of updated SAG. Efforts continue to finalize the rule related to post-Fukushima actions.[72]

As of June 2018 [70], all plants have submitted their earthquake and flooding re-analyses. Based on those re-analyses, 49 reactor sites have completed limited additional earthquake evaluations. Five of 18 sites have completed more detailed seismic probabilistic risk analyses. Forty of 47 sites have completed limited flooding evaluations. One of four sites has completed a more detailed integrated assessment of the flooding impacts on their site.

Initially, recommendations related to SAG were planned to also be addressed in rulemaking. However, in [71], the Commission directed the staff to remove requirements imposing SAMGs from this rulemaking. Rather, the Commission instructed the staff to revise their Reactor Oversight Process, such that the staff would periodically review industry's voluntary implementation of updated SAG. 
Efforts continue to finalize the rule related to post-Fukushima actions.[72] and several aspects of emergency preparedness. The NRC's website includes more information on Fukushima-related actions. [73]

NRC Research Program. As documented in [74,75], the U.S. NRC severe accident research program supplies the agency a strong technical foundation for decision-making related to degraded core phenomena identified in probabilistic risk assessments. The Office of Nuclear Regulatory Research (RES) develops, maintains, and applies computational tools and methods to evaluate and resolve safety issues and to perform risk-informed decision-making. The RES maintains the MELCOR code [8] for the analysis of postulated severe accident progression and the MELCOR Accident Consequence Code System (MACCS) [76] to evaluate offsite consequences from a hypothetical release of radioactive material into the atmosphere.

As noted by Lee [77], NRC severe accident phenomena expertise informed regulatory actions to address post-Fukushima activities. Recognizing the uncertainties in severe accident phenomena, the agency relies on computational tools developed from the severe accident research program to consider these uncertainties and estimate the margins that exist in LWRs during severe accidents. Results obtained from these analyses provide the agency essential input for regulatory decisions. The U.S. NRC continues their severe accident research activities to reduce uncertainties in such input and to assess the importance of new phenomena that may need to be considered in such computational evaluations. Participation in international severe accident research programs, general and specific to Fukushima forensics [75], and collaborating with the U.S. DOE on Fukushima activities leverages the agency's limited resources and maintains staff expertise on emerging issues. As noted in [78], NRC collaboration on Fukushima activities is key for reducing uncertainties related to severe accident phenomena.

\subsubsection{Industry}

In response to the events at Daiichi, industry led efforts within the U.S. to take independent steps to develop diverse and flexible coping strategies for BDBEEs, known as FLEX.[79] The focus in the U.S. was clearly on enhancements to guarantee continued core, containment, and spent fuel pool cooling in the event of beyond design basis accidents, particularly those resulting from extreme external events. The industry continues to utilize Owners Group committees that assess and upgrade the SAG as appropriate "to ensure nuclear energy facilities are capable of a symptom-based response to events that could impact multiple reactors at a single site" as described in "The Way Forward".[80]

Industry developed and documented proposed enhancements and submitted them to NRC for endorsement. These enhancements provided guidance for individual plants concerning acceptable methods for satisfying the issues that led to these NRC Post-Fukushima Orders and recommendations. Industry enhancements include:

- $\quad$ Enhanced mitigation capability for BDBEEs,[79]

- Staffing and communications recommendations,[81]

- Implementation of new spent fuel pool instrumentation,[82]

- Plant walkdowns to ensure adequate flooding protection, [83]

- Reliable containment venting for Mark I and Mark II BWRs,[84]

- Integration of accident management procedures and guidelines,[85]

- Enhanced emergency response preparedness,[86, 87]

- Seismic evaluation guidance,[88,89] and

- On-going maintenance of generic SAGs and support for site specific implementation.[87, 90] 
U.S. enhancements for BDBEEs center around the FLEX concept, which involves strategies to maintain core cooling, containment and spent fuel pool cooling for a wide range of BDBEEs that result in loss of all a.c. power (onsite and offsite) as well as access to the ultimate heat sink for an indefinite period. The strategies rely upon a combination of fixed, in-place and portable equipment protected from BDBEEs. They also involves staffing, communications, procedures and guidelines, and training to assure that strategies are implemented in a timely manner. FLEX defines three phases of response to a BDBEE: 1) initial response using fixed in-place capabilities until portable resources can be implemented, 2) portable onsite resources that are adequate until offsite equipment can be brought to the site and implemented, and 3) portable offsite resources at one of two national centers [90] that can be deployed to a site within 24 hours.

Revisions to BWROG and PWROG severe accident management guidance considered available information from Daiichi. Some of the insights based on events at Daiichi include:

- Hydrogen combustion can occur in structures adjacent to the primary containment,

- Primary containment integrity can be challenged when conditions exceed the design basis,

- Water injection to the reactor vessel is generally preferred over injection to the primary containment, and

- Primary containment venting will assure long term control of fission product releases, and

- Turbine driven pumps can be operated in extreme beyond design basis conditions.

As documented in [23 through 25], the basis for each of these insights was drawn from forensic evidence reviewed by U.S. experts participating in this effort. On-going efforts by industry focus on reducing conservatisms in SAG, improving calculational aides and technical basis that support severe accident strategies, and validating possible instrumentation response during severe accident conditions.[24,25]

\subsubsection{International}

The response to the Fukushima accident has been global, resulting in multiple activities by numerous international stakeholders. Post Fukushima-related topics, such as accident mitigation strategies, accident monitoring systems, and overall reactor safety have been the focus of international working groups and meetings sponsored by various agencies, such as the International Atomic Energy Agency (IAEA), and the Nuclear Energy Agency (NEA) of the Organization for Economic Cooperation and Development (OECD). In addition, associations and groups such as NUclear GENeration II \& III Association (NUGENIA) and the European Nuclear Safety Regulators Group (ENSREG) are focusing on the same safety-related areas. To avoid duplication of effort, it is important that the U.S. program remain cognizant and informed by these efforts. Activities of special interest are summarized below.

\subsubsection{Japan}

Clearly, the D\&D activities underway in Japan are of interest to U.S. DOE efforts. Section 2.3 of this report describes the organizational structure and current roadmap for completing these activities. For our U.S. efforts to be successful (and to minimize the impact of inspection activities), it is critical to remain cognizant of Japanese plans for completing D\&D activities and of results from these activities. Furthermore, it is important that U.S. experts provide timely input to Japan related to their experiences from D\&D activities completed at TMI-2 and results from our safety evaluations. 


\section{- Gap Analysis}

The Atomic Energy Society of Japan completed a severe accident gap analysis within Japan.[91,92] This evaluation focused on quantifying limitations of current reactor systems and identifying research to overcome these limitations. Twelve prioritized research topics were selected using input from the Japan Atomic Energy Agency (JAEA), Toshiba, Hitachi-GE Nuclear Energy, Mitsubishi Heavy Industry (MHI), Central Research Institute of Electric Power Industry (CRIEPI), and several universities (University of Tsukuba and Kyoto University). Identified research areas include: development of new reactor materials (e.g., cladding and core catcher); evaluations of the performance of systems, such as the passive containment cooling system, passive auto-catalytic recombiners, hydrogen removal systems, and filter venting systems; and development of new instrumentation and measurement devices that can survive severe accident conditions. A roadmap was developed to ensure that a systematic approach is used to complete these research activities. Clearly, these areas of research present good opportunities for collaboration between Japan and the U.S. As discussed below, some of these opportunities are covered under existing bilateral agreements between Japan and the U.S. Other opportunities can be pursued through international collaborations in which Japan and the U.S. participate.

\section{- CNWG}

A Civil Nuclear Energy Research and Development Working Group (CNWG) has been established under the U.S.-Japan Bilateral Commission on Civil Nuclear Cooperation to enhance coordination of joint civil nuclear R\&D efforts between the DOE and Japan's Ministry of Economy, Trade and Industry (METI) and Ministry of Education, Culture, Sports, Science and Technology (MEXT).[93] Formal arrangements have been established covering collaboration in multiple areas including several relevant to LWR safety and post-accident evaluation [94]; namely, i) severe accident code assessment, ii) accident tolerant fuel, iii) accident tolerant equipment (including instrumentation), and iv) probabilistic risk assessment. Bilateral collaboration is underway in these areas. In 2016, it was agreed to include the area of reactor examination planning as it relates to informing D\&D activities within Japan.

In addition, METI requested that the U.S. hold a workshop to facilitate transfer to Japan of knowledge that the U.S. gained from D\&D activities at TMI-2. Accordingly, the U.S. DOE and U.S. NRC jointly sponsored the "US-Japan TMI-2 Knowledge Transfer and Relevance to Fukushima," in Idaho Falls, Idaho on October 11-12 2016. Over 35 U.S. experts, currently employed by or previously employed by national laboratories, the U.S. NRC, the U.S. DOE, and industry, such as EPRI, First Energy Corporation (formerly General Public Utilities), and Fauske and Associates, LLC (FAI), attended this event, which featured presentations and panel discussions regarding first-hand knowledge of TMI-2 and other U.S. cleanup activities. Japan sent nearly 35 representatives from METI, Nuclear Damage Compensation and Decommissioning Facilitation Corporation (NDF), TEPCO Holdings, International Research Institute for Nuclear Decommissioning (IRID), JAEA, the Nuclear Regulatory Authority (NRA), and Japan's embassy in Washington, DC. The workshop focused on topics such as an effective safety policy, adequate regulations, and appropriate public communication in a highly charged political environment after an accident. There was great interest among Japanese participants in the process used to design safe shipping and storage casks for the damaged fuel and what was required to address the possibility of re-criticality accidents. Experts also discussed topics such as the use of robotics versus manual clean up tools and balancing of cost versus safety considerations. Appendix E of [3] provides additional information about this meeting. 


\subsubsection{OECD/NEA}

The OECD/NEA is sponsoring Committee for Nuclear Safety Installations (CSNI) and Nuclear Science Committee (NSC) efforts to ensure that the international community is aware of safety insights from the events at Fukushima. $[95,96]$ Activities of special interest are highlighted in this section.

\section{- BSAF Analyses}

An ongoing analysis activity is the OECD/NEA Benchmark Study of the Accident at the Fukushima Daiichi Nuclear Power Plant (BSAF) project.[97] The project, which is hosted by the IAE in collaboration with other Japanese organizations such as JAEA, NRA, and CRIEPI, is an international effort aimed at performing accident reconstruction analyses using a number of severe accident codes, including MELCOR and MAAP. The objective of the project is to improve severe accident codes, to analyze the accident progression and status of $1 \mathrm{~F} 1,1 \mathrm{~F} 2$, and $1 \mathrm{~F} 3$, and provide useful information for the decommissioning of these units. The reconstruction analyses make use of known accident boundary conditions and measurements, such as estimated water injections, operations of emergency equipment [e.g., RCIC, HPCI, etc.], reactor depressurization actions, and containment venting actions. These analyses compare results from a collection of international severe accident analysis codes and provide analytical insights into the estimated damage state of each reactor. Characterization of the damage states includes estimates of the melted core regions, the mass of relocated core materials to the lower head, possible pressure vessel failure locations (e.g., lower head or steam line), and the amount of reactor cavity concrete attack by molten core materials. Hence, results from these analyses inform decommissioning activities by providing estimates of core relocation masses and inform data needs that may be addressed during D\&D activities. In return, examination and photography of upper reactor vessel internals and steam lines can provide valuable information for validating code estimates of damage in these regions.

The first phase of the BSAF project, which focused mainly on the accident progression and core damage phase in the reactor pressure vessels and primary containment vessels for the first six days of the accident, was completed in 2015.[98] A total of 17 organizations from 8 countries participated in this phase of BSAF. The first phase concluded with a comparison of bounding debris endstates and compositions predicted by organizations participating in this effort. Although results differ, these bounding estimates inform D\&D activities by Japan. Participants also identified important uncertainties associated with BWR accident progression phenomena, such as the impact of larger zirconium inventories and the effects of boride and carbide inclusions in relocated BWR materials. Phase 2 of the BSAF project (BSAF2), which started in April 2015, is aimed at characterizing release and transport of fission products outside the PCVs and lengthening the time-span for analyses of the accident events to around three weeks. Environmental releases will include both aqueous pathways as well as atmospheric releases. Validation information will be sought from sampling of radiological depositions along these release pathways, including the ground deposition data for cesium in the countryside around the accident site. Jäckel[99] illustrates the type of information from the Daiichi site that will be used in this effort and conclusions that can be obtained from these evaluations. Phase 2 of this project, which includes organizations from 11 countries, is anticipated to be completed in 2018. In support of these BSAF projects, the IAE has developed a website[43] containing useful information to support Fukushima Daiichi accident analysis and decommissioning activities.

The U.S. DOE and U.S. NRC participate in this NEA project. This participation is important because BSAF analysis results inform on-going DOE activities in evaluating and improving severe accident analysis models. In addition, results from examination activities inform ongoing BSAF analyses, and analyses results may lead to revisions in U.S. information needs. 


\section{- SAREF Research Opportunities from Fukushima}

Another noteworthy effort by the NEA's senior expert group (SEG) on SAfety REsearch opportunities post-Fukushima (SAREF). Created in 2013, the objective of this CSNI effort is to establish a process for identifying and following up on research opportunities to address safety research gaps and advance safety knowledge related to the Fukushima Daiichi nuclear accident and support safe and prompt decommissioning activities in Japan. Organizations from eleven countries participate in this activity. The NRA of Japan chairs the group. The work scope includes identifying research opportunities that use information from Daiichi to gain safety knowledge of common interest to member countries. In their report [100], the SEG identified 16 specific topics of interest in three areas; namely i) severe accident progression, ii) system, structure, and component (SSC) performance, and iii) recovery phase.

The SEG prioritized information from Daiichi with respect to its importance for making decisions regarding safe execution of decommissioning activities and with respect to reactor safety. In addition, the SEG considered the 'ease' of obtaining information without adversely impacting decommissioning activities (e.g., visual examinations that contribute to understanding RCIC system or safety relief valve performance). The SEG recommended that focus is placed on the following areas with high safety and decommissioning interest:

- Severe Accident Progression (In-vessel Phenomena, Ex-vessel Phenomena, Containment Failure and Venting, Fission Product Behavior and Source Term)

- SSC Performance and Conditions (Mission Time and System Survivability)

- Recovery Phase (Long-term Accident Management and Recovery)

The SEG determined that it would be beneficial to undertake some near-term activities to provide additional information for planning long-term activities. Two initial projects, Preparatory Studies for Fuel Debris Analysis (PreADES) and Thermodynamic Characterization of Fuel Debris and Fission Products based on Scenario Analysis for Severe Accident Progression at Fukushima-Daiichi NPS (TCOFF), are underway.[101]

The PreADES project aims to summarize knowledge and expertise regarding fuel debris characteristics generated from a severe accident and to optimize methodologies for assessing fuel debris sampling and retrieval. The project includes the following activities:

- Share and update information and expertise on fuel debris generated from severe nuclear accidents;

- Jointly compile and evaluate selected topical issues based on updated data and information, and identify research gaps and priorities; and

- Prepare future collaborative R\&D plans on analysis of $1 \mathrm{~F}$ fuel debris

The TCOFF project aims to improve the thermodynamic database for fuel debris and fission products by considering available analytical and experimental studies. The improved characterization of fuel debris and fission product behavior will provide valuable input to the decommissioning process already in progress and support prioritizing future sampling in the RPV/PCV. Furthermore, if unpredicted materials are discovered within the RPV/PCV, possible scenarios leading to the formation of such materials will be developed. Project results are also expected to improve the thermodynamic databases for fuel and structural materials used to evaluate fuel assembly degradation and fission product transport.

The U.S. DOE and U.S. NRC participate in the current SAREF and BSAF projects, including the PreADES project. It is envisioned that there will be strong interactions between the PreADES, BSAF, and 
TCOFF projects. It is important for U.S. DOE efforts to be cognizant of and contribute to appropriate international efforts. Ultimately, results from these efforts may lead to the establishment of a larger international examination effort in which the U.S. will participate.

\subsubsection{European Union (EU)}

\section{- NUGENIA/SARNET Research Prioritization}

NUGENIA is an association dedicated to the research and development of nuclear fission technologies, with a focus on Generation II and III nuclear plants. Primarily composed of organizations based in Europe, it includes stakeholders from industry, research, and safety organizations. Synergistic activities sponsored by NUGENIA $[102,103]$ originate within the Severe Accident Research NETwork of Excellence (SARNET) [NUGENIA Technical Area 2] which has the objectives of:

- Improving knowledge on severe accidents to reduce uncertainties on pending issues, thereby enhancing plant safety,

- Coordinating research resources and expertise available in Europe, and

- Preserving the research data and disseminating knowledge.

Participants in SARNET include representatives from 47 organizations; although most organizations are based in Europe, there are organizations from Korea, India, Japan, and the U.S. (e.g., the NRC). Of interest are results from SARNET efforts to prioritize research programs. As discussed within [104], recent SARNET evaluations ranked the six highest priority safety issues as: in-vessel core coolability, molten-core-concrete-interaction (MCCI), fuel-coolant interaction, hydrogen mixing and combustion in containment, impact of oxidizing conditions on source term, and iodine chemistry. Similar to the U.S. DOE strategy, SARNET uses this ranking to 'harmonize' and 'reorient' existing R\&D programs and justify new research topics. Through the NRC, the U.S. collaborates on many EU higher priority research projects (see Section 2.2.1).

\section{- $\quad$ ENSREG Stress Tests}

The European Nuclear Safety Regulators Group (ENSREG) is an independent, authoritative expert body created in 2007 following a decision of the European Commission. It is composed of senior officials from the national nuclear safety, radioactive waste safety or radiation protection regulatory authorities and senior civil servants with competence in these fields from all EU member states and representatives of the European Commission. ENSREG's role is to help to establish the conditions for continuous improvement and to reach a common understanding in the areas of nuclear safety and radioactive waste management.

ENSREG [105] efforts to complete follow-on activities related to "stress tests" on EU nuclear power plants are of special interest. These stress tests, which were requested in March 2011, are targeted reassessments of the safety margins in nuclear power plants. They consider 'extraordinary' external events, such as earthquakes and floods, and the consequences of other initiating events, such as airplane crashes, that have the potential to lead to loss of multiple safety functions. All operators of nuclear power plants in the EU had to review the response of their plants to those extreme situations and identify mitigating measures and actions. The operators' reports were first reviewed by the national nuclear regulators. Then, the regulatory agency from each country prepared National Action Plans (NAcPs) that document actions and measures to improve the safety of nuclear power plants. These NAcPs were peer reviewed by an ENSREG panel. As each country implements these actions and measures, the NAcPs are updated and peer reviewed by ENSREG. Observers from the U.S. NRC and other countries participate in these reviews. 


\subsubsection{Summary}

In summary, a range of post-Fukushima activities are underway. Although none duplicate the effort documented in this report, many international efforts have synergistic objectives. Clearly, it is important that the effort documented in this report benefit from and provide input to other on-going efforts. Future efforts within this effort will continue to be cognizant of and coordinate with other on-going efforts to avoid duplication and to maximize its benefit.

\subsection{Decontamination \& Decommissioning Activities}

Examination efforts by TEPCO Holdings are primarily focused on obtaining data required to support D\&D efforts. However, the government of Japan recognizes information collected from Daiichi is important to not only Japan for D\&D efforts, but also to international organizations for reactor safety.[106] Furthermore, international participation may be beneficial to Japan because of expertise related to severe accident progression and, in the case of the U.S., because of expertise gained from prior TMI-2 and other D\&D efforts. Although financial constraints and national needs dictate that the primary responsibility of TEPCO Holdings is to obtain information required to support D\&D activities at Daiichi, the examination information is being used by the international community to enhance safety (e.g., data for validating severe accident models, source term models, etc.).

Likewise, it is important that the U.S. Forensic Effort be cognizant of the organization and schedule for D\&D activities within Japan. This section highlights the organizational structure for completing D\&D and the strategy for prioritizing D\&D activities. Near-term activities and inputs for key D\&D decisions are outlined to emphasize areas where this U.S. effort could use inspection information to benefit on-going D\&D efforts in Japan and meet U.S. objectives to enhance reactor safety.

\subsubsection{Organization}

In 2014, the government of Japan reorganized organizations involved in D\&D efforts at Daiichi.[106, 107,108] Major organizations involved in this new structure are shown in Figure 2-3. The Nuclear Damage Compensation and Decommissioning Facilitation Corporation (NDF) was established to strengthen decommissioning strategies. NDF has the responsibility to develop and issue annual updates to the "Technical Strategic Plan for Decommissioning of the Fukushima Daiichi Nuclear Power Station of Tokyo Electric Power Company Holdings" (e.g., the Strategic Plan), which contributes to implementation (and future revisions) of the "Mid- and-Long-term Roadmap towards the Decommissioning of TEPCO's Fukushima Daiichi Nuclear Power Station" (e.g., the "Roadmap") issued by the Government of Japan and for ensuring appropriate and steady conduct of decommissioning at Daiichi. In May 2017, the Nuclear Damage Compensation and Decommissioning Facilitation Corporation Act was amended to require TEPCO to deposit decommissioning funds with the NDF. Under the new system, as the organization responsible for managing and supervising decommissioning activities, NDF will: 1) manage the funds for decommissioning; 2) manage the implementing structure of the decommissioning process; and 3) manage the decommissioning work under the decommissioning fund reserve system.[106] As depicted in Figure 2-3, D\&D at Daiichi is accomplished as a coordinated effort between the NDF for making strategy- and technology-related decisions, TEPCO Holdings for developing an "Implementation Plan" for completing on-site operational activities related to D\&D, the International Research Institute for Nuclear Decommissioning (IRID) for implementing R\&D to support technology development for fuel debris retrieval, and JAEA for implement- 
ing required R\&D to support decommissioning technologies. The Nuclear Regulatory Authority (NRA) oversees D\&D activities to ensure that necessary safety measures are taken and that the plant is maintained in a stable condition. To promote collaboration among relevant institutions within Japan, NDF established the Decommissioning R\&D Partnership Council. In addition, JAEA established the Collaborative Laboratories for Advanced Decommissioning Science (CLADS) as a global research and development organization, and JAEA began operating the Naraha Remote Technology Development Center for development and verification testing of D\&D equipment.

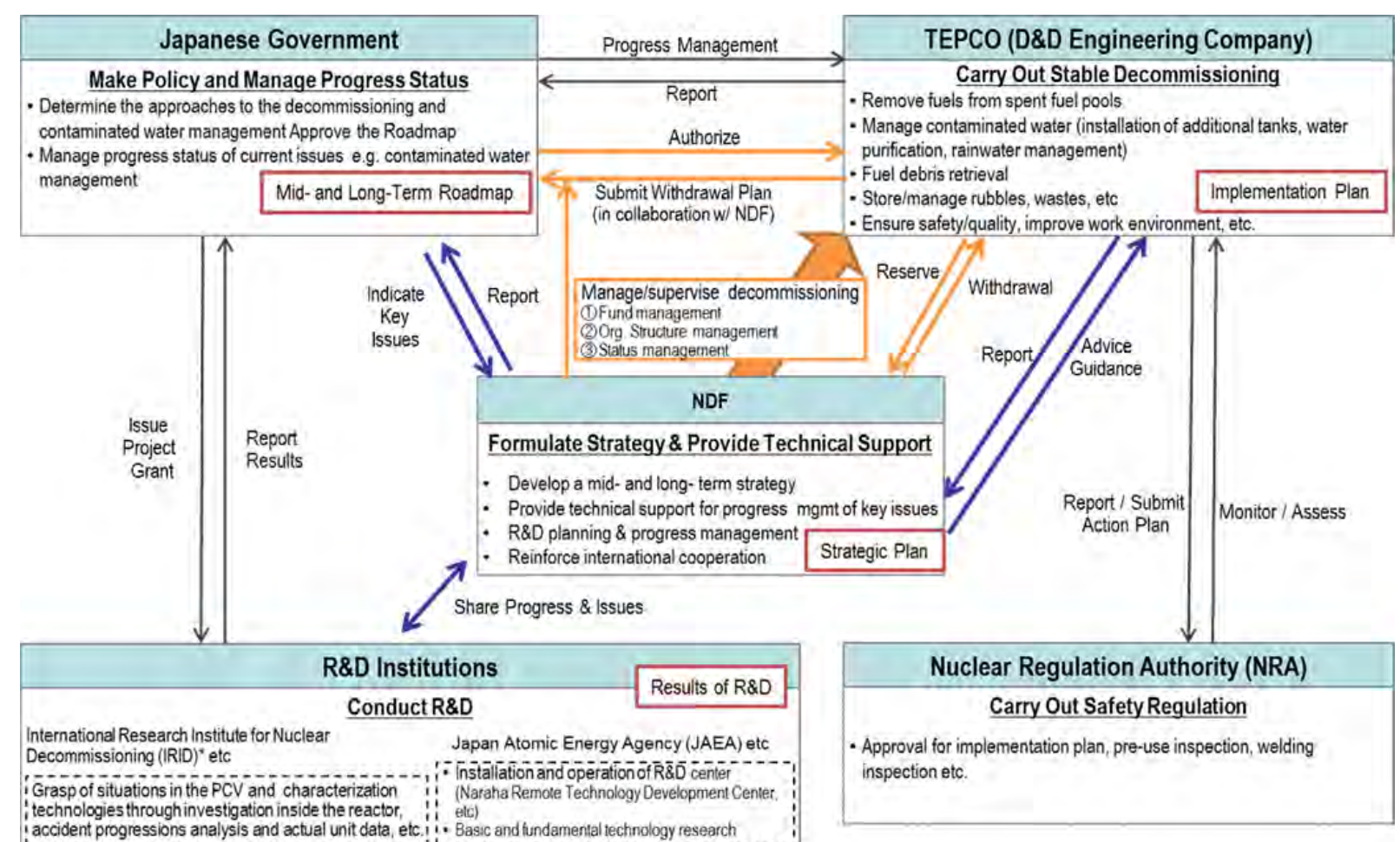

Figure 2-3. Roles and responsibilities of organizations involved in decommissioning Daiichi. (Courtesy of NDF [106])

\subsubsection{Strategic Plan}

Since 2015, NDF has annually developed strategic plans for decommissioning of Daiichi. The 2017 Strategic Plan [106] issued by NDF provides a strong technical basis for implementing the government of Japan's mid-and-long-term roadmap. In addition, it provides strategic proposals for "deciding fuel debris retrieval policies for each unit" and compiles "basic concepts of processing and disposal for solid waste".

There is a high level of uncertainty associated with the characteristics and location of radioactive materials and the damage to equipment and buildings at Daiichi. High radiation levels preclude direct access to the affected units at Daiichi, making it difficult to reduce this uncertainty. Building upon concepts in earlier strategic plans issued by Japan, the 2017 Strategic Plan emphasizes the need for risk reduction by applying five guiding principles:

- Principle 1: Safe-reduction of risks ${ }^{\dagger \dagger}$ posed by radioactive materials and ensuring work safety;

- Principle 2: Proven-highly reliable and flexible technologies; 
- Principle 3: Efficient-effective utilization of resources (human, physical, financial, and space);

- Principle 4: Timely-awareness of time axis;

- Principle 5: Field-oriented-thorough application of the "Three Actuals" (actual field, actual things and actual situation).

Activities to reduce the risk from environmental impacts as well as risk to D\&D workers are considered. The risk levels at Daiichi are based on evaluations of the 'hazard potential' (or consequence), which considers the total amount and form of radioactive materials from various sources and 'safety management' (or likelihood of release), which considers factors such as the integrity of facilities and containment functions. Figure 2-4 shows major risk sources and levels based on information available in March 2017. Areas for each risk source represent uncertainty associated with available data. Results from such analyses are used to group and prioritize D\&D activities based on the potential for risk reduction.

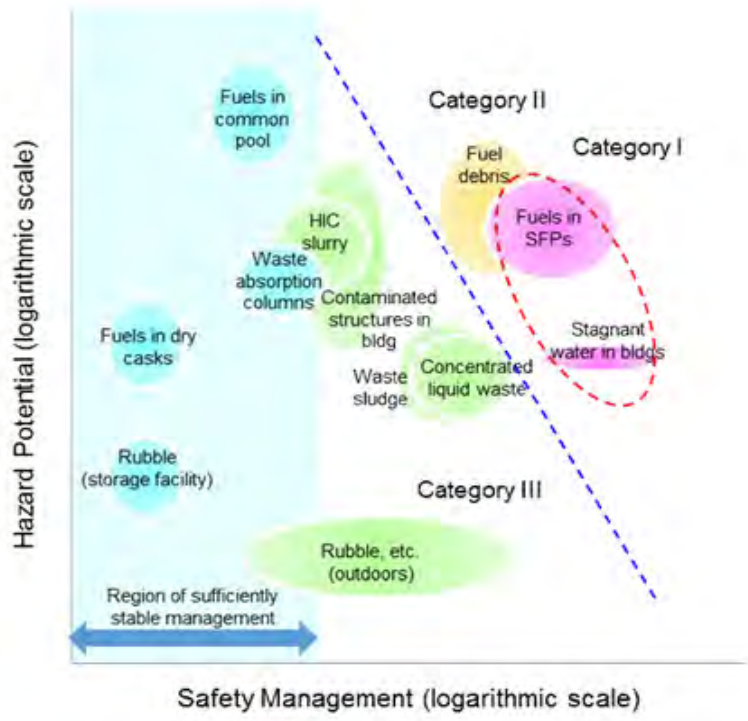

Figure 2-4. Risk associated with various D\&D sources at Daiichi. (Courtesy of NDF [106])

As outlined in [106], D\&D activities are grouped into three categories based on risk reduction:

- Category I risk sources to be addressed as soon as possible (the fuel in SFPs and stagnant water shown in the upper right-hand corner in Figure 2-4);

- Category II risk sources to be addressed in a safe, effective and careful manner with elaborated preparation and technologies, and bring to a more stable state (the fuel debris shown in Figure 2-4);

- Category III risk sources to be systematically addressed to achieve a more stable state (these sources are focused on reducing the risk for the solid wastes, concentrated liquid wastes, and other wastes shown in blue and green in Figure 2-4).

While the primary objective is to complete the D\&D as early as possible, efforts must not adversely impact the safety of the public or plant workers. D\&D activities must be monitored to alleviate concerns about maintaining containment, cooling, criticality control, PCV and RB structural integrity, occupational radiation exposure, radiation releases, increasing hydrogen concentrations, and non-nuclear industrial accidents.

$\dagger$ Environmental impacts and exposure to the workers. 


\subsubsection{Mid-and-Long-Term D\&D Roadmap Activities and Schedule}

Because there is uncertainty in many aspects of the plant conditions, especially with respect to the internal conditions of the PCV, various approaches are being considered for D\&D activities. Current D\&D plans are documented in the Roadmap, which is updated periodically as new knowledge is gained from the affected reactors at Daiichi. The initial "Mid-and-Long-Term Roadmap towards the Decommissioning of TEPCO's Fukushima Daiichi Nuclear Power Station Units 1-4" (i.e., the Mid-and-Long-Term Roadmap) was developed in December 2011 at the 'Government and TEPCO's Mid-to-Long Term Countermeasure Meeting' to indicate processes to recover from the accident at Daiichi. In June 2013, June 2015, and September 2017, revised versions of the roadmap were issued.[108] Further revisions will take place as additional information is obtained about the actual conditions within each unit. Periodic updates on D\&D progress are provided in a format consistent with activities outlined in the Roadmap (e.g., see [108]).

The roadmap provides U.S. experts general insights about the schedule and types of activities completed and underway by TEPCO Holdings. In addition, results from these activities are posted on TEPCO's website and discussed in periodic updates provided by TEPCO Holdings. As discussed in Section 2.3.2, the Mid-and-Long-Term Roadmap divides the time until completion of D\&D into phases, identifies major tasks to be undertaken onsite, and the associated R\&D schedule (see Figure 2-5).

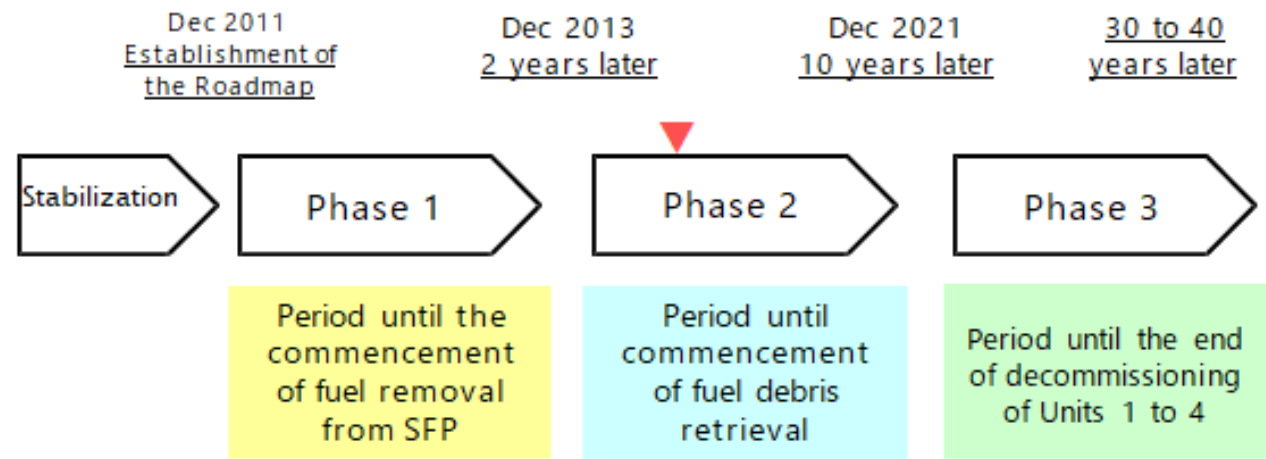

Figure 2-5. Roadmap phase definition; red pointer designates current status. (Courtesy of NDF [107]

Phase 1 represents the time period between plant stabilization (i.e., when radiation levels were low and releases were minimized) until the time when fuel removal from the spent fuel pool (SFP) begins. Phase 2 started in November 2013 with activities to remove the spent fuel from 1F4 and will continue until fuel is removed from the other reactors. Phase 2 includes R\&D for fuel removal and PCV repair operations. This includes $R \& D$ related to removing fuel from the spent fuel pools, preparing for removal of fuel from the $\mathrm{RPV}$, and processing and disposal of solid radioactive waste. In addition, there is R\&D related to alternative options for remote technologies that could reduce the challenges associated with D\&D. Reference [108] provides additional details related to the scope and schedule of R\&D activities. It is estimated that Phase 2 activities will require approximately 10 years to complete. Phase 3 spans from the completion of Phase 2 until the plant is decommissioned. It is currently estimated that Phase 3 activities will be completed within 30 years (resulting in up to 40 years for the complete D\&D of the affected units). The schedule is based on current knowledge of differences in the condition of each unit. For example, because 1F2 experienced less damage to the reactor building, several D\&D activities within the building were completed earlier in this unit. Efforts are made to optimize opportunities to overlap required processes and operations between units. However, schedules may change as additional knowledge is gained. 
Figure 2-6 provides a high level summary of tasks for completing Phase 2 and 3 activities (more detailed schedules showing dates when prior activities were completed and planned dates for completing upcoming activities are provided in Table 2-2). In addition, Appendix D provides more detailed schedules for selected activities from the 2017 Strategic Plan, illustrating how results from other activities, such as the OECD/NEA PreADES, BSAF, and TCOFF efforts, are incorporated into D\&D efforts.[106] As discussed within [108], a step-by-step approach is used, emphasizing reduction in risk to workers and the environment, consideration of various alternatives for debris retrieval and storage, and learning from on-going activities.

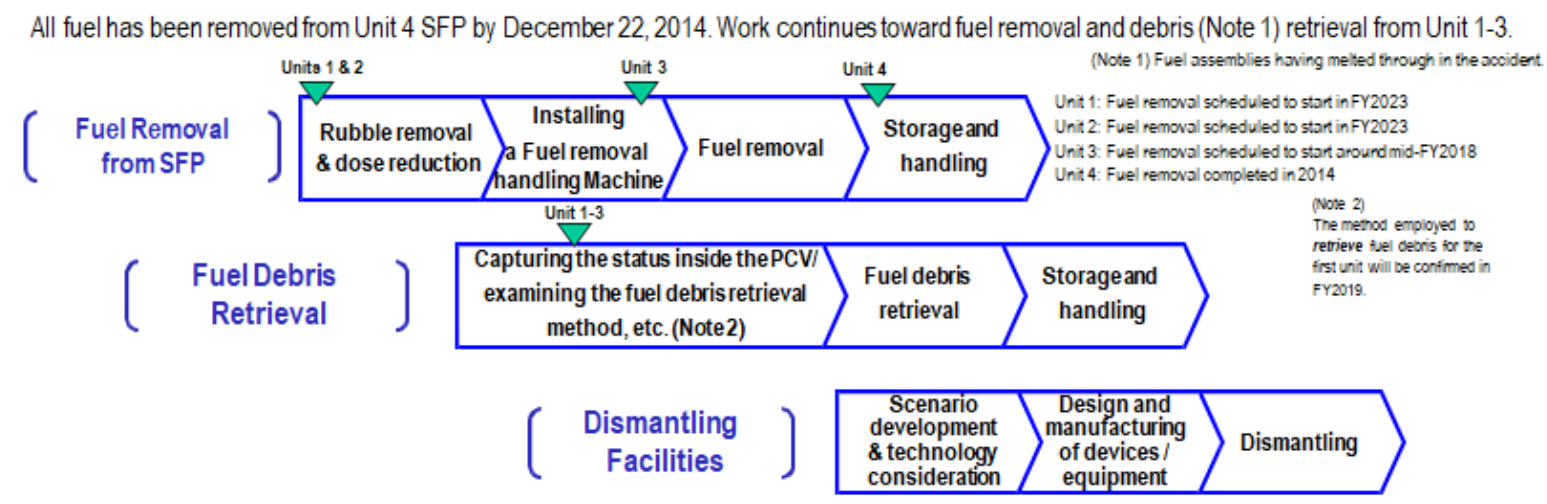

Figure 2-6. Summary schedule showing main decommissioning works, steps, and milestones. (Courtesy of Inter-Ministerial Council for Contaminated Water and Decommissioning Issues [108])

Table 2-2. Major milestones in the Mid-and-Long Term Roadmap (based on information in [108])

\begin{tabular}{|c|c|c|}
\hline Area & Description & Timing ${ }^{\mathrm{a}}$ \\
\hline \multicolumn{3}{|c|}{ 1. Contaminated Water Management } \\
\hline \multicolumn{2}{|c|}{ Reduction of contaminated water generation to about $150 \mathrm{~m}^{3} /$ day } & Within 2020 \\
\hline \multicolumn{2}{|c|}{ All purified water by purification equipment etc. is stored in welding type tank } & FY2018 \\
\hline \multirow{3}{*}{$\begin{array}{l}\text { Completion } \\
\text { of Stagnant } \\
\text { Water } \\
\text { Treatment }\end{array}$} & 1) Separation of the penetrations between Units 1 and 2 and between Units 3 and 4 & FY 2015 \\
\hline & $\begin{array}{l}\text { 2) Reduction of radioactive materials in stagnant water in buildings to } \sim 1 / 10^{\text {th }} \text { FY } 2014 \\
\text { levels }\end{array}$ & FY 2018 \\
\hline & 3) Completion of treatment of stagnant water in buildings & Within 2020 \\
\hline \multicolumn{3}{|c|}{ 2. Fuel Retrieval from Spent Fuel Pools } \\
\hline \multicolumn{2}{|c|}{ 1) Start of fuel retrieval from $1 \mathrm{~F} 1$} & $\begin{array}{l}\text { Estimated } \\
\text { FY2023 }\end{array}$ \\
\hline \multicolumn{2}{|c|}{ 2) Start of fuel retrieval from $1 F 2$} & $\begin{array}{l}\text { Estimated } \\
\text { FY2023 }\end{array}$ \\
\hline \multicolumn{2}{|c|}{ 3) Start of fuel retrieval from $1 \mathrm{~F} 3$} & Mid 2018 \\
\hline \multicolumn{3}{|c|}{ 3. Fuel Debris Retrieval } \\
\hline \multicolumn{2}{|c|}{ 1) Determination of fuel debris retrieval methods for the first implementing unit } & FY2019 \\
\hline \multicolumn{2}{|c|}{ 2) Start of fuel debris retrieval at the first implementing unit } & Within 2021 \\
\hline \multicolumn{3}{|c|}{ 4. Waste Management } \\
\hline \multicolumn{2}{|c|}{ Technical prospects concerning processing/disposal policies and their safety } & FY 2021 \\
\hline
\end{tabular}

a. In Japan, the Fiscal Year (FY) runs from April 1 through March 31. 


\subsubsection{Phase 2 D\&D Activities}

Near term D\&D activities are associated with completing critical milestones for Phase 2 of the Roadmap. Several activities are underway to characterize potential hazards and the ability of tasks to be successfully completed using the five guiding principles outlined in Section 2.3.2. Inspection information and analyses using 'state-of-the-art' computational tools are required to complete these evaluations.

\subsubsection{Fuel Debris Retrieval Methods}

Figure 2-7 shows the three debris retrieval methods under consideration. Due to difficulties associated with debris cooling and radiation levels, dry methods are not being considered for evaluations. Full and some partial water submersion levels utilizing top entry may require removal, shielded storage, and disposal of remnants of major structures, such as the steam dryer, the core plate, the core shroud, etc. The integrity of these structures during the removal process must also be considered. A full submersion water level requires repairs to stop leakage from the PCV. In the case of partial submersion water levels, additional shielding is required (and the weight of such shielding must be considered in evaluating the structural integrity of building structures during D\&D). Hence, it is planned to initially focus on a side-access method with partial submersion that would target any debris relocated to the bottom of the PCV. These efforts will include feasibility evaluations to address issues, such as determining an appropriate water height (to reduce dose levels) and demonstrating the ability to control this water level.

\begin{tabular}{|c|c|c|c|c|}
\hline \multicolumn{2}{|c|}{ Methods } & Submersion-Top Access & Partial Submersion-Top Access & Partial Submersion-Side Access \\
\hline \multirow{6}{*}{\multicolumn{2}{|c|}{$\begin{array}{l}\text { Concept Diagram } \\
\text { (Image) }\end{array}$}} & centionet & contenter & \\
\hline & & & manenant & \\
\hline & & & & \\
\hline & & & & \\
\hline & & & & \\
\hline & & & & \\
\hline \multicolumn{2}{|c|}{ Majpr Technical Requirements } & & & \\
\hline \multirow[t]{2}{*}{$\begin{array}{l}\text { Ensuring } \\
\text { Containment } \\
\text { Capability }\end{array}$} & $\begin{array}{l}\text { Liquid } \\
\text { Phase }\end{array}$ & $\begin{array}{l}\text { Hard to ensure water leak blockage capability of resisting hydrostatic } \\
\text { pressure when being submerged } \\
\text { Hard to ensure containment capability to remotely fix penetration holes for } \\
\text { upper PCV with lots of holes } \\
\text { Emergency water leak prevention measure is required as a large amount } \\
\text { of water is supposed to be kept. }\end{array}$ & $\begin{array}{l}\text { Technical difficulty is slightly lower as hydrostatic pressure is lower than } \\
\text { that of submersion case. } \\
\text { Penetration holes on upper PCV to be fix ed are limited. } \\
\text { It is possible to prevent water leakage even on emergencies depending } \\
\text { on water level settings. }\end{array}$ & $\begin{array}{l}\text { Technical difficultyis sightly lower as hydrostatic pressure is lower than } \\
\text { that of submersion case. } \\
\text { Penetration holes on upper PCV to be fix ed are limited. } \\
\text { It is possible to prevent water leakage even on emergencies depending } \\
\text { on water level settings. }\end{array}$ \\
\hline & $\begin{array}{l}\text { Gas } \\
\text { Phase }\end{array}$ & $\begin{array}{l}\text { Although air conditioning system with capability of maintaining negative } \\
\text { pressure is required, small scale equipment may be good enough. }\end{array}$ & $\begin{array}{l}\text { Air conditioning system with capability of maintaining negative pressure } \\
\text { for containing alpha-emitting nuclides is necessay. The scale of the } \\
\text { equipment will be large, but it can be feasible. }\end{array}$ & $\begin{array}{l}\text { Air conditioning system with capability of maintaining negative pressure } \\
\text { for containing alpha-emitting nuclides is necessary. The scale of the } \\
\text { equipment will be large, but it can be feasible. }\end{array}$ \\
\hline \multicolumn{2}{|c|}{ Maintaining Cooling Capability } & Feasible & Feasible & Feasible \\
\hline \multicolumn{2}{|c|}{ Criticality Management } & Preventing criticality when reactor core is covered with water is an issue. & $\begin{array}{l}\text { There is alow probability of re-criticality as reactor core will not be covered } \\
\text { with water. }\end{array}$ & $\begin{array}{l}\text { There is alow probability of re-criticality as reactor core will not be covered } \\
\text { with water. }\end{array}$ \\
\hline \multicolumn{2}{|c|}{$\begin{array}{l}\text { Stuctural Soundness / Seismic } \\
\text { Resistant Features of PCV and } \\
\text { RIB }\end{array}$} & $\begin{array}{l}\text {-Although the total weight of coolant in PCV and fuel debis retieval } \\
\text { equipment to be installed at upper R/B increases, seismic margin will be } \\
\text { ensured for major components. }\end{array}$ & $\begin{array}{l}\text { Although the total weight of fuel de bis retrieval equipment to be irstled } \\
\text { at upper R/B increases, seismic margin will be ensured for major } \\
\text { components. }\end{array}$ & $\begin{array}{l}\text { Better seismic margin will be ensured as fuel debris retrieval eqimert } \\
\text { will be installed on the first floor. }\end{array}$ \\
\hline \multicolumn{2}{|c|}{$\begin{array}{l}\text { Reducing Occupational } \\
\text { Radiation Ex posure }\end{array}$} & $\begin{array}{l}\text { Occupational radiation exposure would be of several times of the } \\
\text { post annual total ex posure when sealing upper PCV as there are lots of } \\
\text { penetration holes on the upper PCV. }\end{array}$ & $\begin{array}{l}\text { Occupational radiation ex posure would be less than the past annual thi } \\
\text { ex posure when sealing lowerPCV. }\end{array}$ & $\begin{array}{l}\text { Occupational radiation ex posure would be less than the past annual thit } \\
\text { ex posure when sealing lowerPCV. }\end{array}$ \\
\hline \multirow{2}{*}{$\begin{array}{l}\text { Establishing } \\
\text { Access Route }\end{array}$} & $\begin{array}{l}\text { Inner } \\
\text { RPV }\end{array}$ & $\begin{array}{l}\text { Scale of work concerning retrieval of fuel debris located in RPV could } \mathrm{\theta} \\
\text { significant as inner structures of reactor must be removed. }\end{array}$ & $\begin{array}{l}\text { Scale of work conceming retieval of fuel debris located in RPV could } \mathrm{\theta} \\
\text { significant as inner structures of reactor must be removed. }\end{array}$ & $\begin{array}{l}\text { Building anaccess route to fuel debris located inRPV is difficult at } \\
\text { present. }\end{array}$ \\
\hline & $\begin{array}{l}\text { PCV } \\
\text { Bottom }\end{array}$ & $\begin{array}{l}\text { Scale of work conceming rettieval of fuel debris located at the bottom } \\
\text { GPCV could be more significant than that of side-access method as it is } \\
\text { required to bore the bottom of RPV. }\end{array}$ & $\begin{array}{l}\text { Scale of work conceming retieval of fuel debris located at the bottom } \\
\text { GPCV could be more significant than that of side-access method as it is } \\
\text { required to bore the bottom of RPV. }\end{array}$ & $\begin{array}{l}\text { Scale of work conceming reteieval of fuel debris located at the bottom } \\
\text { GPC could be less significant than that of top-access method. }\end{array}$ \\
\hline \multicolumn{2}{|l|}{ Conclusions } & $\begin{array}{l}\text { Development of technologies for remotely fixing penetration holes for w由.t } \\
\text { sealing is difficult. } \\
\text { Total occupational ex posure conceming repair work could be enormous. }\end{array}$ & $\begin{array}{l}\text { It is necessary to continue development of technology for maitaing } \\
\text { negative pressure in order to contain alpha-emiting nuclides. } \\
\text { Both top-access and side-access would be required. }\end{array}$ & $\begin{array}{l}\text { It is necessary to continue development of technology for maitaing } \\
\text { negative pressure in order to contain alpha-emitting nuclides. } \\
\text { Both side-access and top-access would be required. }\end{array}$ \\
\hline
\end{tabular}

Figure 2-7. Debris retrieval methods under evaluation. (Courtesy of NDF [106]) 


\subsubsection{Debris End-state Location and Radionuclide Distribution}

As shown in Figure 2-8, a logic tree has been developed that shows activities used to understand the location, amount, and properties of fuel debris and distribution of fission products (FPs). Final selection of the feasibility of a debris retrieval method will consider examination information, such as i) plant data, ii) investigations using robots within the PCVs (photos, dose surveys, temperatures), and iii) muon tomography; predictions by severe accident analysis codes; and knowledge obtained from past accidents, and experimental investigations.

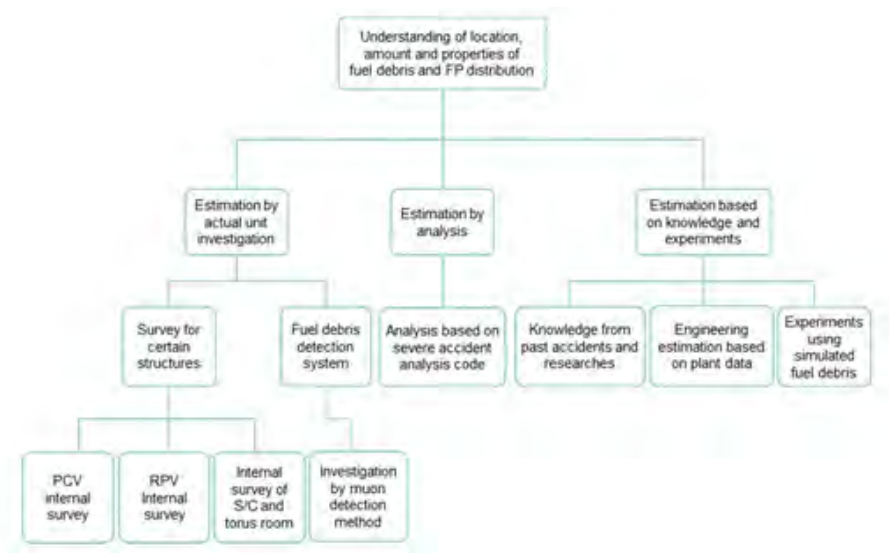

Figure 2-8. Logic tree identifying activities to understand location, amount, and properties of fuel debris and distribution of FPs. (Courtesy of NDF [107])

Using available plant instrumentation data, examination information (radiation surveys, images), and results from analyses performed using systems analysis codes (SAMPSON and MAAP), assessments related to debris end-state are summarized below in Figure 2-9. As shown in this figure, there is considerable uncertainty in such estimates, especially considering uncertainties with respect to BWR accident progression and of the timing of certain actions and events that occurred in each unit. However, these analyses provide important input to Phase 2 debris retrieval decisions, and results are updated as additional information becomes available.

Timely participation by U.S. experts in evaluating inspection information and results from severe accident analyses provide Japan an independent assessment for selecting retrieval options. This input may be of special benefit because U.S. researchers, who developed the models in severe accident analysis codes, are aware of model limitations and effects on subsequent source term assessments, and as noted previously, some U.S. experts were involved in TMI-2 post accident evaluations and relevant testing.

\subsection{Summary}

As part of their D\&D activities, TEPCO Holdings has been and will continue obtaining information of interest to the international community. The government of Japan recognizes that information collected from these reactors is important to Japan and international organizations. Financial constraints and national needs dictate that TEPCO Holdings efforts are primarily on obtaining data required to support D\&D efforts, but these data are also being used by the international community to enhance safety (e.g., data for validating severe accident models, source term models, etc.). 


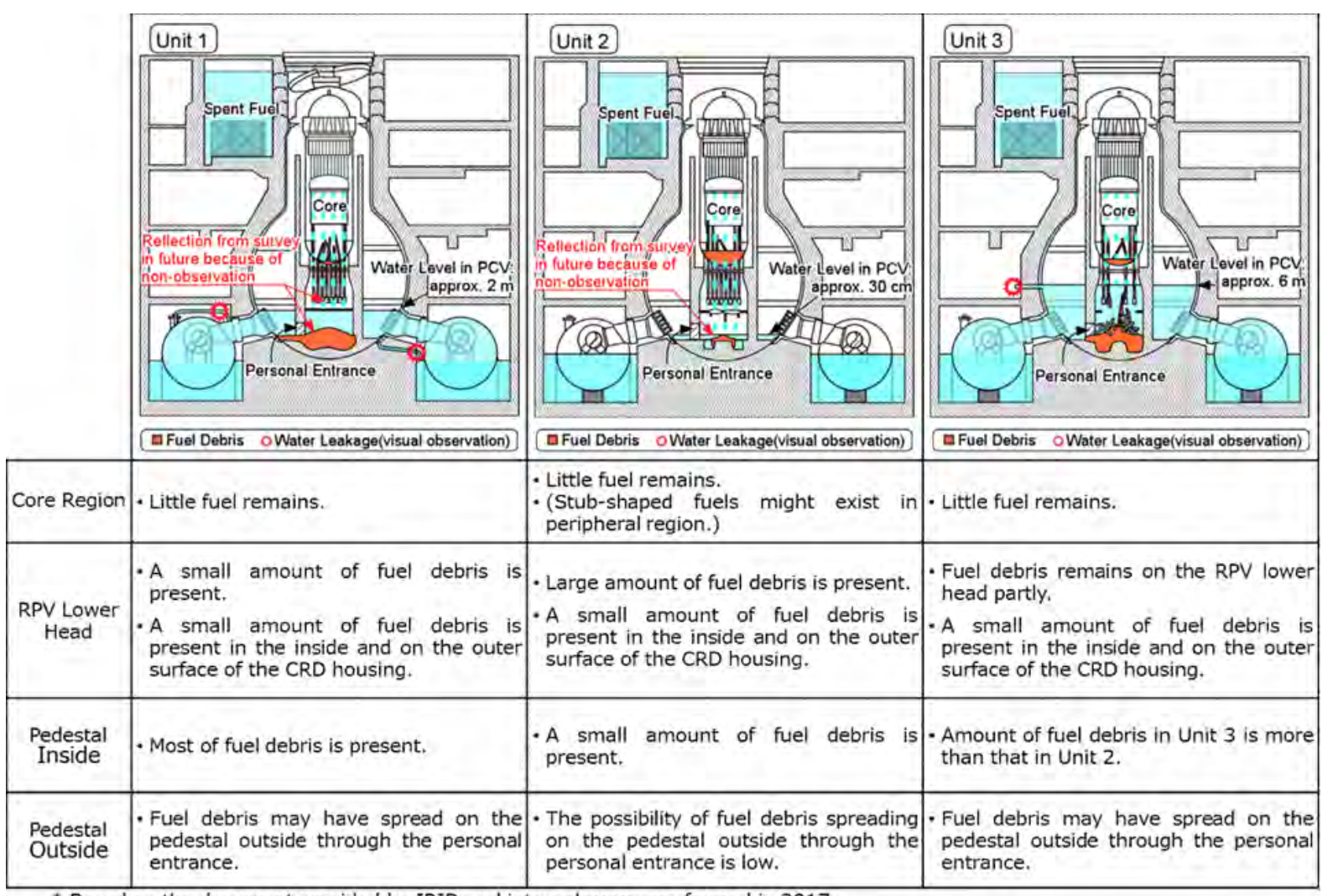

* Based on the document provided by IRID and internal survey performed in 2017.

Figure 2-9. Status of 1F1 through 1F3 including fuel debris location estimates. (Courtesy of NDF [106])

The DOE has established the U.S. Forensics Effort to work with TEPCO Holdings to learn what information is being obtained and to communicate this information to cognizant U.S. experts that could use this information to enhance safety of the U.S. commercial fleet. Appendix C contains lists of consensus information needs identified by U.S. experts. As new inspection information is obtained, U.S. experts can identify where current model predictions may need revision. 


\section{AREA 1 - COMPONENT /SYSTEM PERFORMANCE}

Examinations of components and systems within the RB, PCV, and RPV provide critical information related to their survivability, operability, and peak conditions (e.g., pressure and temperature) experienced during the accident. Damage incurred from seismic events, hydrogen explosions, radiation exposure, and high temperatures can provide insights related to the accident progressions. As observed in [6], component examinations in the TMI-2 containment provided critical evidence of peak temperatures and pressures when instrumentation data were inconsistent.

This section summarizes Fukushima Daiichi examination information that provides insights about component and system degradation and how this information can address uncertainties related to equipment performance and modeling uncertainty. To that end, we begin by identifying uses for this information (Section 3.1). Next, a summary of recent findings is provided (Section 3.2). Section 3.3 highlights recent findings regarding component and system performance from examinations. Additional findings and information previously reported are located in Appendix E. Section 3.4 summarizes insights from examination information and limitations of these insights. Several recommendations and observations are then provided regarding future activities to optimize insights and information gained from forensics studies (Section 3.5). The section concludes with questions and suggestions for additional information that would be beneficial regarding future assessments of equipment performance (Section 3.6). Note that additional information regarding component and system performance may also be found in Sections 4 through 7.

\subsection{Key Questions for Reactor Safety and D\&D}

Available information was evaluated by U.S. experts to address the following questions:

- What visual damage has been observed in components and structures within the RB, PCV, and RPV?

- What plant instrumentation data are available to support component and structure damage assessments?

- What insights can be gained from observed damage with respect to peak temperatures, peak pressures, radiation levels, effect of saltwater, combined effects (e.g., radiation enhanced temperature or mechanical damage, etc.), and multi-unit interactions?

- Can insights regarding component and structure performance be used to enhance reactor safety?

- Can information be used to confirm/improve severe accident guidance?

- Are analysis model improvements needed to predict observed damage?

- Can information from one unit be used to confirm analysis assumptions, assess model adequacy, and predict conditions in another unit?

- Can analyses with enhanced models be used to provide insights for future D\&D activities (e.g., damaged/deformed structures may be more difficult to remove, etc.)?

Answers to these questions can have significant safety impact, and data from the three units at Daiichi offer the potential to reduce modeling uncertainties. Improvements in modeling capabilities can be used to

$\$$ Although radiation survey and instrumentation data are primarily discussed in Sections 4 and 7 , the data also provide insights related to component damage. 
confirm or enhance, if needed, specific components or systems and to improve accident management strategies (e.g., containment venting, water addition, and combustible gas mitigation).

Answers to the above questions are also of interest to Japan with respect to Phase 2 D\&D activities. Component degradation information provides insights related to decisions for debris retrieval method, development of fuel debris retrieval equipment, and implementation of fuel debris retrieval activities with reduced risks from radioactive materials. In particular, improved models for predicting the timing and mode of vessel failure and the mass, composition, and heat content of material relocated to and from the lower head are of interest in making decisions related to the methods for debris removal and measures needed for worker protection from damaged structures and from radiation.

\subsection{Summary of Information}

TEPCO Holdings has performed a wide range of examinations at Daiichi to support their D\&D activities. The outside and inside of the reactor buildings as well as inside the containments have been surveyed by personnel and/or robots. The examination information includes visual (i.e., pictures and videos) as well as limited sampling, dose rate, water level, and temperature data. TEPCO Holdings has published a large amount of data on its publicly accessible website.[9] In particular, reports documenting unconfirmed and unresolved issues [37 through 42] have received special attention in this forensics effort to evaluate equipment performance.

As discussed in Section 1.3.1, the U.S. Forensics Expert Panel identified information needs during FY2015 that could be obtained from these examinations. An updated list of information needs is included in Appendix $\mathrm{C}$ of this report. The information needs address knowledge gaps in severe accident phenomena [53] and reduce uncertainties in equipment performance and modeling predictions. Some insights into component degradation and performance can already be ascertained based on observations from the examinations already performed by TEPCO Holdings. Tables 3-1 through 3-3 summarize the availability of information with respect to the component degradation information needs identified in Appendix $\mathrm{C}$ tables. Key aspects of this information are summarized in this section. 
Table 3-1. Area 1 information needs from the reactor building

\begin{tabular}{|c|c|c|c|}
\hline Item & What/How Obtained ${ }^{\mathrm{a}}$ & $\mathbf{U s e}^{\mathbf{b}}$ & $\begin{array}{c}\text { Data } \\
\text { Available }\end{array}$ \\
\hline RB-1 & $\begin{array}{l}\text { Photos/videos of condition of RCIC valve and pump before drain down } \\
\text { and after disassembly (1F2 and 1F3) }\end{array}$ & $\mathrm{AE}, \mathrm{AM}$ & NA \\
\hline RB-2 & Photos/videos of HPCI System after disassembly (1F1, 1F2, and 1F3) & $\mathrm{AM}$ & NA \\
\hline RB-3a & Photos/videos of damaged walls and structures (1F1) & $\mathrm{AE}, \mathrm{AM}, \mathrm{DD}$ & A \\
\hline $\mathrm{RB}-3 \mathrm{~b}$ & Photos/videos of damaged walls and structures (1F3) & $\mathrm{AE}, \mathrm{AM}, \mathrm{DD}$ & A \\
\hline $\mathrm{RB}-3 \mathrm{c}$ & Photos/videos of damaged walls and structures (1F4 & $\mathrm{AE}, \mathrm{AM}, \mathrm{DD}$ & A \\
\hline RB-4 & $\begin{array}{l}\text { Photos/videos of damaged walls and components and radionuclide } \\
\text { surveys (1F2) }\end{array}$ & AE, AM, DD & A \\
\hline RB-5 & Radionuclide surveys (1F1, 1F2, and 1F3) & $\mathrm{AE}, \mathrm{AM}, \mathrm{DD}$ & A \\
\hline RB-6 & Radionuclide surveys and sampling of ventilation ducts (1F4) & $\mathrm{AE}, \mathrm{AM}, \mathrm{DD}$ & A \\
\hline RB-7 & Isotopic evaluations of obtained concrete samples (1F2) & $\mathrm{AE}, \mathrm{AM}, \mathrm{DD}$ & A \\
\hline RB-8 & $\begin{array}{l}\text { Photos/videos and inspection of seismic susceptible areas (e.g., bellows, } \\
\text { penetrations, structures, supports, etc. in } 1 \mathrm{~F} 1,1 \mathrm{~F} 2,1 \mathrm{~F} 3 \text {, and } 1 \mathrm{~F} 4)\end{array}$ & $\mathrm{AE}, \mathrm{AM}, \mathrm{DD}$ & A \\
\hline \multirow[t]{4}{*}{ RB-9 } & $\begin{array}{l}\text { DW concrete shield radionuclide surveys }(1 \mathrm{~F} 1,1 \mathrm{~F} 2 \text {, and } 1 \mathrm{~F} 3 \text { - before } \\
\text { debris removed) }\end{array}$ & $\mathrm{AE}, \mathrm{AM}, \mathrm{DD}$ & A \\
\hline & DW concrete shield radionuclide surveys ( $1 \mathrm{~F} 1$ - after debris removed) & $\mathrm{AE}, \mathrm{AM}, \mathrm{DD}$ & A \\
\hline & DW concrete shield radionuclide surveys ( $1 \mathrm{~F} 3$ - after debris removed) & $\mathrm{AE}, \mathrm{AM}, \mathrm{DD}$ & A \\
\hline & $\begin{array}{l}\text { Photos/videos around mechanical seals and hatches and electrical } \\
\text { penetration seals (as a means to classify whether joints were in } \\
\text { compression or tension) }\end{array}$ & $\mathrm{AE}, \mathrm{AM}, \mathrm{DD}$ & A \\
\hline RB-10 & $\begin{array}{l}\text { Photos/videos of } 1 \mathrm{~F} 1 \text { (vacuum breaker), } 1 \mathrm{~F} 1,1 \mathrm{~F} 2 \text {, and } 1 \mathrm{~F} 3 \mathrm{PCV} \text { leakage } \\
\text { points (bellows and other penetrations) }\end{array}$ & $\mathrm{AE}, \mathrm{AM}, \mathrm{DD}$ & A \\
\hline RB-11 & $\begin{array}{l}\text { Photos/videos and available information on } 1 \mathrm{~F} 1,1 \mathrm{~F} 2 \text {, and } 1 \mathrm{~F} 3 \\
\text { containment hardpipe venting pathway, standby gas treatment system and } \\
\text { associated reactor building ventilation system }\end{array}$ & $\mathrm{AE}, \mathrm{AM}, \mathrm{DD}$ & A \\
\hline RB-13 & Photos/videos of 1F1, 1F2, and 1F3 recirculation lines and pumps & AM, DD & A \\
\hline RB-14 & $\begin{array}{l}\text { Deposits or particles sampled inside reactor building }(1 \mathrm{~F} 1,1 \mathrm{~F} 2,1 \mathrm{~F} 3) \text {; } \\
\text { e.g., white deposits from HPCI room using FE-SEM, XRD, etc. }\end{array}$ & $\mathrm{AE}, \mathrm{AM}, \mathrm{DD}$ & NA \\
\hline RB-15 & $\begin{array}{l}\text { Examinations of 1F1 RCW surge tank; water level and additional dose } \\
\text { measurements. }\end{array}$ & $\mathrm{AE}, \mathrm{AM}, \mathrm{DD}$ & A \\
\hline
\end{tabular}

a. See list of acronyms.

b. Use: AE - Accident evaluation (code modeling updates), AM- Accident management and prevention, DD - Decontamination and Decommissioning, and PM - Plant maintenance (see Appendix C for more information).

c. Some information available [Green]; NA: no information available [Orange]. 
Table 3-2. Area 1 information needs from the PCV

\begin{tabular}{|c|c|c|c|}
\hline Item & What/How Obtained ${ }^{a}$ & $\mathbf{U s e}^{\mathbf{b}}$ & $\begin{array}{c}\text { Data } \\
\text { Available }^{c}\end{array}$ \\
\hline PC-1 & $\begin{array}{l}\text { Ex-vessel inspections and operability assessments of 1F1, 1F2, and 1F3 } \\
\text { in-vessel sensors and sensor support structures }{ }^{\mathrm{d}}\end{array}$ & AE, AM, DD & NA \\
\hline PC-2 & Photos/videos and radionuclide surveys/ sampling of IC (1F1). & AE, AM, DD & NA \\
\hline \multirow[t]{5}{*}{$\mathrm{PC}-3^{\mathrm{e}}$} & $\begin{array}{l}\text { a) Photos/videos of relocated debris and crust, debris and crust extraction, } \\
\text { hot cell exams, and possible subsequent testing ( } 1 \mathrm{~F} 1-1 \mathrm{~F} 3)\end{array}$ & AE, AM, DD & A \\
\hline & $\begin{array}{l}\text { b) PCV liner examinations (photos/videos and metallurgical exams; } \\
\text { 1F1-1F3) }\end{array}$ & AE, AM, DD & NA \\
\hline & $\begin{array}{l}\text { c) Photos/video, RN surveys, and sampling of pedestal wall and floor } \\
(1 \mathrm{~F} 1-1 \mathrm{~F} 3)\end{array}$ & AE, AM, DD & A \\
\hline & $\begin{array}{l}\text { d) Concrete erosion profile; photos/videos and sample removal and } \\
\text { examination (1F1-1F3) }\end{array}$ & AE, AM, DD & NA \\
\hline & $\begin{array}{l}\text { e). Photos/videos of RPV lower head and of structures and penetrations } \\
\text { beneath the vessel to determine damage and corium hang-up (1F1-1F3) }\end{array}$ & $\mathrm{AE}, \mathrm{AM}, \mathrm{DD}$ & A \\
\hline PC-4 & $\begin{array}{l}\text { Examinations and operability assessments of } 1 \mathrm{~F} 1,1 \mathrm{~F} 2 \text {, and } 1 \mathrm{~F} 3 \text { ex-vessel } \\
\text { sensors and sensor support structure }\end{array}$ & $\mathrm{AE}, \mathrm{AM}$ & NA \\
\hline PC-5 & $\begin{array}{l}\text { Photos/videos of 1F1, 1F2, and 1F3 main steam lines and ADS lines to } \\
\text { end of SRV tailpipes, including instrument lines }\end{array}$ & AE, AM, DD & NA \\
\hline PC-6 & $\begin{array}{l}\text { Visual inspections of } 1 \mathrm{~F} 1,1 \mathrm{~F} 2 \text {, and } 1 \mathrm{~F} 3 \mathrm{SRV} \text { s including standpipes } \\
\text { (interior valve mechanisms) }\end{array}$ & AE, AM, DD & NA \\
\hline PC-7 & $\begin{array}{l}\text { Ex-vessel inspections and operability assessments of 1F1, 1F2, and } \\
1 \mathrm{~F} 3 \text { in-vessel sensors and sensor support structures }{ }^{\mathrm{f}}\end{array}$ & $\mathrm{AE}, \mathrm{AM}, \mathrm{DD}$ & A \\
\hline PC-8 & $\begin{array}{l}\text { Examinations and operability assessments of 1F1, 1F2, and 1F3 } \\
\text { ex-vessel sensors and sensor support structure }\end{array}$ & $\mathrm{AE}, \mathrm{AM}, \mathrm{DD}$ & A \\
\hline PC-9 & Photos/videos of 1F1, 1F2, and 1F3 PC (SC and DW) coatings & PM & $\bar{A}$ \\
\hline PC-10 & $1 \mathrm{~F} 1,1 \mathrm{~F} 2$, and $1 \mathrm{~F} 3 \mathrm{RN}$ surveys in PCV & $\mathrm{AE}, \mathrm{AM}, \mathrm{DD}$ & A \\
\hline$\overline{\mathrm{PC}-11}$ & $\begin{array}{l}\text { Photos/videos of } 1 \mathrm{~F} 1,1 \mathrm{~F} 2 \text {, and } 1 \mathrm{~F} 3 \text { primary system recirculation pump } \\
\text { seal and any potential discharge to containment }\end{array}$ & $\mathrm{AE}, \mathrm{AM}, \mathrm{DD}$ & NA \\
\hline $\mathrm{PC}-12$ & $\begin{array}{l}\text { Photos/videos of 1F1, 1F2, and 1F3 TIP tubes and SRV/IRM tubes } \\
\text { outside the RPV }\end{array}$ & $\begin{array}{l}\text { AE, AM, DD, } \\
\text { PM }\end{array}$ & A \\
\hline $\mathrm{PC}-13$ & $\begin{array}{l}\text { Photos/videos of } 1 \mathrm{~F} 1,1 \mathrm{~F} 2 \text {, and } 1 \mathrm{~F} 3 \text { insulation around piping and the } \\
\text { RPV. }\end{array}$ & $\mathrm{AM}$ & NA \\
\hline PC-14 & $\begin{array}{l}\text { Samples of conduit cabling, and paint from } 1 \mathrm{~F} 1,1 \mathrm{~F} 2 \text {, and } 1 \mathrm{~F} 3 \text { for } \mathrm{RN} \\
\text { surveys. }\end{array}$ & $\mathrm{AE}, \mathrm{AM}$ & NA \\
\hline PC-15 & Samples of water from 1F1, 1F2, and 1F3 for RN surveys. & $\mathrm{AE}, \mathrm{AM}, \mathrm{DD}$ & A \\
\hline PC-16 & $\begin{array}{l}\text { Photos/videos of melted, galvanized, or oxidized 1F1, 1F2, and 1F3 } \\
\text { structures. }\end{array}$ & AE, AM & A \\
\hline
\end{tabular}

a. See list of acronyms.

b. Use: AE - Accident evaluation (code modeling updates), AM- Accident management and prevention, DD - Decontamination and Decommissioning, and PM - Plant maintenance (see Appendix C for more information).

c. Some information available [Green]; NA: no information available [Orange].

d. Available information is limited to the shield plug.

e. As described in Section 5.2.2, in-vessel components have been discovered ex-vessel for two of the affected units (i.e., fuel assembly top tie plate for 1F2 and CR guide tube and CRD index tube for 1F3) indicating that the vessels have failed. In addition, sample evaluations from 1F1 have detected the presence of uranium.

f. Inspections and evaluations [e.g., continuity checks, calibration evaluations, etc.) of sensors [dP cells, water level gauges, TIPs, TCs, CAMs, etc.] and sensor support structures, cables, removed TIPs, etc.; Requires knowledge of sensor operating envelop. 
Table 3-3. Area 1 information needs from the RPV

\begin{tabular}{|c|c|c|c|}
\hline Item & What/How Obtained $^{\text {a }}$ & $\mathbf{U s e}^{\mathbf{b}}$ & $\begin{array}{l}\text { Data } \\
\text { Available }^{c}\end{array}$ \\
\hline \multirow[t]{3}{*}{ RPV-1 } & $\begin{array}{l}\text { 1F1, 1F2, and } 1 \mathrm{~F} 3 \text { dryer integrity and location evaluations } \\
\text { (photos/videos with displacement measurements, sample removal and } \\
\text { exams for fission product deposition, peak temperature evaluations) }\end{array}$ & $\mathrm{AE}, \mathrm{AM}, \mathrm{DD}$ & NA \\
\hline & $\begin{array}{l}\text { Photos/videos, probe inspections, and sample exams of } 1 \mathrm{~F} 1,1 \mathrm{~F} 2 \text {, and } \\
\text { 1F3 MSLs; Interior examinations of MSLs at external locations }\end{array}$ & $\mathrm{AE}, \mathrm{AM}, \mathrm{DD}$ & NA \\
\hline & $\begin{array}{l}\text { Photos/videos and metallurgical examinations of upper internals and } \\
\text { upper channel guides }\end{array}$ & $\mathrm{AE}, \mathrm{AM}, \mathrm{DD}$ & NA \\
\hline \multirow[t]{2}{*}{ RPV-2 } & $\begin{array}{l}\text { Photos/videos of } 1 \mathrm{~F} 1,1 \mathrm{~F} 2 \text {, and } 1 \mathrm{~F} 3 \text { core spray slip fit nozzle } \\
\text { connection, sparger \& nozzles }\end{array}$ & $\mathrm{AE}, \mathrm{AM}, \mathrm{DD}$ & NA \\
\hline & $\begin{array}{l}\text { Photos/videos of } 1 \mathrm{~F} 1,1 \mathrm{~F} 2 \text {, and } 1 \mathrm{~F} 3 \text { feedwater sparger nozzle and } \\
\text { injection points }\end{array}$ & $\begin{array}{l}\mathrm{AE}, \mathrm{AM}, \mathrm{DD}, \\
\text { PM }\end{array}$ & NA \\
\hline RPV-3 & $\begin{array}{l}\text { 1F1, 1F2, and } 1 \mathrm{~F} 3 \text { steam separators' integrity and location } \\
\text { (photos/videos with displacement measurements, sample removal and } \\
\text { exams for FP deposition, peak temperature evaluations) }\end{array}$ & $\mathrm{AE}, \mathrm{AM}, \mathrm{DD}$ & NA \\
\hline \multirow[t]{4}{*}{ RPV-4 } & $\begin{array}{l}\text { 1F1, 1F2, and } 1 \mathrm{~F} 3 \text { shroud inspection (between shroud and RPV wall); } \\
\text { Photos/videos and sample removal and oxidation testing. }\end{array}$ & $\mathrm{AE}, \mathrm{AM}, \mathrm{DD}$ & NA \\
\hline & $\begin{array}{l}\text { 1F1, 1F2, and } 1 \mathrm{~F} 3 \text { shroud head integrity and location (photos/videos, } \\
\text { and metallurgical exams) }\end{array}$ & $\mathrm{AE}, \mathrm{AM}, \mathrm{DD}$ & NA \\
\hline & $\begin{array}{l}\text { Photos/videos of } 1 \mathrm{~F} 1,1 \mathrm{~F} 2 \text {, and } 1 \mathrm{~F} 3 \text { shroud inspection (from core } \\
\text { region) }\end{array}$ & $\mathrm{AE}, \mathrm{AM}, \mathrm{DD}$ & NA \\
\hline & $\begin{array}{l}\text { Photos/videos of } 1 \mathrm{~F} 1,1 \mathrm{~F} 2 \text {, and } 1 \mathrm{~F} 3 \text { core plate and associated } \\
\text { structures }\end{array}$ & $\mathrm{AE}, \mathrm{AM}, \mathrm{DD}$ & NA \\
\hline \multirow[t]{2}{*}{ RPV-5 } & $\begin{array}{l}\text { Remote mapping of } 1 \mathrm{~F} 1,1 \mathrm{~F} 2 \text {, and } 1 \mathrm{~F} 3 \text { core through shroud wall from } \\
\text { annular gap region (muon tomography and other methods, if needed) }\end{array}$ & $\mathrm{AE}, \mathrm{AM}, \mathrm{DD}$ & A \\
\hline & $\begin{array}{l}\text { Mapping of end state of core and structural material (visual, sampling, } \\
\text { hot cell exams, etc.) }\end{array}$ & $\mathrm{AE}, \mathrm{AM}, \mathrm{DD}$ & NA \\
\hline
\end{tabular}

a. See list of acronyms.

b. Use: AE - Accident evaluation (code modeling updates), AM- Accident management and prevention, DD - Decontamination and Decommissioning, and PM - Plant maintenance (see Appendix C for more information).

c. Some information available [Green]; NA: no information available [Orange].

Table 3-4 summarizes several findings based on inspections performed by TEPCO Holdings. The table notes the observed status of various penetrations and equipment. In many instances, examination information has not yet been obtained for a unit's equipment. However, TEPCO Holdings has released a significant amount of information in the years since the accidents, some of which has not been translated into English. Although representatives from TEPCO Holdings participate in the U.S. expert meetings and review draft versions of this report, there may be publicly available information that is not captured in this table. 
Table 3-4. Results from component and system examinations ${ }^{\mathrm{a}}$

\begin{tabular}{|c|c|c|c|}
\hline Area & 1F1 & $1 F 2$ & 1F3 \\
\hline $\begin{array}{l}\mathrm{X}-100 \mathrm{~B} \text { PCV } \\
\text { penetration }^{\mathrm{b}}\end{array}$ & $\begin{array}{l}\text { Possible melted shielding } \\
\text { material [11] }\end{array}$ & TBD & TBD \\
\hline $\mathrm{X}-51 \mathrm{PCV}$ penetration ${ }^{\mathrm{c}}$ & TBD & $\begin{array}{l}\text { No damage observed; } \\
\text { pressurized water could not } \\
\text { penetrate blockage in standby } \\
\text { liquid cooling system line } \\
{[110,111]}\end{array}$ & TBD \\
\hline $\begin{array}{l}\text { X-53 HPCI steam } \\
\text { supply penetration } \\
(1 \mathrm{~F} 2 / 1 \mathrm{~F} 3)^{\mathrm{d}}\end{array}$ & High dose rate measured [16] & No damage observed [112] & No damage observed [113] \\
\hline $\begin{array}{l}\text { X-6 PCV penetration } \\
\text { (CRD hatch) }\end{array}$ & TBD & Melted material $[114,115]$ & $\begin{array}{l}\text { No damage observed from } \\
\text { inside [116] }\end{array}$ \\
\hline Equipment hatch & TBD & TBD & $\begin{array}{l}\text { Water puddle }[117,118] \\
\text { unknown source }\end{array}$ \\
\hline $\begin{array}{l}\text { Personnel hatch and } \\
\text { nearby penetrations }\end{array}$ & No damage observed [119] & TBD & TBD \\
\hline HPCI pipe penetration ${ }^{\mathrm{e}}$ & $\begin{array}{l}\text { No damage observed, but } \\
\text { high dose rates measured; } \\
\text { traces of flow and white } \\
\text { sediment observed }[16, \\
119,120]\end{array}$ & & \\
\hline TIP room & $\begin{array}{l}\text { No leakage observed from } \\
\text { PCV through TIP guide } \\
\text { penetrations. Relatively high } \\
\text { dose rates measured near } \\
\text { other primary system } \\
\text { instrumentation penetrations } \\
(\mathrm{X}-31, \mathrm{X}-32, \mathrm{X}-33)[16,121]\end{array}$ & $\begin{array}{l}\text { Dose surveys do not indicate } \\
\text { leakage from PCV through } \\
\text { TIP guides. High dose levels } \\
\text { in samples of materials from } \\
\text { TIP indexer [122] }\end{array}$ & \\
\hline $\begin{array}{l}\text { Wetwell (WW) vacuum } \\
\text { breaker line }\end{array}$ & $\begin{array}{l}\text { Leakage on expansion joint } \\
\text { of one line }(\mathrm{X}-5 \mathrm{E}) \text { [123] }\end{array}$ & TBD & TBD \\
\hline DW/WW vent bellows & $\begin{array}{l}\text { Water leakage attributed to } \\
\text { vacuum line above [123] }\end{array}$ & No leakage observed [124] & \\
\hline $\begin{array}{l}\text { DW sand cushion drain } \\
\text { pipe }\end{array}$ & Leakage [125] & No leakage observed [124] & TBD \\
\hline SC water level & Almost full [126] & $\begin{array}{l}\text { Consistent with torus room } \\
\text { water level }[126,127]\end{array}$ & $\begin{array}{l}\text { Believed 'almost full' but not } \\
\text { confirmed [126] }\end{array}$ \\
\hline DW Water Level & $\sim 2.8 \mathrm{~m}[126]$ & $\sim 0.3 \mathrm{~m}[126]$ & $\sim 6.5 \mathrm{~m}[126]$ \\
\hline \multirow[t]{3}{*}{ Torus room } & Partially flooded $[128,129]$ & Partially flooded [130] & Partially flooded [130] \\
\hline & $\begin{array}{l}\text { Rusted handrails/equipment } \\
\text { [11] }\end{array}$ & $\begin{array}{l}\text { Non-rusted handrails/ } \\
\text { equipment }[11,131]\end{array}$ & $\begin{array}{l}\text { Non-rusted handrails/ } \\
\text { equipment }[11,132]\end{array}$ \\
\hline & TBD & $\begin{array}{l}\text { Some room penetrations } \\
\text { tested, no leakage observed } \\
{[133]}\end{array}$ & TBD \\
\hline MSIV room & Limited view obtained [16] & $\begin{array}{l}\text { Water leakage cannot be } \\
\text { observed [134] }\end{array}$ & $\begin{array}{l}\text { Leakage in Line D near } \\
\text { bellows [135] }\end{array}$ \\
\hline
\end{tabular}


Table 3-4. Results from component and system examinations ${ }^{\mathrm{a}}$

\begin{tabular}{|l|l|l|l|}
\hline \multicolumn{1}{|c|}{ Area } & \multicolumn{1}{c|}{ 1F1 } & \multicolumn{1}{c|}{ 1F2 } & \multicolumn{1}{c|}{ 1F3 } \\
\hline $\begin{array}{l}\text { DW head and shield } \\
\text { plugs }\end{array}$ & $\begin{array}{l}\text { Reactor well shield plug } \\
\text { displaced [136] }\end{array}$ & \multicolumn{1}{|c|}{ Possible leakage [137] } & Possible leakage [137] \\
\hline $\begin{array}{l}\text { RCIC or other low SC } \\
\text { piping }\end{array}$ & \multicolumn{1}{|c|}{ TBD } & $\begin{array}{l}\text { Suspected leak location, not } \\
\text { confirmed [11] }\end{array}$ \\
\hline RPV lower head & $\begin{array}{l}\text { Ex-vessel debris images } \\
\text { indicate failure [18] }\end{array}$ & $\begin{array}{l}\text { Ex-vessel debris suggest } \\
\text { failure and images confirm } \\
\text { failure location [138] }\end{array}$ & $\begin{array}{l}\text { Ex-vessel debris images } \\
\text { indicate failure [138] }\end{array}$ \\
\hline
\end{tabular}

a. Nomenclature: [Clear]: TBD (To be determined); no information available; [Red]: available information indicates damage or leakage; [Orange]: available information suggests possible damage; [Green]: available information indicates no damage.

b. $\mathrm{X}-100 \mathrm{~B}$ is vacant for $1 \mathrm{~F} 1$, allowing this penetration to be used for $\mathrm{DW}$ investigations.

c. $\mathrm{X}-51$ is an instrument pipe penetration for measuring differential pressure in $1 \mathrm{~F} 2 / 1 \mathrm{~F} 3$. The penetration is joined to the Standby Liquid Cooling (SLC) pump injection line in the drywell. This penetration is designated as X-27 in $1 \mathrm{~F} 1$.

d. $\mathrm{X}-53$ is vacant for $1 \mathrm{~F} 2$ and $1 \mathrm{~F} 3$, allowing these penetrations to be used for DW investigations.

e. $\mathrm{X}-53$ is the HPCI steam supply penetration and X-54 is the HPCI steam instrument pipe penetration for $1 \mathrm{~F} 1$. X-11 is the HPCI steam supply penetration for $1 \mathrm{~F} 2$ and $1 \mathrm{~F} 3$.

U.S. experts reviewing available information observed notable differences in component degradation between 1F1, 1F2, and 1F3. Possible causes for these differences include unit design differences, the ability to inject water during the accidents, the ability to vent the primary system and containment during the accidents, and differences in the hydrogen explosions (or lack thereof) at each unit.

Section 3.3 and Appendix E describe how selected examination information has confirmed revised actions proposed by industry related to water addition strategies to mitigate severe accidents and reduce uncertainties in severe accident systems analysis code models.

\subsection{Recent Findings}

Appendix E summarizes examination information that provides insights regarding system and component performance. Highlights and recent information are summarized in this section.

\subsubsection{Containment Examinations}

PCV examinations are of interest to TEPCO Holdings with respect to D\&D. In addition, this information is of interest to U.S. experts with respect to validating revised severe accident management guidance and verifying the adequacy of code models. Table 3-5 summarizes the dates of investigations inside the $\mathrm{PCV}$, external examinations of the SC, as well as the investigations using muon tomography [138, 139, $140,141,142,143]$. 
Table 3-5. Summary of examination dates and progression

\begin{tabular}{|c|c|c|c|}
\hline \multirow{2}{*}{ Inspection Region } & \multicolumn{3}{|c|}{ Inspection Dates } \\
\cline { 2 - 4 } & $\mathbf{1 F 1}$ & $\mathbf{1 F 2}$ & $\mathbf{1 F 3}$ \\
\hline \multirow{2}{*}{ Inside PCV } & $10 / 2012$ & $3 / 2012$ & $10 / 2015$ \\
\cline { 2 - 4 } & $4 / 2015$ & $8 / 2013$ & $7 / 2017$ \\
\cline { 2 - 4 } & $3 / 2017$ & $1-2 / 2017$ & \\
\cline { 2 - 4 } & & $1 / 2018$ & $7 / 2012$ \\
\hline External to the SC & $11 / 2013$ & $4 / 2012$ & $5-9 / 2017$ \\
\cline { 2 - 4 } & $6 / 2014$ & $4 / 2013$ & \\
\hline
\end{tabular}

As discussed in Section 5.2.2, early photos and videos of structures below the bottom head of the 1F2 RPV indicate some of the cabling may still be intact.[11] More recent images (early 2017) show that some cables and structures are intact while other structures, such as a section of the maintenance platform, may have failed. For 1F3, cables for twelve temperature measurements were observed to have been damaged at a location inside the pedestal and below the bottom of the CRD mechanisms [144]. These cables have a metallic sheaths with a melting point great than $1000^{\circ} \mathrm{C}$. This, in conjunction with the other observations, suggest very high temperatures, likely from molten debris, in the pedestal region at some point. See Section 5 for additional discussion of the 'below-vessel' investigation results.

There have been numerical investigations of the hydrogen event for 1F1 (see Section 6). In one study, two hydrogen leak locations were investigated; through the PCV head flange or a leak in the IC piping [145]. The scenario investigated assuming leakage through the PCV head flanges better reproduced the event observations and building end state than assuming leakage in the IC piping.

For 1F2, a large number of containment penetrations have been identified for damage inspection [141]. Insights related to peak temperatures within the PCV are available from visual examinations, and temperature and pressure data. As shown in Figure 3-1, visual examinations of material from the X-6 penetration suggest that either the chloroprene cable cover or silicon flange seal material melted and dribbled out of this penetration. In their review, U.S. experts concluded this evidence indicates peak temperatures at this location exceeded $300{ }^{\circ} \mathrm{C} / 572^{\circ} \mathrm{F}$ and the dribbling pattern suggests that relocation occurred at low pressure (rather than a high-pressure ejection of material). Plant data [9] indicate that $1 \mathrm{~F} 2$ peak pressures were as high as $0.75 \mathrm{MPa} / 109$ psia on March 15, 2011. Temperature data were not available until March 21, 2011. Calculated saturation temperatures for the measured peak pressure, assuming a pure steam environment and neglecting localized hot spots, indicate values as high as $168{ }^{\circ} \mathrm{C} / 334^{\circ} \mathrm{F}$. While containment reached high pressures, TEPCO Holdings has noted: "We estimate that the leakage from the PCV was caused by the loss of sealing ability due to the high temperature rather than the mechanical operation of the high pressure." [146]

\subsubsection{Primary System Integrity}

To date, there is limited direct information related to the integrity of the primary system. Direct observation of the tailpipes for the SRV, RCIC, HPCI, or the SRVs, MSLs, recirculation piping and pumps, lower head penetrations, etc., have not been made. 

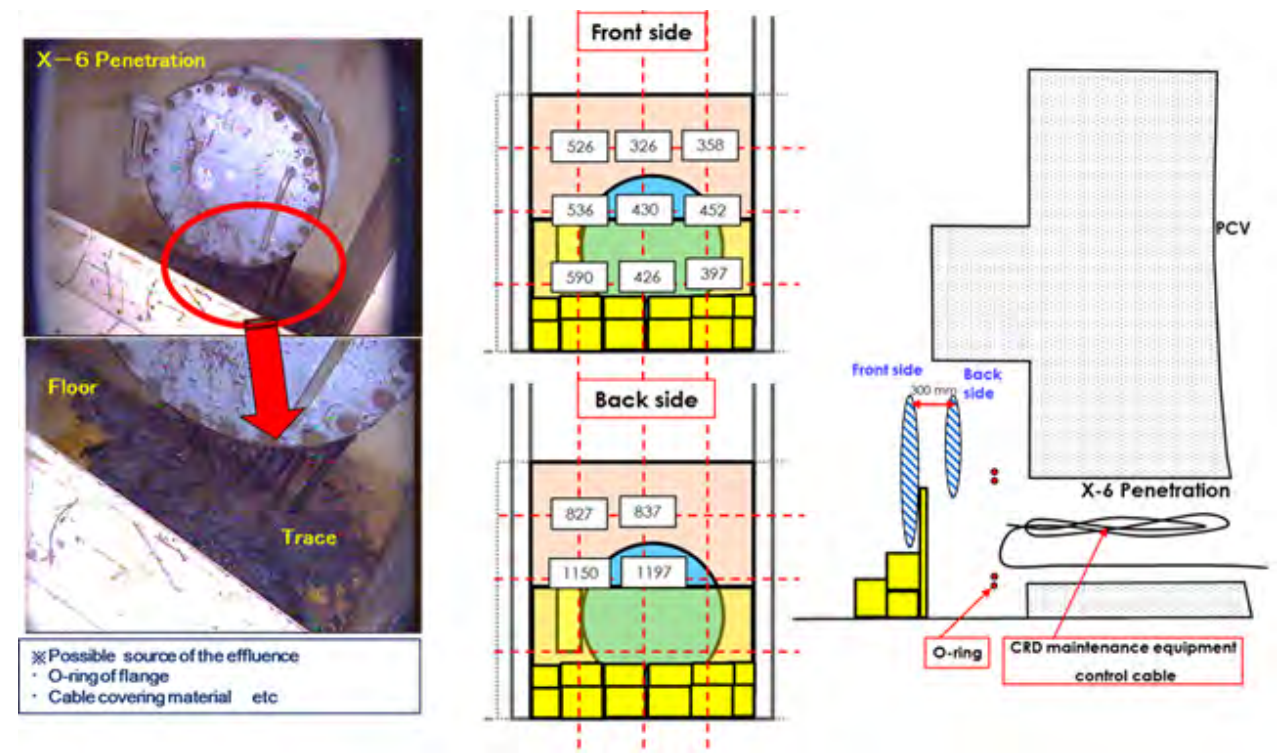

Figure 3-1. Photographs and radiation surveys (in $\mathrm{mSv} / \mathrm{hr}$ ) near $1 \mathrm{~F} 2 \mathrm{X}-6$ penetration (values measured in 13 locations). (Courtesy of TEPCO Holdings $[11,13]$ )

While investigations of the pedestal region have been conducted for 1F2 and 1F3, direct observations of the RPV bottom head have been limited. However, visual evidence show that components from within the 1F2 and 1F3 RPV relocated into the pedestal region and evaluations of water samples indicate that fuel materials are present within the 1F1 PCV, i.e., the bottom heads are damaged in all three units. See Section 5.2 for further discussion.

\subsection{3. $\mathrm{HPCl}$ and $\mathrm{RCIC}$}

To date, the HPCI and/or RCIC systems at $1 \mathrm{~F}$ and $1 \mathrm{~F} 3$ have not been inspected (1F1 has an isolation condenser). These are key systems with respect to the accident sequence and response for 1F2 and 1F3. These systems are also important for accident response in the U.S. BWR fleet. There remains continued interest in the operation and final conditions of the HPCI and RCIC systems at Fukushima Daiichi.

The state of the 1F2 RCIC, given its unanticipated extended operation, is of particular interest. There are ongoing collaborative activities within Japan and the U.S to investigate the potential for an extended operational envelope of a GS-series Terry turbo-pump (i.e., RCIC for BWRs and turbine driven AFW for PWRs).

The cause for trip of the 1F3 RCIC system was reviewed by TEPCO Holdings.[41] The most likely trip mode was identified as high turbine exhaust pressure and not over-speed. This is supported by the available SC pressure data.

Many reports on the sequence of events note the stopping of the 1F3 HPCI. Insight into the decision to intentionally stop the HPCI and the subsequent events were recently provided. [146] The following explanation for intentionally tripping the HPCI was attributed to TEPCO[146]:

After the HPCI start, the rotation speed of the turbine decreased with the decrease of RPV pressure, and it fell below the lower limit of the required operational condition. The HPCI was still 
working although the RPV pressure decreased to the level below which the HPCI essentially stops working, that is, it was isolated. If the SRV was opened in this situation, it would result in the further decrease of RPV pressure and the turbine vibration would become greater. Finally, fatal damage would occur in the turbine system. This damage would produce the spread of steam inside the RPV into the HPCI room. We were anxious that the radioactivity in the steam would hinder the work of the operators for recovery from the accident. This is the reason why we stopped the operation of the HPCI manually.

As to why the 1F3 HPCI could not be restarted, the report notes [146]:

By the action of 'push the HPCI stop button' a magnetic valve was actuated and oil was dumped, oil pressure was released, then the stop valve of the HPCI steam line was closed. At this time the magnetic valve was operable. The inlet valve of the turbine steam line was a DC motor operated valve, and this valve was also operable. At 2:45 on the 13th, the operator tried to open the SRV, but it could not be moved, in spite of the successful actions of the inlet and stop valves just 3 minutes before.

The report also notes that TEPCO stated:

At the time of the HPCI stop, the battery power had decreased considerably, and the SRV could not be operated. But there is still no analysis that gives the definite reason.

\subsection{Insight Summary and Limitations}

A primary limitation associated with current insights is that much of the information is based on visual images (e.g., primarily photographs and videos). Distortions in the photographs may be caused by lighting, image resolution, radiation effects, and surface corrosion; such distortions may influence how experts interpret information in these visual images. The initial condition of equipment is also not known either because 'before' pictures are unavailable or have not been made available. Some of the observed leaks, peeling paint, and corrosion may not be attributed to accident.

Another limitation is that the timing of the observed damage (leakage, corrosion, etc.) with respect to the accident progression can be difficult to ascertain. The early failure of some components could have contributed to further damage of other components or prevented some components from failing. Also, the long-term exposure to post-accident conditions (seawater, elevated temperature and radiation fields, etc.) can obfuscate interpretation of failure timing.

\subsection{Recommendations}

In reviewing available information for this area, including the information in Appendix E, the expert panel formulated several recommendations.

\section{Area 1 Recommendation 1:}

Sensitivity studies should be performed on containment failure location and size with respect to radiological releases (timing, amount) and impact on accident progression. These sensitivity studies should be done with both MAAP and MELCOR to cover a range of predicted containment and primary system conditions. Sensitivities for each unit would provide insight into which failure likely caused 
depressurization, the conditions under which such a failure occurred, and the effect of multiple failures. Some previous sensitivity analyses have been performed for failure of the primary system (SRV versus MSL, etc.) and the containment.

As discussed within this section, several containment penetrations and components are leaking in the three units. The failure of multiple containment penetrations, or even a specific penetration, identified in Table 3-4 is not predicted in best-estimate MAAP or MELCOR simulations of these accidents. Severe accident modeling, particularly as it pertains to probabilistic risk assessment, typically does not evaluate containment impairment in a mechanistic manner. In many models, containment impairments are assumed to develop using the following steps:

- Identify containment boundary locations that tend to exhibit a higher likelihood to become impaired in a severe accident, such as:

- expansion of the structure at flanges or penetrations beyond the capacity for installed seals to prevent a leakage pathway from developing (e.g., lifting of the drywell head flange at appreciably elevated pressures);

- development of localized high stresses because of elevated pressures, ultimately causing localized failure of the structure; and

- weakening of containment boundary seals or structural elements because of combined mechanical, chemical and thermal loads.

- Define mechanical (pressure) and thermal loading criteria (atmospheric gas or structural temperatures) required to induce failure at the locations identified in the previous step.

As discussed in Section 4, reactor building radiological hotspots provide a means to assess inputs to severe accident computer codes, but do not typically facilitate assessment of the actual computer code models. There is, however, one important exception. Namely, mechanical and thermal challenges to the containment boundary predicted by code calculations can be compared with observed locations of impairments. In this regard, continued analytical effort would be of value as part of Fukushima Daiichi accident simulations to assess the potential for drywell head flange impairment due to high pressure and upper drywell temperatures. Photographs of the upper drywell structure could aid in identifying the potential for high upper drywell temperatures.

\section{Area 1 Recommendation 2:}

The expert panel should continue to review available information and update Table 3-4.

The expert panel concurred that information in Table 3-4 was useful for summarizing the status of various components and for comparing the status of the three units. The information in this table, coupled with code predictions, dose measurements, and plant instrumentation information, can provide insights related to the timing of failure for various components. Determining whether failures occurred before or after vessel breach is important for predicting radionuclide transport during an accident and is useful for verifying information contained in revised industry guidance for severe accidents guidance.

\section{Area 1 Recommendation 3:}

A concise comparison should be developed for the predicted conditions by both MAAP and MELCOR at the MSIV (temperature, pressure) for 1F2 and 1F3. The expert panel should continue to review any additional inspection information of the MSIV room or MSLs. 
The leakage of 1F3 in the MSIV room contrasts with the observation of no damage in the MSIV rooms for $1 \mathrm{~F} 2$. As failure in this location bypasses the containment, it would be beneficial to understand why failure occurred in 1F3 but not in 1F2 and why leakage appeared to have occurred in line D and not lines A-C.

\section{Area 1 Recommendation 4:}

The expert panel is interested in 'before' pictures for specific locations from TEPCO Holdings. This recommendation is not currently identified as an information need. As more information becomes available, however, the panel will identify specific places.

Many component status observations are based on photographs or videos. There is a lack of 'before' pictures to compare against the pictures taken after the accident. A potential use is to help discern whether discolored markings on walls near penetrations are due to leakage before or after the accident.

\section{Area 1 Recommendation 5:}

The expert panel should place more emphasis on reviewing available examination information related to spent fuel (i.e., assemblies, pools, casks, etc.) at Fukushima Daiichi. Experts should also consider existing U.S. research that may aid in the decommissioning efforts and identify inspections at Fukushima Daiichi that may benefit ongoing U.S. activities.

To date, U.S. forensics efforts has placed less emphasis on reviewing spent fuel pool examination information from Fukushima Daiichi. The site contains seven spent fuel pools, several existing and a newly built dry storage facilities, and the spent fuel from six operating reactors. The spent fuel and structures experienced 'off-nominal' conditions and remain a key focus area of D\&D efforts. The U.S. may also benefit by reviewing information available from these spent fuel D\&D efforts. Likewise, the Japanese D\&D efforts could benefit from the U.S. experience (The U.S. has a large inventory of spent fuel, with approximately 2500 dry storage casks in operation, and a range of research into related issues, such as spent fuel integrity).

\subsection{Suggestions for Additional Information}

Evaluations by the expert panel led to several suggestions for this area.

\section{Area 1 Suggestion 1:}

To facilitate updates to Table 3-4, the expert panel has requested that TEPCO Holdings continue to review information in this table. In addition, the expert panel will continue to review additional information, such as penetration, component, and system examination results, from TEPCO Holdings and update this table.

\section{Area 1 Suggestion 2:}

As discussed in Section 4, surveys in containment to understand the integrity of the RPV lower head, pedestal, and containment liner are of particular interest. These information needs are identified in Appendix C. 


\section{Area 1 Suggestion 3:}

As discussed in Sections E.1.1 and E.1.2, the RCW system may have played a role in the 1F1 accident progression. Examination information identified in Appendix $\mathrm{C}$ and other information previously obtained by TEPCO Holdings (i.e., dose surveys around the surge tank, system water level, images of system components, etc.) may provide insight into its role during the accident.

These suggestions have been included in the information needs listed in Appendix C. 
ANL-18/24 


\section{AREA 2 - DOSE SURVEYS AND ISOTOPIC SAMPLING}

Dose surveys and radionuclide deposition samples collected within the RB, PCV, and Spent Fuel Pool (SFP) are another important data acquisition area to support D\&D activities. Samples or swipes are of interest because they can provide evidence of FP release fractions and possibly of FP speciation.

This section summarizes recent Fukushima Daiichi D\&D dose survey and isotopic survey and sampling information obtained by TEPCO Holdings. Additional findings and information previously reported are located in Appendix F. As discussed within Sections 3, 5, and 6, survey and sampling information provides insights about component and system degradation, debris end-state location, and combustible gas effects. The section concludes with several recommendations and suggestions for additional information that would be beneficial regarding future assessments.

\subsection{Key Questions for Reactor Safety and D\&D}

Available information was evaluated by U.S. experts to address the following questions that are of international interest for reactor safety and to Japan for completing feasibility studies to support D\&D activities:

- How were fission products transported through various structures?

- What compounds were formed?

- Was deposition and transport affected by hydrogen combustion?

- Are there any observed effects from saltwater addition?

- Can 'mass balances' be obtained for the fuel?

- Can released isotopic species be used to estimate the unit from which the release came and peak core temperatures experienced by the unit?

- Can radiation surveys, combined with analysis results, be used to infer a failed component?

- Can radiation surveys, combined with analysis results, provide insights related to worker dose minimization?

Answers to these questions can have an important safety impact. By obtaining prototypic data from each of the units at Daiichi, there is the potential to reduce modeling uncertainties. Improvements in our modeling capabilities can be used to confirm or enhance, if needed, accident management strategies with respect to containment venting, water addition, and combustible gas generation. This information and associated analyses with improved severe accident codes offer the potential for insights that may be beneficial to Japan in their D\&D activities. Improved models for predicting the events at Daiichi may provide important insights related to radionuclide transport and deposition, which is important in characterizing worker dose during D\&D activities.

\subsection{Information Summary}

As discussed in Section 1.3.1, U.S. experts identified information needs that could be addressed through examinations at Fukushima Daiichi. Requested information needs from the reactor building and 
PCV that relate to Area 2 are summarized in Tables 4-1 through 4-3. These tables also note where information is available to address these information needs (see Appendix C).

Table 4-1. Area 2 information needs from the reactor building

\begin{tabular}{|c|c|c|c|}
\hline Item & What/How Obtained ${ }^{\text {a }}$ & $\mathbf{U s e}^{\mathbf{b}}$ & $\begin{array}{c}\text { Data } \\
\text { Available }\end{array}$ \\
\hline RB-4 & $\begin{array}{l}\text { Photos/videos of damaged walls and components and radionuclide } \\
\text { surveys (1F2) }\end{array}$ & AE, AM, DD & A \\
\hline RB-5 & Radionuclide surveys (1F1, 1F2, and 1F3) & AE, AM, DD & A \\
\hline RB-6 & Radionuclide surveys and sampling of ventilation ducts (1F4) & AE, AM, DD & A \\
\hline RB-7 & Isotopic evaluations of obtained concrete samples (1F2) & $\mathrm{AE}, \mathrm{AM}, \mathrm{DD}$ & A \\
\hline \multirow[t]{4}{*}{ RB-9 } & $\begin{array}{l}\text { DW Concrete Shield Radionuclide surveys (1F1, 1F2, and 1F3 - before } \\
\text { debris removed) }\end{array}$ & AE, AM, DD & A \\
\hline & DW Concrete Shield Radionuclide surveys (1F1 - after debris removed) & $\mathrm{AE}, \mathrm{AM}, \mathrm{DD}$ & A \\
\hline & DW Concrete Shield Radionuclide surveys (1F3 - after debris removed) & AE, AM, DD & A \\
\hline & $\begin{array}{l}\text { Photos/videos around mechanical seals and hatches and electrical } \\
\text { penetration seals (as a means to classify whether joints were in } \\
\text { compression or tension) }\end{array}$ & AE, AM, DD & A \\
\hline RB-15 & $\begin{array}{l}\text { Examinations of 1F1 RCW surge tank; water level and additional dose } \\
\text { measurements. }\end{array}$ & $\mathrm{AE}, \mathrm{AM}, \mathrm{DD}$ & $\mathrm{A}$ \\
\hline
\end{tabular}

a. See list of acronyms.

b. Use: AE - Accident evaluation (code modeling updates), AM- Accident management and prevention, DD - Decontamination and Decommissioning, and PM - Plant maintenance (see Appendix C for more information).

c. Some information available [Green]; NA: no information available [Orange].

Table 4-2. Area 2 information needs from the PCV

\begin{tabular}{|c|c|c|c|}
\hline Item & What/How Obtained $^{\mathrm{a}}$ & Use $^{b}$ & $\begin{array}{c}\text { Data } \\
\text { Available }^{c}\end{array}$ \\
\hline $\mathrm{PC}-2$ & Photos/videos and radionuclide surveys/ sampling of IC (1F1). & $\mathrm{AE}, \mathrm{AM}, \mathrm{DD}$ & NA \\
\hline \multirow[t]{5}{*}{$\mathrm{PC}-3^{\mathrm{d}}$} & $\begin{array}{l}\text { a) Photos/videos of relocated debris and crust, debris and crust extraction, } \\
\text { hot cell exams, and possible subsequent testing (1F1 - 1F3) }\end{array}$ & $\mathrm{AE}, \mathrm{AM}, \mathrm{DD}$ & $\mathrm{A}$ \\
\hline & $\begin{array}{l}\text { b) PCV liner examinations (photos/videos and metallurgical exams; } \\
\text { 1F1-1F3) }\end{array}$ & AE, AM, DD & NA \\
\hline & $\begin{array}{l}\text { c) Photos/video, RN surveys, and sampling of pedestal wall and floor } \\
\text { (1F1-1F3) }\end{array}$ & AE, AM, DD & A \\
\hline & $\begin{array}{l}\text { d) Concrete erosion profile; photos/videos and sample removal and } \\
\text { examination (1F1-1F3) }\end{array}$ & AE, AM, DD & NA \\
\hline & $\begin{array}{l}\text { e). Photos/videos of RPV lower head and of structures and penetrations } \\
\text { beneath the vessel to determine damage and corium hang-up (1F1-1F3) }\end{array}$ & AE, AM, DD & A \\
\hline PC-10 & $1 \mathrm{~F} 1,1 \mathrm{~F} 2$, and $1 \mathrm{~F} 3 \mathrm{RN}$ surveys in PCV & $\mathrm{AE}, \mathrm{AM}, \mathrm{DD}$ & A \\
\hline PC-14 & $\begin{array}{l}\text { Samples of conduit cabling, and paint from } 1 \mathrm{~F} 1,1 \mathrm{~F} 2 \text {, and } 1 \mathrm{~F} 3 \text { for } \mathrm{RN} \\
\text { surveys. }\end{array}$ & $\mathrm{AE}, \mathrm{AM}$ & NA \\
\hline PC-15 & Samples of water from 1F1, 1F2, and 1F3 for RN surveys. & $\mathrm{AE}, \mathrm{AM}, \mathrm{DD}$ & A \\
\hline
\end{tabular}

a. See list of acronyms.

b. Use: AE - Accident evaluation (code modeling updates), AM- Accident management and prevention, DD - Decontamination and Decommissioning, and PM - Plant maintenance (see Appendix C for more information).

c. Some information available [Green]; NA: no information available [Orange].

d. As described in Section 5.2.2, in-vessel components have been discovered ex-vessel for two of the affected units (i.e., fuel assembly top tie plate for $1 F 2$ and CR guide tube and CRD index tube for 1F3) indicating that the vessels have failed. In addition, sample evaluations from $1 \mathrm{~F} 1$ have detected the presence of uranium. 
Table 4-3. Area 2 information needs from the RPV

\begin{tabular}{|c|c|c|c|}
\hline Item & What/How Obtained $^{\text {a }}$ & Use $^{\text {b }}$ & $\begin{array}{c}\text { Data } \\
\text { Available }\end{array}$ \\
\hline \multirow[t]{3}{*}{ RPV-1 } & $\begin{array}{l}\text { 1F1, 1F2, and 1F3 dryer integrity and location evaluations (photos/ } \\
\text { videos with displacement measurements, sample removal and exams } \\
\text { for fission product deposition, peak temperature evaluations) }\end{array}$ & $\mathrm{AE}, \mathrm{AM}, \mathrm{DD}$ & NA \\
\hline & $\begin{array}{l}\text { Photos/videos, probe inspections, and sample exams of } 1 \mathrm{~F} 1,1 \mathrm{~F} 2 \text {, and } \\
\text { 1F3 MSLs; Interior examinations of MSLs at external locations }\end{array}$ & $\mathrm{AE}, \mathrm{AM}, \mathrm{DD}$ & NA \\
\hline & $\begin{array}{l}\text { Photos/videos and metallurgical examinations of upper internals and } \\
\text { upper channel guides }\end{array}$ & $\mathrm{AE}, \mathrm{AM}, \mathrm{DD}$ & NA \\
\hline RPV-3 & $\begin{array}{l}\text { 1F1, 1F2, and 1F3 steam separators' integrity and location (photos/ } \\
\text { videos with displacement measurements, sample removal and exams } \\
\text { for FP deposition, peak temperature evaluations) }\end{array}$ & $\mathrm{AE}, \mathrm{AM}, \mathrm{DD}$ & NA \\
\hline
\end{tabular}

a. See list of acronyms.

b. Use: AE - Accident evaluation (code modeling updates), AM- Accident management and prevention, DD - Decontamination and Decommissioning, and PM - Plant maintenance (see Appendix C for more information).

c. Some information available [Green]; NA: no information available [Orange].

Information related to radionuclide release and transport has been acquired from several sources during and following the three core melt events at Daiichi. During the accident, sources include:

- Radiation doses encountered by plant personnel entering the reactor buildings;

- Elevated radiation doses that developed in control rooms for the affected units;

- Radiation doses on the plant site due to:

- Passage of airborne plumes, either forming from containment venting operations or accidental release after the $1 \mathrm{~F} 1,1 \mathrm{~F} 2$, and $1 \mathrm{~F} 3$ containments became impaired,

- Deposition of fission products from these releases onto the site,

- Dispersal of contaminated structural material over the site due to reactor building explosions when flammable gases combusted inside the $1 \mathrm{~F} 1,1 \mathrm{~F} 2$, and $1 \mathrm{~F} 4$ reactor buildings;

- Drywell and wetwell radiation readings from affected units, acquired when operators re-powered containment air monitors (CAMs).

Following the accident, contaminated water in the various reactor buildings provides additional indications of low-elevation leakage from the damaged units. Specific examples include:

- 1F1: Contaminated water leakage was detected in the reactor building basement, and it was speculated that this leakage arose because of damage to the drywell liner by interaction with ex-vessel core debris;

- 1F2: Very soon after the event, relatively high levels of radiological contamination were measured in water that accumulated in the reactor building basement;

- 1F3: Contaminated water leakage was detected in the reactor building on the first floor near the MSIV.

Available reactor building and offsite radiological contamination information provide important insights that can be used to: 
- Refine understanding of core damage progression and its impact on potential off-site consequences,

- Identify locations at which the containments became impaired to develop insights relevant to enhancing containment protection,

- Understand the isotopic composition of fission product releases to gain detailed understanding of fission product transport and potential off-site consequences.

\subsection{Highlights and Recent Findings}

Appendix F provides additional radiation survey and dose measurement information of interest to the U.S. Forensics Effort. Highlights and recent information are highlighted in this section.

\subsubsection{F1 Status and Highlights}

Figure 4-1 summarizes dose measurements and surveys within the 1F1 reactor building at selected times. This figure also provides indications of the current temperature and water level at selected locations within the reactor building.

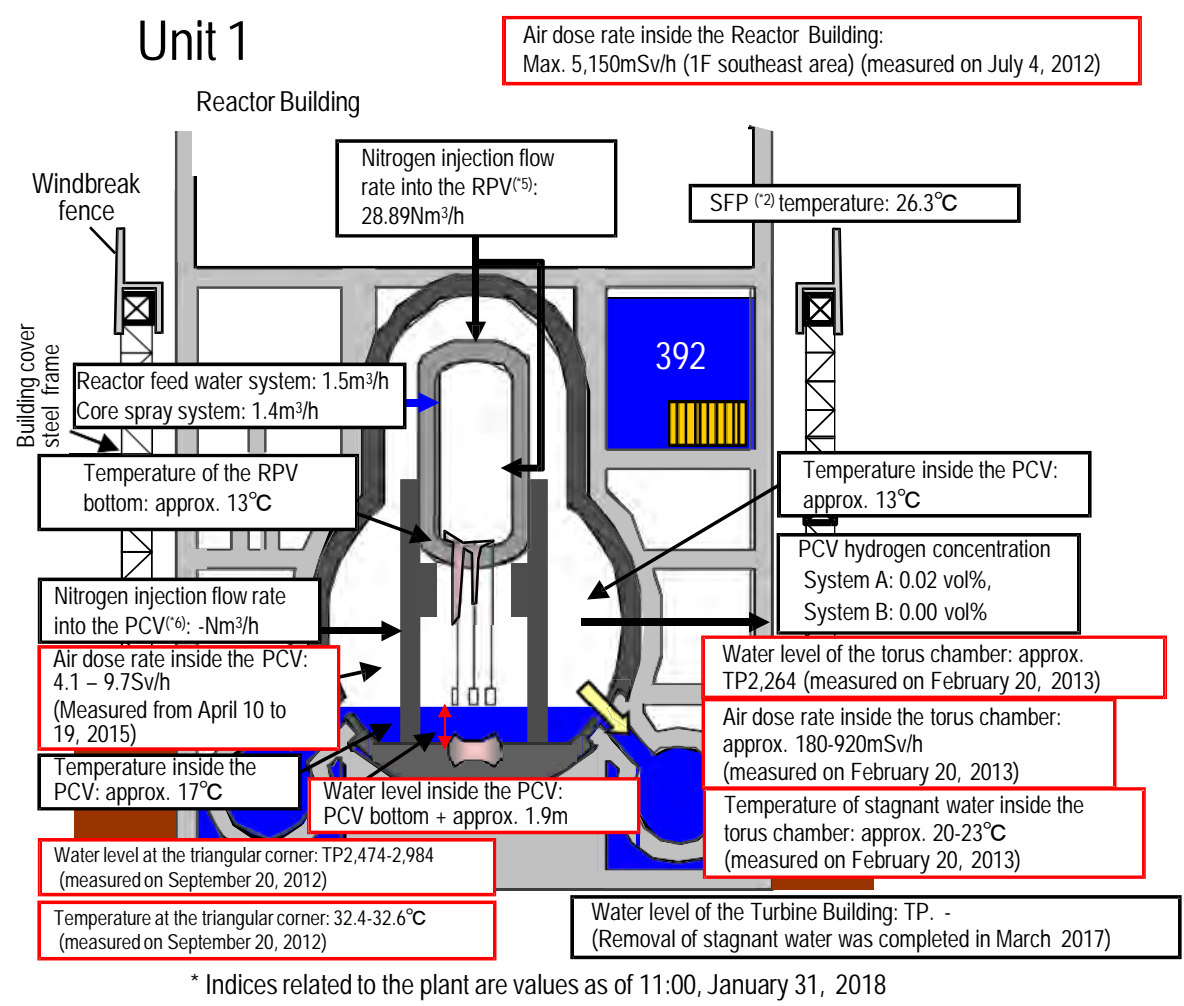

Figure 4-1. 1F1 status. (Courtesy of TEPCO Holdings [108])

Access to the 1F1 reactor building is challenging because of damage to the upper floors from the combustible gas explosion that occurred at 24.8 hours after the earthquake. As discussed in Appendix F, ele- 
vated radiation levels have helped identify several failure locations, such as the wetwell vacuum breaker line expansion joint (see Figure F-1), the Reactor Building Closed Cooling Water System (RCW or RBCCW) heat exchangers (see Figure F-2), the sand cushion drain pipe (see Figure F-3), the torus room (see Figure F-4), and penetrations within the Traversing In-core Probe (TIP) room (see Figure F-5).

In June 2017, TEPCO used a crane to obtain dose measurements around the shield plug (see Figure 4-2). The elevated dose rates measured in the vicinity of the 1F1 drywell head (see Figure 4-3) indicate failure of the 1F1 drywell head seal.

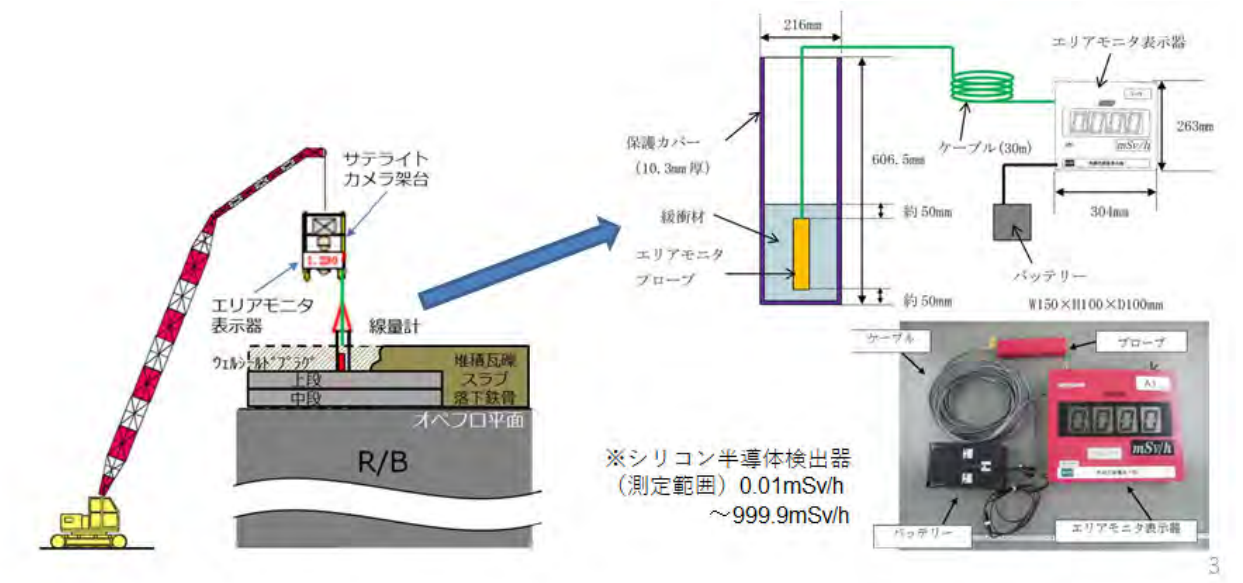

Figure 4-2. Approach for 1F1 RB dose measurements. (Courtesy of TEPCO Holdings [147])

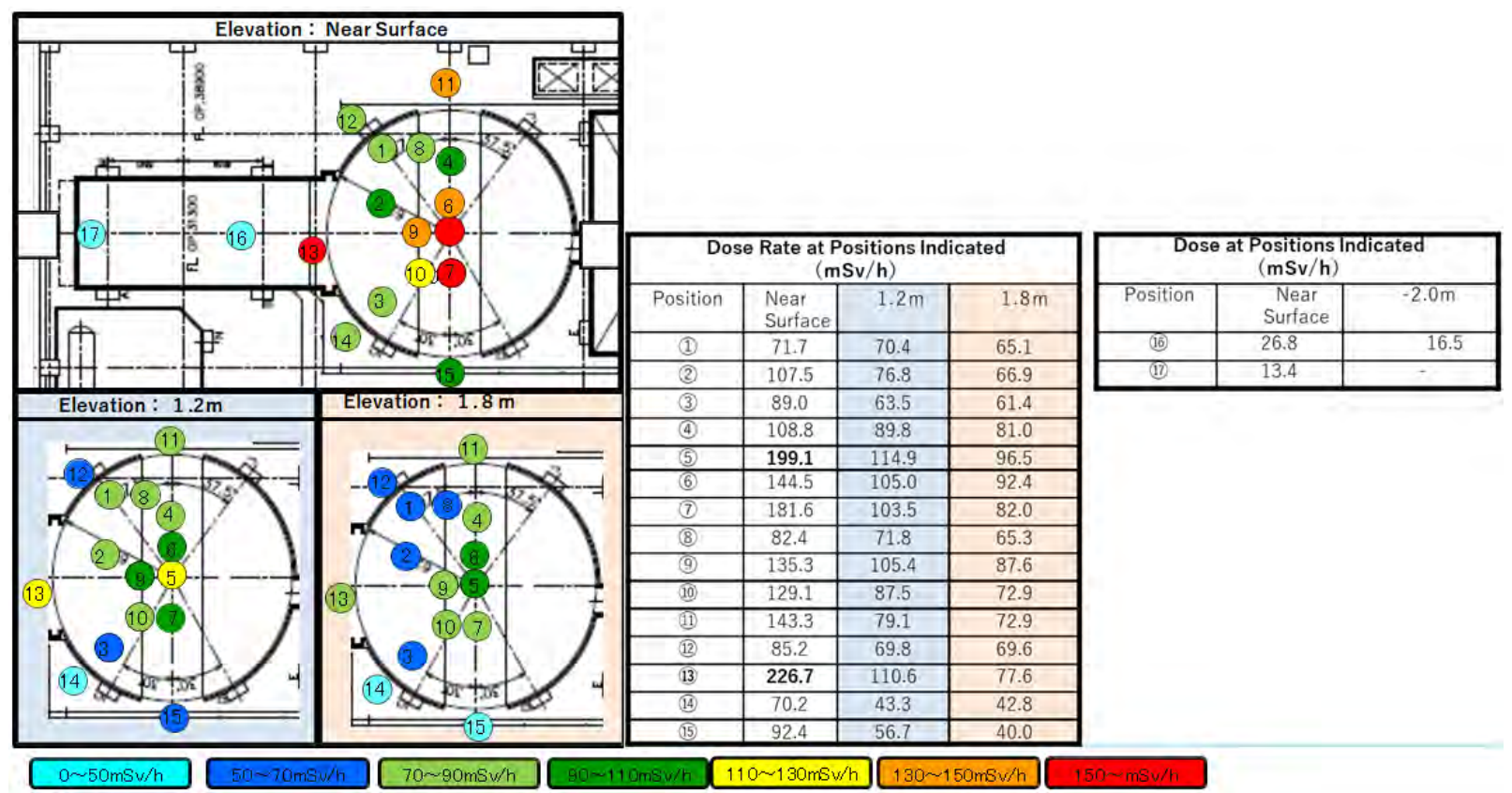

Figure 4-3. 1F1 dose measurements near the shield plug. (Courtesy of TEPCO Holdings [147]) 
As discussed in Section 5.2.3, investigations within the 1F1 PCV identified the presence of sediment on the bottom of the PCV at locations near the X100 penetration (e.g., the BG and D0(3) locations) and near the pedestal opening (e.g., the D1, and D2 locations). Dosimeter measurements were obtained at this location as a position of height from the floor of the pedestal (see Figure 4-4).[148, 149] In [150], results from calculations are presented that evaluate if the measured dose at each location was due to fuel within the sediment or cesium. It is observed that the height of the sediment is much higher (up to $0.9 \mathrm{~m}$ ) at positions D1 and D2), but much shallower (approximately $0.1 \mathrm{~m}$ ) at positions BG and D0. Results for the D1 and D2 positions were inconclusive (because of shielding associated with the thicker sediment layer). However, evaluations indicate that the measured dose was due to Cs- 137 at the BG and D0(3) positions where a shallower sediment layer was observed.[150]

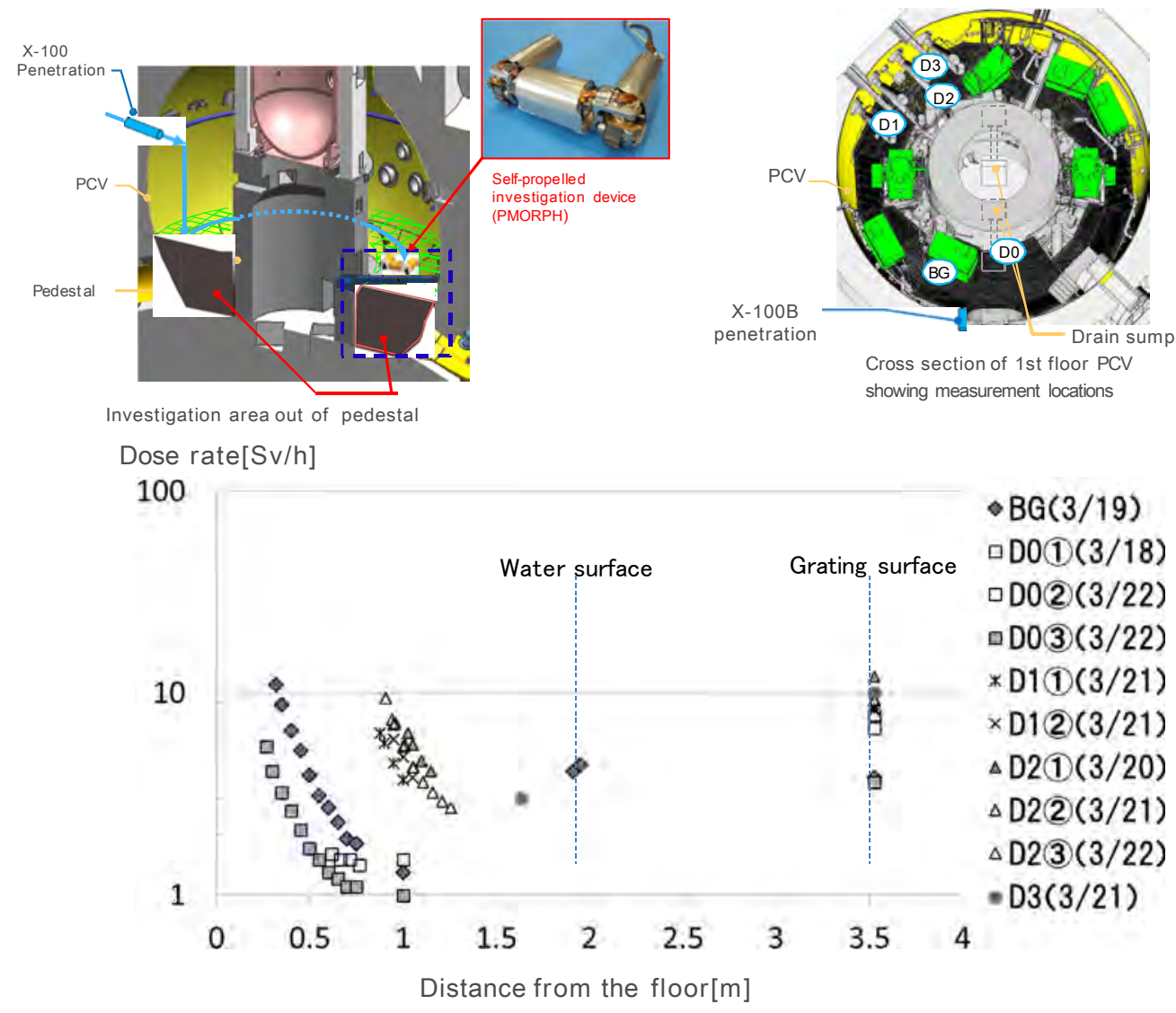

Figure 4-4. 1F1 investigations using the PMORPH Scorpion robot; dose rate measurements taken in March 2017. (Courtesy of TEPCO [148, 149])

\subsubsection{F2 Status and Highlights}

Figure 4-5 summarizes dose measurements and surveys within the 1F2 reactor building at selected times. This figure also provides indications of the current temperature and water level at selected locations within the reactor building. 1F2 air does rates within the reactor building are slightly lower than values but 
nearly an order of magnitude higher in the PC. The higher PCV air dose rates may be partially due to the lower water levels in $1 \mathrm{~F} 2$.

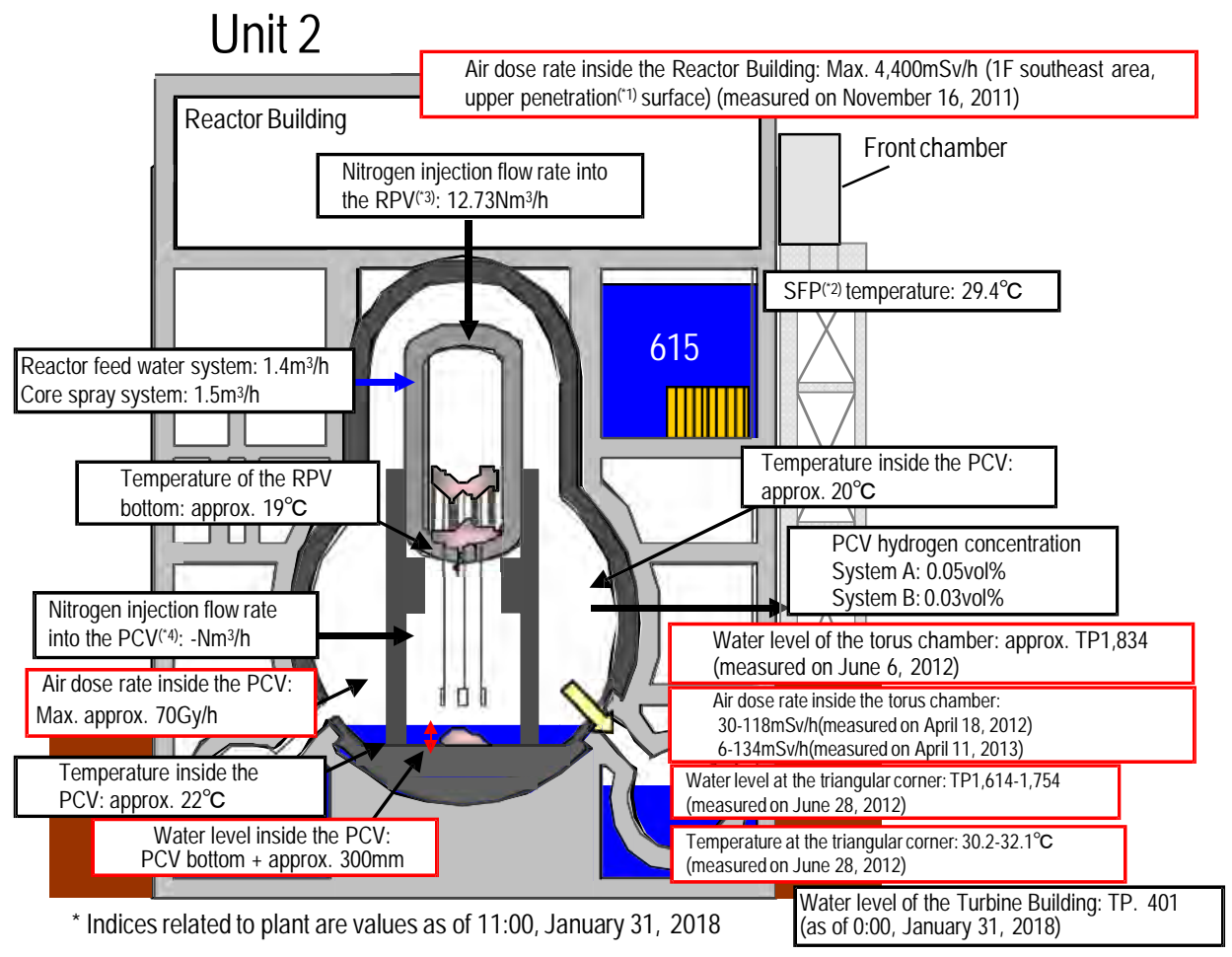

Figure 4-5. 1F2 status. (Courtesy of TEPCO Holdings [108])

Currently, personnel access to the $1 \mathrm{~F} 2$ reactor building is less restricted than at $1 \mathrm{~F} 1$; combustion of any flammable gas leakage from containment impairments did not occur at $1 \mathrm{~F} 2$. This is likely due to the opening of the reactor building blowout panel on the refueling floor, which occurred due to gas rarefaction following the pressure waves propagating away from the $1 \mathrm{~F} 1$ reactor building flammable gas explosion. (Figure 4-6 shows the open blowout panel in the 1F2 reactor building).

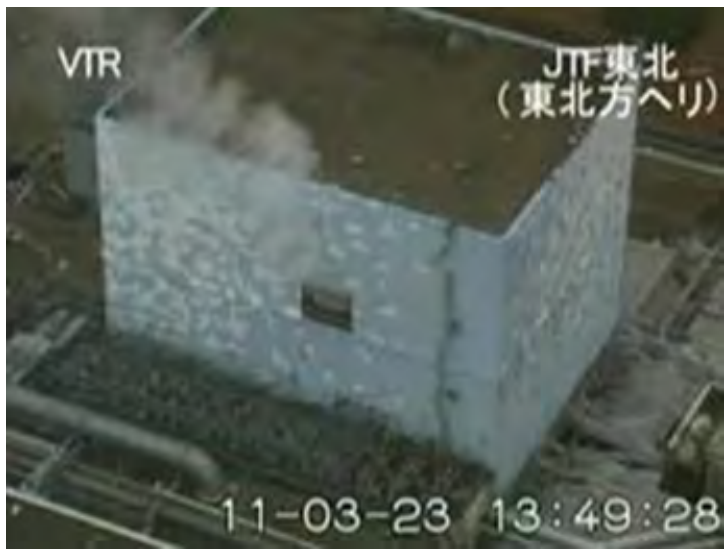

Figure 4-6. 1F2 reactor building with open blowout panel. (Courtesy of TEPCO Holdings [151]) 
As discussed in Appendix F, torus room radiation dose rates measured in 1F2 are lower than values measured in $1 \mathrm{~F} 1$. However, examinations measured elevated radiation doses in front of the X-6 penetration flange (see Figure 3-1), the X-34, and X-29B/C penetrations, and near the shield plugs above the drywell head (see Figure F-8). Unlike 1F1, the RCW equipment is not contaminated. No elevated doses were found inside the 1F2 TIP room nor near penetrations in the TIP room (see Figure F-9).

During the entry into the 1F2 PCV (see Section 5.2.3.1), an estimation of the dose rates in the containment was established.This estimation was calculated along the scaffolding leading from the X-6 penetration to the pedestal region. Upon further evaluation of this reported value, it was found that the calibration used in calculating the number was wrong and the reported dose rates were revised downwards.[152] The initial and revised dose rates can be seen in Figure 4-7.

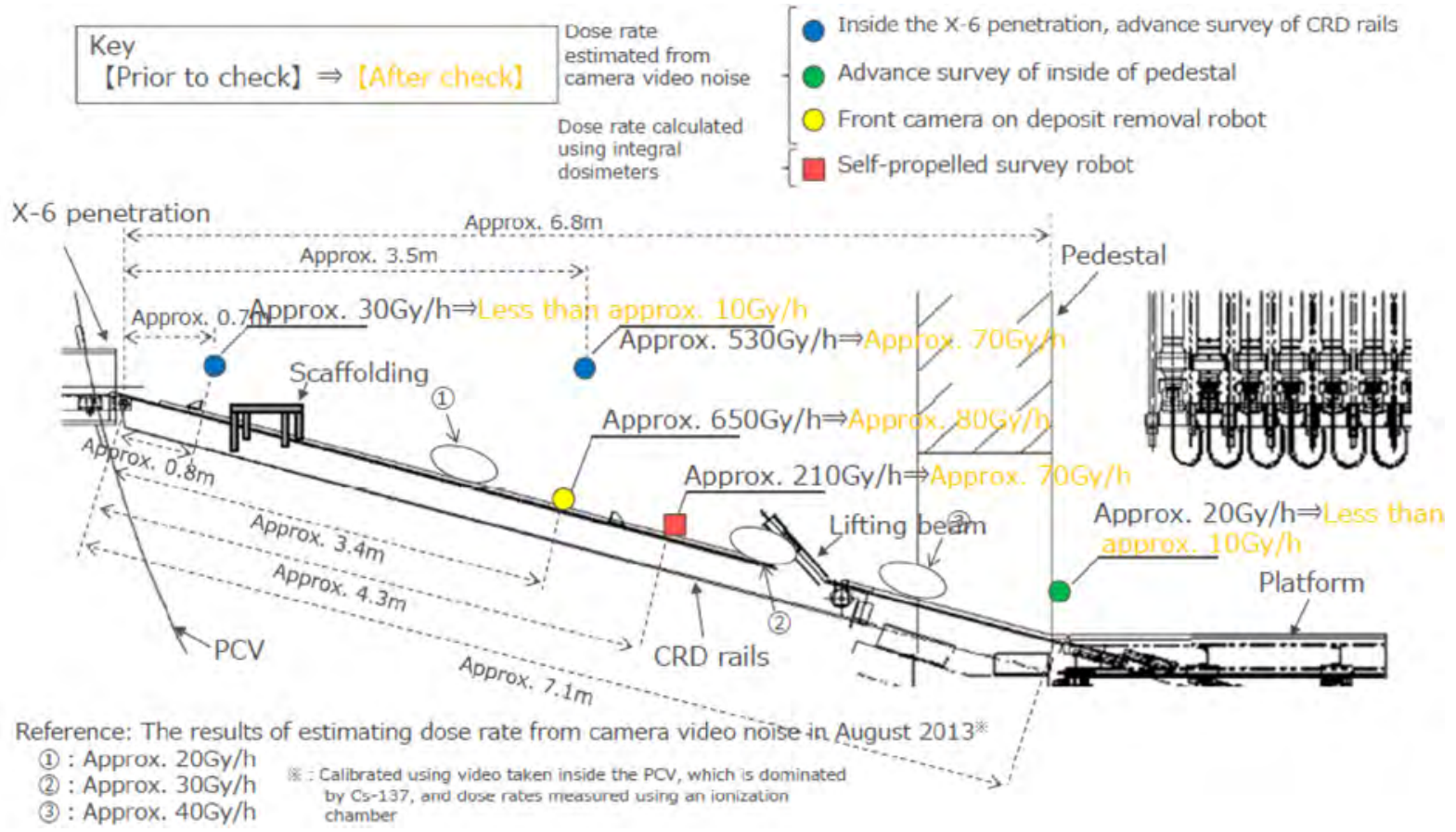

Figure 4-7. Dose revisions calculated during subsequent analysis of 1F2 entry. (Courtesy of TEPCO Holdings [152])

\subsubsection{F3 Status and Highlights}

Figure 4-8 summarizes dose measurements and surveys within the $1 \mathrm{~F} 3$ reactor building at selected times. This figure also provides indications of the current temperature and water level at selected locations within the reactor building. 1F3 air does rates within the reactor building are slightly higher than 1F1 values but higher than $1 F 2$ values. 1F3 PCV air dose rates are lower than values measured in $1 \mathrm{~F} 1$ or $1 \mathrm{~F} 2$. This is attributed to the higher water levels in $1 \mathrm{~F} 3$. 


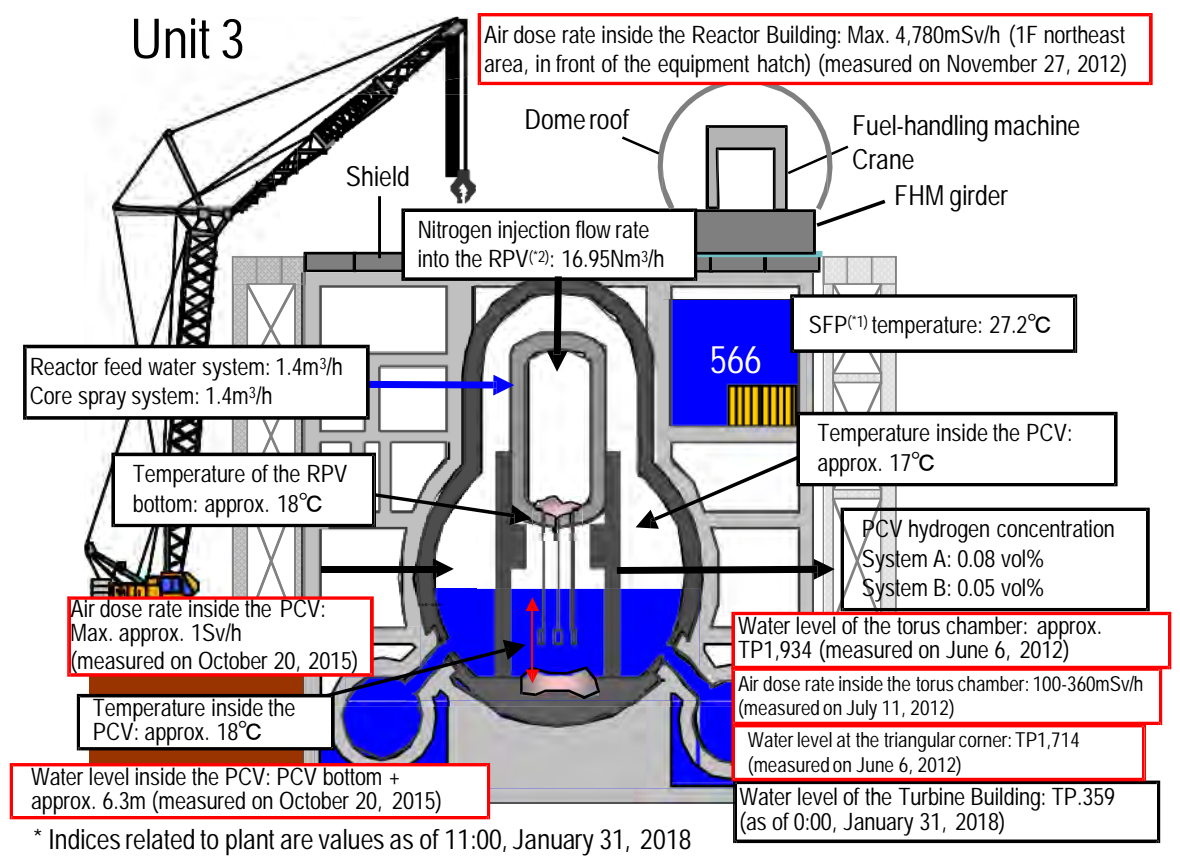

Figure 4-8. 1F3 status. (Courtesy of TEPCO Holdings [108])

As with the $1 \mathrm{~F} 1$ reactor building, access to the $1 \mathrm{~F} 3$ reactor building is difficult because of damage associated with the combustion of flammable gases at 68.7 hours after the earthquake. As discussed in Section 6.2, more extensive damage occurred to lower elevations of the 1F3 reactor building. As described in Appendix F, elevated radiation dose rates were measured in the $1 \mathrm{~F} 3$ reactor building on the first floor near the equipment hatch (see Figure F-10, inside the MSIV room, and above the drywell head (see Figure E-7). Similar to $1 \mathrm{~F} 2$, the RCW equipment is not contaminated (which differs from what was measured in 1F1). No elevated doses were found inside the 1F2 TIP room nor near penetrations in the TIP room.

\subsubsection{Evaluation of Samples from Examinations within the PCV}

As entries into the PCVs of each of the three 1F units continue (see Section 5.2.2), there have been significant efforts by TEPCO to collect and perform analysis of samples of debris found within the containment and pedestal region of each reactor. These include samples taken on the floor of the 1F1, obstructions in the TIP line of 1F2, and samples taken on the exterior of the robots used for entry into 1F2 and 1F3.

In April 2017, deposits under the residual water remaining the 1F1 containment were sampled. The sampling location can be seen in Figure 4-9. These deposits were found lying loosely on hard sandstone-like deposits in the bottom of the containment. Gamma analysis of the sample indicated the presence of $\mathrm{Cs}, \mathrm{Co}$ and $\mathrm{Sb}$. Additionally, X-ray fluorescence and Inductively Coupled Plasma Mass Spectrometry (ICP-MS) analyses indicate the presence of $\mathrm{U}, \mathrm{Fe}, \mathrm{Ni}, \mathrm{Zn}$ and $\mathrm{Pb}$, among other elements. Evaluations [153, $154]$ indicate that these deposits are likely an agglomeration of fuel, PCV internal components, and paints. 


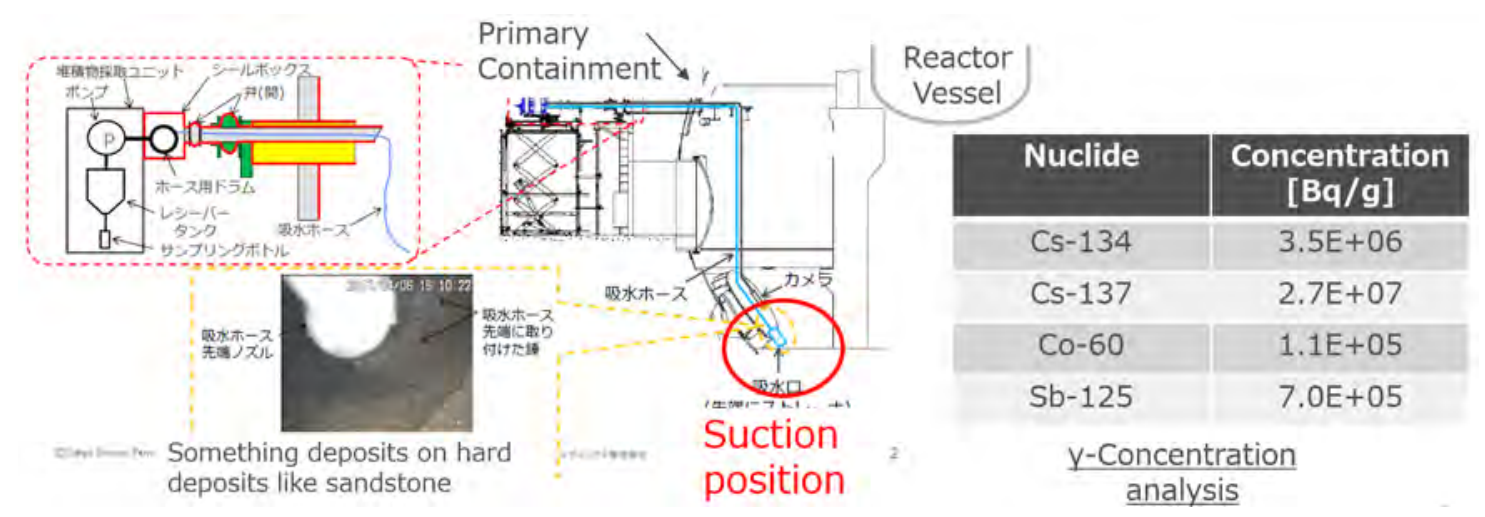

Figure 4-9. Sampling location and gamma dose analysis results of the sediment within 1F1. (Courtesy of TEPCO Holdings [154,154])

To supplement the TEPCO observations $[153,154]$, we note from the SEM-EDS analysis that the samples contain elevated levels of $\mathrm{Na}, \mathrm{Mg}, \mathrm{Al}$, and $\mathrm{Si}$. Na may have been introduced in the form of salt $(\mathrm{NaCl})$ during the seawater injection phase of the accident, but the analysis also indicates $\mathrm{Cl}$ is present at very low levels, much below the 1:1 molar ratio one would expect if the $\mathrm{Na}$ was introduced as salt during the accident. However, chemical reactions between $\mathrm{NaCl}$ and other elements/compounds present in containment may have resulted in a compositional change in which $\mathrm{Cl}$ relocated to other region(s). Potential sources for the elevated levels of $\mathrm{Mg}, \mathrm{Al}$, and $\mathrm{Si}$ in the sample could include sand from seawater injection, insulation, and/or aerosol from concrete decomposition. As noted in Appendix C, the possible source of this material may be determinable by comparing the molar ratios of these elements to those present in the three indicated materials. However, this comparison could not be carried out this fiscal year. We recommend that the Forensics Effort complete this activity in FY19.

Analysis of the sample obstructing the 1F2 TIP pipe confirmed the presence of $\mathrm{Zr}$ in addition to elements used in structural materials including $\mathrm{Fe}, \mathrm{Cr}$, Ni and $\mathrm{Mn}$ through energy-dispersive X-ray spectroscopy (EDS). The TIP line sample along with the associated EDS plot are shown in Figure 4-10.[153]

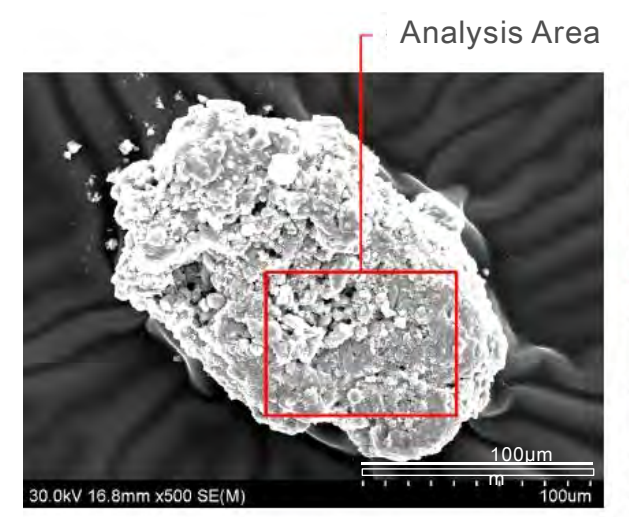

Analysis Area

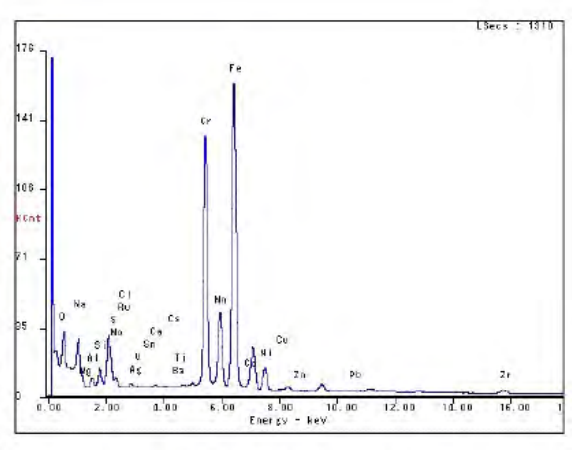

EDS spectrum of Area

Figure 4-10. SEM 1F2 TIP pipe sample (left); EDS of the same sample (right). (Courtesy of TEPCO Holdings [153]) 
Additional samples obtained during the recent entries to the 1F2 and 1F3 PCVs are currently under analysis by the JAEA. The 1F2 sample was obtained using cotton swabs that wiped the bottom of the piping through which the robot entered the containment. This sample location and method can be seen in Figure 4-11. The 1F3 sample was obtained by wiping off the submersible robot that performed the investigation of the pedestal region of 1F3. This sample collection can be seen in Figure 4-11.[153]

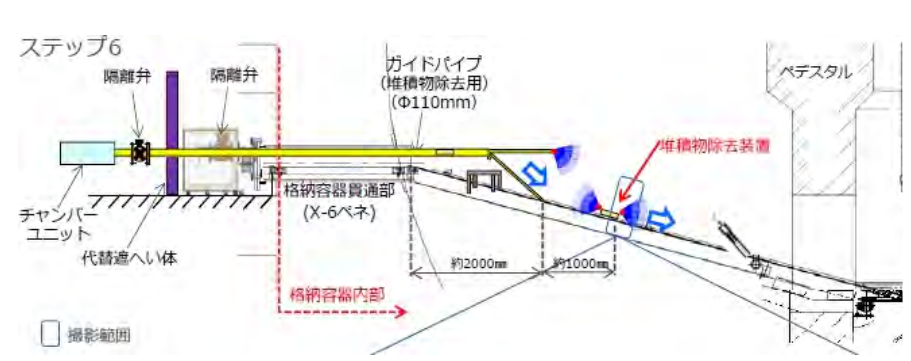

Outline drawing of sediment removal operation

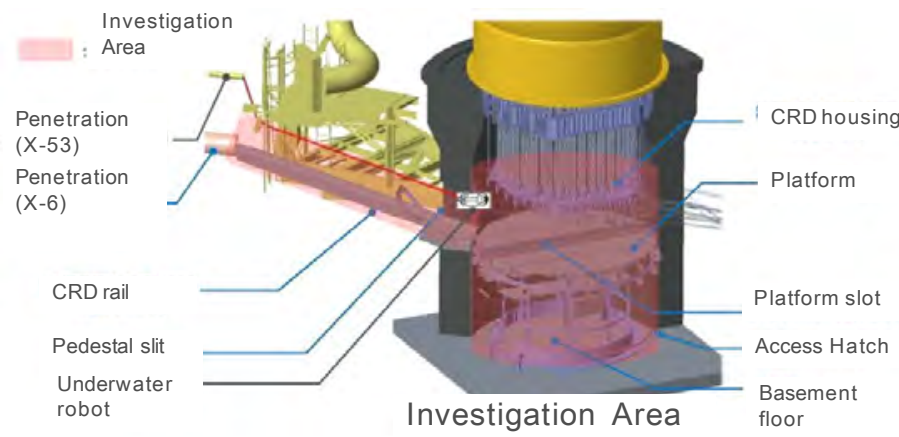

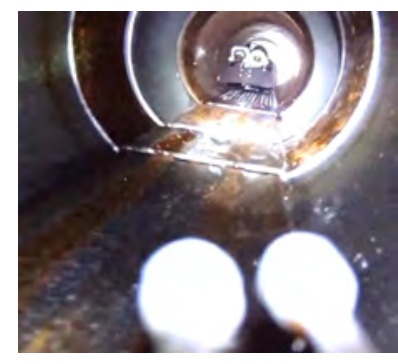

Collecting Sample

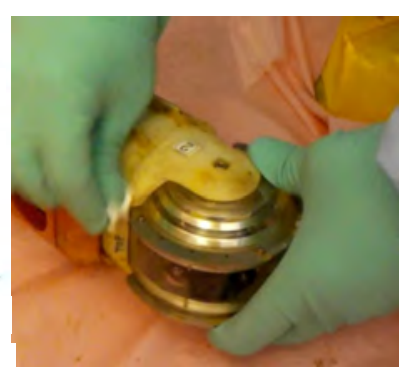

Wiping off robot

Figure 4-11. 1F2 (top) and 1F3 (below) sampling methods used during the recent entries into the containments of both reactors. (Courtesy of TEPCO Holdings [153])

\subsubsection{Insights and Limitations}

Table 4-4 summarizes notable locations of elevated dose rates and associated analyses discussed in Appendix F.[19, 57, 97, 98, 137, 155 through 172] These measurements were reviewed and categorized for the primary purpose of gaining insights into potential locations where containment integrity may have been lost (or impaired). Of specific interest is identifying containment boundary locations that are more likely to become impaired during an accident. This characterization is also relevant for assessing existing assumptions about BWR Mark I containment vulnerabilities applied in existing safety assessments and Probabilistic Risk Assessments (PRAs). 
Table 4-4. Locations of elevated dose rate inside reactor buildings ${ }^{\mathrm{a}}$

\begin{tabular}{|c|c|c|}
\hline Unit & Floor & Note \\
\hline \multirow[t]{4}{*}{$1 \mathrm{~F} 1$} & $1^{\text {st }}$ & $\begin{array}{l}\text { Penetration between the basement and the first floor providing passage for the wetwell } \\
\text { vent line due to failure of wetwell vent line bellows } \\
\text { Higher dose rates near the penetrations in the TIP room [121] }\end{array}$ \\
\hline & $2^{\text {nd }}$ & $\begin{array}{l}\text { Very high dose rates around RCW heat exchangers (see [42] for a detailed discussion of } \\
\text { the fission product flow path out of containment into the RCW system piping) }\end{array}$ \\
\hline & $3^{\text {rd }}$ & $\begin{array}{l}\text { Elevated dose rates observed on east side of the reactor building underneath a stairwell } \\
\text { and associated with a puddle of water }\end{array}$ \\
\hline & Refueling Floor & Investigations have not had same access to the refueling floor as $1 \mathrm{~F} 2$ and $1 \mathrm{~F} 3$ \\
\hline \multirow[t]{4}{*}{$1 \mathrm{~F} 2$} & Torus & $\begin{array}{l}\text { Notable contamination of water in torus room (leakage from damage to RCIC suction } \\
\text { piping suspected [155]) }\end{array}$ \\
\hline & $1^{\text {st }}$ & $\begin{array}{l}\text { Elevated dose rates around X-34 penetration (main steam flow rate instrument piping } \\
\text { penetration) }\end{array}$ \\
\hline & $2^{\text {nd }}$ & Elevated dose rates around X-29B/C penetration (RPV water level instrument piping) \\
\hline & Refueling Floor & Very high dose rates found at the shield plug, above the drywell head \\
\hline \multirow[t]{2}{*}{$1 \mathrm{~F} 3$} & $1^{\mathrm{st}}$ & $\begin{array}{l}\text { Elevated dose rates around water pools accumulating outside the equipment hatch. Dose } \\
\text { rates in the MSIV room slightly higher on the inside of the MSIV room (compared to } \\
\text { dose rates in the } 2^{\text {nd }} \text { floor) }\end{array}$ \\
\hline & Refueling Floor & Very high dose rates found at the shield plug, above the drywell head \\
\hline
\end{tabular}

a. Nomenclature: [Clear]: - No information; [Yellow] - Notable water contamination $(<100 \mathrm{mSv} / \mathrm{h}$; [Orange] - Elevated $(100 \mathrm{mSv} / \mathrm{h}$ to $500 \mathrm{mSv} / \mathrm{h})) ;]$ [Red] - High $(>500 \mathrm{mSv} / \mathrm{h})$.

Reactor building dose rate measurements were acquired by TEPCO Holdings in 2012. Most data acquisition was obtained using dosimeters (hand-held or attached to robots). Above floor gamma camera measurements were performed to locate radiation sources. While these radiation reading are obviously subject to alteration with time due to radioactive decay and instrumentation uncertainty, the available measurements were observed at similar times. Given that the primary source of radiation at this point is from long-lived fission products such as Cs-137, the reporting of raw dose rates is reasonable given the qualitative insights that they are supporting.

The focus of the summary in Table 4-4 is to identify areas of the reactor building where high air dose rates were measured. One exception is noted, however, in reporting of relatively high dose rates in the water of the 1F2 torus room. Unlike 1F1 and 1F3, it has been noted since March of 2011 that water borne radiological release was elevated at $1 \mathrm{~F} 2$, highlighting a leakage location in the torus or connected piping. The summarized locations do not include detailed discussion of air dose rate readings acquired from within the torus rooms of the different units; these measurements tend to be influenced by shine from inside the gas space of the torus and do not provide an indication of containment integrity.

The following insights can be derived from these dose rates measurements:

- As discussed in Appendix E (see Section E.2), pressures and temperatures within the 1F1, 1F2, and 1F3 PCVs exceeded their design envelop. The DW head flange at all three damaged units appears to be the primary point at which containment leakage may have first occurred (see Appendices $\mathrm{E}$ and F). Radiation surveys from $1 \mathrm{~F} 1,1 \mathrm{~F} 2$, and $1 \mathrm{~F} 3$ indicate the DW head flange as a point of leakage because of the high dose rates measured in this region. DW head leakage is also suggested by the 1F1 temperature information (see Appendix E.2.1) and the localized flammable gas 
combustion damage observed on the 1F1 refueling floor (see Section 6.2.2). In addition, the 1F1 shield plug relocation and subsequent dose measurements indicate that the plug DW head flange in this unit likely leaked.

- Degradation of the containment boundary appears to have occurred at all three units through several additional locations, with each unit having a different set of localized containment impairments (see Appendix E.2.1). The range of containment impairments observed so far likely reflects features of the accident that are unique to each unit. In several cases, the additional points of containment impairment are localized around a containment penetration, introducing a point at which liquid leakage has occurred. This presents a challenge with respect to D\&D activities, since it is possible that penetrations higher in the drywell may also be susceptible to liquid leakage that would initiate during any attempt at drywell reflooding.

- In most of these cases, an important limitation is that it is difficult to identify when impairment at these additional locations could have occurred. Late-phase degradation of containment due to persistence of elevated pressure and atmospheric temperature appears to be a likely outcome given the range of observed impairments. While such containment impairments may not be directly relevant to off-site consequences, they have a significant impact on the ability of personnel to access the plant. These longer-term containment impairment modes have had a significant impact during the

event remediation and cleanup phases, notably through the prolonged contamination of ground water.

\subsection{Recommendations}

In reviewing available information for this area, the expert panel formulated several recommendations for future sensitivity studies and evaluations.

\section{Area 2 Recommendation 1:}

Similar to Area 1 Recommendation 1, experts agreed that information on this topic suggests that sensitivity studies should be performed on containment failure location and size with respect to radiological releases (timing, amount) and impact on accident progression. These sensitivity studies should be done with both MAAP and MELCOR to cover a range of predicted containment and primary system conditions. To compare results from simulations of core damage progression and radiological release to the environment, additional analyses with an environmental radiological transport code, such as MACCS, would be useful. Sensitivities for each unit would reduce uncertainties in code modeling by providing insight into which failure likely caused depressurization, the conditions under which such a failure occurred, and the effect of multiple failures. Some previous sensitivity analyses have been performed for failure of the primary system (SRV versus MSL, etc.) and the containment. As discussed within this section, reactor building radiological hotspots provide a means to assess inputs provided to severe accident computer codes, but do not typically facilitate assessment of the code models.

\section{Area 2 Recommendation 2:}

Similar to Area 1 Recommendation 3, concisely compare the predicted conditions by both MAAP and MELCOR at the MSIV (temperature, pressure) for $1 \mathrm{~F} 2$ and $1 \mathrm{~F} 3$. 


\section{Area 2 Recommendation 3:}

Similar to Area 1 Recommendation 4, the expert panel continues to be interested in examination information of MSIV room components. Specific examination needs to support these evaluations are identified in RB-10 and RB-13 of Appendix C.

The above recommendations provide insights for accident modeling, plant maintenance, accident management, as well as information to assist Japan with on-going D\&D efforts. The leakage of 1F3 in the MSIV room contrasts with the observation of no damage in the MSIV rooms for 1F2. As failure in this location bypasses the containment, it would be beneficial to understand why failure occurred in 1F3 but not in 1F2. Similarly, the condition of the explosive guide tube sealing valve is desired to gain insights regarding the dose rates measured near the penetrations in the 1F1 TIP room are so much higher than in the other two units. An important component of such an evaluation is determining both the potential point in the accident when failure occurred and the relevance of this failure to gaseous releases from the impairment. As noted in this report, several different locations of containment impairment have been identified. It is currently suspected that many of these impairments were of primary relevance either after the containment depressurized or as a location through which aqueous leakage occurred. Reductions in modeling uncertainties provide insights regarding the endstate location of debris. In addition, the location of impairments are critically relevant to on-site personnel performing accident management and remediation activities, although their influence on off-site radiological contamination is far less significant. As discussed with this section and Appendix F, the impairment to the drywell head flange is believed to be the primary source through which the most significant radiological release occurred with respect to off-site contamination.

\section{Area 2 Recommendation 4:}

The expert panel recommends that the U.S. Forensics Effort continue to evaluate information obtained from examinations of RPVs within each unit impairment location. Additional visual information would be particularly useful in Area 2 Recommendation 1 sensitivity studies.

Given the strong indications of early RPV pressure boundary impairment, visual data from each of the damaged units relevant to RPV pressure boundary integrity would be of significant value for enhancing the severe accident knowledge base at reactor scale. RPV upper internals and steam line/tail pipe assembly visual data would be of considerable value. The occurrence of an early impairment in the RPV (prior to lower head breach) is an important aspect in evaluating CAM response. This recommendation provides insights for reducing code modeling uncertainties and assist Japan with on-going D\&D efforts.

\section{Area 2 Recommendation 5:}

The expert panel recommends that the U.S. Forensics Effort complete an evaluation to determine the source of $\mathrm{Na}, \mathrm{Mg}, \mathrm{Al}$, and Si measured in the SEM-EDS analysis (see Section 4.3.4). This evaluation should be completed by comparing the measured molar ratios with representative values found in sand from seawater injection, insulation, and/or aerosol from concrete decomposition to determine the source of $\mathrm{Na}, \mathrm{Mg}, \mathrm{Al}$, and $\mathrm{Si}$.

If the molar ratios are consistent with values from concrete decomposition, results could provide important insights regarding the occurrence of MCCI that could be used to reduce code modeling uncertainties and assist Japan with on-going D\&D efforts. 


\subsection{Suggestions for Additional Information}

As illustrated within this section, dose survey and isotopic survey and sampling information provides insights about component and system degradation, debris end-state location, and combustible gas effects. The expert panel continues to be interested in this information, as it becomes available. The expert panel is interested in information obtained from isotopic evaluations from samples of concrete obtained within the reactor building. Based on insights obtained from evaluations of current information, one suggestion is offered at this time.

\section{Area 2 Suggestion 1:}

Continue planned additional isotopic evaluations.

If additional samples of concrete are obtained, evaluations of concrete samples extracted from a common location for all three units would be of interest. For example, further information that could be acquired regarding isotopic composition from the shield plugs above the drywell heads at 1F1 and 1F3 would be useful to evaluate fission product release and transport [See Appendix C Information Need RB-7]. Furthermore, the expert panel should continue to monitor any additional off-site ${ }^{134} \mathrm{Cs}$ to ${ }^{137} \mathrm{Cs}$ isotopic ratio data obtained from soil samples. As noted in [173], JAEA and IRID are monitoring the ${ }^{90} \mathrm{Sr}$ to ${ }^{137} \mathrm{Cs}$ isotopic ratio obtained from such samples. As noted in Table 4-1, this information provides insights for accident management, accident evaluation, and on-going D\&D efforts. 
ANL-18/24 


\section{AREA 3 - DEBRIS END-STATE}

The expert panel also selected debris end-state as an area of emphasis with respect to examination information. Post-accident examinations at TMI-2 [44] demonstrated that the end-state of debris is an important finding from forensics inspections and critical for developing and validating models within severe accident analysis codes. Debris end-state location information is of interest at Daiichi because comparisons can be made between the multiple units that were affected. In addition, it is desired to gain insights about core debris relocation behavior and morphology within the reactor vessel, debris coolability, the effects of saltwater, and ex-vessel debris spreading and coolability from examinations. As discussed within this section, answers to questions about debris end-state are also required by TEPCO Holdings for successful and safe completion of D\&D activities. High radiation levels currently limit the ability to gain direct examination information to address such questions. Hence, indirect as well as emerging direct observations, coupled with analysis model predictions, are providing the basis for debris removal planning.

This section summarizes findings from the Fukushima Daiichi forensics efforts to date in terms of how they relate to debris end-state configuration and how these findings can be used to address uncertainties in such analyses. To that end, we begin by first providing a summary of relevant information obtained to date, with emphasis placed on how these findings relate to reactor safety evaluations. This is followed by a summary of our preliminary insights and a brief description of the limitations of these insights. We then provide a few recommendations and observations for additional activities that could provide insights related to information gained from available forensics information. The section concludes with suggestions for additional information that would be beneficial regarding debris end-state evaluations. Additional findings and information previously reported are located in Appendix G.

\subsection{Questions for Reactor Safety and D\&D}

Available information was evaluated to address the following questions that are of international interest for reactor safety and to Japan in making decisions for future D\&D activities:

- What is the mass, composition, morphology, and decay heat of materials relocated to the lower head?

- Has vessel lower head failure occurred? What was the timing and mode of such failure (e.g., has global, localized, or penetration failure occurred)?

- What is the mass, composition, decay heat, morphology, and spreading characteristics of material relocated from the lower head and to what extent has this material interacted with below vessel structure during relocation?

- Are analysis model improvements needed to predict observed end-state?

- Are there any observed effects from saltwater addition?

- Can observed end-states of debris and structures be used to estimate the amount of combustible gas generated during relocation and during molten core concrete interactions (MCCIs)?

- Can information from one unit be used to confirm analysis models and predict conditions in another unit?

- Can information provide insights about the integrity of structures within the PCV and the reactor building? 
Answers to these questions have important safety impacts. By obtaining prototypic data from the three units at Daiichi, there is the potential to reduce modeling uncertainties. Improvements in our modeling capabilities can be used to confirm or enhance, if needed, accident management strategies with respect to containment venting, water addition, and combustible gas generation.

Answers to the above questions also are of interest with respect to Phase II D\&D activities. As discussed in Section 2.3.4, debris end-state characterization studies provide key input for decisions related to the debris retrieval approach, development of the fuel debris retrieval equipment, and implementation of fuel debris retrieval activities with reduced risks from radioactive materials. In particular, improved models for predicting the timing and mode of vessel failure and the mass, composition, and decay heat of material relocated to and from the lower head are of interest in making decisions related to the methods for debris removal and measures needed for worker protection from damaged structures and from radiation.

\subsection{Information Summary}

As discussed in Section 1.3.1, U.S. experts identified information needs that could be addressed through examinations at Fukushima Daiichi. Requested information needs from the reactor building, PCV, and RPV that relate to debris end-state location are summarized in Tables 5-1 through 5-3. These tables also note if any information is available to address these information needs (see Appendix C). As these tables indicate, some direct information has been obtained regarding debris end-state location for the affected units, and more information continues to become available. This information has been gathered using robotic examinations and stand-off methods such as muon tomography. Aside from direct information, there are several other data sources available to indirectly infer the debris end-state location in each unit. For all units, there are data from instruments, such as temperature information obtained during and immediately after the accident, gas concentration data from the gas treatment system, and neutron and gamma detector data from sub-criticality monitoring systems. In terms of direct observations, images of what appear to be relocated core debris residing in the pedestal regions of all three affected units have been obtained via robotic examinations; these same examinations have also provided images of core debris interaction and holdup on below vessel structure which, in turn, has provided insights into likely vessel failure location(s)

Table 5-1. Area 3 information needs from the reactor building

\begin{tabular}{|c|l|c|c|}
\hline Item & \multicolumn{1}{|c|}{ What/How Obtained $^{\mathbf{a}}$} & Use $^{\mathbf{b}}$ & $\begin{array}{c}\text { Data } \\
\text { Available }^{\mathbf{c}}\end{array}$ \\
\hline RB-14 & $\begin{array}{l}\text { Chemical analysis of white deposits found in 1F1 HPCI room using } \\
\text { XRD or other methods. }\end{array}$ & AE, AM, DD & NA \\
\hline
\end{tabular}

a. See list of acronyms.

b. Use: AE - Accident evaluation (code modeling updates), AM- Accident management and prevention, DD - Decontamination and Decommissioning, and PM - Plant maintenance (see Appendix C for more information).

c. Some information available [Green]; NA: no information available [Orange]. 
Table 5-2. Area 3 information needs from the PCV

\begin{tabular}{|c|c|c|c|}
\hline Item & What/How Obtained ${ }^{\text {a }}$ & Use $^{b}$ & $\begin{array}{l}\text { Data } \\
\text { Available }^{c}\end{array}$ \\
\hline \multirow[t]{5}{*}{$P C-3^{d}$} & $\begin{array}{l}\text { a) Photos/videos of relocated debris and crust, debris and crust } \\
\text { extraction, hot cell exams, and possible subsequent testing (1F1 - 1F3) }\end{array}$ & $\mathrm{AE}, \mathrm{AM}, \mathrm{DD}$ & A \\
\hline & $\begin{array}{l}\text { b) PCV liner examinations (photos/videos and metallurgical exams; } \\
\text { 1F1-1F3) }\end{array}$ & AE, AM, DD & NA \\
\hline & $\begin{array}{l}\text { c) Photos/video, RN surveys, and sampling of pedestal wall and floor } \\
\text { (1F1-1F3) }\end{array}$ & $\mathrm{AE}, \mathrm{AM}, \mathrm{DD}$ & A \\
\hline & $\begin{array}{l}\text { d) Concrete erosion profile; photos/videos and sample removal and } \\
\text { examination (1F1-1F3) }\end{array}$ & AE, AM, DD & NA \\
\hline & $\begin{array}{l}\text { e) Photos/videos of RPV lower head and of structures and penetrations } \\
\text { beneath the RPV to determine damage and corium hang-up (1F1-1F3) }\end{array}$ & AE, AM, DD & A \\
\hline PC-17 & $\begin{array}{l}\text { Chemical analysis of upper layer of sediment on drywell floor at the } \\
\mathrm{X}-100 \mathrm{~B} \text { penetration location in } 1 \mathrm{~F} 1 \text {. The upper surface of the sediment } \\
\text { is } \sim 30 \mathrm{~cm} \text { above drywell floor }\end{array}$ & AE, AM, DD & NA \\
\hline PC-18 & $\begin{array}{l}\text { Evaluate the nature of the material below the upper surface of the } \\
\text { debris at the X-100B penetration location in } 1 \mathrm{~F} 1 \text { to determine if it is } \\
\text { additional sediment or other material such as core debris }\end{array}$ & AE, AM, DD & NA \\
\hline PC-19 & $\begin{array}{l}\text { Chemical analysis (XRF) of black material discovered on CRD } \\
\text { exchange rail in } 1 \mathrm{~F} 2 \text { at X-6 penetration location }\end{array}$ & AE, AM, DD & NA \\
\hline PC-20 & $\begin{array}{l}\text { Chemical analysis of black material on 'existing structure' in 1F1 } \\
\text { image at location 'D3' }\end{array}$ & AE, AM, DD & NA \\
\hline PC-21 & Images from examinations in $1 \mathrm{~F} 3 \mathrm{X}-53$ penetration. & AE, AM, DD & A \\
\hline
\end{tabular}
a. See list of acronyms.
b. Use: AE - Accident evaluation (code modeling updates), AM- Accident management and prevention, DD - Decon- tamination and Decommissioning, and PM - Plant maintenance (see Appendix C for more information).
c. Some information available [Green]; NA: no information available [Orange].
d. As described in Section 5.2.2, in-vessel components have been discovered ex-vessel for two of the affected units (i.e., fuel assembly top tie plate for 1F2 and CR guide tube and CRD index tube for 1F3) indicating that the vessels have failed. In addition, sample evaluations from $1 \mathrm{~F} 1$ have detected the presence of uranium.

Table 5-3. Area 3 information needs from the RPV

\begin{tabular}{|c|c|c|c|}
\hline Item & What/How Obtained $^{\text {a }}$ & $\mathbf{U s e}^{\mathbf{b}}$ & $\begin{array}{c}\text { Data } \\
\text { Available }^{c}\end{array}$ \\
\hline \multirow[t]{2}{*}{ RPV-5 } & $\begin{array}{l}\text { Remote mapping of } 1 \mathrm{~F} 1,1 \mathrm{~F} 2 \text {, and } 1 \mathrm{~F} 3 \text { core through shroud wall from } \\
\text { annular gap region (muon tomography and other methods, if needed) }\end{array}$ & $\mathrm{AE}, \mathrm{AM}, \mathrm{DD}$ & A \\
\hline & $\begin{array}{l}\text { Mapping of end state of core and structural material (visual, sampling, } \\
\text { hot cell exams, etc.) }\end{array}$ & $\mathrm{AE}, \mathrm{AM}, \mathrm{DD}$ & NA \\
\hline
\end{tabular}
a. See list of acronyms.
b. Use: AE - Accident evaluation (code modeling updates), AM- Accident management and prevention, DD - Decon- tamination and Decommissioning, and PM - Plant maintenance (see Appendix C for more information).
c. Some information available [Green]; NA: no information available [Orange]. 


\subsubsection{Thermocouple Measurements}

TEPCO Holdings has extensively used readings from thermocouples located on the reactor vessel to make inferences related to debris location (see Appendix G). Results, which are consistent with muon tomography examination information and results from systems analysis calculations, indicate that varying degrees of core material relocated from the vessel.

One recent finding from 1F3 reinforces the idea that data need to be carefully examined for reliability and potential failure mechanisms. In particular, TEPCO Holdings has recently identified the possibility of damage to thermocouple lead cabling for 1F3 [174] (see Figure 5-1). These types of considerations need to be factored into data evaluations and subsequent inferences made regarding potential debris locations based on thermocouple measurements.

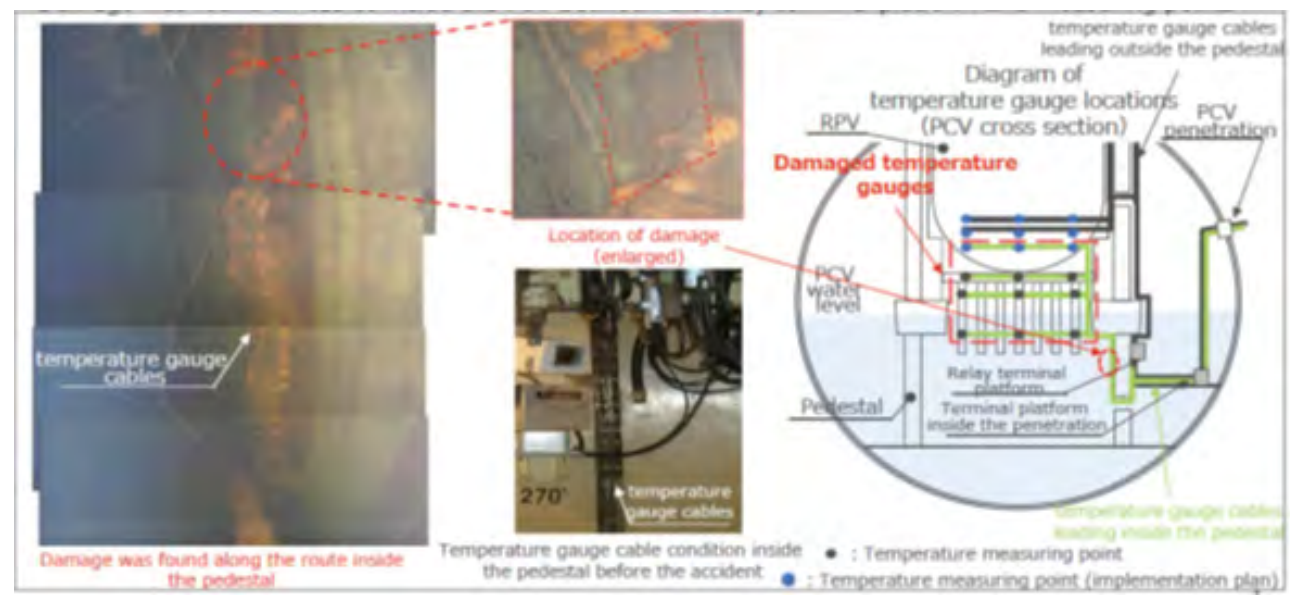

Figure 5-1. Evidence of damage to thermocouple cabling inside the PCV for 1F3. (Courtesy of TEPCO Holdings [174])

\subsubsection{Images from Inspections within the PCV}

Table 3-5 lists various types of examinations conducted in each unit at Daiichi. TEPCO Holdings has recently obtained valuable information for $1 \mathrm{~F} 1$ from sample evaluations (see Section 4.3.4). In addition, new information has been obtained for $1 \mathrm{~F} 2$ and $1 \mathrm{~F} 3$ using robotics examinations through containment penetrations. Similar robotic examinations were previously completed for 1F1; the data and inferences made from the data are provided in Appendix G.

\subsubsection{F1 Examinations}

As documented in Appendix G, limited robotic examinations within the PCV of 1F1 have been conducted to date. These efforts have identified the presence of significant accumulations of material in the drywell outside the pedestal doorway ( 0.8-1.0 m [150]), as well as at the X-100B location, which is located $\sim 130$ degrees from the pedestal doorway ( $\sim 30 \mathrm{~cm}$ deep) [168]. The upper surface of these accumulations is covered with loose sediment, and it is not currently known how far down the loose sediment extends, and whether the sediment covers other material (e.g., core debris). 
After these PCV internal investigations in April 2015, additional examinations were conducted in March-April 2017 with the goal of characterizing this sediment to support future D\&D activities [175]. A device was inserted to extract a sample of this loose material by pulling suction through a strainer located just above the sediment layer at the X-100B location. The sediment was then analyzed using X-Ray Fluorescence (XRF) and gamma spectroscopy to determine elemental and radionuclide content. In addition to fission products, uranium was detected. The detection of uranium ex-vessel serves as a strong indicator that the reactor vessel for $1 \mathrm{~F} 1$ has also failed, as has been confirmed for $1 \mathrm{~F} 2$ and $1 \mathrm{~F} 3$. This is consistent with both US and international severe accident code analyses predicting that the reactor vessel for $1 \mathrm{~F} 1 \mathrm{had}$ almost certainly failed. More recent analysis of the sediment has been completed using higher resolution techniques including SEM-EDS [154]. These results, which provide interesting initial insights into the possible origin(s) of this material, are described in Section 4.3.4.

\subsubsection{1F2 Examinations}

Valuable data continues to emerge from 1F2 examinations $[138,139,143]$ to augment the initial findings reported in late 2016 and early 2017.[176-179] Access inside the PCV has been gained through the X-6 penetration, allowing robot access to the CRD exchange rail (Figure 5-2). The initial investigations [176-178] revealed the presence of black material laying on the surface of the exchange rail near the CRD platform (Figure 5-3). The composition of the black material has not been determined. Possibilities include melted CRD cabling insulation or core material. Thus, evaluations of this material could provide evidence of the temperatures that the below vessel structure experienced during the accident, as well as possibly confirming lower head failure if the material contains a significant amount of core debris.

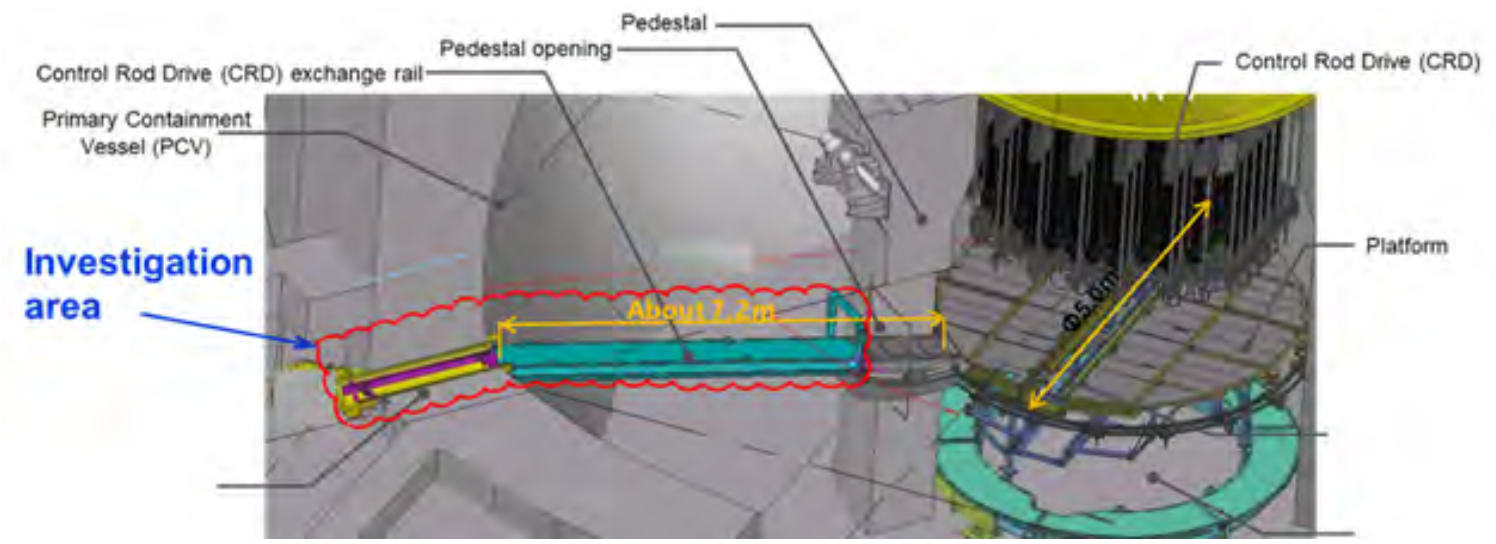

Figure 5-2. Access path through the X-6 penetration in 1F2 allowing initial examinations along the CRD exchange rail. (Courtesy of TEPCO Holdings [176])

The initial investigations into the 1F2 containment resulted in images of the pedestal region. A combination of the different pictures taken is shown in Figure 5-4. The metal grating is failed in multiple locations and depressed elsewhere. This figure suggests that a portion of the corium relocated ex-vessel after a vessel failure event. This is further reinforced by the pictures of 1F5 (see Figure 5-5), which was shut down at the time of the tsunami.[177] As discussed in Appendix G, this is also consistent with thermocouple data[11] and muon tomography images.[179] The grating images show evidence of gradual plastic deformation (in the form of sagging grating), as though a large mass of very hot but somewhat solid corium material came to rest on the grating and caused it to gradually deform under the thermal loading and weight associated with this material. Other grating failure locations show characteristics of more aggressive thermal attack and failure.[177] 


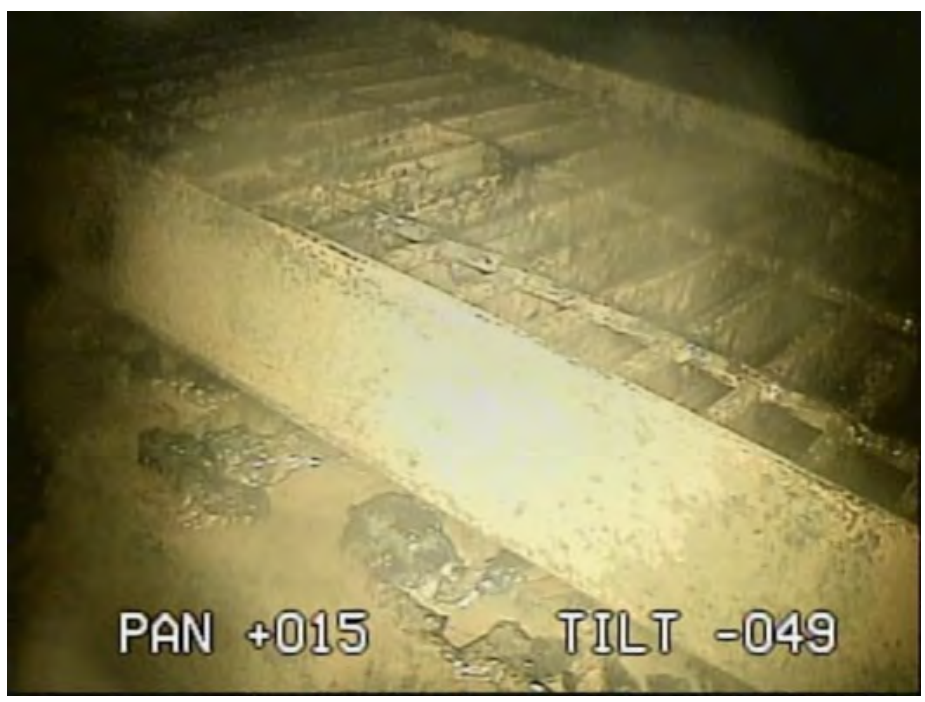

Figure 5-3. Photograph of CRD exchange rail surface near the CRD platform showing the presence of black material. (Courtesy of TEPCO Holdings [176])

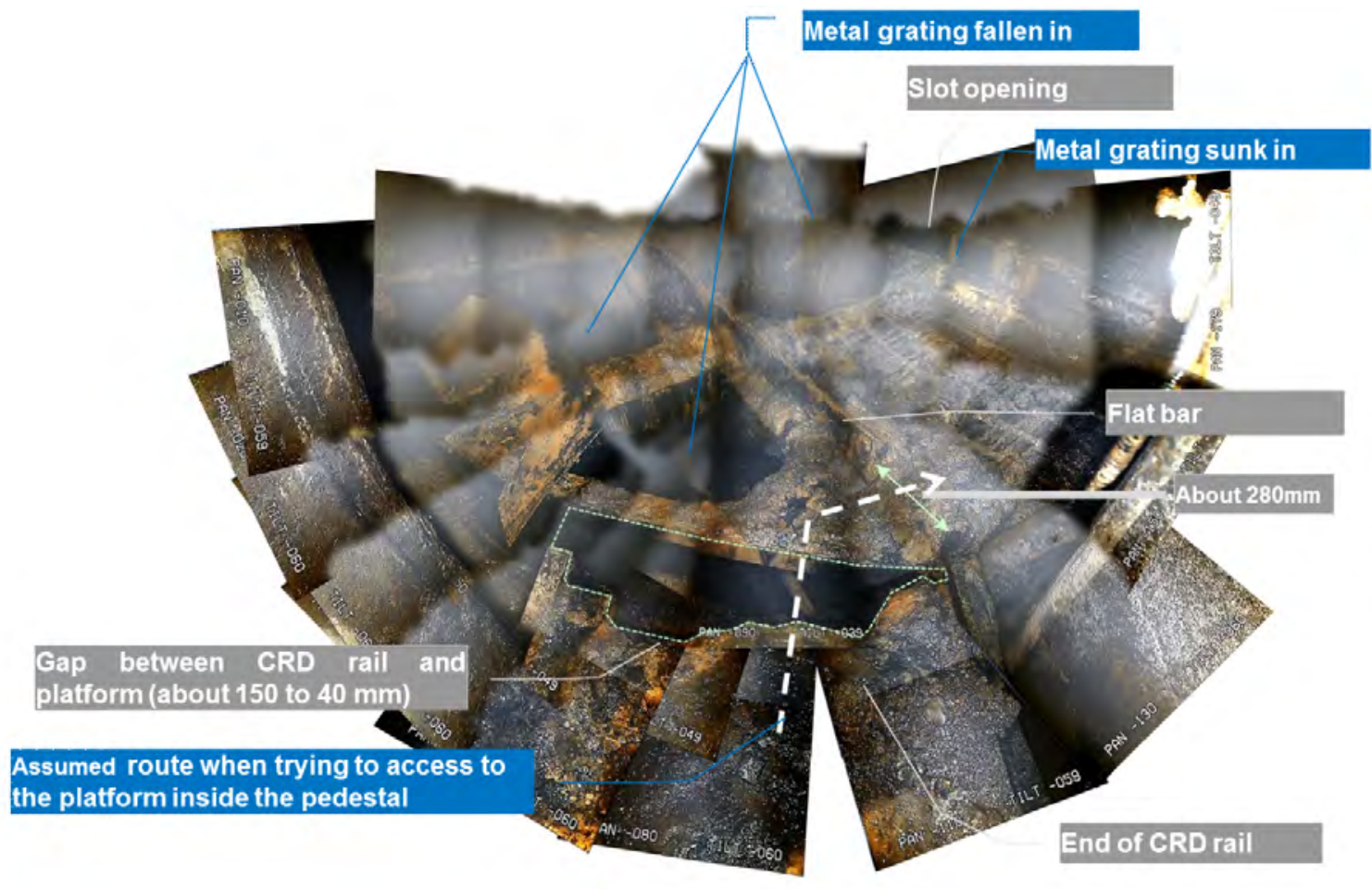

Figure 5-4. Combined images from entry into 1F2 pedestal region, indicating findings. (Courtesy of TEPCO Holdings [177]) 


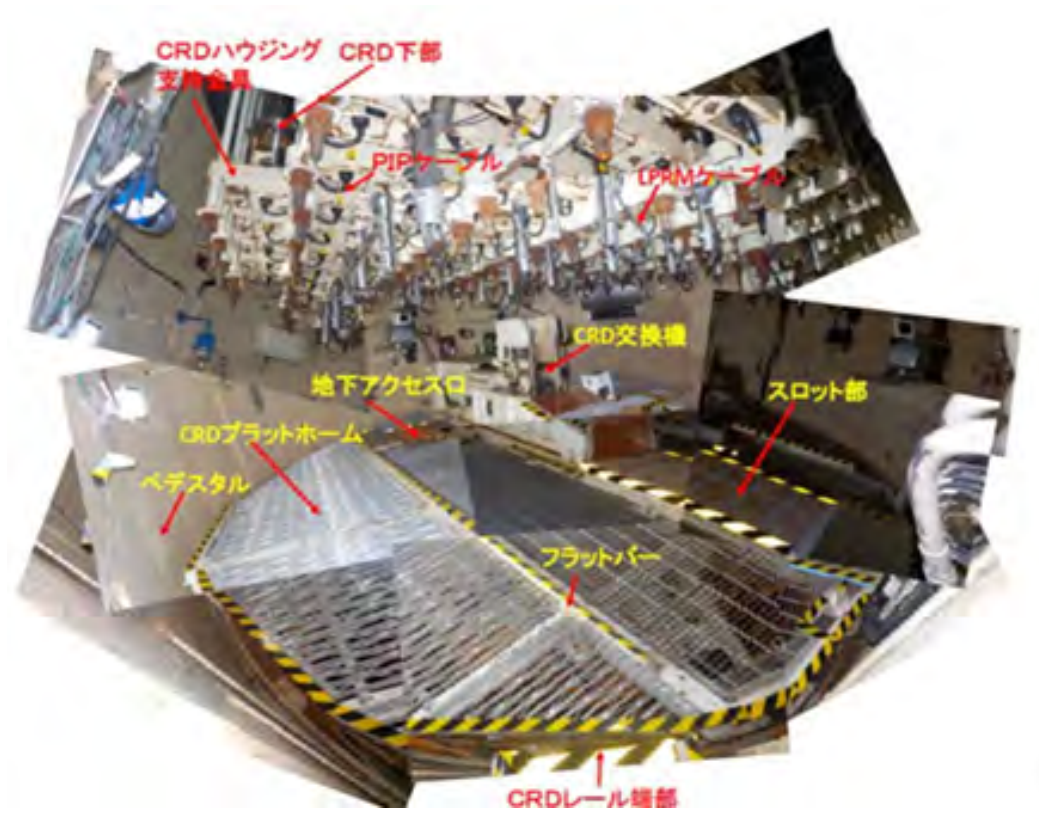

Figure 5-5. Image of 1F5 pedestal region, included for reference. (Courtesy of TEPCO Holdings [177])

An additional entry through the 1F2 X-6 penetration was successfully completed on 19 January 2018 (Figure 5-6). This entry featured a more sophisticated robot designed to drop a camera into the pedestal region and thereby provide additional information on potential debris locations. This work revealed enhanced images of damage to, and material deposition on, below vessel structure as well as the pedestal floor. Initial photographs obtained during this entry are shown in Figures 5-7 and 5-8. The entire bottom of the pedestal was found to be covered with clay-like deposits. One very important finding is that a fuel assembly component (i.e., top tie plate; see Figures 5-8 and 5-9) had fallen from the vessel and was on the floor of the pedestal surrounded by material thought to be core debris.

TEPCO Holdings has recently carried out more detailed analyses of the video data obtained during the January 2018 entry [143] using advanced image processing techniques to produce much higher quality renderings of the material distributions in the 1F2 pedestal region [138]. The results of this work showing damage to the top platform and lower head structures is provided in Figures 5-10 and 5-11, respectively. As is evident from Figure 5-11, solidified core debris is adhering to traversing in-core guide probe (TIP) tubing, as well as local power range monitor (LPRM) and position indicator probe (PIP) cabling. The platform grating immediately below this location is missing (Figure 5-10), providing evidence that this is a likely failure location for the lower head. Further examination of the mid-level platform located below the top platform (see Figure 5-12) indicate that grating on this platform had also failed in the same locations where the top platform had failed (see Figure 5-11), further reinforcing the idea that this is a vessel failure point. 


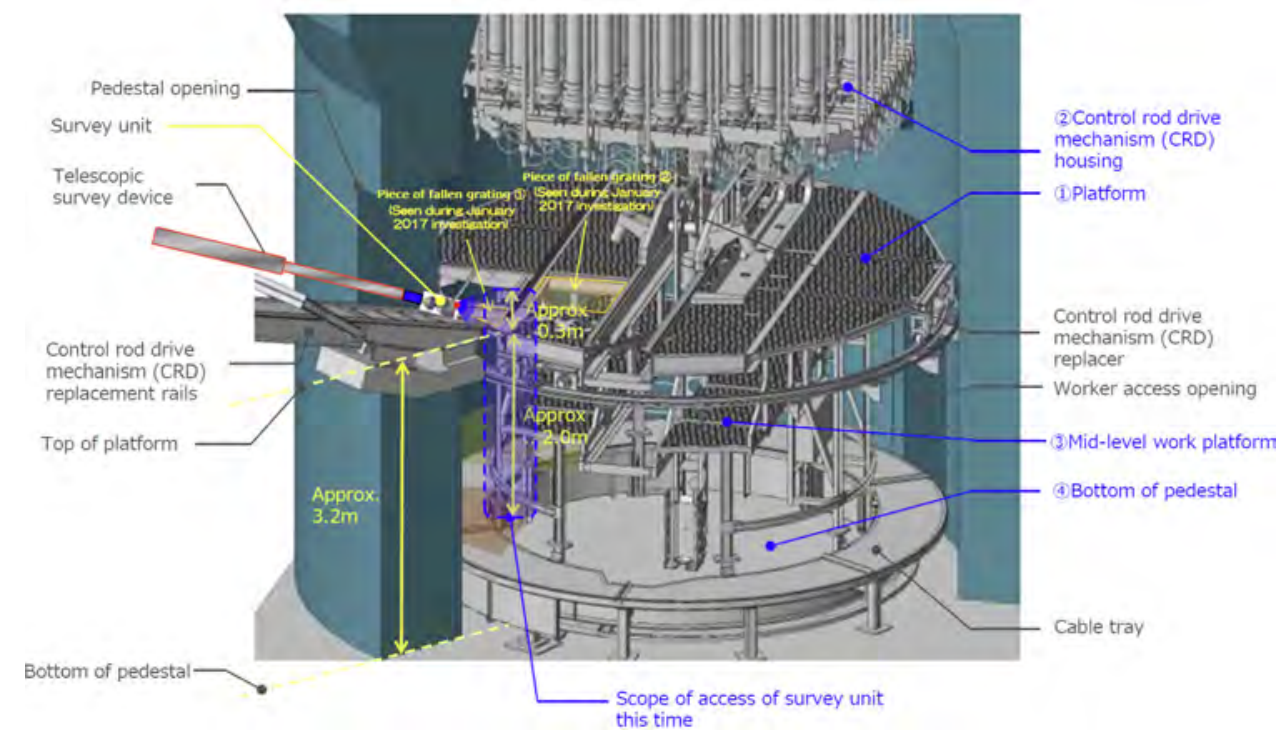

Figure 5-6. Access path through the X-6 penetration in $1 F 2$ for the second examination along the CRD exchange rail and below into the pedestal. (Courtesy of TEPCO Holdings [139])

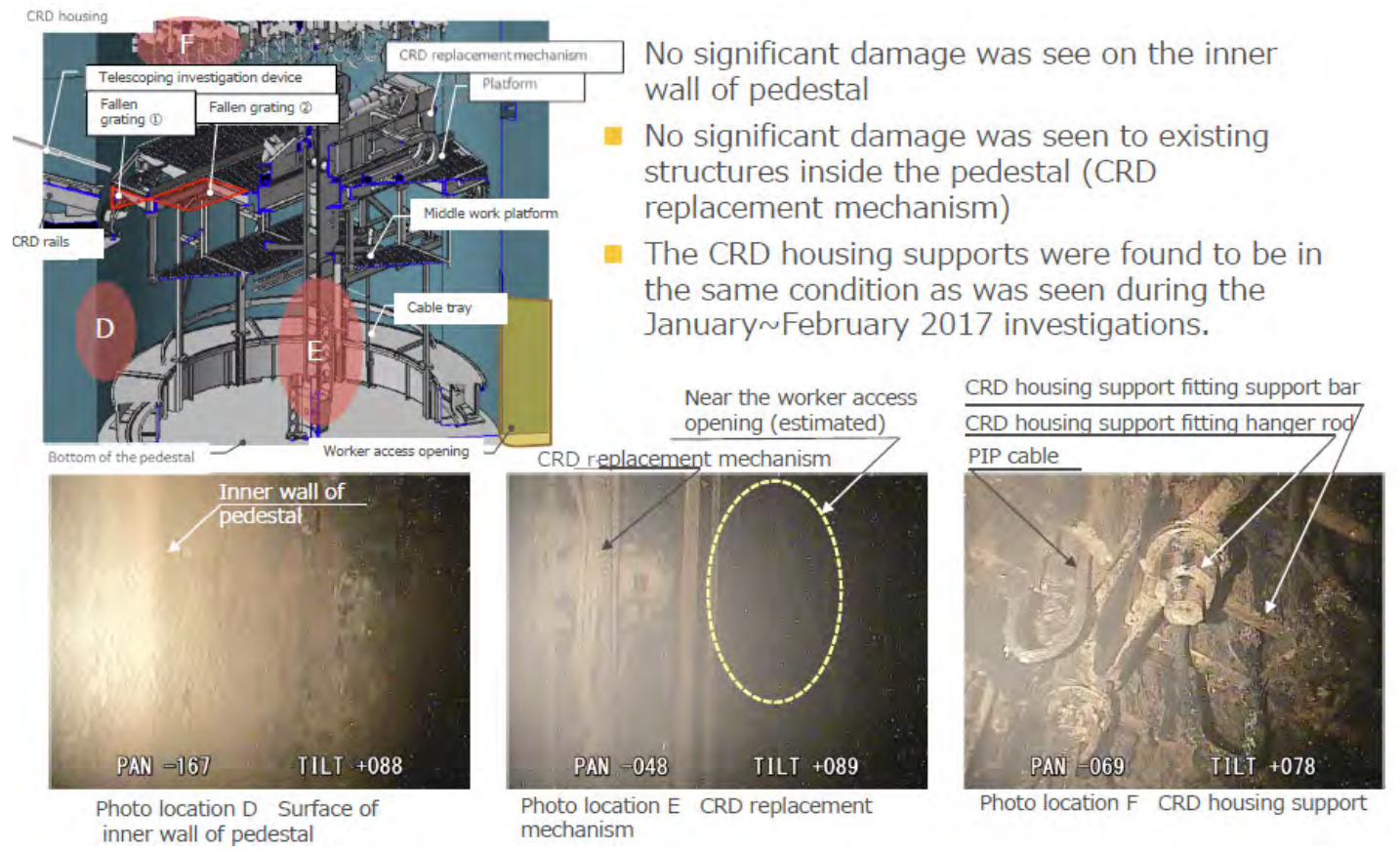

Figure 5-7. Photographs of vertical structures inside 1F2 pedestal. (Courtesy of TEPCO Holdings [143]) 


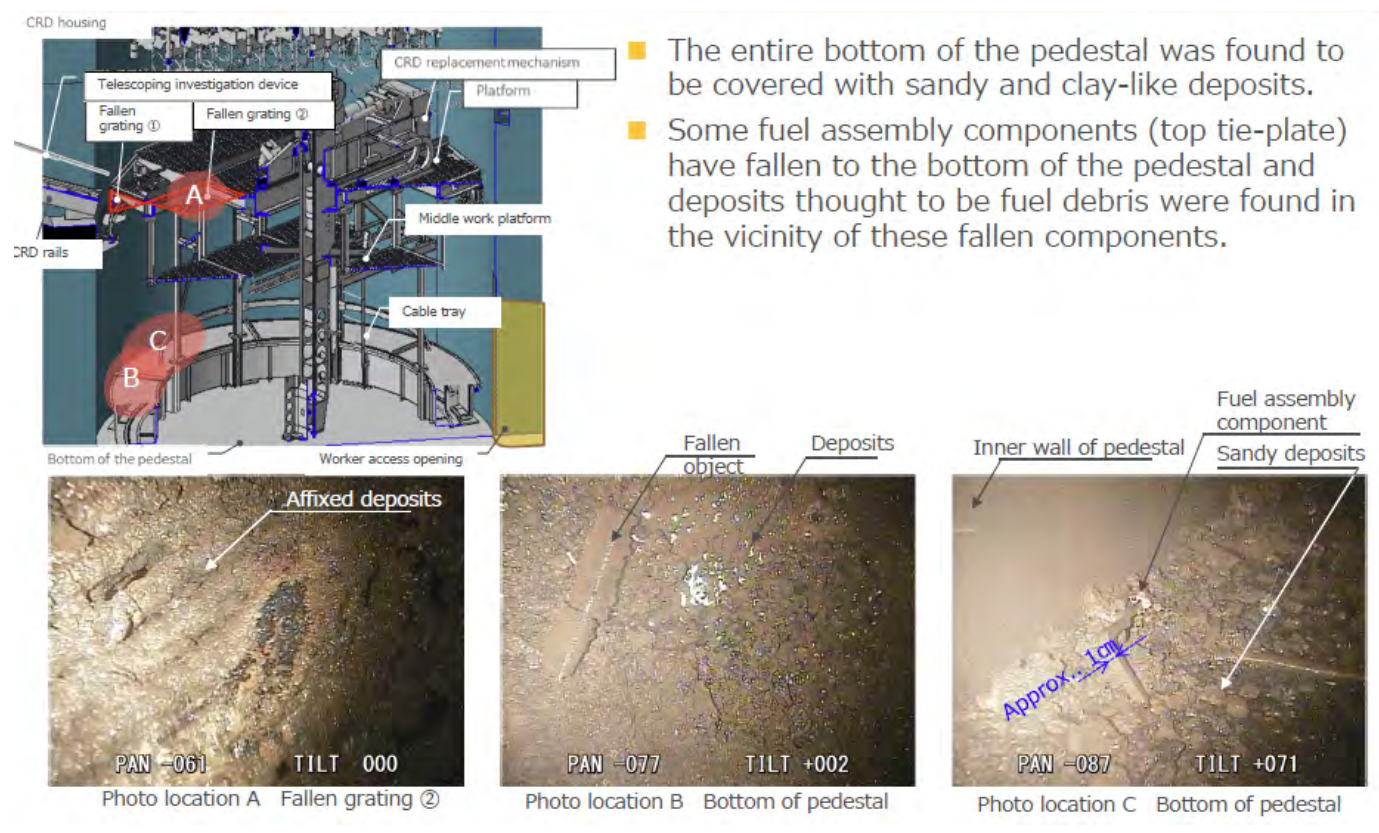

Figure 5-8. Photographs of horizontal surfaces inside the pedestal for 1F2. (Courtesy of TEPCO Holdings [143])

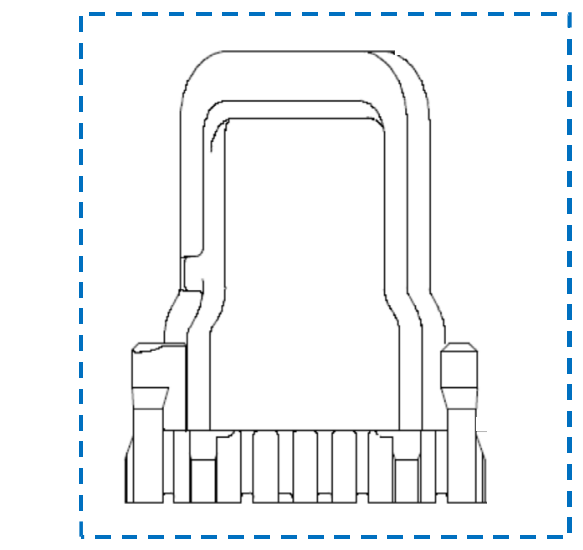

Simple drawing of fuel assembly component (top tie-plate)

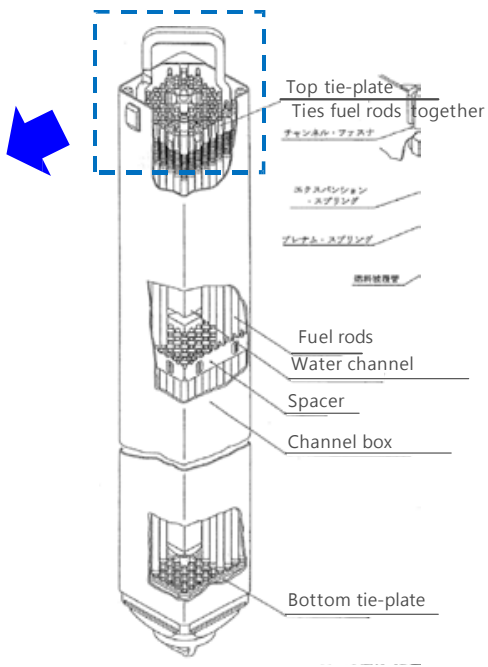

Simple drawing of fuel assembly

Figure 5-9. Fuel assembly design showing top tie-plate features. (Courtesy of TEPCO Holdings [143]) 


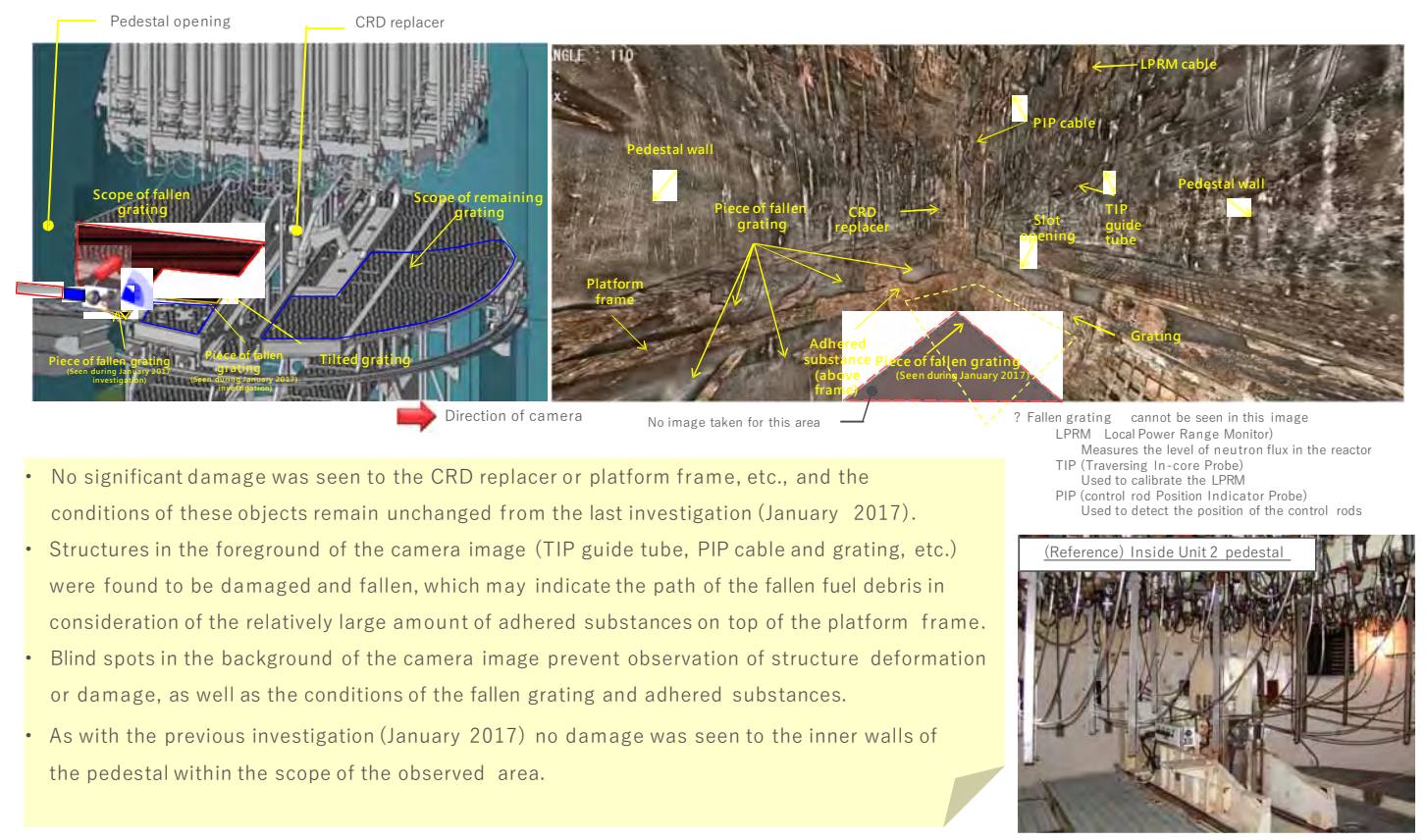

Figure 5-10. Photograph of the top platform showing damage inflicted by relocating core debris. (Courtesy of TEPCO Holdings [139])

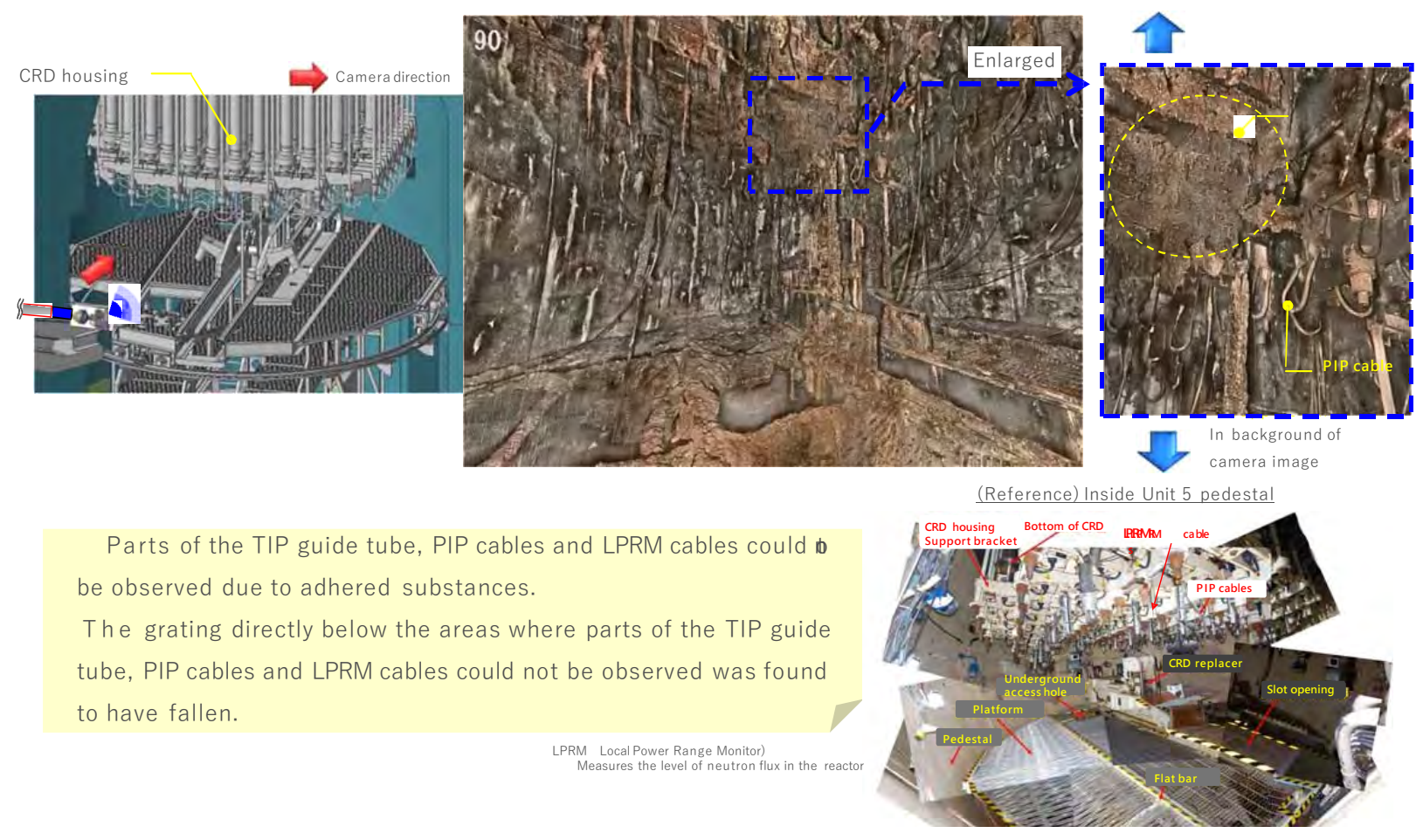

Figure 5-11. Photograph of lower head showing core debris adhering to TIP guide tube and PIP and LPRM cables in the region where platform grating has failed. (Courtesy of TEPCO Holdings [139]) 

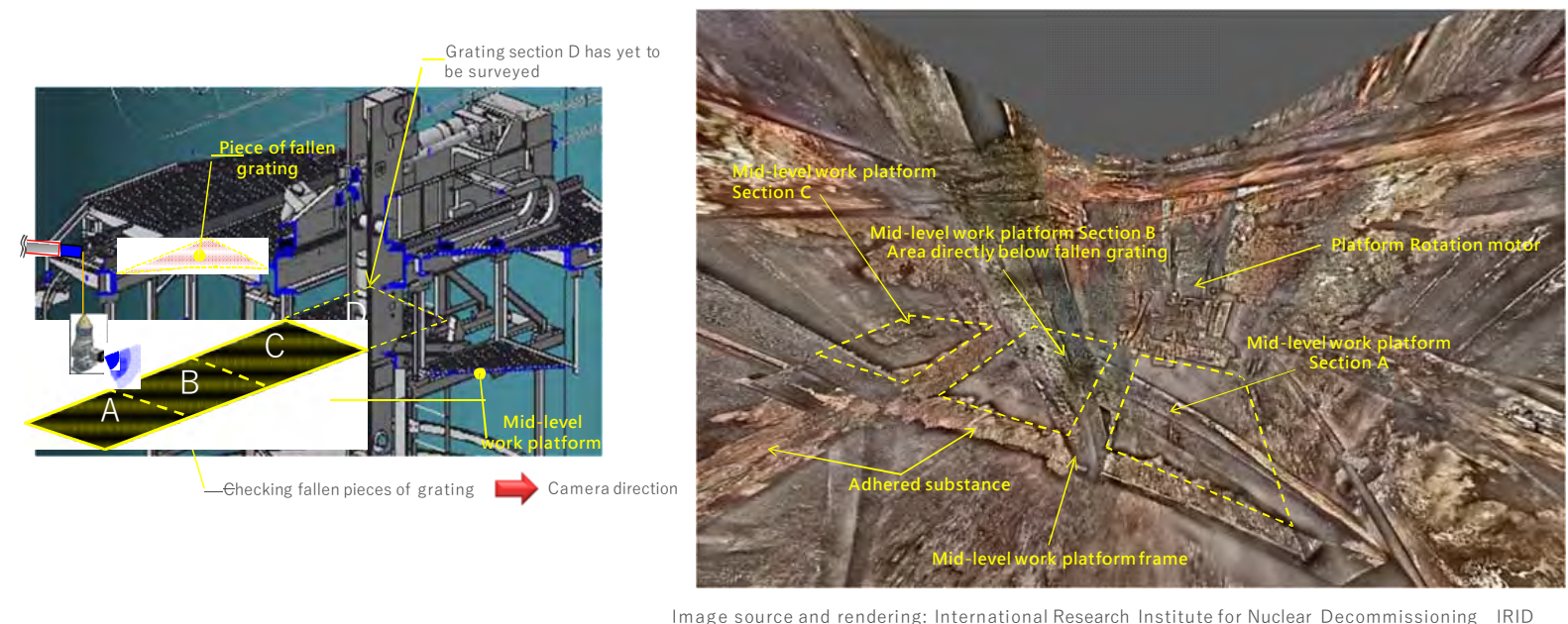

- It was confirmed that the grating (Sections $A \sim C$ ) in the foreground of the location where the camera was lowered has fallen. Locations where Section B and C grating has fallen show the same conditions as the platform. No significant deformation or damage was seen to the mid-level work platform frame

Figure 5-12. Mid-level platform conditions. (Courtesy of TEPCO Holdings [139])

Further image reconstruction by TEPCO Holdings has yielded fairly detailed renderings of the core debris distribution on the pedestal floor; see Figure 5-13. No significant damage was observed to the pedestal walls, CRD replacer rotating frame, struts, or cable trays. This could indicate that the core debris was of lower temperature and had lower decay heat level due to high metal content in the pedestal region (since most fission products reside in the oxide phase). Another plausible explanation is that water was present on the cavity floor during relocation and was subsequently supplied at a rate that was able to keep the core debris covered and effectively cooled with water.

Additional investigations by TEPCO Holdings revealed important information about the elevations of the debris in the pedestal (see Figure 5-12). In particular, given the fact that the cable tray is $\sim 70 \mathrm{~cm}$ above the pedestal floor (see Figure 5-6), it was concluded that the height of the debris in the location where the grating is missing is above $70 \mathrm{~cm}$. Furthermore, the height of the debris diametrically opposite this location (i.e., in the vicinity of the pedestal doorway) is also above $70 \mathrm{~cm}$. Similarly, based on known dimensions of the CRD replacer elevator located near the center of the pedestal, it was concluded that debris heights in this area are lower; i.e., 40-50 cm. Evidence of in-core components located on top the core debris in the vicinity of the elevated mound across from the pedestal doorway is further evidence that this is a location where the vessel failed. Taken together, the collection of data from 1F2 suggests multiple vessel failure points, with failures occurring near the periphery of the reactor vessel based on the assumption that the highest debris depths would correspond to locations where the core debris actually poured. Finally, note that the camera was not able to obtain any views of the drywell annulus outside the doorway, so it is not clear whether the core debris was able to penetrate into this region or not.

One final observation is relevant based on the current findings of the 1F2 investigation. That is, the water level over the drywell floor is known to be $\sim 30 \mathrm{~cm}$,[42] whereas the core debris heights in the pedestal are above this elevation. However, temperature readings from instruments co-located with the inserted camera all indicate temperatures near ambient (i.e., $20^{\circ} \mathrm{C}$ ).[135] Thus, this indicates that water is 


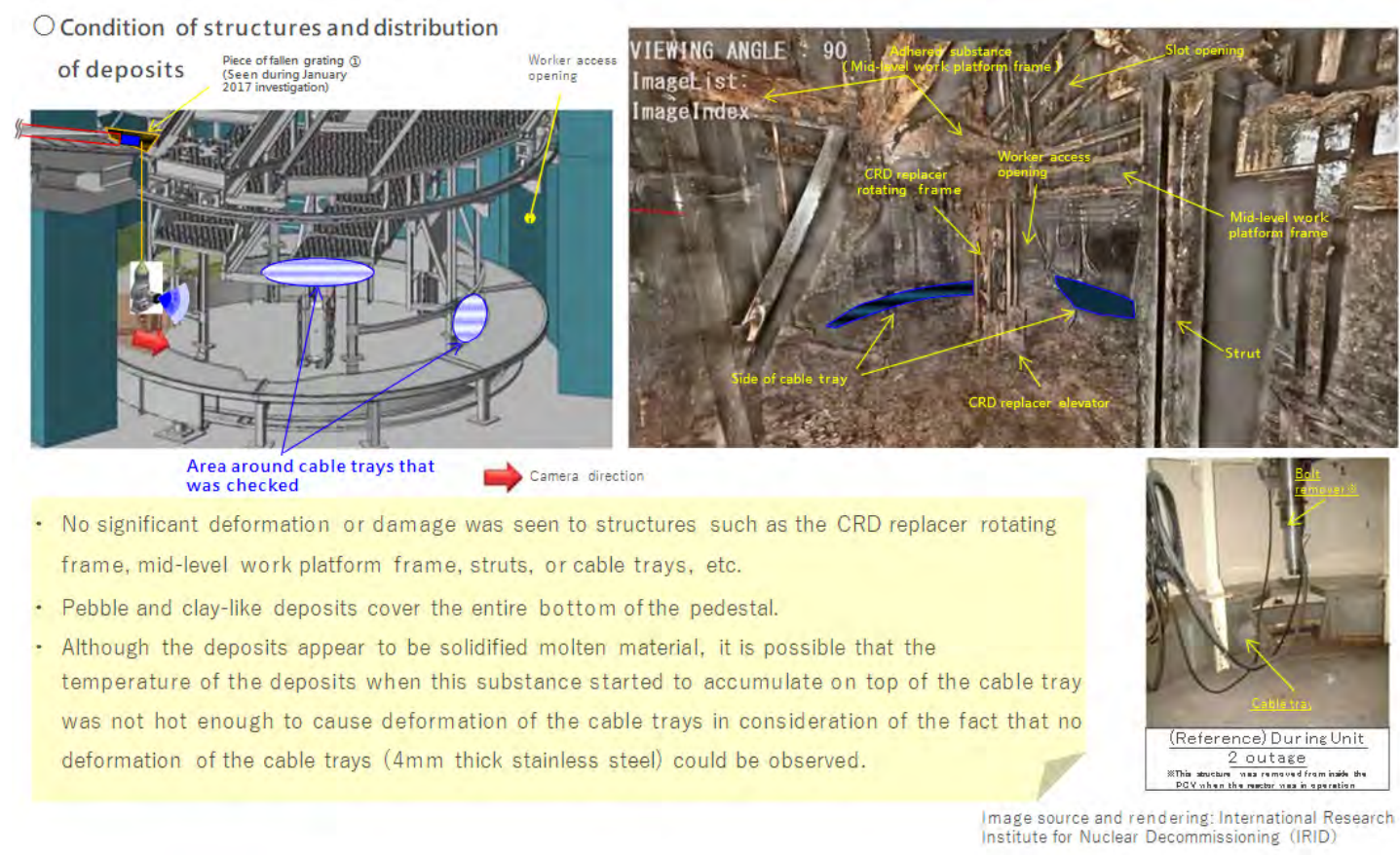

Figure 5-13. View of core debris on the floor of the pedestal region. (Courtesy of TEPCO Holdings [139])

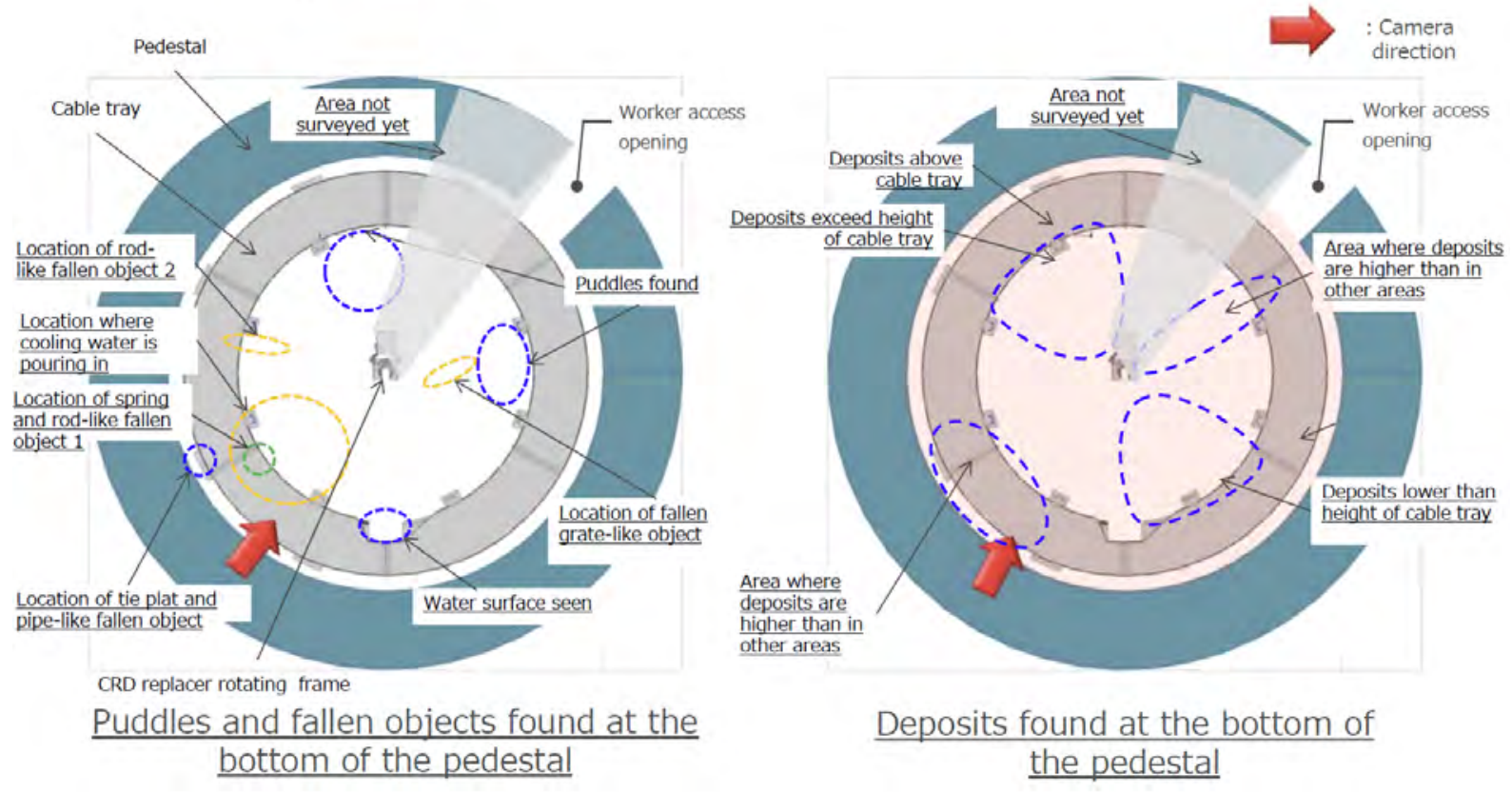

Figure 5-14. Details of core debris surface characteristics for 1F2. (Courtesy of TEPCO Holdings [139]) 
able to effectively cool the core debris as it flows over this material on its way to the drywell region where the low water elevation exists. This supports the industry viewpoint that water injection through the core is the preferred injection pathway, as opposed to other potential methods such as drywell sprays.

\subsubsection{1F3 Examinations}

Investigations into the 1F3 containment performed in July 2017 [138, 140, 181,182,183] have also yielded important information that is consistent with thermocouple data[11] and muon tomography images.[184,185] Numerous images were obtained of relocated material from cameras that were installed on the submersible robot, "Little Sunfish," which was inserted into the X-53 penetration (Figure 5-15). These images indicate that some relocated materials were deposited on CRD housing and cable structures that remained relatively intact. However, in general, the damage to structures beneath the RPV lower head appear more severe than observed in $1 \mathrm{~F} 1$ and $1 \mathrm{~F} 2$ examinations (grating structures were no longer present, some CRD support structures had fallen onto the platform, and a significant amount of previously relocated material was detected on the containment floor within the pedestal region (see Figures 5-16 through 5-18). Additional evaluations and examinations are planned in order to determine the composition of these relocated materials.

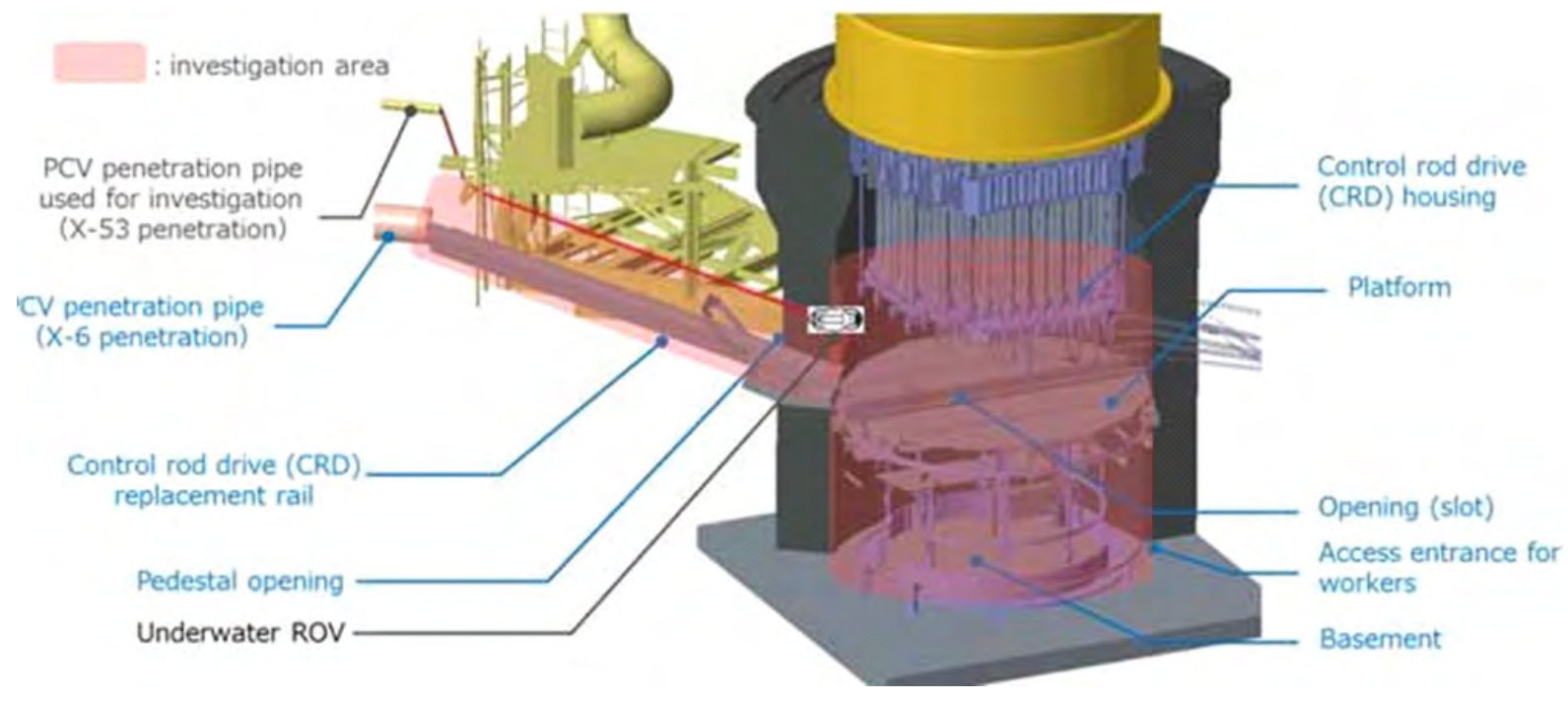

Figure 5-15. Area explored by the "Little Sunfish" submersible robot within the 1F3 PCV. (Courtesy of TEPCO Holdings [181])

Given the video data obtained during the July 2017 PCV investigations, a 3-D model of the entire pedestal region was constructed using a method called Structure from Motion (SfM).[140] Figure 5-19 provides the results of this rendering showing all materials identified within the pedestal, while Figure 5-20 provides a simplified view with extraneous structures removed so that just rendering of the core debris upper surface distribution is shown. The height of the deposits were estimated based on the location of the 


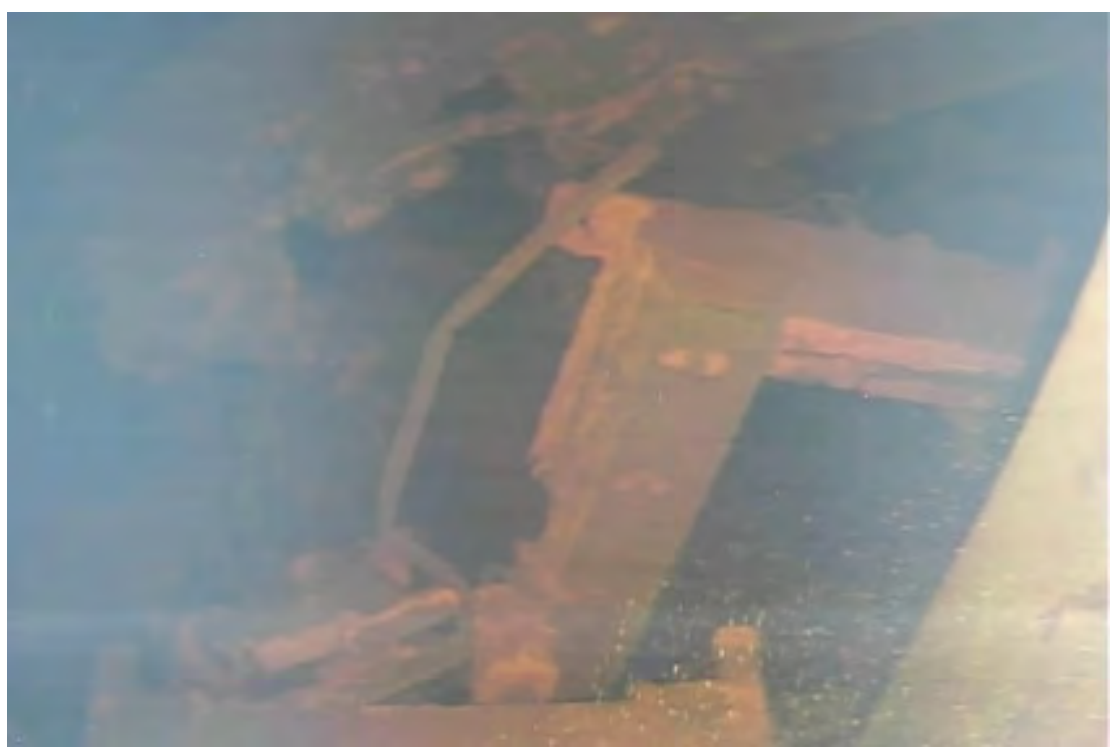

Figure 5-16. Image of relocated CRD rail on the 1F3 platform with no grating; obtained on July 19, 2017. (Courtesy of TEPCO Holdings [181])

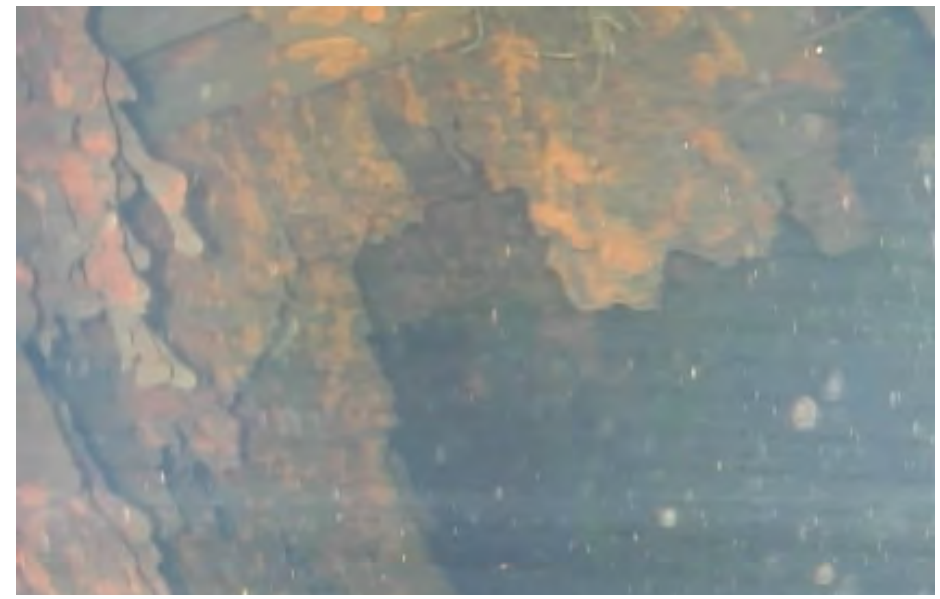

Figure 5-17. Image of relocated material adhered to remaining 1F3 CRD housing and cable structures; obtained on July 21, 2017. (Courtesy of TEPCO Holdings [182])

pedestal doorway and a portion of the rotating rail support brackets since these structures appeared to be undamaged. The results of this study indicated that the platform has been dislodged from the rails and a portion of it is buried under core debris. The height of the deposits is highest in the center of the pedestal, and falls off as the pedestal wall is approached. The fact that the debris is highest in the center would be consistent with lower head failure near the centerline of the RPV (as opposed to 1F2 for which the data suggest that the lower head failed near the periphery; see discussion above). From the renderings, the debris seem to be quite deep; quantitative estimates were provided in [140]. 


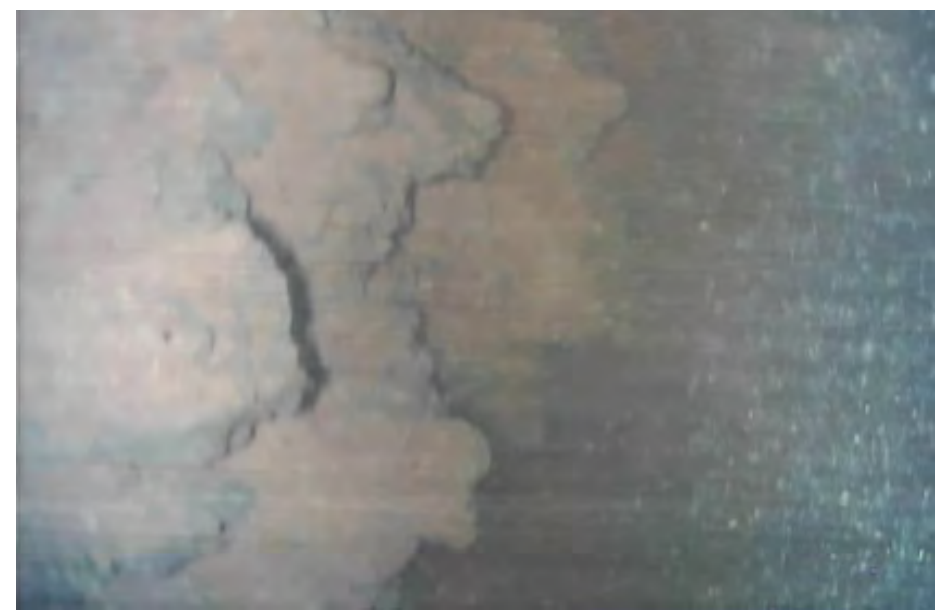

Figure 5-18. Image of material that had relocated beneath the $1 \mathrm{~F} 3$ platform into the pedestal area; obtained on July 22, 2017. (Courtesy of TEPCO Holdings [183])

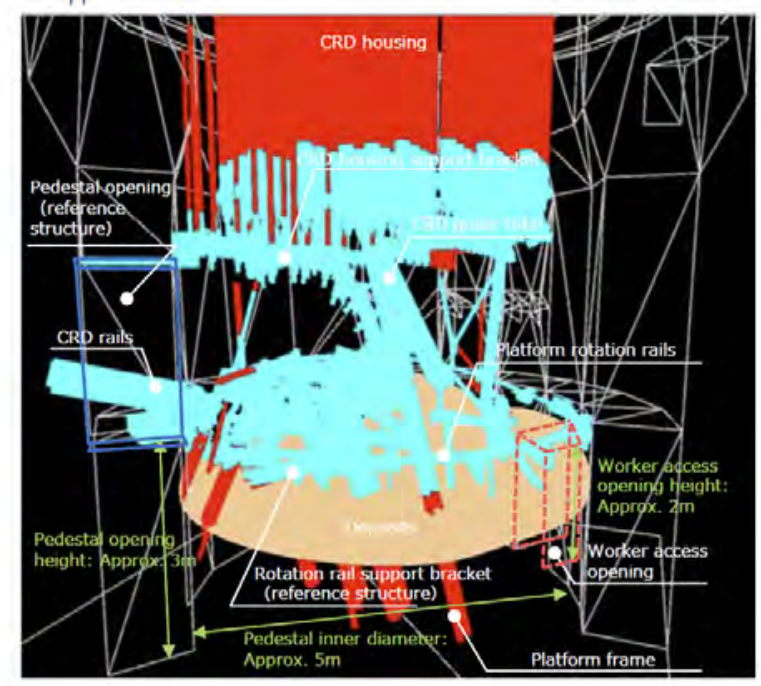

Structures identified in the videos
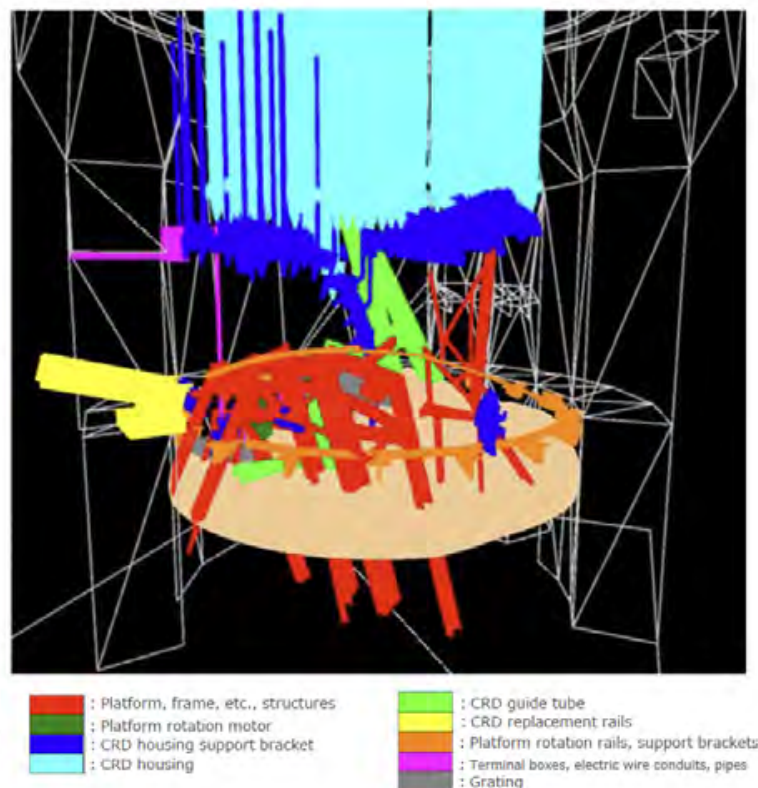

Figure 5-19. 3-D reconstruction of structures located in the pedestal region for 1F3. (Courtesy of TEPCO Holdings [140])

\subsubsection{Modeling Implications from Examinations within the PCV}

Examinations from within the PCVs of $1 F 2$ and $1 \mathrm{~F} 3$ indicate that a significant amount of core debris is held up in the pedestal regions for these units at depths that appear to significantly exceed the torus downcomer inlet elevations in the drywell (thought to be $\sim 30 \mathrm{~cm}$ ). These deep accumulations can have consequences in terms of how well the debris can be cooled when flooded from above, and also on the extent that the debris can be covered with water depending upon water injection pathway (e.g., core injection versus drywell sprays). Thus, the ability to model these types of non-uniform debris distributions is important from an accident management viewpoint. 

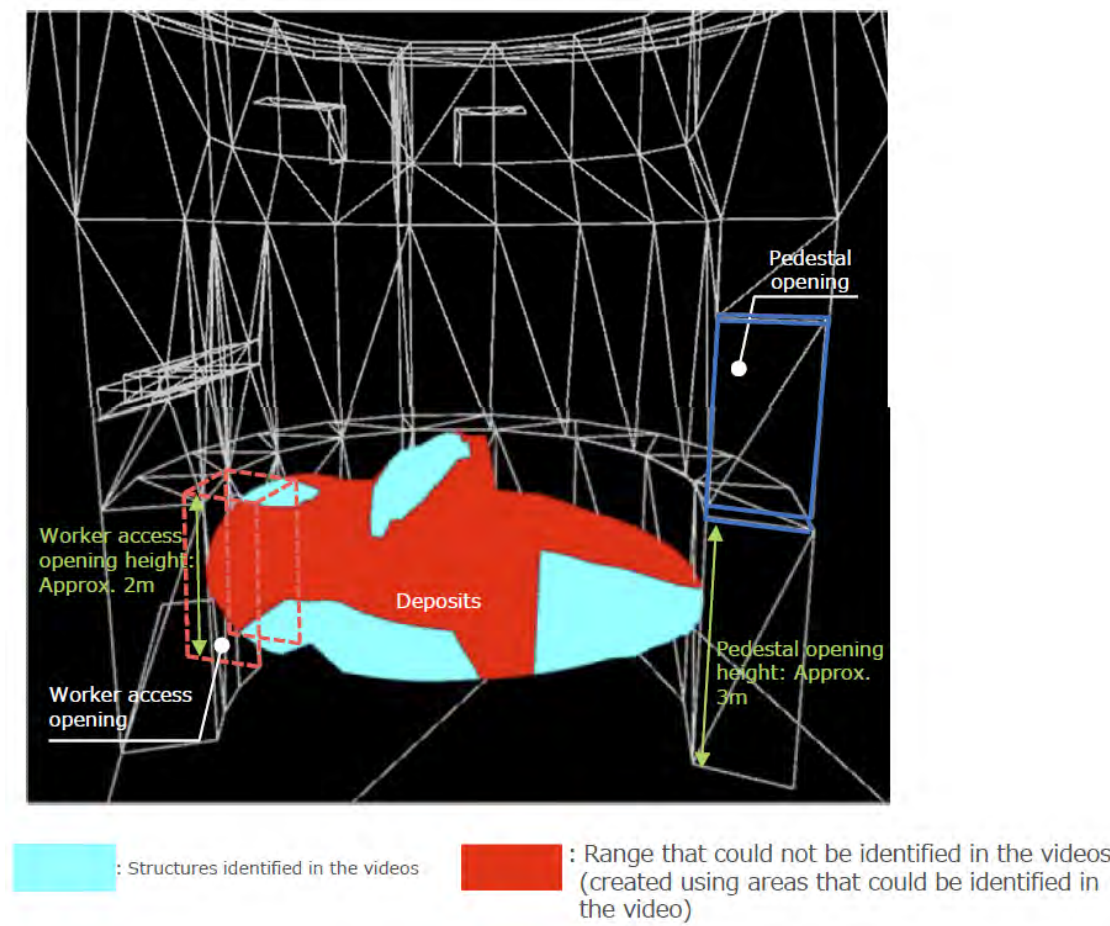

Figure 5-20. 3-D reconstruction of core debris distribution in the pedestal region of 1F3. (Courtesy of TEPCO Holdings [140])

In addition, based on observations from $1 \mathrm{~F} 2$, there is some evidence that the core debris in the pedestal region may have a relatively high metal content. This can impact the coolability of the material by virtue of changes to debris mechanical properties, which impact the water ingression cooling mechanism, as well as reduced decay heat level in this material as fission products tend to concentrate in the oxide phase. Thus, the ability to model non-uniform debris distributions both in terms of spreading and core-concrete interaction behavior is important from the viewpoint of assessing debris coolability. Furthermore, there is evidence that material is held up on below vessel structure (BVS) that includes the CRD drives and grating below the vessel used to access the drives for maintenance and replacement.

Another observation from $1 \mathrm{~F} 2$ and $1 \mathrm{~F} 3$ is that a significant amount of core debris appears to be held up on below vessel structures. A question is whether material held up on these structures can have an impact on containment response during a severe accident which, if shown to be the case, would indicate the need to model this behavior in system level severe accident codes. In particular, core debris held up on BVS may not be cooled by injected water, and so decay heat within this material would be dissipated directly to containment atmosphere as opposed to being cooled by overlying water. In this event, the PCV gas temperature (and, as a result, pressure) would likely rise above saturation, even if all core debris on the floor is covered with water.

What we do know at this point from the reported water levels in the affected units [42] is that core debris on BVS is not covered by water for $1 \mathrm{~F} 2$, but it is covered by water for 1F3. It is not clear from the information reported to date at what point the cavity was flooded up to the level it is currently in 1F3. Thus, it is it is difficult to make direct comparisons between these two cases in terms of potential impact on 
containment response based on what we currently know about the accidents at Fukushima. On this basis, a simple model of this behavior is provided here to scope out whether it is important to model core debris holdup on BVS during a severe accident. The approach is to assume that saturated steam produced by cooling of core debris relocated to the floor of the PVC steadily rises and removes decay heat from debris on BVS. Simplifying assumptions are as follows:

1. Sensible energy removed during debris quenching is neglected; i.e., steam is produced by decay heat removal only. The impact of this assumption is that additional steam production will reduce superheating.

2. Containment is treated adiabatically; heat loss to the containment heat sink would reduce superheating.

3. Heat sink via subcooling of injected water is neglected; subcooling would reduce the steaming rate, thereby increasing superheating of steam passing through BVS.

4. Steam bypass flow material on BVS is neglected. Bypass flow will lead to increased heating of steam that does cool debris on BVS and little to no superheating of steam that bypasses.

5. Produced steam is steadily vented from containment.

Under these assumptions, then the following general mass and energy balances can be written:

$\left\{\begin{array}{c}\text { Steam production rate from core } \\ \text { debris covered by water on PCV floor }\end{array}\right\}=\dot{m}=\frac{X_{f} m_{T} \dot{q}_{d e c}}{h_{l v}}\left(1-F_{B V S}\left(1-F_{B V S-C}\right)\right)$

and

$\left\{\begin{array}{c}\text { Decay heat dissipated by } \\ \text { superheating steam on } B V S\end{array}\right\}=\dot{Q}=F_{B V S}\left(1-F_{B V S-C}\right) X_{f} m_{T} \dot{q}_{d e c}$

In the above expressions and those that follow:

$\dot{q}_{d e c}=$ decay heat in core debris (W/kg fuel)

$X_{f} \quad=$ weight fraction fuel in core debris

$F_{B V S}=$ fraction of core debris retained in BVS

$F_{B V S-C}=$ fraction of core debris retained in BVS and cooled by water injection

$m_{T} \quad=$ total melt pour mass

$h_{l v} \quad=$ water latent heat of vaporization $(\sim 2.2 \mathrm{MJ} / \mathrm{kg})$

$c_{v} \quad=$ steam specific heat $(\sim 2000 \mathrm{~J} / \mathrm{kg}-\mathrm{K})$

$\Delta T_{\text {sup }}=$ required steam superheat to dissipate decay heat

From a simple energy balance $\left(\dot{Q}=\dot{m} c_{v} \Delta T_{\text {sup }}\right)$, the required steam superheat to dissipate decay heat in core debris retained on BVS is thus found as:

$\Delta T_{\text {sup }}=\left\{\frac{F_{B V S}\left(1-F_{B V S-C}\right)}{1-F_{B V S}\left(1-F_{B V S-C}\right)}\right\}\left(\frac{h_{l v}}{C_{v}}\right)$

Conversely, given the steam superheat, then the above equation could be used to predict the fraction of core debris not cooled by water (e.g., retained on BVS or remaining as an outer ring inside the RPV); i.e., 
$F_{B V S}=\frac{\frac{c_{v} \Delta T_{\text {sup }}}{h_{l v}}}{\left(1+\frac{c_{v} \Delta T_{\text {sup }}}{h_{l v}}\right)\left(1-F_{B V S-C}\right)}$

For an adiabatic system, these solutions are found to be independent of total melt mass and decay heat level.

The solution for case in which $F_{B V S-C}=0$ (i.e. no cooling of core debris on BVS by water draining from RPV) and $T_{\text {sat }}=100{ }^{\circ} \mathrm{C}$ is shown in Figure 5-21. The corresponding increase in PCV pressure above the saturation point by superheating of steam due to cooling of core debris retained on BVS is shown in Figure 5-22.

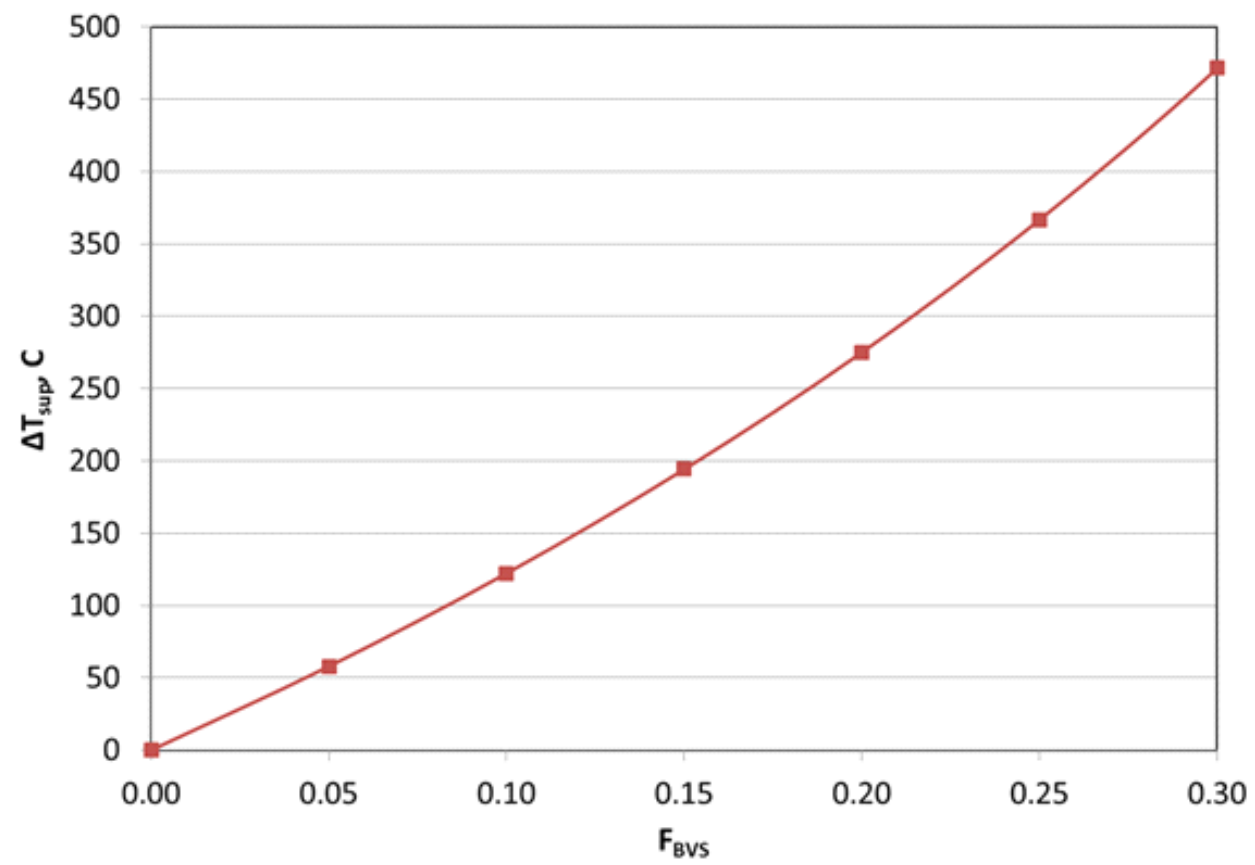

Figure 5-21. Steam superheat solution for case in which $\mathrm{F}_{\mathrm{BVS}-\mathrm{C}}=0$ and $\mathrm{T}_{\mathrm{sat}}=100^{\circ} \mathrm{C}$ as a function of fraction of core debris retained on BVS. (Courtesy of ANL)

To summarize, the current simplistic model indicates that for as little as $5 \%$ core debris holdup on BVS, then containment atmosphere could be superheated by over $50{ }^{\circ} \mathrm{C}$ relative to saturation temperature at system pressure, and this would result in an increase in containment pressure by $15 \%$ relative to the case in which all the core debris is covered by water and cooled by boiling heat transfer. For a large BWR, a typical core mass would be of the order 300 metric tons. Thus, $5 \%$ debris holdup would amount to $\sim 15$ metric tons of material. Hence, results from this simple analysis suggest it would be prudent to consider debris holdup in future system level code improvement activities. 


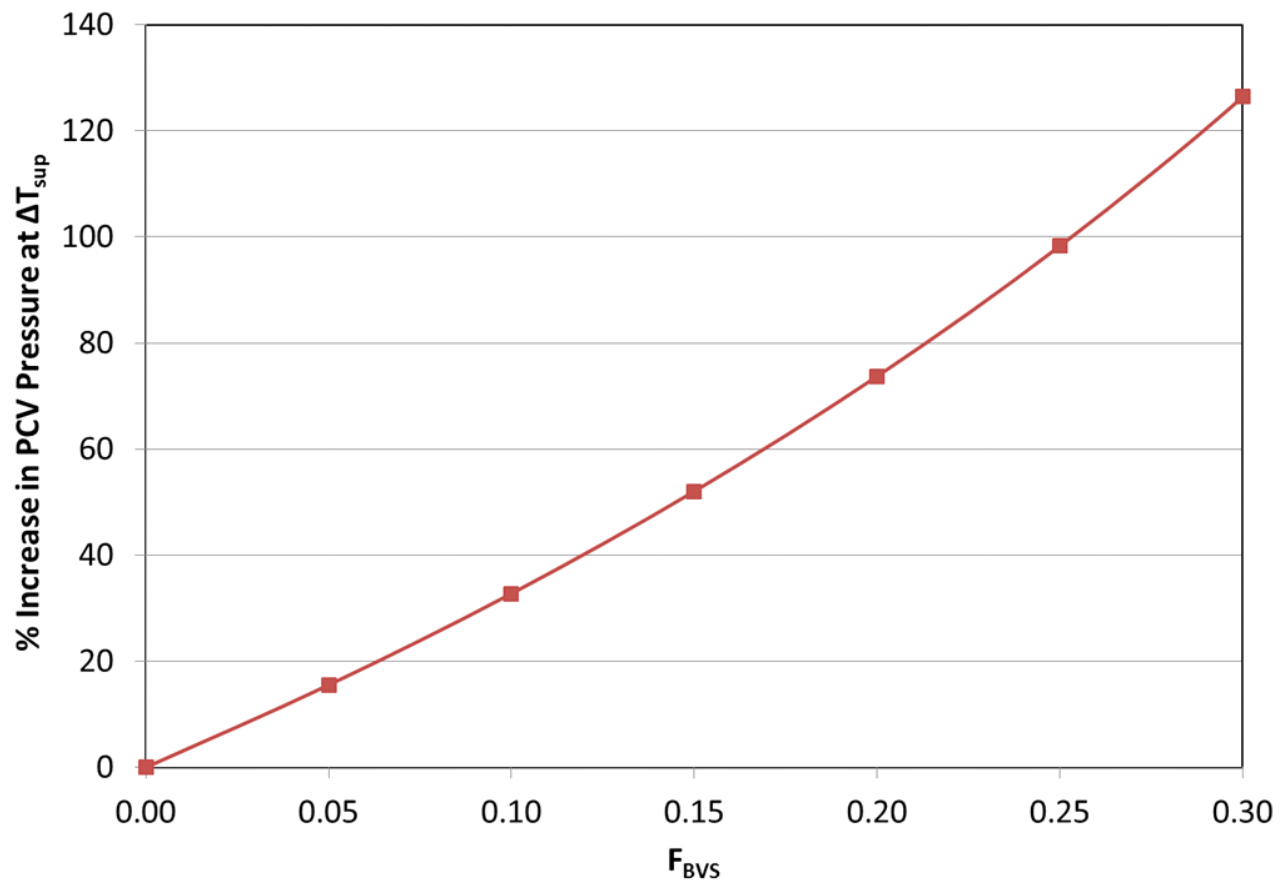

Figure 5-22. Corresponding PCV pressure increase. (Courtesy of ANL)

\subsection{Insight Summary and Limitations}

Available inspection information and analysis results have led to several important insights about debris end-state location and associated answers to Section 5.1 questions. The insights provided below are based on new information provided in this section as well as the historical information summarized in Appendix G.

\section{Thermocouple data:}

- Available thermocouple data and information about water injection are consistent with analysis results suggesting that vessel failure occurred in $1 \mathrm{~F} 1,1 \mathrm{~F} 2$, and $1 \mathrm{~F} 3$.

- Available thermocouple data suggest that most of the debris relocated through the failed 1F1 vessel and that a smaller mass of debris relocated through the failed 1F2 and 1F3 vessels.

- Available thermocouple data confirm the benefit of water addition measures adopted in new SAG (e.g., the benefit of core injection to cool not only any residual core debris remaining in-vessel, but also any core debris that may have relocated ex-vessel. For BWRs, this goal is best achieved by core spray injection).

- Ongoing analyses, using more refined nodalization, may provide more detailed information about the mass, composition, and decay heat of relocated debris. 


\section{Visual Images within PCV and Reactor Building:}

- Images obtained from the $1 \mathrm{~F} 1 \mathrm{X}-100 \mathrm{~B}$ penetration indicate peak temperatures in excess of $328^{\circ} \mathrm{C}$ (due to the absence of lead shielding that melts at this temperature). Such high gas space temperatures support the hypothesis that core debris relocated ex-vessel during the accident, as these temperatures are very difficult to rationalize otherwise.

- The camera inserted into the X-100B penetration found a relatively deep (i.e. $\sim 30 \mathrm{~cm}$ ) layer of sediment on the drywell floor. It is not clear if this material is all sediment or if there is a smaller amount of sediment covering core debris that spread from the pedestal doorway opening. Determining if core debris exists at this location would help to resolve modeling uncertainties related to ex-vessel core debris spreading behavior, in addition to insights relating to the melt pour conditions that are strongly linked to in-vessel behavior.

- Additional photographs near the pedestal doorway in 1F1 show accumulations of material on the floor and in the sumps. The nature of this material is difficult to determine due to overlying sediment, but splatter material on structures looks similar to core debris splattered by melt eruptions in experiments.

- Images showing that the $1 \mathrm{~F} 1$ sand cushion drain line is leaking suggest a failure in the PCV liner. Such failures could be from creep rupture due to the elevated containment pressures $(\sim$ twice the design pressure) at the time of the accidents. Liner failed in 1F1 is consistent with MELTSPREAD code predictions and with measured radiation levels in the 1F1 reactor building (see Section 4).

- The findings that the closed loop RCW sump cooling system in 1F1 has been breached and is highly contaminated suggest that high temperature core debris entered the sump, causing the system to fail.

- Recent observations in 1F2 indicate the existence of black accumulations on the CRD exchange rail near the CRD scaffolding. If the material is found to consist of core debris, this observation would be consistent with lower head failure as has been predicted by several severe accident codes.

- Recently obtained photographs in $1 \mathrm{~F} 2$ confirm that the reactor vessel has failed and material has been discharged into containment, as evidenced by the finding of a fuel assembly top tie-plate on the pedestal floor in this unit.

- Camera inspections in 1F3 have also confirmed that the reactor vessel has failed and material has been discharged into containment, as evidenced by the fact that items resembling core components may have been discovered outside of the reactor vessel.

- Findings for 1F2 and 1F3 indicate a substantial amount of material holdup on below vessel structures. A simple scoping analysis indicates that direct dissipation of decay heat within this material to containment atmosphere can impact containment response and should be modeled in severe accident codes.

- For $1 \mathrm{~F} 2$, the water level over the drywell floor is $\sim 30 \mathrm{~cm}$, whereas the core debris heights in the pedestal are above this elevation. However, temperature readings from within the pedestal indicate temperatures near ambient (i.e., $20^{\circ} \mathrm{C}$ ). Thus, this indicates that water is able to effectively cool the core debris as it flows over and through this material on its way to the drywell region where the low water elevation exists. This supports the industry viewpoint that water injection through the core is the preferred pathway, as opposed to other potential methods such as drywell sprays. 


\section{Muon Tomography Investigations:}

- Results from muon tomography suggest that much, if not all, of the fuel debris is absent from the $1 F 1$ core region; this is consistent with results from MELCOR and MAAP analyses.

- Results from muon tomography for 1F2 suggest that approximately one third to one half of the lower head is filled with dense core debris. Based on a simple conservation of mass argument (see Appendix G), this suggests that one half to two thirds of the core material is ex-vessel.

- Results from muon tomography for $1 \mathrm{~F} 3$ suggest that the amount of core debris left in the lower head is less than that compared to $1 \mathrm{~F} 2$.

\section{Gas Cleanup System Measurements:}

- Concentration measurements from gas cleanup systems, in conjunction with CORQUENCH analysis results, confirm the conclusion that the debris within 1F1 PCV was quenched and stabilized.

The amount of information obtained thus far on debris locations is limited but expanding due to dedicated inspection efforts by Japan. Observations obtained with remote cameras have provided definitive information indicating that core debris is likely ex-vessel for 1F2 and 1F3 (i.e., the presence of in-vessel components discovered ex-vessel for these two units. The identified structures are a fuel assembly top tie plate for 1F2 and CR guide tube and CRD index tube for 1F3). Muon tomography images are also providing data on debris location, but the resolution of obtained images is limited. Finally, TEPCO Holdings has effectively used thermocouple measurements on the RPV coupled with variations in water injection flowrate and location to make inferences on debris location. One limitation with this last technique is the fact that many of the TCs on the RPV were pushed well outside their qualification envelop during the accident, which raises questions about calibration as well as potential failures that are difficult to diagnose; e.g., formation of false junctions within the TCs that can provide erroneous indications of temperature at a given location. Aside from potential damage to the instruments themselves, there is also the possibility of damage to instrument cabling as recent investigations have revealed.

Despite these limitations in the available information, it is important to note that the information has provided many insights on accident progression as well as important data for validation of both system-level and separate effect codes that are used for reactor safety evaluations.

\subsection{Recommendations}

As summarized in Section 5.2, both system-level [55,56] as well as separate effect [58] code analyses have provided tangible predictions for evaluation against the debris end-state information being obtained by TEPCO Holdings. In a rough sense, these calculations can be considered to be half-blind benchmarking exercises that are useful in gaging the accuracy and adequacy of the models as additional information on debris end-state conditions becomes available. A few additional analysis activities were identified as part of this initial evaluation that would be beneficial in terms of benchmarking the models, reducing modeling uncertainties, and further informing D\&D efforts at the site. This type of analysis would inform accident management guidance for accident scenarios in which ex-vessel core debris may be frozen to structures above water levels in the primary containment. 


\section{Area 3 Recommendation 1:}

As alluded to in Section 5.2, refine the MAAP and MELCOR RPV nodalization schemes for the 1F1, 1F2, and 1F3 RPVs with the aim of predicting the measured temperatures shown in Figures G-1 through G-3. The post-accident debris locations predicted inside the RPV, coupled with changes in water addition rate and location, may provide a means for assessing the accuracy of the debris end-state predictions. This comparison may also provide insights into appropriate modeling of in-core melt progression that has been identified as a key uncertainty in the MAAP-MELCOR crosswalk exercise.[57]

Also, the findings from 1F2 and 1F3 suggest that a non-negligible amount of core debris may be held up on structures below the reactor vessel. System analysis codes should first be enhanced to account for this behavior and then exercised assuming a range of core debris holdup in a situation that is not cooled by water to investigate the impact of heat sources not covered by water on PCV gas phase temperature and pressure. This type of analysis would inform accident management guidance for accident scenarios in which ex-vessel core debris may be frozen to structures above water levels in the primary containment.

\section{Area 3 Recommendation 2:}

Repeat the MELTSPREAD-CORQUENCH analysis that was originally done for 1F1[58] for 1F2. Various system-level code analyses, as well as recent images, indicate that vessel failure occurred at this unit. However, it is suspected that vessel likely occurred much later in the accident sequence due to the continued operation of RCIC for $\sim 72$ hours in an unregulated mode. This study may be useful in showing that it is unlikely that the melt contacted the liner in this late pour scenario, or if it did, that the shell likely remained intact due to reduced thermal loading. As discussed in [11], no evidence of liner failure has been found for $1 \mathrm{~F} 2$, and this would provide a means for rationalizing that observation relative to the finding that the liner in $1 \mathrm{~F} 1$ has been damaged.

\subsection{Suggestions for Additional Information}

The results of this forensic analysis activity related to debris end-state conditions have illustrated the intrinsic value of information for providing insights on accident progression, informing SAG enhancements, and validating severe accident codes that are used for plant safety evaluations.

Regarding additional information needs for this topical area, the primary need is for higher fidelity data on debris locations. In this early stage of the D\&D process, initial insights are being gained on ex-vessel conditions. Due to the high radiation levels, the only practical means for obtaining this data is through stand-off methods which TEPCO Holdings has actively and successfully pursued; i.e., muon tomography and robotics inspections. These methods have already proven to be valuable. Based on insights obtained from evaluations of current information, additional suggestions are offered at this time:

\section{Area 3 Suggestions:}

- Perform chemical analysis of high radiation deposits or particles found inside the reactor building (1F1, 1F2, and 1F3); e.g., the white deposits from the HPCI room using FE-SEM, XRD, etc.

- Perform chemical analysis of sediment on drywell floor at the X-100B penetration location in $1 \mathrm{~F} 1$. The upper surface of the sediment is $\sim 30 \mathrm{~cm}$ above drywell floor. 
- Evaluate the nature of the material below the upper surface of the debris at the X-100B penetration location in $1 \mathrm{~F} 1$ to determine if it is additional sediment or other material such as core debris.

- Perform chemical analysis (XRF) of black material discovered on CRD exchange rail in 1F2 at $\mathrm{X}-6$ penetration location

- Perform chemical analysis of black material on 'existing structure' in 1F1 images at location 'D3'

- Obtain additional images from examinations in 1F3 X-53 penetration.

The list of information needs in Appendix $\mathrm{C}$ was updated to reflect these additional items and revisions to items previously requested. Discussions [186] with TEPCO Holdings indicate that there are plans to implement several of these requests from U.S. experts. 
ANL-18/24 


\section{AREA 4 - COMBUSTIBLE GAS EFFECTS}

During the November 2015 meeting, the expert panel agreed to include the area of combustible gas effects as a fourth topic of investigation. The panel included this topic because it was recognized that damage within the affected units at Daiichi could provide important insights related to the sources for and transport of combustible gas and the ignition point and damage caused by each explosion.

This section summarizes insights with respect to reactor safety and future D\&D activities obtained by reviewing examination information from Daiichi. With this goal in mind, available visual information is summarized. This is followed by a summary of our preliminary insights and a brief description of the limitations of these insights. We then provide recommendations and observations for additional U.S. activities that could provide further insights related to information gained from forensics examinations. Suggestions for future TEPCO Holdings examinations to support these activities are also identified.

\subsection{Questions for Reactor Safety and D\&D}

Available information was evaluated by U.S. experts to address the following questions which are of international interest for reactor safety and to Japan for completing feasibility studies to support D\&D activities:

- Where and how did ignition occur, and how did flame propagate from ignition floor to other floors?

- How does combustible gas migrate during a severe accident?

- Can damage to structures provide insights about combustion characteristics, such as ignition location and pre-explosion concentration of combustible gas, which can be used in guidance for severe accident mitigation?

- What are the D\&D impacts with respect to hydrogen combustion related to the integrity of structures within the RB and PCV and to radiation release and transport?

- What severe accident measures should be implemented to reduce damage associated with combustible gas explosions?

- How much does MCCI contribute to combustible gas generation effects?

- Are analysis model improvements needed for predicting combustible gas generation, migration through degraded seal and penetrations, and accumulation?

- Can analysis provide insights related to D\&D worker safety and radiation exposure?

Answers to these questions have important safety impacts. By obtaining prototypic data from the affected units at Daiichi, there is the potential to reduce modeling uncertainties. Improvements in our modeling capabilities can be used to confirm or enhance, if needed, accident management strategies for addressing the consequences of combustible gas phenomena. This information and associated analyses with improved severe accident codes offer the potential for insights that may be beneficial to Japan in their D\&D activities. In particular, improved models for predicting the events at Daiichi may provide important insights related to radionuclide transport and deposition, which is important in characterizing worker dose during D\&D activities and to structural damage, which is important in assessing hazard potential. 


\subsection{Information Summary}

As discussed in Section 1.3.1, U.S. experts identified information needs that could be addressed through examinations at Fukushima Daiichi. Requested information needs from the reactor building and PCV that relate to combustible gas generation are summarized in Tables 6-1 and 6-2. These tables also note if any information is available to address these information needs (see Appendix C). Visual information includes photos and videos taken during and after the explosions. In addition, radiation survey and seismic acceleration data provide insights about combustible gas generation, transport, and ignition. In addition, TEPCO Holdings reports evaluating damage associated with explosions at the affected units [187 through 189] and TEPCO Holdings unsolved issues reports [37 through 42] contain important information on this topic. Data from plant instrumentation was also used to provide insights. This section reviews this information and provides insights related to reactor safety and D\&D activities.

Table 6-1. Area 4 information needs from the reactor building

\begin{tabular}{|c|c|c|c|}
\hline Item & What/How Obtained ${ }^{\text {a }}$ & $\mathbf{U s e}^{\mathbf{b}}$ & $\begin{array}{l}\text { Data } \\
\text { Available }^{c}\end{array}$ \\
\hline RB-3a & Photos/videos of damaged walls and structures (1F1) & $\mathrm{AE}, \mathrm{AM}, \mathrm{DD}$ & A \\
\hline $\mathrm{RB}-3 \mathrm{~b}$ & Photos/videos of damaged walls and structures (1F3) & AE, AM, DD & A \\
\hline $\mathrm{RB}-3 \mathrm{c}$ & Photos/videos of damaged walls and structures (1F4 & $\mathrm{AE}, \mathrm{AM}, \mathrm{DD}$ & A \\
\hline RB-4 & $\begin{array}{l}\text { Photos/videos of damaged walls and components and radionuclide } \\
\text { surveys (1F2) }\end{array}$ & $\mathrm{AE}, \mathrm{AM}, \mathrm{DD}$ & A \\
\hline RB-6 & Radionuclide surveys and sampling of ventilation ducts (1F4) & $\mathrm{AE}, \mathrm{AM}, \mathrm{DD}$ & A \\
\hline RB-7 & Isotopic evaluations of obtained concrete samples (1F2) & $\mathrm{AE}, \mathrm{AM}, \mathrm{DD}$ & A \\
\hline \multirow[t]{4}{*}{ RB-9 } & $\begin{array}{l}\text { DW Concrete Shield Radionuclide surveys (1F1, 1F2, and 1F3 - before } \\
\text { debris removed) }\end{array}$ & $\mathrm{AE}, \mathrm{AM}, \mathrm{DD}$ & A \\
\hline & DW Concrete Shield Radionuclide surveys (1F1 - after debris removed) & $\mathrm{AE}, \mathrm{AM}, \mathrm{DD}$ & A \\
\hline & DW Concrete Shield Radionuclide surveys (1F3 - after debris removed) & $\mathrm{AE}, \mathrm{AM}, \mathrm{DD}$ & A \\
\hline & $\begin{array}{l}\text { Photos/videos around mechanical seals and hatches and electrical } \\
\text { penetration seals (as a means to classify whether joints were in } \\
\text { compression or tension) }\end{array}$ & $\mathrm{AE}, \mathrm{AM}, \mathrm{DD}$ & A \\
\hline RB-10 & $\begin{array}{l}\text { Photos/videos of } 1 \mathrm{~F} 1 \text { (vacuum breaker), } 1 \mathrm{~F} 1,1 \mathrm{~F} 2 \text {, and } 1 \mathrm{~F} 3 \mathrm{PCV} \text { leakage } \\
\text { points (bellows and other penetrations) }\end{array}$ & $\mathrm{AE}, \mathrm{AM}, \mathrm{DD}$ & A \\
\hline RB-11 & $\begin{array}{l}\text { Photos/videos and available information on } 1 \mathrm{~F} 1,1 \mathrm{~F} 2 \text {, and } 1 \mathrm{~F} 3 \\
\text { containment hardpipe venting pathway, standby gas treatment system and } \\
\text { associated reactor building ventilation system }\end{array}$ & $\mathrm{AE}, \mathrm{AM}, \mathrm{DD}$ & A \\
\hline RB-13 & Photos/videos of $1 \mathrm{~F} 1,1 \mathrm{~F} 2$, and $1 \mathrm{~F} 3$ recirculation lines and pumps & AM, DD & A \\
\hline
\end{tabular}
a. See list of acronyms.
b. Use: AE - Accident evaluation (code modeling updates), AM- Accident management and prevention, DD - Decon- tamination and Decommissioning, and PM - Plant maintenance (see Appendix C for more information).
c. Some information available [Green]; NA: no information available [Orange]. 
Table 6-2. Area 4 information needs from the PCV

\begin{tabular}{|c|c|c|c|}
\hline Item & What/How Obtained ${ }^{\text {a }}$ & $\mathrm{Use}^{\mathrm{b}}$ & $\begin{array}{l}\text { Data } \\
\text { Available }^{c}\end{array}$ \\
\hline PC-1 & $\begin{array}{l}\text { Ex-vessel inspections and operability assessments of } 1 \mathrm{~F} 1,1 \mathrm{~F} 2 \text {, and } \\
1 \mathrm{~F} 3 \text { in-vessel sensors and sensor support structures }{ }^{\mathrm{d}}\end{array}$ & $\mathrm{AE}, \mathrm{AM}, \mathrm{DD}$ & NA \\
\hline \multirow[t]{5}{*}{$\mathrm{PC}-3^{\mathrm{e}}$} & $\begin{array}{l}\text { a) Photos/videos of relocated debris and crust, debris and crust } \\
\text { extraction, hot cell exams, and possible subsequent testing (1F1 - 1F3) }\end{array}$ & AE, AM, DD & A \\
\hline & $\begin{array}{l}\text { b) PCV liner examinations (photos/videos and metallurgical exams; } \\
\text { 1F1-1F3) }\end{array}$ & AE, AM, DD & NA \\
\hline & $\begin{array}{l}\text { c) Photos/video, RN surveys, and sampling of pedestal wall and floor } \\
\text { (1F1-1F3) }\end{array}$ & AE, AM, DD & A \\
\hline & $\begin{array}{l}\text { d) Concrete erosion profile; photos/videos and sample removal and } \\
\text { examination (1F1-1F3) }\end{array}$ & AE, AM, DD & NA \\
\hline & $\begin{array}{l}\text { e) Photos/videos of RPV lower head and of structures and penetrations } \\
\text { beneath the RPV to determine damage and corium hang-up (1F1-1F3) }\end{array}$ & AE, AM, DD & A \\
\hline PC-4 & $\begin{array}{l}\text { Examinations and operability assessments of 1F1, 1F2, and 1F3 } \\
\text { ex-vessel sensors and sensor support structure }\end{array}$ & $\mathrm{AE}, \mathrm{AM}$ & NA \\
\hline
\end{tabular}

a. See list of acronyms.

b. Use: AE - Accident evaluation (code modeling updates), AM- Accident management and prevention, DD - Decontamination and Decommissioning, and PM - Plant maintenance (see Appendix C for more information).

c. Some information available [Green]; NA: no information available [Orange].

d. Available information is limited to the shield plug.

e. As described in Section 5.2.2, in-vessel components have been discovered ex-vessel for two of the affected units (i.e., fuel assembly top tie plate for 1F2 and CR guide tube and CRD index tube for 1F3) indicating that the vessels have failed. In addition, sample evaluations from $1 \mathrm{~F} 1$ have detected the presence of uranium.

\subsubsection{TEPCO Holdings Reports}

In 2011, two of the reports issued by TEPCO Holdings [187, 188] evaluated damage associated with explosions at the affected units. The purpose of the reports was to find out whether it was necessary to implement urgent measures for seismic reinforcement rather than analyze the cause of the explosions. These reports contain important and useful information, such as reactor building damage surveys in the form of photos and building damage diagrams (see Figures 6-1 and 6-2 for 1F1; Figures 6-3 through 6-5 for 1F3; and Figure 6-6 for 1F4).

\subsubsection{F1 Explosion}

The upper part of the $1 \mathrm{~F} 1$ reactor building above the operating floor (the $5^{\text {th }}$ floor) experienced an apparent hydrogen explosion on March 12, 2011 at 3:36 pm, approximately 25 hours after the seismic event.[189] It is believed that this hydrogen was primarily due to reactions between steam and the fuel zircaloy cladding. As discussed in Sections 3 and 4, the exact pathway through which the hydrogen flowed is unknown, but available information on the explosion damage suggests that it leaked into the building through degraded seals on the head of the PCV and accumulated in the refueling floor ( $5^{\text {th }}$ floor) to a significant level (see Figure 6-7). 

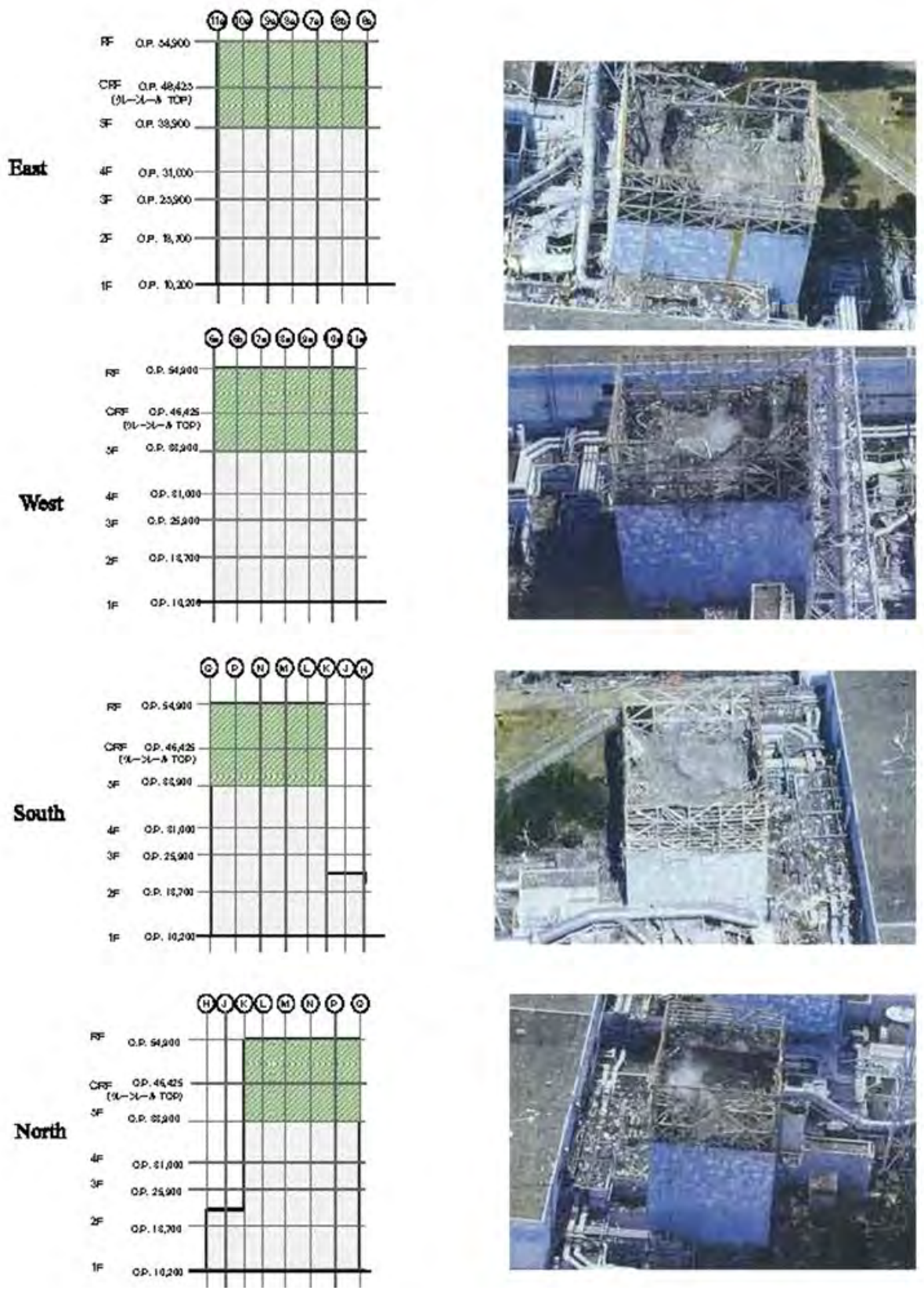

Figure 6-1. 1F1 reactor building damage following explosion. (Courtesy of TEPCO Holdings [187])

As documented by TEPCO Holdings,[187] the explosion heavily damaged the $5^{\text {th }}$ floor but did no damage to the floors below except for limited damage observed near the equipment hatch opening in the southwest corner of the 4 th floor.[191] The walls on the $5^{\text {th }}$ floor consisted of a steel framework structure fixed with steel plates and were susceptible to internal pressure increases. The collapse of the walls resulted in a release of inside pressure minimizing any damage to structures below the $5^{\text {th }}$ floor. In addi- 


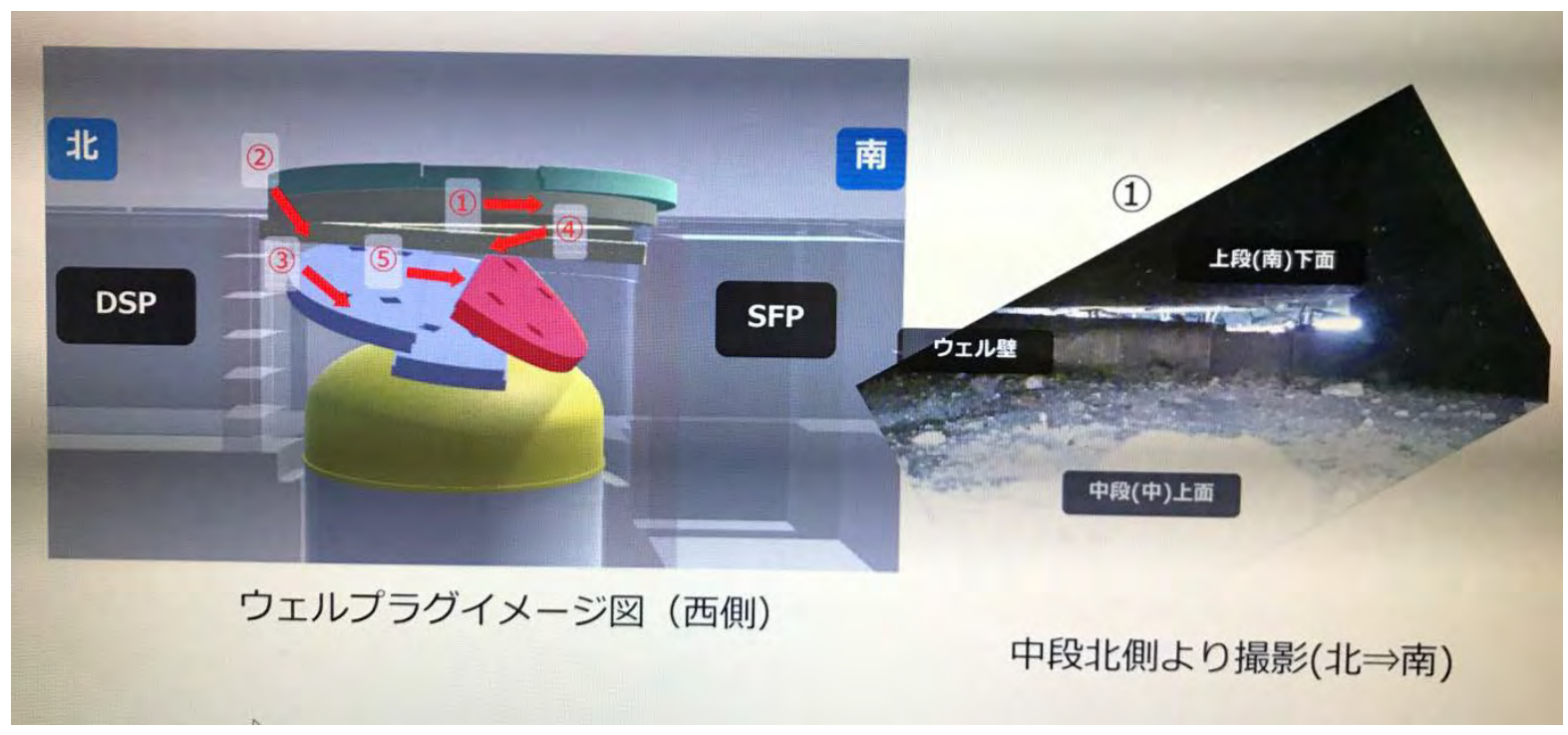

Figure 6-2. Dislocation of 1F1 drywell head shield plugs. (Courtesy of TEPCO Holdings [192])

tion, a dislocation of the concrete shield plugs was found during inspections (from November 2016 to February 2017) of 1F1 operating floor damage conditions.[192] The shield plugs are removable, segmented, three-layered reinforced concrete plugs that shield the refueling floor from the drywell, and are normally even with the floor. There are three shield plug pieces (segments) in each layer forming a circular shape. Each layer is $62.5 \mathrm{~cm}$ thick. The upper and middle layers of the shield plugs were found to have dislocated to positions above the floor of the operating floor while the plug pieces from the bottom layer fell to the drywell head (see Figures 6-2 and E-1).

An analysis of the $1 \mathrm{~F} 1$ reactor building explosion has been performed by TEPCO Holdings using the Computational Fluid Dynamics (CFD)-based FLACS code to confirm that ignition was not initiated from the $4^{\text {th }}$ floor due to leakage from isolation piping.[21,42] Two cases were performed. Case 1 assumed an $8.3 \% \mathrm{H}_{2}$ concentration in the $5^{\text {th }}$ floor with ignition initiated from the center of the shield plug. Case 2 assumed an $8.3 \% \mathrm{H}_{2}$ concentration in the $5^{\text {th }}$ floor and a stratified layer of $20-30 \% \mathrm{H}_{2}$ beneath the ceiling of the 4th floor. Ignition was initiated from the stratified layer. The thickness of the stratified layer was about half of the $4^{\text {th }}$ floor height. Based on the speed and direction of the blast generated by the code, it was concluded that the ignition was initiated from the $5^{\text {th }}$ floor.

The hydrogen explosion at 1F1 significantly hindered other recovery efforts. Debris from the explosion damaged power lines that had been laid down at 1F2 as well as the power lines being readied at 1F3. This adversely impacted work being done to restore power at both 1F2 and 1F3. In addition, as discussed in Section 4.3.2, it is believed that pressure waves from the 1F1 explosion caused the 1F2 reactor building blowout panel to open (see Figure 4-6). This opening is believed to have averted an explosion in the 1F2 building because it allowed any accumulated hydrogen to vent. 

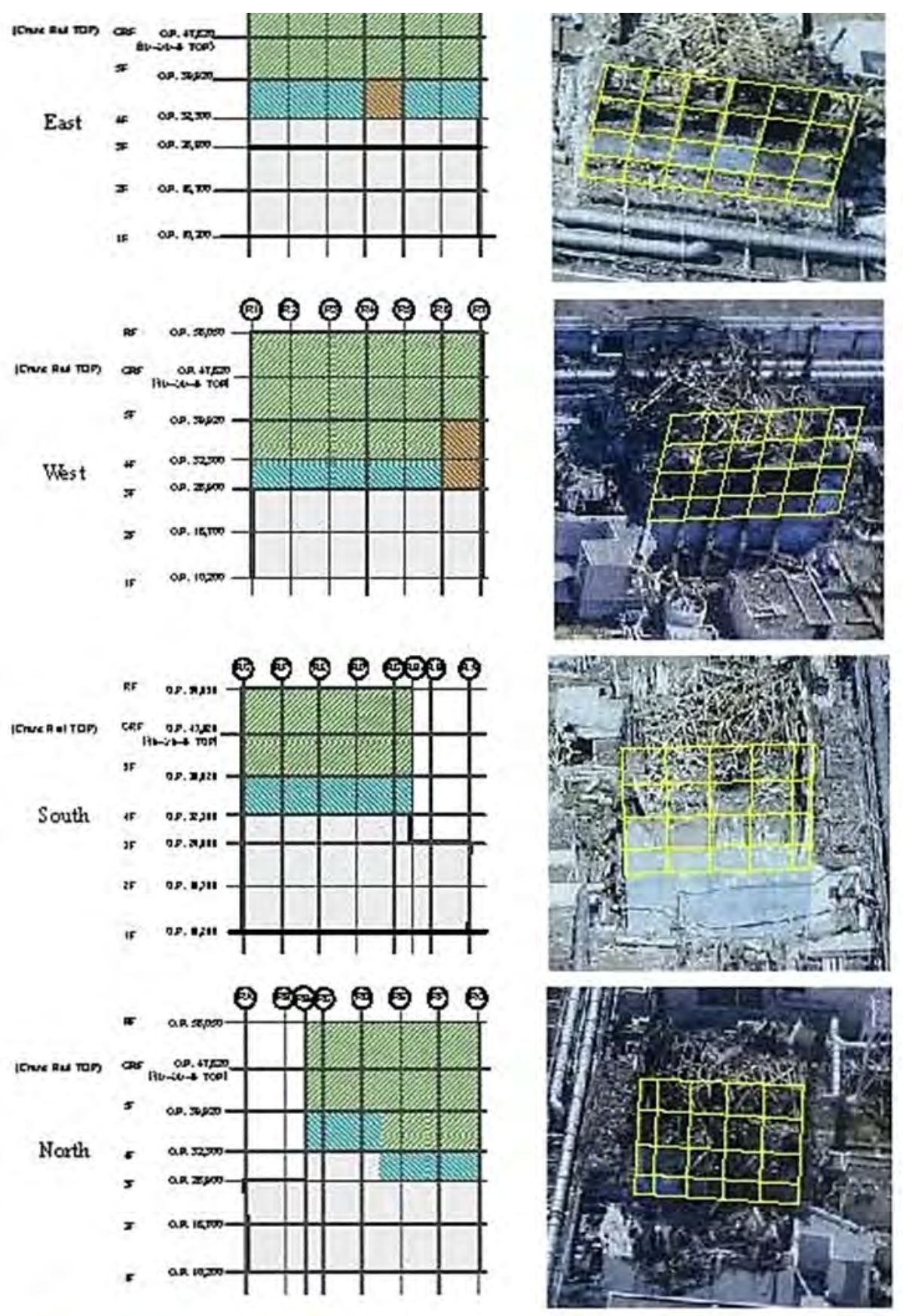

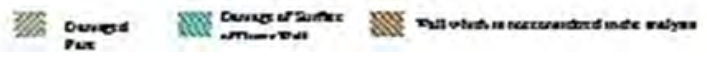

Figure 6-3. 1F3 reactor building damage following explosion. (Courtesy of TEPCO Holdings [188]) 

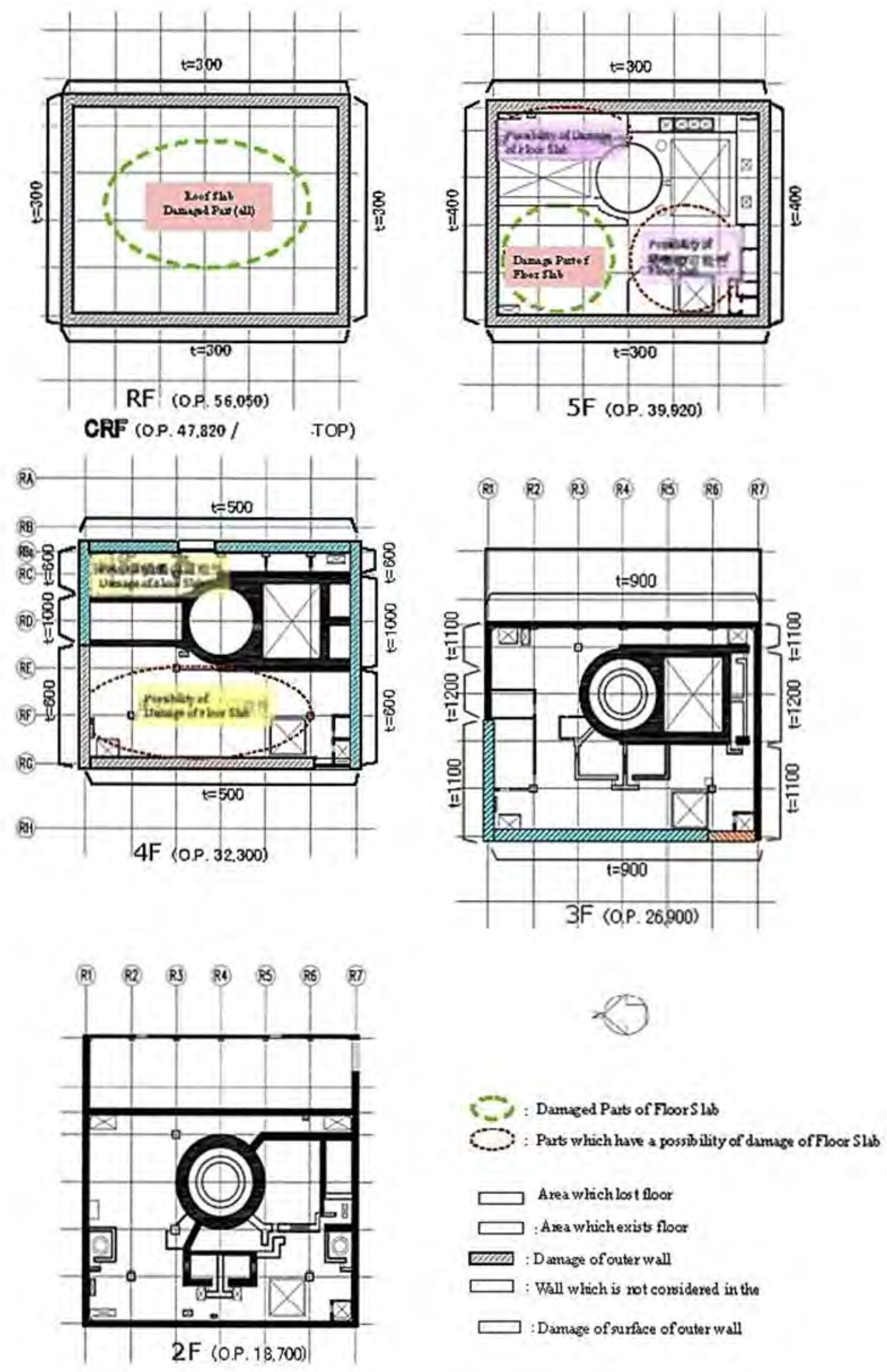

Figure 6-4. Damaged areas on 1F3 reactor building floor plan. (Courtesy of TEPCO Holdings [188]) 


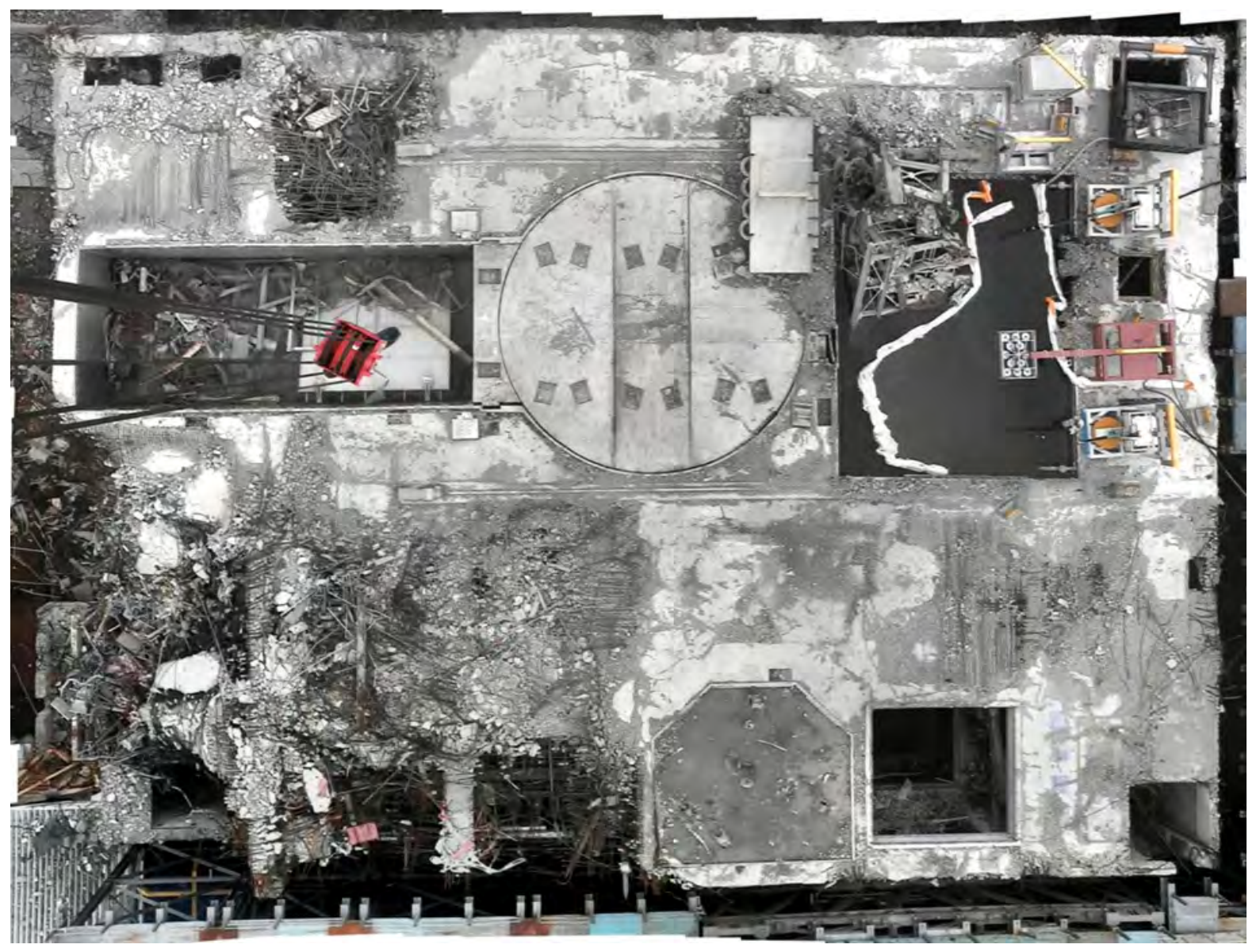

Figure 6-5. Damaged areas on 1F3 reactor building floor. (Courtesy of TEPCO Holdings [16])

\subsubsection{F3 Explosion}

The upper part of the $1 \mathrm{~F} 3$ reactor building above the refueling floor (the $5^{\text {th }}$ floor) also underwent an apparent hydrogen explosion on March 14, 2011 at 11:01 am.[189] Videos show that the explosion and damage were much more extensive than the $1 \mathrm{~F} 1$ explosion. In fact, the $1 \mathrm{~F} 3$ explosion damaged the fire engines and hoses being readied at 1F2 to the extent that they could no longer be used.

In [188], TEPCO Holdings observed the following damage:

- Collapsed steel framework and concrete were piled up on, and above, the $5^{\text {th }}$ floor (Figure 6-3);

- The east side wall was lost on the $5^{\text {th }}$ floor, but the columns survived;

- The west side wall was lost on the $5^{\text {th }}$ and $4^{\text {th }}$ floors; the $3^{\text {rd }}$ floor was partially damaged except for the elevator area on the southwest corner;

- The south side wall was lost on the $5^{\text {th }}$ floor and was partially damaged on the $4^{\text {th }}$ floor;

- The north side wall was lost on the $5^{\text {th }}$ floor and on part of the $4^{\text {th }}$ floor; the columns were lost;

- The north-west part of the floor on the $5^{\text {th }}$ floor was also damaged; part of the collapsed steel framework and concrete accumulated on the $4^{\text {th }}$ floor (Figure 6-4); 

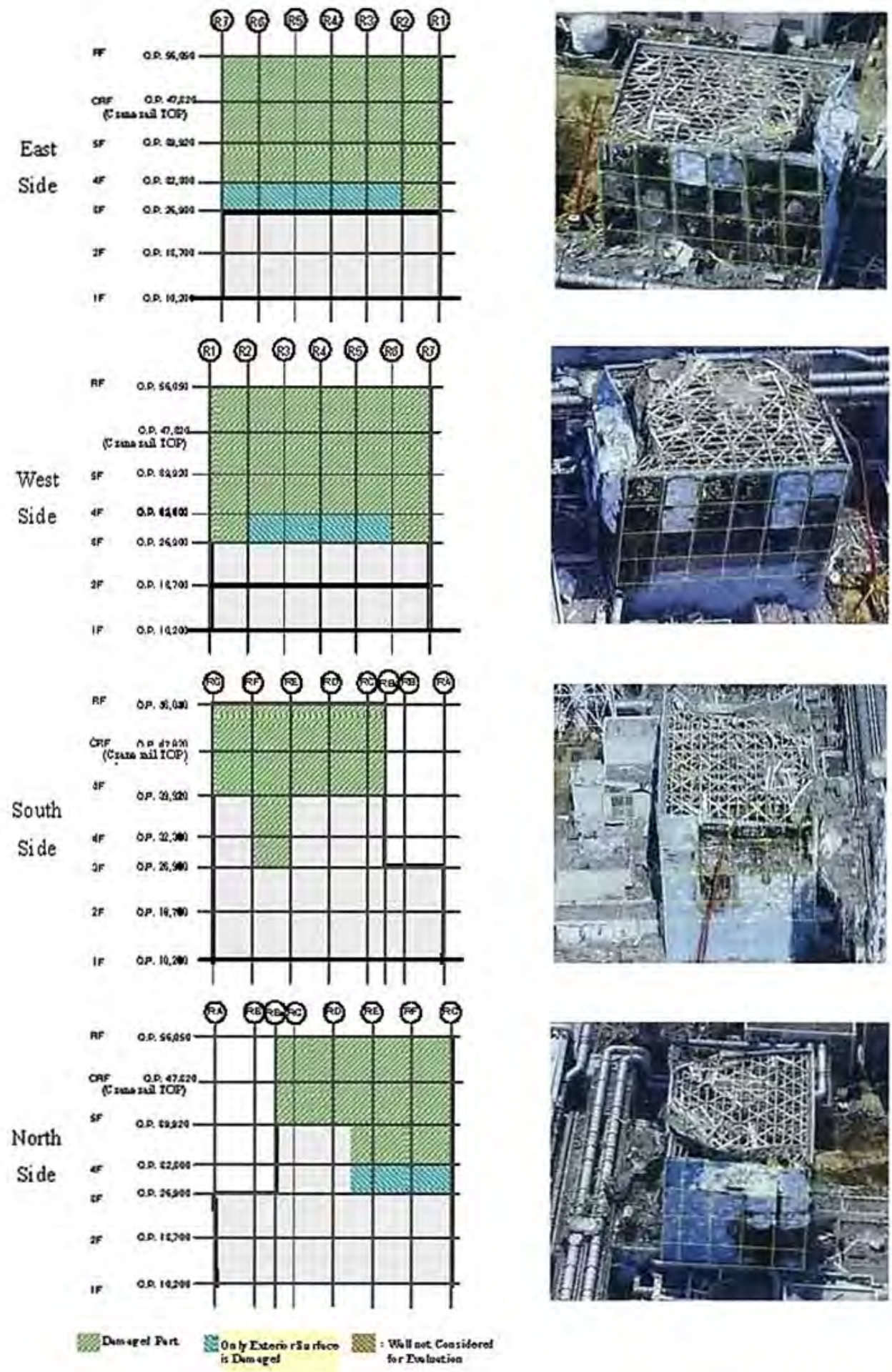

Figure 6-6. 1F4 reactor building damage following explosion. (Courtesy of TEPCO Holdings [187]) 


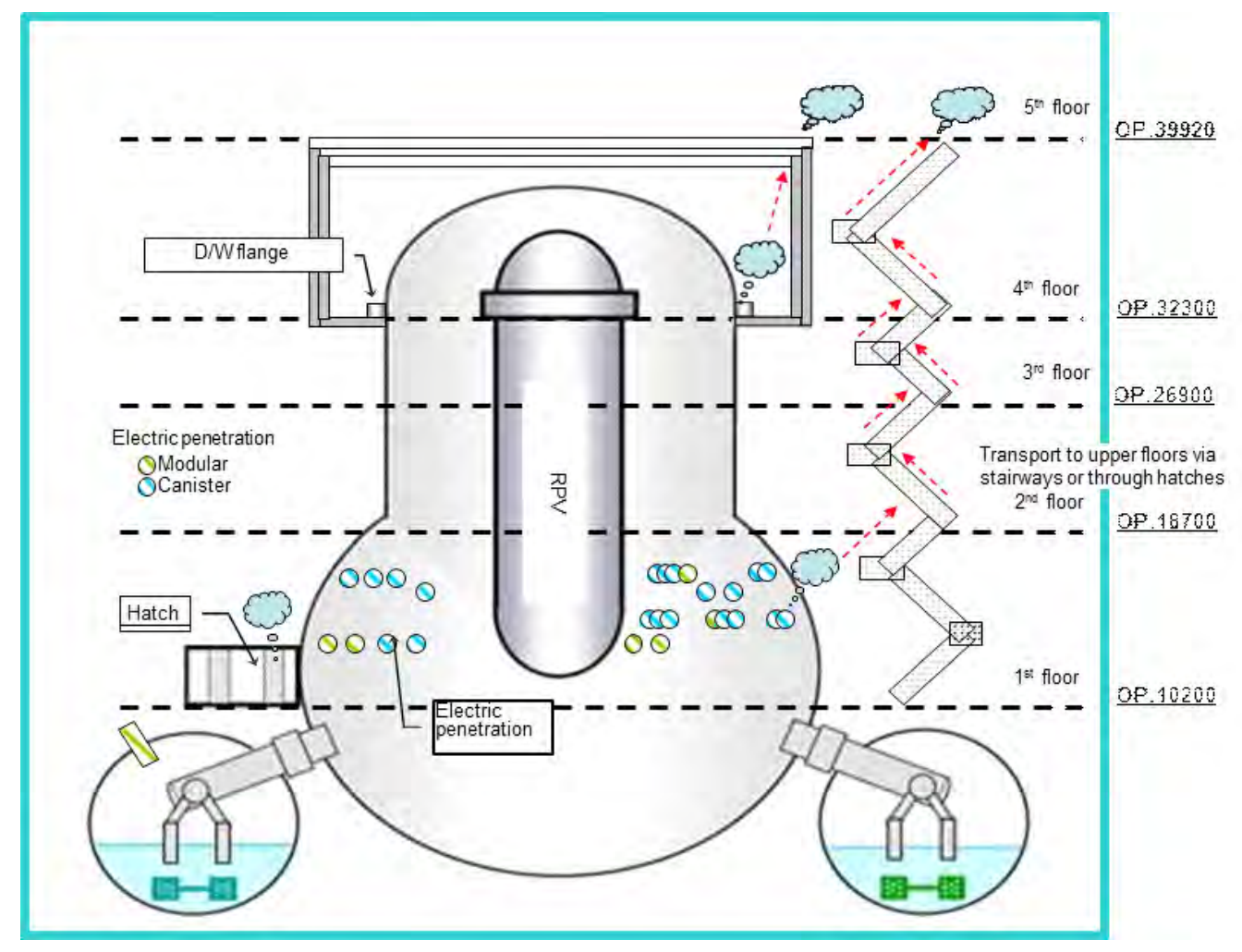

Figure 6-7. Inferred leakage paths; flow paths differ from $1 \mathrm{~F} 1$ and $1 \mathrm{~F} 3$ due to system configuration. (Courtesy of TEPCO Holdings [190]

- The $4^{\text {th }}$ floor walls were largely damaged;

- The overhead crane dropped onto the floor of the $5^{\text {th }}$ floor;

- The roof of the turbine building experienced some damage;

- The top of the two-story Radwaste Building adjacent to the 1F3 RB also experienced some damage.

More recent photos taken in 2014 after debris removal show that about one fourth of the concrete floor of the $5^{\text {th }}$ floor was severely damaged with big holes through the floor (Figure 6-5). Unlike 1F1, the shield plugs remained in normal positions.

Available information on the explosion damage suggests that there was a likely accumulation of extremely high concentrations of combustible gases in both the $4^{\text {th }}$ and $5^{\text {th }}$ floors at the time of the explosion. However, it is unknown at this time how such a level of accumulation occurred on the $4^{\text {th }}$ floor.

\subsubsection{F4 Explosion}

The 1F4 explosion in the reactor building is estimated to have occurred on March 15, 2011 at 6:14 am.[189] There were no videos capturing the explosion when it occurred. Unlike 1F1, the structure of 1F4 is a reinforced concrete structure whose wall resistance is supposedly stronger against inside pressure. 
Most of the roof slab and walls were blown off leaving only the frame structure of the pillar and beams.[187] Most walls on the $4^{\text {th }}$ floor and some walls on the $3^{\text {rd }}$ floor were damaged (Figure 6-6).

Evaluations of the explosion at 1F4 have led TEPCO Holdings [42,189] to conclude that vented gases, including hydrogen, flowed from 1F3 into 1F4 (Figure 6-8). This conclusion is based upon the following:

- Examinations of the filter train of the standby gas treatment system (SGTS) at 1F4. Measurements indicate that the concentration of radioactive materials accumulated at the outlet was higher than at the inlet. This implies that contaminated gas flowed into the 1F4 SGTS pipe from the outlet to the inlet (see Figure 6-9).

- Field investigations near the 1F4 SGTS duct on the $4^{\text {th }}$ floor. Damage to the $4^{\text {th }}$ floor (along with the floors above and below this floor) and remaining pieces of the SGTS exhaust duct work support the concept that the explosion originated at this location (see Figure 6-10).

- Examinations of the fuel in spent fuel pool for 1F4. At the time of the accident, the 1F4 reactor had been completely defueled with the fuel placed in the spent fuel pool for planned work on RPV internals. Thus, the only credible source of hydrogen for this unit during the accident would have been under-cooling of the assemblies in the fuel pool. However, all assemblies were subsequently removed from the 1F4 fuel pool, and physical observations made as each assembly was removed indicate no damage (over and above that experienced during normal reactor operation).

These findings are consistent with the hypothesis that the wetwell vent flow from $1 \mathrm{~F} 3$ traveled into the $2^{\text {nd }}$ floor of $1 \mathrm{~F} 4$ and then into other areas of the 1F4 reactor building via pipes and the SGTS ducts.

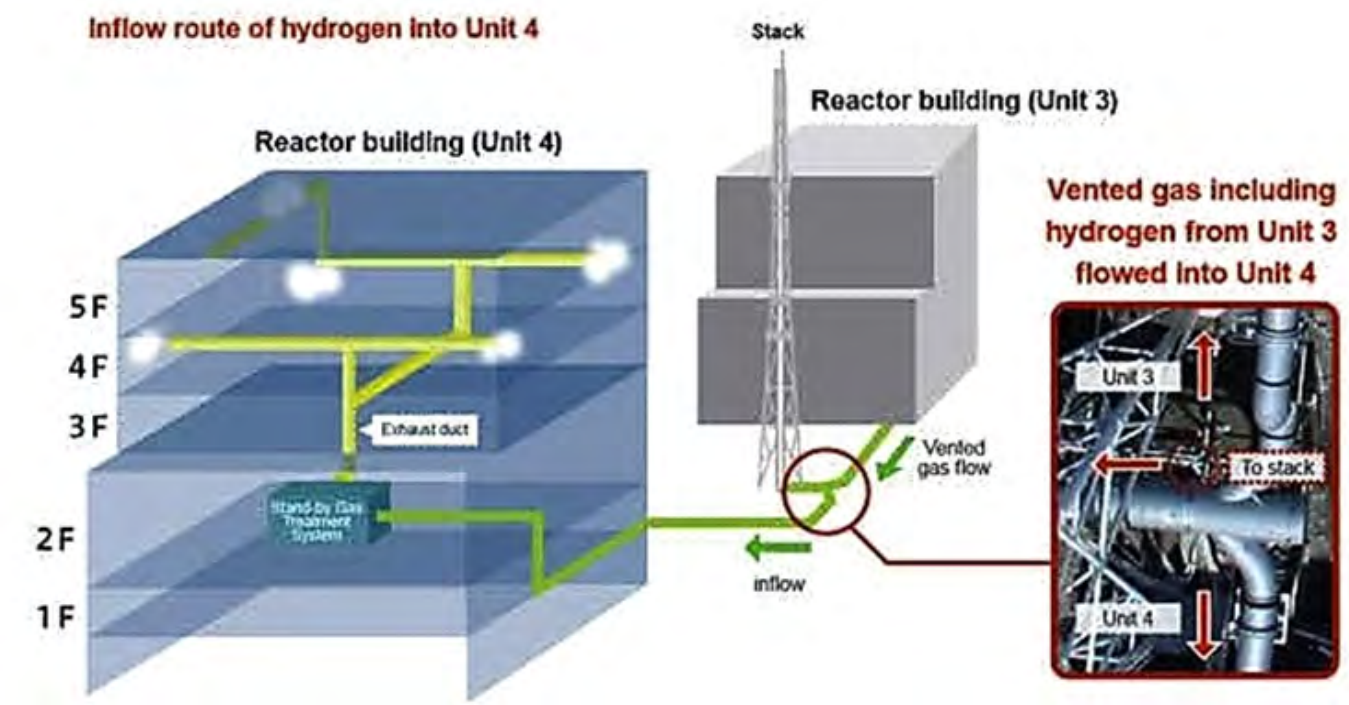

Figure 6-8. Hydrogen transport path from 1F3 to 1F4. (Courtesy of TEPCO Holdings [189])

* Normally, the SGTS is on standby or shut down, and system valves are closed to prevent flow of vented gas between adjacent units. However, venting of the 1F3 PCV was conducted while all AC power sources were lost, and the resulting line configuration allowed vented gas to flow from the 1F3 PCV into 1F4 through a SGTS pipe. 


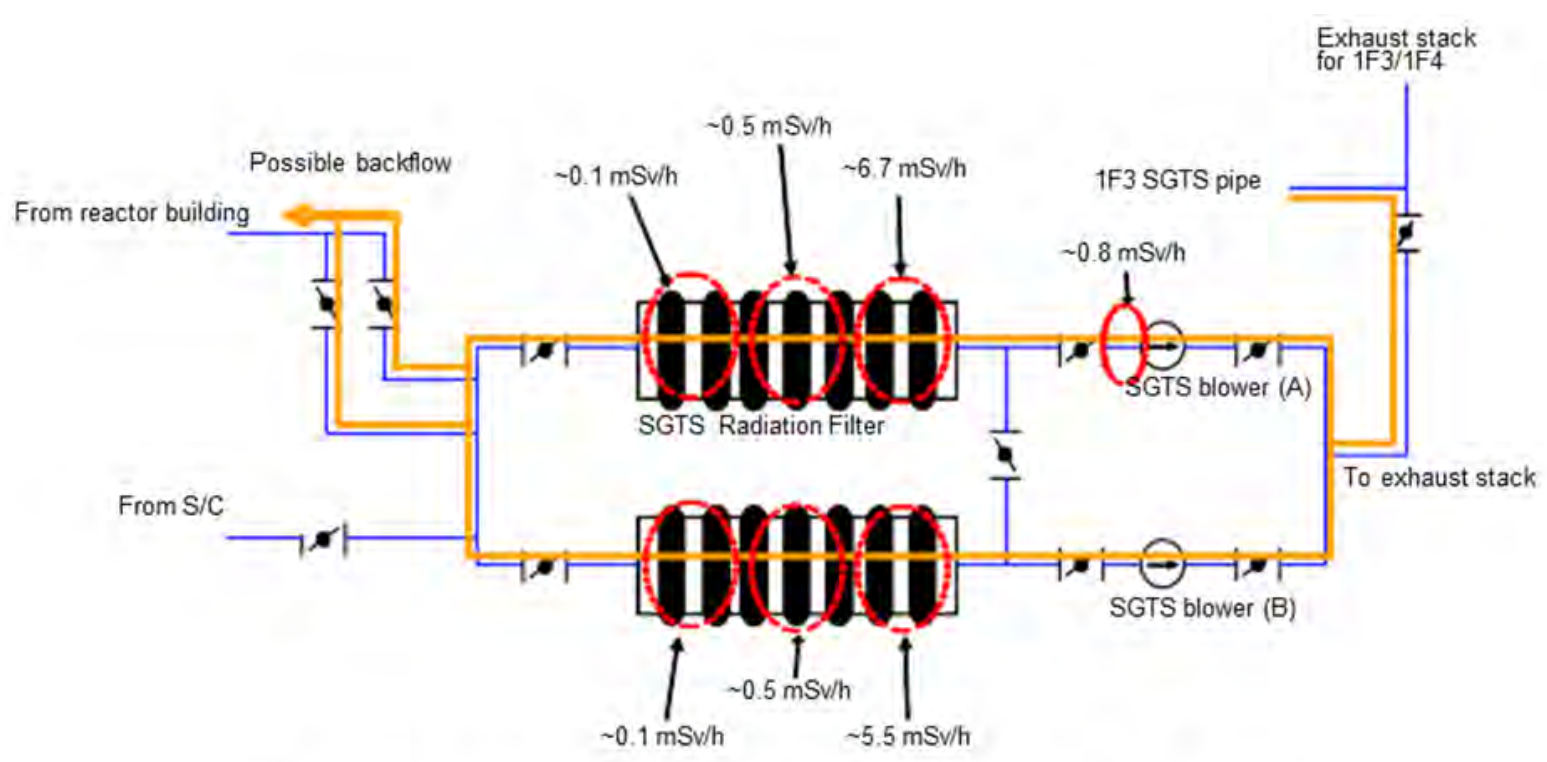

Radiation measurements in $1 F$ SGTS (conducted August 25, 2011)

Figure 6-9. 1F4 SGTS radiation measurement results. (Courtesy of TEPCO Holdings [189])

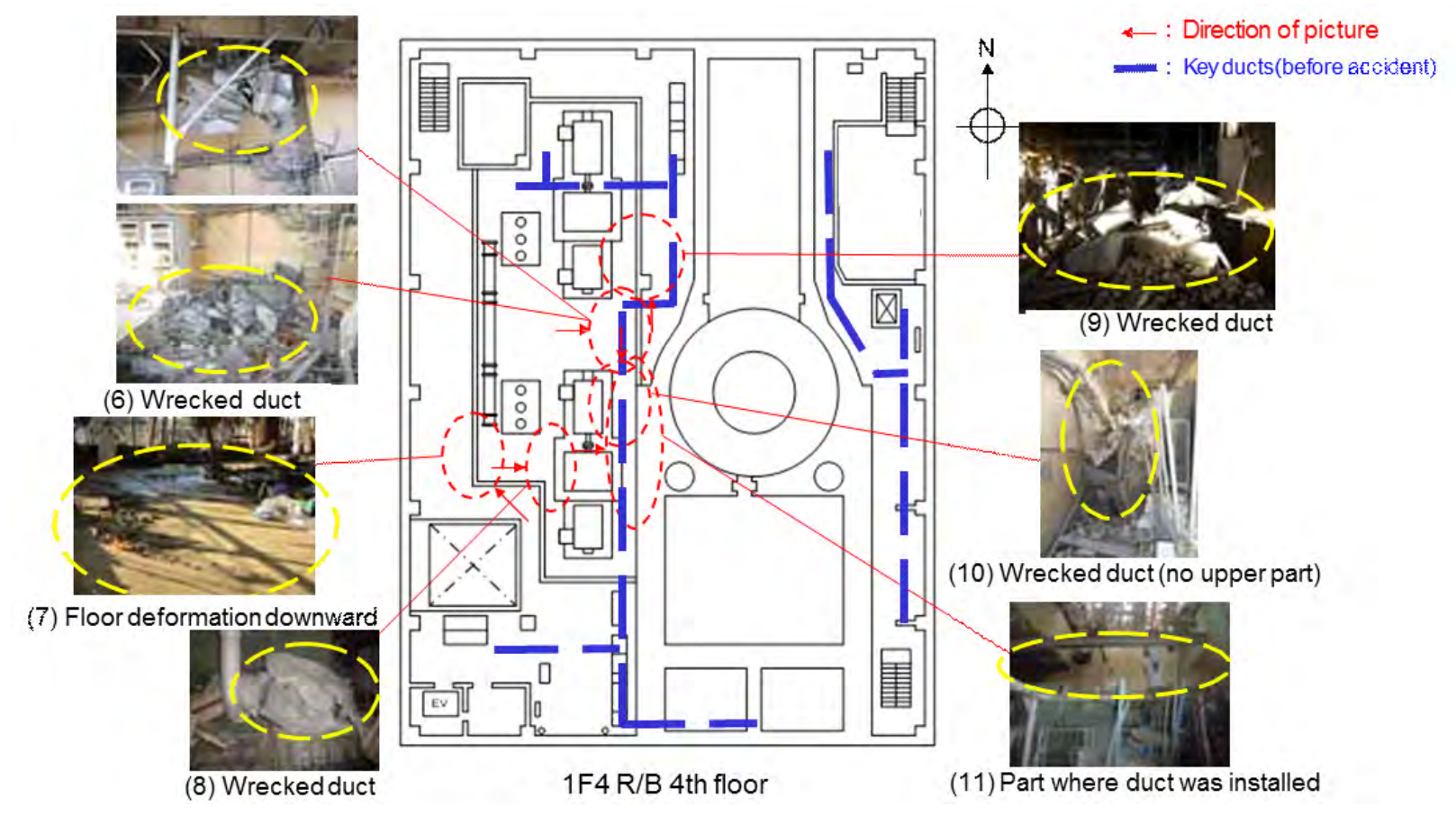

Figure 6-10. Field investigation of the $1 \mathrm{~F} 44^{\text {th }}$ floor. (Courtesy of TEPCO Holdings [189]) 


\subsubsection{Video Capturing Explosions}

Figure 6-11 shows one-second interval snapshots from Fukushima Central Television Company, LTD (FCT) videos capturing the 1F3 explosion for the first 9 seconds (about the duration of the explosion).[193] Figure 6-12 shows millisecond-time scale snapshots of images before and after the appearance of a "flash fire" (an orange flame) which first appeared in the 0.099-s frame and disappeared in the 0.495-s frame.
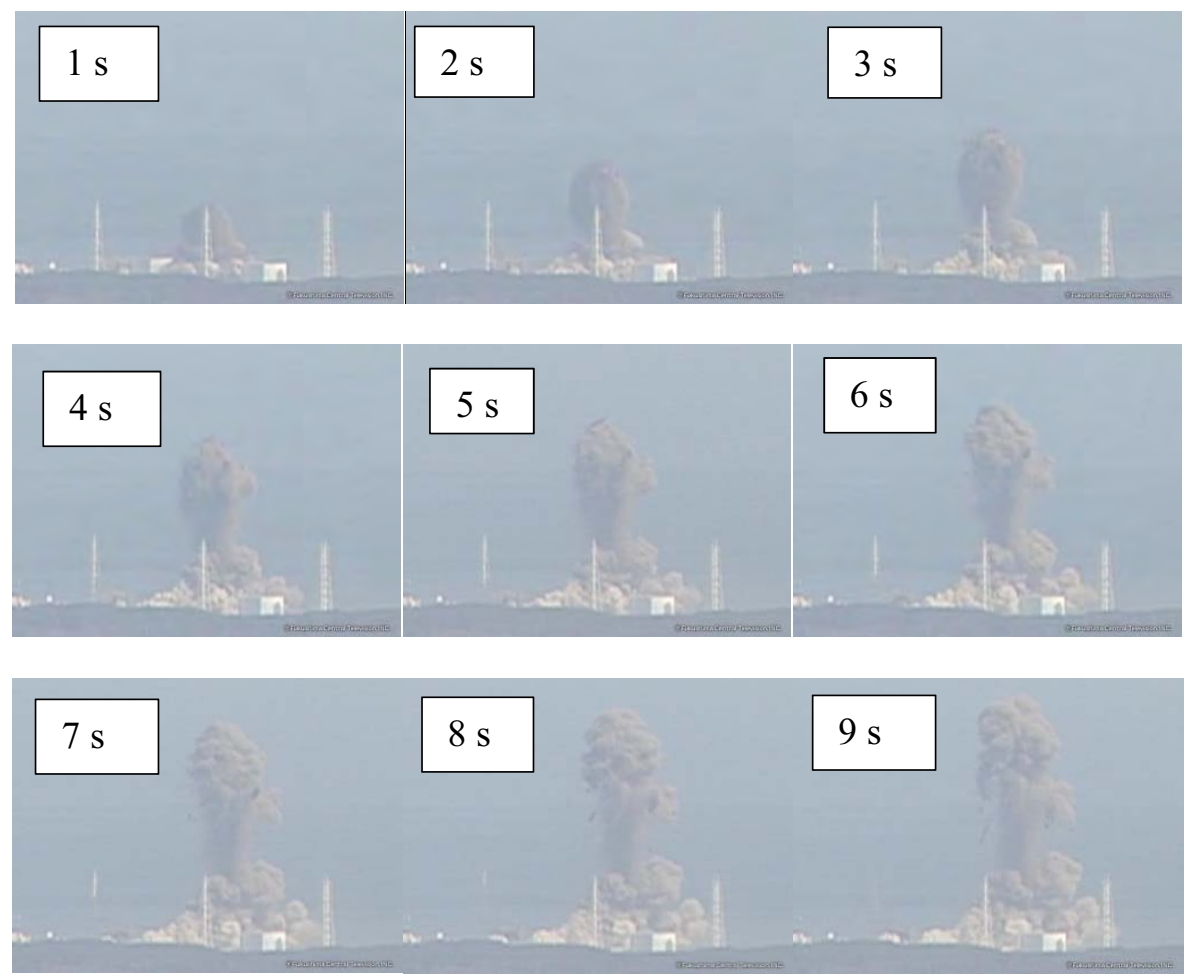

Figure 6-11. Images of 1F3 explosions at 1-second intervals. (Courtesy of FCT [193])

U.S. and Japanese expert evaluations of information related to hydrogen combustion, $[21,194,195,196]$ as well as videos of the explosions, indicate that the hydrogen explosion at the 1F3 reactor building was very different from the explosion of $1 \mathrm{~F} 1$. The combustion process of the explosion at $1 \mathrm{~F} 1$ was a fast deflagration of hydrogen accumulated in the operating bay ( $5^{\text {th }}$ floor) of the reactor building.[195] A video of the explosion indicates the presence of a condensation shock wave (for about a 0.5 -second duration) propagating into an open air at about the speed of sound after the initial bursting of the $1 F 1$ reactor building. The deflagration was not fast enough to transition to detonation. As shown in the left side of Figure 6-14, the explosion "smoke" at about one second after the initial bursting appeared light in color, suggesting it was primarily dust. The "smoke" was dispersed relatively close to the building in the vertical direction and was directed northward (toward the left in the picture) due to the prevailing wind at that time. The building roof and side panels were blown away by the explosion, but concrete pillars remained intact with little damage.

In an effort to further explore the 1F3 explosion, signal analysis software was used to examine the video sound frequency. As shown Figure 6-13, the resultant sound frequencies found on the audio appeared like an echo. Upon contacting the video owners, $[197,198]$ it was determined that the audio was not an echo but was added to the video after it was filmed. 

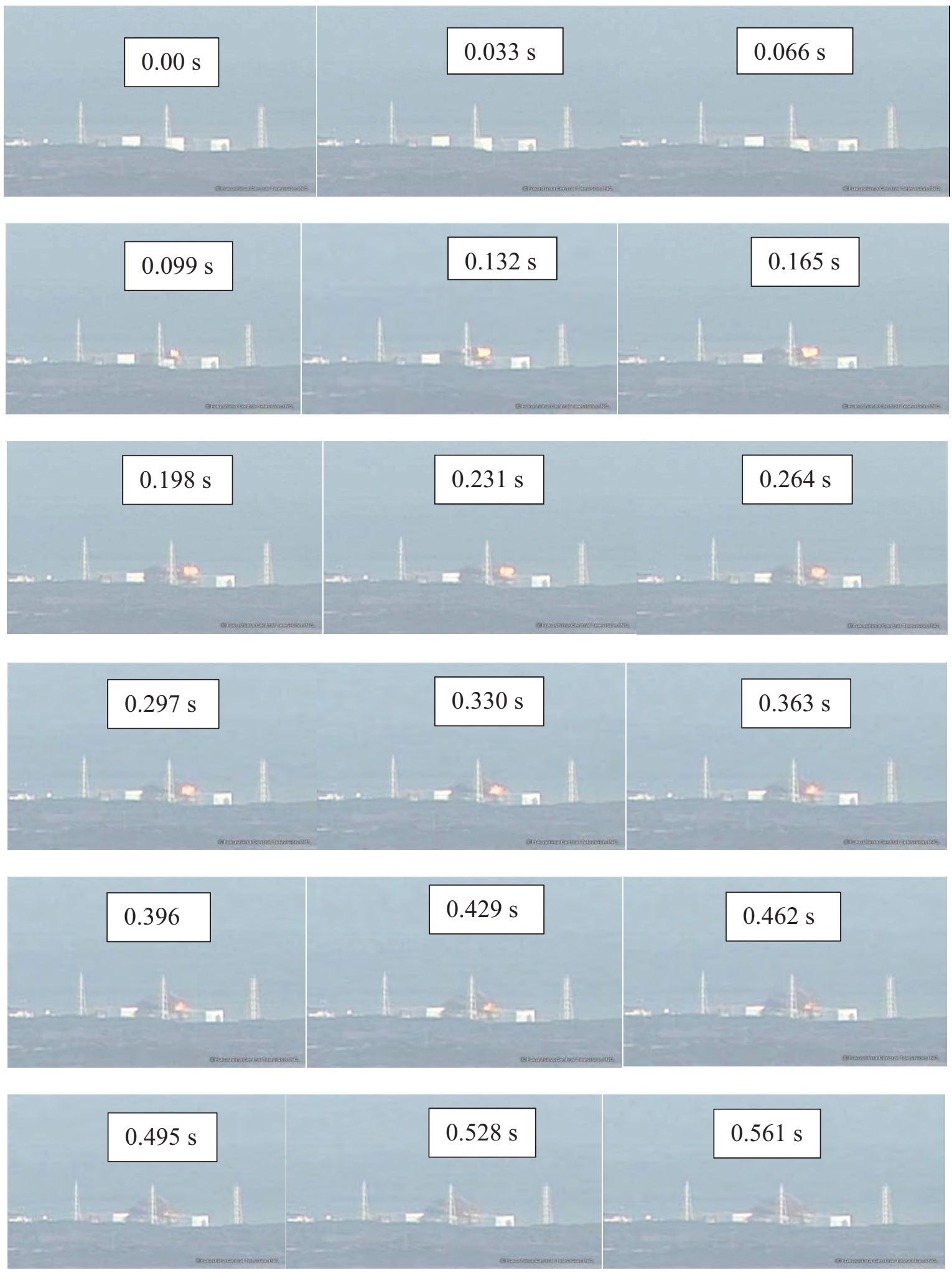

Figure 6-12. Images of 1F3 explosions during an appearance of a flash fire. (Courtesy of FCT [193]) 


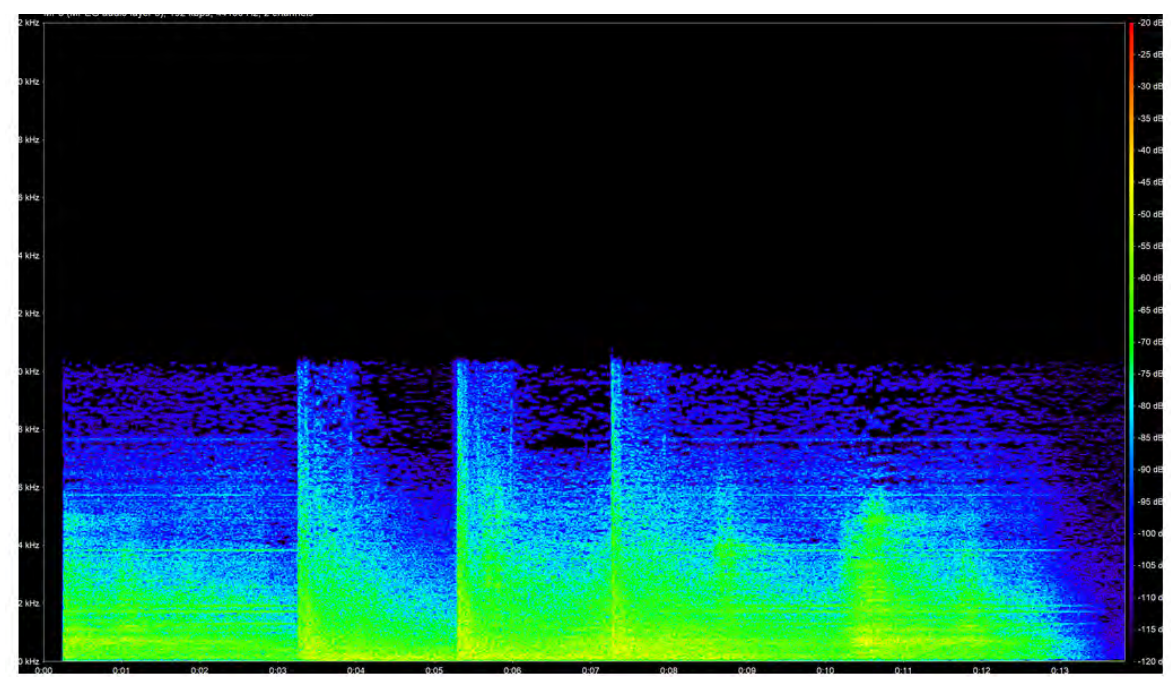

Figure 6-13. Sonic frequency analysis of $1 \mathrm{~F} 3$ reactor building explosion video. Acoustic wave examination shows a large peak replicated three times at approximately 2 second intervals; discussions with FCT indicate that video had no sound detection capabilities (Courtesy of SNL, [197, 198])

U.S. evaluations indicate that the explosion at $1 \mathrm{~F} 3$ was a multi-mode combustion, and thus was quite different in appearance and much more energetic (Figure 6-14). There appeared to be at least two modes of combustion involved in the explosion. The first was similar to the $1 \mathrm{~F} 1$ explosion which was a deflagration of hydrogen (and possibly CO) accumulated in the operating bay ( $5^{\text {th }}$ floor). The flame front apparently propagated to the $4^{\text {th }}$ floor (based on damage seen in Figure 6-3) and resulted in the deflagration of flammable gaseous mixture accumulated in the $4^{\text {th }}$ floor at that time. This first mode of combustion occurred inside the reactor building and could not be seen in the available video until the initial bursting of the 1F3 reactor building. Following the bursting of the $1 \mathrm{~F} 3$ reactor building, the top floor of the reactor building became roof-less, and the second mode of combustion began in an open air on top of the reactor building. The second mode was combustion of a hydrogen (and possibly CO) gas cloud in an open air in the form of a rising and expanding spherical fireball over the reactor building (Figures 6-11 and 6-12). The second mode of combustion was directed vertically with an almost perfect spherical fireball appearing above the building and shooting up high into the sky (about three times the vent stack height). Large chunks of materials appeared to be carried upward with the fireball. Unlike the explosion at 1F1, available $1 \mathrm{~F} 3$ images indicate that concrete pillars on the building top floor were highly damaged. The "smoke" resulted from fire ball appeared in darker color of dust and debris than that of the $1^{\text {st }}$ mode of combustion, which appeared white (in the image) and remained at lower elevations close to the building (Figure 6-11).

The fact that the $1 \mathrm{~F} 3$ explosion was much more powerful than the $1 \mathrm{~F} 1$ explosion requires that the amount of combustible gases involved in the entire multi-mode explosion must also be much greater. In the 1F1 explosion, the deflagration apparently burned the entire combustible gas-air mixture that initially existed in the $5^{\text {th }}$ floor of the reactor building. In the $1 F 3$ explosion, a similar deflagration of initially existed combustible gas-air mixture is postulated since this mode of combustion could not be seen in the video until the initial bursting of the $1 \mathrm{~F} 3$ reactor building. (The video was also taken from a much farther distance than the 1F1 explosion resulting in the loss of resolution for details.) It is then expected that most of the combustible gas mixture would be consumed in the first deflagration and the explosion would be over. However, this is not the case for the $1 \mathrm{~F} 3$ explosion. Following the bursting of the reactor building 


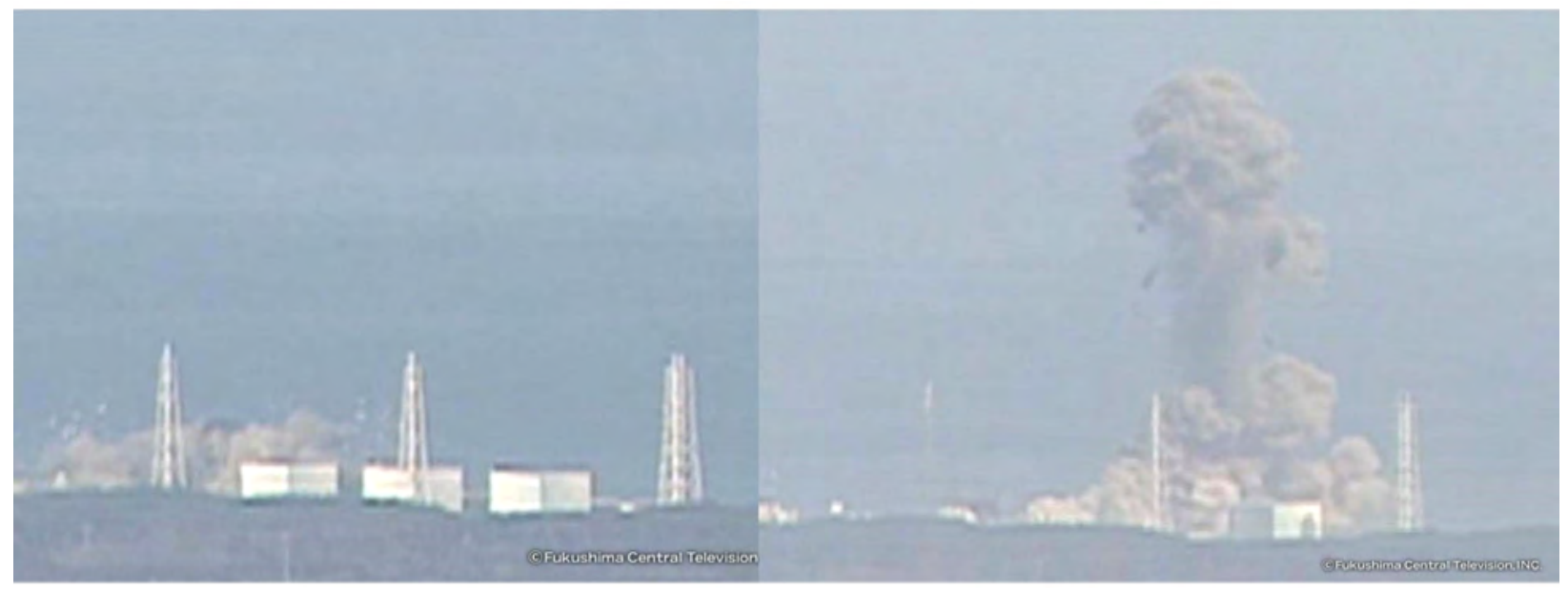

1F1

$1 F 3$

Figure 6-14. Images of 1F1 explosion compared with 1F3 explosion. (Courtesy of FCT [193])

due to deflagration, there was a huge fireball burning immediately over the reactor building. For this to happen, there must be an additional source of combustible gases (which did not exist in the 1F1 explosion) that fueled the fireball combustion. This point is further discussed in Section 6.2.6.

\subsubsection{Plant Data}

\subsubsection{1. $1 \mathrm{~F} 3$}

The time of the 1F3 explosion, 11:01 am, March 14, 2011, was about the same time when the 1F3 PCV pressure dropped significantly from about 0.52 to about $0.39 \mathrm{MPa}$ (Figure 6-15). From 10:55 am to 11:02 am, about 6 minutes prior to the explosion, the drywell pressure dropped from $0.52 \mathrm{MPa}$ to $0.48 \mathrm{MPa}$. The average depressurization rate for this 6 minute duration prior to the explosion was $95 \mathrm{~Pa} /$ second. Then, after the explosion from 11:02 am to 11:15 am, the drywell pressure dropped further from $0.48 \mathrm{MPa}$ to $0.39 \mathrm{MPa}$. The average depressurization rate for this 13-minute duration after the explosion was $115 \mathrm{~Pa} /$ second.

The significant drop in pressure is believed to correspond to drywell upper head seal failure. This PCV failure would release a hot hydrogen-steam gaseous mixture into the $5^{\text {th }}$ floor of the reactor building around the drywell plug lifted by pressure buildup below it. It was possible that these hot vented gases (among other random ignition sources) could have ignited hydrogen gas, which leaked earlier and accumulated on the $5^{\text {th }}$ floor (and $4^{\text {th }}$ floor) of the reactor building. Ignition of this hydrogen resulted in the first combustion mode whose burning mechanism (i.e., deflagration) was postulated to have occurred in a similar way as the $1 \mathrm{~F} 1$ explosion. Then, a gross failure of the 1F3 drywell upper head seal (whose symptom already appeared 6 minutes prior to the explosion as the PCV experienced a relatively significant depressurization) would have provided a large, continual supply of hydrogen gas from inside the drywell through the failed head seal. 


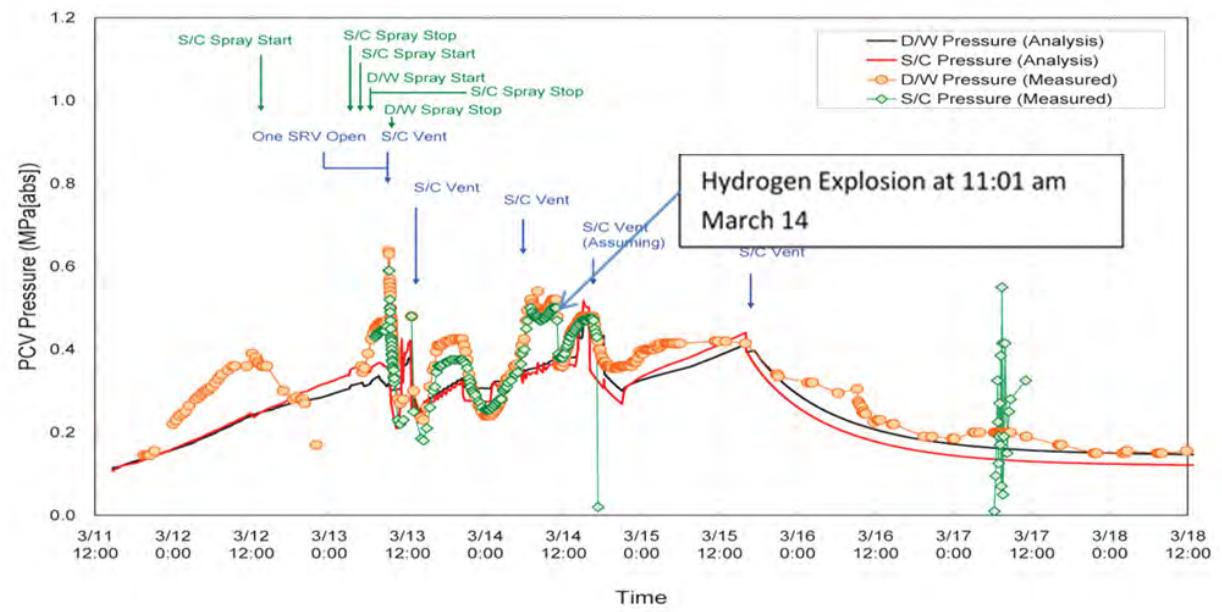

Figure 6-15. 1F3 PCV pressure - Rapid drop in PCV pressure coincides well with the timing of 1F3 explosion at 11:01 am March 14, 2011. (Courtesy of TEPCO Holdings [199])

It is noted that it would require about $6.9 \mathrm{psi} / 48 \mathrm{kPa}$ differential pressure $(\Delta p)$ to lift the drywell shield plug where $\Delta p=\rho g H$, and for the purpose of approximation, $\rho=$ reinforced concrete shield plug density $\sim 2600 \mathrm{~kg} / \mathrm{m}^{3}, g=9.8 \mathrm{~m} / \mathrm{s}^{2}$, and $\mathrm{H}=$ shield plug thickness $\sim 1.875 \mathrm{~m}(3 \times 0.625 \mathrm{~m})$. This magnitude of $\Delta p$ was achievable with the prevailing drywell pressure at the time of the explosion. Let $P_{1}, T_{1}$ and $V_{1}$ be the drywell gas pressure, temperature, and volume, respectively. Let $T_{2}$ and $V_{2}$ be the temperature and volume of the well below the shield plug. Let $\Delta N$ be the number of moles of gas that must leak from the drywell head into the refueling well above it in order to raise the pressure in the well by $\Delta p$ is $\Delta N=\Delta p V_{2} / R T_{2}$ (with $R$ representing the universal gas constant). Because of this leakage of $\Delta N$ moles of gases, the drywell pressure will decrease from $P_{1}$ to $\mathrm{P}_{1} *$ where $P_{1} *$ is given by

$P_{1}^{*}=P_{1}-\frac{V_{2}}{V_{1}} \frac{T_{1}}{T_{2}} \Delta p$

Assuming typical values of $V_{1}=3940 \mathrm{~m}^{3}, V_{2}=566 \mathrm{~m}^{3}, T_{1}=700 \mathrm{~K}, T_{2}=600 \mathrm{~K}$, and with $P_{1}=0.52 \mathrm{MPa}$ and $\Delta p=48 \mathrm{kPa}, \Delta N$ is calculated to be $5.45 \mathrm{~kg}$-moles, and the new drywell pressure is calculated to be $P_{1}^{*}=0.512 \mathrm{MPa}$. This new pressure of $0.512 \mathrm{MPa}$ is even higher than the plant data of $0.48 \mathrm{MPa}$ at $1 \mathrm{~min}-$ ute after the explosion as mentioned above. This implies that for the 6-minute period prior to the explosion when the drywell pressure decreased from $0.52 \mathrm{MPa}$ to $0.48 \mathrm{MPa}$ (if the depressurization is assumed to be caused by leakage alone and the leakage is assumed to go into the refueling well above the drywell head), there would be more than a sufficient amount of combustible gases in the refueling well (with a free volume of more than $500 \mathrm{~m}^{3}$ ) to lift the shield plug (or leak through gaps between segmented concrete plugs) and enter into the $5^{\text {th }}$ floor of the reactor building in the form of a forced jet flow. Based on this calculation, it is reasonable to say that this path of hydrogen movement is a possible mechanism that fueled the observed spectacular fireball combustion.

This combustible gas jet entrained surrounding air as it moved upward and burned in the form of an unconfined "gas cloud explosion" as a large fireball emanating from the reactor building into the sky. The first appearance of combustible gas jet was in the form of a flash fire [visible from the video snapshot at the very beginning (less than $0.5 \mathrm{~s}$ ) of the 1F3 explosion transient shown in Figure 6-12]. At the beginning, the combustible gas jet was just forming. The gas cloud was then initially burned as a flash fire. The flash 
fire anchored at the same location for about 0.4 seconds. When more combustible gas from the jet came out, the flash fire disappeared and the energetic fireball explosion began its process as shown in Figure 6-11. The observed combustion phenomena were the consequence of the PCV leakage that started 6 minutes before the explosion and supplied sufficient amount of combustible gas to feed the fireball explosion. There is a clear linkage between the fireball explosion, the observed flash fire, and the PCV failure (the drywell head seal failure).

According to [200], the formation of a rising fireball during an explosion is typical of combustion conditions where a release of fuel and ignition occur simultaneously. The combustible gases are not well mixed with the air at the time of ignition. The gases continue burning as they mix with ambient air. The rising fireball forms. Then a strong convective column (as seen in 1F3 explosion) is formed below the rising fireball. Alternatively, a rising fireball can also be developed after the explosion of over-enriched fuel-air mixtures when the explosion products, still containing a great amount of fuel, continue to burn with the ambient air. These two mechanisms, including a combination of both mechanisms, are possible explanations for the 1F3 explosion given the limited evidence available at this time.

There is not consensus among US experts about the combustion events at $1 \mathrm{~F} 3$, even when taking into account the video evidence of the event. An alternative explanation is that there was a rapidly propagating deflagration or detonation in the upper floors of the reactor building, involving a significantly larger amount of $\mathrm{H}_{2}$ and $\mathrm{CO}$ generation than what occurred in $1 \mathrm{~F}$, followed by a plume of hot air and ash rising above the reactor building, in the several seconds following the combustion event.

Further, there is doubt regarding that plant data support multi-mode combustion events. Given the rapid progression of the $1 \mathrm{~F} 3$ event, it cannot be concluded that the drywell depressurization contributed in any significant way to a second hydrogen explosion. The depressurization of the drywell occurred over a 20 minute period from 11:01 to 11:20. At 11:01, the pressure was near 0.52 MPa. At 11:02, the pressure was slightly decreased to $0.48 \mathrm{MPa}$. At 11:15, the pressure was at $0.38 \mathrm{MPa}$. Finally at 11:20 AM, the pressure stabilizes near $0.36 \mathrm{MPa}$. It is probable that a failure of the drywell led to an initial spark triggering the explosion. However, given that the following depressurization was not instantaneous, there is not supporting plant data for a multi-mode explosion hypothesis. Indeed the next recorded data point, following the explosion, was only $0.04 \mathrm{MPa}$ lower than the one immediately before the explosion.

Given that there was extensive in-vessel and ex-vessel hydrogen generation, followed by an extended period of what could be drywell leakage between 6:35 AM and 11:00, introduces uncertainty regarding any conclusions regarding an instantaneous depressurization fueling a second explosion.

\subsubsection{1F2}

Although there was no explosion at 1F2 (as discussed in Section 4.3.2), there is evidence that a substantial amount of hydrogen was generated during a water injection into the 1F2 RPV by fire trucks. Injection by fire trucks into the 1F2 RPV began at 8 pm (March 14, 2011), two hours after the manual opening of SRV which depressurized the RPV pressure to near a 0.6-MPa level.[201] However, the injection did not go smoothly. An intermittent RPV re-pressurization, which appeared as three pressure spikes near the tail of the RPV pressure curve in Figure 6-16 occurred three times one after another. These pressure spikes prevented continuous injection from the fire trucks. A significant increase in the drywell pressure to 0.75 MPa, which can be seen in Figure 6-17 during the second pressure spike, indicates that a significant amount of hydrogen was generated from metal-water reactions in conjunction with the second pressure 
spike. (The likely explanation for this is a core relocation into the lower plenum that produced a significant amount of steam for zircaloy oxidation.) According to TEPCO calculations, almost all zircaloy inventory in the core would need to be oxidized to reproduce the observed high drywell pressure.

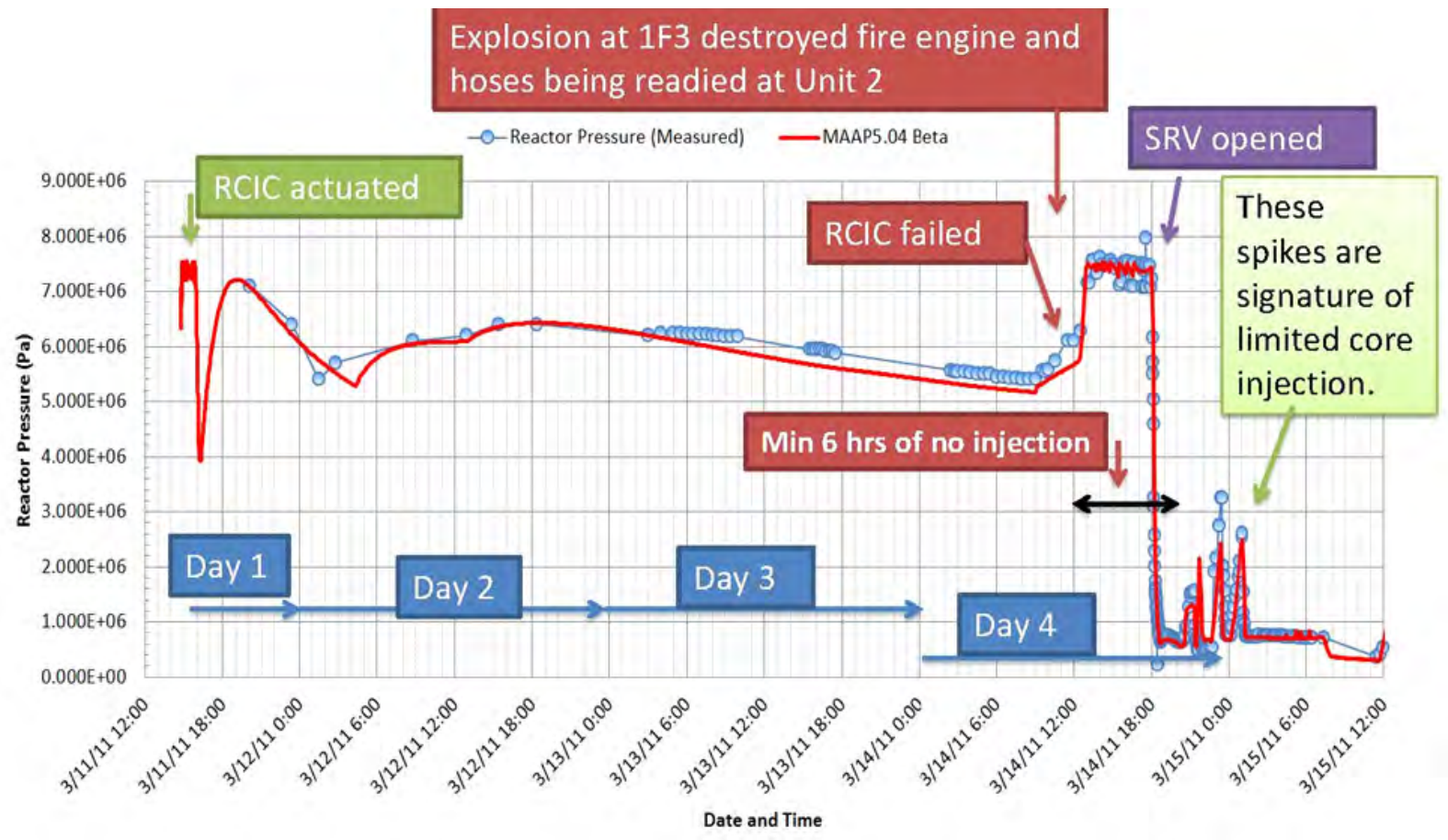

Figure 6-16. Timing of 1F2 RCIC failure and 1F3 explosion. (Courtesy of FAI)

\subsection{Insight Summary and Limitations}

In summary, available inspection examination information and plant data have led to several important insights about combustible gas effects and answers to Section 6.1 questions.

- The 1F3 explosion was not a stand-alone randomly occurring event. The 1F3 explosion was most likely initiated by failure of the drywell upper head seal when it was at high PCV pressure $(0.53 \mathrm{MPa})$. The released hot gas was likely the ignition source and became a source of fuel that supplied the highly energetic fireball burning at and above the building. The hot hydrogen/steam mixture was released as a jet from the periphery of the lifted drywell shield plug. The fireball appeared in dark color of dust and debris (rather than the white color of a water vapor condensation cloud). A significant amount of reactor building concrete dust and debris was generated from the explosion.

- The damage to the 1F3 building was more extensive compared to damage incurred at 1F1 and 1F4. The extent that the damage caused by the energetic explosion was a consequence of drywell head seal failure leading to a PCV blowdown at high pressure and temperature is a question to be answered. Large objects were thrown high into the sky. Big pieces of concrete and equipment were also thrown into the spent fuel pool. Further evaluations are needed to investigate if this type of explosion can cause containment structural failure at other locations.

- The events at Daiichi provide a real-world example of hazard propagation on a multi-unit site. As mentioned in Section 6.2.3, the explosion at 1F3 damaged mobile equipment, such as fire 


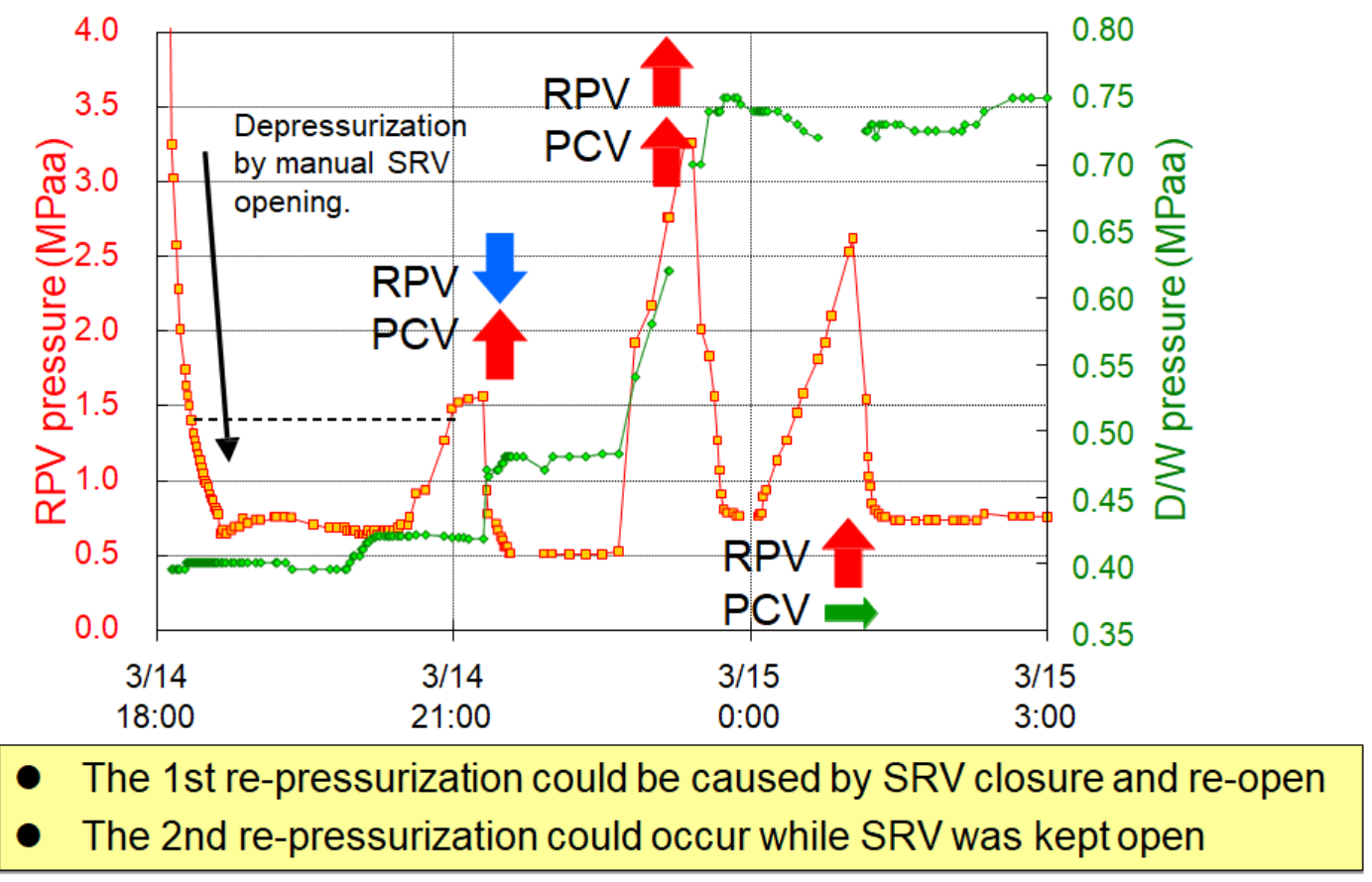

Figure 6-17. 1F2 PCV pressure trend - Rapid increase in PCV pressure coincides well with the second RPV pressure spike following the injection with fire trucks at 20:00, March 14, 2011. (Courtesy of TEPCO Holdings [201])

engines and hoses, being readied for core cooling of $1 \mathrm{~F} 2$ to the extent that it could no longer be used. The timing of the 1F3 explosion coincided with the failure of 1F2 RCIC that had been operating for nearly 3 days (Figure 6-16). Following this event, 1F2 experienced a period of no core cooling for more than 6 hours. The meltdown of the 1F2 core might have been avoided if the explosion at 1F3 had occurred at a different time. Thus, these events are a real-world example of hazard propagation on a multi-unit site in that an event at a damaged unit propagated to an adjacent intact unit and resulted in core damage.

- The shared vent stack between 1F3 and 1F4 allowed hydrogen that was vented from 1F3 to enter the 1F4 reactor building. Radionuclide surveys and examination information confirm that the shared vent stack was the reason for the explosion in the $1 \mathrm{~F} 4$ reactor building. The design of such vent stacks should take into consideration the safety implication of this experience.

In summary, available information has already provided many important insights related to combustible gas generation. However, questions remain in this area. More information is needed to evaluate the contribution of gases generated from MCCI to the observed explosions. This question is, in turn, related to the extent of MCCI following RPV failure as well as the point at which the core debris is quenched and rendered coolable. As D\&D activities progress, it is anticipated that planned examinations by TEPCO Holdings will address these questions. 


\subsection{Recommendations}

The explosions at Daiichi caused significant damage to the reactor building structures. Assessments of the Fukushima Daiichi event scenarios at each unit highlight the correlation between core damage modeling and the potential for flammable conditions to develop in reactor buildings.

Results from recent studies comparing MAAP5 and MELCOR calculations [57] have identified how limited knowledge regarding in-core damage progression can lead to significant differences in code predictions for hydrogen production. Differences between code predictions stem from a lack of experimental data that would clarify appropriate modeling assumptions regarding in-core melt progression behavior. As a result, the two codes predict different amounts of in-core hydrogen generation, with MAAP5 typically predicting lesser amounts of in-core hydrogen generation relative to MELCOR.[57] Evaluations with MAAP5 tend to find that this has important consequences for the development of flammable conditions in the $1 \mathrm{~F} 1$ and $1 \mathrm{~F} 3$ reactor buildings. Figures 6-18 and 6-19 compare results from a MAAP5 uncertainty evaluation of the 1F3 accident.[60] These figures show the predicted hydrogen concentrations on the refueling and fourth floors of the $1 \mathrm{~F} 3$ reactor building, respectively, at the time of the actual $1 \mathrm{~F} 3$ explosion (68.7 hours after the earthquake), versus the timing of RPV lower head breach.

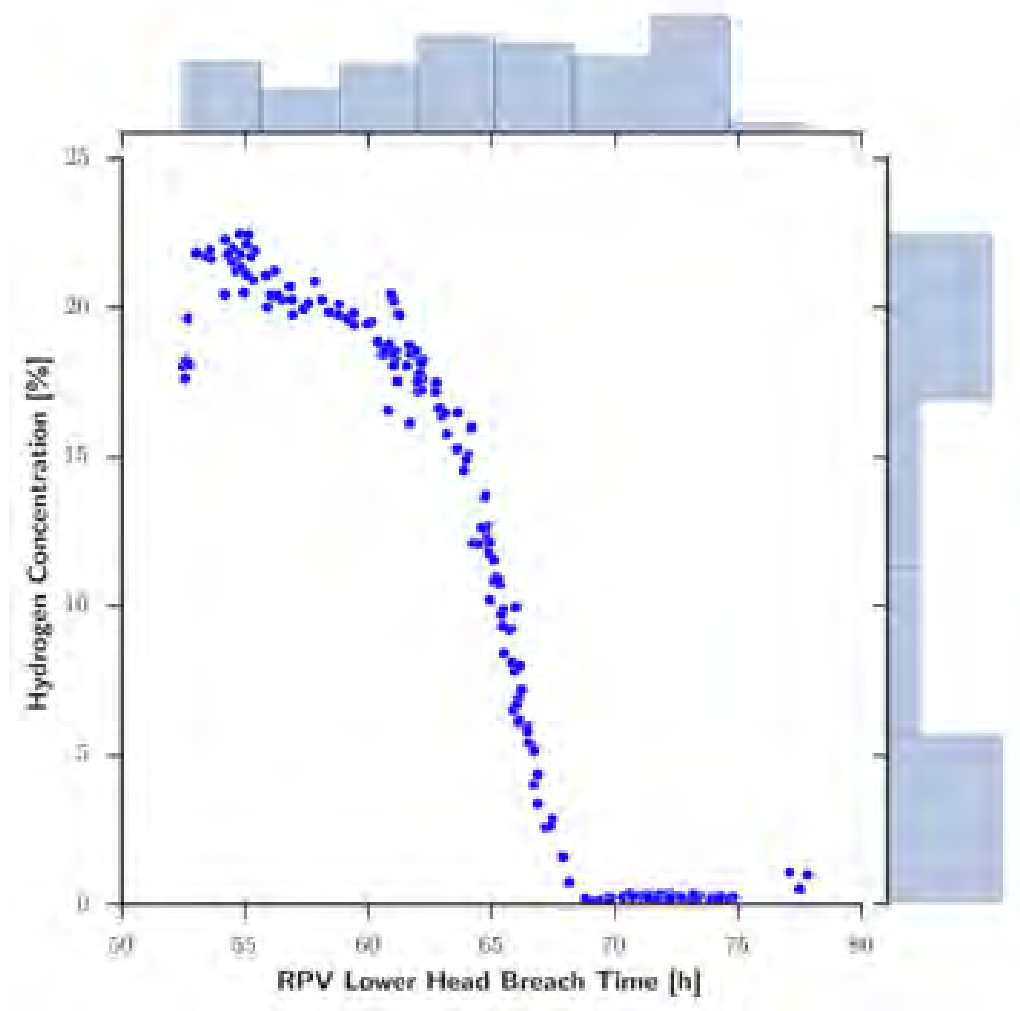

Figure 6-18. MAAP 1F3 modeling uncertainty evaluation: refueling floor hydrogen build-up at time of $1 \mathrm{~F} 3$ reactor building explosion. (Courtesy of EPRI [60])

These results illustrate that for simulations predicting RPV lower head breach occurs after $\sim 65$ hours, there is limited potential for flammable conditions to develop on either the $1 \mathrm{~F} 3$ refueling or $4^{\text {th }}$ floors. That is, MAAP5 simulations of scenarios with in-vessel retention, at least up to the point of the actual 1F3 explosion, do not support the necessary conditions for combustion. This is due to relatively low amounts of 


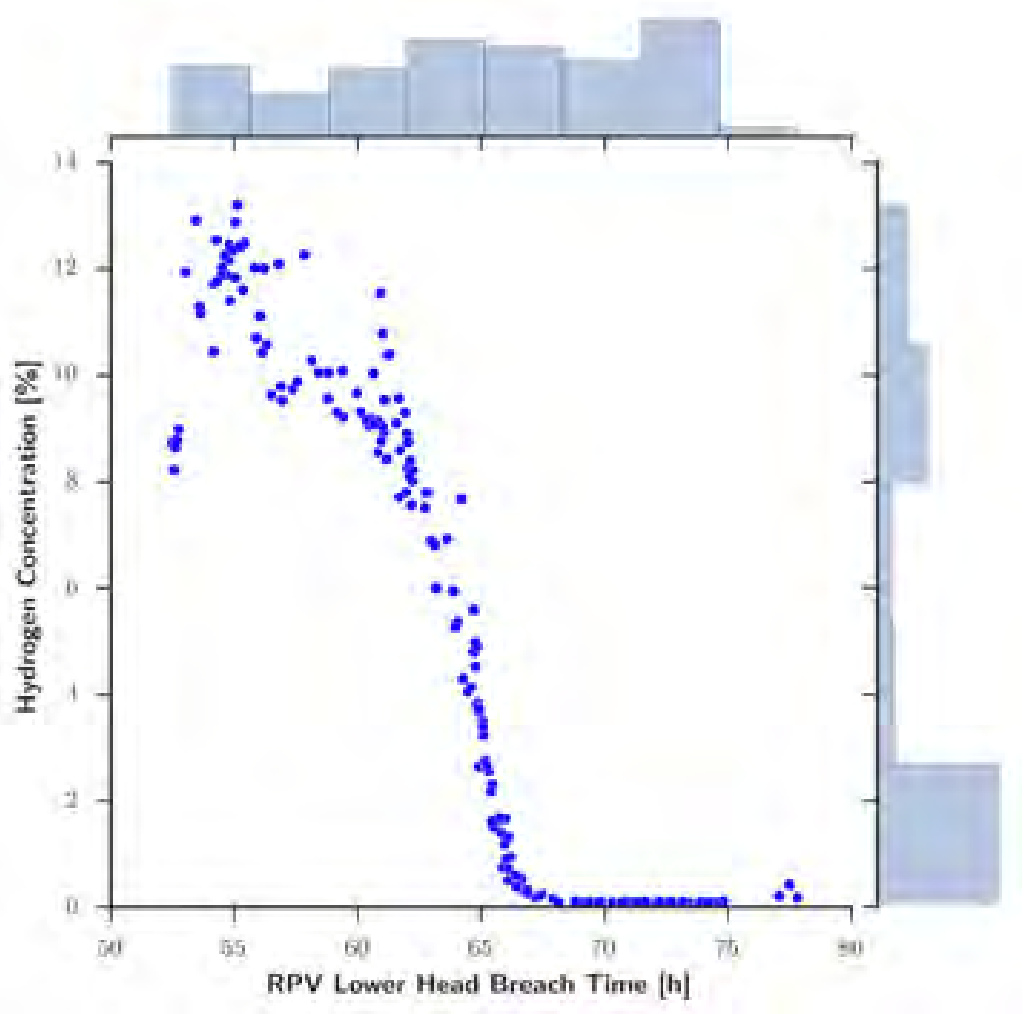

Figure 6-19. MAAP 1F3 modeling uncertainty evaluation: fourth floor hydrogen build-up at time of 1F3 reactor building explosion. (Courtesy of EPRI [60])

in-core hydrogen generation being predicted. By contrast, MELCOR simulations can evolve enough hydrogen to support conditions for flammable gas combustion in the reactor building.[97]

From the observed explosions, a rough approximation or 'ballpark estimate' was obtained for the total amount of $\mathrm{H}_{2}$ that must be generated in $1 \mathrm{~F} 3$ to support its own explosions and an explosion at 1F4.[202] This estimate provides a constraint on the timing of vessel failure that must be predicted by MAAP5 and MELCOR calculations. Thus, this rough estimate provides additional insights on vessel failure time by making reasonable (but highly uncertain) assumptions on the hydrogen concentrations at the time of the $1 \mathrm{~F} 3$ and 1F4 explosions. It was also estimated that a venting time of slightly more than an hour is sufficient to transfer the necessary amount of hydrogen from 1F3 to 1F4.[202] TEPCO considers that either the first venting (which occurred from 9:10 am to 11:00 am on March 13, 2011, more than 24 hours prior to $1 \mathrm{~F} 3$ explosion) or the second venting (from $12: 30 \mathrm{pm}$ to $2: 10 \mathrm{pm}$ on the same day) was responsible for transferring hydrogen gas from $1 \mathrm{~F} 3$ to $1 \mathrm{~F} 4$.[203] Based on $1 \mathrm{~F} 3$ drywell and wetwell pressure data, it was concluded in 2015 that the subsequent $\left(3^{\mathrm{rd}}, 4^{\text {th }}\right.$, and $\left.5^{\text {th }}\right)$ PCV depressurizations in $1 \mathrm{~F} 3$ were not due to venting, but rather due to drywell leakages.[226]

Based on the magnitude of explosions at 1F3 and 1F4, a ballpark estimate of the necessary amount of $\mathrm{H}_{2}$ required in each explosion was estimated by assuming plausible $\mathrm{H}_{2}$ concentrations at the time the explosions occurred. Figure 6-20 depicts the process, and Table 6-3 lists the ballpark numbers and associated assumptions of $\mathrm{H}_{2}$ concentrations used to obtain these estimates. Also, the ballpark estimate of the necessary amount of $\mathrm{H}_{2}$ that must be vented to the environment via the common vent stack and the neces- 
sary amount that must be leaked from $1 \mathrm{~F} 3$ to $1 \mathrm{~F} 4$ were obtained. The transfer of $\mathrm{H}_{2}$ from $1 \mathrm{~F} 3$ to $1 \mathrm{~F} 4$ during venting is assumed to be subject to an updated value of $35 \%$ leakage of the vented gas to $1 \mathrm{~F} 4$ and a $65 \%$ discharge to the environment.[203] The final number in Table 6-3 is the total amount of $\mathrm{H}_{2}$ that must be generated in-vessel and ex-vessel. This number is then subtracted by the largest typical amount of in-vessel $\mathrm{H}_{2}$ generation calculated by MAAP5 $(550 \mathrm{~kg})$ and MELCOR $(2000 \mathrm{~kg})$. $[98,202]$ The resulting number is the required ex-vessel $\mathrm{H}_{2}$ generation whose typical rate can be assumed based on code calculation results. From these values, the time required to produce the ex-vessel $\mathrm{H}_{2}$ can be determined. This required time is then subtracted from the 1F3 explosion time of 68.3 hours.[98] The result is the latest time required for vessel failure. The time required for vessel failure for MAAP5 is shown in Table 6-4 and for MELCOR in Table 6-5. Because ex-vessel CO generation in terms of moles is not significant, it is ignored in this estimate.

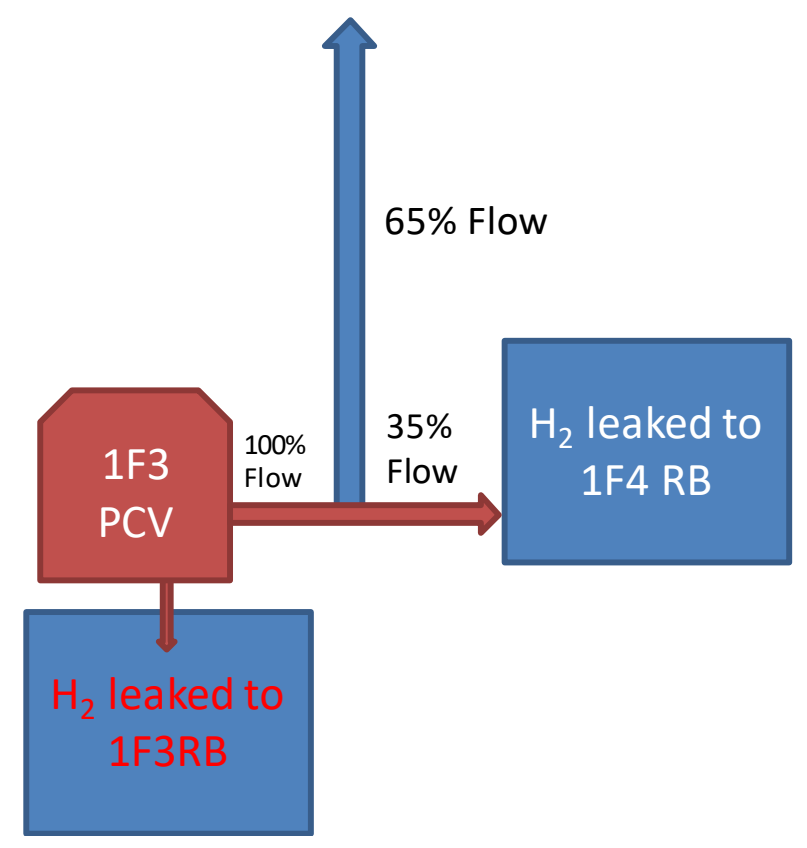

Figure 6-20. Process used to obtain ballpark estimate of the latest vessel failure time. (Courtesy of FAI [202]) 
Table 6-3. Ballpark estimate of required hydrogen generation

\begin{tabular}{|l|c|l|}
\hline \multicolumn{1}{|c|}{ Source of $\mathbf{H}_{2}$} & $\begin{array}{c}\text { Amount of } \mathbf{H}_{2}(\mathbf{k g}) \text { based on } \\
\text { assumed } \mathbf{H}_{\mathbf{2}} \%\end{array}$ & \multicolumn{1}{c|}{$\begin{array}{c}\text { Assumed } \mathrm{H}_{2} \text { Concentrations\% at time of } \\
\text { Explosion }\end{array}$} \\
\hline $\mathrm{H}_{2}$ in 1F3 RB & 370 & $\sim 20 \% \mathrm{H}_{2}$ in $5 \mathrm{~F}, 15 \% \mathrm{H}_{2}$ in $4 \mathrm{~F}$ \\
\hline $\mathrm{H}_{2}$ in 1F4 RB & 370 & $\sim 15 \% \mathrm{H}_{2}$ in $5 \mathrm{~F}, 4 \mathrm{~F}, 3 \mathrm{~F}$ \\
\hline $\mathrm{H}_{2}$ in 1F3 PCV & 640 & 5 bars, $\sim 30 \% \mathrm{H}_{2}$ in drywell, $\sim 40 \% \mathrm{H}_{2}$ in wetwell \\
\hline $\begin{array}{l}\mathrm{H}_{2} \text { vented through } \\
1 \mathrm{~F} 3-1 \mathrm{~F} 4 \text { common stack }\end{array}$ & $\begin{array}{l}(65 / 35) \times \mathrm{H}_{2} \text { leaked to } 1 \mathrm{~F} 4 \mathrm{RB} \\
=(65 / 35) \times 370=687 \mathrm{~kg}\end{array}$ & $\begin{array}{l}35 \% \text { of vent flow from 1F3 leaked to } 1 \mathrm{~F} 4 \mathrm{RB} \\
65 \% \text { of vent flow to environment }[203]\end{array}$ \\
\hline $\begin{array}{l}\text { Total } \mathrm{H}_{2} \text { leaked and } \\
\text { vented }\end{array}$ & $370+370+687=1427 \mathrm{~kg}$ & \\
\hline $\begin{array}{l}\text { Total } \mathrm{H}_{2} \text { that must be } \\
\text { generated in-vessel and } \\
\text { ex-vessel }\end{array}$ & $1427+640=2067 \mathrm{~kg}$ & \\
\hline
\end{tabular}

Table 6-4. Ballpark estimate of required latest vessel failure time for MAAP5 analysis of 1F3

\begin{tabular}{|l|l|}
\hline \multicolumn{1}{|c|}{ In-vessel $\mathbf{H}_{2}$ generation } & \multicolumn{1}{c|}{$\mathbf{5 5 0} \mathbf{~ k g}$ (MAAP5.04) [202] } \\
\hline Required ex-vessel $\mathrm{H}_{2}$ generation mass & $2067-550=1517 \mathrm{~kg}$ \\
\hline Ex-vessel $\mathrm{H}_{2}$ generation rate & $100 \mathrm{~kg} / \mathrm{hr}[98]$ \\
\hline Time required for ex-vessel generation to generate $1517 \mathrm{~kg} \mathrm{H}$ & $1517 \mathrm{~kg} / 100 \mathrm{~kg} / \mathrm{hr}=15.2 \mathrm{hr}$ \\
\hline Required latest vessel failure time & $=$ Time of $1 \mathrm{~F} 3 \mathrm{explosion}-$ required ex-vessel time \\
& $=68.3 \mathrm{hr}-15.2 \mathrm{hr}$ \\
& $=53.1 \mathrm{hr}$ from accident initiation time \\
& $=3 / 13 / 2011,8: 06 \mathrm{pm}$ \\
\hline
\end{tabular}

Table 6-5. Ballpark estimate of required latest vessel failure time for MELCOR analysis of 1F3

\begin{tabular}{|l|l|}
\hline \multicolumn{1}{|c|}{ In-vessel $\mathbf{H}_{2}$ generation } & \multicolumn{1}{c|}{ 2000 kg MELCOR [98] } \\
\hline Required ex-vessel $\mathrm{H}_{2}$ generation mass & $2067-2000=67 \mathrm{~kg}$ \\
\hline Ex-vessel $\mathrm{H}_{2}$ generation rate & $42 \mathrm{~kg} / \mathrm{hr}[98]$ \\
\hline Time required for ex-vessel generation to generate $67 \mathrm{~kg} \mathrm{H} \mathrm{H}_{2}$ & $=67 \mathrm{~kg} / 42 \mathrm{~kg} / \mathrm{hr}=1.6 \mathrm{hr}$ \\
\hline Latest vessel failure time & $=$ Time of $1 \mathrm{~F} 3 \mathrm{explosion}-$ required ex-vessel time \\
& $=68.3 \mathrm{hr}-1.6 \mathrm{hr}$ \\
& $=66.7 \mathrm{hr}$ from accident initiation time \\
& $=3 / 14 / 2011,9: 42 \mathrm{am}$ \\
\hline
\end{tabular}

In summary, the expert panel formulated several recommendations for this area.

\section{Area 4 Recommendation 1:}

To date, the thermal hydraulic and core nodalizations of the reactor pressure vessel in both MAAP and MELCOR have been shown to well represent the physics within the core. However, there are still uncertainties in hydrogen generation driven by modeling of core relocation behavior and debris bed geometry in partially mitigated and unmitigated severe accidents. It is currently unclear if most hydrogen generation in the Fukushima units occurred in-vessel or ex-vessel, with both MAAP and MELCOR indicating different answers. The differences in the two codes in modeling core debris behavior inside the RPV can have significant downstream effects on eventual MCCI 
and ex-vessel non-condensible gas generation. To address these important gaps in severe accident progression, the expert panel recommends that evaluations of combustible gas generation differ-

ences resulting from in-core relocation and debris bed morphology be continued with the goal of reducing uncertainties.

There are also uncertainties with respect to hydrogen migration paths from the PCV to various floors of the $\mathrm{RB}$ and ignition sources or the mechanism required to cause ignition within the $\mathrm{RB}$ during such an extended Station Blackout (SBO). Two recommendations have been developed to gain insights related to this uncertainty.

\section{Area 4 Recommendation 2:}

Better knowledge on hydrogen migration paths through degraded seals and penetrations from the PCV to the RB is desirable. The expert panel should continue to review available information for insights.

\section{Area 4 Recommendation 3:}

There is little knowledge about ignition sources or the mechanisms that lead to ignition during such an extended SBO for all the explosions at Daiichi; the expert panel should continue to review available information for insights.

\subsection{Suggestions for Additional Information}

As discussed above, available information has already provided many important insights related to accident management. However, as indicated in Tables 6-1 and 6-2, there are still information needs that have not yet been met in this area. Information is needed to evaluate the contribution of gases generated from MCCI to the observed explosions. This question is, in turn, related to the extent of MCCI following RPV failure as well as the point at which the core debris is quenched and rendered coolable (see Section 5). Based on insights obtained from evaluations of current information, one suggestion is offered at this time:

\section{Area 4 Suggestion:}

Continue to obtain visual information, radiation surveys, and isotopic evaluations to ascertain the source (e.g., in-vessel, ex-vessel, or both) of combustible gas generation within the affected units.

As D\&D activities progress, it is anticipated that planned examinations by TEPCO Holdings will provide these insights. 
ANL-18/24 


\section{AREA 5 - OPERATIONS AND MAINTENANCE - PLANT INSTRUMENTATION}

Data from instrumentation within the RB, PCV, and RPV provided critical information regarding the accident progression in each of the affected units. As observed in [6], instrumentation data, in combination with examination information and analyses, were essential for unraveling the events that occurred during the TMI-2 accident. This section summarizes results from U.S. expert evaluations of TEPCO data from Fukushima Daiichi Units 1 through $3(1 \mathrm{~F} 1,1 \mathrm{~F} 2$, and 1F3). U.S. efforts focused on determining which instrumentation data were true, which were in error, and when instrumentation started producing erroneous data. Additional details from this effort are found in Appendix $\mathrm{H}$.

As in other sections of this report, we first begin by identifying information needs identified by U.S. experts and uses from this evaluation that impact reactor safety, plant operations and maintenance, and future D\&D activities by TEPCO Holdings (Section 7.1). Next, we present results from our evaluation of instrumentation information (Section 7.2). To provide additional insights regarding instrumentation survivability, Section 7.3 summarizes systems analysis code predictions of environmental conditions to which instrumentation systems were exposed. This is followed by a brief discussion of the insights that were obtained from these evaluations and limitations associated with these insights (Section 7.4). The section concludes with several suggestions for additional examination information that would be beneficial regarding future assessments of instrumentation survivability and recommendations for future U.S. activities for implementing insights gained from these evaluations (Section 7.5).

\subsection{Questions for Reactor Safety, Plant Operations, and D\&D}

Available information was evaluated by U.S. experts to address the following questions:

- How accurate were instrument readings which were taken during the early days of the accident at Fukushima Daiichi Nuclear Plant Units 1-3 (1F1-1F3)?

- Could the indications be validated with other data or by considering other event information?

- What visual damage has been observed in plant instrumentation systems within the RB, PCV, and RPV (e.g., the sensors, the transmitters, and the associated cabling)?

- Can validated instrumentation data be used to reduce modeling uncertainties and confirm/improve severe accident guidance and implemented accident mitigation measures?

- Can this information be used to enhance plant operations and maintenance or to improve future D\&D activities (e.g., by extending calibration intervals or environmental qualification of the instruments, by making recommendations for improvements to enhance safety, etc.)?

Answers to these questions can have significant impact on safety, operations, and 1F D\&D activities. Validated data offer the potential to reduce modeling uncertainties. However, it is essential to have confidence in the validity of the data prior to making changes in these models. Once benchmarked with validated data, the improved model can be used to confirm or enhance, if needed, specific components or systems and to improve accident managements strategies (e.g., containment venting, water addition, and combustible gas mitigation). Analyses completed with systems analyses codes containing improved models are also of interest to Japan in making D\&D decisions related to the methods for debris removal and measures needed for worker protection from damaged structures and from radiation. 


\subsection{Summary of Information}

As discussed in Section 1.3.3, U.S. experts identified information needs that could be addressed through examinations at Fukushima Daiichi. Requested information needs from the PCV that relate to instrumentation are summarized in Table 7-1. As noted in this table, some information is already available to address these information needs (see Appendix C).

Table 7-1. Area 5 information needs from the PCV

\begin{tabular}{|c|l|c|c|}
\hline Item & \multicolumn{1}{|c|}{ What/How Obtained $^{\mathbf{a}}$} & \multicolumn{1}{|c|}{ Use $^{\mathbf{b}}$} & $\begin{array}{c}\text { Data } \\
\text { Available }^{\mathbf{c}}\end{array}$ \\
\hline PC-5 & $\begin{array}{l}\text { Photos/videos of 1F1, 1F2, and 1F3 main steam lines and ADS } \\
\text { lines to end of SRV tailpipes, including instrument lines }\end{array}$ & AE, AM, DD & A \\
\hline PC-7 & $\begin{array}{l}\text { Ex-vessel inspections and operability assessments of 1F1, 1F2, } \\
\text { and 1F3 in-vessel sensors and sensor support structures }\end{array}$ & AE, AM, DD & A \\
\hline PC-8 & $\begin{array}{l}\text { Examinations and operability assessments of 1F1, 1F2, and 1F3 } \\
\text { ex-vessel sensors and sensor support structure }\end{array}$ & AE, AM, DD & A \\
\hline
\end{tabular}

a. See list of acronyms.

b. Use: AE - Accident evaluation (code modeling updates), AM- Accident management and prevention, DD - Decontamination and Decommissioning, and PM - Plant maintenance (see Appendix C for more information).

c. Some information available [Green]; NA: no information available [Orange].

d. Inspections and evaluations [e.g., continuity checks, calibration evaluations, etc.) of sensors [dP cells, water level gauges, TIPs, TCs, CAMs, etc.] and sensor support structures, cables, removed TIPs, etc.; Requires knowledge of sensor operating envelop.

\subsubsection{Instrumentation Characteristics and Location}

U.S. evaluations focused on readings from instrumentation listed in Table 7-2. Using information from TEPCO Holdings and knowledge about instrumentation installed at similar BWRs in a U.S. plant, the Browns Ferry Nuclear Plant (BFN), characteristics of this instrumentation and locations of key components of the instrumentation system are also provided in this table.

Survivability evaluations must consider all components within the instrumentation system. For example, water level instruments evaluate difference in pressure head between RPV and a reference leg within the PCV (see Figure 7-1). Piping from reference leg tap and variable leg tap comes to panels with the transmitter (meter) at locations in the reactor building shown in Table 7-2. Then, cable takes signals to the control room. The positions of interest for evaluating the performance of this instrument include the pressure and temperature within the containment near the RPV fuel zone and at the transmitter location. 
Table 7-2. Instrumentation considered in U.S. evaluations [204,205]

\begin{tabular}{|c|c|c|c|c|c|}
\hline Instrument $\mathrm{t}^{\mathrm{a}}$ & Unit & $\begin{array}{c}\text { Qualification } \\
\text { Envelop }\end{array}$ & $\begin{array}{c}\text { Manufacturer / } \\
\text { Model }\end{array}$ & Accuracy & Location \\
\hline \multirow[t]{5}{*}{$\begin{array}{c}\text { RPV water } \\
\text { level }\end{array}$} & 1 & $\begin{array}{l}\sim 3000 \text { to } \\
5000 \mathrm{~mm} \\
0=\mathrm{TAF}\end{array}$ & Hitachi EDR & $\begin{array}{c}\sim 1.5 \% \\
(2 \sigma)\end{array}$ & $\begin{array}{l}\text { Reference leg tap is in PCV at elevation near RPV fuel zone. } \\
\text { For BFN, transmitter panel is at elevation } 565\left(1^{\text {st }} \text { floor }\right. \\
\text { elevation-grade level) near Drywell. See Appendix H; } \\
\text { Drawing 3-RB-565 (Panel } 25-229 \text { or } 25-51) \text {. }\end{array}$ \\
\hline & 2 & $\begin{array}{l}-3700 \text { to } \\
\sim 5000 \mathrm{~mm} \\
0=\mathrm{TAF}\end{array}$ & $\begin{array}{c}\text { Toshiba/ } \\
\text { TOSMAC AP }\end{array}$ & & $\begin{array}{l}\text { Reference leg tap is in PCV at elevation near RPV fuel zone. } \\
\text { For BFN, transmitter panel is at elevation } 565 \text { ( } 1^{\text {st }} \text { Floor) near } \\
\text { drywell. See Appendix H; Drawing 3-RB-565 (Panel 25-229 } \\
\text { or 26-52). }\end{array}$ \\
\hline & $\begin{array}{l}3 \text { Wide } \\
\text { Range }\end{array}$ & $\begin{array}{c}-4000 \text { to } \\
\sim 1500 \mathrm{~mm} \\
0=\mathrm{TAF}+4170 \\
\mathrm{~mm}\end{array}$ & & & $\begin{array}{l}\text { Reference leg tap is in PCV at elevation near RPV fuel zone. } \\
\text { For BFN elevation } 593 \text { (2 } 2^{\text {nd }} \text { floor) near drywell. See } \\
\text { Appendix H; Drawing 3-RB-593 (Panel 25-5 and 25-6). }\end{array}$ \\
\hline & $\begin{array}{c}3 \\
\text { Narrow } \\
\text { Range }\end{array}$ & $\begin{array}{l}0 \text { to } \sim 1500 \\
0=\mathrm{TAF}+ \\
4170 \mathrm{~mm}\end{array}$ & & & $\begin{array}{l}\text { Reference leg tap is in PCV at elevation near RPV fuel zone. } \\
\text { For BFN elevation } 593 \text { near drywell. See Appendix H; Panel } \\
25-5 \text { and } 25-6 \text { on Drawing 3-RB-593 }\end{array}$ \\
\hline & $\begin{array}{l}3 \text { Fuel } \\
\text { Zone }\end{array}$ & $\begin{array}{l}-3700 \text { to } \\
\sim 5000 \mathrm{~mm} \\
0=\mathrm{TAF}\end{array}$ & & & $\begin{array}{l}\text { Reference leg tap is in PCV at elevation near RPV fuel zone. } \\
\text { For BFN elevation } 565\left(1^{\text {st }} \text { floor elevation-grade level) near }\right. \\
\text { DW. See Appendix H; Drawing 3-RB-565 (Panel 25-51 or } \\
25-52)\end{array}$ \\
\hline \multirow{2}{*}{$\begin{array}{c}\text { RPV } \\
\text { pressure }\end{array}$} & 1 & \multirow{2}{*}{$\begin{array}{l}0 \text { to } \sim 10 \\
\mathrm{MPa}_{\mathrm{abs}}\end{array}$} & Hitachi EDR & \multirow[t]{2}{*}{$\sim 0.5 \%(\sigma)$} & \multirow{2}{*}{$\begin{array}{l}\text { For BFN elevation } 593 \text { near reactor building (See Appendix } \\
\text { H; Panel 25-5 and 25- 6). Tap is from reference leg RPV } \\
\text { water level tap. }\end{array}$} \\
\hline & 2 and 3 & & $\begin{array}{c}\text { Toshiba/ } \\
\text { TOSMAC AP }\end{array}$ & & \\
\hline \begin{tabular}{c|} 
RPV Metal \\
Temperature
\end{tabular} & & 0 to $\sim 300{ }^{\circ} \mathrm{C}$ & $\begin{array}{c}\text { Sukegawa / } \\
\text { Type T }\end{array}$ & $0.75 \%$ & See Figure 7-2. \\
\hline $\begin{array}{l}\text { DW and SC } \\
\text { Temperature }\end{array}$ & $\begin{array}{l}1,2, \\
\text { and } 3\end{array}$ & & TBD & & See Figure 7-3. \\
\hline \multirow{2}{*}{$\begin{array}{c}\text { DW and SC } \\
\text { Pressure }\end{array}$} & 1 & & Hitachi EDR & \multirow[t]{2}{*}{$1.5 \%(2 \sigma)$} & \multirow{2}{*}{$\begin{array}{l}\text { For BFN, DW transmitter panel is at elevation 593' (second } \\
\text { floor) at panel 25-5 and 25-6. See Appendix H; BFN Drawing } \\
\text { 3-RB-593. } \\
\text { For BFN SC pressure transmitter located EL } 519 \text { panel 25-34 } \\
\text { q-R20. See BFN 'Torus Pressure Transmitter. }\end{array}$} \\
\hline & 2 and 3 & & $\begin{array}{c}\text { Toshiba/ } \\
\text { TOSMAC AP }\end{array}$ & & \\
\hline \multirow[t]{3}{*}{ DW CAMS } & 1 & \multirow{3}{*}{$\begin{array}{c}10^{-2} \text { to } \\
\sim 10^{-5} \mathrm{mSv} / \mathrm{h}\end{array}$} & Toshiba & $10 \%$ & \multirow[t]{3}{*}{ Located el 560' (top of torus) R19, R-line Bay 13} \\
\hline & 2 & & & $20 \%$ & \\
\hline & 3 & & GEH & $20 \%$ & \\
\hline SC CAMS & $\begin{array}{c}1,2, \\
\text { and } 3\end{array}$ & & & & $\begin{array}{l}\text { For BFN, (2) located at top of torus elevation 557' 6" (grade } \\
\text { level is } 565^{\prime} \text { ) azimuth } 45 . \text { Second one is same elevation } \\
\text { azimuth } 270 \text { degrees. }\end{array}$ \\
\hline
\end{tabular}

a. See list of acronyms.

It should be noted that temperature values reported by TEPCO [206] do not correspond to specific measuring points shown in [207]. TEPCO engineers cite 'representative' values based on engineering judgment of thermocouple reliability.[205] Because the response from some selected 'representative' thermocouple degraded over time, reported values are the peak conditions for locations shown in Figure 7-2. In general, RPV temperatures were reported for values up to $400{ }^{\circ} \mathrm{C}$, the maximum value on temperature scales in most locations. ${ }^{*}$ However, Type $\mathrm{T}$ thermocouples were only qualified up to $300^{\circ} \mathrm{C}$. Locations for the SC and PCV reported temperatures are depicted in Figure 7-3.

* Higher values were reported for some 1F3 locations. 


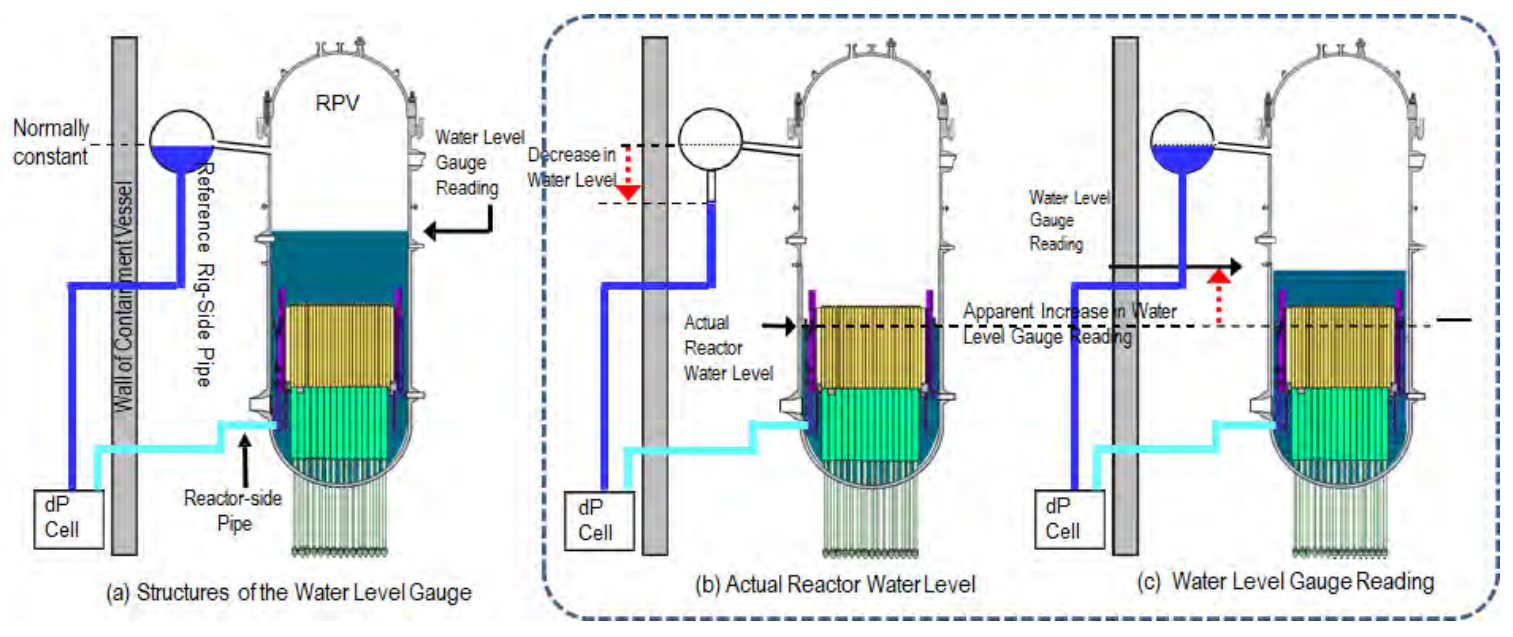

Figure 7-1. Water level instrument diagram. (Courtesy of TEPCO Holdings [42])

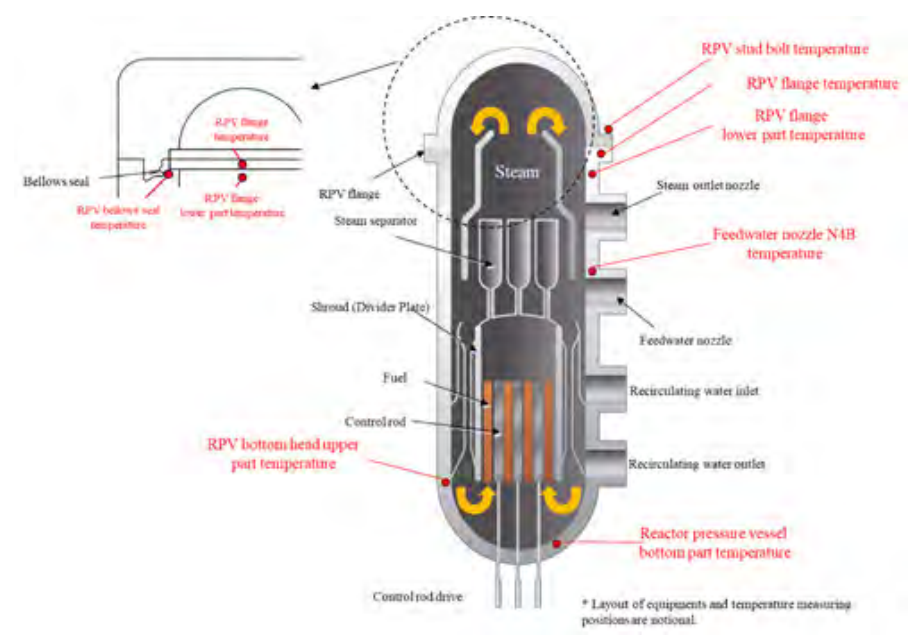

Figure 7-2. Approximate location for reported RPV vessel temperatures. (Courtesy of TEPCO Holdings [208])

\subsubsection{Evaluation Approach}

Different sensors were available for different times after the tsunami waves inundated $1 \mathrm{~F} 1,1 \mathrm{~F} 2$, and 1F3. Up until power was lost, there was no question about any data provided by the instrumentation. Degradation to components within each unit occurred at different times. To validate instrument readings, U.S. efforts by the BWROG adhered to the following principles [24]:

- Confirm each fact with two or three "witnesses" (independent sources)

- For each action, there should be a reaction (look for feedback)

- Trends and changes in trends may be true even when absolute values are not

- Look for physical explanations

- Keep in mind the sequence of events 


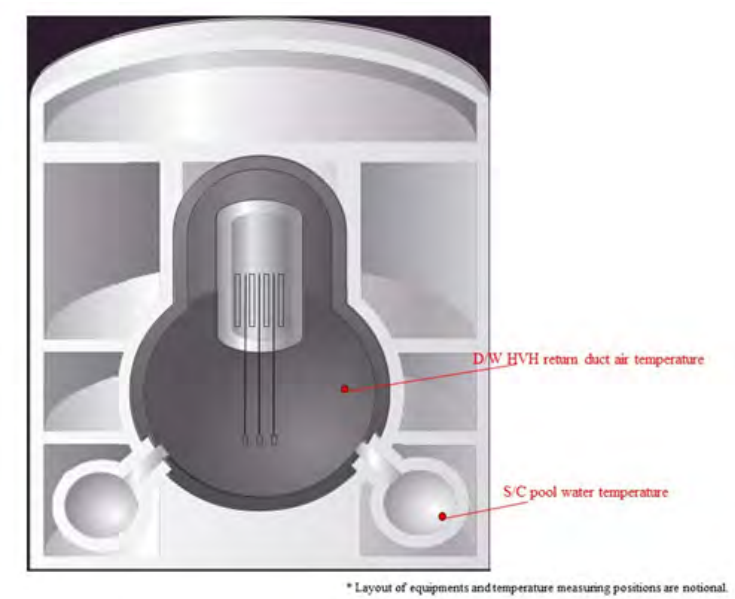

Figure 7-3. Approximate location for reported PCV and SC temperatures. (Courtesy of TEPCO Holdings [208])

These principles were developed by and are being used by the BWROG as part of their efforts to update Technical Support Guidance (TSG) and SAMGs. These principles can be used to assess the validity of Fukushima 1F1, 1F2, and 1F3 data. In addition, these principles can be used to detect when instrumentation started reporting erroneous data and the cause for the erroneous data. The PWROG SAGs also recommend checks to provide confidence in readings provided by instrumentation.

\subsubsection{F1 Instrumentation}

Evaluations focus on reviewing 1F1 data for water level, pressure, and temperature data. Staff observations, such as the timing of the hydrogen explosion at 1F1 (15:36 on March 12,2011), high radiation levels (21:50 on March 12, 2011) in the reactor building, and steam (03:45 March 12, 2011) within the reactor building, were also used in developing insights regarding $1 \mathrm{~F} 1$ instrumentation data.

\subsubsection{Instrumentation Data}

Figures 7-4 through 7-7 present data focused upon in $1 \mathrm{~F} 1$ evaluations.

\subsubsection{Instrumentation Performance}

\section{Before Tsunami Inundation - RPV pressure and water level}

Until the tsunami inundated $1 \mathrm{~F} 1$, there was no reason to question RPV and water level data. RPV pressure remained high, cycling between the SRV lift and reseat pressures. Containment pressures and temperatures also precluded flashing of RPV water level reference legs. When the tsunami struck, AC and DC power was lost. The last RPV water level reading was $+0.90 \mathrm{~m}$ (+35.5”) at 15:36 on March 11, 2011.[209]

* Plots are based on data released by TEPCO [9] up through August 31, 2011. The data do not include corrections issued by TEPCO after this date. However, we believe that insights obtained from the data are still valid. 


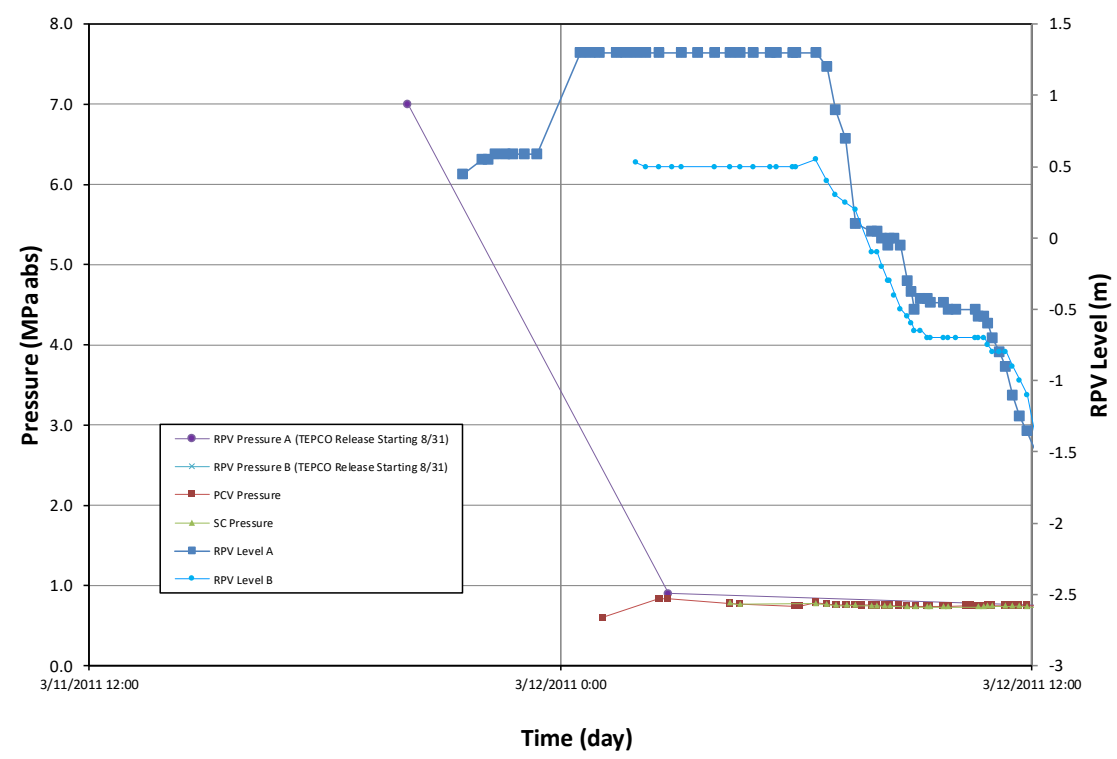

Figure 7-4. Available 1F1 pressure and water level data until noon on March 12, 2011. (Data courtesy of TEPCO Holdings [9])

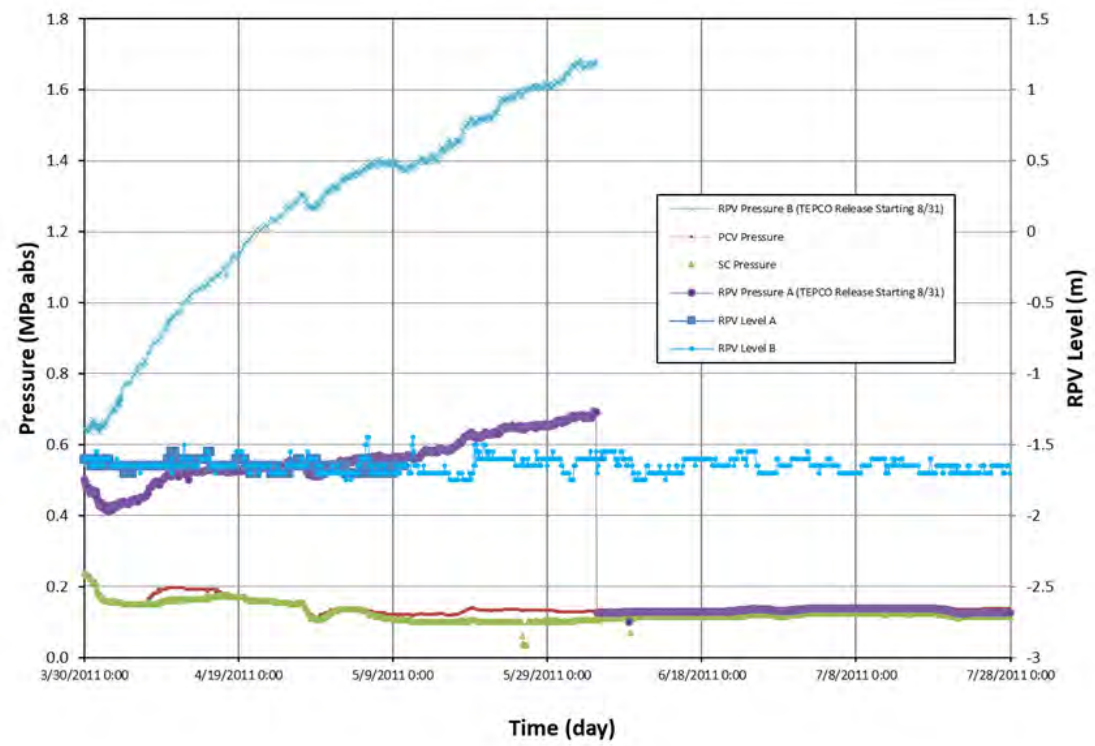

Figure 7-5. 1F1 pressure and water level data until July 28, 2011. (Data courtesy of TEPCO Holdings [9]) 


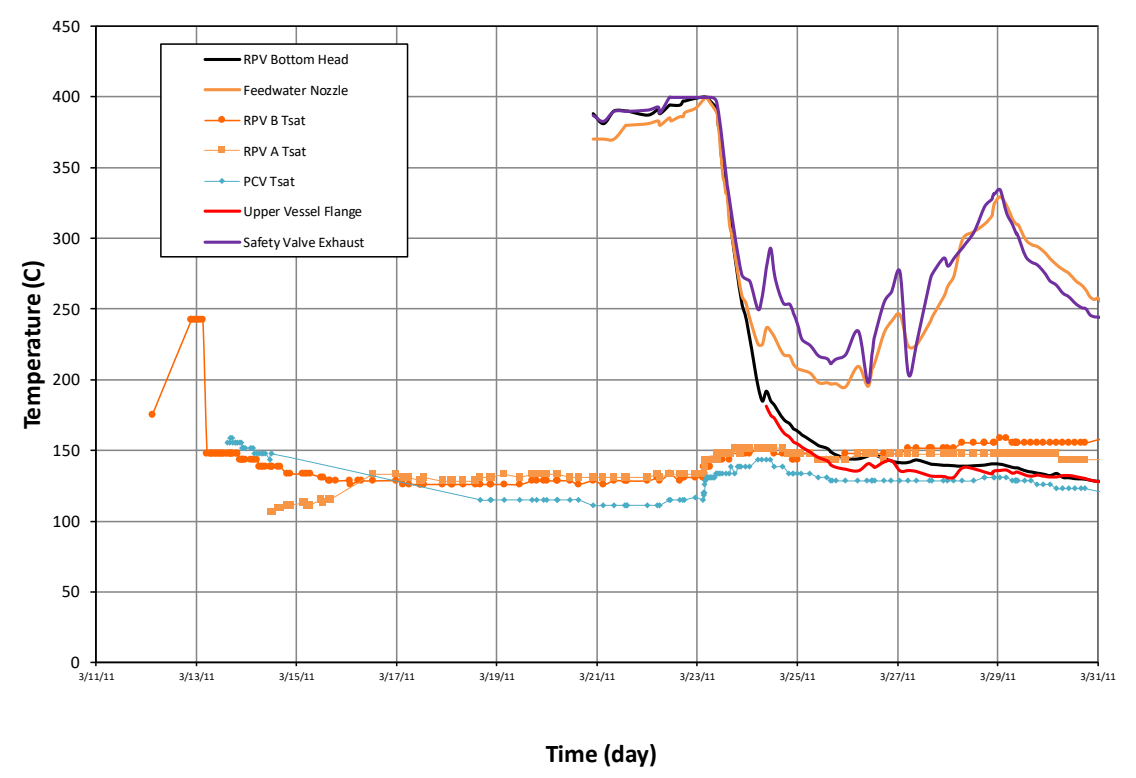

Figure 7-6. 1F1 temperature data through March 31, 2011. (Data courtesy of TEPCO Holdings [9])

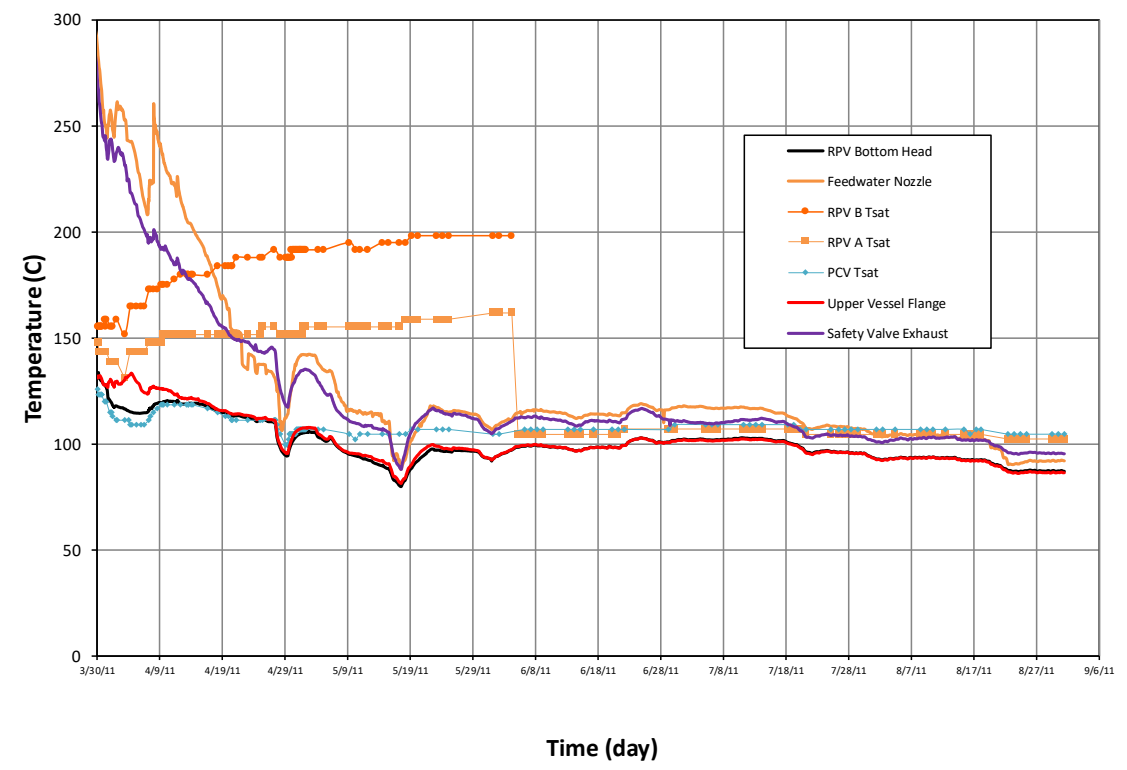

Figure 7-7. 1F1 temperature data through September 6, 2011. (Data courtesy of TEPCO Holdings [9]) 
At 16:45, 17:00 and 17:07 on March 11, 2011, readings of the wide range RPV water level were obtained when some power returned before fading permanently.[209] Using these data, it is estimated that the top of active fuel (TAF) would be reached slightly before 18:30 on March 11, 2011 (see Appendix H).

\section{After Tsunami Inundation - Pressure and Water Level and Vessel Breach Indications}

Figure 7-4 shows water level and pressure data obtained for the first 20 hours after power was restored to the water level and pressure instrumentation. At 20:07 on March 11, 2011, a value of $7 \mathrm{MPa}$ (1000 psig) was obtained for the RPV A pressure transmitter. If this value is accurate, it rules out the possibility of flashing of reference legs for RPV water level instruments before this time. The first values for the post-accident RPV water level instruments (also known as the fuel zone level instruments) were obtained at 21:30 and 22:00 on March 11, 2011.

The first available DW pressure is 0.6 MPa at 01:05 on March 12, 2011. At 02:45 on March 12, 2011, available data indicate that the DW and RPV pressures are nearly equal (within the limits of the instrumentation). ${ }^{*}$ If the DW were at saturation conditions, the DW temperature would be at $175^{\circ} \mathrm{C}\left(347{ }^{\circ} \mathrm{F}\right)$. The SC pressure became available at 04:19 on March 12, 2011. At that time, readings indicate the SC pressure is $0.79 \mathrm{MPa}-a b s$ (99.9 psig) and the DW pressure is $0.78 \mathrm{MPa}-\mathrm{abs}(98.5 \mathrm{psig})$. These values tend to validate each other. At this time, the relation of DW to SC pressure, with DW pressure being slightly below SC pressure, indicates that the energy is first being deposited in the SC. At 06:30 on March 12, 2011, the relationship switches, and the DW pressure is slightly above the SC pressure. At this time, the RPV A and B water levels also begin to lower. U.S. evaluations suggest that the simultaneous occurrence of the switch in the relationship between the DW and SC pressures and the drop in RPV water level readings could be indications of the time when RPV breach occurred. It should be acknowledged that other evaluations have drawn similar conclusions regarding the timing of vessel breach. For example, a TEPCO evaluation based upon off-site dosimetry data [42] indicates that 1F1 vessel breach occurred at 06:00 on March 12, 2011.

Although initial water level readings (starting 21:30 on March 11, 2011) are above TAF (the zero for 1F1 RPV water level instruments), they must be corrected for RPV pressure and DW temperature. For RPV pressure of 7.0 MPa-abs (1000.5 psig), the RPV A water level indication of $0.45 \mathrm{~m}$ (17.7") corrected for pressure would be $-0.37 \mathrm{~m}\left(-14.4^{\prime \prime}\right)$ if DW temperature were $57{ }^{\circ} \mathrm{C}\left(135^{\circ} \mathrm{F}\right) .^{\dagger}$ If this value were corrected for a higher DW temperature (e.g., the saturation temperature for the indicated pressure, $\sim 175^{\circ} \mathrm{C}$ $\left(350^{\circ} \mathrm{F}\right)$, the corrected water level would be well below TAF [-0.61 m (-24”)].

Available data indicate that RPV level trends are incorrect, and that water levels are below the TAF. This conclusion is supported by the fact that operators logged that access to the reactor building was restricted due to high dose rates (21:50 on March 12, 2011). The high dose rates support that the true RPV water level is well below TAF [ 1.0 m/ (40 inches) below TAF] and that the peak clad temperature has exceeded $1200{ }^{\circ} \mathrm{C}\left(2200{ }^{\circ} \mathrm{F}\right)$, the temperature where significant exothermic reactions are occurring due to oxidation of fuel cladding. Hence, it is suspected that high DW temperatures may have caused some flashing of the reference legs, resulting in their giving erroneous readings.

* Most instrument in nuclear power plants are most accurate in their normal operating range. So, the 0-10 MPa (0-1500 psig) RPV pressure instruments aren't as accurate as the DW pressure instruments, which address a 0-2 MPa (0-300 psig) range.

$\dagger \quad$ The initial temperatures report for the SC were approximately $57^{\circ} \mathrm{C}$; However, SC pool temperature data were not reported until April 2, 2011. 
The second fuel zone level indication (B) is obtained at 01:55 on March 12, 2011. It reads $0.53 \mathrm{~m}$ ( 21"), which is $\sim 0.5 \mathrm{~m}(\sim 30 ")$ below the RPV A water level fuel zone reading of $1.3 \mathrm{~m}$ (51"). It is speculated that this discrepancy is due to different amounts of water in the reference leg flashing.

It is important to note that the water level instrumentation system (e.g., transmitter, cabling, etc.) were still providing a signal. The transmitters were located in the reactor building (based on a U.S. BWR/4 housed in a Mark I containment, the $1^{\text {st }}$ and $2^{\text {nd }}$ floors in the reactor building) and subjected to high dose rates. As noted above, data at 06:30 on March 12, 2011 indicates possible RPV breach. Lower water levels readings could indicate draining or flashing of RPV variable legs until empty. Although no useful information is obtained from the RPV water level transmitters after this point in time (it is likely that the reference and variable legs evaporated), their transmitters are still working.

Figure 7-5 shows pressure data and water level data until July 18, 2011. By March 23, both the RPV A and B pressure signals were drifting high. However, data suggest that transmitters survived 12 days in a humid, hot, radiation field. Data indicate that the RPV B pressure signal drifted and failed high on June 4, 2011, 85 days after the initial events at 1F1. As noted above, operators logged that components of this system was subject to high temperatures, steam, high radiation levels, and shock waves associated with the seismic events and hydrogen explosions at the site. Additional examination information would be useful to understand why the RPV B pressure signal experienced a failure on June 4, 2011.

Figure 7-6 shows RPV metal and SRV tailpipe (safety valve exhaust pipe) temperatures through March 31, 3011. Temperatures exceeded $400{ }^{\circ} \mathrm{C}$ until on March 23 when instrumentation data came on-scale due to cooling from water that was injected into the RPV starting on March 23, 2011 (available information indicates that water was injected into the system for 5.5 hours before the temperatures dropped on-scale). The initial water is cooling very hot material and generating superheated steam. As the temperature of the steam and the hot material lower, the system cools towards the saturation temperature for the system pressure. If the system pressure is indicated by the RPV pressure, temperatures should lower to $\sim 150^{\circ} \mathrm{C}\left(302^{\circ} \mathrm{F}\right)$ for $\sim 0.55 \mathrm{MPa}(65 \mathrm{psig})$. If the PCV pressure represents the true system pressure of the $\mathrm{SC}$ and $\mathrm{DW}$, then the temperature indications should lower to $\sim 130^{\circ} \mathrm{C}\left(266^{\circ} \mathrm{F}\right)$ for $\sim 0.27 \mathrm{MPa}$ (24 psig). Temperature data for the RPV bottom head and RPV upper vessel flange indicate the DW and SC pressures are more accurate than the RPV pressure indicators by this time. Thus, temperature data tend to confirm the accuracy of DW/SC pressures as true, or closer than RPV pressures; and the DW/SC pressures tend to confirm the temperatures are reading accurately. Data in Figure 7-5 indicate that the DW and SC pressure trend together, confirming the system pressure by two independent (diverse and redundant) indications. The temperatures also provide confidence that DW and SC are still accurate.

\section{Temperature Data}

The RPV lower head and upper vessel flange temperature data also suggest that operators were able to stabilize ex-vessel core debris. Higher temperatures within the RPV, such as the safety valve exhaust and the feedwater nozzle, indicate that some core debris is still not cooled for the time period shown in Figure 7-6. The downturn on March 29, 2011 may be caused by a change in injection rate that occurred on this date. This illustrates the principle that trends may be true even when absolute values are not.

As shown in Figure 7-7, all temperature data were below saturation by August 19, 2011. By the time that water injection was switched to the core sprays in December 2011, no decrease in temperature was observed (see Appendix G). This fact is consistent with muon tomography data indicating no large amount of fuel remains in the RPV. 


\subsubsection{Summary}

Using the principles outlined in Section 7.2.2, $1 \mathrm{~F} 1$ data were evaluated to obtain insights regarding when instrumentation data are and aren't valid. Data provide insights regarding key events during accident progression, such as the timing of fuel uncovery and vessel failure. Evaluations emphasize the importance of performing real-time validation of signals obtained during an accident and the importance of using data trends, when it is known that the absolute values from instrumentation are no longer correct. Such evaluations for 1F1 indicate that RPV water levels should be corrected by March 11, 2011 and that RPV pressures were drifting high by March 23, 2011. RPV temperatures, after returning to on-scale values below $400{ }^{\circ} \mathrm{C}$, appear to be fairly accurate for months after the initial event. However, [205] indicates that 'representative' values were reported for particular locations. Hence, the survivability of particular thermocouples cannot be discerned from available data. In summary, $1 \mathrm{~F} 1$ evaluations indicate that trend data were available to provide insights regarding accident progression up to 85 days into the event and that transmitters for most sensors were still working for this period.

With respect to additional examination needs, it is suggested that additional focus be placed on understanding why the RPV B pressure transmitter failed before other transmitters.

\subsubsection{F2 Instrumentation}

Evaluations focus on reviewing $1 \mathrm{~F} 2$ data for water level, pressure, temperature, and radiation data. Staff observations, such as the timing when RCIC suction is changed from the condensate storage tank (CST) to the suppression pool (01:30 on 3/12/11), were also used in developing insights regarding the validity of data from $1 \mathrm{~F} 2$ instrumentation.

\subsubsection{Instrumentation Data}

Figures 7-8 through 7-12 present data focused upon in 1F2 evaluations.

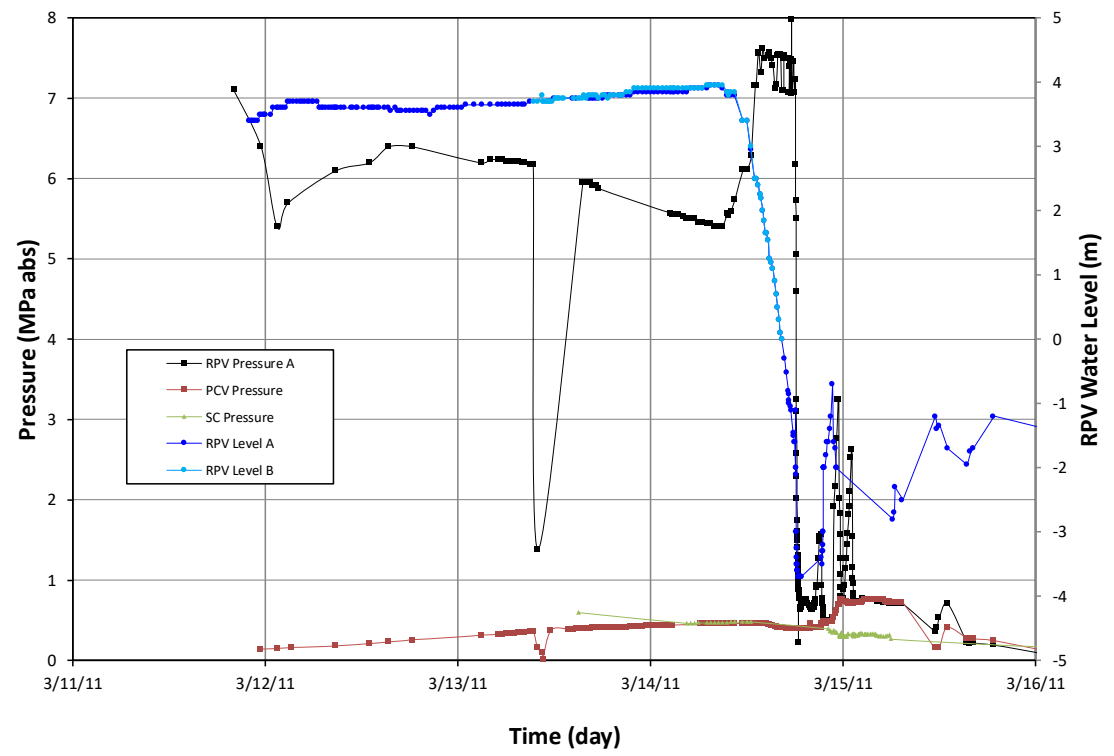

Figure 7-8. 1F2 pressure and water level data through March 16, 2011. (Data courtesy of TEPCO Holdings [9]) 


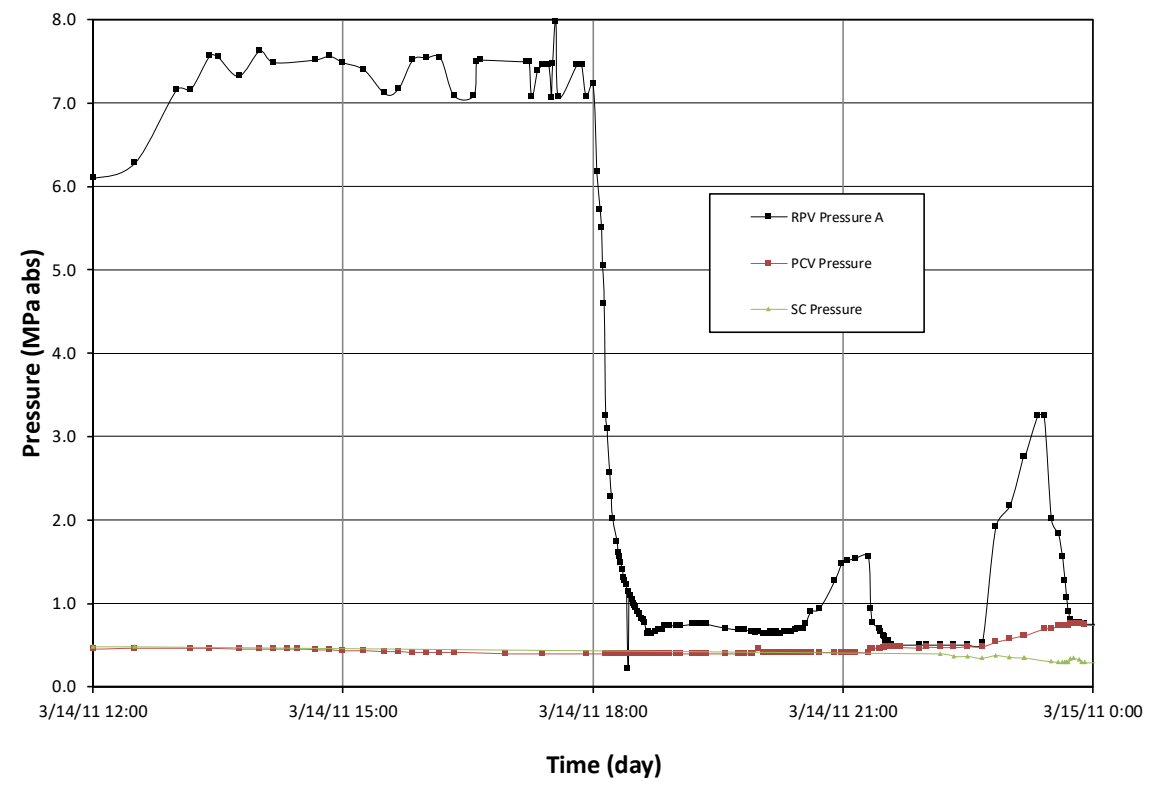

Figure 7-9. 1F2 pressure data through March 14, 2011. (Data courtesy of TEPCO Holdings [9])

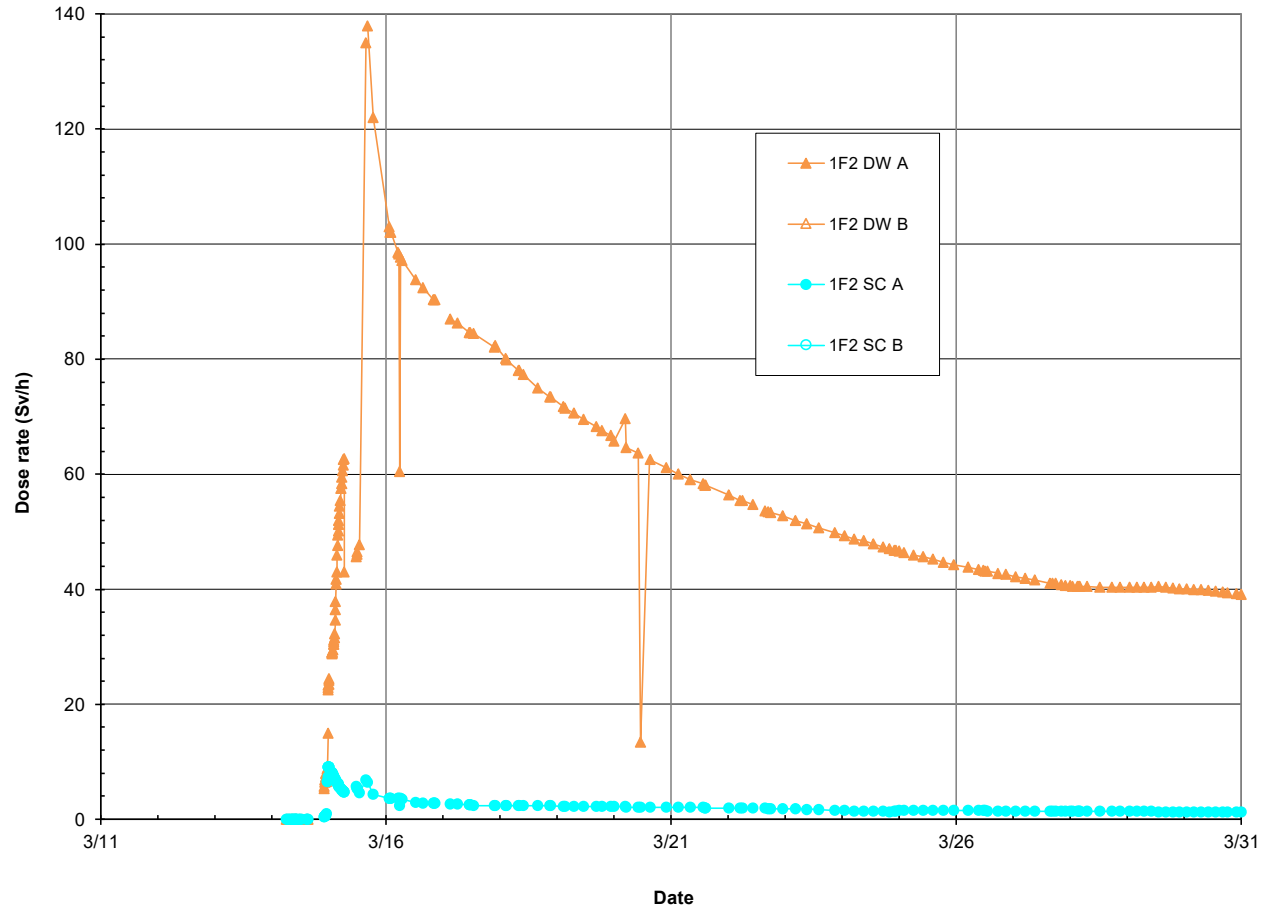

Figure 7-10. 1F2 radiation measurement data through March 31, 2011. (Data courtesy of TEPCO Holdings [9]) 


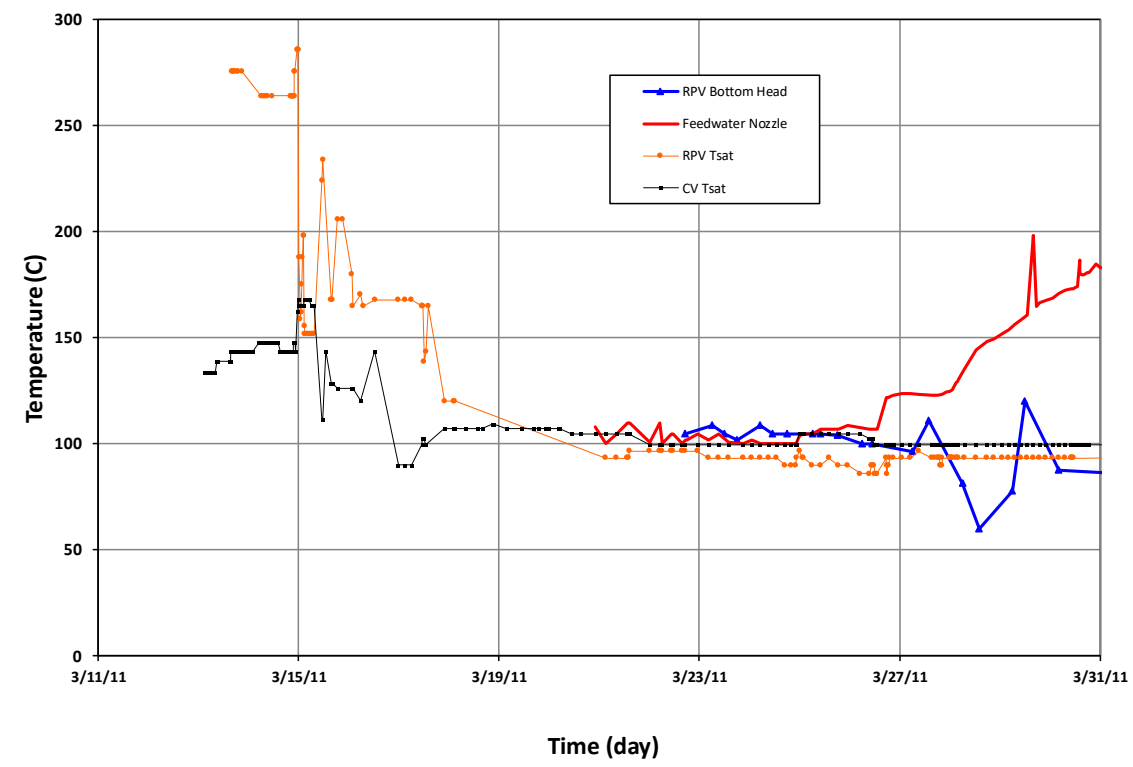

Figure 7-11. 1F2 temperature data through March 31, 2011. (Data courtesy of TEPCO Holdings [9])

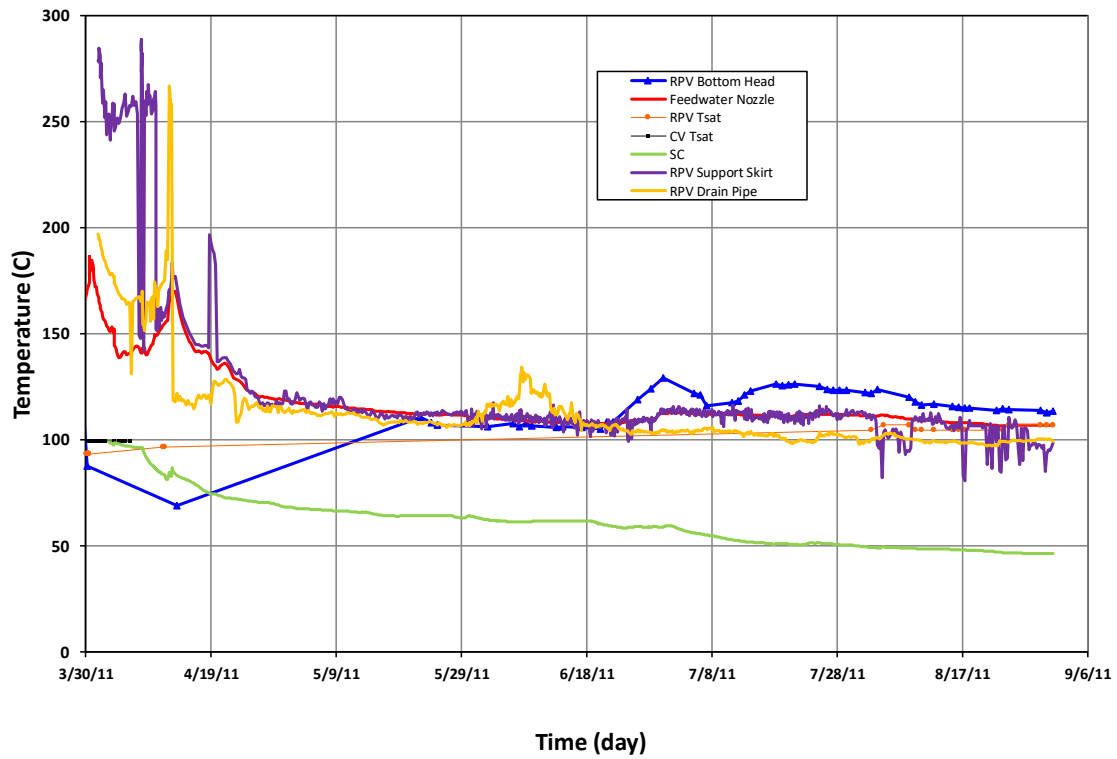

Figure 7-12. 1F2 temperatures through September 6, 2011. (Data courtesy of TEPCO Holdings [9])

\subsubsection{Instrumentation Performance}

\section{RPV Pressure}

Figure 7-8 shows the changing trend of RPV pressure when RCIC suction is changed from the CST to the suppression pool $(01: 30$ on $3 / 12 / 11)$. The pressure increases because suppression pool water is hotter than CST water and because RCIC is controlling RPV pressure during this time. Later (after 18:30 on 
March 12, 2011), RPV pressure begins lowering, possible due to the decrease in decay energy. The cause for the drop in RPV and PCV pressure at 09:33 on March 13, 2011 is not known. However, in general, the RCIC was controlling RPV pressure between 01:30 on March 12, 2011 and March 14, 2011, indicating that it was removing all the decay energy generated by the fuel. The increase in RPV pressure at 9:35 on March 14, 2011 is believed to be due to failure or significant deterioration of the performance of the RCIC.

After RCIC failed (9:35 on March 14, 2011), pressure in the RPV rose to the SRV lift setpoint [7.55 MPa-abs ( 1080.3 psig)] and cycled (13:30 on March 14, 2011). At this time, RPV pressure data can be checked for accuracy. As shown in Figure 7-9, most RPV pressure data are at or below $7.55 \mathrm{MPa}$-abs (1080.3 psig), which is consistent with INPO information for the SRV lift pressure.[210] Data readings suggest that the SRV reseat pressure is about 6.96 MPa-abs (1010 psig). With the exception of one reading of 7.98 MPa-abs (1142 psig) at 17:33 on March 14, 2011, which is suspect, the remaining readings appear to be within $0.07 \mathrm{MPa}$-abs (10 psig) of the lift pressure. RPV pressure remained high, cycling at the valve lift setpoint until an SRV is manually opened between 18:00 and 18:06 on March 14, 2011.

At 20:20 on March 14, 2011, the RPV pressure increased from 0.664 to $1.564 \mathrm{MPa}$-abs (78 to 212 psig). This rise is attributed to the SRV closing. When two other SRVs are opened between 21:18 and 21:20 on March 14, 2011, the RPV pressure begins lowering, and the RPV water level begins rising.

\section{Drywell and Suppression Chamber Pressure}

Initial data (starting at 05:00 on March 13, 2011) for SC pressure confirm the validity of DW pressure readings. SC pressure readings are slightly higher than DW pressure readings. This relationship confirms that heat was first transferred to the suppression pool. After 14:30 on March 13, 2011, the vacuum breaker equalized DW and SC pressures, within limits of the vacuum breaker opening and closing. The vacuum breaker operation should keep the drywell within the opening pressure of the vacuum breakers $[3.4 \mathrm{kPa}$ $(0.5 \mathrm{psig})]$. The $\mathrm{SC}$ pressure is about $20.7 \mathrm{kPa}$ (3 psig) above the DW pressure. This suggests the readings are accurate within approximately $[17.2 \mathrm{kPa}(2.5 \mathrm{psig})]$.

Comparisons between the suppression pool temperature data and the saturation temperature data for the DW and SC can be used to confirm the accuracy of these instruments. After restoring power to the recorders and transmitters (07:00 on March 14, 2011), operators logged that the suppression pool temperature was $146^{\circ} \mathrm{C}\left(295^{\circ} \mathrm{F}\right)$, the DW pressure was $0.455 \mathrm{MPa}$-abs $(51.3 \mathrm{psig})$, and the SC pressure was $0.473 \mathrm{MPa}-a b s(53.9 \mathrm{psig})$. The saturation temperatures for measured pressures are $148.3^{\circ} \mathrm{C}\left(299.0^{\circ} \mathrm{F}\right)$ and $149.8^{\circ} \mathrm{C}\left(301.6^{\circ} \mathrm{F}\right)$ respectively. At $12: 30$ on March 14,2011 , the SC pool was recorded at $149{ }^{\circ} \mathrm{C}$ $\left(301^{\circ} \mathrm{F}\right)$, the DW pressure was $0.465 \mathrm{MPa}$-abs $(52.7 \mathrm{psig})$ with a saturation temperature of $149.1{ }^{\circ} \mathrm{C}$ $\left(300.4^{\circ} \mathrm{F}\right)$, and the suppression chamber pressure was $0.485 \mathrm{MPa}-\mathrm{abs}(55.7 \mathrm{psig})$ with a saturation temperature of $150.7^{\circ} \mathrm{C}\left(303.4^{\circ} \mathrm{F}\right)$. The close agreement between these indications (within two degrees) confirms the accuracy of all three instruments at this time. Under normal conditions the saturation temperatures of the DW and SC chamber would not be near the SC pool temperature. It is only true at this time because the pool temperature had risen, and the pool had stratified and quit condensing RCIC discharge steam. Steam had made its way into the drywell so that the entire containment was at saturated conditions. This is an example of the BWROG approach described in Section 7.2.2. Namely, updated TSG developed by the BWROG is emphasizing the approach of validating readings from different instruments prior to returning it to service during a severe accident, e.g., testing instrument output against other diverse and redundant indications. 
DW pressure begins lowering at the same time the RPV pressure reaches the SRV lift setpoint pressure ( 13:30 on March 14, 2011). When SRVs begin cycling, the DW and SC pressures begin lowering. At this time, the containment was not venting and it is suspected that the DW was not leaking. Hence, this drop in pressure is attributed to increased mixing of the suppression pool associated with the SRVs cycling (overcoming stratification induced by the RCIC exhaust steam). The SRVs were manually opened at $\sim 18: 06$ on March 14, 2011. By this time, the DW pressure quits lowering, indicating that mixing is complete. By 18:09 on March 14, the DW and SC are both indicating a pressure of $\sim 0.40 \mathrm{MPa}-a b s$ ( $\sim 3$ psig) [and a corresponding saturation temperature of $\left.143^{\circ} \mathrm{C}\left(290^{\circ} \mathrm{F}\right)\right]$.

Later on March 14, 2011, trends for the DW and SC pressure data diverge (see Figure 7-9). Between 21:10 and 23:52 on March 14, 2011, the DW pressure rises from $\sim 0.48$ to $0.75 \mathrm{MPa}$-abs (55 to $94 \mathrm{psig}$ ), while SC pressure lowers from 0.40 to $0.33 \mathrm{MPa}$-abs (43 to $33 \mathrm{psig}$ ). Determining which data are valid requires several considerations. Supporting information or 'witnesses' for the suppression chamber pressure being accurate include: (1) the containment vent hasn't opened, and the rupture disc shouldn't open until differential pressures exceed $0.43 \mathrm{MPa}(62 \mathrm{psig})$. The witnesses for DW pressure include: (1) The SRVs can lower RPV pressure down to 0 differential pressure with discharge location, but cannot physically lower pressure below the pressure of its discharge location; (2) RPV pressure agrees with DW pressure. The fact RPV pressure data stabilized at the DW pressure supports the conclusion that DW pressure is correct and SC pressure is drifting low. Other information also confirms DW pressure data. For example, the maximum pressure difference between the DW and SC when the DW pressure is higher is the head of water between the downcomer openings and the suppression pool level. This head, which is estimated to be approximately 0.055 to $0.062 \mathrm{MPa}(8-9 \mathrm{psig})$, suggests that either the DW pressure or SC pressure was drifting.

\section{Water Injection Effects}

TEPCO reports that one fire truck resumed injecting into the RPV at 19:54 on March 14, 2011. A second truck resumed injection at 19:57 on March 14, 2011. Between 19:54 and 20:23 on March 14, 2011, the DW generally trended upward from 0.40 to $0.42 \mathrm{MPa}$-abs (43.3 to $46.2 \mathrm{psig}$ ) but the RPV pressure remained somewhat stable, oscillating between 0.661 and $0.664 \mathrm{MPa}-\mathrm{abs}(81.2$ and $81.6 \mathrm{psig}$ ) because steam and hydrogen produced from injected water reaching the overheated core was vented through an open SRV. For successful injection, the fire engines must overcome the combined head associated with DW and RPV pressure and the elevation of the jet pump injection line as well as losses through the fire hoses which may be significant depending on their configuration. ${ }^{*}$ When the drywell pressure reached $0.42 \mathrm{MPa}-a b s$ (46.2 psig), the DW pressure quits rising. It is speculated that the steam and hydrogen produced from injected water increased pressure sufficiently to prevent successful injection. Nevertheless, data suggest that injection was successful for 19 minutes (from 19:54 to 20:13 on March 14, 2011).

Figure 7-9 provides a closer view of the first two peaks in drywell pressure. As noted above, it is speculated that the first bump in DW pressure (from 19:54 and 20:23 on March 14, 2011) is due to injection from the fire engines. It is speculated that the second DW peak, rising from 0.42 to $0.47 \mathrm{MPa}$-abs (46.2 to 53.4 psig) at 21:20 on March 14, 2011 is due to the opening of the SRVs (calculations in Appendix H indicate that the combined head is too high for successful injection). The SRV opening generates some flashing steam which passes through the core and causes some steam and hydrogen production. Successful

* The height of the jet pump injection line is $23.3 \mathrm{~m}$ (76.3 feet) and the site level is $10.0 \mathrm{~m}$ (32.8 feet) above sea level. So, the elevation head is $13.3 \mathrm{~m}$ (43.5 feet) or $0.13 \mathrm{MPa}$-diff (18.9 psig). 
injection from the fire engines does not appear to resume until after 21:31 on March 14, 2011, when the combined head drops to values that can be overcome by the fire engines.

\section{Water Level}

Until the time that the SRV was manually opened, the RPV pressure was sufficiently high to keep the reference leg for the RPV water level instruments from flashing due to high temperature. Hence, the RPV water level readings are considered reliable for three days into the event. In Figure 7-8, initial indications of RPV water level A $(22: 35$ on March 11,2011), when corrected for the off-calibration conditions indicate that RPV water level is above the reference leg tap, which is located at +0.59 (+233") above TAF. RPV water level A and B trend together. Decreases in RPV water level readings (at 10:00 on March 14, 2011) are due to the rise in RPV pressure. After 12:00 on March 14, 2011, RPV water level indications, after corrections, indicate that RPV water level is below the reference leg tap. However, considering the RPV pressure and DW pressure saturation temperature $\left(148{ }^{\circ} \mathrm{C}\right.$ per Figure $\left.7-11\right)$, the actual level would read higher than the indicated level.

Bottom of scale for the 1F2 fuel zone level indications are -3.68 m (-145"). Relative to TAF, this point corresponds to the bottom of the active fuel (BAF). Evaluations (see Figure 7-13) indicate that the RPV fuel zone level instruments (after correction) were indicating true up until around 18:10 on March 14, 2011, the approximate time that corrected data suggest that water levels dropped to BAF.[42,211]

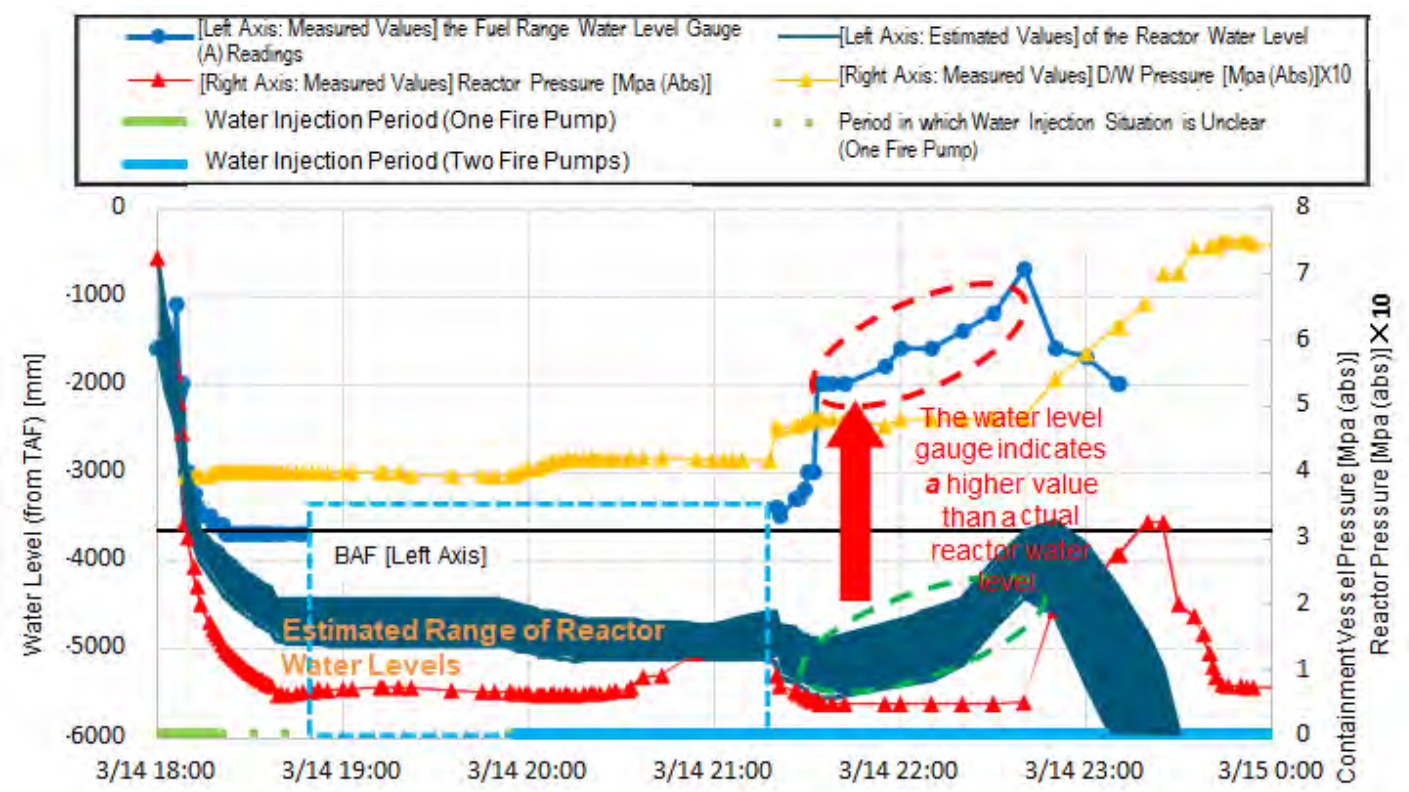

Figure 7-13. Estimated range for corrected water level for 1F2 (Courtesy of TEPCO [42])

When the SRV is opened at 21:18 on March 14, 2011, the RPV water level readings are most likely below BAF with some evaporation of reference leg water occurring. When the SRV is opened, the rapid rise of RPV water level from -3.0 to $-2.0 \mathrm{~m}$ (-118 to -78.7 inches) between 21:30 and 21:33 on March 14, 2011 is due to the flashing of the reference leg. Evaluations suggest that the peak value of $-0.7 \mathrm{~m}(-27.6$ ") at 22:40 was actually a level of $-2.31 \mathrm{~m}(-91$ ”) or less, e.g., slightly more than $40 \%$ of the core covered. After 23:11,-2.0 m (-78.7”) indicates BAF or lower.[42, 211] 


\section{Drywell and Suppression Chamber Radiation Data}

Drywell and suppression chamber radiation data are shown in Figure 7-10. Radiation levels remained low until after 21:55 on March 14, 2011, which is after the time that corrected data from fuel zone level instruments were indicating that RPV water levels were BAF. The low initial readings from the DW CAMs suggest that the steam flow past the core through the SRV was enough to maintain cooling until RPV water levels were near BAF. Only when the RPV pressure reached a low value did the core begin heating up. Thus, 1F2 radiation data, in conjunction with water level and pressure data, support the feasibility of the steam cooling strategy documented in BWROG Emergency Procedures.

\section{Indication of $\mathrm{H}_{2}$ Generation}

Indication of $\mathrm{H}_{2}$ generation without monitors is given by the concurrent trends of water level lowering, DW and RPV pressures increasing, and DW radiation levels rising. Between 22:40 on March 14, 2011 and 00:10 on March 15, 2011, RPV water level begins trending downward, and RPV and DW pressures start rising (see Figure 7-8). During this time, DW radiation also begins increasing (see Figure 7-10). Together, these trends suggest that water within the RPV is boiling down and core temperatures are increasing. Hydrogen generation from cladding oxidation and steam production from water injection cause DW and RPV pressures to increase until BAF is reached. At that time (after 23:54 on March 14, 2011), DW pressure quits increasing. As discussed previously, injection from the fire engines ceases to be successful when the combined RPV and PCV pressure head and injection line elevation head exceed the pumping capacity. At that time, the RPV pressure lowers to the DW pressure. DW radiation increases are due to the fission products released at elevated fuel temperatures from failed cladding into the RPV. As noted above, the absolute value of RPV water level cannot be trusted at this time due to reference leg flashing. However, the trend indicated from this sensor can be considered because the variable leg has stayed filled with RPV water level at or near BAF. It is also important to recognize that after 81 hours into this event, the RPV water level, RPV pressure, and DW and SC pressure transmitters are still working.

\section{Indication of Primary Integrity Loss and Vessel Breach}

Even though data are erroneous for March 15, 2011, the RPV water level transmitter was still working. When the breach occurs, it is suspected that both reference and variable legs inside the DW are steam. The loss of primary containment integrity is indicated by the lowering of drywell pressure (between 7:20 and 11:25 on March 15, 2011) after the SC instrument went hard downscale. After this, the RPV pressure and DW pressure separated slightly and the DW radiation lowers, which indicates some of the radioactive gases and particles are moved outside the PCV. Evaluations suggest that RPV breach occurred between 13:00 and 15:25 on March 15, 2011. This conclusion is supported by rising RPV and DW pressure trends and by the increase in DW radiation followed by the decreasing difference between the RPV and DW pressures (see Figures 7-8 and 7-10). The breach occurs approximately 22 hours after TAF was reached.

\section{RPV Metal Temperatures}

Initially reported metal temperatures, which range from 105 to $150^{\circ} \mathrm{C}\left(221\right.$ to $\left.302^{\circ} \mathrm{F}\right)$, appear reasonable. RPV support skirt temperature data, which did not become available until April 1, 2011, peaked at $287^{\circ} \mathrm{C}\left(549^{\circ} \mathrm{F}\right)$. Some RPV component temperatures were still above $100{ }^{\circ} \mathrm{C}\left(212^{\circ} \mathrm{F}\right)$ when injection transferred to the core spray header (mid-September 2011). As discussed in Appendix G, the drop in temperature when injection was switched suggests that core debris in the RPV cooled when water was injected. As observed in Appendix G, this is consistent with images obtained using muon tomography. 


\subsubsection{Summary}

Principles outlined in Section 7.2.2 were applied to 1F2 data and insights were obtained regarding when instrumentation data are and aren't valid. Examples within this section demonstrate how knowledge of SRV setpoints and comparisons from diverse instrumentation can validate instrumentation data. Data provide insights regarding the timing of fuel uncovery, vessel failure, and loss of PCV integrity. Evaluations also emphasize the importance of performing real-time validation of signals obtained during an accident and the importance of using data trends, when it is known that the absolute values from instrumentation are no longer correct. Such evaluations for 1F2 indicate that RPV water levels should be corrected for off-calibration by March 11, 2011 but were generally reliable without flashing of reference legs until March 14, 2011 and that SC pressures were drifting by March 14, 2011. RPV temperatures were fairly accurate for months after the initial event. However, [205] indicates that 'representative' values were reported for particular locations. Hence, the survivability of particular thermocouples cannot be discerned from available data. In summary, $1 \mathrm{~F} 2$ evaluations indicate 'trend' data were available for 17 days into the event, and that transmitters for most sensors worked throughout this period.

\subsubsection{F3 Instrumentation}

Evaluations focus on reviewing $1 \mathrm{~F} 3$ data for water level, pressure, temperature, and radiation data. Staff observations, such as the timing of RCIC turbine trip (11:36 on March 12, 2011), HPCI operation, and the timing of the $\mathrm{H}_{2}$ explosion (11:01 on March 14, 2011), were also used in developing insights regarding the validity of data from $1 \mathrm{~F} 3$ instrumentation.

\subsubsection{Instrumentation Data}

Figures 7-14 through 7-18 present data focused upon in 1F3 evaluations.

\subsubsection{Instrumentation Performance}

\section{RPV Water Level}

When the RCIC turbine tripped at 11:36 on March 12, 2011 (see Figure 7-14), the RPV water level dropped from +0.2 to $-0.45 \mathrm{~m}$ (with zero corresponding to TAF). When water level lowered to its low-low level setpoint (TAF) at approximately 12:35 on March 12, 2011, HPCI started automatically and restored RPV water level to normal ranges. As discussed in Appendix H, evaluations using the BWROG-developed methodology in TSG-2 were applied to estimate the time required for water level to decrease. The ability to use this guidance and obtain consistent times provides some confirmation that water level instrument readings were valid up through 12:35 on March 12, 2011.

After 12:10 on March 12, 2011, HPCI began depressurizing the RPV through the injection of cold water and through steam demand for the HPCI turbine. Once HPCI begins lowering the RPV pressure, water level readings increase. TEPCO evaluations[211] indicate water level readings should be corrected when pressure is decreased (for density changes and flashing). TEPCO analyses [211] indicate that water levels again dropped below TAF on 9:10 on March 13, 2011. Depending on assumptions, TEPCO analyses [211] indicate that BAF was reached between 12:00 and 15:10 on March 13, 2011. However, US evaluations suggest that BAF was reached earlier, by 05:00 on March 13, 2011 (Appendix H, Section H.3.3). 


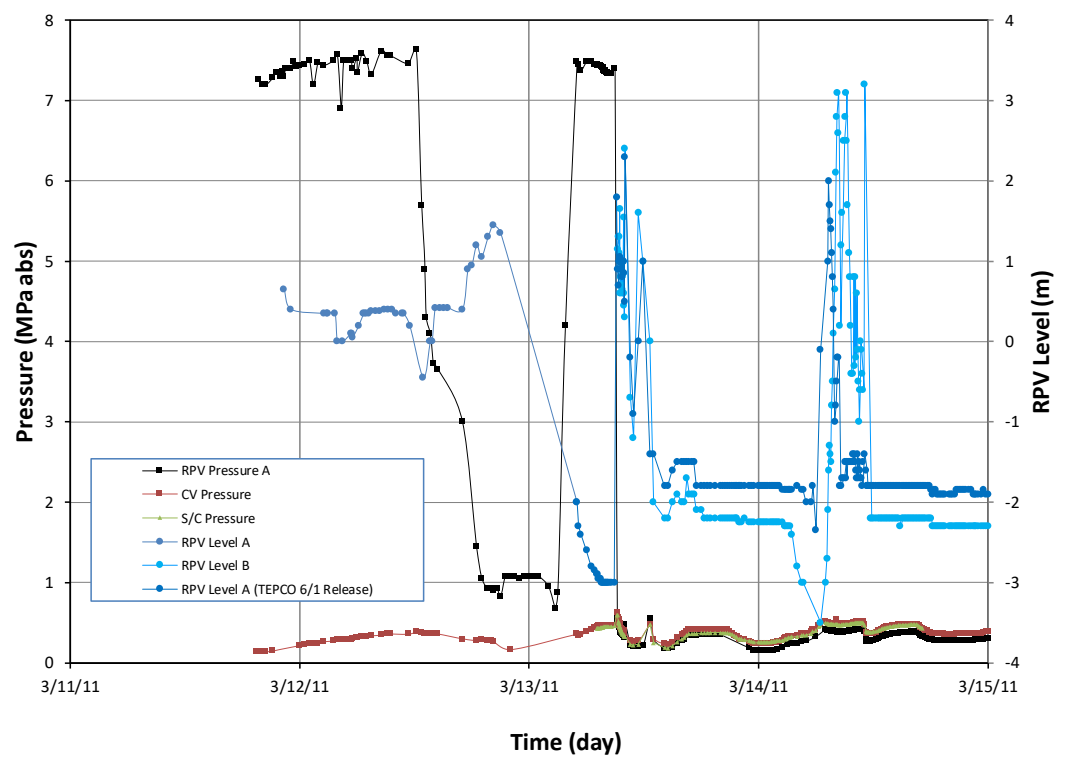

Figure 7-14. 1F3 pressure and water level data through March 15, 2011. (Data courtesy of TEPCO Holdings [9])

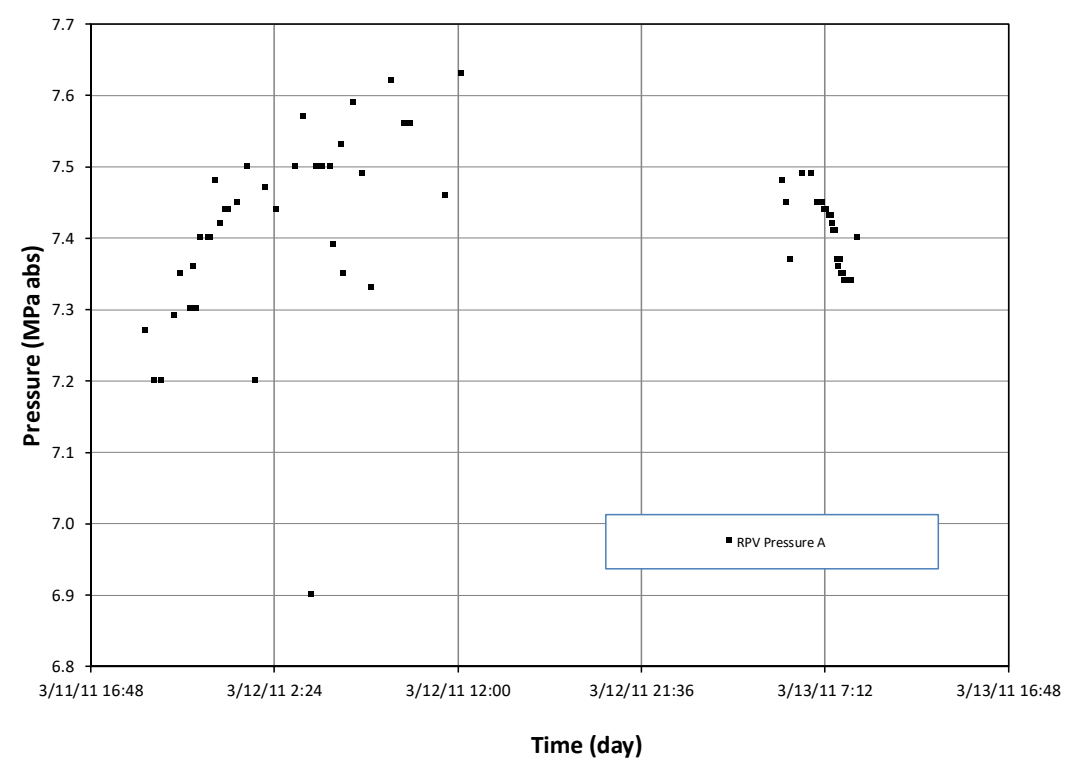

Figure 7-15. Enlarged view of 1F3 RPV pressure data on through 16:48 on March 13, 2011. (Data courtesy of TEPCO Holdings [9]) 


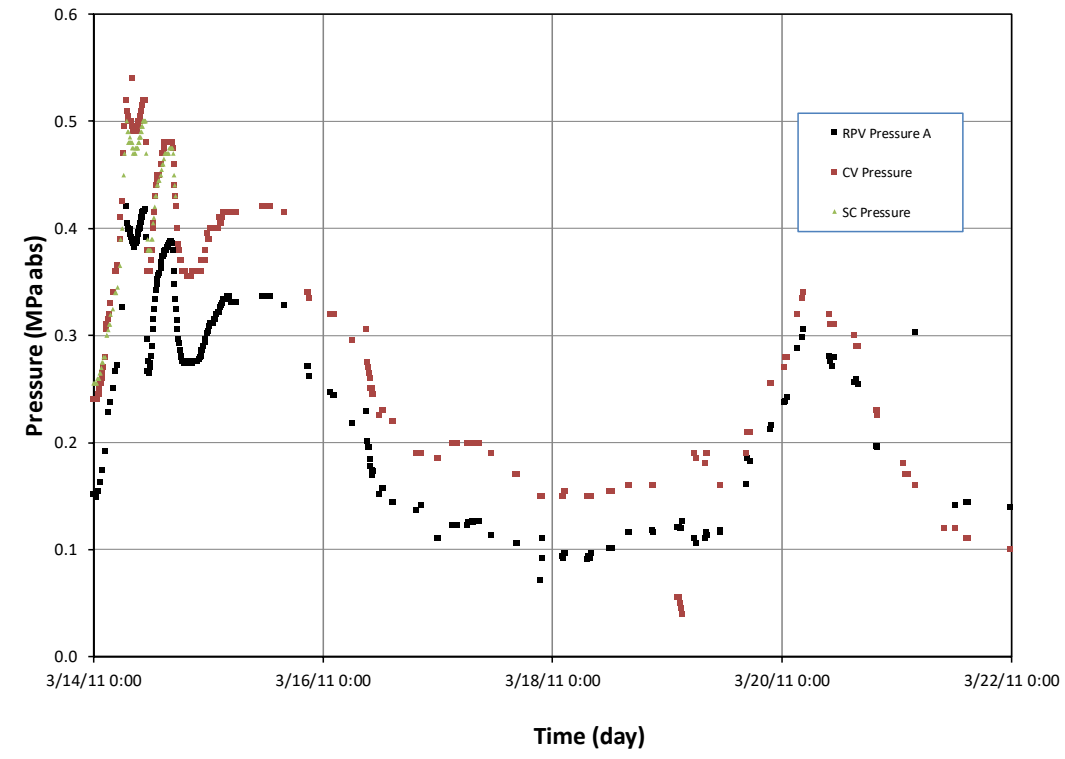

Figure 7-16. Enlarged view of 1F3 pressure data March 14-22, 2011. (Data courtesy of TEPCO Holdings [9])

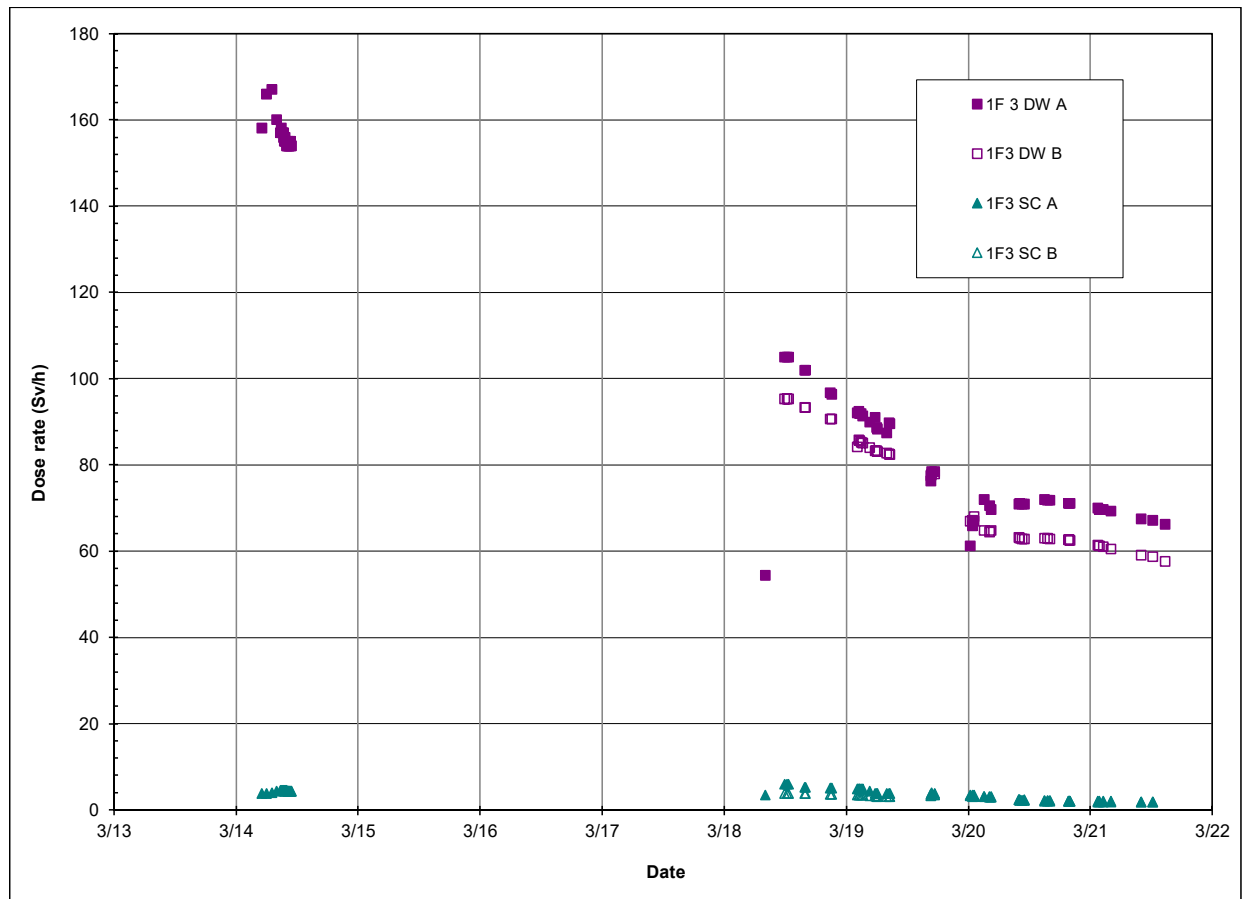

Figure 7-17. 1F3 DW and SC radiation data through March 22, 2011. (Data courtesy of TEPCO Holdings [9]) 


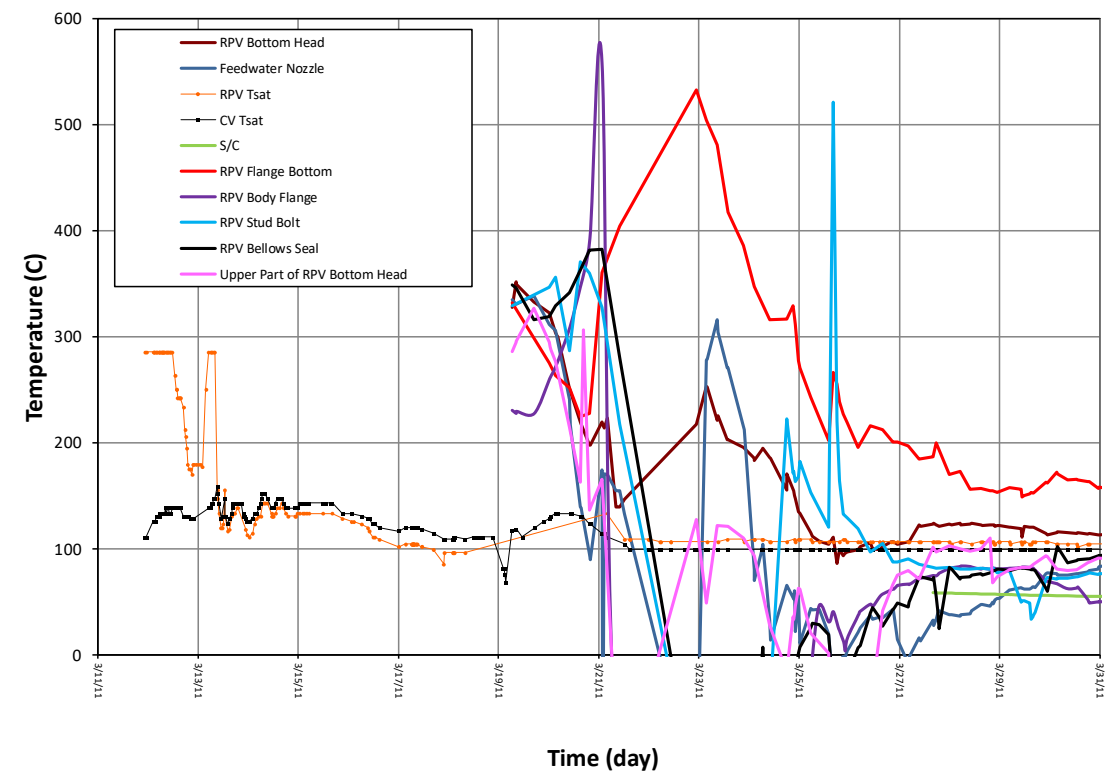

Figure 7-18. 1F3 temperature data through March 31, 2011. (Data courtesy of TEPCO Holdings [9])

TEPCO reports that HPCI did not shutdown until approximately 3:00 on March 13, 2011.[211] However, U.S. evaluations (Appendix H) indicate that injection is not guaranteed for RPV pressures below $\sim 1.0 \mathrm{MPa}$-diff (150 psig). At around 4 hours later, the RPV Level A stopped lowering at -3.0 meters (-118) on March 13, 2011 (at 07:39). In light of the low RPV pressures at this time, it is speculated that RPV level stopped lowering when BAF was reached at 07:39 on March 13, 2011 rather than later times (between 12:00 and 15:10 on March 13, 2011) predicted by analyses reported in [211].

After the 1F3 explosion (11:01 on March 14, 2011). water level transmitters are still working. However, it is suspected that both reference legs and variable legs are empty, impacting both RPV water level and pressure indications.

\section{RPV Pressure}

RPV pressure data corresponding to the period when SRVs are cycling (starting at 3:55 on March 12, 2011) can be validated by considering SRV information. For 1F3, the lowest relief valve opens at 7.55 MPa-abs (1080.3 psig).[210] During the time RCIC operated (up through 12:00 on March 12, 2011), RCS pressure could have been reduced through a second SRV, which opens at 7.62 MPa-abs (1090 psig). Although pressures within the RPV exceed 7.62 MPa-abs, the oscillatory behavior of data (reaching values down to 7.3 MPa-abs), suggest that relief through the 7.52 MPa-abs SRV is unlikely (see Figure 7-15).

Prior to the time that HPCI initiated (12:35 on March 12, 2011), RPV pressure data appear to oscillate around 7.55 MPa-abs (1080.3 psig). After HPCI initiation (07:12 on March 13, 2011), RPV pressures range from $\sim 0.07$ to $0.21 \mathrm{MPa}$-diff ( 10 to $30 \mathrm{psig}$ ) lower than expected values. These reduced values are attributed to flashing of the reference legs. The RPV pressure instruments are calibrated assuming the head 
of water from the tap to the transmitter. With some of the reference leg flashed, steam would occupy the reference leg and a lower pressure would be transmitted. For a reference leg inside the drywell of $6.1 \mathrm{~m}$ (20 feet) and a water density of $1000 \mathrm{~kg} / \mathrm{m}^{3}\left(62.4 \mathrm{lb}_{\mathrm{m}} / \mathrm{ft}^{3}\right)$, the difference could be about $0.06 \mathrm{MPa}$-diff (9 psig). Therefore, to a rough approximation, RPV pressure indications appear to be accurate (taking into account the reduced pressure from HPCI operation and the impact of losing water in the reference leg).

No data for RPV pressure A are reported between 20:00 and 23:00 on March 13, 2011. After RPV A pressure indication is recovered (23:00 on March 13, 2011), it trends with DW and SC pressures although nearly 0.1 MPa-diff (14.5 psig) lower than DW and SC pressures. RPV pressure is not accurate because physically it can't be less than DW and SC pressure. As noted above in the discussion for water level readings, the difference is attributed to flashing of the reference leg, the lower RPV pressure, and the fact that the RPV pressure instrument has a much larger range than does the drywell pressure instrument.

\section{Drywell and Suppression Chamber Pressure}

After 9:20 on March 13, 2011, SC and DW pressure data confirm each other. At this time, data indicate that the DW pressure is being raised and the SC pressure is following (see Figure 7-14). At 08:55 on March 13, 2011, the plant staff had the containment ready to vent (with the exception of the rupture disc.) Even with a peak DW pressure of $0.47 \mathrm{MPa}$-abs (53.45 psig), the SC vent remained closed inferring that the pressure seen by the rupture disc is still below the $0.53 \mathrm{MPa}-\mathrm{abs}$ (62 psig) disc opening pressure. This would make the indication accurate within $0.06 \mathrm{MPa}$-diff ( 9 psig) or less.

DW pressure is also confirmed by SC pressure [readings are within $0.1 \mathrm{MPa}$-diff ( $7 \mathrm{psig}$ ), and trends are similar]. Also, data trends indicate that released energy is first pressurizing the DW (suggesting that the DW pressure rise may be due to production of non-condensible gases). DW pressure quits rising when RPV water level quits lowering (from 14:30 to 20:30 on March 13, 2011 and from 7:00 to 11:02 and from 14:50 to 16:20 on March 14, 2011; see Figure 7-14). Operators were using the diesel driven fire pump into the DW spray header periodically on March 13 and 14, 2011. As discussed above, evaluations indicate that water levels dropped below TAF on 9:10 on March 13, 2011. RPV water level data indicate that BAF was reached at 07:39 and again, at 14:10 on March 13,2011. When corrected, it is estimated that RPV water level remained below BAF (after approximately19:12 on March 14, 2011). At that time, it is believed that the oxidation lowered or ceased, stabilizing DW pressure.

DW and SC pressures respond to containment venting at 20:30 on March 13, 2011. As noted above, when RPV A pressure indication is recovered $(23: 00$ on March 13, 2011), it trends with DW and SC pressures (although RPV pressure is inaccurate because it cannot physically be less than DW and SC pressure). As shown in Figure 7-16, DW and SC pressures trend together even after the 1F3 explosion (11:01 on March 14, 2011). At later times (after 14:40 on March 13, 2011), data indicate that containment pressure approaches atmospheric conditions (see Figure 7-16).

\section{RPV Breach by Core Debris}

The RPV pressure peak at 10:00 on March 13, 2011 (see Figure 7-14) is speculated to correspond to the time when core debris relocated into the lower plenum. At this time, RPV pressure and RPV A and B water level increase, but DW and SC pressure do not respond. It is suspected that the peak at 12:40 on March 13, 2011 is RPV breach. At this time, increases occur in the RPV, DW, and SC pressures, as well as RPV water levels A and B. 


\section{Drywell Radiation and Loss of PCV Integrity}

As shown in Figure 7-17, DW CAM A and SC CAM A radiation data became available between 05:00 and 10:25 on March 14, 2011. Radiation data trend with DW and SC pressure and with RPV pressure. Pressure and radiation data indicate leakage begins from the drywell at 07:00 on March 14, 2011. At that time, the peak in DW radiation data begins lowering and DW, SC, and RPV pressures also cease to rise and start lowering. Hence, DW radiation A and B confirm each other and SC radiation A and B confirm each other.

\section{Temperature}

1F3 temperature data are plotted in Figure 7-18. Initially reported metal temperatures, which range from 100 to $160{ }^{\circ} \mathrm{C}$ (212 to $320^{\circ} \mathrm{F}$ ), appear reasonable. RPV body flange temperature data, which did not become available until March 19,2011 , peaked at $558^{\circ} \mathrm{C}\left(1036^{\circ} \mathrm{F}\right)$. Some RPV component temperatures were still above $100{ }^{\circ} \mathrm{C}\left(212^{\circ} \mathrm{F}\right)$ when injection transferred to the core spray header (early-September 2011). As discussed in Appendix G, the drop in temperature when injection was switched suggests that core debris in the RPV cooled when water was injected through the core spray header. As observed in Appendix G, this information is consistent with images obtained using muon tomography.

\subsubsection{Summary}

Principles outlined in Section 7.2.2 were also applied to evaluate $1 F 3$ data to gain insights regarding when instrumentation data are and aren't valid. Examples within this section demonstrate the importance of comparing data from diverse instrumentation to assess the accuracy of instrumentation data for pressure and water level. Data provide insights regarding the timing of fuel uncovery, vessel failure, and loss of PCV integrity. Evaluations also emphasize the importance of performing real-time validation of signals obtained during an accident and the importance of using data trends, when it is known that the absolute values from instrumentation are no longer correct. Such evaluations for 1F3 indicate that RPV water levels should be corrected by March 12, 2011 and that RPV pressure data require corrections by March 13, 2011. RPV temperatures were fairly accurate for several weeks after the initial event. However, [205] indicates that 'representative' values were reported for particular locations. Hence, the survivability of particular thermocouples cannot be discerned from available data. In summary, 1F3 evaluations indicate that 'trend' data were available for 11 days into the event, and that transmitters for most sensors were still working throughout this period.

\subsection{Environmental Conditions Predicted by Systems Analysis Codes}

During the November 2017 expert panel meeting, it was agreed that it would be useful to obtain plant data environmental conditions predicted by systems analysis codes. These estimates can be compared with available plant data to provide confidence in instrumentation measurements and can provide insights regarding instrumentation survivability when data aren't available. For FY2018, predictions from MELCOR 2.2 evaluations were available for such comparisons. 


\subsubsection{F1 Instrumentation}

Pressures, water level, and corresponding saturation temperatures predicted by MELCOR are shown for selected 1F1 locations in Figures 7-19 and 7-20. The predictions reach a steady state prior to $\mathrm{t}=0$, the time when the earthquake and SCRAM are assumed to occur. A user-defined main steam line rupture is assumed to occur at 6.1 hours. At this time, hot gases from fuel degradation are postulated to have resulted in a creep rupture of the hot-leg of the main steam line. MELCOR tracks water level within the entire reactor pressure vessel (with zero corresponding to TAF).

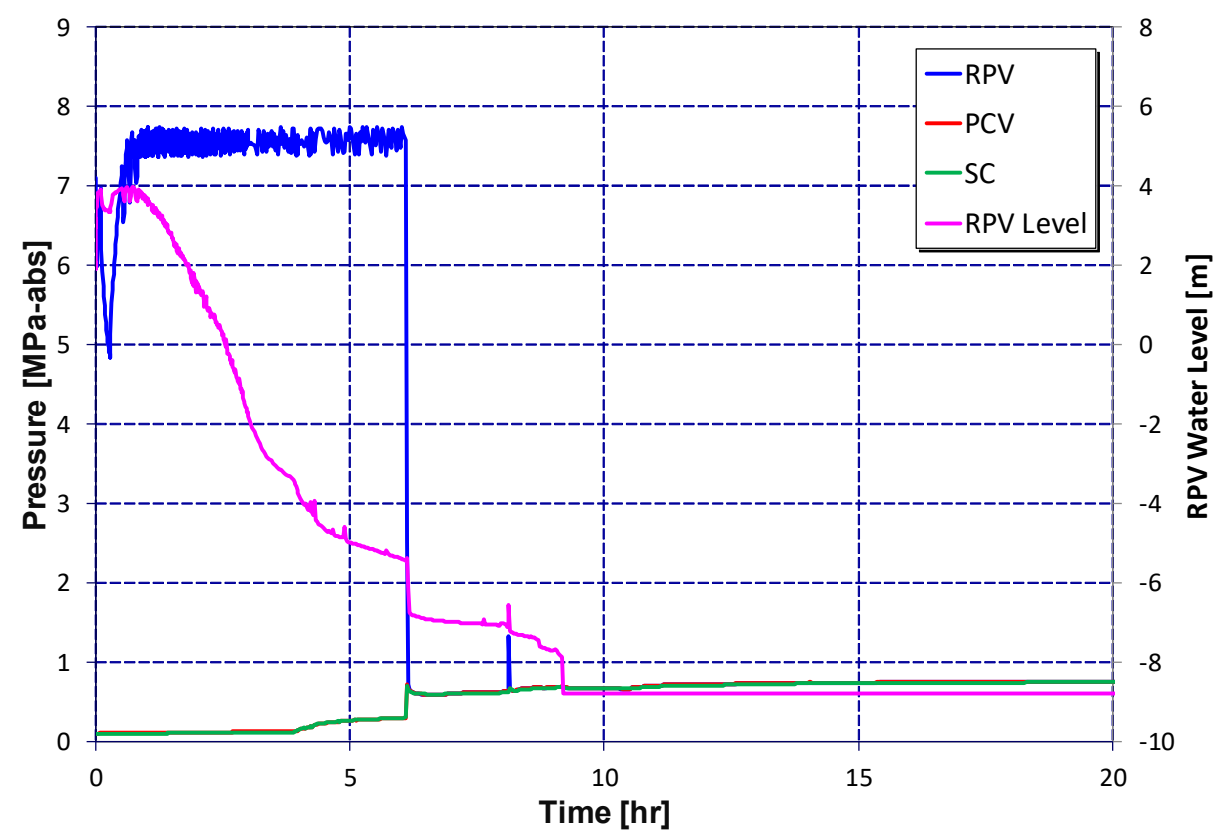

Figure 7-19. MELCOR estimates for pressure and water levels at selected $1 \mathrm{~F} 1$ locations $[\mathrm{t}=0.0$ corresponds to 14:46 on March 11, 2011; RPV water level of 0 corresponds to TAF]. (Courtesy of SNL)

Estimates for pressure within the RPV, PCV, and SC within Figure 7-19 are consistent with the limited pressure data available from instrumentation shown in Figure 7-4. This increases confidence in Figure 7-20 saturation temperature predictions by MELCOR at these locations and the survivability of pressure sensors at these pressures and temperatures.

As discussed in Sections 7.2.1 and 7.2.4.2, it is expected that predicted RPV water levels shown in Figure 7-19 would be lower than values indicated by instrumentation in Figure 7-4. MELCOR evaluations indicate that water levels are below TAF (the zero on Figure 7-19) at approximately 2.6 hours after the start of the event; whereas plant instrumentation indicate water levels reach TAF by 18:30 on March 11, 2011 in Figure 7-4 (approximately 3.7 hours after the event). 


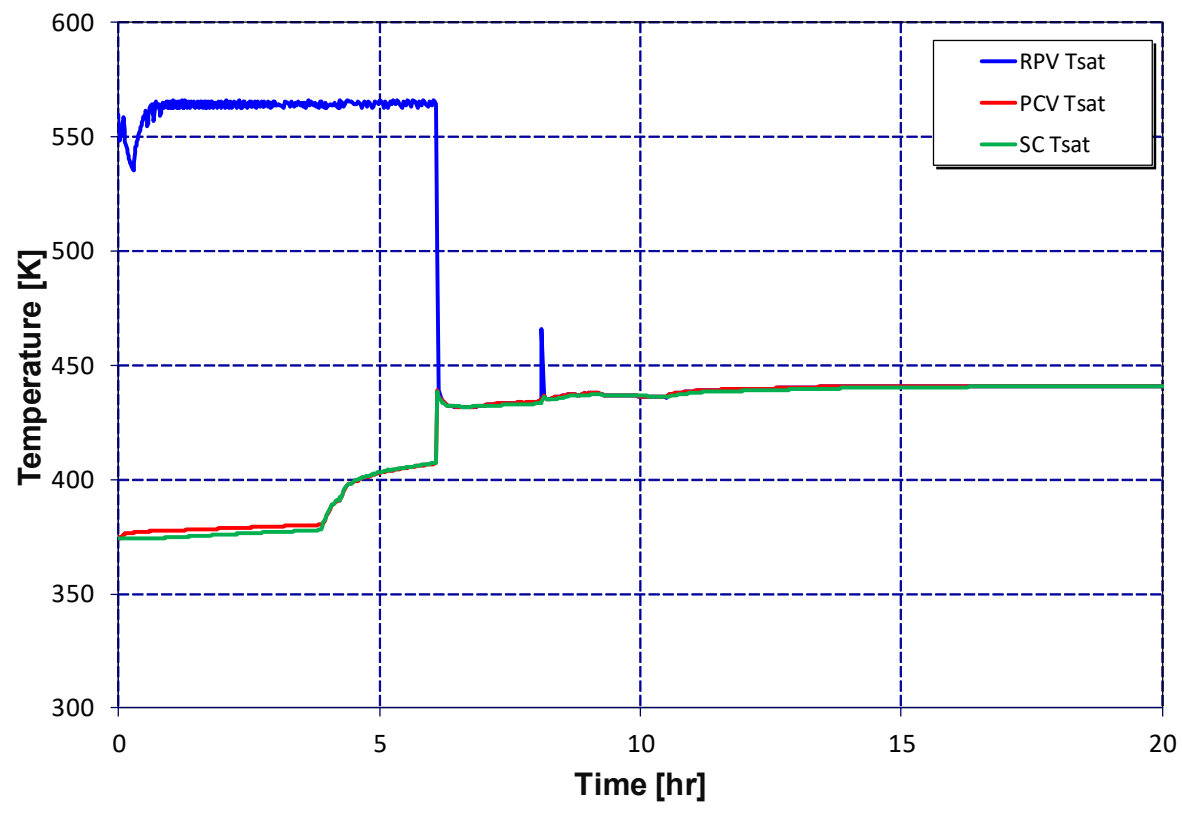

Figure 7-20. MELCOR estimates for saturation temperatures at selected $1 \mathrm{~F} 1$ locations $[\mathrm{t}=0.0$ corresponds to 14:46 on March 11, 2011]. (Courtesy of SNL)

\subsubsection{F2 Instrumentation}

Pressures, water level, and corresponding saturation temperatures predicted by MELCOR are shown for selected 1F2 locations in Figures 7-21 and 7-22. The predictions reach a steady state prior to $t=0$, the time when the earthquake and SCRAM are assumed to occur. The 1F2 MELCOR model assumes that the torus room flooded to $30 \%$ of its total free volume. This provided the necessary heat sink to maintain the containment pressure at values near the reported values. In Figure 7-21, MELCOR tracks water level within the entire reactor pressure vessel (with zero corresponding to TAF). The initial water level increase because of the assumed RCIC injection, which takes the water level to the height of the main steam line.

Estimates for pressure within the 1F2 RPV, PCV, and SC within Figure 7-21 are consistent with the limited pressure data available from instrumentation shown in Figure 7-8. The lack of any sudden decrease in pressure at 09:33 on March 13, 2011 (approximately 43 hours after the start of the event) suggest that RPV and SC instrumentation readings for this time are in error. (As noted in Section 7.2.4.2, the cause for the drop in measured data was not known).

As discussed in Sections 7.2.1 and 7.2.4.2, estimated RPV water levels shown in Figure 7-21 are higher than values indicated by instrumentation in Figure 7-8. The 1F2 MELCOR calculation indicates that the water level reached the height of the main steam line (because of RCIC injection). This result is physically confirmed by the degraded RCIC performance of the reactor. MELCOR predicts that water levels remain stable until approximately 70 hours and then decrease, reaching TAF at approximately 75.2 hours. Instrumentation data indicate that water levels are stable until approximately 66.8 hours (09:35 on March 14, 2011). Then, water level readings decrease, reaching TAF after 73.6 hours (16:20 on March 14, 2011). It is speculated that differences between measured instrumentation and MELCOR predictions is primarily caused by how the RCIC system is modeled for $1 \mathrm{~F} 2$. 


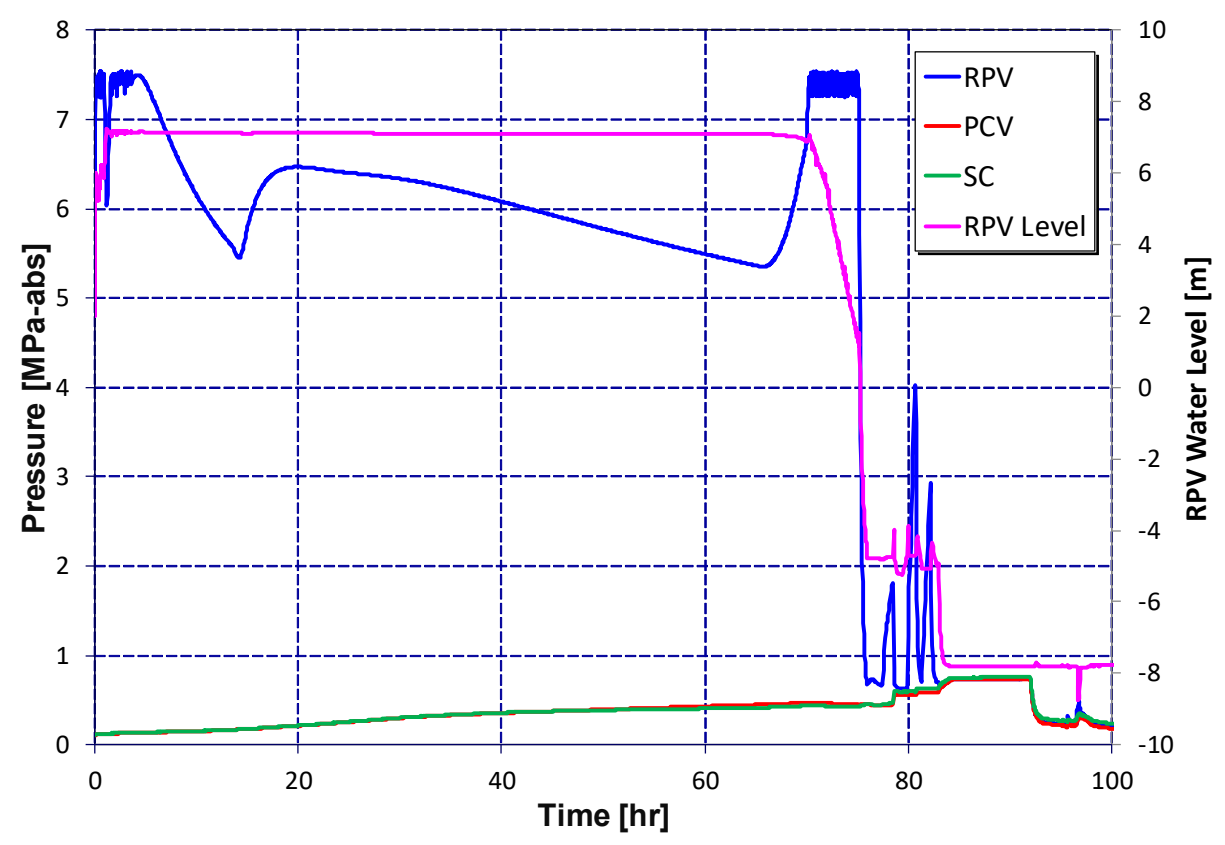

Figure 7-21. MELCOR estimates for pressure and water levels at selected $1 \mathrm{~F} 2$ locations [ $\mathrm{t}=0.0$ corresponds to 14:46 on March 11, 2011; RPV water level of 0 corresponds to TAF]. (Courtesy of SNL)

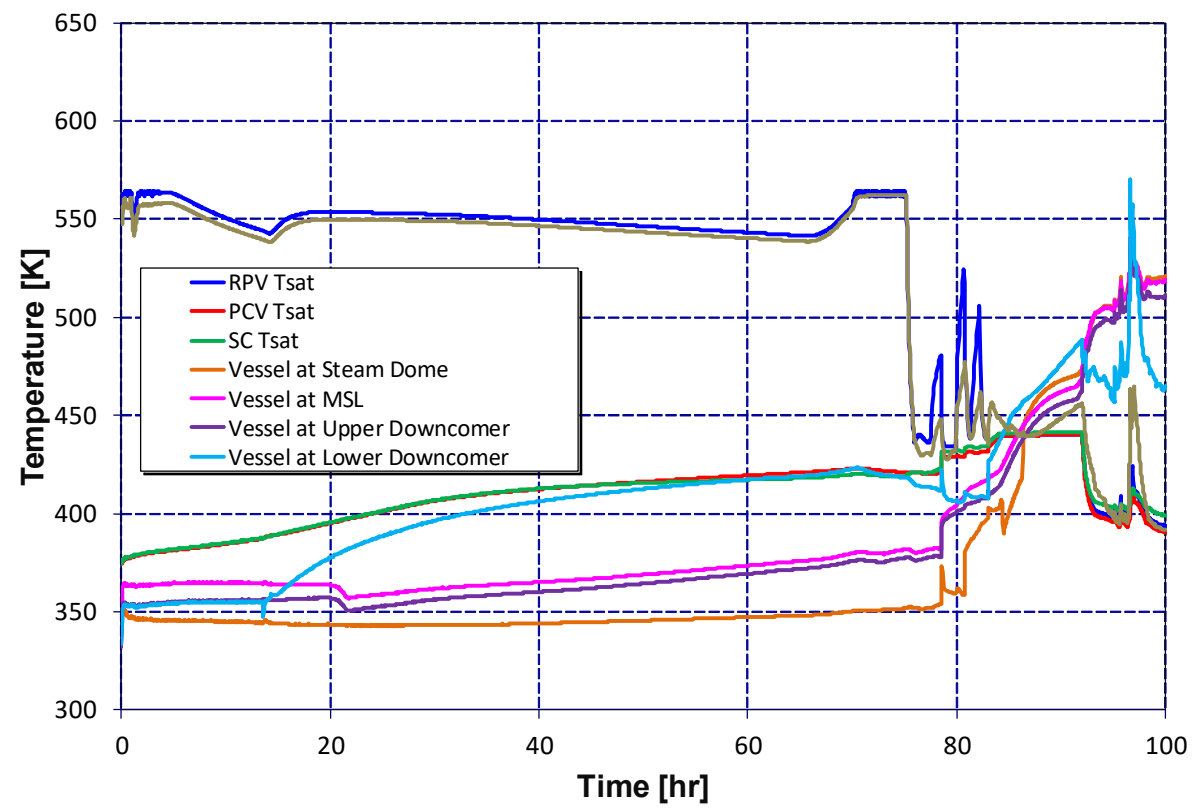

Figure 7-22. MELCOR estimates for temperatures at selected $1 \mathrm{~F} 2$ locations [ $\mathrm{t}=0.0$ corresponds to 14:46 on March 11, 2011]. (Courtesy of SNL) 
Consistency between predicted and measured 1F2 SC, PCV, and RPV pressures provides confidence in estimated saturation temperatures for the measured pressures (see Figure 7-22). As discussed in Section 7.2.4, there is also confidence in pressure and temperature instrumentation data because measured temperatures at selected locations (e.g., the RPV bottom head and feedwater nozzle) are consistent with predicted saturation temperatures at the RPV and PCV pressure (see Figure 7-11). Temperatures predicted by MELCOR for the PCV, SC, and RPV provide insights regarding the environmental conditions that 1F2 sensors experienced at early times during the event before temperature data became available.

\subsubsection{F3 Instrumentation}

Pressures, water level, and corresponding saturation temperatures predicted by MELCOR are shown for selected 1F3 locations in Figures 7-23 and 7-24. The predictions reach a steady state prior to $\mathrm{t}=0$, the time when the earthquake and SCRAM are assumed to occur. In this MELCOR simulation for 1F3, a user-defined main steam line rupture was specified at 42.3 hours. At this time, hot gases from fuel degradation are postulated to have resulted in a creep rupture of the hot-leg of the main steam line.

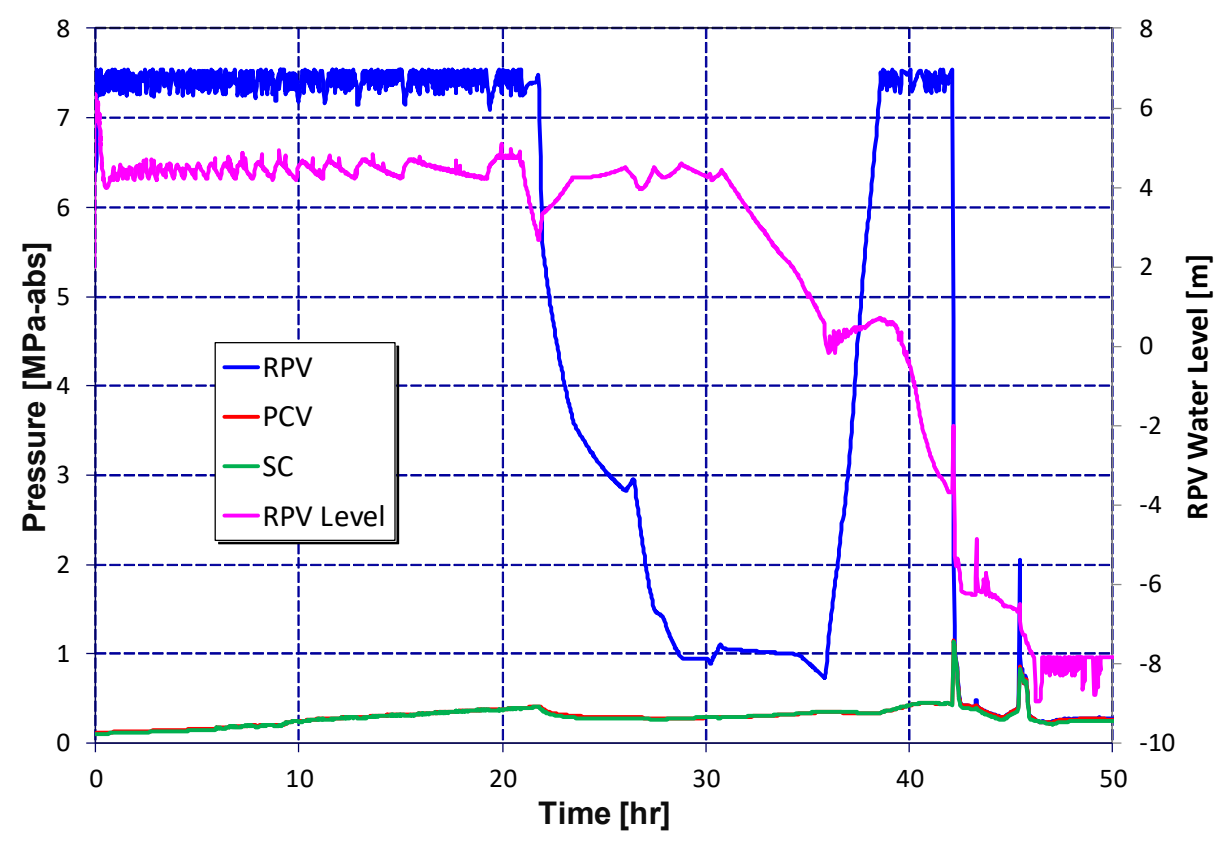

Figure 7-23. MELCOR estimates for pressure and water levels at selected $1 \mathrm{~F} 3$ locations $[\mathrm{t}=0.0$ corresponds to 14:46 on March 11, 2011; RPV water level of 0 corresponds to TAF]. (Courtesy of SNL)

Estimates for pressure within the RPV, PCV, and SC within Figure 7-23 are consistent with the pressure instrumentation data shown in Figure 7-14. MELCOR predicts similar trends, as well as the magnitudes, for pressures at these locations.

As shown in Figure 7-14, water levels first drop below TAF on 3:55 on March 12, 2011. As discussed in Sections 7.2.1 and 7.2.5.2, water level readings at later times are affected by water injection and pressures and temperatures within the RCS and the PCV. Water levels shown in Figure 7-23 should be much higher than values indicated by instrumentation in Figure 7-8. MELCOR evaluations (see Figure 7-23) indicate different magnitudes and trends for water levels than measured by instrumentation. Differences 


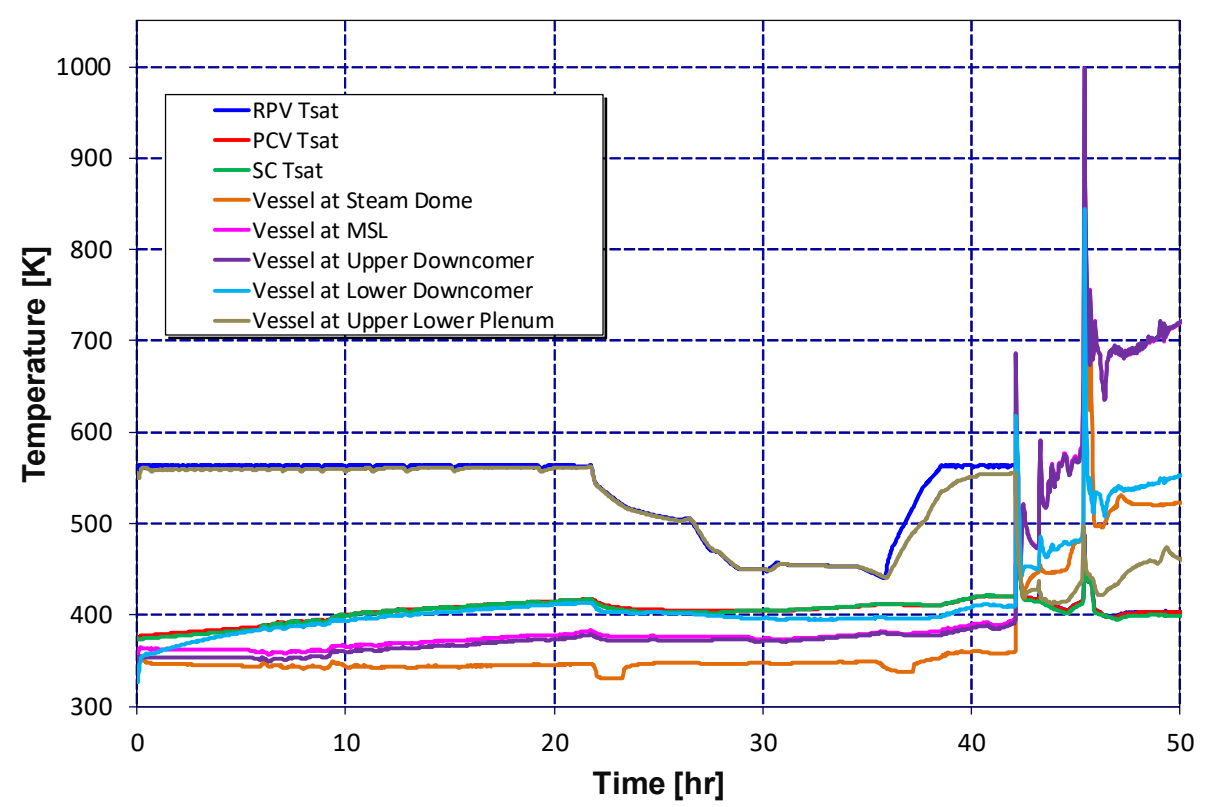

Figure 7-24. MELCOR estimates for saturation temperatures at selected $1 \mathrm{~F} 3$ locations $\mathrm{t}=0.0$ corresponds to $14: 46$ on March 11, 201]. (Courtesy of SNL)

can be attributed to the "forensic" approach taken for these 1F3 MELCOR calculations. Priority was taken to match pressure responses from results as well as the observed source term, instead of local temperature measurements.

Figure 7-24 shows MELCOR predictions for the first 50 hours, which is prior to when any temperature instrumentation was available for 1F3. Consistency between predicted and measured 1F3 SC, PCV, and RPV pressures provides confidence in estimated saturation temperatures for the measured pressures at selected locations. As discussed in Section 7.2.5, when measured temperature data became available, values were very erratic (see Figure 7-18). Temperatures predicted by MELCOR for the PCV, SC, and RPV provide insights regarding the environmental conditions that $1 \mathrm{~F} 3$ sensors experienced at early times during the event before temperature data became available. After 42 hours, sharp temperature increases are predicted to occur within the vessel downcomer, with peak temperatures of $1000 \mathrm{~K}\left(727^{\circ} \mathrm{C}\right)$.

\subsubsection{Summary}

MELCOR calculations support that instrumentation at 1F1, 1F2 and 1F3 appears to have survived harsher environmental conditions longer than predicted by environmental qualification calculations. The ability to quantify these conditions and times may permit the extension of calibration intervals or environmental qualifications for some instruments. Assessments of such extensions should consider that the updated owner guidance seeks other means to validate readings. Assessments should also note that some trend information provides knowledge of the unit more accurately than instantaneous readings so accuracy of measurements is not always critical to understand the physics of the event. 


\subsection{Insight Summary and Limitations}

Evaluations of instrumentation data provide critical information about accident progression events that cannot be obtained elsewhere. The timing of key events, such as when RPV water levels dropped below the TAF and BAF, when PCV integrity was lost, when significant core debris relocated to the lower plenum, and when RPV breech occurred, cannot be obtained elsewhere. During the initial hours of the event, instrumentation data are typically the only information available to staff for monitoring the plant status.

Table 7-3 summarizes issues identified for particular instrumentation systems. Issues are highlighted to emphasize which data should not be used for benchmarking new models. However, it should be noted that trend data were available for most sensors at 1F1, 1F2, and 1F3 for extended periods (between 11 and 85 days) and that transmitters for most sensors were still working. In most cases, RPV metal and drywell temperatures and SRV tailpipe temperature instrumentation gave reasonable data for 6 months or longer, allowing TEPCO Holdings staff to monitor the plant under cold shutdown conditions. Clearly, much of the plant instrumentation survived conditions (e.g., radiation levels, shocks from seismic events and combustible gas explosions, temperatures, humidity, etc.) well beyond their qualification envelop.

Table 7-3. Summary of survivability insights

\begin{tabular}{|c|c|c|c|}
\hline \multirow{2}{*}{ Instrumentation } & \multicolumn{3}{|c|}{ Survivability } \\
\hline & 1F1 & $1 \mathrm{~F} 2$ & $1 F 3$ \\
\hline $\begin{array}{l}\text { NR and WR Water } \\
\text { Level }\end{array}$ & $\begin{array}{l}\text { Should be corrected for } \\
\text { off-calibration conditions by } \\
\text { March } 11,2011 \text {; unreliable by } \\
\text { March 12, 2011. Transmitters } \\
\text { worked for much longer (at least } \\
85 \text { days). }\end{array}$ & $\begin{array}{l}\text { Should be corrected for } \\
\text { off-calibration by March } 11 \text {, } \\
2011 \text {; unreliable due to flashing } \\
\text { by March } 14,2011 \text {. Transmitters } \\
\text { worked for much longer. }\end{array}$ & $\begin{array}{l}\text { Should be corrected for } \\
\text { off-calibration by March 11, } \\
2011 \text {; unreliable due to flashing } \\
\text { by March } 14,2011 \text {. Transmitters } \\
\text { worked for much longer. }\end{array}$ \\
\hline RPV pressure & $\begin{array}{l}\text { By March 23, 2011, both RPV A } \\
\text { and B pressure signals were } \\
\text { drifting high. }\end{array}$ & No known issues. & $\begin{array}{l}\text { De-calibrated by March } 13, \\
2011 \text {, due to reference legs } \\
\text { flashing. However, trends appear } \\
\text { to be valid. Instruments are fairly } \\
\text { reading } 0.156 \text { to } 0.163 \mathrm{MPa}(8-9 \\
\text { psid) low due to decalibration } \\
\text { required for reference leg water } \\
\text { level. }\end{array}$ \\
\hline $\begin{array}{l}\text { RPV Metal } \\
\text { Temperatures }\end{array}$ & $\begin{array}{l}\text { Only 'representative' values } \\
\text { reported; Fairly accurate even } \\
\text { when temperatures exceeded } \\
\text { qualification envelop. }\end{array}$ & $\begin{array}{l}\text { Only 'representative' values } \\
\text { reported; Fairly accurate even } \\
\text { when temperatures exceeded } \\
\text { qualification envelop. }\end{array}$ & $\begin{array}{l}\text { Only 'representative' values } \\
\text { reported; Fairly accurate even } \\
\text { when temperatures exceeded } \\
\text { qualification envelop. }\end{array}$ \\
\hline DW Pressure & No known issues. & No known issues. & No known issues. \\
\hline DW Temperature & No known issues. & No known issues. & No known issues. \\
\hline DW CAMs & No known issues. & No known issues. & No known issues. \\
\hline SC Pressure & No known issues. & $\begin{array}{l}\text { SC pressures were drifting by } \\
\text { March } 14,2011\end{array}$ & No known issues. \\
\hline SC Temperature & No known issues. & No known issues. & No known issues. \\
\hline SC CAMS & No known issues. & No known issues. & No known issues. \\
\hline
\end{tabular}

It is important to recognize limitations associated with plant instrumentation. Data from some instrumentation systems, such as CAM and thermocouple systems, weren't initially available; and some sensors 
degraded due to extended exposures to extreme conditions (e.g., high temperatures, radiation levels, and humidity). Thus, it is important to validate instrumentation data.

Some instrumentation measurements can be compared with MELCOR predictions for each unit. Confidence in pressure instrumentation is provided by the similar values predicted by MELCOR. Furthermore, MELCOR analyses predict fairly high temperatures in the RPV, which were much higher than the upper limits for $1 \mathrm{~F}$ thermocouples. These sensors continued to transmit a signal when temperatures were reduced below the upper scale for these thermocouples. Hence, $1 \mathrm{~F}$ information suggests that these thermocouples should be given credit for operating in conditions beyond their qualification envelop.

\subsection{Recommendations}

In reviewing available information for this area, including the information in Appendix TBD, the expert panel formulated several recommendations.

\section{Area 5 Recommendation 1:}

The expert panel recommends that calculations be completed with MAAP, similar to those completed with MELCOR, to estimate conditions to which sensors were exposed during these events. .

As discussed within this section, instrumentation continued to provide useful information during the events at Fukushima. Efforts are underway to revise guidance and training to help operators cope with limited and possibly degraded data should be assessed using insights from instrumentation evaluations. It is recognized that instrumentation was exposed to conditions beyond their qualification envelop. To support such efforts, it would be useful to estimate the extent of conditions to which instrumentation was exposed using MAAP, similar to what has been completed with MELCOR.

\section{Area 5 Recommendation 2:}

The expert panel recommends that an exploratory exercise be performed in modeling the reference RPV water level reference leg in codes such as MELCOR and MAAP.

As discussed within this section, the RPV water level, data and measurement, continue to be of key importance in interpreting the events at Fukushima Daiichi. The potential heatup and boiling of the reference legs of the various RPV water level instrumentation has been discussed by various members of the expert panel (as well as other experts) since early after the accidents. The influences of the reference leg on the indicated RPV water level are important when comparing simulation results to actual field data and when extrapolating simulation results to what operators/response personnel may observe. Current MELCOR and MAAP models for Fukushima Daiichi (and BWRs in general) do not model the reference leg. On this basis, it is recommended that an exploratory effort in modeling this component be initiated.

\subsection{Suggestions for Additional Information}

In reviewing available information for this area, the expert panel formulated one suggestion. This suggestion has been added to the information need requests, PC-7 and PC-8. 


\section{Area 5 Suggestion 1:}

As noted in Section 7.2.3, additional examination information would be useful to understand why the RPV B pressure signal experienced a failure prior to other transmitters at $1 \mathrm{~F} 1$.

Data indicate that the RPV B pressure signal drifted and failed high on June 4, 2011, 85 days after the initial events at $1 \mathrm{~F} 1$. Components of this system was subject to high temperatures, steam, high radiation levels, and shock waves associated with the seismic events and hydrogen explosions at the site. However, additional examination information (e.g., photos, continuity checks, etc.) would be useful to understand why the RPV B pressure signal experienced a failure prior to other sensors at $1 \mathrm{~F} 1$. 


\section{SUMMARY AND INSIGHT IMPLEMENTATION}

Information obtained from Daiichi is required to inform D\&D activities. This section summarizes the examination information evaluated by the U.S. expert panel and the recommendations formulated from these evaluations. In addition, this section identifies on-going and completed actions to use insights gained from forensics examinations to reduce severe accident modeling uncertainties and confirm or enhance severe accident management guidance. For example, FY18 examinations and evaluations have highlighted the need to enhance systems analysis code models by considering holdup on ex-vessel structures to inform industry guidance regarding water addition and the use of instrumentation in conditions beyond their qualification envelop. Activities to implement such insights are beneficial to the U.S. because they provide additional assurance that current severe accident guidance is appropriate (or identify the need for future revisions to such guidance). Activities to reduce uncertainties in modeling severe accident phenomena are also beneficial to the U.S. and Japan for enhancing reactor safety. Reduced uncertainties in severe accident evaluations are beneficial to Japan because improved realism in reactor safety evaluations support D\&D activities by improving the capability to characterize reactor component performance during the accident and to estimate post-accident fuel location and fission product deposition and form. This improves the technical basis for characterizing potential hazards to workers involved with cleanup activities.

\subsection{Evaluations and Recommendations}

Significant examination information is already available for evaluation. In the U.S. forensics effort, the expert panel agreed to focus evaluations in the five areas identified in Table 8-1. This table also lists the types of information available for evaluation in each area. As indicted in Table 8-1, available information is primarily visual images, plant instrumentation data , radiation surveys, and sample evaluations.

Table 8-1. Evaluation areas and types of evaluated examination information

\begin{tabular}{|c|c|}
\hline Area & Types of Examination Information Evaluated \\
\hline $\begin{array}{l}\text { Area 1 - } \\
\text { Component } \\
\text { Degradation }\end{array}$ & $\begin{array}{l}\text { - Visual information (photos and videos gathered using robotic examinations and stand-off methods such } \\
\text { as muon tomography). } \\
\text { - Sampling. } \\
\text { - Dose rate measurements. } \\
\text { - Water level and temperature measurements. } \\
\text { - TEPCO Holdings reports documenting unconfirmed and unresolved issues. }\end{array}$ \\
\hline $\begin{array}{l}\text { Area } 2 \text { - Dose } \\
\text { Surveys and } \\
\text { Isotopic Surveys } \\
\text { and Samples }\end{array}$ & $\begin{array}{l}\text { - Radiation doses accumulated by plant personnel during the accident and during post-accident } \\
\text { examinations. } \\
\text { - Dose rate measurements obtained during and after the accident (including perimeter and adjacent area } \\
\text { surveys). } \\
\text { - CAM readings in the drywell and wetwell. } \\
\text { - Sampling of contaminated water in various reactor buildings, of soil, and evaluations of discharge } \\
\text { effluents. }\end{array}$ \\
\hline $\begin{array}{l}\text { Area } 3 \text { - Debris } \\
\text { Endstate }\end{array}$ & $\begin{array}{l}\text { Visual information (photos and videos gathered using robotic examinations and stand-off methods such } \\
\text { as muon tomography). } \\
\text { - Data from plant instrumentation (temperature information obtained during and immediately after the } \\
\text { accident, gas concentration data from the gas treatment system, and neutron and gamma detector data } \\
\text { from subcriticality monitoring systems). }\end{array}$ \\
\hline
\end{tabular}


Table 8-1. Evaluation areas and types of evaluated examination information

\begin{tabular}{|c|c|}
\hline Area & Types of Examination Information Evaluated \\
\hline $\begin{array}{l}\text { Area } 4 \text { - } \\
\text { Combustible Gas } \\
\text { Effects }\end{array}$ & $\begin{array}{l}\text { Visual information (photos and videos gathered using robotic examinations and stand-off methods such } \\
\text { as muon tomography). } \\
\text { Data from plant instrumentation (temperature information obtained during and immediately after the } \\
\text { accident, gas concentration data from the gas treatment system, pressure data, and neutron and gamma } \\
\text { detector data from monitoring systems). }\end{array}$ \\
\hline $\begin{array}{l}\text { Area 5- Operations } \\
\text { and Maintenance - } \\
\text { Instrumentation } \\
\text { Survivability }\end{array}$ & $\begin{array}{l}\text { Data from plant instrumentation (water level data, pressure data,. temperature information obtained } \\
\text { during and immediately after the accident, gas concentration data from the gas treatment system, and } \\
\text { neutron and gamma detector data from monitoring systems). } \\
\text { - Operator and staff observations. }\end{array}$ \\
\hline
\end{tabular}

Forensics evaluations by the expert panel led to the identification of several recommendations for future U.S. activities. Table 8-3 lists the recommendations identified for each area. As indicated in this table, recommendations were primarily related to additional calculations to resolve modeling uncertainties and the need for continued evaluations as additional information becomes available. In general, these recommendations are consistent with those provided in our FY2017 report. Changes were made to reflect new information obtained from TEPCO (e.g., examination information indicates that vessel failure occurred in all three units operating on March 11,2011) and to accommodate requests associated with the addition of Area 5, Operations and Maintenance -Instrumentation. As discussed in Section 7, calculations related to the conditions experienced by instrumentation offer important insights regarding the survivability of sensors and cabling during severe accidents and are important for validating updated severe accident guidance provided to operators.

Table 8-2. Recommendations for future U.S. activities

\begin{tabular}{|c|c|}
\hline Area & Recommendations \\
\hline \multirow[t]{5}{*}{$\begin{array}{l}\text { Area } 1 \text { - } \\
\text { Component } \\
\text { Degradation }\end{array}$} & $\begin{array}{l}\text { Sensitivity studies should be performed on containment failure location and size with respect to radiological } \\
\text { releases (timing, amount) and impact on accident progression. These sensitivity studies should be done with } \\
\text { both MAAP and MELCOR to cover a range of predicted containment and primary system conditions. } \\
\text { Sensitivities for each unit would provide insight into which failure likely caused depressurization, the } \\
\text { conditions under which such a failure occurred, and the effect of multiple failures. Some previous } \\
\text { sensitivity analyses have been performed for failure of the primary system (SRV versus MSL, etc.) and the } \\
\text { containment. }\end{array}$ \\
\hline & The expert panel should continue to review available information and update Table $3-4$. \\
\hline & $\begin{array}{l}\text { A concise comparison should be developed for the predicted conditions by both MAAP and MELCOR at } \\
\text { the MSIV (temperature, pressure) for 1F2 and 1F3. The expert panel should continue to review any } \\
\text { additional inspection information of the MSIV room or MSLs. }\end{array}$ \\
\hline & $\begin{array}{l}\text { The expert panel is interested in 'before' pictures for specific locations from TEPCO Holdings. This } \\
\text { recommendation is not currently identified as an information need. As more information becomes available, } \\
\text { however, the panel will identify specific places. }\end{array}$ \\
\hline & $\begin{array}{l}\text { The expert panel should place more emphasis on reviewing available examination information related to } \\
\text { spent fuel (i.e., assemblies, pools, casks, etc.) at Fukushima Daiichi. Experts should also consider existing } \\
\text { U.S. research that may aid in the decommissioning efforts and identify inspections at Fukushima Daiichi } \\
\text { that may benefit ongoing U.S. activities. }\end{array}$ \\
\hline
\end{tabular}


Table 8-2. Recommendations for future U.S. activities

\begin{tabular}{|c|c|}
\hline Area & Recommendations \\
\hline \multirow[t]{5}{*}{$\begin{array}{l}\text { Area } 2 \text { - Dose } \\
\text { Surveys and } \\
\text { Isotopic Surveys } \\
\text { and Samples }\end{array}$} & $\begin{array}{l}\text { Similar to Area } 1 \text { Recommendation 1, experts agreed that information on this topic suggests that sensitivity } \\
\text { studies should be performed on containment failure location and size with respect to radiological releases } \\
\text { (timing, amount) and impact on accident progression. These sensitivity studies should be done with both } \\
\text { MAAP and MELCOR to cover a range of predicted containment and primary system conditions. To } \\
\text { compare results from simulations of core damage progression and radiological release to the environment, } \\
\text { additional analyses with an environmental radiological transport code, such as MACCS, would be useful. } \\
\text { Sensitivities for each unit would reduce uncertainties in code modeling by providing insight into which } \\
\text { failure likely caused depressurization, the conditions under which such a failure occurred, and the effect of } \\
\text { multiple failures. Some previous sensitivity analyses have been performed for failure of the primary system } \\
\text { (SRV versus MSL, etc.) and the containment. As discussed within this section, reactor building radiological } \\
\text { hotspots provide a means to assess inputs provided to severe accident computer codes, but do not typically } \\
\text { facilitate assessment of the computer code models. }\end{array}$ \\
\hline & $\begin{array}{l}\text { Similar to Area } 1 \text { Recommendation 3, concisely compare the predicted conditions by both MAAP and } \\
\text { MELCOR at the MSIV (temperature, pressure) for } 1 \mathrm{~F} 2 \text { and } 1 \mathrm{~F} 3 \text {. }\end{array}$ \\
\hline & $\begin{array}{l}\text { Similar to Area } 1 \text { Recommendation 4, the expert panel continues to be interested in examination } \\
\text { information of MSIV room components. Specific examination needs to support these evaluations are } \\
\text { identified in RB-10 and RB-13 of Appendix C. }\end{array}$ \\
\hline & $\begin{array}{l}\text { The expert panel recommends that the U.S. Forensics Effort continue to evaluate information obtained from } \\
\text { examinations of RPVs within each unit impairment location. Additional visual information would be } \\
\text { particularly useful in Area } 2 \text { Recommendation } 1 \text { sensitivity studies. }\end{array}$ \\
\hline & $\begin{array}{l}\text { The expert panel recommends that the U.S. Forensics Effort complete an evaluation to determine the source } \\
\text { of } \mathrm{Na}, \mathrm{Mg}, \mathrm{Al} \text {, and } \mathrm{Si} \text { measured in the SEM-EDS analysis (see Section 4.3.4). This evaluation should be } \\
\text { completed by comparing the measured molar ratios with representative values found in sand from seawater } \\
\text { injection, insulation, and/or aerosol from concrete decomposition to determine the source of } \mathrm{Na}, \mathrm{Mg}, \mathrm{Al} \text {, } \\
\text { and } \mathrm{Si} \text {. }\end{array}$ \\
\hline \multirow[t]{2}{*}{$\begin{array}{l}\text { Area } 3 \text { - Debris } \\
\text { Endstate }\end{array}$} & $\begin{array}{l}\text { As alluded to in Section 5.2, refine the MAAP and MELCOR RPV nodalization schemes for the 1F1, 1F2, } \\
\text { and 1F3 RPVs with the aim of predicting the measured temperatures shown in Figures G-1 through G- } 3 \text {. } \\
\text { The post-accident debris locations predicted inside the RPV, coupled with changes in water addition rate } \\
\text { and location, may provide a means for assessing the accuracy of the debris end-state predictions. This } \\
\text { comparison may also provide insights into appropriate modeling of in-core melt progression that has been } \\
\text { identified as a key uncertainty in the MAAP-MELCOR crosswalk exercise.[57] } \\
\text { Also, the findings from 1F2 and 1F3 suggest that a non-negligible amount of core debris may be held up on } \\
\text { structures below the reactor vessel. System analysis codes should first be enhanced to account for this } \\
\text { behavior and then exercised assuming a range of core debris holdup in a situation that is not cooled by } \\
\text { water to investigate the impact of heat sources not covered by water on PCV gas phase temperature and } \\
\text { pressure. This type of analysis would inform accident management guidance for accident scenarios in } \\
\text { which ex-vessel core debris may be frozen to structures above water levels in the primary containment. }\end{array}$ \\
\hline & $\begin{array}{l}\text { Repeat the MELTSPREAD-CORQUENCH analysis that was originally done for 1F1[58] for 1F2. Various } \\
\text { system-level code analyses, as well as recent images, indicate that vessel failure occurred at this unit. } \\
\text { However, it is suspected that vessel likely occurred much later in the accident sequence due to the } \\
\text { continued operation of RCIC for } \sim 72 \text { hours in an unregulated mode. This study may be useful in showing } \\
\text { that it is unlikely that the melt contacted the liner in this late pour scenario, or if it did, that the shell likely } \\
\text { remained intact due to reduced thermal loading. As discussed in [11], no evidence of liner failure has been } \\
\text { found for } 1 \mathrm{~F} 2 \text {, and this would provide a means for rationalizing that observation relative to the finding that } \\
\text { the liner in } 1 \mathrm{~F} 1 \text { has been damaged. }\end{array}$ \\
\hline
\end{tabular}


Table 8-2. Recommendations for future U.S. activities

\begin{tabular}{|l|l|}
\hline \multicolumn{1}{|c|}{ Area } & \multicolumn{1}{c|}{ Recommendations } \\
\hline $\begin{array}{l}\text { Area 4 - } \\
\text { Combustible Gas } \\
\text { Effects }\end{array}$ & $\begin{array}{l}\text { To date, the thermal hydraulic and core nodalizations of the reactor pressure vessel in both MAAP and } \\
\text { MELCOR have been shown to well represent the physics within the core. However, there are still } \\
\text { uncertainties in hydrogen generation driven by modeling of core relocation behavior and debris bed } \\
\text { geometry in partially mitigated and unmitigated severe accidents. It is currently unclear if most hydrogen } \\
\text { generation in the Fukushima units occurred in-vessel or ex-vessel, with both MAAP and MELCOR } \\
\text { indicating different answers. The differences in the two codes in modeling core debris behavior inside the } \\
\text { RPV can have significant downstream effects on eventual MCCI and ex-vessel non-condensible gas } \\
\text { generation. To address these important gaps in severe accident progression, the expert panel recommends } \\
\text { that evaluations of combustible gas generation differences resulting from in-core relocation and debris bed } \\
\text { morphology be continued with the goal of reducing uncertainties. }\end{array}$ \\
\cline { 2 - 3 } $\begin{array}{l}\text { Better knowledge on hydrogen migration paths through degraded seals and penetrations from the PCV to } \\
\text { the RB is desirable. The expert panel should continue to review available information for insights. }\end{array}$ \\
\cline { 2 - 3 } & $\begin{array}{l}\text { There is little knowledge about ignition sources or the mechanisms that lead to ignition during such an } \\
\text { extended SBO for all the explosions at Daiichi; the expert panel should continue to review available } \\
\text { information for insights. }\end{array}$ \\
\hline $\begin{array}{l}\text { Area 5- Operations } \\
\text { and Maintenance - } \\
\text { Instrumentation } \\
\text { Survivability }\end{array}$ & $\begin{array}{l}\text { The expert panel recommends that calculations be completed with MAAP, similar to those completed with } \\
\text { MELCOR, to estimate conditions to which sensors were exposed during these events. }\end{array}$ \\
\cline { 2 - 3 } & $\begin{array}{l}\text { The expert panel recommends that an exploratory exercise be performed in modeling the reference RPV } \\
\text { water level reference leg in codes such as MELCOR and MAAP. }\end{array}$ \\
\hline
\end{tabular}

The expert panel also developed suggestions for additional examination information. These suggestions are summarized in Table 8-3. As indicated in this table, suggestions were primarily to continue with planned D\&D examinations and are, in general, consistent with those provided in our FY2017 report. Changes were made to accommodate requests associated with new information obtained from recent examinations and the addition of Area 5, Operations and Maintenance - Instrumentation.

Table 8-3. Suggestions for additional examinations

\begin{tabular}{|l|l|}
\hline \multicolumn{1}{|c|}{ Area } & \multicolumn{1}{c|}{ Suggestions for Additional Examination Information } \\
\hline $\begin{array}{l}\text { Area 1 - } \\
\text { Component } \\
\text { Degradation }\end{array}$ & $\begin{array}{l}\text { To facilitate updates to Table 3-4, the expert panel has requested that TEPCO Holdings continue to review } \\
\text { information in this table. In addition, the expert panel will continue to review additional information, such } \\
\text { as penetration, component, and system examination results, from TEPCO Holdings and update this table. }\end{array}$ \\
\cline { 2 - 3 } & $\begin{array}{l}\text { As discussed in Section 4, surveys in containment to understand the integrity of the RPV lower head, } \\
\text { pedestal, and containment liner are of particular interest. These information needs are identified in } \\
\text { Appendix C. }\end{array}$ \\
\cline { 2 - 3 } & $\begin{array}{l}\text { As discussed in Sections E.1.1 and E.1.2, the RCW system may have played a role in the 1F1 accident } \\
\text { progression. Examination information identified in Appendix C and other information previously obtained } \\
\text { by TEPCO Holdings (i.e., dose surveys around the surge tank, system water level, images of system } \\
\text { components, etc.) may provide insight into its role during the accident. }\end{array}$ \\
\hline $\begin{array}{l}\text { Area 2 - Dose } \\
\text { Surveys and } \\
\text { Isotopic Surveys } \\
\text { and Samples }\end{array}$ & \begin{tabular}{l} 
Continue planned additional isotopic evaluations. \\
\hline
\end{tabular}
\end{tabular}


Table 8-3. Suggestions for additional examinations

\begin{tabular}{|c|c|}
\hline Area & Suggestions for Additional Examination Information \\
\hline \multirow[t]{5}{*}{$\begin{array}{l}\text { Area } 3 \text { - Debris } \\
\text { Endstate }\end{array}$} & $\begin{array}{l}\text { Perform chemical analysis of high radiation deposits or particles found inside the reactor building (1F1, } \\
1 \mathrm{~F} 2 \text {, and } 1 \mathrm{~F} 3) \text {; e.g., the white deposits from the HPCI room using FE-SEM, XRD, etc. }\end{array}$ \\
\hline & $\begin{array}{l}\text { Perform chemical analysis of sediment on drywell floor at the X-100B penetration location in } 1 \mathrm{~F} 1 \text {. The } \\
\text { upper surface of the sediment is } \sim 30 \mathrm{~cm} \text { above drywell floor. } \\
\text { Evaluate the nature of the material below the upper surface of the debris at the X-100B penetration location } \\
\text { in } 1 \mathrm{~F} 1 \text { to determine if it is additional sediment or other material such as core debris. }\end{array}$ \\
\hline & $\begin{array}{l}\text { Perform chemical analysis (XRF) of black material discovered on CRD exchange rail in 1F2 at X-6 } \\
\text { penetration location }\end{array}$ \\
\hline & Perform chemical analysis of black material on 'existing structure' in 1F1 images at location 'D3' \\
\hline & Obtain additional images from examinations in 1F3 X-53 penetration. \\
\hline $\begin{array}{l}\text { Area } 4 \text { - } \\
\text { Combustible Gas } \\
\text { Effects }\end{array}$ & $\begin{array}{l}\text { Continue to obtain visual information, radiation surveys, and isotopic evaluations to ascertain the source } \\
\text { (e.g., in-vessel, ex-vessel, or both) of combustible gas generation within the affected units. }\end{array}$ \\
\hline $\begin{array}{l}\text { Area 5- Operations } \\
\text { and Maintenance - } \\
\text { Instrumentation } \\
\text { Survivability }\end{array}$ & $\begin{array}{l}\text { As noted in Section 7.2.3, additional examination information would be useful to understand why the RPV } \\
\text { B pressure signal experienced a failure prior to other transmitters at } 1 \mathrm{~F} 1 \text {. }\end{array}$ \\
\hline
\end{tabular}

\subsection{Implementation Activities for Forensics Insights}

Results from the examinations at Daiichi are already being used to address many items listed in Objective 2 (Section 1.1); namely, to enhance guidance for PWR and BWR severe accident mitigation and to reduce uncertainties in severe accident code models. Selected implementation activities are discussed below. As described in this section, some of the examination data may lead to the industry gaining extended credit for instrumentation and component survivability under conditions that exceed their environmental qualification envelop. Examination data related to debris holdup on ex-vessel structures and spreading within the containment are also deemed to be important for improving severe accident code predictions and guidance for PWR and BWR severe accident mitigation.

\subsubsection{Industry Accident Management Guidance}

Insights gained from the Fukushima accident have been used, and are continuing to be used, to enhance industry Severe Accident Guidance (SAG).[22, 23, 24, 25, 80, 87, 212, 213] The Emergency Procedures Committees for the BWROG maintain generic Severe Accident Guidelines (SAGs) and for the PWROG maintain generic Severe Accident Management Guidelines (SAMGs). ${ }^{\dagger}$ New information is continuously evaluated as new information becomes available (e.g., examination information from the Fukushima accidents and from issues identified by member utilities), and the generic SAG is periodically enhanced based on this new information. U.S. plants have voluntarily committed to implemented site specific SAGs or SAMGs within 3 years or 2 refueling cycles following an update to the Owner Group generic SAGs or SAMGs. Specific examples in which industry guidance is benefiting from the U.S. Fukushima Forensics efforts include:

$\dagger$ The BWROG SAGs and PWROG SAMGs are terms used by the owners group to refer to their generic SAG. 
- Primary Containment Venting - As discussed in Sections 3, 4, and 6, the three operating units at Daiichi exhibited different patterns of PCV leakage of fission products and hydrogen. The variability introduced by unit-to-unit differences at Fukushima points to uncertainties in actual leakage locations and confirms the importance of maintaining containment conditions below specific temperature and pressure limits as an appropriate strategy.

Fukushima accident insights lead to improvements in the BWROG containment venting strategies both before and after core damage occurred. The BWROG Emergency Planning Guidelines (EPGs)/ SAGs provide guidance on venting the primary containment when the pressure reaches the Primary Containment Pressure Limit (PCPL). The PCPL is the lesser of:

- The pressure capability of the primary containment (may exceed design pressure)

- The maximum primary containment pressure at which vent valves sized to reject all decay heat from the containment can be opened and closed

- The maximum primary containment pressure at which RPV vent valves can be opened and closed.

The PCPL is a function of primary containment water level. Exceeding the limit may challenge primary containment vent valve operability, SRV operability, RPV vent valve operability, or the structural integrity of the primary containment.

Containment venting in BWRs is focused on using the suppression pool to prevent or mitigate core damage and minimize radionuclide release. The BWROG SAGs provide guidance on water management to maximize the use of the suppression pool's scrubbing capability during containment venting. The preferred containment vent path is through the wetwell making use of the harden vent path in Mark I and II containment designs.

The PWROG SAMGs also provide guidance on containment venting and is based on their specific containment design features and equipment performance. Venting is initiated for one of two reasons, to lower the containment pressure or to lower the hydrogen concentration.* The status of the containment spray and cooling systems will also determine if venting should be performed. For US PWRs, there is not a hardened containment vent so that the ability to re-close the vent cannot be guaranteed. However, once containment pressure is restored to design pressure (or half the venting setpoint for ice condenser containments), the PWROG SAMGs direct station personnel to attempt to isolate the vent to minimize the total release. As pressure approaches the containment venting setpoint, actions are taken to prepare for venting including evacuation of personnel from the area around the vent location.

- Water Addition Pathways - As discussed in Section 5, currently available information from 1F1, $1 F 2$, and $1 F 3$ indicates that there are differences in the core debris end-state location. It is believed that these differences are due to differences in the accident progression at each unit, particularly decay heat levels and the timing and rate of periodic water addition prior to stabilizing the core debris. (RCIC/HPCI operation, injection from fire engines, etc.).

The BWROG SAGs and PWROG SAMGs have always placed a higher priority on injection of water to the reactor vessel compared to the primary containment.

$\$$ PWR venting does not necessarily lower containment hydrogen concentrations because the venting discharges a gas mixture of steam, air and hydrogen (if the hydrogen is uniformly mixed). Therefore, venting does not change the concentration of any of these gases in the containment per se. However, venting would cause some of the water pooled in the lower regions of containment to "flash to steam" and thereby increase the steam partial pressure which, in turn, decreases the hydrogen and air concentrations. 
The BWROG SAGs provide guidance on the injection of water to the reactor vessel versus the primary containment. In most conditions, the generic guidance is for vessel injection (this is a function of containment design and other conditions). If the reactor vessel is failed, the injected water is expected to flow through the reactor vessel breach to the core debris in the primary containment. This ensures that core debris is cooled with injected water (and possibly submerged in water) regardless of its location. The improvements to water addition/management guidance, based on insights from Fukushima, provides additional strategies that reduce the offsite doses from containment venting and or failure (water is required to cool core debris in all possible locations and scrub fission products; primary containment and in the reactor vessel).

The PWROG SAMGs provide for adding water to the reactor vessel as a higher priority than adding water to containment but provide guidance for adding water to both the reactor vessel and containment if sufficient resources are available. In general, the priority for water addition in the PWROG SAMGs is: 1) steam generators (to protect the integrity of the steam generator tubes, prevent a containment bypass release, and provide core cooling), 2) reactor coolant system, and 3) the containment. However, the actual priority during a severe accident is determined by the Diagnostic Process Guideline which sets priorities based on plant conditions and challenges to fission product barriers. The PWROG SAMG for addition of water to containment is meant to provide a water pool for quenching and cooling core debris entering containment if reactor vessel failure occurs (because injection to the reactor vessel was not effective). Any water addition to containment is limited to prevent flooding of important equipment and instrumentation in the containment.

- Hydrogen Combustion Outside Primary Containment - As discussed in Section 6, there were differences in hydrogen accumulation and combustion phenomena for each of the four units. The BWROG and PWROG generic guidance was enhanced after the Fukushima accident to include venting the reactor and auxiliary buildings. The variability in the source of the hydrogen and its accumulation in the reactor building across the damaged units points to uncertainties and confirms the SAG enhancements (BWROG/ PWROG) to include strategies for venting buildings adjacent to the primary containment as an appropriate action when primary containment pressure exceeds a predetermined value based on containment design features. The BWROG SAG and PWROG SAMG include criteria for ventilating the reactor and auxiliary buildings if normal ventilation is not available. For BWRs, doors at higher elevations within the reactor building are opened on entry to severe accident guidance. Once there is evidence of hydrogen, doors are also opened at lower elevations to promote natural circulation. For PWRs, doors and higher level vents are opened to create a flow path when containment pressure exceeds design basis values and the normal ventilation system is not running.

- Instrumentation - As discussed in Sections 3 and 5, instrumentation and control system logic (e.g., RCIC) anomalies contributed to the accident progression at Fukushima, or influenced the decision-making related to accident management. Because of these Fukushima insights, both the BWROG and PWROG Technical Support Guidance (TSG) for instrumentation was enhanced to include additional calculational aids to make better use of the available instrumentation and to better interpret its response. The BWROG is working with the DOE (SNL) to make these calculational aids functional on iPhone, iPad, or Android devices to improve their usability during an accident or training exercise. The enhanced BWROG and PWROG guidance is used to improve the understanding of the expected response trends of instrumentation, tie that response to known severe accident phenomena (Fukushima Case Studies) and compare the instrumentation response from several instruments where possible. 
As discussed in Section 7, adequate instrumentation at 1F1, 1F2, and 1F3 appears to have survived harsher environmental conditions longer than predicted by environmental qualification calculations. In addition to enhancing severe accident guidance, the ability to quantify these conditions and times may permit the extension of calibration intervals or environmental qualifications for some instruments. Assessments of such extensions should consider that the updated owner guidance seeks other means to validate readings. Assessments should also note that some trend information provides knowledge of the unit more accurately than instantaneous readings so accuracy of measurements is not always critical to understand the physics of the event.

- Severe Accident Models - The BWROG SAG and PWROG SAMG are symptom based and use insights/first principles from the severe accident phenomena behavior described in the EPRI Technical Basis Report (TBR).[214, 215]The BWROG and PWROG SAGs are largely independent of the severe accident predictions by either severe accident integral codes MAAP or MELCOR. In addition, the BWROG symptom based EPGs/SAGs and the PWROG SAMGs are focused on addressing anything physically reasonable. For the PWROG SAMGs, MAAP has been used to revise the containment venting setpoint to delay venting as long as possible and reduce offsite releases due to nuclear decay. MAAP has also been used to validate the venting closure setpoint to minimize the total releases.

As discussed in Sections 3 through 7 and summarized in Section 8.2.2, there are certain aspects of the accidents at the Fukushima Daiichi units that are not well modeled by systems analysis codes (MAAP and MELCOR). Specific examples for which data are (or are expected to be available) from Fukushima forensic information include the amount of hydrogen generation from zirconium water reactions in the late phases of core degradation, environmental conditions near primary containment penetrations and core debris holdup on ex-vessel structures and spreading following reactor vessel failure. These examples illustrate that significant uncertainties still exist in the code predictions that may be due to the limited database for model development.

Insights from the Fukushima Forensics activities particularly for hydrogen generation, temperature conditions at penetrations, and ex-vessel core holdup on structures and debris spreading can be used to further improve severe accident code predictions. In addition, these insights may be of benefit to improving the guidance found in the BWROG SAG and PWROG SAMG, as well as Volume 2 of the TBR. The DOE Forensics effort should continue to work with these organizations (BWROG, PWROG, and EPRI) to foster improvements in the guidance and documents when appropriate.

As discussed in Section 2.2.1.3, application of severe accident analysis for a specific BWR application is presented in NEI 13-02 [84]. A summary of this application is described in the Introduction section of NEI 13-02, repeated below:

Analysis and calculations performed in conjunction with participation in the Containment Protection and Release Reduction (CPRR) rulemaking, as documented in Reference 27 [Reference 215 in this report], has confirmed that water addition in conjunction with venting that can be accomplished under severe accident conditions provides more safety benefit than venting alone, including events involving extensive core damage and reactor vessel breach. The safety benefit comes from the cooling effect of the added water on the containment temperatures. The reduction in containment temperature provides reasonable assurance that the probability of gross containment leakage due to temperature related effects is minimized. Water addition that can be provided to the Reactor Pressure Vessel (RPV) or Drywell under severe accident conditions has been termed Severe Accident Water Addition (SAWA). The analysis also shows that in-vessel retention may occur with 
RPV injection. The preservation of the wetwell vent path which is accomplished by managing the water addition flow rate to the extent that the wetwell vent line remains available until other means of severe accident coping are available is termed Severe Accident Water Management (SAWM). Severe Accident Coping is defined in Appendix A and SAWM is described in Appendix C.

The analysis performed to support the SAWA/SAWM strategies established timing for specific accident sequences (e.g., RCIC failure at $\mathrm{T}=0,1$ hour to core damage, 8 hours to establish SAWA flow) that conform to the reference plant in Reference 27 [215]. Licensees should ensure procedures and designs consider the early deployment of portable equipment to facilitate expedited water addition and to repower needed equipment and instrumentation such that no unnecessary delays in deployment are introduced into accident response. This expectation is to encourage licensees to take reasonable actions to minimize SAWA equipment deployment times, but does not imply that licensees are required to modify existing or construct additional structures for SAWA equipment storage, or to choose alternate SAWA connections points from those otherwise complying with Orders EA-12-049 and EA-13-109."

- Operation of Turbine Driven Pumps - As discussed in Section 3, information from 1F2 and 1F3 provide valuable insights related to operation of turbine driven pumps (RCIC and HPCI) under beyond design basis conditions. Operation of RCIC was critical in delaying core damage for days (almost three days for 1F2) even though the turbine-pump system ran without DC power for valve control and with high water temperatures from the BWR wetwell. The RCIC system apparently operated in a self-regulating mode supplying water to the core and maintaining core-cooling until it eventually failed at about 72 hours (at the same time as the 1F3 explosion). For 1F3, RCIC stopped when a protection signal (dc power was still available) tripped the pump. HPCI auto-started on 'lo-lo' reactor vessel water level and ran until the reactor vessel pressure dropped below the operating range of the HPCI turbine; HPCI was operated in 'Test Mode' most of the time with only periodic flow to the reactor vessel which is thought to have resulted in low steam flow to the turbine.

BWROG and PWROG accident management strategies provide guidance on the use of turbine driven pumps (RCIC and HPCI for BWRs and AFW for PWRs) to maintain core cooling. As a result of forensic information, the BWROG has provided enhanced guidance on the operation of turbine driven pumps under beyond design basis conditions. The PWROG is considering enhancements to guidance on operating turbine driven pumps under beyond design basis conditions for training and guidance.

The DOE is considering further testing to gain additional insights related to operation of turbine driven pumps. Self-regulation of RCIC with water level is a very important accident management strategy that if implemented in the BWR fleet would significantly simplify the management of accidents. Activities in this area should be fostered and supported to the extent possible. Once the technical basis is firmly established, DOE working with the BWROG's emergency procedures committee can make a significant improvement in reducing the core damage frequency in BWRs.

\subsubsection{Code Modeling Enhancements}

Analyses of the events at Daiichi and information from forensics examinations are also being used (and will continue to be used) to reduce uncertainties in systems analysis code models. In particular, recent evaluations showing that core materials have relocated ex-vessel emphasize the importance of refining 
models for predicting vessel failure, holdup on ex-vessel structures, and ex-vessel debris spreading. Because this area affects both MELCOR and MAAP, it is highlighted as a separated topic in this section.

\subsubsection{Vessel Failure and Ex-vessel Debris Heat Transfer}

Severe accident analyses using the MAAP and MELCOR computer codes (pre-Fukushima) assume that the vessel fails at a single location and that any ex-vessel core debris will spread uniformly over the floor of the compartment into which it is discharged at reactor vessel failure. Examination information from probes inserted into the primary containment for the three Fukushima units (1F1, 1F2 and 1F3) has provided important information on the location and composition of the core debris in each unit that is not in agreement with these analysis models and affect heat transfer from ex-vessel debris to the containment.

For 1F1, examination information (see Section 5 and Appendix G) indicates that most of the core is no longer in the reactor vessel based on evaluations of muon tomography images and thermocouple data indicating that coolant temperatures were well below saturation prior to the time that injection was switched to core spray injection. The entire drywell is flooded to a depth of about 2 meters. In 2012 and 2017, a probe inserted through the X-100B penetration revealed that debris is present on the drywell floor. The 2012 probe only observed conditions directly below the X-100B penetration, while the 2017 probe was able to observe conditions near the opening between the pedestal and drywell. Based on simulations with various computer codes, the spreading of the core debris is quite uncertain because it depends on a number of modeling assumptions including temperature of the debris when it was released from the reactor vessel as the time history of the release. While it is known that the core debris is covered with water, there is no further information about the depth of core debris in the pedestal region (where it has likely eroded the basemat) and the drywell floor.

For $1 \mathrm{~F} 2$, it has been determined that only a fraction of the core debris is ex-vessel in the pedestal region of the drywell (see Section 5 and Appendix G). There was evidence of continued steam generation for the water covering this core debris and only minimal core concrete interactions are expected. Observations using the X-6 penetration indicate that some core debris adhered to the control rod drive mechanisms outside the reactor vessel. The majority of the core debris has been determined to be inside the reactor vessel with most of that in the bottom head; some peripheral fuel assemblies may still be in the "core region" in a degraded state. Much of this evidence is drawn from the decrease in temperatures when cooling was switched from feedwater to core sprays. Subsequent 1F2 investigation implies multiple locations of vessel failure. The entire bottom of the pedestal is covered with sandy and clay-like deposits; some fuel assembly components have fallen to the bottom of the pedestal, and deposits thought to be fuel debris were found in the vicinity of these fallen components. There is some information about the depth of core debris in the pedestal region and the drywell floor. Although examination information indicates that some of the relocated debris in the pedestal region is not submerged, data suggest that this material was effectively cooled by water flowing over this material on its way to the drywell region.

For $1 \mathrm{~F} 3$, there have been observations using probes through the X-6 penetration (see Section 5 and Appendix G). Based on variations in temperature change switching from feedwater to core sprays, it was estimated that most of the core debris is in the lower head of the reactor vessel or ex-vessel in the pedestal region or the drywell. Recent images obtained from $1 \mathrm{~F} 3$ X-6 penetration examinations implies multiple areas of reactor vessel failure as well as areas on the surface of the water where water may be dripping from vessel failure locations. For 1F3, drywell spraying was performed for more than an hour in response to the accident. Movement of fuel debris from the pedestal region to the drywell could have been sup- 
pressed considering a water level on drywell floor at the time of core relocation to the pedestal region due to reactor vessel failure. As with $1 \mathrm{~F} 1$, examination information indicate that the ex-vessel core debris is covered with water, but there is limited information about the depth of core debris in the pedestal region and the drywell floor.

The Fukushima evidence suggests three areas for further severe accident management strategy review:

- Core materials may relocate from the vessel in multiple failure locations. The impact of multiple failure locations should be evaluated to determine the impact on heat transfer and accident management strategies.

- Ex-vessel core debris spreading in the primary containment may not be very uniform. Accident management guidance should be reviewed to determine the degree to which any guidance is based on the modeling assumption of a uniform core debris spreading on the floor of the primary containment. In some cases, this may result in an increase in the recommended long-term water level in the primary containment.

- Ex-vessel core debris may be frozen on structures above the drywell water level, and the decay heat from that core debris is likely being transferred directly to the drywell atmosphere. This could occur due to dynamic processes that can occur at reactor vessel failure, such as a pressure-driven core debris ejection from the reactor vessel, or a passive core debris "pour" from a localized vessel breach. Accident management guidance should be reviewed to determine appropriate strategies for accident scenarios in which ex-vessel core debris may be frozen to structures above water levels in the primary containment.

- Core debris that remained in the reactor vessel (peripheral fuel assemblies and debris in the bottom head) can be effectively cooled by injection to the reactor vessel at a level above the original core location (i.e., injection directly to the reactor vessel rather than to the reactor vessel downcomer). Accident management strategies should be reviewed to assure that some injection to the reactor vessel at a location above the core is maintained in the long term to provide cooling to in-vessel core debris to minimize the heat load to primary containment atmosphere as well as to prevent further movement of the in-vessel core debris.

\subsubsection{MELCOR 2.2}

\section{Code Characteristics and Overview}

MELCOR is a fully integrated, engineering-level computer code with the primary purpose of modeling the progression of accidents in light water reactor nuclear power plants. A broad spectrum of severe accident phenomena in both boiling and pressurized water reactors is treated in MELCOR in a unified framework. Uses of MELCOR include estimation accident progressions and the determination of fission product source terms. MELCOR can also be used to evaluate sensitivities and uncertainties of these calculations.

The MELCOR code is composed of an executive driver and a number of major modules, or packages, that together model the major systems of a reactor plant and their generally coupled interactions. Reactor plant systems and their response to off-normal or accident conditions include:

- Thermal-hydraulic response of the primary reactor coolant system, the reactor cavity, the containment, and the confinement buildings 
- Core uncovering (loss of coolant), fuel heatup, cladding oxidation, fuel degradation (loss of rod geometry), and core material melting and relocation

- Heatup of reactor vessel lower head from relocated fuel materials and thermal and mechanical loading and failure of the vessel lower head, and transfer of core materials to the reactor vessel cavity

- Core-concrete attack and ensuing aerosol generation

- In-vessel and ex-vessel hydrogen production, transport, and combustion

- Fission product release (aerosol and vapor), transport, and deposition

- Behavior of radioactive aerosols in the reactor containment building, including scrubbing in water pools, and aerosol mechanics in the containment atmosphere such as particle agglomeration and gravitational settling

- Impact of engineered safety features on thermal-hydraulic and radionuclide behavior

The various code packages have been written using a modular structure with interfaces between them. This allows the exchange of information among them so that all phenomena are explicitly coupled at every step.

\section{MELCOR 2.2 Description and Relevant Improvements}

The analyses performed and insights gained from participating in the OECD/NEA BSAF Phase I Project (see Section 2.2.2.2) highlighted several key areas where MELCOR 2.1 could be enhanced by improving model robustness and implementing new dedicated models to better capture phenomenological behavior and key boundary conditions that drive source term. Code improvements have been directed in the following areas to better simulate the Fukushima-Daiichi Power Station response: detailed safety system modeling, RCIC behavior and modeling, ex-vessel behavior, and code performance during core reflood.

The necessity of the new MELCOR homologous pump model was highlighted by the behavior of the 1F2 RCIC system. The updated model is similar to that found in RELAP (RELAP5-3D, RELAP4) but with some distinguishing features. A user can fully specify 1) rated pump conditions, 2) single/two-phase pump performance via homologous curve input, 3) pump friction torque as a polynomial, 4) pump inertia as a polynomial, 5) pump speed and motor torque controls, and 6) pump trips. Additionally, pump data from the Semiscale and Loft experiments are included as a "built-in" option with a "universal correlation" taken from the literature. [216] More recent evaluations emphasize that RCIC performance is impacted by assumptions regarding torus flooding. As indicated in [217], the gravity head associated with water accumulated within the wetwell impacts the timing of CST to WW switchover. Sensitivity studies indicated that available data are best matched when the torus room is assumed to be $30 \%$ flooded.

The accident progressions in both $1 \mathrm{~F} 2$ and $1 \mathrm{~F} 3$, where alternative water injection was introduced across various core degradation states, required improving code robustness and performance during reflood. One key set of changes temporally relaxes the rate-of-change of the quench velocity and causes the quench velocity to be smoothly driven to zero within a small distance of the pool level. Several model corrections and numerical improvements to the MELCOR quench model were developed and implemented and have significantly improved the robustness of the code for reflood conditions.

Akin to this, a temporal relaxation model was introduced within the code. Many physical processes in MELCOR are modeled by correlation based relationships developed from steady-state experiments. These 
models do not represent the time it takes for these processes to respond as conditions change. As a result, temporal "rate-of-change" aspects of MELCOR simulations are not expected to be highly accurate and numerical instabilities can be magnified when sudden changes occur. Temporal relaxation is a simple way to introduce a user-imposed time-scale based model that limits how quickly processes being modeled can change in time. This has made it significantly easier to perform forensic analysis of core oxidation and relocation behavior for analysis and improved code robustness.

In the case of core degradation, SNL and the US NRC decided to take a "wait-and-see" approach to changing the phenomenology of core degradation within MELCOR. Future changes to this portion of the code will be highly informed by entry into the reactor pressure vessel and/or the primary containments of each unit. That said, we are currently assessing MELCOR crust formation and molten pool/crust formation modeling with a focus on steam permeability to severely damaged core regions and its effects on hydrogen generation and on sensible heat gain and convective heat loss from such degraded regions. This is partly motivated by recent MELCOR/MAAP crosswalk studies comparing the two code modeling paradigms and also from deep analysis of the Fukushima Daiichi Unit "three peaks" time period (see Section 7.2.4.2) where there is evidence of core degradation processes affecting hydrogen generation and PCV pressurization. This investigation could result in further refinement of MELCOR core degradation modeling.

On-going efforts to revive the dedicated MELCOR U-Zr-O eutectic model are expected to enhance future Fukushima evaluations. The updated eutectic model will estimate the liquefaction temperature of $\mathrm{UO} 2 / \mathrm{ZrO} 2$ based on local composition. Initial evaluations of the new model indicate that core damage may increase, leading to larger pools of molten materials within the core region.

MELCOR 2.2 is a significant official release of the MELCOR code with many new models and model improvements. This section provides a quick review and characterization of new models added, significant code changes and their impact on analyzing the Fukushima-Daiichi accidents. More detailed information is found in "Quicklook Overview of Model Changes in MELCOR 2.2: Rev 6342 to Rev 9496" [216] as well as the MELCOR User Guide and Reference Manuals.[8] These changes have made it possible for 500-hour long source term calculations of Fukushima-Daiichi Power Station to be performed in under 50 hours of computational time.

MELCOR is developed by Sandia National Laboratories under contract to the U.S. NRC. Analyses presented in this document were performed by SNL and use MELCOR 2.2 official builds 10326 for Unit 1, 10721 for Unit 2 and 11085 for Unit 3.

\subsubsection{MAAP}

Since the initial MAAP evaluations of the accident progression in each of the affected units at Fukushima-Daiichi, the MAAP5 code has been continuously improved in many areas. These improvements were supported by EPRI and the Commitment of Decommissioning / Safety Fundamental Technology for Power Reactor by Ministry of Economy, Trade and Industry of Japan in cooperation with EPRI. Major improvements to the MAAP5 code are described below.

New BWR reactor coolant system thermal hydraulic model in MAAP 5.04[218]: The MAAP5 BWR thermal hydraulics models were improved to provide the same level of detail as the existing MAAP5 PWR thermal hydraulics models. Implemented enhancements refine water node definitions within the reactor vessel and recirculation system and improve simulation of transients where pressure differences between 
the RCS nodes significantly influence thermal hydraulic response. MAAP will now model these transients in a manner similar to other contemporary thermal hydraulic codes. Nodalization of the vessel was increased to 17 nodes including two recirculation loops and two steam line nodes. The mass and energy of gas and water are tracked in each node and each node has its own pressure and temperatures. Masses of fission products are also tracked in each node. A detailed jet pump model was added. In addition to the pressure driven flow between the nodes, counter-current flows (single-phase water, two-phase, and gas) are calculated for all vertical junctions when colder (or denser) fluids are on top of warmer (or lighter) fluids.

Core model improvements in MAAP 5.03[219]: In MAAP versions prior to MAAP 5.03, the core model did not explicitly model the details of the BWR specific non-fuel nodes such as fuel support pieces and the core plate. Also, the major relocation path from the core to the lower plenum was based on a TMI-2 like side crust failure. Improvements were made to model detailed BWR-specific geometries explicitly including the fuel support piece, inlet orifice, and external bypass region with the core plate. A potential shroud melt-through relocation path (through the downcomer to the lower plenum) was added. Relocation through this path can be caused by core debris in contact with the inner surface of the core shroud. In addition, the upper plenum-to-core natural circulation model was enhanced to include a downflow pathway through the external bypass and an upflow pathway through the in-core bypass when the fuel channel boxes are intact.

For the upcoming MAAP5 5.05 version, the following core models are being improved:

- $\mathrm{B}_{4} \mathrm{C}$ oxidation model for control blades in BWR

- Core channel to channel sideward corium relocation (propagation of molten pool in the core)

- Improvement of the core crust node concept such that a certain node can reverse into a porous node from the fully packed crust node if melting occurs (i.e., modeling of melting of metallic crust)

Lower plenum debris pool layering model in MAAP 5.04: Versions of MAAP prior to MAAP 5.04 model the BWR and PWR lower plenum debris pool using a single oxide debris pool, a light metal layer, a heavy metal layer, a single particulate bed, and crusts. The lower plenum debris bed model has been improved to include a new layering model and radially nodalized particulate beds consistent with the core channel radial nodalization. In the new layering model, the oxide debris bed is axially nodalized according to the vessel lower head axial nodalization. In each layer, crust on the reactor vessel wall, crusts surrounding CRD tubes, and central region are modeled. The mass, material composition, and energy are tracked in each layer. Moreover, the material compositions and energy in individual crust components are tracked separately and temperature and solid fraction are calculated for each layer. By layering the material arriving in the lower plenum, the history of different material relocations to the lower plenum can be preserved and used for more accurate assessment of the vessel wall response. For example, during the TMI-2 accident, it is estimated that the first material relocating to the lower head contained ceramic and metallic material which formed a basal crust structure that survived to protect the lower head. With the layering model, a "hot spot" evaluation is also possible. A "hot spot" occurs when molten debris comes in direct contact with the vessel wall, either due to the absence of a protective layer or by disruption of the crust. For typical plant scenarios, including the Fukushima transients, the layering model can calculate the axial corium temperature distribution in the lower plenum more accurately based on the relocation history of corium from the core and the effect of water (mass and depth) in the lower plenum at the time of relocation.

CRD tube modeling improvements in MAAP 5.03: In versions of MAAP prior to MAAP 5.03, BWR CRD tube housings in the lower plenum were previously modeled as one heat sink with five axial nodes. 
Improvements were made such that the CRD tubes are axially and radially nodalized according to the vessel lower head axial nodalization and according to the core radial nodalization. For a given CRD tube node, a corium crust can be formed outside of the tube if the tube is submerged under the corium. The mass and energy of the crust are tracked. In addition, the CRD tube model has been extended to model the CRD tubes in the region below the reactor vessel. This modeling includes conduction and radiation heat transfer between the lower head, CRD tubes, pedestal gas and pedestal wall. The possibility of corium melt flowing into collapsed CRD tubes and causing creep rupture of CRD tubes outside the reactor vessel, leading to vessel failure, is now considered. Lastly, ex-vessel CRD tube melting is considered due to interaction with the corium jet exiting the breached reactor vessel. For the upcoming MAAP5 5.05 version, the mass and decay heat of the corium trapped inside of CRD tubes below the vessel will be tracked. In addition, the corium frozen outside of CRD tubes due to splashing of corium at the time of vessel failure will be tracked.

Vessel failure mechanisms: For the most recent versions of MAAP5 (Versions 5.03 and 5.04), BWR and PWR models have been developed to represent the influence of increasing core temperatures on the Source Range Monitor (SRM)/Intermediate Range Monitor (IRM) and TIP dry tubes as well as the rate of steam and hydrogen discharge to the containment pedestal and drywell if any of these should fail. Subsequent to the gas and fission product discharges, these core materials would be liquefied, or melted and would flow downward and into the open flow paths. Rapid cooling and freezing of these materials may occur as they flow downward through the core and the lower plenum, which could cause these relatively small flow paths to become plugged by the frozen debris. Once the core material relocates into the lower plenum, melting of the plugged corium in the SRM/IRM could occur resulting in a small pathway leading to a localized failure. For the upcoming MAAP5 5.05 version, the corium flow calculation through the vessel failure opening and ablation of the vessel wall will be improved to reflect the corium temperature and solid fraction of each layer based on the new lower plenum debris layering model. In addition, the corium debris holdup on structures below the vessel will be modeled.

Containment thermal stratification model in MAAP 5.04: Versions of MAAP5 prior to 5.04 had a generalized containment model (for BWRs and PWRs) with lumped nodes and junctions. For a given node, it was assumed that atmospheric conditions are uniformly distributed and each node had one gas temperature and one water temperature. The Fukushima-Daiichi core melt events have identified the importance of fluid stratification effects for determining the overall containment thermal hydraulic response. Improvements were made to the generalized containment model such that the gas region for a given node is divided into two zones (a less dense upper zone and a more dense lower zone) and the zonal boundary is calculated dynamically. The new model can calculate thermal and gas (hydrogen) stratification within a node. For a suppression pool, thermal stratification is calculated and one water pool can be sub-divided into many layers with different temperatures.

Aerosol turbulent deposition in pipes in MAAP 5.04: The latest version of MAAP5 (Version 5.04) models turbulent deposition of aerosols in pipes and at bends for BWR containment vent pipe systems. Turbulent deposition is significant in pipes and bends, but not in open areas of the containment. The mass of aerosols deposited on each component of the hard pipe vent is a function of the mass of aerosols that enter the hard pipe vent from the donor compartment. The deposition model calculates aerosol turbulent deposition using formulas for mono-dispersed aerosols, particles which are all the same size. Because real aerosols contain particles that range in size, these aerosol turbulent deposition formulas are combined with particle size calculations already available in earlier versions of MAAP to produce aerosol turbulent deposition calculations for a range of particle sizes. Particle removal rates are summed for all particle sizes to 
yield hard pipe vent component decontamination factors and the total decontamination factor for the entire hard pipe vent.

MCCI related models: In versions of MAAP prior to MAAP 5.02, the corium debris pool in containment (for BWRs and PWRs) did not consider particulates. It only considered a molten pool with upper, side, and bottom crusts. However, the heat transfer effect of a molten jet from the vessel flowing into a deep water pool in the containment and breaking into smaller particles causing enhanced heat transfer to water was considered. Improvements were made to model the particulates explicitly such that mass and energy are tracked. The source of particulates are the initial breakup of molten jet at the time of vessel failure and particulates entrained from the molten pool due to a melt eruption due to gas flow from MCCI.

In versions of MAAP prior to MAAP 5.03, the combined BWR pedestal and sump shape was approximated as a single right cylinder, with vertical walls and a horizontal floor. The previous versions of MAAP could not simulate deep sumps in the pedestal region below the RPV. The model was improved to add a combined pedestal and sump shape model for MCCI in the containment. The new model includes a right cylinder for the pedestal with a box-like shape for the sump region to more realistically resemble the true shape of the sump.

The versions of MAAP prior to MAAP 5.04 relied upon user-defined nominal heat transfer coefficients for sideward and downward core-concrete heat transfer. New mechanistic heat transfer correlations have been developed based on bubble agitation plus natural convection in MAAP 5.04. These correlations are applied for BWR and PWR evaluations.

In some MCCI experiments,[220, 221, 222] stratification between the metallic phase and oxide phase was observed. The impact of ex-vessel corium pool stratification is investigated by calculating the heat transfer coefficients of the metal and oxide layers independently. Given that a majority of the decay heat will reside in the oxide layer, the metal layer heat transfer coefficients are reformulated to include the interfacial resistance between the layers. The heat transfer coefficient between the corium pool and the floor/walls of the containment node are calculated as contact surface area weighted averages of the oxide and reformulated metal layer heat transfer coefficients. These new heat transfer coefficients are applied for BWR and PWR evaluations.

Debris coolability model: A bulk cooling model was added in the MAAP 5.04 code. Thus, the latest version of MAAP 5.04 models all major coolability mechanisms: bulk cooling, melt eruption, and water ingression. The improved model, which is used for both BWR and PWR evaluations, was compared with the latest MCCI experiments, the CCI-2, CCI-3, and CCI-6 tests.[223]

Mechanistic RCIC/HPCI model in MAAP 5.04: The RCIC system of 1F2 operated in an unpowered, unattended mode for the nearly three days. The unpowered state also entailed loss of RPV level control, which resulted in flooding of the main steam line, including the steam extraction line that drives the RCIC steam turbine. The resulting two-phase flow drove the turbine for an extended duration during the accident. A mechanistic model of the RCIC steam extraction line and Terry ${ }^{\mathrm{TM}}$ turbine was developed. The new model treats normal single-phase steam operation and the transition to two-phase flow operation after ELAP initiation. The new model demonstrates that the RCIC system, in concert with the connected RPV, yields a self-regulating behavior that gradually adjusts and equilibrates the RCIC pump inflow to the RPV with the RCIC extraction line outflow from the RPV. 


\subsubsection{Possible Future Code Applications and Enhancements}

As discussed within this report, several future changes may be implemented based on information obtained from the affected reactors at Daiichi. Selected examples include:

Primary Containment Integrity Challenges - As discussed in Sections 3, 4, and 6, the three operating units exhibited different patterns of PCV leakage of fission products and hydrogen. Many of these leakage points are not routinely modeled by systems level severe accident codes (MELCOR, MAAP, etc.). Both MAAP and MELCOR simulations predict drywell head failure for the three units. It is evident that other penetrations and piping failures should be considered in systems analysis codes, including the impact of failure locations and sizes.

MELCOR and MAAP Nodalization Studies - As discussed in Sections 3, 4, and 5, MAAP and MELCOR RPV nodalization studies to improve temperature predictions could also provide insights related to post-accident debris end-state predictions, as well as provide insights related to modeling of in-core melt progression, particularly as it pertains to maintaining PCV liner integrity.

MELCOR and MAAP Vessel Failure Debris Holdup Studies - Findings from 1F2 and 1F3 suggest that core materials may have exited the vessel from multiple failure locations and that a non-negligible amount of core debris may be held up on structures below the reactor vessel. System analysis codes should be exercised assuming a range of core debris holdup in a situation that is not cooled by water to investigate the impact of heat sources not covered by water on PCV gas phase temperature and pressure. In the next revision of the MAAP code, it is planned to include a model that explicitly tracks the interaction between a debris pour from a vessel failure location and the structures below the reactor vessel. Debris will be able to adhere and transfer energy directly to the structure and to the containment environment

1F2 MELTSPREAD-CORQUENCH Analysis - As discussed in Section 5, ex-vessel debris spreading analyses have only been performed for $1 \mathrm{~F} 1$. System-level code analyses indicated that there is the potential for vessel failure to also have occurred at $1 F 2$. An evaluation of $1 F 2$ may prove useful for rationalizing differences in future observations obtained from $1 \mathrm{~F} 1$ and $1 \mathrm{~F} 2$.

Combustible Gas Production, Transport, and Mitigation - As discussed in Section 6, MAAP core melt progression models do not predict as much in-core hydrogen generation as MELCOR. The ex-vessel combustible gas generation predictions are similar due to modeling of MCCI being similar in MAAP and MELCOR. However, MAAP requires more ex-vessel hydrogen generation from MCCI than MELCOR to predict sufficient accumulation of combustible gas that leads to the large explosions that occurred in 1F1 and 1F3. In addition, as noted above, both MAAP and MELCOR do not predict that seal degradation would occur and allow combustible gas to accumulate within the reactor building. Thus, gas stratification/ combustion and seal leakage models in these codes should be reviewed to determine if modeling upgrades are warranted to reduce modeling uncertainties.

\subsection{Summary}

TEPCO Holdings examinations at Daiichi to inform D\&D activities improves their ability to characterize potential hazards and to ensure the safety of workers involved with cleanup activities. The U.S. Forensics Effort is identifying examination needs from the affected units at Daiichi and evaluating information obtained by TEPCO Holdings to address these needs. Examples presented in this report illustrate 
the intrinsic value of this information. Significant safety insights are already being obtained in the areas of component performance, fission product release and transport, debris end-state location, combustible gas effects, and in plant operations and maintenance. Future examinations are anticipated to provide additional insights regarding vessel failure, debris holdup on ex-vessel structures, and spreading within the containment. In addition to reducing uncertainties related to severe accident modeling progression, it is important that these safety insights continue to be used by industry to update and improve PWR and BWR guidance for severe accident prevention, mitigation, and emergency planning. 


\section{REFERENCES}

1. J. Rempe, M. Farmer, M. Corradini, L. Ott, R. Gauntt, and D. Powers, "Revisiting Insights from Three Mile Island Unit 2 Post-Accident Examinations and Evaluations in View of the Fukushima Daiichi Accident," Nuclear Science and Engineering, 172, November 2012, pp 223-248.

2. J. Rempe, M. Corradini, M. Farmer, J. Gabor, R. Gauntt, T. Hara, W. Luangdilok, R. Lutz, D. Luxat, S. Mizokami, K. Robb, M. Plys, K. Tateiwa, Y. Yamanaka, "Safety Insights from Forensics Evaluations at Daiichi," invited paper, Fukushima Daiichi Special Edition, Journal of Nuclear Materials and Energy, December 2016. http://dx.doi.org/10.1016/j.nme.2016.08.010.

3. J. Rempe (editor) P. Amway, N. Andrews, S. Basu, R. Bunt, M. Corradini, P. Ellison, M. Farmer, T. Farthing, J. Gabor, R. Gauntt, C. Gerardi, T. Hara, P. Humrickhouse, S. Kraft, R. Linthicum, S. Mizokami, W. Luangdilok, R. Lutz, D. Luxat, C. Negin, C. Paik, M. Plys, J. Rempe, K. Robb, R. Sanders, R. Wachowiak, B. Williamson, and D. Yamada, US Efforts in Support of Examinations at Fukushima Daiichi - 2017 Evaluations, ANL/LWRS-17/02, August 2017.

4. J. L. Rempe (editor), Amway, N. Andrews, W. Bixby, R. Bunt, M. Corradini, P. Ellison, M. Farmer, T. Farthing, M. Francis, J. Gabor, R. Gauntt, C. Henry, P. Humrickhouse, S. Kraft, R. Linthicum, W. Luangdilok, R. Lutz, D. Luxat, J. Maddox, C. Negin, C. Paik, M. Plys, J. Rempe, K. Robb, R. Sanders, R. Wachowiak, B. Williamson, US Efforts in Support of Examinations at Fukushima Daiichi 2016 Evaluations, August 2016, ANL/LWRS-16/02.

5. J. L. Rempe (editor), P. Amway, R. Bunt, M. Corradini, P. Ellison, M. Farmer, M. Francis, J. Gabor, R. Gauntt, C. Henry, D. Kalinich, S. Kraft, R. Linthicum, W. Luangdilok, R. Lutz, D. Luxat, C. Paik, M. Plys, C. Rabiti, J. Rempe, K. Robb, R. Wachowiak, and B. Williamson, US Efforts in Support of Examinations at Fukushima Daiichi, ANL/LWRS-15/02, August 2015.

6. J. L. Rempe and D. L. Knudson, "Instrumentation Performance during the TMI-2 Accident", IEEE Transactions on Nuclear Science, 61, Issue 4, January 2014, pp 1963-1970.

7. EPRI, Modular Accident Analysis Program (MAAP), Version 5.02, EPRI Product No. 3002001978/ 3002001979LLC, 2013.

8. Sandia National Laboratories, MELCOR Computer Code Manuals, Vol. 1: Primer and User's Guide, and Vol. 2: Reference Manual, Version 2.2.9541, SAND 2017-0455 O, Sandia National Laboratories, January 2017 (ADAMS Accession No. ML17040A429).

9. TEPCO Holdings, Website, http://www.tepco.co.jp/en/index-e.html, http://photo.tepco.co.jp/en/

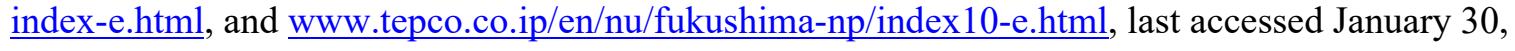
2017.

10. K. Tateiwa, "Fukushima Update," presentation at the first DOE Meeting on Reactor Safety Gap Evaluation and Fukushima Forensics at Argonne National Laboratory, January 7, 2015.

11. Y. Yamanaka, "The Facts obtained from the Investigation Activities at Fukushima Daiichi NPS," presentation at the first DOE Meeting on Reactor Safety Gap Evaluation and Fukushima Forensics at Argonne National Laboratory, January 7, 2015. 
12. Y. Yamanaka, "Investigation Plan of Inside RPV," presentation at the first DOE Meeting on Reactor Safety Gap Evaluation and Fukushima Forensics at Argonne National Laboratory, January 7, 2015.

13. Y. Yamanaka, "Outline of the $3^{\text {rd }}$ Progress Report on the Investigation of Unresolved Issues," presentation at the second DOE Meeting on Fukushima Forensics, Washington, DC, May 27, 2015.

14. Y. Yamanaka, "1F-1 PCV inside inspection results," presentation at the second DOE Meeting on Fukushima Forensics, Washington, DC, May 27, 2015.

15. D. Yamada, Y. Yamanaka, and S. Mizokami, "Progress for Applying Reactor Imaging Technology by Cosmic Ray Muon in Fukushima Daiichi," presentation at the second DOE Meeting on Fukushima Forensics, Washington, DC, May 27-28, 2015.

16. D. Yamada, T. Futatsugi, S. Mizokami, (1) Dose rate distribution and gamma spectrum analysis on refueling floor at Unit 3, presented at DOE Fukushima Forensic Meeting, Washington DC, April 28-29, 2016.

17. D. Yamada, T. Honda, and S. Mizokami, "Fukushima Update (2) Hot spots found around penetration pipes in Unit-1 Reactor buildings," Tokyo Electric Power Company, presented at DOE Fukushima Forensic Meeting, Washington D.C., April 28-29, 2016.

18. IRID and IAE, "Estimation on Fuel Debris Location," presentation given by K. Nozaki, TEPCO Holdings, at DOE Fukushima Forensic Meeting, Washington D.C., November 15, 2016.

19. D. Yamada, TEPCO Holdings, "Latest Drywell Investigation in Unit-1 and 2," presentation at DOE Forensics meeting, NEI, Washington, D.C., May 24-25, 2017.

20. D. Yamada, TEPCO Holdings, "Analysis of samples obtained in 1F plants," Reactor Safety Technology Expert Panel Forensics Meeting, NEI, Washington, D.C., May 24-25, 2017.

21. S. Mizokami, TEPCO Holdings, Analysis of Hydrogen Explosion of 1F1 Reactor Building, Reactor Safety Technology Expert Panel Forensics Meeting, NEI, Washington, D.C., May 24-25, 2017.

22. B. Williamson and P. Ellison, "Instrument Challenges Observed at Fukushima Daiichi - An Operations Point of View" presentation at the second DOE Meeting on Fukushima Forensics, Washington, DC, May 27, 2015.

23. R. Lutz and B. Williamson, "Insights from DOE Expert Panel Forensics for LWR Accident Management," presentation at Reactor Safety Technologies Expert Panel Forensics Meeting, Washington, DC, April 28-29, 2016.

24. B. Williamson, "Validation of Instrumentation Response," Reactor Safety Information Conference 2018 (RIC2018), March 13-15, 2018, Bethesda, Maryland.

25. R. Linthicum, "PWROG Severe Accident Activities," presentation at the NRC Regulatory Information Conference, March 13-15, 2018, Bethesda, MD.

26. K. Robb, J. Gabor, and J. Rempe, “Component Inspections," presentation at Reactor Safety Technologies 4th Experts Panel Meeting, November 9-10, Washington, DC. 
27. J. Gabor and K. Robb, "Component/System Performance," presentation at Reactor Safety Technologies Experts Panel Meeting, November 15-16, 2016, Washington, DC.

28. K Robb, “Code Uncertainties," presentation at Reactor Safety Technologies Experts Panel Meeting, November 15-16, 2016, Washington, DC.

29. R. Sanders, "Understanding Dose Rate Information Following Fukushima Accident," presentation at Reactor Safety Technologies Experts Panel Meeting, November 15-16, 2016, Washington, DC.

30. N. Andrews, J. Cardoni, R. Gauntt, R. Schmidt, and L. Humphries, "Informing Fukushima Decommissioning with Extended MELCOR Calculations," presentation at Reactor Safety Technologies Experts Panel Meeting, November 15-16, 2016, Washington, DC.

31. N. Andrews, J. Cardoni, M. Denman, R. Gauntt, L. Humphries, C. Faucett, S. Belon, C. Bouillet, H. Bonneville, J. Fleurot, M-M. Bonnet, R. Lee, H. Esmaili, and M. Salay, "Preliminary Results of ASTEC-MELCOR Crosswalk," presentation at Reactor Safety Technologies Experts Panel Meeting, November 15-16, 2016, Washington, DC.

32. N. Andrews, J. Cardoni, and R. Gauntt, "Preliminary Analyses of Dose at Fukushima Daiichi," presentation at Reactor Safety Technologies Experts Panel Meeting, November 15-16, 2016, Washington, DC.

33. N. Andrews, J. Cardoni, R. Gauntt, and Z. Jankovsky, "Fukushima Daiichi Radionuclide Inventories - (SAND2016-9065 R), presentation at Reactor Safety Technologies Experts Panel Meeting, November 15-16, 2016, Washington, DC.

34. R. Gauntt, "Uncertainty Analysis of Fukushima Daiichi Unit 1 Damage Condition," presentation at Reactor Safety Technologies Experts Panel Meeting, November 15-16, 2016, Washington, DC.

35. W. Luangdilok and N. Andrews, "Combustible Gas Effects," presentation at Reactor Safety Technologies Experts Panel Meeting, November 15-16, 2016, Washington, DC.

36. M. T. Farmer and R. Gauntt, "Debris Location," Presentation at RST Expert Panel Forensics Meeting, Nuclear Energy Institute, Washington, DC November 9-10, 2015.

37. TEPCO Holdings, Evaluation of the situation of cores and containment vessels of Fukushima Daiichi Nuclear Power Station Units-1 to 3 and Examination into Unsolved Issues in the Accident Progression - Progress Report No. 1, December 13, 2013.

38. TEPCO Holdings, Report on the Investigation and Study of Unconfirmed/Unclear Matters in the Fukushima Nuclear Accident Progress Report No. 2, August 6, 2014.

39. TEPCO Holdings, Report on the Investigation and Study of Unconfirmed/Unclear Matters in the Fukushima Nuclear Accident - Progress Report No. 3, May 2015. http://www.tepco.co.jp/en/press/ corp-com/release/betu15 e/images/150520e0101.pdf, last accessed May 2018.

40. TEPCO Holdings, Evaluation of the Situation of Cores and Containment Vessels of Fukushima Daiichi Nuclear Power Station Units-1 to 3 and Examination into Unsolved Issues in the Accident Progression - Progress Report No. 4, December 17, 2016 (with attachments). 
41. TEPCO Holdings, The 4th Progress Report on the Investigation and Examination of Unconfirmed and Unresolved Issues on the Development Mechanism of the Fukushima Daiichi Nuclear Accident, December 17, 2015.

42. TEPCO Holdings, 1F Accident Unresolved Issues: 5th Update Report, http://www.tepco.co.jp/en/ decommision/accident/images/171225e0101.pdf and http://www.tepco.co.jp/en/press/corp-com/ release/betu17 e/images/171225e0201.pdf, December 25, 2017, last accessed April 2018.

43. Institute for Applied Energy, "Information Portal for the Fukushima Daiichi Accident Analysis and Decommissioning Activities," https://fdada.info/en/home2/, last accessed March 2017.

44. J. R. Wolf, J. L. Rempe, L. A. Stickler, G. E. Korth, D.R. Diercks, L.A. Neimark, D.W. Akers, B.K. Schuetz, T. L. Shearer, S. A. Chàvez, G. L. Thinnes, R. J. Witt, M. L. Corradini, and J. A. Kos, Integration Report, OECD-NEA-TMI-2 Vessel Investigation Project, TMI V(93) EG10, October 1993. (Also issued as NUREG/CR-6197, EGG-2734, March 1994).

45. J. Rempe, L. Stickler, S. Chàvez, G. Thinnes, R. Witt, and M. Corradini, "Margin-to-Failure Calculations for the TMI-2 Vessel," Nuclear Safety, Special Edition featuring papers from TMI-2 research, 35, No. 2, July-December 1994, p 313.

46. M. L. Russell, R. K. McCardell, M. D. Peters, M. R. Martin, J. O. Carlson, and J. M. Broughton, "TMI-2 Accident Evaluation Program Sample Acquisition and Examination Plan," EGG-TMI-7132, January 1986.

47. J. Rommel, et al "Criticality Safety Evaluation for Increasing the TMI-2 Safe Fuel Mass Limit," GPU Nuclear Report 4710-3220-89-1, Rev. 0, February 1989.

48. GPU Nuclear Corporation, "Safety Evaluation Report for Defueling of the TMI-2 Reactor Vessel," GPU Nuclear Report SA-4350-3261-85-1, 15737-2-G-07-108, Rev. 10, May 15, 1986.

49. GPU, “Technical Plan for Pyrophoricity,” GPU TOP/TMI-127, Rev. 0, December 1984.

50. GPU Nuclear Corporation, "Safety Evaluation Report for Core Stratification Sample Acquisition," GPU Nuclear Report SA-4350-3261-85-02, 15737-2-G-07-109, Rev. 4, July 3, 1985.

51. G. Skillman, personal conversation with J. Rempe, January 23, 2017.

52. M. T. Farmer, M. Corradini, J. Rempe, R. Reister, and D. Peko, "United States Department of Energy Severe Accident Research Following the Fukushima Daiichi Accidents," Nuclear Technology, 196, November 2016.

53. M. Farmer, R, Bunt, M. Corradini, P. Ellison, M. Francis, J. Gabor, R. Gauntt, C. Henry, R. Linthicum, W. Luangdilok, R. Lutz, C. Paik, M. Plys, C. Rabiti, J. Rempe, K. Robb, R. Wachowiak, "Reactor Safety Gap Evaluation of Accident Tolerant Components and Severe Accident Analysis," Invited Paper for NURETH 16 Special Edition, Nuclear Science and Engineering, 183 (3), pp 296-304, November 2016. http://dx.doi.org/10.13182/NT16-42. 
54. M. T. Farmer (editor), D. Peko, M. Farmer, J. Rempe, M Corradini, P. Humrickhouse, H. Zhao, J. O’Brien, K. Robb, R. Gauntt, and D. Osborn, Reactor Safety Technologies Pathway Technical Program Plan, INL/EXT-15-35976, Rev. 2, July 2017.

55. R. O. Gauntt, et al., Fukushima Daiichi Accident Study, SAND2012-6173, 2012.

56. D. Luxat and J. Gabor, Fukushima Technical Evaluation: Phase 1 - MAAP5 Analysis, EPRI Report No. 1025750 (2013).

57. D. Luxat, J. Hanophy, and D. Kalinich, Modular Accident Analysis Program (MAAP) - MELCOR Crosswalk, Phase 1 Study, EPRI Report No. 3002004449 (2014).

58. K. R. Robb, M. T. Farmer, and M. W. Francis, Enhanced Ex-Vessel Analysis for Fukushima Daiichi Unit 1: Melt Spreading and Core-Concrete Interaction, ORNL/TM-2012/455, 2013.

59. K. R. Robb, M. T. Farmer, M. W. Francis, Ex-Vessel Core Melt Modeling Comparison between MELTSPREAD-CORQUENCH and MELCOR 2.1, ORNL/TM-2014/1, 2014.

60. EPRI, Technical Evaluation of Fukushima Accidents: Phase 2, Final Report 3002005301, December 2015.

61. U.S. NRC, "Near-Term Report and Recommendations for Agency Actions Following the Events in Japan,” SECY-11-0093, U. S. Nuclear Regulatory Commission, July 2011.

62. U.S. NRC, “Title 10 of the Code of Federal Regulations, Part 50.109, "Backfitting," Nuclear Regulatory Commission.

63. U.S. NRC, "Regulatory Analysis Guidelines of the U.S. Nuclear Regulatory Commission," Revision 4 to NUREG/BR-0058, September 2004.

64. U.S. NRC, "Issuance of Order to Modify Licenses with Regard to Requirements for Mitigation Strategies for Beyond-Design-Basis External Events,” EA-12-049, March 2012.

65. U.S. NRC, "Issuance of Order to Modify Licenses with Regard to Reliable Hardened Containment Vents," EA-12-050, March 2012.

66. U.S. NRC, "Issuance of Order to Modify Licenses with Regard to Reliable Spent Fuel Pool Instrumentation," EA-12-051, March 2012.

67. U.S. NRC, "Issuance of Order Modifying Licenses with Regard to Reliable Hardened Containment Vents Capable of Operation Under Severe Accident Conditions," Order EA-13-109, June 2013.

68. U.S. NRC, "Request for Information Pursuant to Title 10 of the Code of Federal Regulations 50.54(f) Regarding Recommendations 2.1, 2.3, and 9.3, of the Near-Term Task Force Review of Insights from the Fukushima Daiichi Accident," March 2012.

69. U.S. NRC "Staff Requirements - SECY-15-0085 - Evaluation of the Containment Protection and Release Reduction for Mark I and Mark II Boiling Water Reactors Rulemaking Activities (10 CFR Part 50) (RIN-3150-AJ26),” August 19, 2015. 
70. U.S. NRC, "Backgrounder on NRC Response to Lessons Learned from Fukushima," June 2018, https://www.nrc.gov/reading-rm/doc-collections/fact-sheets/japan-events.html, last accessed August 2018.

71. U.S. NRC, "Staff Requirements Memorandum - SECY-15-0065 - Proposed Rulemaking: Mitigation of Beyond-Design-Basis Events (RIN 3150-AJ49), August 27, 2015.

72. U.S. NRC, "Draft Final Rule - Mitigation of Beyond-Design-Basis Events," SECY-16-0142, dated December 15, 2016.

73. U.S. NRC Webpage, "Japan Lessons Learned," https://www.nrc.gov/reactors/operating/ops-experience/japan-dashboard.html, last accessed August 2018.

74. Advisory Committee on Reactor Safeguards, Biennial Review and Evaluation of the Nuclear Regulatory Commission Safety Research Program, February 26, 2018, https://www.nrc.gov/docs/ML1805/ ML18057B139.pdf, last accessed May 22, 2018.

75. U.S. NRC, Research Activities FY 2015-FY 2017, NUREG-1925, Rev. 4, March 2018, https:// www.nrc.gov/reading-rm/doc-collections/nuregs/staff/sr1925/, last accessed August 2018.

76. U.S. NRC, “MACCS (MELCOR Accident Consequence Code System (NUREG/BR-0527),” https:// www.nrc.gov/reading-rm/doc-collections/nuregs/brochures/br0527/, last accessed August 2018.

77. R. Lee, U.S. NRC, "Thoughts on Fukushima Forensics on BWR Accident Analysis," Embedded Workshop on Fukushima," Japan-U.S. Seminar on Two-Phase Flow Dynamics 2015, Purdue University, West Lafayette, Indiana, May 13, 2015.

78. R.Lee, U.S. NRC, “An update on NRC Fukushima Activities,” DOE Reactor Safety Technologies Expert Panel Forensics Meeting, November 1-2, 2017.

79. NEI, "Diverse and Flexible Coping Strategies (FLEX) Implementation Guide," NEI 12-06, Revision 3, Nuclear Energy Institute, September 2016.

80. NEI, INPO, and EPRI, “The Way Forward”, https://www.nrc.gov/docs/ML1116/ML111640571.pdf, last accessed June 10, 2018.

81. NEI, "Guideline for Assessing Beyond Design Basis Accident Response Staffing and Communications Capabilities,” NEI 12-01, Nuclear Energy Institute, May 2012.

82. NEI, "Industry Guidance for Compliance with NRC Order EA-12-051, "To Modify Licenses with Regard to Reliable Spent Fuel Pool Instrumentation," NEI 12-02, Nuclear Energy Institute, May 2012.

83. NEI, "Guidelines for Performing Verification Walkdowns of Plant Flood Protection Features," NEI 12-07, Nuclear Energy Institute, May 2012.

84. NEI, "Industry Guidance for Compliance with Order EA-13-109," NEI 13-02, Revision 1, Nuclear Energy Institute, April 2015. 
85. NEI, "Emergency Response Procedures and Guidelines for Extreme Events and Severe Accidents", NEI 14-01, Nuclear Energy Institute, September 2014.

86. NEI, "Enhancements to Emergency Response Capabilities for Beyond Design Basis Events and Severe Accidents," NEI 13-06, Nuclear Energy Institute, April 2014.

87. B. Williamson, P. Ellison, J. Lyter, D. Roniger, K Klass, T. Masuo, and L. Schulze, "BWROG Emergency Procedures and Severe Accident (EPG/SAG) Revision 4 Highlights, presented at the IAEA International Conference on Topical Issues in Nuclear Installation Safety: Safety Demonstration of Advanced Water Cooled Nuclear Power Plants, CN-251, June 6-9, 2017.

88. EPRI, “Seismic Evaluation Guidance," EPRI Report 3002000704 Draft, Electric Power Research Institute, April 2013.

89. EPRI, "Fleet Seismic Core Damage Frequency Estimates for Central and Eastern U.S. Nuclear Power Plants Using New Site-Specific Seismic Hazard Estimates," Letter to Nuclear Energy Institute, March 2014.

90. NEI, "White Paper: National SAFER Response Centers,” Nuclear Energy Institute, September 2014.

91. H. Nakamura, K, Arai, H. Oikawa, T. Fujii, S. Umezawa A. Ohnuki, Y. Nishi, Y. Abe, J. Sugimoto, S. Koshizuka, and A. Yamaguchi, "AESJ New Thermo-Hydraulics Roadmap for LWR Safety Improvement based on Lessons-Learned from Fukushima Daiichi Accident," Japan-U.S. Seminar on Two-Phase Flow Dynamics 2015, Purdue University, West Lafayette, Indiana, May 13, 2015.

92. J. Sugimoto, "Severe Accident Research in Japan After the Fukushima Daiichi Nuclear Power Station Accident," Nuclear Technology, 96:2, 149-160, https://doi.org/10.13182/NT16-21.

93. U.S. Department of State, "Facts on U.S.-Japan Commission on Civil Nuclear Cooperation", http:// iipdigital.usembassy.gov/st/english/texttrans/2013/11/20131105285763.html\#axzz3eljx8UhK, last visited February 9, 2016.

94. H. Nakahara and D. Peko, LWR Working Group Leads, "Current Status of Cooperation for the Light-Water Reactor R\&D Sub-Working Group," presentation at the CNWG, January 28, 2016, Tokyo, Japan.

95. J. Niel (Chair), et al., NEA Committee on Nuclear Regulatory Activities (CNRA), B. Sheron (Chair), et al., NEA Committee on the Safety of Nuclear Installations (CNSI), and A. McGarry (Chair) et al., NEA Committee on Radiation Protection and Public Health (CRPPH), The Fukushima Daiichi Nuclear Power Plant Accident: OECD/NEA Nuclear Safety Response and Lessons Learnt, NEA No. 7161, Organisation for Economic Co-operation and Development, Paris, France, 2013.

96. Nuclear Energy Agency, "Five Years after the Fukushima Daiichi Accident: Nuclear Safety Improvements and Lessons Learnt," NEA No. 7284, Organisation for Economic Co-operation and Development, Paris, France, 2016.

97. Nuclear Energy Agency, "NEA Benchmark Study of the Accident at the Fukushima Daiichi Nuclear Power Plant (BSAF) Project," see http://www.oecd-nea.org/jointproj/bsaf.html, last accessed January $1,2017$. 
98. Nuclear Energy Agency, "Benchmark Study of the Accident at the Fukushima Daiichi Nuclear Power Plant (BSAF Project)," Phase I Summary Report March 2015, Nuclear Regulation NEA/ CSNI/R(2015)18, February 2016.

99. Bernd Jäckel, PSI “Activity Data Interpretation from Land Contamination of Fukushima Daiichi Accident," BSAF Phase II, Paris, France, 2014.

100. Nuclear Energy Agency, "Safety Research Opportunities Post-Fukushima -Initial Report of the Senior Expert Group, NEA/CSNI(2016)19, 2016.

101. A. Nakoayoshi, T. Washiya, M. Kurata, K. Yano, Y. Nagae, M. Osaka, H. Ogino, “OECD/NEA International Joint Research Project regarding Fuel Debris Characterization PreADES \& TCOEFF," presented at the $2^{\text {nd }}$ International Forum on the Decommissioning of the Fukushima Daiichi Nuclear Power Station - Moving Forward Together, July 3, 2017.

102. NUclear GENeration II \& III Association (NUGENIA), http://www.nugenia.org/, last accessed January $24,2017$.

103. Severe Accident Research NETwork of Excellence (SARNET), http://www.sar-net.eu/, last accessed January 24, 2017.

104. W. Klein-Hessling, M. Sonnenkalb, D. Jacquemain, B. Clement, E. Raimond, H. Dimmelmeier, G. Azarian, G. Ducos, C. Journeau, L. E. Herranz Puebla, A. Schumm, A Miassoedov, I. Kljenak, G. Pascal, S. Bechta, S. Suntay, M. K. Koch, I*. Ivanov, A. Auvinen, and I. Lindholm, "Conclusions on Severe Accident Research Priorities”, Annals of Nuclear Energy, 74, 2014.

105. European Nuclear Safety Regulators Group (ENSREG), http://www.ensreg.eu/, last accessed January 1, 2016.

106. Nuclear Damage Compensation and Decommissioning Facilitation Corporation, "Toward developing "Technical Strategic Plan 2017 for Decommissioning of the Fukushima Daiichi Nuclear Power Station of Tokyo Electric Power Company Holdings, Inc.”, includes Summary, Overview, and Full Report, Draft, dated August 2017.

107. Nuclear Damage Compensation and Decommissioning Facilitation Corporation, "Technical Strategic Plan 2017 for Decommissioning of the Fukushima Daiichi Nuclear Power Station of Tokyo Electric Power Company Holdings, Inc.”, includes a Summary, Overview, and Full Report, July 13, 2016.

108. Inter-Ministerial Council for Contaminated Water and Decommissioning Issues, Progress Status and Future Challenges of the Mid-and-Long-Term Roadmap towards the Decommissioning of TEPCO's Fukushima Daiichi Nuclear Power Station Units 1-4 (Outline), April 2018. http://www.meti.go.jp/ english/earthquake/nuclear/decommissioning/, with periodic updates last accessed May 22, 2018.

109. TEPCO Holdings, http://www.tepco.co.jp/en/nu/fukushima-np/images/handouts_120927_02-e.pdf, last accessed Feb. 2016.

110. TEPCO Holdings, http://www.tepco.co.jp/en/nu/fukushima-np/images/handouts 121003 01-e.pdf, last accessed Feb. 2016. 
111. TEPCO Holdings, http://www.tepco.co.jp/nu/fukushima-np/roadmap/images/m120730_05-j.pdf, (in Japanese) last accessed March 2016.

112. TEPCO Holdings, http://www.tepco.co.jp/nu/fukushima-np/roadmap/images/m111226_08-j.pdf, (in Japanese), last accessed March 2016.

113. TEPCO Holdings, http://www.tepco.co.jp/en/nu/fukushima-np/handouts/2015/images/handouts 151020_01-e.pdf, last accessed February 2016.

114. TEPCO Holdings, http://www.tepco.co.jp/nu/fukushima-np/roadmap/images/d151001_08-j.pdf, last accessed Feb. 2016.

115. TEPCO Holdings, http://www.tepco.co.jp/nu/fukushima-np/roadmap/images/d150827 08-j.pdf, last accessed Feb. 2016.

116. TEPCO Holdings, http://www.tepco.co.jp/en/nu/fukushima-np/handouts/2015/images/handouts 151022 01-e.pdf, last accessed Feb. 2016.

117. TEPCO Holdings, http://www.tepco.co.jp/en/nu/fukushima-np/images/handouts 120419 03-e.pdf, last accessed February 2016.

118. TEPCO Holdings, http://www.tepco.co.jp/nu/fukushima-np/handouts/2015/images/handouts 151127 08-j.pdf, last accessed February 2016.

119. TEPCO Holdings, http://www.tepco.co.jp/en/nu/fukushima-np/handouts/2013/images/handouts 130409 10-e.pdf, last accessed Feb. 2016.

120. TEPCO Holdings, http://www.tepco.co.jp/nu/fukushima-np/roadmap/images/d151224_08-j.pdf, (in Japanese), last accessed March 2016.

121. TEPCO Holdings, http://www.tepco.co.jp/nu/fukushima-np/roadmap/images/d151029_08-j.pdf, (in Japanese), last accessed March 2016.

122. TEPCO Holdings, http://photo.tepco.co.jp/en/date/2013/201307-e/130708-02e.html, last accessed March 2016.

123. TEPCO Holdings, http://www.tepco.co.jp/en/nu/fukushima-np/handouts/2014/images/handouts 140527 07-e.pdf, last accessed Feb. 2016.

124. TEPCO Holdings, http://www.tepco.co.jp/en/nu/fukushima-np/handouts/2013/images/handouts 130315 01-e.pdf, last accessed Feb. 2016.

125. TEPCO Holdings, http://www.tepco.co.jp/en/nu/fukushima-np/handouts/2013/images/handouts 131114 05-e.pdf, last accessed Feb. 2016.

126. T. Kotaki, "The Behavior of FP Estimated by the Investigation of Fukushima Daiichi NPS Units 1 3," JAEA-sponsored CLADS Decommissioning Workshop and Seminar (5) FP behavior, November 12, 2015. 
127. TEPCO Holdings, http://www.tepco.co.jp/en/nu/fukushima-np/handouts/2014/images/handouts 140121 04-e.pdf, last accessed Feb. 2016.

128. TEPCO Holdings, http://www.tepco.co.jp/en/nu/fukushima-np/handouts/2013/images/handouts_130221 02-e.pdf, last accessed Feb. 2016.

129. TEPCO Holdings, http://www.tepco.co.jp/en/nu/fukushima-np/images/handouts 120627 02-e.pdf, last accessed Feb. 2016.

130. TEPCO Holdings, http://www.tepco.co.jp/en/nu/fukushima-np/images/handouts 120607 02-e.pdf, last accessed Feb. 2016.

131. TEPCO Holdings, http://www.tepco.co.jp/en/nu/fukushima-np/images/handouts 120418_04-e.pdf, last accessed Feb. 2016.

132. TEPCO Holdings, http://www.tepco.co.jp/en/nu/fukushima-np/images/handouts_120712_03-e.pdf, last accessed Feb. 2016.

133. TEPCO Holdings, http://www.tepco.co.jp/en/nu/fukushima-np/handouts/2014/images/handouts_140728_05-e.pdf, last accessed Feb. 2016.

134. TEPCO Holdings, http://www.tepco.co.jp/en/nu/fukushima-np/handouts/2013/images/handouts 130416_06-e.pdf, last accessed Feb. 2016.

135. TEPCO Holdings, http://photo.tepco.co.jp/en/date/2014/201405-e/140515-01e.html, last accessed Feb. 2016.

136. TEPCO Holdings, http://www.tepco.co.jp/nu/fukushima-np/roadmap/images1/images1/ d160128_07-j.pdf, last accessed Feb. 2017.

137. TEPCO Holdings, "Air dose rates in the buildings," http://www.tepco.co.jp/en/nu/fukushima-np/f1/ surveymap/index-e.html, last accessed March 2016.

138. TEPCO Holdings, http://www.tepco.co.jp/nu/fukushima-np/roadmap/2018/images1/ d180426_08-j.pdf, last accessed May 2018.

139. TEPCO Holdings, http://www.tepco.co.jp/en/nu/fukushima-np/handouts/2018/images/handouts 180426 02-e.pdf, last accessed August 2018.

140. TEPCO Holdings, http://www.tepco.co.jp/en/nu/fukushima-np/handouts/2018/images/handouts_180426_03-e.pdf, last accessed August 2018.

141. Nuclear Damage Compensation and Decommissioning Facilitation Corporation, "Technical Strategic Plan 2017 for Decommissioning of the Fukushima Daiichi Nuclear Power Station of Tokyo Electric Power Company Holdings, Inc.”, August 31, 2017. http://www.dd.ndf.go.jp/en/strategic-plan/ book/20171005_SP2017eFT.pdf, last accessed Feb. 2018. 
142. TEPCO Holdings, "Locating Fuel Debris inside the Unit 3 Reactor Using a Muon Measurement Technology at Fukushima Daiichi Nuclear Power Station," September 28, 2017, https:// www4.tepco.co.jp/en/nu/fukushima-np/handouts/2017/images/handouts_170928 01-e.pdf, last accessed Feb. 2018.

143. TEPCO Holdings, "Fukushima Daiichi Nuclear Power Station Unit 2 Primary Containment Vessel Internal Investigation Results," presentation by Tokyo Electric Power Company Holdings, Inc., http://www.tepco.co.jp/en/nu/fukushima-np/handouts/2018/images/handouts 180201 01-e.pdf, February 1, 2018, last accessed March 2018.

144. TEPCO Holdings, "Partial damage to temperature gauge cables for the Reactor Pressure Vessel (RPV) found during the Fukushima Daiichi NPS Unit 3 Primary Containment Vessel (PCV) internal investigation," November 20, 2017, http://www.tepco.co.jp/en/nu/fukushima-np/handouts/2017/ images/handouts 171130 02-e.pdf, last accessed Feb. 2018.

145. TEPCO Holdings, "Fukushima nuclear accident - Detailed progress after occurrence concerning mechanism and unconfirmed / unresolved matter, The 5th Progress Report on the results of investigation and review," Dec. 12, 2017, in Japanese, http://www.tepco.co.jp/press/release/2017/pdf2/ 171225j0101.pdf, last accessed Feb. 2018.

146. Science Council of Japan Sub-Committee on Fukushima Nuclear Accident Comprehensive Synthetic Engineering Committee, "Reflections and Lessons from the Fukushima Nuclear Accident," (Second Report), SCJ 23th term -290214-23551300-056, 2/14/17.

147. TEPCO Holdings, Slides (in Japanese), http://www.tepco.co.jp/nu/fukushima-np/roadmap/2017/ images2/d170727 07-j.pdf, last accessed March 2018.

148. TEPCO Holdings, "Unit 1 Primary Containment Vessel Internal Investigation”, http:// www.tepco.co.jp/en/nu/fukushima-np/handouts/2017/images/handouts_170327 01-e.pdf, last accessed March 2018.

149. D. Peko, S. Basu, S. Kraft, S. Mizokami, and J. Rempe, "Working Together to Enhance Reactor Safety," Nuclear News, (Featured Cover Article), April 2018.

150. TEPCO Holdings, "Unit 1 Primary Containment Vessel Internal Investigation $\sim$ Analysis of image data and dose data," http://www.tepco.co.jp/en/nu/fukushima-np/handouts/2017/images/handouts 170727 02-e.pdf, last accessed March 2018.

151. TEPCO Holdings, http://www.tepco.co.jp/en/press/corp-com/release/betu15 e/images/ 151217e0104.pdf, (in English) last accessed June 2016.

152. TEPCO Holdings, "Internal Exploration of the Unit 2 Primary Containment Vessel (PCV) $\sim$ Reevaluation of Dose Rate Estimate " July 27, 2017, http://www.tepco.co.jp/en/nu/fukushima-np/handouts/ 2017/images/handouts_170727_03-e.pdf, last accessed August 1, 2018.

153. TEPCO Holdings, "NRA Meeting on 1F Issues," http://www.nsr.go.jp/data/000207804.pdf, October 30, 2017, last accessed August 1, 2018. 
154. TEPCO Holdings, http://www.tepco.co.jp/nu/fukushima-np/roadmap/2018/images2/ d180726 08-j.pdf\#page=15; July 26, 2018, last accessed August 1, 2018.

155. D. Yamada, S. Mizokami, T. Honda, D. Yamauchi, Y. Yamanaka, "Recent Findings on the Damaged Reactors and Containment Vessels of Fukushima Daiichi NPS," NURETH-16, Chicago, August 30-September 4, 2015.

156. TEPCO Holdings, http://www.tepco.co.jp/en/nu/fukushima-np/f1/surveymap/images/ f1-sv3-20130227-e.pdf, (in English) last accessed June 2016.

157. TEPCO Holdings, "Results of Investigation around Lower Parts of Unit 1 Vent Pipes at Fukushima Daiichi NPS (First Day)," http://www.tepco.co.jp/en/nu/fukushima-np/handouts/2013/images/handouts 131113 11-e.pdf, November 13, 2013

158. TEPCO, "Results of Investigation on Upper Part of S/C (Suppression Chamber of Unit 1 at Fukushima Daiichi NPSA (outside around west/south side)," http://www.tepco.co.jp/en/nu/ fukushima-np/handouts/2014/images/handouts 140530_11-e.pdf, May 30, 2014.

159. TEPCO Holdings, http://www.tepco.co.jp/nu/fukushima-np/roadmap/images/d151029 08-j.pdf, last accessed March 2017.

160. TEPCO Holdings, "Survey Results of TIP Room in Ground-floor at Reactor Building, Unit 2 at Fukushima Daiichi Nuclear Power Station (Conducted on March 21, 2012), http://www.tepco.co.jp/ en/nu/fukushima-np/images/handouts_120322_01-e.pdf,_(in English), last accessed March 2017.

161. TEPCO Holdings, "Fukushima Daiichi Nuclear Power Station Unit 2 Reactor Building Inspection Result ( $3^{\text {rd }}-5^{\text {th }}$ Floor) (June 13, 2012)," http://www.tepco.co.jp/en/nu/fukushima-np/images/handouts_120614_03-e.pdf, June 14, 2012.

162. TEPCO Holdings, http://www.tepco.co.jp/nu/fukushima-np/roadmap/images/m121225 05-j.pdf, last accessed August 2017.

163. TEPCO Holdings, "Results of Additional Work in Soundness Inspection of Unit 2 TIP Guide Pipe July 19, 2013, http://www.tepco.co.jp/en/nu/fukushima-np/handouts/2013/images/handouts 130719 07-e.pdf, last accessed March 2017.

164. TEPCO Holdings, "Air dose Rates in the Buildings" March 22, 2013, http://www.tepco.co.jp/en/nu/ fukushima-np/fl/surveymap/index-e.html, (in English), issued March 22, 2013.

165. TEPCO Holdings, "Fukushima Daiichi Nuclear Power Station Unit 3 Reactor Building First Floor TIP Room Environment Investigation Result (May 23, 2012)” March 22, 2013, http:// www.tepco.co.jp/en/nu/fukushima-np/images/handouts_120524 06-e.pdf (in English), last accessed March 2017.

166. Email from D. Yamada, TEPCO Holdings, to J. Rempe, Rempe and Associates, LLC, August 15, 2017. 
167. H. Tsurata, Y. Oura, M. Ebihara, T. Ohara, and T. Nakajima, "First Retrieval off Hourly Atmospheric Radionuclides Just After the Fukushima Accident by Analyzing Filter-Tapes of Operational Air Pollution Monitoring Stations," Scientific Reports, 4:6717, DOE: 10.1037, http:// www.nature.com/articles/srep06717, last accessed March 2017.

168. TEPCO Holdings, "Unit 1 Primary Containment Vessel Internal Investigation," March 27, 2017, http://www.tepco.co.jp/en/nu/fukushima-np/handouts/2017/images/handouts 170327 01-e.pdf, last accessed August 1, 2017.

169. S. Mizokami, TEPCO Holdings, to J. Rempe, Rempe and Associates, email, dated July 24, 2017.

170. D. Yamada, TEPCO Holdings, to D. Luxat, Jensen-Hughes, private communication, January 22, 2016.

171. H. Nagai, H. Terada, M. Chino, G. Katata, S. Mikami, and K. Saito, "Source Term Estimation for the Fukushima Daiichi Nuclear Power Station Accident by Combined Analysis of Environmental Monitoring and Plant Data through Atmospheric Dispersion Simulation," 16th International Topical Meeting on Nuclear Reactor Thermal Hydraulics (NURETH-16), Chicago, IL, USA, August 30-September 4, 2015.

172. J. Cardoni and Z. Jankovsky, "Fukushima Daiichi Radionuclide Inventories," SAND-2006-9065 R, Unclassified Unlimited Release, September 2016.

173. Y. Koma, A. Shibat, and T. Ashida, "Radioactive contamination of several materials following the Fukushima Daiichi Nuclear Power Station Accident," Nuclear Materials and Energy, 10, pp 35-41, https://doi.org/10.1016/j.nme.2016.08.015, January 2017.

174. TEPCO Holdings, "Partial Damage to Temperature Gauge Cables for the Reactor Pressure Vessel (RPV) Found During the Fukushima Daiichi NPS Unit 3 Primary Containment Vessel (PCV) Internal Investigation," presentation by Tokyo Electric Power Company Holdings, Inc., http:// www.tepco.co.jp/en/nu/fukushima-np/handouts/2017/images/handouts_171130_02-e.pdf, November 30, 2017, last accessed March 2018.

175. TEPCO Holdings, "On the Internal Survey of Unit 1 Reactor Containment Vessel - Analysis Result of Sediment," (in Japanese), presentation by Tokyo Electric Power Company Holdings, Inc., http:// www.tepco.co.jp/nu/fukushima-np/roadmap/2017/images1/d170525 08-j.pdf, May 25, 2017.

176. TEPCO Holdings, "Pre-investigation results of X-6 penetration for the Unit 2 Primary Containment Vessel Investigation at Fukushima Daiichi Nuclear Power Station”, http://www.tepco.co.jp/en/nu/ fukushima-np/handouts/2017/images/handouts_170126_01-e.pdf, January 26, 2017; last accessed January 2017.

177. TEPCO Holdings, "Unit 2 Primary Containment Vessel Investigation at Fukushima Daiichi Nuclear Power Station (By the self-propelled investigation device)," http://www.tepco.co.jp/en/nu/ fukushima-np/handouts/2017/images/handouts 170215 01-e.pdf, February 15, 2017. 
178. TEPCO Holdings, "Pre-investigation results of the area inside the pedestal for the Unit 2 Primary Containment Vessel Investigation at Fukushima Daiichi Nuclear Power Station (examination results of digital images)," http://www.tepco.co.jp/en/nu/fukushima-np/handouts/2017/images/handouts 170202 01-e.pdf, February 2, 2017.

179. TEPCO Holdings, "Locating Fuel Debris inside the Unit 2 Reactor Using a Muon Measurement Technology at Fukushima Daiichi Nuclear Power Station,” http://www.tepco.co.jp/en/nu/ fukushima-np/handouts/2016/images/handouts 160728 01-e.pdf, July 28, 2016, last accessed April 2017.

180. S. A. Hodge, "BWR Reactor Vessel Bottom Head Failure Modes," Boiling Water Reactor Severe Accident Technology (BWRSAT) Program, Oak Ridge National Laboratory, Published as CONF-890546-3, 1989.

181. TEPCO Holdings, "Progress of Unit 3 PCV Internal Investigation (Preliminary report of July 19 investigation)," http://www.tepco.co.jp/en/nu/fukushima-np/handouts/2017/images/handouts 170719 01-e.pdf, July 19, 2017, last accessed August 1, 2017.

182. TEPCO Holdings, "Progress of Unit 3 PCV Internal Investigation (Preliminary report of July 21 investigation)," http://www.tepco.co.jp/en/nu/fukushima-np/ TEPCO Holdings /2017/images/handouts 170721 01-e.pdf, July 21, 2017, last accessed August 1, 2017.

183. TEPCO Holdings, "Progress of Unit 3 PCV Internal Investigation (Preliminary report of July 22 investigation)," http://www.tepco.co.jp/en/nu/fukushima-np/handouts/2017/images/handouts 170722 01-e.pdf, July 22, 2017, last accessed August 1, 2017.

184. TEPCO Holdings, "Unit 3 Primary Containment Vessel Internal Investigation," presentation by Tokyo Electric Power Company Holdings, Inc., http://www.tepco.co.jp/en/nu/fukushima-np/handouts/2017/images/handouts 171130 03-e.pdf, November 30, 2017, last accessed March 2018.

185. TEPCO Holdings, "Locating Fuel Debris inside the Unit 3 Reactor Using a Muon Measurement Technology at Fukushima Daiichi Nuclear Power Station (Interim Report),” http://www.tepco.co.jp/ en/nu/fukushima-np/handouts/2017/images/handouts_170727_01-e.pdf, July 27, 2017, last accessed August 2017.

186. K. Nozaki, TEPCO Holdings, private communication (email) to J. Rempe, Rempe and Associates, January 25, 2017 and June 1, 2017.

187. TEPCO Holdings, "The Report on the Investigation into the Current Seismic Safety and Reinforcement of the Reactors at Fukushima Daiichi Nuclear Station (No. 1)," http://www.tepco.co.jp/en/ press/corp-com/release/betu11_e/images/110528e16.pdf, May 2011.

188. TEPCO Holdings, "The Report on the Investigation into the Current Seismic Safety and Reinforcement of the Reactors at Fukushima Daiichi Nuclear Station (No. 2)," http://www.tepco.co.jp/en/ press/corp-com/release/betu11_e/images/110713e20.pdf, July 13, 2011.

189. TEPCO Holdings, "The Development of and Lessons from the Fukushima Daiichi Nuclear Accident", http://www.tepco.co.jp/en/decommision/accident/images/outline01.pdf, last accessed February 2016 . 
190. TEPCO Holdings, "Fukushima Nuclear Accident Analysis Report (Interim Report) Summary," http:/ /www.tepco.co.jp/en/press/corp-com/release/betu11 e/images/111202e14.pdf, December 2, 2011.

191. TEPCO Holdings, Photos of Unit 1 Reactor Building taken on 2/21/2015, Photos \#101-117, http:// photo.tepco.co.jp/date/2015/201502-j/150221-04j.html, last accessed March 2016.

192. TEPCO Holdings, http://www.tepco.co.jp/nu/fukushima-np/roadmap/2017/images1/ d170330 07-j.pdf, (in Japanese) last accessed July 2017.

193. J. Maru, General Manager, News Department, Fukushima Central Television Company, LTD, "Permission for Using Snap Shots", email with photos to J. Rempe, Rempe and Associates, LLC, June 3, 2016.

194. W. Luangdilok, E. van Heerden, P. McMinn, "Calculation of the Probability of DDT during Severe Accidents," NURETH-16, Chicago, IL, August 30 - September 4, 2015.

195. J.E. Shepherd, The Crisis at Fukushima Daiichi Nuclear Plant, Apr 9, 2011 Presentation to Caltech Community, updated Apr 22, 2012.

196. M. Ogino, "Study on the Issues about Hydrogen Explosion at Fukushima Daiichi NPS," Technical Workshop on the Accident of TEPCO's Fukushima Daiichi NPS, July 2012.

197. Sandia National Laboratory, “1F3 Explosion,” Email from R. Gauntt, SNL, to J. Rempe, Rempe and Associates, LLC, January 22, 2018.

198. T. Hara, TEPCO Holdings, Email to J. Rempe, Rempe and Associates, LLC, conveying response from FCT, January 24, 2018.

199. H. Yanagisawa, H. Takeuchi, M. Akinaga, S. Mizokami, T. Honda, and M. Watanabe, "The Accident Analysis for Unit 3 at Fukushima Daiichi Nuclear Power Station," 9th Int. Topical Meeting on Nuclear Thermal Hydraulics, Operation and Safety (NUTHOS-9), Kaohsiung, Taiwan, September 9-13, 2012.

200. S.B. Dorofeev, V.P. Sidorov, A.A. Efimenko, A.S. Kochurko, M.S. Kuznetsov, B.B. Chaivanov, D. I. Matsukov, A.K. Pereverzev, V.A. Avenyan, "Fireballs from Deflagration and Detonation of Heterogeneous Fuel-rich Clouds,” Fire Safety Journal, 25, 323-336, 1995,

201. S. Kawamura, S. Mizokami, and T. Honda, "Progression of Fukushima Accident - Accident Progression at Unit 2," Workshop on Advances in Understanding the Progression of Severe Accident in Boiling Water Reactors, https://www.iaea.org/NuclearPower/Downloadable/Meetings/2017/ 2017-07-17-07-21-NPTDS/2. Technical_Session_2/TS2-5_20170717_Fukushima_Accident_(1F-2).pdf, Vienna, Austria, July 17-21, $201 \overline{7}$.

202. W. Luangdilok, "Fukushima Forensics: Combustible Gas Effects, Reactor Safety Technology Expert Panel Forensics Meeting," NEI, Washington, D.C., May 24-25, 2017.

203. K. Nozaki, T. Honda, D. Yamauchi, M. Mizokami, and S. Mizokami, "Evaluation of Inflow of Venting Gas of Fukushima Daiichi Unit 3 into Unit 4 using GOTHIC," NURETH-17, September 3-8, 2017, Xi'an, Shaanxi, China. 
204. M. Yamamoto, TEPCO Holdings, email to G. Bisconti, US DOE, 3/21/2011.

205. S. Mizokami, TEPCO Holdings, email to J. Rempe, Rempe \& Associates, LLC, November 23, 2017.

206. TEPCO Holdings, "Plant Data of Fukushima Daiichi Nuclear Power Station at the time of the Tohoku-Chihou-Taiheiyou-Oki Earthquake," http://www.tepco.co.jp/en/nu/fukushima-np/ index10-e.html, last accessed December 2017.

207. TEPCO Holdings, "Fukushima Daiichi Nuclear Power Station, Units 1, 2, and 3, Thermometers of Safety Regulations,” http://www.tepco.co.jp/en/nu/fukushima-np/f1/pla/2017/images/figure-e.pdf, last accessed December 2017.

208. TEPCO Holdings, "Measuring Positions," http://www.tepco.co.jp/en/nu/fukushima-np/f1/images/ measuring positions-e.pdf, last accessed May 2018.

209. S. Mizokami, TEPCO Holdings, personal communication to B, Williamson, TVA, November 22, 2013.

210. INPO, "Special Report on the Nuclear Accident at the Fukushima Daiichi Nuclear Power Station," INPO-11-005, November 2011.

211. T. Hara, TEPCO Holdings, "Fukushima Japan Accident and Current Situation,' MIT Nuclear Plant Safety Course, June 21, 2017, June 21, 2017.

212. R. Lutz and R. Williamson, "The Importance of Reliable Indications for Accident Management," $24^{\text {th }}$ International Congress on Nuclear Energy (ICONE 24), Charlotte, N.C., June 2016.

213. R. Prior, "Enhancements to PWR SAMG Since Fukushima," Proceedings of the 10th International Conference of the Croatian Nuclear Society, Zadar, Croatia, 5-8 June 2016.

214. "Severe Accident Management Technical Basis Report," Electric Power Research Institute, TR-1025395, October 2012.

215. "Technical Basis for Severe-Accident Mitigating Strategies - Volume 1," Electric Power Research Institute, TR-3002003301, April 2015.

216. L. L. Humphries, "Quicklook overview of model changes in MELCOR 2.2: Rev 6342 to Rev 9496," SAND2017-5599, May 2017.

217. T. Haskin, N. Andrews, L. Humphries, and R. Gauntt, "Informing Future MELCOR Development Activities from the 1F2 Severe Accident", presentation at 2017 Fukushima Forensics Meeting, November 1, 2017, Washington, DC.

218. EPRI, Modular Accident Analysis Program (MAAP), Version 5.04, EPRI Product No. 3002007340/ $3002007341,2016$.

219. EPRI, Modular Accident Analysis Program (MAAP), Version 5.03, EPRI Product No. 3002002550 , 2014. 
220. M. Cranga, L. Ferry, J. F. Haquet, C. Journeau, B. Michel, C. Mun, P. Piluso, G. Ratel, and K. Atkhen, "MCCI in an Oxide/Metal pool: Lessons Learnt from VULCANO, Greene, ABI and BALISE experiments and remaining uncertainties," 4th European Review Meeting on Severe Accident Research (ERMSAR-2010), Bologna, Italy, May 11-12, 2010.

221. Tourniaire, B. and Bonnet, J.M., 2003, "Study of the Mixing of Immiscible Liquids by Sparging Gas Results of the BALISE Experiments," 10th International Topical Meeting on Nuclear Reactor Thermal Hydraulics (NURETH-10), Seoul, Korea, Oct. 5-9.

222. J.J. Foit, M. Fischer, C. Journeau, and G. Langrock, "Experiments on MCCI with oxide and steel', Annals of Nuclear Energy, 74 (2014) 100-109

223. M. T. Farmer, S. Lomperski, D. J. Kilsdonk, and R. W. Aeschlimann, "OECD MCCI Project 2-D Core Concrete Interaction (CCI) Tests: Final Report," OECD/MCCI-2005-TR05, Argonne National Laboratory, Argonne, IL, February 2006.

224. C. Igarashi and N. Shikazono, "Sound-Producing Sand in Japan: Major Element Composition and Its Minerals Determined by X-ray Diffraction and X-ray Fluorescence," Analytical Sciences, Vol. 19, pp. 1371-1374 (2003).

225. "Concrete Reference Reactor Building Core Boring Sample Radioactivity Analysis," August 29, Heisei 20, Japan Atomic Energy Agency (in Japanese)

226. TEPCO Holdings, http://www.tepco.co.jp/en/press/corp-com/release/betu15 e/images/ 151217e0137.pdf, (in English) last accessed February 2018.

227. TEPCO Holdings, "Examination of the Interior of Units 1 and 2 Exhaust Stack Using Drones at Fukushima Daiichi Nuclear Power Station," http://www.tepco.co.jp/en/nu/fukushima-np/handouts/ 2016/images/handouts 161020 02-e.pdf, last accessed Feb. 2017.

228. TEPCO Holdings, http://www.tepco.co.jp/nu/fukushima-np/handouts/2013/images/handouts_130918_13-j.pdf, (in Japanese), last accessed Feb. 2017.

229. TEPCO Holdings, http://www.tepco.co.jp/nu/fukushima-np/handouts/2013/images/handouts 131007 06-j.pdf, (in Japanese), last accessed Feb. 2017.

230. TEPCO Holdings, "Reevaluation of Seismic Safety of Unit $1 / 2$ Exhaust Cabinet (Interim report)]" http://www.tepco.co.jp/nu/fukushima-np/roadmap/2017/images1/d170629 14-j.pdf, June 29, 2017, last accessed July 2017.

231. TEPCO Holdings, Reevaluation of Seismic Safety of Unit $1 / 2$ Exhaust Case (Interim Report), http:// www.tepco.co.jp/nu/fukushima-np/roadmap/2017/images1/d170629_14-j.pdf, June 29, 2017, last accessed Feb. 2018.

232. TEPCO Holdings, "Status of inspection work of the main turbine of Unit 4," http://www.tepco.co.jp/ en/nu/fukushima-np/images/handouts_120112_05-e.pdf, last accessed Feb. 2017.

233. TEPCO Holdings, "Fukushima Nuclear Accident Analysis Report,” June 20, 2012. 
234. D. Yamada, et. al., "Fukushima Nuclear Accident TEPCO Insights and Discoveries $\sim 1 F 2$, , TEPCO Holdings, BWROG TSG Skill Set Workshop, Sept 27-30, 2016.

235. Nuclear Emergency Response Headquarters, Government of Japan, “The Accident at TEPCO's Fukushima Nuclear Power Stations (Second Report)" Additional Report of the Japanese Government to the IAEA Ministerial Conference on Nuclear Safety, September 2011.

236. TEPCO Holdings, "Result of temperature measurement by infrared camera from right above the reactor," uploaded Oct 15,2011, pictured on Oct 13, 2011. http://photo.tepco.co.jp/en/date/2011/ 201110-e/111015-03e.html, last accessed July 2017.

237. TEPCO Holdings, "Progress of Dismantling Work of the Building Cover of Fukushima Daiichi Nuclear Power Station Unit 1," Document 2 A-1 (1), Presentation by TEPCO Holdings Company, November 21, 2016. http://www.tepco.co.jp/nu/fukushima-np/roadmap/images1/images2/ 1161121 10-j.pdf, (in Japanese) last accessed July 2017.

238. TEPCO Holdings, "About the results of the survey on the condition of the garbage on the operating floor of Unit 1 reactor building (additional investigation)," http://www.tepco.co.jp/nu/fukushima-np/ roadmap/2017/images2/d170928 07-j.pdf, Sept. 28, 2017, last accessed Feb. 2018.

239. TEPCO Holdings, "Fukushima Daiichi Nuclear Power Station Unit 1 Results of Refueling Floor Survey (Interim)," Presentation by TEPCO Holdings Company, dated March 30, 2017, reference provided to US experts during May 2017 meetings.

240. M. T. Farmer, K. R. Robb, and M. W. Francis, "Fukushima Daiichi Unit 1 Ex-Vessel Prediction: Core Melt Spreading,” Nuclear Technology, Vol. 196, No. 3, pp. 446-460, December 2016.

241. M. T. Farmer and K. R. Robb, "Status Report on Ex-Vessel Coolability and Water Management," ANL/NE-16/18, September 15, 2016.

242. M. T. Farmer, S. Lomperski, R. W. Aeschlimann, and D. J. Kilsdonk, "Category 2 Coolability Engineering Enhancement Tests: Final Report,” OECD/MCCI-2010-TR02, November 2010.

243. TEPCO Holdings, "Fukushima Daiichi Nuclear Power Station Unit1 Parameters of Water level and Pressure," http://www.tepco.co.jp/en/nu/fukushima-np/f1/pla/2011/images/110613teisei table_summary-e.pdf, last accessed July 2017.

244. TEPCO Holdings, "Isolation Condenser of Unit 1, Fukushima Daiichi Nuclear Power Station," Video uploaded Oct 21, 2011. http://photo.tepco.co.jp/en/date/2011/201110-e/111021-02e.html, last accessed July 2017.

245. TEPCO Holdings "The fourth floor of Unit 1 Reactor Building at Fukushima Daiichi Nuclear Power Station (March 28, 2013)," Video uploaded March 28, 2013. http://photo.tepco.co.jp/en/date/2013/ 201303-e/130328-01e.html, last accessed July 2017.

246. Tennessee Valley Authority, Browns Ferry Nuclear Plant - Electronic FSAR, Amendment 18, https:/ /www.nrc.gov/docs/ML9935/ML993540095.pdf, last accessed July 2017. 
247. TEPCO Holdings, "The Soundness of Unit 4 Reactor Building and Spent Fuel Pool at Fukushima Daiichi Nuclear Power Station,” August 30, 2012, http://www.tepco.co.jp/en/nu/fukushima-np/ images/handouts_120830_03-e.pdf, last accessed Feb. 2017.

248. TEPCO Holdings, "Results of the Sixth Soundness Inspection of Unit 4 Reactor Building at Fukushima Daiichi Nuclear Power Station,” August 28, 2013, http://www.tepco.co.jp/en/nu/ fukushima-np/handouts/2013/images/handouts_130828 09-e.pdf, last accessed Feb. 2017.

249. TEPCO Holdings, Transportation of leakage and deformed fuels to the common pool from the spent fuel pool at Unit 4, Fukushima Daiichi Nuclear Power Station, http://www.tepco.co.jp/en/nu/ fukushima-np/handouts/2014/images/handouts 140731 07-e.pdf, last accessed Feb. 2017.

250. TEPCO Holdings, "Soundness Investigation of the Unused (Unirradiated) Fuel Removed from Unit 4 Spent Fuel Pool at Fukushima Daiichi Nuclear Power Station," http://www.tepco.co.jp/en/nu/ fukushima-np/images/handouts_120828_01-e.pdf, last accessed Feb. 2017.

251. TEPCO Holdings, "Soundness Investigation of the Unused (Unirradiated) Fuel Removed from Unit 4 Spent Fuel Pool at Fukushima Daiichi Nuclear Power Station," http://www.tepco.co.jp/en/nu/ fukushima-np/images/handouts_120829 01-e.pdf, last accessed Feb. 2017.

252. TEPCO Holdings, External Visual Inspection Results of the Fuels Removed from the Spent Fuel Pool at Unit 4 in the Fukushima Daiichi Nuclear Power Station," http://www.tepco.co.jp/en/nu/ fukushima-np/handouts/2014/images/handouts 140430 07-e.pdf, last accessed Feb. 2017.

253. D. Yamada, et al, "Fukushima Nuclear Accident $\sim$ TEPCO Insights and Discoveries $\sim 1 F 4$ and beyond," BWROG TSG Skill Set Workshop, TEPCO Holdings, September 26 - 30, 2016.

254. TEPCO Holdings, "Fukushima Daiichi Nuclear Power Station Investigation results with an underwater camera in Unit 3 Spent Fuel Pool," http://www.tepco.co.jp/en/nu/fukushima-np/handouts/2015/ images/handouts 150804 01-e.pdf, last accessed Feb. 2017.

255. TEPCO Holdings, Photos of the Accident at Fukushima Daiichi Nuclear Power Station (Publicized on February 1, 2013), Photo taken on 2011.3.17, http://photo.tepco.co.jp/en/date/2013/201302-e/ 130201-01e.html, last accessed Feb. 2017.

256. TEPCO Holdings, Report of Inspection Results of the First Dry Storage Cask at Fukushima Daiichi Nuclear Power Station, http://www.tepco.co.jp/en/nu/fukushima-np/handouts/2013/images/handouts 130327 04-e.pdf, last accessed Feb. 2017.

257. TEPCO Holdings, "Summary of Decommissioning and Contaminated Water Management," http:// www.tepco.co.jp/en/nu/fukushima-np/roadmap/images/d161124_01-e.pdf, last accessed Feb. 2017.

258. A. Barto, et al., "Consequence Study of a Beyond-Design-Basis Earthquake Affecting the Spent Fuel Pool for a U.S. Mark I Boiling Water Reactor," U.S. Nuclear Regulatory Commission, NUREG-2161, Sept. 2014.

259. EPRI, "Seismic Evaluation Guidance: Spent Fuel Pool Integrity Evaluation,” 3002009564, January 2017. 
260. TEPCO Holdings, "Result of checking the site situation of Unit 3 spent fuel pool gate (in Japanese)" April 6, 2015. http://www.tepco.co.jp/nu/fukushima-np/handouts/2015/images/handouts 150406 04-j.pdf, last accessed April 2017.

261. TEPCO Holdings, "Results of Investigation on $5^{\text {th }}$ Floor of the Reactor Building Unit 4," June 30, 2011. http://photo.tepco.co.jp/library/110630 4/handouts 110630 03-e.pdf, last accessed April 2017.

262. K. Robb, J. Gabor, and J. Rempe, “Component Inspections," presentation at Reactor Safety Technologies 4th Experts Panel Meeting, November 9-10, 2015, Washington, DC.

263. T. L. George, Fukushima Technical Evaluation, Phase 2- Revised GOTHIC Analysis, EPRI, Palo Alto, CA, 3002005295, July 2015.

264. M. Solom, K.V. Kirkland, "Experimental investigation of BWR Suppression Pool stratification during RCIC system operation,” Nuclear Engineering and Design, 310, pp 564-569, 2016.

265. S. Mizokami, TEPCO, email to J. Rempe, Rempe and Associates, LLC, "Potential to Gain Information related to MSL SRV Setpoints," dated June 14, 2016.

266. M. Sogalla, M. Sonnenkalb, C. Richter, and B. Klobes, "Severe accident progression and LDR measurements. BSAF Project Phase 2", $3^{\text {rd }}$ PRG Meeting, July 2016.

267. EPRI, "Technical Evaluation of Fukushima Accidents: Phase 2-Potential for Recriticality During Degraded Core Reflood,” EPRI Report 3002005298, April 26, 2016.

268. S. K. Shaukat, J. E. Jackson, D. F. Hatcher, "Regulatory Analysis for Generic Issue 23: Reactor Coolant Pump Seal Failure,” NUREG-1401, April 1991.

269. H. Bonneville and A. Luciani, "Simulation of the Core Degradation Phase of the Fukushima Accidents Using the ASTEC Code," Nuclear Engineering and Design, 272, 2012.

270. N. Andrews, T. Haskin and C. Faucett, "Modular Accident Analysis Program (MAAP) - MELCOR Crosswalk: Phase II, Analyzing a Partially Recovered Accident Scenario," SAND2017-11975, October 2017.

271. "Development of a Technology to Investigate Inside the Reactor Primary Containment Vessel (PCV)" TEPCO Holdings presentation, http://www.tepco.co.jp/en/nu/fukushima-np/handouts/2015/ images/handouts 150430_04-e.pdf, April 30, 2015, last accessed March 2016.

272. J. K. Fink, D. H. Thompson, D. R. Armstrong, B. W. Spencer, and B. R. Sehgal, "Aerosol and Melt Chemistry in the ACE Molten Core-Concrete Interaction Experiments," High Temperature and Materials Science, Vol. 33, p. 51, 1995.

273. M. T. Farmer, D. J. Kilsdonk, and R. W. Aeschlimann, "Corium Coolability under Ex-Vessel Accident Conditions for LWRs,” Nuclear Eng. Technology, Vol. 41, pp. 575-602, June 2009.

274. "Various Approaches for Understanding State of Nuclear Fuel," TEPCO Holdings, http:// www.tepco.co.jp/en/nu/fukushima-np/images/handouts_111130_07-e.pdf, November 30, 2011. 
275. Institute for Nuclear Power Operations, "Lessons Learned from the Nuclear Accident at the Fukushima Daiichi Nuclear Power Station,” INPO 11-005, November 2011.

276. Tennessee Valley Authority, "Procedure for Estimation of the Extent of Core Damage under Accident Conditions", 0-Technical Instruction 88, Revision 7, March 7, 2007.

277. M.M. El-Wakil, Nuclear Heat Transport, International Textbook Company, 1971. 
ANL-18/24 


\title{
APPENDIX A. FY2018 Meeting Agenda and Attendee List
}

\section{A.1. November 1-2, 2017 Meeting Agenda}

\author{
Reactor Safety Technology Expert Panel Forensics Meeting \\ Meeting Agenda \\ November 1-2, 2017 \\ Nuclear Energy Institute, 1201 F St., NW, Suite 1100, Washington, DC \\ Call-in number: +1 719-457-0705 Passcode: 498334\#
}

Wednes day. November 1.2017

\begin{tabular}{|c|c|c|}
\hline 8:30 AM & $\begin{array}{l}\text { Welcome to NEI, Administrative Matters, and Safety } \\
\text { Minute }\end{array}$ & S. Kraft, NEI \\
\hline 8:35 AM & $\begin{array}{l}\text { Welcome and Overview - DOE-NE } \\
\text { DOE-EM Activities within Japan }\end{array}$ & D. Peko, DOE-NE \\
\hline 8:45 AM & $\begin{array}{l}\text { DOE LWRS RST Pathway Lead Comments } \\
\text { - Overview of activities and relationship to Forensics }\end{array}$ & M. Farmer, ANL \\
\hline 9:00 AM & NRC Comments & R. Lee, NRC \\
\hline 9:15 AM & Objective and Planned Agenda & $\begin{array}{r}\text { J. Rempe, Rempe and } \\
\text { Associates, LLC }\end{array}$ \\
\hline 9:30 AM & TEPCO Update & T. Honda, TEPCO \\
\hline 10:45 AM & Break & All \\
\hline 11:00 AM & Code Analysis Insights and Updates & $\begin{array}{r}\text { C Paik, FAI } \\
\text { R. Gaunt/ N. Andrews, SNL }\end{array}$ \\
\hline $12: 15$ & $\begin{array}{l}\text { Working Lunch } \\
\text { Website Discussion - Status and Recommendations } \\
\text { Note: Include discussion of IAE and TEPCO websites }\end{array}$ & $\begin{array}{r}\text { All } \\
\text { P. Humrickhouse, INL }\end{array}$ \\
\hline 1:00 PM & $\begin{array}{l}\text { Topic } 5 \text { - Operations \& Maintenance } \\
\text { Insights from Daiichi Units 1,2, and } 3 \text { Instrumentation } \\
\text {-Implications for Operations, Maintenance, Severe } \\
\text { Accident Mitigation, and Accident Analysis } \\
\text { - Information /Examination Need Updates }\end{array}$ & $\begin{array}{r}\text { B. Williamson/P. Ellison, } \\
\text { TVA \& BWROG } \\
\text { K. Shearer, PWROG } \\
\text { J. Rempe, } \\
\text { Rempe \& Associates, LLC }\end{array}$ \\
\hline 2:30 PM & Break & All \\
\hline 2:45 PM & $\begin{array}{l}\text { Topic } 1 \text { - Component /System Examinations } \\
\text { Updates Related to New Material Available } \\
\text { Insights/Comments on Information Consistency and } \\
\text { Adequacy for Reactor Safety Insights }\end{array}$ & $\begin{array}{r}\text { K. Robb, ORNL/ } \\
\text { J. Gabor, Jensen Hughes }\end{array}$ \\
\hline & Additional information requests (if needed) & \\
\hline
\end{tabular}




\section{Reactor Safety Technology Expert Panel Forensics Meeting \\ Meeting Agenda \\ November 1-2, 2017}

Nuclear Energy Institute, 1201 F St., NW, Suite 1100, Washington, DC Call-in number: +1 719-457-0705 Passcode: 498334\#

\section{Wednesday, Novemher 1,2017 (Continued)}

$\begin{array}{llr}\text { 4:15 PM } & \text { Topic } 3 \text { - Dose Measurements /Surveys } & \text { N.Andrews, SNL/ } \\ & \text { Updates Related to New Material } & \text { D. Luxat, Jensen Hughes } \\ & \text { Insights/Comments on Information Consistency and } & \\ & \text { Adequacy for Reactor Safety Insights } & \\ & \text { Additional information requests (if needed) } & \\ \text { 5:00 } & \text { Adjourn } & \end{array}$

Thursday_November2,2017

$\begin{array}{ll}\text { 8:30 AM } & \text { Update on PreADES Project } \\ \text { 9:00 AM } & \text { Topic 3 - Core Debris Location Evaluations } \\ & \text { Updates based on New Material } \\ & - \text { Recent Exams } \\ & \text { - NDF Strategic Plan Calculations Regarding Endstate } \\ & \text { Insights/Comments on Information Consistency and } \\ & \text { Adequacy for Reactor Safety Insights } \\ & \text { Additional information requests (if needed) } \\ & \text { Break } \\ \text { 10:30 AM 10:45 AM } & \text { Topic 4 - Combustible Gas Effects } \\ & \text { Updates based on New Material } \\ & \text { Insights/Comments on Information Consistency and } \\ & \text { Adequacy for Reactor Safety Insights } \\ & \text { Additional information requests (if needed) } \\ & \text { Next Steps } \\ & \text { - Proposed report outline } \\ \text { 11:15 AM Action items and schedule } & \text { Adjourn } \\ \text { Noon } & \end{array}$

T. Washiya, JAEA

M. Farmer, ANL/

R. Gauntt and/or N. Andrews, SNL/

M. Plys, FAI
D. Luxat, Jensen Hughes

N.Andrews, SNL

J. Rempe, Rempe and Associates, LLC

All 


\section{A.2. November 1-2, 2017 Attendees}

\begin{tabular}{|c|c|c|}
\hline Number & Name & Organization \\
\hline 1 & Nathan Andrews & SNL \\
\hline 2 & Sud Basu & McGill Engineering Associates \\
\hline 3 & Randy Bunt & Southern Nuclear Company (by telephone) \\
\hline 4 & Phillip G. Ellison & GE-Hitachi \\
\hline 5 & Hossein Esmaili & U.S. NRC \\
\hline 6 & Mitchell T. Farmer & ANL \\
\hline 7 & Terri V. Farthing & GE Hitachi (by telephone) \\
\hline 8 & Edward Fuller & U.S. NRC \\
\hline 9 & Jeff Gabor & Jensen Hughes \\
\hline 10 & Randy Gauntt & SNL \\
\hline 11 & Craig Gerardi & ANL \\
\hline 12 & Takashi Hara & TEPCO Holdings \\
\hline 13 & Don Helton & U.S. NRC (by telephone) \\
\hline 14 & Paul Humrickhouse & INL \\
\hline 15 & Takeshi Honda & TEPCO Holdings \\
\hline 16 & Stephen Kraft & NEI \\
\hline 17 & Richard Lee & U.S. NRC \\
\hline 18 & David Luxat & Jensen Hughes \\
\hline 19 & S. Mizokami & TEPCO Holdings JAEA (CLADS) \\
\hline 20 & Chan Paik & Fauske and Associates, LLC \\
\hline 21 & Damian Peko & U.S. DOE \\
\hline 22 & Marty Plys & Fauske and Associates, LLC \\
\hline 23 & Joy Rempe & Rempe and Associates, LLC \\
\hline 24 & Kevin Robb & ORNL \\
\hline 25 & Michael Salay & U.S. NRC \\
\hline 26 & Kyle Shearer & PWROG/Westinghouse \\
\hline 27 & Richard Wachowiak & EPRI \\
\hline 28 & Tadahiro Washiya & JAEA \\
\hline 29 & Bill T. Williamson & TVA \\
\hline
\end{tabular}


ANL-18/24

A-4 


\section{APPENDIX B. Website to Support Forensics Evaluations}

\section{B.1. Background}

During the November 2016 meeting, it was agreed that a website should be developed that provided a searchable location for archived information relied upon by the U.S. Forensics Effort. To ensure that this website addresses needs for this effort, it was agreed to populate an initial website framework and present it at the May 2017 expert panel meeting for review by program participants. To ensure that information in this website would be archived, this framework was developed under the auspices of the Idaho National Laboratory (INL) digital library (https://inldigitallibrary.inl.gov) at https://doeforensics.inl.gov. The INL digital library archives INL reports and publications, the DOE Idaho Operations Office Public Reading Room, and information related to the cleanup of TMI-2, including the NRC TMI-2 Knowledge Management Library (https://tmi2kml.inl.gov). This appendix describes the new DOE forensics website framework as it has been implemented, along with planned further additions and modifications.

The need to have access to archived information from inspections, analyses, and other relevant sources has been recognized internationally. There are several existing websites that support this need, including the website developed and maintained by TEPCO Holdings (http://www.tepco.co.jp/en/index-e.html and http://photo.tepco.co.jp/en/index-e.html) and the website developed by the Institute for Applied Energy supports SAREF Research activities (https://fdada.info/en/home2/). Although this effort relies on information contained in these two websites (and links to these websites may be accessed from the U.S Forensics website), it was agreed that a unique website was needed to archive information relied upon for analyses and evaluations completed within the U.S. Forensics Effort.

\section{B.2. Website Design}

The primary purpose of the U.S. Forensics Effort website is to display, filter, and search for relevant documents, and the interface is designed with these functions in mind. At the right side of the page, several categories are listed in which one or more filters can be applied; at the center of the page, the list of documents matching the selected filter criteria appears. The default view of this page, in which no filters are applied, is shown in Figure B-1; in this case all documents in the database are listed (15 per page).

There are several categories on which to filter the document list:

- Date. This can be an arbitrary range of dates entered by the user.

- Date Added. This allows users to quickly identify information that is new, added within the last week, the last month, the last year, or over a year.

- Source. This is the issuing agency. Sources include EPRI, the Government of Japan (GoJ), IAE, IAEA, INL IRID, JAEA, LBLN, METI, NDR, NRA, Science Council of Japan, SNL, Springer, TEPCO Holdings, etc. Note that links are provided, as appropriate, to address copyright issues.

- Media Type. This includes articles, books, photos, reports, slides, spreadsheets, videos, websites, etc.

- Topic. Site materials are presently organized under four topics (the list will continue to grow as more documents are added):

- Accident Analysis 


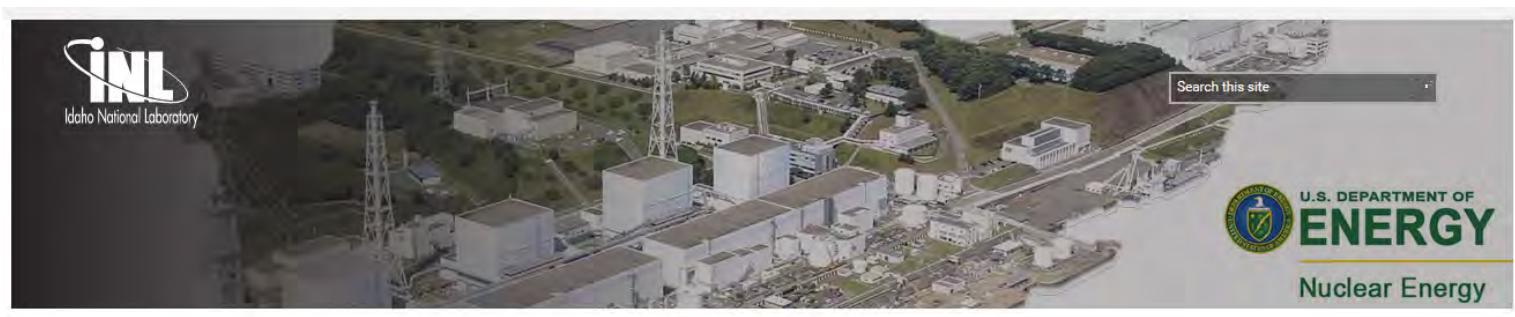

\section{Home}

DOE Forensics Home

\begin{tabular}{|c|c|c|}
\hline Home & 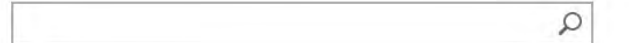 & Document Date Search: \\
\hline & 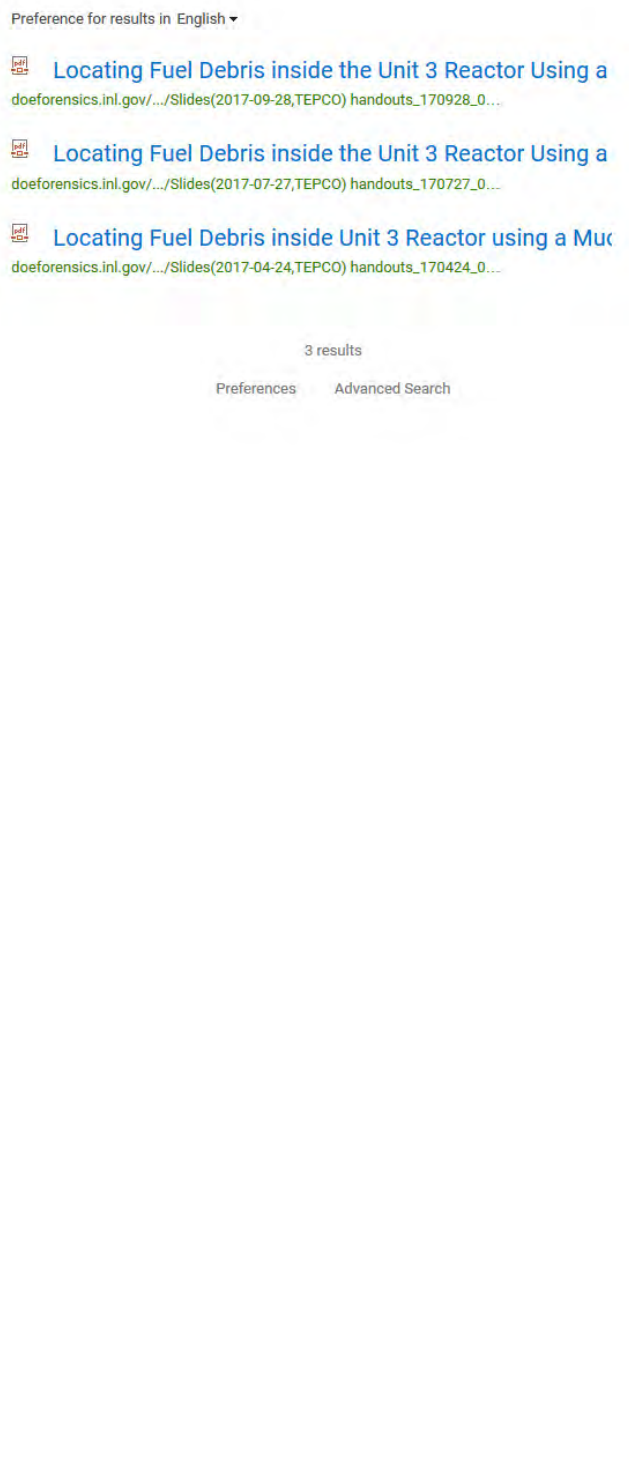 & 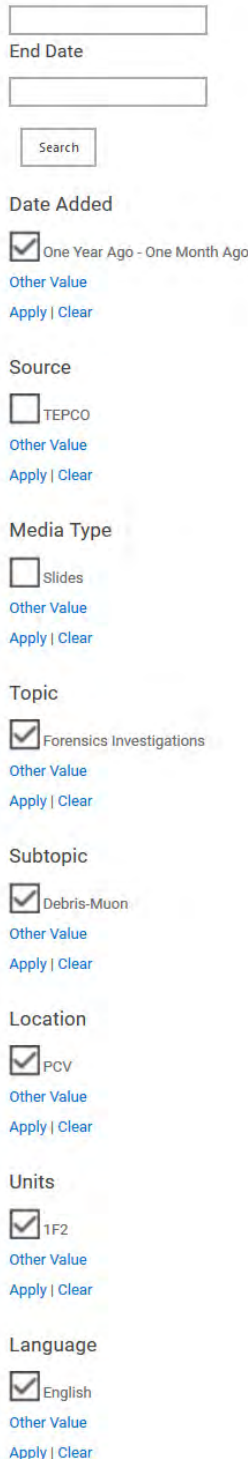 \\
\hline
\end{tabular}

Figure B-1. Representative view of the website with filters applied. (Courtesy of INL) 
- Forensics Investigations

- Lessons Learned

- Planning (Activities and Schedules)

- Plant Data

- Status (Current Conditions)

- Unresolved Issues (UI)

- Subtopic. This is a more specific description of the document content; examples include: Combustible Gas, Debris-Muon, Debris- Robot, Debris-Sample, Instrumentation Data, MCCI, Operations and Maintenance, Radiation-Samples, Radiation-Survey, SSC-Images, SSC-Performance, SSC-Sample, Source Term, etc. This list will also continue to grow as documents are added.

- System, Structure, and Component (SSC). This is a more specific description of what SSCs are discussed in the document. Examples include: Electrical and I\&C Equipment, HPCI, Instrumentation, Isolation Condenser, PCV, Penetration, RCIC, Shield Plug, and Vents. This list will also continue to grow as documents are added.

- Location. This can be within a particular unit, such as the PCV, RB, RPV, SFP, Torus, Torus Room, Turbine Building, and the Site. "All" is also included as an option.

- Units. This is can be a particular unit (e.g. 1F2), or multiple units (1, 2, 3, and/or 4).

- Language. This is for filtering to Japanese or English documents.

The current options under each filter category are not exhaustive; these attributes are assigned to a document when uploaded. It is expected that they will be updated based on user input. As documents are added, the number of options in most categories will grow.

Filters are applied by selecting the applicable check box in each category and clicking "Apply." This must be done for each category in which one wishes to filter, which can be any number of categories. Similarly, removing a filter requires un-checking the corresponding box and clicking "Apply." All checked boxes in each category can be removed simultaneously by clicking "Clear."

In addition to the filters described above, a simple search utility is included that allows users to search for text within the (optionally) filtered document list. This search function acts not just on titles and document descriptions, but also to the entire text of documents (provided, e.g. in the case of PDF files, it contains searchable embedded text and not simply scanned images).

The website is built on the SharePoint platform, and users must have an account to access it. Accounts are available to both internal (INL) and external users. Future development will focus on adding materials and implementing further features identified by the expert panel. 
ANL-18/24 


\section{APPENDIX C. Information Needs}

As described in Section 1.1, primary objectives of the U.S. forensics effort are to develop and update consensus U.S. input for high priority time-sequenced examination tasks and supporting research activities that can be completed with minimal disruption of D\&D plans for Daiichi. Initial objectives were developed in 2014. Every year, these objectives are updated. Section C.1 presents the current version of these information needs. As described in Section 1.3, these information needs are organized into tables for each location (e.g., the reactor building, the PCV, and the RPV). Since 2014, several new information requests were added and the status of several U.S. information requests was modified. For example, several information needs have been addressed by recent examinations completed by TEPCO Holdings. In addition, because of renewed U.S. interest in the integrity of instrumentation data (PC-7 and PC-8), TEPCO Holdings agreed to provide results regarding the qualification envelop of sensors and estimates regarding the conditions to which these sensors were exposed.

During the May 2017 meeting, it was agreed that more detailed requests should be developed for the following high priority, nearer term information needs:

- $\mathrm{RB}-9 \mathrm{~b}$

- RB-10

- $\mathrm{RB}-15$

- $\mathrm{PC}-1$

- $\quad$ PC-3a, 3b, 3c, 3d, and 3e

- $\mathrm{PC}-5$

- $\mathrm{PC}-6$

- $\quad$ PC-17, PC-18, PC-19, and PC-20 (combined)

- $\mathrm{PC}-21$

- RPV-1b

- $\quad$ RPV-4 and RPV-5 (combined)

These more detailed requests, which are found in Section C.2, provide additional details regarding the benefits of obtaining this information, how this information would be used, the methods and/or tools required to obtain this information, the expected schedule for when this information would be available, and any expected preparations to obtain or follow-on research that may be required to use this information. 


\section{C.1. Summary Information Needs}

Table C-1. Information needs from the reactor building

\begin{tabular}{|c|c|c|c|c|c|}
\hline Item & $\begin{array}{l}\text { What/How } \\
\text { Obtained }\end{array}$ & Why & Expected Benefit /Use & When & Status \\
\hline RB-1 & $\begin{array}{l}\text { Photos/ } \\
\text { videos }^{\mathrm{a}} \text { of } \\
\text { condition of } \\
\text { RCIC valve } \\
\text { and pump } \\
\text { before drain } \\
\text { down and after } \\
\text { disassembly } \\
(1 \mathrm{~F} 2 \text { and } 1 \mathrm{~F} 3)\end{array}$ & $\begin{array}{l}\text { Determine turbine } \\
\text { condition. } \\
\text { Gain insights about } \\
\text { status of valve and } \\
\text { pump at time of fail- } \\
\text { ure [PWRs have } \\
\text { almost identical } \\
\text { pumps for AFW]. }\end{array}$ & $\begin{array}{l}\text { Impacts BWR AM strategies } \\
\text { (cause of RCIC room } \\
\text { flooding). Use to support } \\
\text { RCIC testing project (for } \\
\text { confirmation of testing } \\
\text { results). Potential PWR } \\
\text { impacts (e.g., modeling, AM } \\
\text { strategies, etc.). }\end{array}$ & $\begin{array}{l}\text { Currently } \\
\text { flooded } \\
\text { (requires } \\
\text { underwater } \\
\text { investigations } \\
\text { unless drained). } \\
\text { Inspections } \\
\text { could be } \\
\text { completed more } \\
\text { easily at Daini. }\end{array}$ & $\begin{array}{l}\text { Not currently considered by } \\
\text { TEPCO Holdings. If torus } \\
\text { not drained, requires } \\
\text { underwater technology } \\
\text { available. } \\
\text { If photos or data are } \\
\text { obtained as part of D\&D } \\
\text { activities, please provide } \\
\text { (but the U.S. recognizes that } \\
\text { additional information may } \\
\text { not be obtained). }\end{array}$ \\
\hline RB-2 & $\begin{array}{l}\text { Photos/videos } \\
\text { of HPCI } \\
\text { System after } \\
\text { disassembly } \\
(1 \mathrm{~F} 1,1 \mathrm{~F} 2 \text {, and } \\
1 \mathrm{~F} 3)\end{array}$ & 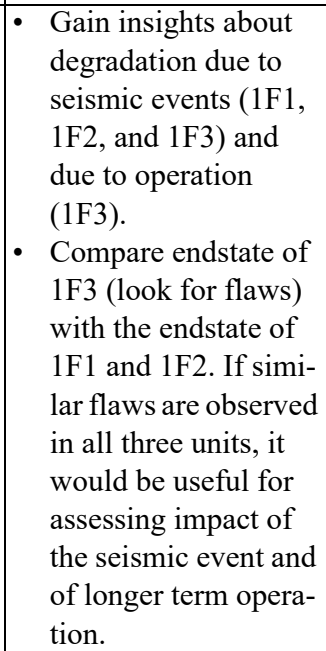 & $\begin{array}{l}\text { Impacts AM strategies } \\
\text { (equipment utilization). }\end{array}$ & $\begin{array}{l}\text { Currently } \\
\text { flooded } \\
\text { (requires other } \\
\text { alternatives for } \\
\text { underwater } \\
\text { investigations } \\
\text { unless drained). }\end{array}$ & $\begin{array}{l}\text { Not currently considered by } \\
\text { TEPCO Holdings; If torus } \\
\text { not drained, requires } \\
\text { underwater technology. } \\
\text { If photos are obtained as part } \\
\text { of D\&D activities, please } \\
\text { provide (but the U.S. } \\
\text { recognizes that additional } \\
\text { information may not be } \\
\text { obtained and that system } \\
\text { degradation may be due to } \\
\text { long term exposure to water } \\
\text { since the accident). }\end{array}$ \\
\hline
\end{tabular}


Table C-1. Information needs from the reactor building

\begin{tabular}{|c|c|c|c|c|c|}
\hline Item & $\begin{array}{l}\text { What/How } \\
\text { Obtained }\end{array}$ & Why & Expected Benefit /Use & When & Status \\
\hline RB-3a & $\begin{array}{l}\text { Photos/videos } \\
\text { of damaged } \\
\text { walls and } \\
\text { structures } \\
(1 \mathrm{~F} 1)\end{array}$ & $\begin{array}{l}\text { Determine mode of } \\
\text { explosion in } 1 \mathrm{~F} 1 \mathrm{com}- \\
\text { pared to } 1 \mathrm{~F} 3 \text {. }\end{array}$ & $\begin{array}{l}\text { Understanding what } \\
\text { happened; assist D\&D } \\
\text { efforts. Potential BWR } \\
\text { improvements; Impacts BWR } \\
\text { AM strategies and code } \\
\text { models (venting and } \\
\text { interconnection between } \\
\text { units); Potential PWR } \\
\text { impacts (e.g., modeling, AM } \\
\text { strategies, etc.) }\end{array}$ & $\begin{array}{l}\text { Now (whenever } \\
\text { TEPCO } \\
\text { Holdings goes } \\
\text { into 1F1) and } \\
\text { after debris } \\
\text { removal. }\end{array}$ & \multirow{3}{*}{$\begin{array}{l}\text { TEPCO Holdings has some } \\
\text { information (Dose rate } \\
\text { distribution measurement } \\
\text { around SGTS filter was } \\
\text { performed for 1F4 and 1F3. } \\
\text { Visual inspection inside R/B } \\
\text { was performed from view of } \\
\text { integrity of structures for } \\
\text { 1F4). } \\
\text { If additional images are } \\
\text { obtained as part of D\&D } \\
\text { activities, please include } \\
\text { reference length scales (or } \\
\text { information about } \\
\text { component dimensions). } \\
\text { The U.S. will monitor the } \\
\text { NRA website for images. In } \\
\text { particular, if D\&D strategy } \\
\text { allows additional photos of } \\
\text { the shield plugs for all units, } \\
\text { include a reference length of } \\
\text { damaged components, if } \\
\text { possible. If shield plugs are } \\
\text { removed, time lapsed videos } \\
\text { during removal are } \\
\text { requested. Photos after } \\
\text { debris removal are also of } \\
\text { interest. }\end{array}$} \\
\hline RB-3b & $\begin{array}{l}\text { Photos/videos } \\
\text { of damaged } \\
\text { walls and } \\
\text { structures } \\
(1 \mathrm{~F} 3)\end{array}$ & $\begin{array}{l}\text { Determine mode of } \\
\text { explosion in } 1 \mathrm{~F} 3 \text {. } \\
\text { Gain insight about } \\
\text { highly energetic } \\
\text { explosions in } 1 \mathrm{~F} 3 \\
\text { compared to } 1 \mathrm{~F} 1 \text {. }\end{array}$ & $\begin{array}{l}\text { Understanding what } \\
\text { happened; assist D\&D } \\
\text { efforts. Potential BWR } \\
\text { improvements; Impacts BWR } \\
\text { AM strategies and code } \\
\text { models (venting and } \\
\text { interconnection between } \\
\text { units); Potential PWR } \\
\text { impacts (e.g., modeling, AM } \\
\text { strategies, etc.). }\end{array}$ & $\begin{array}{l}\text { Now (whenever } \\
\text { TEPCO } \\
\text { Holdings goes } \\
\text { into 1F3) and } \\
\text { after debris } \\
\text { removal. }\end{array}$ & \\
\hline RB-3c & $\begin{array}{l}\text { Photos/videos } \\
\text { of damaged } \\
\text { walls and } \\
\text { structures } \\
(1 \mathrm{~F} 4)\end{array}$ & $\begin{array}{l}\text { Determine mode of } \\
\text { explosion in } 1 \mathrm{~F} 4 \text {. }\end{array}$ & $\begin{array}{l}\text { Understanding what } \\
\text { happened; assist D\&D } \\
\text { efforts. Potential BWR } \\
\text { improvements; Impacts BWR } \\
\text { AM strategies and code } \\
\text { models (venting and } \\
\text { interconnection between } \\
\text { units); Potential PWR } \\
\text { impacts (e.g., modeling, AM } \\
\text { strategies, etc.). }\end{array}$ & $\begin{array}{l}\text { Now (whenever } \\
\text { TEPCO } \\
\text { Holdings goes } \\
\text { into 1F4) and } \\
\text { after debris } \\
\text { removal. }\end{array}$ & \\
\hline RB-4 & $\begin{array}{l}\text { Photos/videos } \\
\text { of damaged } \\
\text { walls and } \\
\text { components } \\
\text { and } \\
\text { radionuclide } \\
\text { surveys (1F2) }\end{array}$ & $\begin{array}{l}\text { Cause of depressur- } \\
\text { ization. } \\
\text { - Cause of } \mathrm{H}_{2} \text { genera- } \\
\text { tion. }\end{array}$ & $\begin{array}{l}\text { Understanding what } \\
\text { happened; assist D\&D } \\
\text { efforts. Impacts BWR AM } \\
\text { strategies (equipment } \\
\text { utilization and venting); } \\
\text { Improved BWR code } \\
\text { simulations for training; } \\
\text { Potential PWR impacts (e.g., } \\
\text { modeling, AM strategies, } \\
\text { etc.). }\end{array}$ & Completed. & $\begin{array}{l}\text { TEPCO Holdings has dose } \\
\text { distribution information. } \\
\text { This item has been } \\
\text { addressed. }\end{array}$ \\
\hline
\end{tabular}


Table C-1. Information needs from the reactor building

\begin{tabular}{|c|c|c|c|c|c|}
\hline Item & $\begin{array}{c}\text { What/How } \\
\text { Obtained }\end{array}$ & Why & Expected Benefit /Use & When & Status \\
\hline RB-5 & $\begin{array}{l}\text { Radionuclide } \\
\text { surveys (1F1, } \\
1 \mathrm{~F} 2 \text {, and } 1 \mathrm{~F} 3)\end{array}$ & $\begin{array}{l}\text { Leakage path identi- } \\
\text { fication. } \\
\text { - Dose code bench- } \\
\text { marks. }\end{array}$ & $\begin{array}{l}\text { Understanding what } \\
\text { happened; assist D\&D } \\
\text { efforts. Improved BWR } \\
\text { Accident Management (plant } \\
\text { robustness, training, SAMG). } \\
\text { Improved BWR code } \\
\text { simulations and dose code } \\
\text { benchmarks, Potential PWR } \\
\text { impacts (e.g., modeling, AM } \\
\text { strategies, etc.). }\end{array}$ & $\begin{array}{l}\text { Now and later } \\
\text { (as debris is } \\
\text { removed). }\end{array}$ & $\begin{array}{l}\text { TEPCO Holdings has survey } \\
\text { information in 1F1, 1F2, and } \\
1 \mathrm{~F} 3 \mathrm{R} / \mathrm{B} \text {. some concrete } \\
\text { samples analyzed to } \\
\text { investigate Cs permeation } \\
\text { inside concrete floor. Dose } \\
\text { rate distribution } \\
\text { measurements on 1F2 and } \\
1 \mathrm{~F} 3 \text { including top of shield } \\
\text { plug. Dose surveys obtained } \\
\text { around 1F1, 1F2, and 1F3 } \\
\text { pipe penetrations (outside } \\
\text { end of penetrations through } \\
\text { PCV) in R/B. W/W vent line } \\
\text { in 1F1 extremely } \\
\text { contaminated such as AC } \\
\text { piping in R/B 1st floor, } \\
\text { SGTS filter train area, } \\
\text { piping connected to stack. } \\
\text { Dose rate around rupture } \\
\text { disc of 1F2 W/W vent line } \\
\text { was performed. No } \\
\text { contamination around } \\
\text { rupture disc } 1 \mathrm{~F} 2 \text {, but SGTS } \\
\text { filter was highly } \\
\text { contaminated. } \\
\text { If isotopic composition of } \\
\text { samples/swipes from } \\
\text { drywell head are obtained, } \\
\text { data are of interest. In } \\
\text { particular, Ru information is } \\
\text { of interest. Dose map of } 1 \mathrm{~F} 1 \\
\text { after cleanup is of interest. }\end{array}$ \\
\hline RB-6 & $\begin{array}{l}\text { Radionuclide } \\
\text { surveys and } \\
\text { sampling of } \\
\text { ventilation } \\
\text { ducts (1F4) }\end{array}$ & $\begin{array}{l}\text { Isotope concentra- } \\
\text { tion could be used for } \\
\text { determining source of } \\
\mathrm{H}_{2} \text { production for } \\
\text { CCI. }\end{array}$ & $\begin{array}{l}\text { Understanding what } \\
\text { happened. Potential BWR } \\
\text { plant improvements } \\
\text { (hardened vent use, AM } \\
\text { strategies, and multi-unit } \\
\text { effects, etc.). Potential PWR } \\
\text { impacts (e.g., modeling, AM } \\
\text { strategies, multi-unit effects). }\end{array}$ & Completed. & $\begin{array}{l}\text { TEPCO Holdings is not } \\
\text { planning any additional } \\
\text { examinations. } \\
\text { This item is closed. If } \\
\text { additional information } \\
\text { become available, please } \\
\text { provide. }\end{array}$ \\
\hline
\end{tabular}


Table C-1. Information needs from the reactor building

\begin{tabular}{|c|c|c|c|c|c|}
\hline Item & $\begin{array}{l}\text { What/How } \\
\text { Obtained }\end{array}$ & Why & Expected Benefit /Use & When & Status \\
\hline RB-7 & $\begin{array}{l}\text { Isotopic } \\
\text { evaluations of } \\
\text { obtained } \\
\text { concrete } \\
\text { samples (1F2) }\end{array}$ & $\begin{array}{l}\text { Code assessments. } \\
\text { Possible model } \\
\text { improvements for } \\
\text { building retention } \\
\text { assumptions. }\end{array}$ & $\begin{array}{l}\text { Understanding what } \\
\text { happened; assist D\&D } \\
\text { efforts. Improved BWR } \\
\text { modeling and emergency } \\
\text { planning; cross check of RN } \\
\text { surveys. Potential PWR } \\
\text { impacts (e.g., modeling, AM } \\
\text { strategies, etc.). }\end{array}$ & Now. & $\begin{array}{l}\text { JAEA has obtained surface } \\
\text { RN concentrations and RN } \\
\text { distribution from boring } \\
\text { concrete samples. Surface } \\
\text { radionuclide concentrations } \\
\text { and distribution of } \\
\text { radionuclides of boring core } \\
\text { samples were obtained. } \\
\text { If additional samples or } \\
\text { surveys are obtained, } \\
\text { isotopic composition is of } \\
\text { interest (but the U.S. } \\
\text { recognizes that additional } \\
\text { information may not be } \\
\text { obtained). }\end{array}$ \\
\hline RB-8 & $\begin{array}{l}\text { Photos/videos } \\
\text { and inspection } \\
\text { of seismic } \\
\text { susceptible } \\
\text { areas (e.g., } \\
\text { bellows, } \\
\text { penetrations, } \\
\text { structures, } \\
\text { supports, etc. } \\
\text { in 1F1, 1F2, } \\
1 \mathrm{~F} 3 \text {, and } 1 \mathrm{~F} 4)\end{array}$ & $\begin{array}{l}\text { To confirm with data } \\
\text { that there were no } \\
\text { seismic-induced fail- } \\
\text { ures. }\end{array}$ & $\begin{array}{l}\text { Understanding what } \\
\text { happened; assist D\&D } \\
\text { efforts. Improved plant } \\
\text { robustness; observed } \\
\text { differences between 1F1 and } \\
\text { 1F3. Potential PWR impacts } \\
\text { (e.g., similar penetrations). }\end{array}$ & $\begin{array}{l}\text { Now and later } \\
\text { (as debris is } \\
\text { removed); Note } \\
\text { that debris } \\
\text { currently } \\
\text { precludes data } \\
\text { from being } \\
\text { obtained. }\end{array}$ & $\begin{array}{l}\text { 1F1: The IC main unit, } \\
\text { major pipes, and major } \\
\text { valves visually investigated } \\
\text { to confirm whether there } \\
\text { was any damage that could } \\
\text { cause reactor to lose coolant. } \\
\text { Since inside area of PCV } \\
\text { inaccessible, IC, pipes, and } \\
\text { valves outside PCV } \\
\text { checked. } \\
\text { 1F2: No large abnormality } \\
\text { was found in the robot } \\
\text { camera's visual inspection. } \\
\text { Visual inspection inside } \\
\text { PCV performed in 1F1, 1F2, } \\
\text { and 1F3 but inspection range } \\
\text { limited. } \\
\text { If additional information is } \\
\text { obtained as part of planned } \\
\text { D\&D activities, please } \\
\text { provide it (but the U.S. } \\
\text { recognizes that additional } \\
\text { information may not be } \\
\text { obtained). }\end{array}$ \\
\hline
\end{tabular}


Table C-1. Information needs from the reactor building

\begin{tabular}{|c|c|c|c|c|c|}
\hline Item & $\begin{array}{c}\text { What/How } \\
\text { Obtained }\end{array}$ & Why & Expected Benefit /Use & When & Status \\
\hline \multirow[t]{2}{*}{ RB-9 } & $\begin{array}{l}\text { DW Concrete } \\
\text { Shield } \\
\text { Radionuclide } \\
\text { surveys (1F1, } \\
1 \mathrm{~F} 2 \text {, and } 1 \mathrm{~F} 3 \text { - } \\
\text { after debris } \\
\text { removed) }\end{array}$ & $\begin{array}{l}\text { To understand leak- } \\
\text { age amounts and } \\
\text { locations. }\end{array}$ & $\begin{array}{l}\text { Improved AM strategies } \\
\text { (Plant improvements, } \\
\text { training, and education). } \\
\text { Improved codes. } \\
\text { Understanding what } \\
\text { happened; assist D\&D } \\
\text { efforts. }\end{array}$ & $\begin{array}{l}\text { Now and later } \\
\text { (as debris is } \\
\text { removed). }\end{array}$ & $\begin{array}{l}\text { TEPCO Holdings has photos } \\
\text { and some RN surveys; more } \\
\text { will be obtained. } \\
\text { If additional information is } \\
\text { obtained as part of planned } \\
\text { D\&D activities, please } \\
\text { provide (but the U.S. } \\
\text { recognizes that additional } \\
\text { information may not be } \\
\text { obtained). US industry } \\
\text { agreed to compile a list of } \\
\text { high interest locations } \\
\text { (based on benefits to } \\
\text { maintenance). }\end{array}$ \\
\hline & $\begin{array}{l}\text { Photos/videos } \\
\text { around } \\
\text { mechanical } \\
\text { seals and } \\
\text { hatches and } \\
\text { electrical } \\
\text { penetration } \\
\text { seals (as a } \\
\text { means to } \\
\text { classify if } \\
\text { joints in } \\
\text { compression } \\
\text { or tension) }\end{array}$ & $\begin{array}{l}\text { Potential leakage } \\
\text { paths for RN and } \\
\text { hydrogen release. }\end{array}$ & $\begin{array}{l}\text { Improved AM strategies } \\
\text { (Plant improvements for } \\
\text { BWR and PWRS, which have } \\
\text { similar seals). Improved } \\
\text { codes. Understanding what } \\
\text { happened; assist D\&D } \\
\text { efforts. }\end{array}$ & Now and later. & $\begin{array}{l}\text { TEPCO Holdings has photos } \\
\text { and some dose survey } \\
\text { information (see RB-10). } \\
\text { If photos are obtained as part } \\
\text { of planned D\&D activities, } \\
\text { please provide (but the U.S. } \\
\text { recognizes that additional } \\
\text { information may not be } \\
\text { obtained). US industry } \\
\text { agreed to compile a list of } \\
\text { high interest locations } \\
\text { (based on benefits to } \\
\text { maintenance). }\end{array}$ \\
\hline RB-10 & $\begin{array}{l}\text { Photos/videos } \\
\text { and dose } \\
\text { surveys of 1F1 } \\
\text { (vacuum } \\
\text { breaker), 1F1, } \\
\text { 1F2, and 1F3 } \\
\text { PCV leakage } \\
\text { points } \\
\text { (bellows, } \\
\text { penetrations) }\end{array}$ & $\begin{array}{l}\text { Potential leakage } \\
\text { paths for RN and } \\
\text { hydrogen release. }\end{array}$ & $\begin{array}{l}\text { Improved AM strategies } \\
\text { (Plant improvements for } \\
\text { more robustness, training, } \\
\text { education); applicable to } \\
\text { BWRs and PWRs (which } \\
\text { have similar penetration } \\
\text { designs). Improved codes. } \\
\text { Improved understanding of } \\
\text { events; assist D\&D efforts. }\end{array}$ & Now and later. & $\begin{array}{l}\text { TEPCO Holdings has } \\
\text { considerable information } \\
\text { related to this information } \\
\text { need. }{ }^{\mathrm{c}} \text { Now, restoring works } \\
\text { for PCV to stop water } \\
\text { leakage are prioritized and } \\
\text { no plan to scrutinize the } \\
\text { damaged area or degree of } \\
\text { PCV. } \\
\text { If additional photos or } \\
\text { information is obtained, } \\
\text { please provide (but the U.S. } \\
\text { recognizes that additional } \\
\text { information may not be } \\
\text { obtained). US industry } \\
\text { agreed to compile a list of } \\
\text { high interest locations } \\
\text { (based on benefits to } \\
\text { maintenance). }\end{array}$ \\
\hline
\end{tabular}


Table C-1. Information needs from the reactor building

\begin{tabular}{|c|c|c|c|c|c|}
\hline Item & $\begin{array}{l}\text { What/How } \\
\text { Obtained }\end{array}$ & Why & Expected Benefit /Use & When & Status \\
\hline RB-11 & $\begin{array}{l}\text { Photos/videos } \\
\text { and dose } \\
\text { information on } \\
1 \mathrm{~F} 1,1 \mathrm{~F} 2 \text {, and } \\
1 \mathrm{~F} 3 \\
\text { containment } \\
\text { hardpipe } \\
\text { venting } \\
\text { pathway, } \\
\text { SGTS and } \\
\text { associated } \\
\text { reactor } \\
\text { building } \\
\text { ventilation } \\
\text { system }\end{array}$ & $\begin{array}{l}\text { To assess perfor- } \\
\text { mance of seals under } \\
\text { high temperature and } \\
\text { radiation conditions. }^{\text {d }}\end{array}$ & $\begin{array}{l}\text { Improved AM strategies } \\
\text { (Plant improvements). } \\
\text { Improved understanding of } \\
\text { events, assist D\&D efforts. }\end{array}$ & Completed. & $\begin{array}{l}\text { 1F1: Dose rate of venting } \\
\text { pathway and the point in } \\
\text { front of SGTS room. } \\
\text { Because of high dose rate, } \\
\text { access to SGTS room is } \\
\text { difficult. } \\
\text { 1F2 and 1F3: Photos and } \\
\text { dose rate of SGTS trains and } \\
\text { venting pathway available. } \\
\text { This item has been } \\
\text { completed. }\end{array}$ \\
\hline RB-12 & $\begin{array}{l}\text { Photos/videos } \\
\text { at appropriate } \\
\text { locations near } \\
\text { identified } \\
\text { leakage points } \\
\text { in } 1 \mathrm{~F} 1,1 \mathrm{~F} 2 \text {, } \\
\text { and } 1 \mathrm{~F} 3 \text {. }\end{array}$ & $\begin{array}{l}\text { To discern reason for } \\
\text { leakage from the } \\
\text { reactor building into } \\
\text { the turbine building. }\end{array}$ & $\begin{array}{l}\text { Improved BWR AM } \\
\text { strategies (Plant } \\
\text { improvements); potential } \\
\text { PWR impacts, depending on } \\
\text { identified leakage path. } \\
\text { Assist D\&D efforts. }\end{array}$ & Now. & $\begin{array}{l}\text { Not currently considered by } \\
\text { TEPCO Holdings; some } \\
\text { visual information available. } \\
\text { This item has been } \\
\text { addressed. If additional } \\
\text { photos are obtained as part } \\
\text { of planned D\&D activities, } \\
\text { please provide (but the U.S. } \\
\text { recognize that additional } \\
\text { information may not be } \\
\text { obtained). }\end{array}$ \\
\hline
\end{tabular}


Table C-1. Information needs from the reactor building

\begin{tabular}{|c|c|c|c|c|c|}
\hline Item & $\begin{array}{l}\text { What/How } \\
\text { Obtained }\end{array}$ & Why & Expected Benefit /Use & When & Status \\
\hline RB-13 & $\begin{array}{l}\text { Photos/ videos } \\
\text { of } 1 \mathrm{~F} 1,1 \mathrm{~F} 2, \\
\text { and } 1 \mathrm{~F} 3 \text { main } \\
\text { steam lines at } \\
\text { locations } \\
\text { outside the } \\
\text { PCV }\end{array}$ & $\begin{array}{l}\text { To determine PCV } \\
\text { failure mode. }\end{array}$ & $\begin{array}{l}\text { BWR AM strategies (plant } \\
\text { mods, etc.) and better } \\
\text { simulations for training. } \\
\text { Assist D\&D efforts. }\end{array}$ & Now and later. & $\begin{array}{l}\text { 1F2: TEPCO Holdings has } \\
\text { some visual information } \\
\text { related to 1F2 MSIV. } \\
\text { 1F3: Water leak from near } \\
\text { expansion joint (bellows) of } \\
\text { MSL D in MSIV room was } \\
\text { confirmed. The water level } \\
\text { in the PCV is estimated at } \\
\text { about } 2 \text { m above the reactor } \\
\text { building first floor by } \\
\text { converting the S/C pressure } \\
\text { obtained by the existing } \\
\text { pressure indicators to water } \\
\text { head, and this was } \\
\text { confirmed during first PCV } \\
\text { entry investigation. This } \\
\text { elevation is on the level of } \\
\text { PCV penetrations for main } \\
\text { steam lines, thus indicating } \\
\text { the possibility of water leaks } \\
\text { from the PCV penetration of } \\
\text { MSL. TEPCO Holdings has } \\
\text { some temperatures around } \\
\text { MSIV recorded since } \\
\text { September } 2011 \text { for } 1 F 2 \text { and } \\
1 \text { F3. Some evidence also on } \\
\text { 1F1 and 1F2 provided by } \\
\text { Yamada at } 4 / 28 / 16 \text { meeting. } \\
\text { This item has been } \\
\text { addressed; However, if more } \\
\text { information is obtained as } \\
\text { part of planned D\&D } \\
\text { activities, please provide } \\
\text { (but the U.S. recognizes that } \\
\text { additional information may } \\
\text { not be obtained). }\end{array}$ \\
\hline RB-14 & $\begin{array}{l}\text { Perform } \\
\text { chemical } \\
\text { analysis of } \\
\text { high radiation } \\
\text { deposits or } \\
\text { particles found } \\
\text { inside the } \\
\text { reactor } \\
\text { building (1F1, } \\
1 \mathrm{~F} 2, \text { and } 1 \mathrm{~F} 3) \text {; } \\
\text { e.g., the white } \\
\text { deposits from } \\
\text { the HPCI } \\
\text { room using } \\
\text { FE-SEM, } \\
\text { XRD, etc. }\end{array}$ & $\begin{array}{l}\text { Presence of Si would } \\
\text { indicate MCCI. }\end{array}$ & $\begin{array}{l}\text { Assist D\&D efforts for } \\
\text { determining debris location. }\end{array}$ & Now. & $\begin{array}{l}\text { TEPCO Holdings to send } \\
\text { white deposits to JAEA for } \\
\text { evaluation. }\end{array}$ \\
\hline
\end{tabular}


Table C-1. Information needs from the reactor building

\begin{tabular}{|c|c|c|c|c|c|}
\hline Item & $\begin{array}{l}\text { What/How } \\
\text { Obtained }\end{array}$ & Why & Expected Benefit /Use & When & Status \\
\hline RB-15 & $\begin{array}{l}\text { Examinations } \\
\text { of 1F1 RCW } \\
\text { surge tank; } \\
\text { water level } \\
\text { and additional } \\
\text { dose } \\
\text { measurements }\end{array}$ & $\begin{array}{l}\text { During events at 1F1, } \\
\text { contaminated water } \\
\text { may have entered } \\
\text { RCW and/or water } \\
\text { may have flowed out } \\
\text { of RCW into contain- } \\
\text { ment. }\end{array}$ & $\begin{array}{l}\text { Determine the role of the } \\
\text { RCW during } 1 \mathrm{~F} 1 \text { accident. }\end{array}$ & Now. & $\begin{array}{l}\text { TEPCO Holdings has } \\
\text { obtained some dose rate } \\
\text { measurements in the area } \\
\text { around the surge tank. }\end{array}$ \\
\hline
\end{tabular}

a. With the exception of general area views, photos and videos should be obtained with a reference length (ruler) at appropriate locations. In particular, it would be extremely useful for RB-1, RB-2, and RB-13; it is required for photos and videos to be most effective for RB-9 and RB-10.

b. For PWR containments, the containment actually grows radially as pressure and temperature are increased so penetrations that may have been in compression (e.g., hatches) may now be in tension.

c. 1F1: Water leaks from a sand cushion drain pipe and an expansion joint (bellows) for vacuum breaker tube observed. The water leak from a sand cushion drain pipe was confirmed since the vinyl chloride pipe (connecting the sand cushion drain tube and drain funnel with an insertion-type joint) had been displaced. Water leaks could not be confirmed at other seven drain pipes, since the drain tubes had not been displaced. However, concrete seams (joints) below sand cushion drain piping were observed to be wet all around on the concrete wall, which indicates that leaked water is filled in the sand cushion area outside of PCV wall. The water leak from bellows of vacuum breaker tube is located in the direction of access opening of pedestal wall in the PCV floor where molten corium might spread out first.

1F2: It was confirmed $\mathrm{S} / \mathrm{C}$ water level changes together with torus room water level. This indicates water is leaking from the lower position of S/C including suction piping. No water leakage from sand cushion drain pipes or vent pipe was observed. As of now, water leakage is not specified.

1F3: Water leak from near the expansion joint (bellows) of main steam line D in MSIV room was confirmed. The water level in the PCV is estimated at about $2 \mathrm{~m}$ above the reactor building first floor by converting the S/C pressure obtained by the existing pressure indicators to water head. This elevation is on the level of PCV penetrations for main steam lines, thus indicating the possibility of water leaks from the PCV penetration of MSL.

1F3: Water seeping from equipment hatch is inferred from the following observations.

- Rust was observed along with the hatch interface lower than D/W water level (in November 2015). Upper part of the interface does not have the rust.

-The increasing dose rate on the floor towards the equipment hatch was observed (in November 2015), which indicates contaminated water had flown from $\mathrm{D} / \mathrm{W}$ side.

- Equipment hatch rail was dry in December 2015. Current D/W water level is lowest since 2011. The D/W water level in 2011 was higher and water seeping from D/W through equipment hatch seal would be higher.

- The observed high dose rate at the rail in front of shield plug for equipment hatch (in September 2011) would be attributed to water leak through equipment hatch seal.

- Water dripping due to rain fall observed (in November 2015, rainy day), which might be intruding from refueling floor.

No specific observation regarding gas phase leakage other than dose rate distribution on refueling floor and steam discharging from refueling floor.

d. Passage of high temperature gas from venting operations at $1 \mathrm{~F} 1$ and $1 \mathrm{~F} 3$ may have affected seals. The effluent vented from Units 1 and 3 would also have subjected these components to high radiation fields. Note that, at present, available evidence indicates that Unit 2 may not have been successfully vented. The high radiation fields in components of the $1 \mathrm{~F} 2$ reactor building ventilation system appears to have been caused by $1 \mathrm{~F} 1$ vent effluent bypassing the vent stack shared by $1 \mathrm{~F} 1$ and 1F2. Many PWRs have safety grade fan cooler units for post-loss of coolant accident containment heat removal; PWRs would be interested if there is anything to learn. 
Table C-2. Information needs from the primary containment vessel

\begin{tabular}{|c|c|c|c|c|c|}
\hline Item & $\begin{array}{l}\text { What/How } \\
\text { Obtained }\end{array}$ & Why & Expected Benefit /Use & When & Status \\
\hline$\overline{\mathrm{PC}-1}$ & 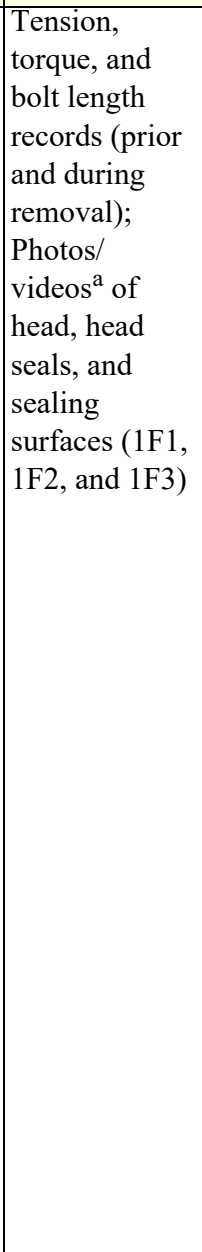 & $\begin{array}{l}\text { Determine how } \\
\text { head lifted. } \\
\text { Determine peak } \\
\text { temperatures. } \\
\text { - Look for indicators } \\
\text { of degradation due } \\
\text { to high tempera- } \\
\text { ture hydrogen, } \\
\text { including hydro- } \\
\text { gen-induced } \\
\text { embrittlement. }\end{array}$ & $\begin{array}{l}\text { AM Strategies; What } \\
\text { happened with respect to } \\
\text { the leak path; better } \\
\text { simulations for training. } \\
\text { Assist D\&D efforts. }\end{array}$ & $\begin{array}{l}\text { Now (initial data } \\
\text { and photos) and } \\
\text { later (if head } \\
\text { removed). }\end{array}$ & $\begin{array}{l}\text { TEPCO Holdings observed that } \\
\text { tensioning is done based on gap } \\
\text { requirements; no record } \\
\text { available. TEPCO Holdings may } \\
\text { have last outage tension records } \\
\text { and has obtained photos } \\
\text { indicating: } \\
\text { 1F1: Shield plug seems to have } \\
\text { moved upward, which was } \\
\text { observed by camera's visual } \\
\text { inspection in the operating floor. } \\
\text { 1F2: No large abnormality was } \\
\text { found in the robot camera's } \\
\text { visual inspection in the } \\
\text { operating floor. Rubber boots } \\
\text { remained standing on the shield } \\
\text { plug. } \\
\text { 1F3: Deformation of part of } \\
\text { shield plug was observed, which } \\
\text { was found in the visual } \\
\text { inspection after removing } \\
\text { building rubbles. } \\
\text { Additional photos may become } \\
\text { available. } \\
\text { The U.S. would appreciate any } \\
\text { additional information (although } \\
\text { the U.S. recognizes that this } \\
\text { information may not be } \\
\text { available). Visual images of } \\
\text { deformation and RN samples } \\
\text { (with isotopic content) are of } \\
\text { particular interest. }\end{array}$ \\
\hline$\overline{\mathrm{PC}-2}$ & $\begin{array}{l}\text { Photos/videos } \\
\text { and } \\
\text { radionuclide } \\
\text { surveys/ } \\
\text { sampling of } \\
\text { IC (1F1) }\end{array}$ & $\begin{array}{l}\text { Evaluate for seis- } \\
\text { mic damage. } \\
\text { - Evaluate final valve } \\
\text { position. } \\
\text { - } \begin{array}{l}\text { Gain insights about } \\
\text { hydrogen transport. }\end{array}\end{array}$ & $\begin{array}{l}\text { AM Strategies (plant } \\
\text { robustness, use of } \\
\text { equipment in limited } \\
\text { number of plants with ICs } \\
\text { and new passive plants); } \\
\text { better simulations for } \\
\text { training. Assist D\&D } \\
\text { efforts. }\end{array}$ & Completed. & $\begin{array}{l}\text { TEPCO Holdings has some } \\
\text { photos (and no damage } \\
\text { observed); no RN sampling } \\
\text { planned (due to radiation levels) } \\
\text { This item has been addressed. }\end{array}$ \\
\hline
\end{tabular}


Table C-2. Information needs from the primary containment vessel

\begin{tabular}{|c|c|c|c|c|c|}
\hline Item & $\begin{array}{l}\text { What/How } \\
\text { Obtained }\end{array}$ & Why & Expected Benefit /Use & When & Status \\
\hline \multirow[t]{5}{*}{$\mathrm{PC}-3$} & $\begin{array}{l}\text { a) Photos/ } \\
\text { videos of } \\
\text { relocated } \\
\text { debris and } \\
\text { crust, debris } \\
\text { and crust } \\
\text { extraction, hot } \\
\text { cell exams, } \\
\text { and possible } \\
\text { subsequent } \\
\text { testing (1F1 - } \\
\text { 1F3) }\end{array}$ & $\begin{array}{l}\text { Code assessments } \\
\text { Possible model } \\
\text { updates for mass, } \\
\text { height, composi- } \\
\text { tion, morphology } \\
\text { (e.g., coolability), } \\
\text { topography of } \\
\text { debris, spreading, } \\
\text { splashing, and salt } \\
\text { effects. }\end{array}$ & $\begin{array}{l}\text { BWR AM Strategies } \\
\text { (plant robustness, use of } \\
\text { equipment, inform cavity } \\
\text { flooding strategies) and } \\
\text { better simulations for } \\
\text { training. Potential PWR } \\
\text { impacts (e.g., modeling.). } \\
\text { Assist D\&D efforts. }\end{array}$ & $\begin{array}{l}\text { Now and }>5 \\
\text { years (per } \\
\text { TEPCO } \\
\text { Holdings } \\
\text { roadmap). }\end{array}$ & $\begin{array}{l}\text { TEPCO Holdings has obtained } \\
\text { some samples and some photos } \\
\text { from inside of } 1 \mathrm{~F} 1,1 \mathrm{~F} 2 \text {, and } 1 \mathrm{~F} 3 \\
\mathrm{PCV} \text {, more are planned. } \\
\text { When additional information is } \\
\text { available, please provide. }\end{array}$ \\
\hline & $\begin{array}{l}\text { b) PCV liner } \\
\text { examinations } \\
\text { (photos/videos } \\
\text { and } \\
\text { metallurgical } \\
\text { exams; 1F1- } \\
\text { 1F3) }\end{array}$ & $\begin{array}{l}\text { - } \text { Code assessments. } \\
\text { improvible model } \\
\text { predicting liner } \\
\text { failure and Molten } \\
\text { Core Concrete } \\
\text { Interactions } \\
\text { (MCCI). }\end{array}$ & $\begin{array}{l}\text { AM Strategies (improved } \\
\text { plant robustness); better } \\
\text { simulations for training. } \\
\text { Assist D\&D efforts. }\end{array}$ & $\begin{array}{l}\text { Now and }>5 \\
\text { years (per } \\
\text { TEPCO } \\
\text { Holdings } \\
\text { roadmap). }\end{array}$ & $\begin{array}{l}\text { TEPCO Holdings has some } \\
\text { bellows information and may } \\
\text { obtain additional visual } \\
\text { information. TEPCO Holdings } \\
\text { may do metallurgical exams (if } \\
\text { warranted). } \\
\text { When additional information is } \\
\text { available, please provide. }\end{array}$ \\
\hline & $\begin{array}{l}\text { c) Photos/ } \\
\text { video, RN } \\
\text { surveys, and } \\
\text { sampling of } \\
\text { pedestal wall } \\
\text { and floor } \\
(1 \mathrm{~F} 1-1 \mathrm{~F} 3)\end{array}$ & $\begin{array}{l}\text { For benchmarking } \\
\text { code predictions of } \\
\text { vessel failure loca- } \\
\text { tion and area, mass, } \\
\text { morphology (e.g., } \\
\text { coolability), and } \\
\text { composition of ex- } \\
\text { vessel debris, and } \\
\text { MCCI }\end{array}$ & $\begin{array}{l}\text { BWR AM Strategies, } \\
\text { better simulations, etc. } \\
\text { Potential PWR impacts } \\
\text { (e.g., modeling, AM } \\
\text { strategies, etc.). Assist } \\
\text { D\&D efforts. }\end{array}$ & Now and later. & $\begin{array}{l}\text { TEPCO Holdings has some } \\
\text { information and may obtain } \\
\text { additional information later. For } \\
1 \mathrm{~F} 1,1 \mathrm{~F} 2 \text {, and } 1 \mathrm{~F} 3 \text {, robots with } \\
\text { cameras and dose rate meters } \\
\text { were inserted inside PCV and } \\
\text { retained water in D/W was } \\
\text { sampled for radioactivity } \\
\text { analysis. Sediment (1F1) or } \\
\text { relocated core components (1F2 } \\
\text { and } 1 \mathrm{~F} 3 \text { ) have been observed. If } \\
\text { debris samples obtained, a } \\
\text { collaborative evaluation } \\
\text { program may be possible. }\end{array}$ \\
\hline & $\begin{array}{l}\text { d) Concrete } \\
\text { erosion } \\
\text { profile; } \\
\text { photos/videos } \\
\text { and sample } \\
\text { removal and } \\
\text { examination } \\
(1 \mathrm{~F} 1-1 \mathrm{~F} 3)\end{array}$ & $\begin{array}{l}\text { For benchmarking } \\
\text { code predictions of } \\
\text { MCCI. }\end{array}$ & $\begin{array}{l}\text { BWR AM Strategies } \\
\text { (plant mods, etc.) and } \\
\text { better simulations for } \\
\text { training; Potential PWR } \\
\text { impacts (e.g., modeling, } \\
\text { AM strategies, etc.). Assist } \\
\text { D\&D efforts. }\end{array}$ & Now and later. & $\begin{array}{l}\text { TEPCO Holdings has no plans } \\
\text { to obtain at this time. TEPCO } \\
\text { Holdings may consider in the } \\
\text { future. If end-state is observed, a } \\
\text { collaborative program to } \\
\text { evaluate samples may be } \\
\text { possible. }\end{array}$ \\
\hline & $\begin{array}{l}\text { e) Photos / } \\
\text { videos of RPV } \\
\text { lower head } \\
\text { and of } \\
\text { structures and } \\
\text { penetrations } \\
\text { beneath the } \\
\text { vessel to } \\
\text { determine } \\
\text { damage and } \\
\text { corium hang- } \\
\text { up (1F1-1F3) }\end{array}$ & $\begin{array}{l}\text { - } \text { Code assessments. } \\
\text { - Possible model } \\
\text { improvements. }\end{array}$ & $\begin{array}{l}\text { BWR AM Strategies } \\
\text { (plant modifications, etc.) } \\
\text { and better simulations for } \\
\text { training (improved models } \\
\text { for predicting containment } \\
\text { pressure-temperature } \\
\text { response); Potential PWR } \\
\text { impacts (e.g., modeling, } \\
\text { AM strategies, etc.). Assist } \\
\text { D\&D efforts. }\end{array}$ & Now and later. & $\begin{array}{l}\text { TEPCO Holdings will obtain } \\
\text { some information. } \\
\text { The U.S. believes this } \\
\text { information is very important for } \\
\text { benchmarking models. Please } \\
\text { provide additional information } \\
\text { when available. }\end{array}$ \\
\hline
\end{tabular}


Table C-2. Information needs from the primary containment vessel

\begin{tabular}{|c|c|c|c|c|c|}
\hline Item & $\begin{array}{l}\text { What/How } \\
\text { Obtained }\end{array}$ & Why & Expected Benefit /Use & When & Status \\
\hline PC-4 & $\begin{array}{l}\text { Photos/videos } \\
\text { of } 1 \mathrm{~F} 1,1 \mathrm{~F} 2, \\
\text { and } 1 \mathrm{~F} 3 \\
\text { recirculation } \\
\text { lines and } \\
\text { pumps }\end{array}$ & $\begin{array}{l}\text { To determine PCV } \\
\text { failure mode and } \\
\text { relocation path. }\end{array}$ & $\begin{array}{l}\text { AM Strategies (plant } \\
\text { mods, etc.) and better } \\
\text { simulations for training. }\end{array}$ & Completed. & $\begin{array}{l}\text { TEPCO Holdings has some } \\
\text { pressure and temperature } \\
\text { measurements at Primary Loop } \\
\text { Recirculation (PLR) pump inlet } \\
\text { since April 2011. No additional } \\
\text { inspections planned. } \\
\text { The U.S. continues to have } \\
\text { interest in this visual } \\
\text { information. However, the U.S. } \\
\text { recognizes that additional } \\
\text { information may not become } \\
\text { available. }\end{array}$ \\
\hline$\overline{\mathrm{PC}-5}$ & $\begin{array}{l}\text { Photos/videos } \\
\text { of 1F1, 1F2, } \\
\text { and 1F3 main } \\
\text { steam lines } \\
\text { and ADS lines } \\
\text { to end of SRV } \\
\text { tailpipes, } \\
\text { including } \\
\text { instrument } \\
\text { lines }\end{array}$ & $\begin{array}{l}\text { To determine RPV } \\
\text { failure mode. }\end{array}$ & $\begin{array}{l}\text { BWR AM Strategies } \\
\text { (plant mods, etc.) and } \\
\text { better simulations for } \\
\text { training; Potential PWR } \\
\text { impacts (e.g., modeling, } \\
\text { AM strategies, etc.). }\end{array}$ & Now and later. & $\begin{array}{l}\text { TEPCO Holdings has not } \\
\text { considered photographic exams. } \\
\text { TEPCO Holdings has some } \\
\text { temperatures around SRV and } \\
\text { MSIV recorded since September } \\
2011 \text { for 1F2 and 1F3. } \\
\text { The U.S. continues to have } \\
\text { interest in photos to resolve } \\
\text { questions regarding SRV failure } \\
\text { versus main steam line rupture. } \\
\text { In particular, some visual } \\
\text { inspection of MSL would be } \\
\text { very valuable. However, the } \\
\text { U.S. recognizes that additional } \\
\text { information may not become } \\
\text { available. }\end{array}$ \\
\hline PC-6 & $\begin{array}{l}\text { Visual } \\
\text { inspections of } \\
1 \mathrm{~F} 1,1 \mathrm{~F} 2 \text {, and } \\
1 \mathrm{~F} 3 \mathrm{SRV} \\
\text { including } \\
\text { standpipes } \\
\text { (interior valve } \\
\text { mechanisms) }\end{array}$ & $\begin{array}{l}\text { To determine if } \\
\text { there was any fail- } \\
\text { ure of SRVs and } \\
\text { associated piping. }\end{array}$ & $\begin{array}{l}\text { BWR AM Strategies } \\
\text { (maintenance practices, } \\
\text { etc.), SRV functioning in } \\
\text { test facility data, and better } \\
\text { simulations for training; } \\
\text { Potential PWR impacts } \\
\text { (e.g., modeling, AM } \\
\text { strategies, etc.). }\end{array}$ & Later. & $\begin{array}{l}\text { TEPCO Holdings has not } \\
\text { considered photographic exams. } \\
\text { TEPCO Holdings has some } \\
\text { temperatures around SRV and } \\
\text { MSIV recorded since September } \\
2011 \text { for 1F2 and 1F3. } \\
\text { The U.S. continues to have } \\
\text { interest in photos to resolve } \\
\text { questions regarding SRV failure } \\
\text { versus main steam line rupture. } \\
\text { In particular, some visual } \\
\text { inspection of MSL would be } \\
\text { very valuable. However, the } \\
\text { U.S. recognizes that additional } \\
\text { information may not become } \\
\text { available. }\end{array}$ \\
\hline
\end{tabular}


Table C-2. Information needs from the primary containment vessel

\begin{tabular}{|c|c|c|c|c|c|}
\hline Item & $\begin{array}{l}\text { What/How } \\
\text { Obtained }\end{array}$ & Why & Expected Benefit /Use & When & Status \\
\hline PC-7 & \begin{tabular}{|l|} 
Ex-vessel \\
inspections \\
and \\
operability \\
assessments of \\
$1 \mathrm{~F} 1,1 \mathrm{~F} 2$, and \\
$1 \mathrm{~F} 3$ in-vessel \\
sensors and \\
sensor support \\
structures
\end{tabular} & $\begin{array}{l}\text { Data qualification } \\
\text { for code assess- } \\
\text { ment. } \\
\text { - Identification of } \\
\text { vessel depressur- } \\
\text { ization paths. } \\
\text { - Understanding why } \\
\text { the RPV B pressure } \\
\text { signal experienced } \\
\text { a failure prior to } \\
\text { other transmitters at } \\
\text { 1F1 }\end{array}$ & $\begin{array}{l}\text { Equipment qualification } \\
\text { life (1F1 at } 40 \text { years; } \\
\text { underwater cabling); } \\
\text { better simulations for } \\
\text { training. }\end{array}$ & Now and later. & $\begin{array}{l}\text { TEPCO Holdings completed } \\
\text { some examinations and } \\
\text { recalibrations and plans to } \\
\text { perform more evaluations. Cable } \\
\text { integrity examinations by TDR } \\
\text { (time domain reflectrometry) } \\
\text { were performed for 1F1, 1F2, } \\
\text { and 1F3; and cable damage was } \\
\text { confirmed. In 1F2, it was } \\
\text { confirmed TIP index tube was } \\
\text { stuck. } \\
\text { In 1F2, it was found SLC } \\
\text { injection tube in RPV was stuck, } \\
\text { which indicates blockage by } \\
\text { molten core. } \\
\text {-New thermocouple was inserted } \\
\text { into nearby N-10 nozzle to } \\
\text { reinforce RPV temperature } \\
\text { monitoring in Oct. 2012. } \\
\text {-Beforehand SLC line integrity } \\
\text { was confirmed by injecting } \\
\text { water and monitoring discharge } \\
\text { pressure change. } \\
\text {-Pressurized water of about } \\
7 \text { MPa could not penetrate SLC } \\
\text { line into RPV. } \\
\text { TEPCO Holdings will provide } \\
\text { additional information regarding } \\
\text { sensor qualification envelop and } \\
\text { conditions exposed to during the } \\
\text { accident to address renewed US } \\
\text { interest in this topic. }\end{array}$ \\
\hline PC-8 & \begin{tabular}{|l|}
$\begin{array}{l}\text { Examinations } \\
\text { and } \\
\text { operability } \\
\text { assessments of } \\
1 \mathrm{~F} 1,1 \mathrm{~F} 2 \text {, and } \\
1 \mathrm{~F} 3 \text { ex-vessel } \\
\text { sensors and } \\
\text { sensor support } \\
\text { structures }^{\mathrm{d}}\end{array}$ \\
\end{tabular} & $\begin{array}{l}\text { Data qualification } \\
\text { for code assess- } \\
\text { ment. } \\
\text { Identification of } \\
\text { vessel depressur- } \\
\text { ization paths. } \\
\text { the RPV B pressure } \\
\text { signal experienced } \\
\text { a failure prior to } \\
\text { other transmitters at } \\
1 F 1\end{array}$ & $\begin{array}{l}\text { BWR and possible PWR } \\
\text { equipment qualification } \\
\text { life; better qualifications } \\
\text { for training. }\end{array}$ & Now and later. & $\begin{array}{l}\text { TEPCO Holdings has completed } \\
\text { some examinations and } \\
\text { recalibrations and plans to } \\
\text { perform more evaluations. } \\
\text { TEPCO Holdings will provide } \\
\text { additional information regarding } \\
\text { sensor qualification envelop and } \\
\text { conditions exposed to during the } \\
\text { accident to address renewed US } \\
\text { interest in this topic. }\end{array}$ \\
\hline$\overline{\mathrm{PC}-9}$ & $\begin{array}{l}\text { Photos/videos } \\
\text { of } 1 \mathrm{~F} 1,1 \mathrm{~F} 2, \\
\text { and } 1 \mathrm{~F} 3 \mathrm{PCV} \\
\text { (SC and DW) } \\
\text { coatings }\end{array}$ & $\begin{array}{l}\text { Assess impact for } \\
\text { coating survivabil- } \\
\text { ity. }\end{array}$ & $\begin{array}{l}\text { BWR and possible PWR } \\
\text { maintenance upgrades. }\end{array}$ & Now and later. & $\begin{array}{l}\text { Visual examinations inside PCV } \\
\text { performed in } 1 \mathrm{~F} 1,1 \mathrm{~F} 2 \text {, and } 1 \mathrm{~F} 3 \text {, } \\
\text { although inspection range } \\
\text { limited. TEPCO Holdings may } \\
\text { obtain more data. } \\
\text { Please provide additional } \\
\text { information when available and } \\
\text { consider evaluating presence of } \\
\text { coating materials in elemental } \\
\text { evaluations of other samples. }\end{array}$ \\
\hline
\end{tabular}


Table C-2. Information needs from the primary containment vessel

\begin{tabular}{|c|c|c|c|c|c|}
\hline Item & $\begin{array}{l}\text { What/How } \\
\text { Obtained }\end{array}$ & Why & Expected Benefit /Use & When & Status \\
\hline PC-10 & $\begin{array}{l}1 \mathrm{~F} 1,1 \mathrm{~F} 2 \text {, and } \\
1 \mathrm{~F} 3 \mathrm{RN} \\
\text { surveys in } \\
\text { PCV }\end{array}$ & $\begin{array}{l}\text { Dose code assess- } \\
\text { ments. } \\
\text { - Possible model } \\
\text { improvements. }\end{array}$ & $\begin{array}{l}\text { BWR and possible PWR } \\
\text { AM strategies/Better } \\
\text { simulations (plate out). } \\
\text { Assist D\&D efforts }\end{array}$ & Now and later. & $\begin{array}{l}\text { TEPCO Holdings has some } \\
\text { sample evaluation and survey } \\
\text { information and may obtain } \\
\text { more data later. Radioactivity } \\
\text { data obtained from retained } \\
\text { water in basement of each } \\
\text { building. Sampling water in } \\
\text { D/W was performed for 1F1, } \\
1 \mathrm{~F} 2 \text {, and } 1 \mathrm{~F} 3 \text {. Sampling drain } \\
\text { water and dust of exhaust gas } \\
\text { from drywell was performed for } \\
1 \mathrm{~F} 1,1 \mathrm{~F} 2 \text {, and } 1 \mathrm{~F} 3 \text {. S/C water } \\
\text { not evaluated. } \\
\text { The U.S. remains very interested } \\
\text { in isotopic information from RN } \\
\text { surveys/samples for code } \\
\text { assessments (but the U.S. } \\
\text { recognizes that this information } \\
\text { may not become available). }\end{array}$ \\
\hline PC-11 & $\begin{array}{l}\text { Photos/videos } \\
\text { of } 1 \mathrm{~F} 1,1 \mathrm{~F} 2, \\
\text { and } 1 \mathrm{~F} 3 \\
\text { primary } \\
\text { system } \\
\text { recirculation } \\
\text { pump seal and } \\
\text { any potential } \\
\text { discharge to } \\
\text { containment }\end{array}$ & $\begin{array}{l}\text { To assess perfor- } \\
\text { mance under high } \\
\text { temperature/ high } \\
\text { pressure condi- } \\
\text { tions. }^{\text {e }}\end{array}$ & $\begin{array}{l}\text { Improved BWR AM } \\
\text { strategies (plant } \\
\text { improvements). Improved } \\
\text { understanding of events. } \\
\text { Assist D\&D efforts. } \\
\text { Potential PWR impacts. }\end{array}$ & $\begin{array}{l}\text { Now and later. } \\
\text { Exams may be } \\
\text { completed more } \\
\text { easily at Daini. }\end{array}$ & $\begin{array}{l}\text { Not currently considered by } \\
\text { TEPCO Holdings; some photos } \\
\text { may already be available. } \\
\text { The U.S. remains interested in } \\
\text { additional photographs from } \\
\text { Daiichi or Daini (but the U.S. } \\
\text { recognizes that this information } \\
\text { may not become available). }\end{array}$ \\
\hline PC-12 & $\begin{array}{l}\text { Photos/videos } \\
\text { of } 1 \mathrm{~F} 1,1 \mathrm{~F} 2, \\
\text { and } 1 \mathrm{~F} 3 \mathrm{TIP} \\
\text { tubes and } \\
\text { SRV/Intermed } \\
\text { iate Range } \\
\text { Monitor } \\
\text { (IRM) tubes } \\
\text { outside the } \\
\text { RPV }\end{array}$ & $\begin{array}{l}\text { To determine if } \\
\text { failure of TIP tubes } \\
\text { and SRV/IRM } \\
\text { tubes outside the } \\
\text { RPV led to depres- } \\
\text { surization. }\end{array}$ & $\begin{array}{l}\text { BWR AM Strategies and } \\
\text { maintenance practices, } \\
\text { SRV performance } \\
\text { insights, and better } \\
\text { simulations for training. } \\
\text { Potential PWR impacts } \\
\text { (e.g., modeling, AM } \\
\text { strategies, etc.). Assist } \\
\text { D\&D efforts. }\end{array}$ & Later. & $\begin{array}{l}\text { An attempt was made to insert a } \\
\text { fiber optic scope through the } \\
\text { 1F2 TIP guide tube. The scope } \\
\text { was stuck at the TIP indexer and } \\
\text { could not get past that location. } \\
\text { 1F2 SLC injection line blockage } \\
\text { was confirmed (see PC-7). } \\
\text { Also, see item PC-14 for SLC } \\
\text { injection line stuck in RPV. } \\
\text { The U.S. continues to have } \\
\text { interest in this information. } \\
\text { However, the U.S. recognizes } \\
\text { that additional information may } \\
\text { not become available. }\end{array}$ \\
\hline PC-13 & $\begin{array}{l}\text { Photos/videos } \\
\text { of } 1 \mathrm{~F} 1,1 \mathrm{~F} 2, \\
\text { and } 1 \mathrm{~F} 3 \\
\text { insulation } \\
\text { around piping } \\
\text { and the RPV }\end{array}$ & $\begin{array}{l}\text { To determine } \\
\text { potential for } \\
\text { adverse effects on } \\
\text { long-term cooling } \\
\text { due to insulation } \\
\text { debris. }\end{array}$ & $\begin{array}{l}\text { Improved BWR and PWR } \\
\text { AM strategies (plant } \\
\text { improvements). }\end{array}$ & Now and later. & $\begin{array}{l}\text { Not currently considered by } \\
\text { TEPCO Holdings; some photos } \\
\text { may already be available. } \\
\text { The U.S. continues to have } \\
\text { interest in this visual } \\
\text { information. However, the U.S. } \\
\text { recognizes that additional } \\
\text { information may not become } \\
\text { available. }\end{array}$ \\
\hline
\end{tabular}


Table C-2. Information needs from the primary containment vessel

\begin{tabular}{|c|c|c|c|c|c|}
\hline Item & $\begin{array}{l}\text { What/How } \\
\text { Obtained }\end{array}$ & Why & Expected Benefit /Use & When & Status \\
\hline PC-14 & $\begin{array}{l}\text { Samples of } \\
\text { conduit } \\
\text { cabling, and } \\
\text { paint from } \\
1 \mathrm{~F} 1,1 \mathrm{~F} 2 \text {, and } \\
1 \mathrm{~F} 3 \text { for RN } \\
\text { surveys }\end{array}$ & $\begin{array}{l}\text { Dose code assess- } \\
\text { ments. } \\
\text { - Possible model } \\
\text { improvements. }\end{array}$ & $\begin{array}{l}\text { BWR and possible PWR } \\
\text { AM strategies/Better } \\
\text { simulations (plate out). }\end{array}$ & Now and later. & $\begin{array}{l}\text { TEPCO Holdings has some } \\
\text { sample information. } \\
\text { The U.S. continues to have } \\
\text { interest in this information but } \\
\text { recognizes that additional } \\
\text { information may not become } \\
\text { available. }\end{array}$ \\
\hline PC-15 & $\begin{array}{l}\text { Samples of } \\
\text { water from } \\
1 \mathrm{~F} 1,1 \mathrm{~F} 2 \text {, and } \\
1 \mathrm{~F} 3 \text { for } \mathrm{RN} \\
\text { surveys }\end{array}$ & $\begin{array}{ll}- & \text { Dose code assess- } \\
\text { ments. } \\
\text { - } \\
\text { Possible model } \\
\text { improvements. }\end{array}$ & $\begin{array}{l}\text { BWR and possible PWR } \\
\text { AM strategies/Better } \\
\text { simulations. Assist D\&D } \\
\text { efforts. }\end{array}$ & Completed. & $\begin{array}{l}\text { TEPCO Holdings has some } \\
\text { sampling information. Sampling } \\
\text { water in } \mathrm{D} / \mathrm{W} \text { was performed for } \\
1 \mathrm{~F} 1,1 \mathrm{~F} 2 \text {, and } 1 \mathrm{~F} 3 \text {. Sampling } \\
\text { drain water and dust of exhaust } \\
\text { gas from drywell was performed } \\
\text { for } 1 \mathrm{~F} 1,1 \mathrm{~F} 2 \text {, and } 1 \mathrm{~F} 3 \text {. } \\
\text { This item is closed. }\end{array}$ \\
\hline PC-16 & $\begin{array}{l}\text { Photos/videos } \\
\text { of melted, } \\
\text { galvanized, or } \\
\text { oxidized } 1 \mathrm{~F} 1 \text {, } \\
\text { 1F2, and } 1 \mathrm{~F} 3 \\
\text { structures }\end{array}$ & $\begin{array}{l}\text { To provide indica- } \\
\text { tions of peak tem- } \\
\text { peratures (for } \\
\text { possible model } \\
\text { improvements). }\end{array}$ & $\begin{array}{l}\text { Improved AM strategies } \\
\text { (Plant improvements). }\end{array}$ & $\begin{array}{l}\text { Now and later. } \\
\text { Exams may be } \\
\text { completed more } \\
\text { easily at Daini. }\end{array}$ & $\begin{array}{l}\text { Some photos may be available. } \\
\text { The U.S. continues to have } \\
\text { interest in this visual } \\
\text { information but recognizes that } \\
\text { additional information may not } \\
\text { become available. }\end{array}$ \\
\hline PC-17 & $\begin{array}{l}\text { Chemical } \\
\text { analysis of } \\
\text { upper layer of } \\
\text { sediment on } \\
\text { drywell floor } \\
\text { at the X-100B } \\
\text { penetration } \\
\text { location in } \\
\text { 1F1.The upper } \\
\text { surface of the } \\
\text { sediment is } \\
30 \text { cm above } \\
\text { drywell floor }\end{array}$ & $\begin{array}{l}\text { Presence of Si } \\
\text { would indicate } \\
\text { MCCI } \\
\text { Possible model } \\
\text { improvements. }\end{array}$ & $\begin{array}{l}\text { Assist D\&D efforts for } \\
\text { determining debris } \\
\text { location and improved } \\
\text { accident management } \\
\text { strategies. }\end{array}$ & Now. & $\begin{array}{l}\text { TEPCO Holdings is also } \\
\text { interested in this information. }\end{array}$ \\
\hline PC-18 & $\begin{array}{l}\text { The nature of } \\
\text { material below } \\
\text { the upper } \\
\text { surface of } \\
\text { debris at the } \\
\text { X-100B } \\
\text { penetration } \\
\text { location in } \\
1 \mathrm{~F} 1 \text { to } \\
\text { determine if it } \\
\text { is additional } \\
\text { sediment or } \\
\text { other material } \\
\text { such as core } \\
\text { debris. }\end{array}$ & $\begin{array}{l}\text { Presence of Si or } \\
\text { core material debris } \\
\text { would indicate } \\
\text { MCCI } \\
\text { - Possible model } \\
\text { improvements. }\end{array}$ & $\begin{array}{l}\text { Assist D\&D efforts for } \\
\text { determining debris } \\
\text { location and improved } \\
\text { accident management } \\
\text { strategies. }\end{array}$ & Now. & $\begin{array}{l}\text { TEPCO Holdings is also } \\
\text { interested in this information. }\end{array}$ \\
\hline
\end{tabular}


Table C-2. Information needs from the primary containment vessel

\begin{tabular}{|c|c|c|c|c|c|}
\hline Item & $\begin{array}{l}\text { What/How } \\
\text { Obtained }\end{array}$ & Why & Expected Benefit /Use & When & Status \\
\hline PC-19 & $\begin{array}{l}\text { Chemical } \\
\text { analysis } \\
(\mathrm{XRF}) \text { of } \\
\text { black material } \\
\text { discovered on } \\
\text { CRD } \\
\text { exchange rail } \\
\text { in 1F2 at X-6 } \\
\text { penetration } \\
\text { location. }\end{array}$ & $\begin{array}{l}\text { Identification of } \\
\text { material could pro- } \\
\text { vide an indicator of } \\
\text { peak structure tem- } \\
\text { peratures and } \\
\text { potential for struc- } \\
\text { ture failure. } \\
\text { - Possible model } \\
\text { improvements. }\end{array}$ & $\begin{array}{l}\text { Assist D\&D efforts for } \\
\text { determining debris } \\
\text { location and improved } \\
\text { accident management } \\
\text { strategies. }\end{array}$ & Now. & $\begin{array}{l}\text { TEPCO Holdings is also } \\
\text { interested in this information. }\end{array}$ \\
\hline PC-20 & $\begin{array}{l}\text { Chemical } \\
\text { analysis of } \\
\text { black material } \\
\text { on 'existing } \\
\text { structure' in } \\
1 \mathrm{~F} 1 \text { images at } \\
\text { location 'D3' }\end{array}$ & $\begin{array}{l}\text { Presence of Si or } \\
\text { core material debris } \\
\text { would indicate } \\
\text { MCCI } \\
\text { - Possible model } \\
\text { improvements. }\end{array}$ & $\begin{array}{l}\text { Assist D\&D efforts for } \\
\text { determining debris } \\
\text { location and improved } \\
\text { accident management } \\
\text { strategies. }\end{array}$ & Now. & $\begin{array}{l}\text { TEPCO Holdings is also } \\
\text { interested in this information. }\end{array}$ \\
\hline PC-21 & $\begin{array}{l}\text { Images from } \\
\text { examinations } \\
\text { in } 1 \mathrm{~F} 3 \mathrm{X}-53 \\
\text { penetration }\end{array}$ & $\begin{array}{l}\text { Possible model } \\
\text { improvements }\end{array}$ & $\begin{array}{l}\text { Assist D\&D efforts for } \\
\text { determining debris } \\
\text { location and improved } \\
\text { accident management } \\
\text { strategies. }\end{array}$ & Now. & $\begin{array}{l}\text { TEPCO Holdings is also } \\
\text { interested in this information. } \\
\text { Some images have been } \\
\text { obtained. The U.S. would } \\
\text { appreciate any additional images } \\
\text { that become available. }\end{array}$ \\
\hline
\end{tabular}

a. With the exception of general area views, photos and videos should be obtained with reference length scales at appropriate locations. In particular, it would be extremely useful for PC-3(b), PC-3(e), PC-9, PC-12, PC-13.

b. Key to applicability for PWRs will be if melt composition does not significantly impact spreading; with different core materials, molten core debris may behave differently. If forensics can confirm basic properties or models, information could be applicable to all LWRs.

c. Ex-vessel inspections and evaluations [e.g., continuity checks, calibration evaluations, etc.) of in-vessel sensors [dP cells, water level gauges, TIPs, TCs, etc.] and sensor support structures, cables, removed TIPs, etc.; requires knowledge of sensor operating envelop.

d. Inspections and evaluations (e.g., continuity checks, calibration evaluations, etc.) of suppression pool, PCV, and ex-vessel sensors (e.g., containment air monitors, pressure sensors, TCs, etc.) and sensor support structures and cables; requires sensors operating envelop knowledge.

e. Some PWRs have inside containment recirculation systems for Emergency Core Cooling and Containment Spray. BWR recirculation pump seals and PWR reactor coolant pump seals have many material similarities; there may also be some information relevant to reactor coolant pump seals and their ability to function following recovery or provide core cooling with core debris in-vessel. 
Table C-3. Information needs from the reactor pressure vessel

\begin{tabular}{|c|c|c|c|c|c|}
\hline Item & What/How Obtained & Why & $\begin{array}{l}\text { Expected Benefit } \\
\text { /Use }\end{array}$ & When & Status \\
\hline \multirow[t]{3}{*}{ RPV-1 } & $\begin{array}{l}\text { 1F1, 1F2, and 1F3 } \\
\text { dryer integrity and } \\
\text { location evaluations } \\
\text { (photos/videos }{ }^{\mathrm{a}} \text { with } \\
\text { displacement } \\
\text { measurements, sample } \\
\text { removal and exams for } \\
\text { fission product } \\
\text { deposition, peak } \\
\text { temperature } \\
\text { evaluations) }\end{array}$ & 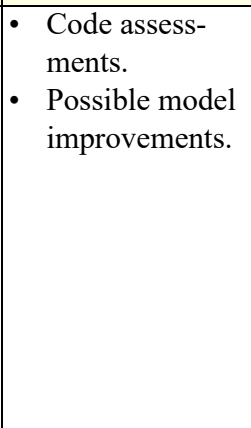 & $\begin{array}{l}\text { Improved AM } \\
\text { strategies; Improved } \\
\text { simulations for } \\
\text { training. Assist } \\
\text { D\&D efforts. }\end{array}$ & $\begin{array}{l}\text { Later (after } \\
2017 \text { based } \\
\text { on current } \\
\text { roadmap). }\end{array}$ & $\begin{array}{l}\text { TEPCO Holdings will conduct visual, } \\
\text { some metallurgical and fission product } \\
\text { exams. } \\
\text { The U.S. remains interested in this } \\
\text { information but recognizes that it may } \\
\text { not be available. Laser-Induced } \\
\text { Breakdown Spectroscopy methods } \\
\text { might reduce costs for chemical } \\
\text { evaluations in exams (ongoing R\&D at } \\
\text { JAEA may make it easier to obtain this } \\
\text { information). }\end{array}$ \\
\hline & $\begin{array}{l}\text { Photos/videos, probe } \\
\text { inspections, and } \\
\text { sample exams of } 1 \mathrm{~F} 1 \text {, } \\
1 \mathrm{~F} 2 \text {, and } 1 \mathrm{~F} 3 \mathrm{MSLs} \\
\text { Interior examinations } \\
\text { of MSLs at external } \\
\text { locations }\end{array}$ & $\begin{array}{ll}\text { - } & \text { Code assess- } \\
\text { ments. } \\
\text { - } \\
\text { Possible model } \\
\text { improvements. }\end{array}$ & $\begin{array}{l}\text { Improved AM } \\
\text { strategies; Improved } \\
\text { simulations for } \\
\text { training. Assist } \\
\text { D\&D efforts. }\end{array}$ & $\begin{array}{l}\text { Later (after } \\
2017 \text { based } \\
\text { on current } \\
\text { roadmap). }\end{array}$ & $\begin{array}{l}\text { TEPCO Holdings has no plans for any } \\
\text { such exams. See PC- } 3 \text { for water } \\
\text { leakage information from MSL } \\
\text { penetration through PCV. } \\
\text { The U.S. remains interested in this } \\
\text { information but recognizes that it may } \\
\text { not be available. }\end{array}$ \\
\hline & $\begin{array}{l}\text { Photos/videos and } \\
\text { metallurgical } \\
\text { examinations of upper } \\
\text { internals and upper } \\
\text { channel guides }\end{array}$ & $\begin{array}{ll}\text { - } & \text { Code assess- } \\
\text { ments. } \\
\text { - Possible model } \\
\text { improvements } \\
\text { (for predicting } \\
\text { peak tempera- } \\
\text { tures, displace- } \\
\text { ment, melting). }\end{array}$ & $\begin{array}{l}\text { Improved AM } \\
\text { strategies; Possible } \\
\text { plant modifications; } \\
\text { Improved } \\
\text { simulations for } \\
\text { training. Assist } \\
\text { D\&D efforts. }\end{array}$ & $\begin{array}{l}\text { Later (after } \\
2017 \text { based } \\
\text { on current } \\
\text { roadmap). }\end{array}$ & $\begin{array}{l}\text { TEPCO Holdings will conduct visual } \\
\text { exams and some metallurgical exams. } \\
\text { The U.S. remains interested in this } \\
\text { information but recognizes that it may } \\
\text { not be available. }\end{array}$ \\
\hline \multirow[t]{2}{*}{ RPV-2 } & $\begin{array}{l}\text { Photos/videos of 1F1, } \\
\text { 1F2, and 1F3 core } \\
\text { spray slip fit nozzle } \\
\text { connection, sparger \& } \\
\text { nozzles }\end{array}$ & \multirow{2}{*}{$\begin{array}{l}\text { Assess opera- } \\
\text { bility. } \\
\text { Assess salt } \\
\text { water effects } \\
\text { (including cor- } \\
\text { rosion). } \\
\text { - Applicable to } \\
\text { BWRs and } \\
\text { PWRs. }\end{array}$} & \multirow{2}{*}{$\begin{array}{l}\text { Improved AM } \\
\text { strategies; Improved } \\
\text { simulations for } \\
\text { training; Possible } \\
\text { use in BWR Vessel } \\
\text { and Internals } \\
\text { Program (VIP) } \\
\text { [depending on plant } \\
\text { condition]. Assist } \\
\text { D\&D efforts. }\end{array}$} & \multirow[t]{2}{*}{$\begin{array}{l}\text { Now and } \\
\text { later. }\end{array}$} & \multirow{2}{*}{$\begin{array}{l}\text { TEPCO Holdings has some } \\
\text { information) and will obtain more } \\
\text { data. When water injected through CS } \\
\text { line in } 1 \mathrm{~F} 1,1 \mathrm{~F} 2 \text { and } 1 \mathrm{~F} 3 \text {, it was } \\
\text { confirmed that RPV bottom } \\
\text { temperature responds. When water } \\
\text { injected through FDW line in } 1 \mathrm{~F} 1 \text {, } \\
1 \mathrm{~F} 2 \text {, and } 1 \mathrm{~F} 3 \text {, it was confirmed that } \\
\text { RPV bottom temperature responds. } \\
\text { The U.S. remains interested in this } \\
\text { information but recognizes that it may } \\
\text { not be available. }\end{array}$} \\
\hline & $\begin{array}{l}\text { Photos/videos of 1F1, } \\
1 \mathrm{~F} 2, \text { and } 1 \mathrm{~F} 3 \\
\text { feedwater sparger } \\
\text { nozzle and injection } \\
\text { points }\end{array}$ & & & & \\
\hline RPV-3 & $\begin{array}{l}\text { 1F1, 1F2, and 1F3 } \\
\text { steam separators' } \\
\text { integrity and location } \\
\text { (photos/videos with } \\
\text { displacement } \\
\text { measurements, sample } \\
\text { removal and exams for } \\
\text { FP deposition, peak } \\
\text { temperature } \\
\text { evaluations) }\end{array}$ & $\begin{array}{l}\text { - Code assess- } \\
\text { ments. } \\
\text { - Possible model } \\
\text { improvements. }\end{array}$ & $\begin{array}{l}\text { Improved AM } \\
\text { strategies, Improved } \\
\text { simulations for } \\
\text { training. Assist } \\
\text { D\&D efforts. }\end{array}$ & $\begin{array}{l}\text { Later (after } \\
2017 \text { based } \\
\text { on current } \\
\text { roadmap). }\end{array}$ & $\begin{array}{l}\text { TEPCO Holdings will conduct visual, } \\
\text { some metallurgical and fission product } \\
\text { deposition exams. } \\
\text { The U.S. remains interested in this } \\
\text { information. }\end{array}$ \\
\hline
\end{tabular}


Table C-3. Information needs from the reactor pressure vessel

\begin{tabular}{|c|c|c|c|c|c|}
\hline Item & What/How Obtained & Why & $\begin{array}{c}\text { Expected Benefit } \\
\text { /Use }\end{array}$ & When & Status \\
\hline \multirow[t]{4}{*}{ RPV-4 } & $\begin{array}{l}\text { 1F1, 1F2, and 1F3 } \\
\text { shroud inspection } \\
\text { (between shroud and } \\
\text { RPV wall); } \\
\text { Photos/videos and } \\
\text { sample removal and } \\
\text { oxidation testing. }\end{array}$ & $\begin{array}{ll}\text { - } & \text { Code assess- } \\
\text { ments. } \\
\text { - } \\
\text { Possible model } \\
\text { improvements. }\end{array}$ & $\begin{array}{l}\text { Improved AM } \\
\text { strategies; Improved } \\
\text { simulations for } \\
\text { training. Assist } \\
\text { D\&D efforts. }\end{array}$ & $\begin{array}{l}\text { Now and } \\
\text { later (after } \\
2017 \text { based } \\
\text { on current } \\
\text { roadmap). }\end{array}$ & $\begin{array}{l}\text { TEPCO Holdings has some } \\
\text { information and will conduct visual } \\
\text { exams. 1F2 PLR pump responded } \\
\text { after increasing water flowrate from } \\
\text { FDW, indicating a certain amount of } \\
\text { water is retained outside shroud. } \\
\text { The U.S. remains interested in this } \\
\text { information but recognizes that some } \\
\text { information may not be obtained. }\end{array}$ \\
\hline & $\begin{array}{l}\text { 1F1, 1F2, and 1F3 } \\
\text { shroud head integrity } \\
\text { and location } \\
\text { (photos/videos, and } \\
\text { metallurgical exams) }\end{array}$ & $\begin{array}{l}\text { - Code assess- } \\
\text { ments. } \\
\text { - Possible model } \\
\text { improvements. }\end{array}$ & $\begin{array}{l}\text { Improved AM } \\
\text { strategies; Improved } \\
\text { simulations for } \\
\text { training. }\end{array}$ & $\begin{array}{l}\text { Later (after } \\
2017 \text { based } \\
\text { on current } \\
\text { roadmap). }\end{array}$ & $\begin{array}{l}\text { TEPCO Holdings will conduct visual } \\
\text { exams and some metallurgical exams. } \\
\text { The U.S. remains interested in this } \\
\text { information but recognizes that some } \\
\text { information may not be obtained. }\end{array}$ \\
\hline & $\begin{array}{l}\text { Photos/videos of } 1 \mathrm{~F} 1 \text {, } \\
1 \mathrm{~F} 2 \text {, and } 1 \mathrm{~F} 3 \text { shroud } \\
\text { inspection (from core } \\
\text { region) }\end{array}$ & $\begin{array}{ll}\text { - } & \text { Code assess- } \\
\text { ments. } \\
\text { - Possible model } \\
\text { improvements. }\end{array}$ & $\begin{array}{l}\text { Improved AM } \\
\text { strategies; Possible } \\
\text { plant modifications; } \\
\text { Improved } \\
\text { simulations for } \\
\text { training. Assist } \\
\text { D\&D efforts. }\end{array}$ & $\begin{array}{l}\text { Later (after } \\
2017 \text { based } \\
\text { on current } \\
\text { roadmap). }\end{array}$ & $\begin{array}{l}\text { TEPCO Holdings will conduct visual } \\
\text { exams. } \\
\text { The U.S. remains interested in this } \\
\text { information but recognizes that some } \\
\text { information may not be obtained. }\end{array}$ \\
\hline & $\begin{array}{l}\text { Photos/videos of } 1 \mathrm{~F} 1, \\
1 \mathrm{~F} 2, \text { and } 1 \mathrm{~F} 3 \text { core } \\
\text { plate and associated } \\
\text { structures }\end{array}$ & $\begin{array}{ll}\text { - } & \text { Code assess- } \\
\text { ments. } \\
\text { - Possible model } \\
\text { improvements. }\end{array}$ & $\begin{array}{l}\text { Improved AM } \\
\text { strategies; Possible } \\
\text { plant modifications; } \\
\text { Improved } \\
\text { simulations for } \\
\text { training. Assist } \\
\text { D\&D efforts. }\end{array}$ & $\begin{array}{l}\text { Later (after } \\
2017 \text { based } \\
\text { on current } \\
\text { roadmap). }\end{array}$ & $\begin{array}{l}\text { TEPCO Holdings will conduct visual } \\
\text { exams. } \\
\text { The U.S. remains interested in this } \\
\text { information but recognizes that some } \\
\text { information may not be obtained. }\end{array}$ \\
\hline \multirow[t]{2}{*}{ RPV-5 } & $\begin{array}{l}\text { Remote mapping of } \\
1 \mathrm{~F} 1,1 \mathrm{~F} 2 \text {, and } 1 \mathrm{~F} 3 \\
\text { core through shroud } \\
\text { wall from annular gap } \\
\text { region (muon } \\
\text { tomography and other } \\
\text { methods, if needed) }\end{array}$ & $\begin{array}{l}\text { Code assess- } \\
\text { ments. } \\
\text { - Possible model } \\
\text { improvements. }\end{array}$ & $\begin{array}{l}\text { Improved AM } \\
\text { strategies; Possible } \\
\text { plant modifications; } \\
\text { Improved } \\
\text { simulations for } \\
\text { training. Assist } \\
\text { D\&D efforts. }\end{array}$ & $\begin{array}{l}\text { Now and } \\
\text { later (after } \\
2017 \text { based } \\
\text { on current } \\
\text { roadmap). }\end{array}$ & $\begin{array}{l}\text { TEPCO Holdings has deployed and } \\
\text { provided results from muon } \\
\text { tomography examinations. }\end{array}$ \\
\hline & $\begin{array}{l}\text { Mapping of end state } \\
\text { of core and structural } \\
\text { material (visual, } \\
\text { sampling, hot cell } \\
\text { exams, etc.) }\end{array}$ & \begin{tabular}{|l} 
- Code assess- \\
ments. \\
Possible model \\
improvements \\
for predicting \\
debris com- \\
position, mass, \\
and morphol- \\
ogy (e.g., \\
coolability, \\
topography of \\
debris, spread- \\
ing, splashing, \\
and salt effects.
\end{tabular} & $\begin{array}{l}\text { Improved BWR and } \\
\text { potential PWR AM } \\
\text { strategies; plant } \\
\text { modifications, and } \\
\text { improved } \\
\text { simulations for } \\
\text { training. Assist } \\
\text { D\&D efforts. }\end{array}$ & $\begin{array}{l}\text { Later (after } \\
2017 \text { based } \\
\text { on current } \\
\text { roadmap). }\end{array}$ & $\begin{array}{l}\text { TEPCO Holdings has not yet } \\
\text { considered but will probably perform, } \\
\text { as necessary for defueling and D\&D. } \\
\text { If samples are obtained, a } \\
\text { collaborative program to evaluate may } \\
\text { be possible. }\end{array}$ \\
\hline
\end{tabular}

a. With the exception of general area views, photos and videos should be obtained with reference length scales at appropriate locations. In particular, it is required for photos and videos to be most effective for RPV-1(b), RPV- 2(a), RPV-3 and RPV4(d) 


\section{C.2. Detailed Information Needs}

Table C-4. Detailed information need for RB-9b and RB-10

- Name(s) /Description(s) - Name (ID \#), description of desired information, unit (1F1, 1F2, 1F3), and location from where it should be obtained (PCV, RPV, Reactor Building):

RB-9b: Photos/videos around mechanical seals and hatches and electrical penetration seals

RB-10: Photos/videos of 1F1 (vacuum breaker), 1F1, 1F2, and 1F3 PCV leakage points (bellows and other penetrations)

High-resolution images (photos/videos) of PCV penetrations and other vulnerable areas (i.e., access hatches, piping/electrical penetrations, expansion joints/bellows). Images of similar locations from each unit (1F1, 1F2, 1F3, 1F4) allows for comparison of damage and end state between units. 1F4 photos will provide a good baseline of a vessel not over pressurized. Imaging should be sufficient to estimate whether damage has occurred. External PCV images may be sufficient. Images taken internal to the PCV and of disassembled penetrations (i.e., hatch sealing faces and seal material) are desired if obtained during D\&D. History on penetration leakage or repairs correlated to images is also desired.

- Benefits - Safety, Operational, Economic, D\&D, or other benefits:

Safety - Desired for improving reactor safety analysis models and accident management.

Operational - Provides for weak link assessment of penetration capacity.

Economic - Provide insight into seal performance capability; could be used to adjust maintenance and inspection

D\&D - Impacts D\&D because of constraints on contaminated water release, airborne radionuclide release path. Can

influence D\&D method by identifying where containment is leaking and to what level containment can be flooded.

- Use/Motivation - Tie to specific use (code models, maintenance, operations, accident management, etc.) and timeframe when needed:

Locations of PCV failure and leakage can affect the accident progression with respect to timing, accident mitigation actions, venting, and radionuclide and combustible gas releases. This information can be used to validate and/or enhance the current understanding of the conditions required for PCV failure and the locations of such failures. It can also impact operations and maintenance considerations, such as gasket and seal material selection and replacement. Linkage of repaired or degraded penetrations performance in over design conditions can provide insights to improve realistic estimates of failures and investigate improvements in repair methods.

- Methods/Tools Needed to Collect Information or Data:

- High resolution imaging system - external to PCV

- Dose survey meter or gamma camera (3D image).

- Irradiation resistant high-resolution imaging system - internal to PCV

- Personnel observations indicating leakage (water dripping, discoloration, puddles)

- Roadmap Timeframe - Near-term and/or later; Tie to specific inspections planned for 1F1, 1F2 and 1F3:

Near-term and later (continued inspections of containment and identification of leakage points for units 1F1, 1F2 and 1F3). Base line information from $1 \mathrm{~F} 4$ can be gathered now. History of penetration maintenance and repair can support investigation of radiological releases and flood-up plans

- Preparatory or Follow-on Research/Supporting Information (beyond what is obtained from 1F examinations)

Identification of actual penetration characteristics (e.g. geometry, seal material) may be needed to apply observations to other units.

Prediction of conditions of penetration during accident (i.e., stress, temperature, pressure). Although multiple scenarios may lead to the observed endstate, comparisons between predicted and observed endstates may allow identification of possible scenarios and elimination of other scenarios.

U.S. industry should develop a list of high interest penetrations/areas because of maintenance benefits and provide to TEPCO Holdings.

Tabletop exercises with operation and reactor safety experts should be conducted to develop potential penetration failure scenario list. 
Table C-5. Detailed information need for RB-15

- Name(s) /Description(s) - Name (ID \#), description of desired information, unit (1F1, 1F2, 1F3), and location from where it should be obtained (PCV, RPV, Reactor Building):

RB-15: Reactor Building Closed Cooling Water system (RCW) inspection 1F1

Water level measurement of RCW.

Dose survey around RCW surge tank.

Images of the RCW system inside of containment are desired if obtained during D\&D.

- Benefits - Safety, Operational, Economic, D\&D, or other benefits:

Safety - Desired for understanding 1F1 accident progression and the potential role of the RCW during an accident.

D\&D - Could influences D\&D efforts by identifying where containment is leaking.

- Use/Motivation - Tie to specific use (code models, maintenance, operations, accident management, etc.) and timeframe when needed:

TEPCO Holdings and the U.S. expert panel have identified the potential the failure of the 1F1 RCW sump heat exchanger piping in containment. The RCW system may have influenced the accident progression by allowing releases from containment and/or supplying cooling water to the ex-vessel debris in containment. Understanding the status of the RCW system will aid in determining the role the RCW system had during the accident.

- Methods/Tools Needed to Collect Information or Data:

- Dose survey meter or gamma camera (3D image).

- Water level may possibly be obtained from gauge on surge tank or a dip stick. If water level is lower than surge tank, alternate assessment methods and locations may be required.

- Roadmap Timeframe - Near-term and/or later; Tie to specific inspections planned for 1F1, 1F2 and 1F3:

Near-term, the RCW surge tank and reactor building floors appear accessible. The surge tank inspection could accompany any future investigation of the nearby IC.

Long-term, images of the RCW inside of containment (sump heat exchanger piping) may be obtained during D\&D or its planning.

- Preparatory or Follow-on Research/Supporting Information (beyond what is obtained from 1F examinations)

Identifying the design water volume of the RCW system. 
Table C-6. Detailed information need for PC-1

- Name(s) /Description(s) - Name (ID \#), description of desired information, unit (1F1, 1F2, 1F3), and location from where it should be obtained (PCV, RPV, Reactor Building):

PC-1: Photos and/or videos of the drywell head, head seals, and sealing surfaces for 1F1, 1F2, and 1F3

There is also interest in obtaining the tension, torque, and bolt length records of bolts used to close the drywell head. This information is of interest both prior and during removal.

- Visual - signs of asymmetric lift or leakage paths. Look for thermal deformation due to high temperatures over time.

- RN Swabbing

- Visual inspection of seal

- Visual inspection of the head. Look for evidence of permanent strain in the head flange or bulging of the head hemisphere and for evidence of bending/bowing of the bolts along their length that could result from head flange strain and result in permanent leakage location even after PCV decompression.

- Inspect shield plug - visual inspection of cracks.

- Benefits - Safety, Operational, Economic, D\&D, or other benefits:

AM Strategies; What happened with respect to the leak path; better simulations for training. Improved understanding of PCV response to overpressure that could inform accident management, especially PCV venting strategies.

- Use/Motivation - Tie to specific use (code models, maintenance, operations, accident management, etc.) and timeframe when needed:

Determine how head lifted with emphasis on the state of the flange closure gap and any evidence of permanent strain/deformation such that permanent leak paths would persist beyond the simple elastic bolt stretching behavior. Determine peak temperatures. Look for indicators of degradation due to high temperature hydrogen, including hydrogen induced embrittlement.

- Methods/Tools Needed to Collect Information or Data:

- Mostly photographic

- Roadmap Timeframe - Near-term and/or later; Tie to specific inspections planned for 1F1, 1F2 and 1F3:

When reactor head is opened for decommissioning purposes.

- Preparatory or Follow-on Research/Supporting Information (beyond what is obtained from 1F examinations)

None 
Table C-7. Detailed information need for PC-3a

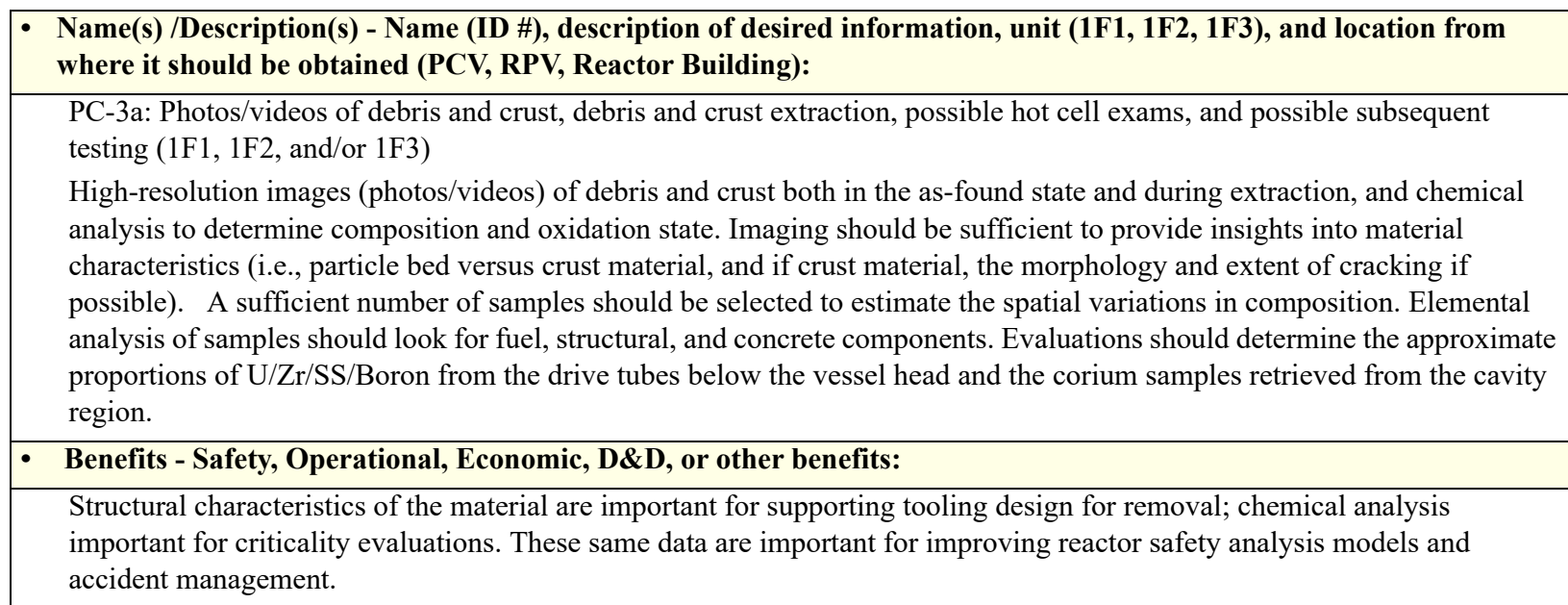

- Use/Motivation - Tie to specific use (code models, maintenance, operations, accident management, etc.) and timeframe when needed:

Benchmark and reduce uncertainty in models for predicting molten core concrete interaction (MCCI) phenomena. MCCI phenomena are important for assessing combustible gas generation during late phase accident progression, as well as the extent of attack on containment structures. It is important to reduce uncertainty in this phenomenon because it affects strategies for venting and water addition. Improved knowledge will be used to enhance accident management strategies.

- Methods/Tools Needed to Collect Information or Data:

- Irradiation resistant high-resolution imaging system

- Hot cell elemental analysis system, and/or in-situ elemental analysis using Laser Induced Breakdown Spectroscopy (LIBS) and/or X-ray Florescence

- Ultimately, D\&D cutting and removal tools able to extract materials

- Roadmap Timeframe - Near-term and/or later; Tie to specific inspections planned for 1F1, 1F2 and 1F3: Near-term and/or later (Sample removal possible within next 2 years).

- Preparatory or Follow-on Research/Supporting Information (beyond what is obtained from 1F examinations)

Obtaining /using this information may require additional material property and coolability testing (Young's modulus, linear expansion, ultimate strength, hardness, tensile strength, etc.) for cutting tool development and for model development.

Evaluation of this information may require composition information for concrete (to distinguish between sand and concrete). 
Table C-8. Detailed information need for PC-3b

- Name(s) /Description(s) - Name (ID \#), description of desired information, unit (1F1, 1F2, 1F3), and location from where it should be obtained (PCV, RPV, Reactor Building):

PC-3b: PCV liner examinations (photos/videos and metallurgical exams; 1F1-1F3)

High-resolution images (photos/videos) of PCV liner, with particular emphasis in regions contacted by core debris. In areas that were contacted, the imaging should be sufficient to provide insights into the nature/extent of heat transfer and/or thermochemical attack on the liner (e.g., distortion/displacement and extent of ablation if that occurred). A sufficient number of samples should be selected in eroded areas to determine if the boundary temperature during erosion was determined by simple melting or by eutectic formation. Evaluations should determine the approximate proportions of Uranium/Zirconium/Stainless Steel/Boron from corium samples retrieved from the cavity region.

- Benefits - Safety, Operational, Economic, D\&D, or other benefits:

For D\&D, plugging leaks in the liner will reduce the extent of water leakage from the PCV and determining leakage locations via liner examinations is crucial to this process. These same data are important for improving reactor safety analysis models and accident management.

- Use/Motivation - Tie to specific use (code models, maintenance, operations, accident management, etc.) and timeframe when needed:

Benchmark and reduce uncertainty in models for predicting liner thermal heatup and attack by core debris for ex-vessel accident scenarios. Improved knowledge will be used to enhance accident management strategies.

- Methods/Tools Needed to Collect Information or Data:

- Irradiation resistant high-resolution imaging system.

- Laser imaging systems to reconstruct liner distortion and/or ablation profiles.

- Roadmap Timeframe - Near-term and/or later; Tie to specific inspections planned for 1F1, 1F2 and 1F3: Near-term and/or later.

- Preparatory or Follow-on Research/Supporting Information (beyond what is obtained from 1F examinations) None. 
Table C-9. Detailed information need for PC-3c

- Name(s) /Description(s) - Name (ID \#), description of desired information, unit (1F1, 1F2, 1F3), and location from where it should be obtained (PCV, RPV, Reactor Building):

PC-3c: Photos/video, RN surveys, and sampling of pedestal wall and floor (1F1-1F3).

High-resolution images (photos/videos), RN surveys, and sampling of 1F1, 1F2, and 1F3 pedestal wall and floor. Imaging should be sufficient to provide insights into structural integrity and/or damage incurred during the accident. A sufficient number of samples should be selected to estimate the RN distribution on the pedestal wall and floor. Evaluations should determine the approximate proportions of $\mathrm{U} / \mathrm{Zr} / \mathrm{SS} /$ Boron from corium samples retrieved from the cavity region.

- Benefits - Safety, Operational, Economic, D\&D, or other benefits:

Determining the pedestal wall and floor structural integrity as well as RN distributions is important for safety evaluations of D\&D activities.

- Use/Motivation - Tie to specific use (code models, maintenance, operations, accident management, etc.) and timeframe when needed:

Benchmark and reduce uncertainty in models for predicting structure heatup and degradation during a severe accident. It is important to reduce uncertainties in this area since heat sink inside the PCV can impact predictions of water availability to cool core debris. Improved knowledge will be used to enhance accident management strategies.

- Methods/Tools Needed to Collect Information or Data:

- Irradiation resistant high-resolution imaging system

- Robotic methods for extraction of samples for determining RN distributions.

- Roadmap Timeframe - Near-term and/or later; Tie to specific inspections planned for 1F1, 1F2 and 1F3: Near-term and/or later (Sample removal possible within next 2 years).

- Preparatory or Follow-on Research/Supporting Information (beyond what is obtained from 1F examinations) None. 
Table C-10. Detailed information need for PC-3d

- Name(s) /Description(s) - Name (ID \#), description of desired information, unit (1F1, 1F2, 1F3), and location from where it should be obtained (PCV, RPV, Reactor Building):

PC-3d: Concrete erosion profile; photos/videos and sample removal and examination (1F1-1F3)

High-resolution images (photos/videos) of concrete erosion with possible sample removal and elemental analysis. Imaging should be sufficient to estimate the total volume of relocated core material and the damaged volume of concrete. In addition, imaging should be of sufficient resolution to characterize the morphology (e.g., cracks, gaps, etc.) of the debris and concrete. A sufficient number of samples shall be selected to estimate the spatial variations in composition and oxidation state of relocated materials. Elemental analysis of samples should look for fuel, structural, and concrete components. Evaluations should determine the approximate proportions of $\mathrm{U} / \mathrm{Zr} / \mathrm{SS} /$ Boron from the corium samples retrieved from the cavity region.

- Benefits - Safety, Operational, Economic, D\&D, or other benefits:

Required for D\&D facilitate planning for debris removal, and also for evaluation of the mechanical integrity of critical structures such as the reactor pedestal. Desired for improving reactor safety analysis models and accident management.

- Use/Motivation - Tie to specific use (code models, maintenance, operations, accident management, etc.) and timeframe when needed:

Benchmark and reduce uncertainty in models for predicting molten core concrete interaction (MCCI) phenomena. MCCI is important in assessing combustible gas generation during late phase accident progression. It is important to reduce uncertainty in MCCI phenomena because it affects strategies for venting and water addition. Improved knowledge will be used to enhance accident management strategies.

- Methods/Tools Needed to Collect Information or Data:

- Irradiation resistant high-resolution imaging system

- Hot cell elemental analysis system

- D\&D cutting and removal tools able to extract materials

- Roadmap Timeframe - Near-term and/or later; Tie to specific inspections planned for 1F1, 1F2 and 1F3: Near-term and/or later (Sample removal possible within next 2 years).

- Preparatory or Follow-on Research/Supporting Information (beyond what is obtained from 1F examinations)

Obtaining /using this information may require additional material property and coolability testing (Young's modulus, linear expansion, ultimate strength, hardness, tensile strength, etc.) for cutting tool development and for model development.

Evaluation of this information may require composition information for concrete (to distinguish between sand and concrete). 
Table C-11. Detailed information need for PC-3e

- Name(s) /Description(s) - Name (ID \#), description of desired information, unit (1F1, 1F2, 1F3), and location from where it should be obtained (PCV, RPV, Reactor Building):

PC-3e: Photos/videos of RPV lower head and of structures and penetrations beneath the vessel to determine damage and corium hang-up (1F1-1F3)

High-resolution images (photos/videos) of structures and penetrations with retained corium. Imaging should be sufficient to estimate the total volume of relocated core material and the damage to structures and penetrations.

- Benefits - Safety, Operational, Economic, D\&D, or other benefits:

Required for D\&D facilitate planning for debris removal and for evaluation of the mechanical integrity of critical structures such as the reactor pedestal. Desired for improving reactor safety analysis models and accident management.

- Use/Motivation - Tie to specific use (code models, maintenance, operations, accident management, etc.) and timeframe when needed:

Benchmark and reduce uncertainty in models for predicting the mass and heat content of material that relocates from the reactor vessel, which in turn, affects PCV gas temperature, PCV pressure, and the potential for MCCI.

- Methods/Tools Needed to Collect Information or Data:

- Irradiation resistant high-resolution imaging system

- Hot cell elemental analysis system

- D\&D cutting and removal tools able to extract materials

- Roadmap Timeframe - Near-term and/or later; Tie to specific inspections planned for 1F1, 1F2 and 1F3: Near-term and/or later (Robotic examinations underway).

- Preparatory or Follow-on Research/Supporting Information (beyond what is obtained from 1F examinations)

Initial findings from 1F2 and 1F3 suggest that a non-negligible amount of core debris may be held up on structures below the reactor vessel. System analysis codes should be exercised assuming a range of core debris holdup in a situation that is not cooled by water to investigate the impact of heat sources not covered by water on PCV gas phase temperature and pressure. 
Table C-12. Detailed information need for PC-5

- Name(s) /Description(s) - Name (ID \#), description of desired information, unit (1F1, 1F2, 1F3), and location from where it should be obtained (PCV, RPV, Reactor Building):

PC-5: Photos/videos and temperatures of 1F1, 1F2, and 1F3 main steam lines and ADS lines to end of SRV tailpipes, including instrument lines.

- Benefits - Safety, Operational, Economic, D\&D, or other benefits:

BWR AM Strategies (plant mods, etc.) and better simulations for training; Potential PWR impacts (e.g., modeling, AM strategies, etc.).

- Use/Motivation - Tie to specific use (code models, maintenance, operations, accident management, etc.) and timeframe when needed:

To determine RPV failure mode.

Initial examinations should focus on identifying failure mode(s) and location(s). For example, if images indicate that vessel lower head failure occurred, images should be of sufficient resolution to determine if the failure was a gross unzipping or a limited area. If images suggest that vessel depressurization was due to penetration failure, images should be of sufficient resolution to determine the number, type(s) [e.g., control rod drive, instrument tube, and/or drain line], and failure mode(s) [e.g., tube ejection and/or tube rupture].

Evaluations of MSLs and ADS lines should also focus on identifying failure mode(s) and location(s). Initial images may not be able to detect failure locations. Hence, dose surveys, gamma camera (3D) images, and temperature measurements may be needed to detect where radiation has leaked from the RPV.

- Methods/Tools Needed to Collect Information or Data:

- Irradiation resistant high-resolution imaging system (1 $\mathrm{mm}$ to $1 \mathrm{~cm}$ gaps or cracks).

- Dose survey meter or gamma camera (3D image).

- Thermal imaging to observe hot spots $\left(>100^{\circ} \mathrm{C}\right.$ increases $)$

- Roadmap Timeframe - Near-term and/or later; Tie to specific inspections planned for 1F1, 1F2 and 1F3: Near-term and/or later.

- Preparatory or Follow-on Research/Supporting Information (beyond what is obtained from 1F examinations) None. 
Table C-13. Detailed information need for PC-6

- Name(s) /Description(s) - Name (ID \#), description of desired information, unit (1F1, 1F2, 1F3), and location from where it should be obtained (PCV, RPV, Reactor Building):

PC-6: Visual inspections of 1F1, 1F2, and 1F3 SRVs including standpipes in the torus and drywell (interior valve mechanisms)

- Benefits - Safety, Operational, Economic, D\&D, or other benefits:

BWR AM Strategies (maintenance practices, etc.), SRV functioning in test facility data, and better simulations for training; Potential PWR impacts (e.g., modeling, AM strategies, etc.).

- Use/Motivation - Tie to specific use (code models, maintenance, operations, accident management, etc.) and timeframe when needed:

To determine if there was any failure of SRVs and associated piping.

- Methods/Tools Needed to Collect Information or Data:

- Irradiation resistant high-resolution imaging system

- Roadmap Timeframe - Near-term and/or later; Tie to specific inspections planned for 1F1, 1F2 and 1F3: Near-term and/or later.

- Preparatory or Follow-on Research/Supporting Information (beyond what is obtained from 1F examinations) None. 
Table C-14. Detailed information need for PC-17, PC-18, PC-19, and PC-20

\begin{tabular}{|c|c|}
\hline & $\begin{array}{l}\text { Name(s) /Description(s) - Name (ID \#), description of desired information, unit (1F1, 1F2, 1F3), and location from } \\
\text { where it should be obtained (PCV, RPV, Reactor Building): }\end{array}$ \\
\hline & $\begin{array}{l}\text { PC-17: Chemical analysis of upper layer of sediment on drywell floor at the X-100B penetration location in } 1 \mathrm{~F} 1 \text {. The upper } \\
\text { surface of the sediment is } \sim 30 \mathrm{~cm} \text { above drywell floor }\end{array}$ \\
\hline & $\begin{array}{l}\text { PC-18: Evaluate nature of material below the sediment at the } \mathrm{X}-100 \mathrm{~B} \text { penetration location in } 1 \mathrm{~F} 1 \text { to determine if core debris } \\
\text { is present }(1 \mathrm{~F} 1)^{\mathrm{a}}\end{array}$ \\
\hline & PC-19: Chemical analysis (XRF) of black material discovered on CRD exchange rail in 1F2 at X-6 penetration location \\
\hline & PC-20: Chemical analysis of black material on 'existing vertical wall structure' in $1 \mathrm{~F} 1$ picture outside pedestal doorway \\
\hline & $\begin{array}{l}\text { These four information requests are for determining the chemical composition of materials observed at locations in } 1 \mathrm{~F} 1 \text { (i.e., } \\
\text { sediment and underlying material on the drywell floor below the X-100b penetration, and on existing vertical structure near } \\
\text { the pedestal doorway), and black material discovered on the CRD exchange rail in 1F2 from the X- } 6 \text { penetration. Elemental } \\
\text { analysis of samples should look for fuel, structural, and concrete components and should also include a measurement of } \\
\text { oxygen content if possible. }\end{array}$ \\
\hline & Benefits - Safety, Operational, Economic, D\&D, or other benefits: \\
\hline & Required for D\&D; desired for improving reactor safety analysis models and accident management. \\
\hline & $\begin{array}{l}\text { Use/Motivation - Tie to specific use (code models, maintenance, operations, accident management, etc.) and timeframe } \\
\text { when needed: }\end{array}$ \\
\hline & $\begin{array}{l}\text { Benchmark and reduce uncertainty in models for predicting vessel failure, in-vessel cladding oxidation and hydrogen } \\
\text { production, holdup on ex-vessel structures, and MCCI phenomena. Vessel failure, holdup on ex-vessel structures, and MCCI } \\
\text { phenomena are important for assessing combustible gas generation during late phase accident progression. It is important to } \\
\text { reduce uncertainty in these phenomena because they affect strategies for venting and water addition. }\end{array}$ \\
\hline & $\begin{array}{l}\text { Data from PC-19 and PC- } 20 \text { evaluations can be used to confirm RPV failure, and additional analysis of PC-19 can be used to } \\
\text { assess the extent of in-vessel cladding oxidation. Data from PC-18 evaluations can be used to determine if core debris is } \\
\text { present and the X-100B location, thereby providing insights on the extent of core debris location which is also a critical } \\
\text { uncertainty impacting accident management strategy. Knowledge gained from these analyses will be used to enhance these } \\
\text { strategies. Data from PC-17 can be used to determine if the composition of this sediment varies with height. }\end{array}$ \\
\hline & Methods/Tools Needed to Collect Information or Data: \\
\hline & $\begin{array}{l}\text { - Hot cell elemental analysis system and/or in-situ elemental analysis using Laser Induced Breakdown Spectroscopy (LIBS) } \\
\text { and/or X-ray Florescence (XRF). } \\
\text { - Robotics systems for collecting samples, and for probing the sediment at X-100B location to determine the (loose material) } \\
\text { sediment depth. }\end{array}$ \\
\hline & Roadmap Timeframe - Near-term and/or later; Tie to specific inspections planned for 1F1, 1F2 and 1F3: \\
\hline & Near-term and/or later. \\
\hline & Preparatory or Follow-on Research/Supporting Information (beyond what is obtained from 1F examinations) \\
\hline
\end{tabular}

a. See "Technical Supplement for PC-18 Evaluation".

\section{Technical Supplement for PC-18 Evaluation}

Examinations at the X-100b location in $1 \mathrm{~F} 1$ (located $\sim 130$ degrees counter-clockwise from the pedestal doorway opening) indicate a layer of material covering the drywell floor that is $\sim 30 \mathrm{~cm}$ deep. This material was identified during the initial entries through the X-100b penetration in 2012 and was reconfirmed during later entries in 2016 that provided additional data on the actual depth of the material. It is known that additional sediment had not accumulated at this location over the intervening four years because unique surface characteristics (i.e., grayish blue material thought to be lead) were still present. The upper surface of the material was determined to be loose sediment. It is not known whether this sediment extends down the entire $30 \mathrm{~cm}$ depth, or whether the sediment is a partial layer covering other material such as core debris. 
There are a variety of potential sources for this sediment material that may include decomposed/flaked paint, thermal insulation, cable insulation, sand/sediment from low quality seawater injection, aerosol from core concrete interaction, among others. If the material is sand entrained with the seawater that was injected or concrete aerosol from core-concrete interaction, then it may be possible to determine the origin based on the relative proportions of dominant concrete oxides such as $\mathrm{SiO}_{2}, \mathrm{CaO}, \mathrm{Al}_{2} \mathrm{O}_{3}$, and $\mathrm{MgO}$ in the sediment. For sand from seawater injection, analysis of a sample of beach sand obtained at the site would provide definitive data for direct comparison with elemental analysis data obtained from a sample of the sediment. In lieu of this information, the composition of sand from 12 different beaches along the east and west coasts of Japan have been reported in the literature.[224] The compositions of key compounds varied considerably; i.e., 61.4-99.2 $\mathrm{wt} \% \mathrm{SiO}_{2}, 0.04-5.8 \mathrm{wt} \% \mathrm{CaO}, 1.3-19.0 \mathrm{wt} \% \mathrm{Al}_{2} \mathrm{O}_{3}$, and $0-2.0 \mathrm{wt} \% \mathrm{MgO}$. In terms of mass ratios of key elements, the resultant ratio for $\mathrm{Si}-\mathrm{Al}$ is determined to range from 2.7 to 67 and for $\mathrm{Si}$ to $\mathrm{Ca}$ is determined to range from 6.9 to 1600.

Fortunately, the composition of concrete from the Daiichi site has also been measured for two samples to provide data for comparison to these ranges; see Table C-4.[225] Iron shown in Table C-4 is not considered in the current discussion as it could arise from corrosion (rust) of steel within the PCV, of which there is a massive amount. The corresponding mass ratios for Fukushima Daiichi concrete for the key elements in the two concrete samples are $\mathrm{Si} / \mathrm{Al}$ : 3.6-4.2, and $\mathrm{Si} / \mathrm{Ca}: 2.7-3.5$. The $\mathrm{Si} / \mathrm{Al}$ ratio for the concrete versus sand samples from around the island of Japan cannot be discriminated. However, the range of $\mathrm{Si} / \mathrm{Ca}$ ratios does not overlap. In particular, the range boundaries are separated by a factor of $\sim 2$. Thus, if the $\mathrm{Si} / \mathrm{Ca}$ ratio is lower and in the range of 2.7-3.5, it is likely concrete aerosol from MCCI. Conversely, if it is higher, $\sim 7$ or above, it is likely sand from seawater injection. Aerosol from core-concrete interaction also nominally contains a small amount of fuel (U) which would also be a discriminating factor.

Table C-15. Composition data from analysis of two concrete samples at $1 \mathrm{~F}$ site.[225]

\begin{tabular}{|c|c|c|c|c|}
\hline \multirow{2}{*}{ Sample Number } & \multicolumn{4}{|c|}{ Mass\% } \\
\cline { 2 - 5 } & Al & Ca & Fe & Si \\
\hline 1 & $7.0 \pm 1$ & $7.8 \pm 1$ & $3.6 \pm 1$ & $25 \pm 1$ \\
\hline 3 & $6.5 \pm 1$ & $9.1 \pm 1$ & $3.3 \pm 1$ & $27 \pm 1$ \\
\hline
\end{tabular}


Table C-16. Detailed information need for PC-21

\section{- Name(s) /Description(s) - Name (ID \#), description of desired information, unit (1F1, 1F2, 1F3), and location from} where it should be obtained (PCV, RPV, Reactor Building):

\section{PC-21: Images from examinations in 1F3 X-53 penetration}

High-resolution images (photos/videos) of external surfaces of RPV (especially of vessel failure locations); of material collected on structures beneath vessel (e.g., cables, control rod drives, support structures, gratings; and of concrete erosion on floor of PCV.

Imaging should be sufficient to estimate the total volume of relocated core material at each location and the damaged volume of the vessel, any ex-vessel structures, and the concrete. In addition, imaging should be of sufficient resolution to characterize the morphology (e.g., cracks, gaps, etc.) of the debris and concrete. Measurements of dose rates and collection of samples for elemental analysis is desired. Ultimately, a sufficient number of samples shall be selected to be able to estimate the spatial variations in composition. Elemental analysis of samples should look for fuel, structural, and concrete components.

- Benefits - Safety, Operational, Economic, D\&D, or other benefits: Required for D\&D; desired for improving reactor safety analysis models and accident management.

- Use/Motivation - Tie to specific use (code models, maintenance, operations, accident management, etc.) and timeframe when needed:

Benchmark and reduce uncertainty in models for predicting vessel failure, holdup on ex-vessel structures, and molten core concrete interaction (MCCI) phenomena. Vessel failure, holdup on ex-vessel structures, and MCCI phenomena are important for assessing combustible gas generation during late phase accident progression. It is important to reduce uncertainty in these phenomena because they affect strategies for venting and water addition. Improved knowledge will be used to enhance accident management strategies.

- Methods/Tools Needed to Collect Information or Data:

- Irradiation resistant high-resolution imaging system

- Hot cell elemental analysis system

- Systems to obtain dose rate measurements and collecting fluid or small particles during FY2017 examination (if it is possible).

- Ultimately, D\&D cutting and removal tools able to extract materials

- Roadmap Timeframe - Near-term and/or later; Tie to specific inspections planned for 1F1, 1F2 and 1F3: Near-term and/or later (Sample removal possible within next 2 years).

- Preparatory or Follow-on Research/Supporting Information (beyond what is obtained from 1F examinations)

Obtaining /using this information may require additional material property and coolability testing (Young's modulus, linear expansion, ultimate strength, hardness, tensile strength, etc.) for cutting tool development and for model development.

Evaluation of this information may require composition information for concrete (to distinguish between sand and concrete). 
Table C-17. Detailed information need for RPV-1b

- Name(s) /Description(s) - Name (ID \#), description of desired information, unit (1F1, 1F2, 1F3), and location from where it should be obtained (PCV, RPV, Reactor Building):

RPV-1b: Photos/videos, probe inspections, and sample exams of 1F1, 1F2, and 1F3 MSLs.

Interior examinations of MSLs at external locations, looking for evidence of thermal/pressure strain and/or rupture, including nature of any ruptures such as fish mouth or more global rupture. Would like to know the approximate size of any rupture failure locations.

- Benefits - Safety, Operational, Economic, D\&D, or other benefits: Improved AM strategies; Improved simulations for training.

- Use/Motivation - Tie to specific use (code models, maintenance, operations, accident management, etc.) and timeframe when needed:

- Code assessments and validation of current structural yielding modeling used in codes

- Possible model improvements.

- Methods/Tools Needed to Collect Information or Data:

- Visual inspection

- Roadmap Timeframe - Near-term and/or later; Tie to specific inspections planned for 1F1, 1F2 and 1F3: Near-term and/or later.

- Preparatory or Follow-on Research/Supporting Information (beyond what is obtained from 1F examinations) None. 
Table C-18. Detailed information need for RPV-4 and RPV-5

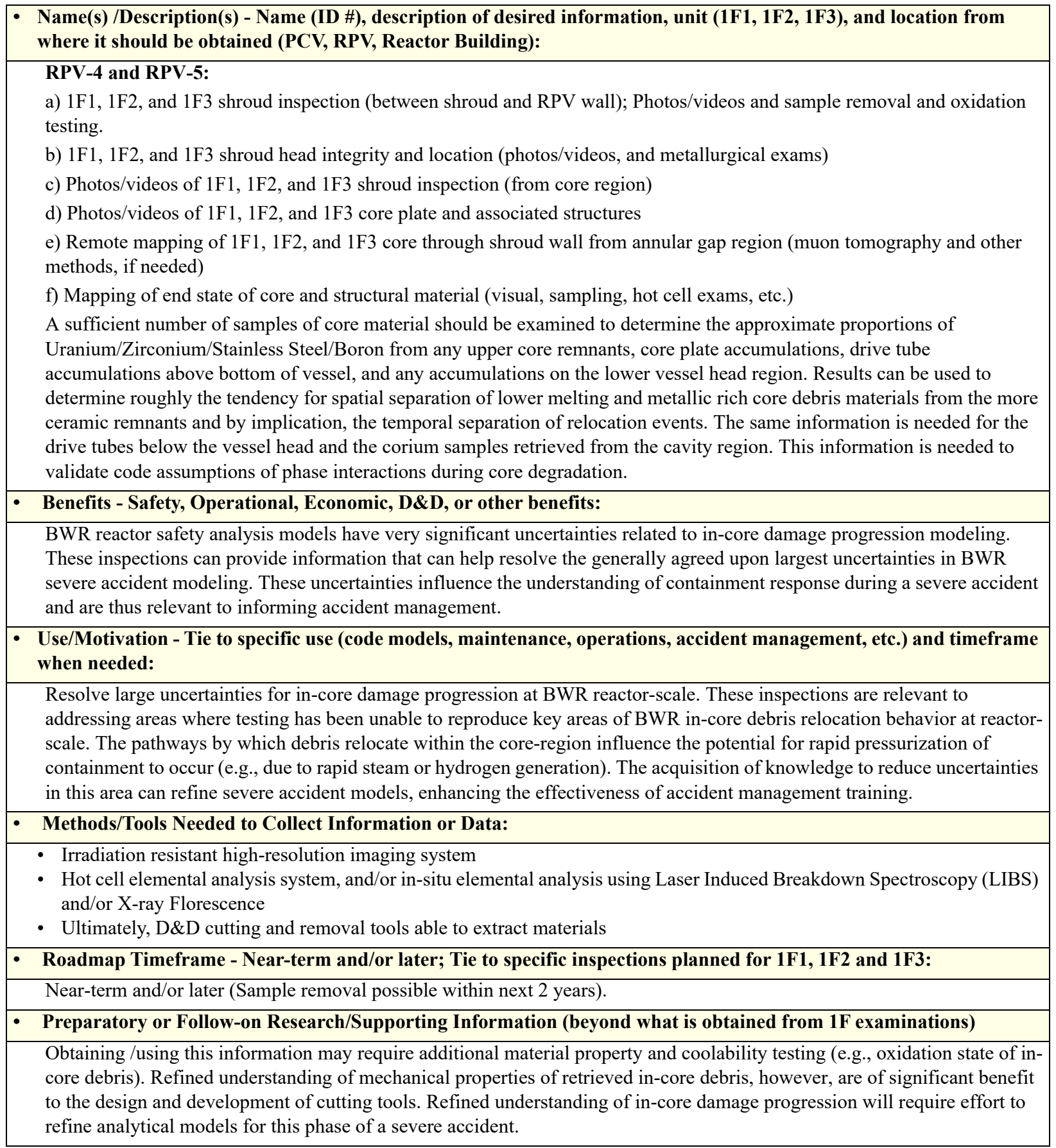


ANL-18/24 


\section{APPENDIX D. Roadmap Phase 2 Activities}

As discussed in Section 2.3, This appendix contains selected figures from the 2017 Strategic Plan.[106] These figures were selected because they provide additional information of special interest to the U.S. Forensics Effort.

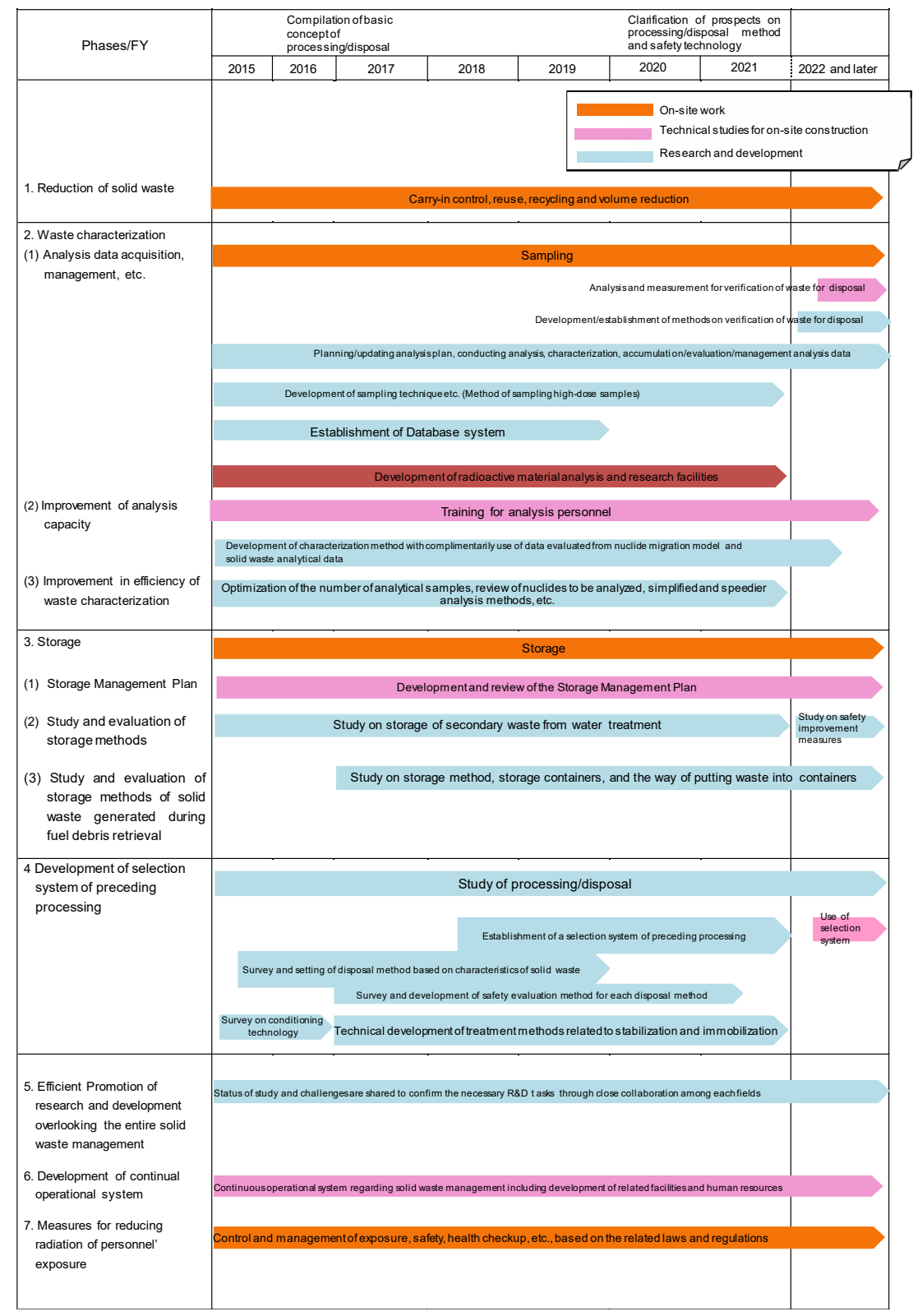

Figure D-1. Near-term measures and R\&D plan for waste management. (Courtesy of NDF [106]) 


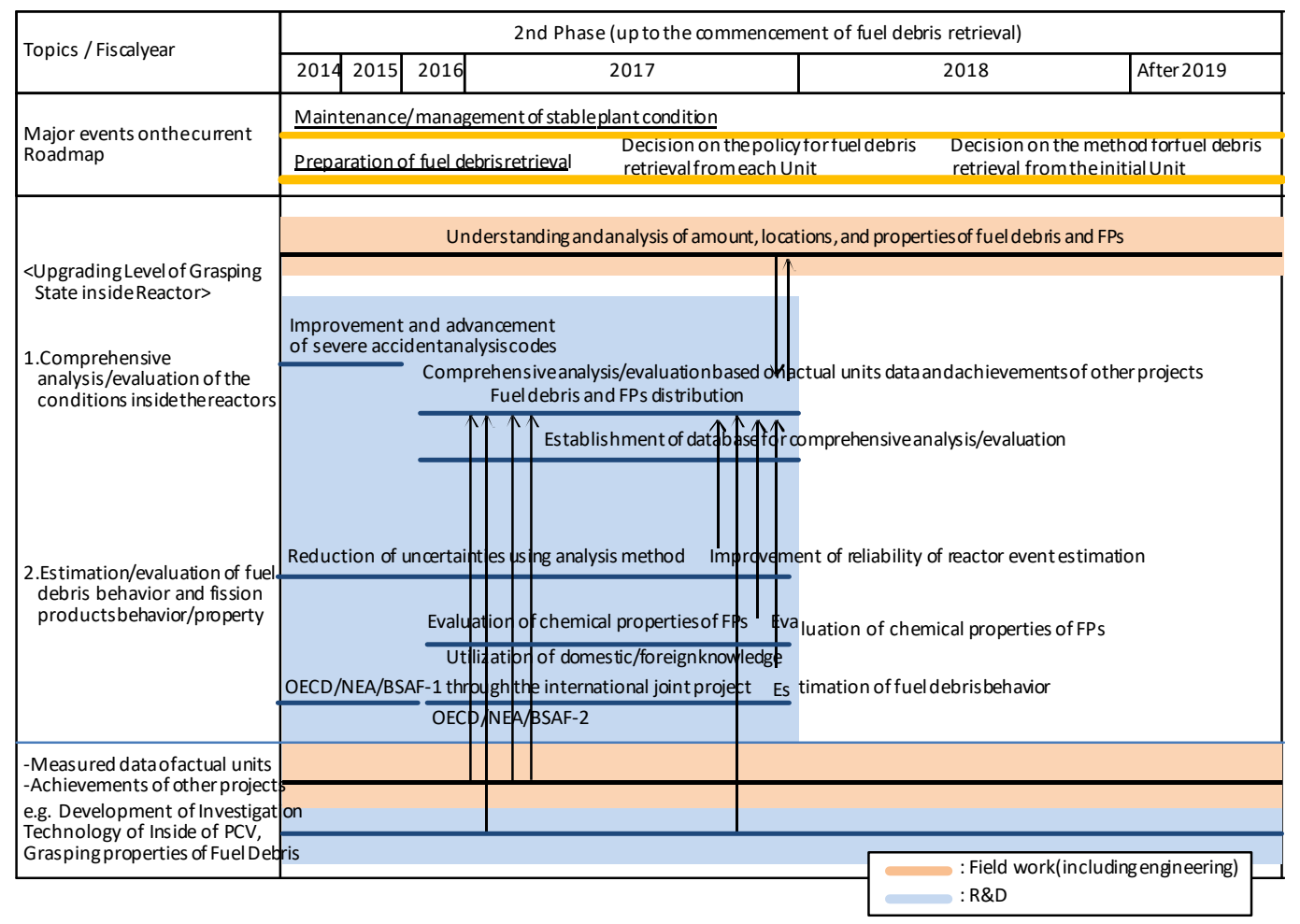

Figure D-2. Processes to improve understanding of conditions within each reactor. (Courtesy of NDF [106])

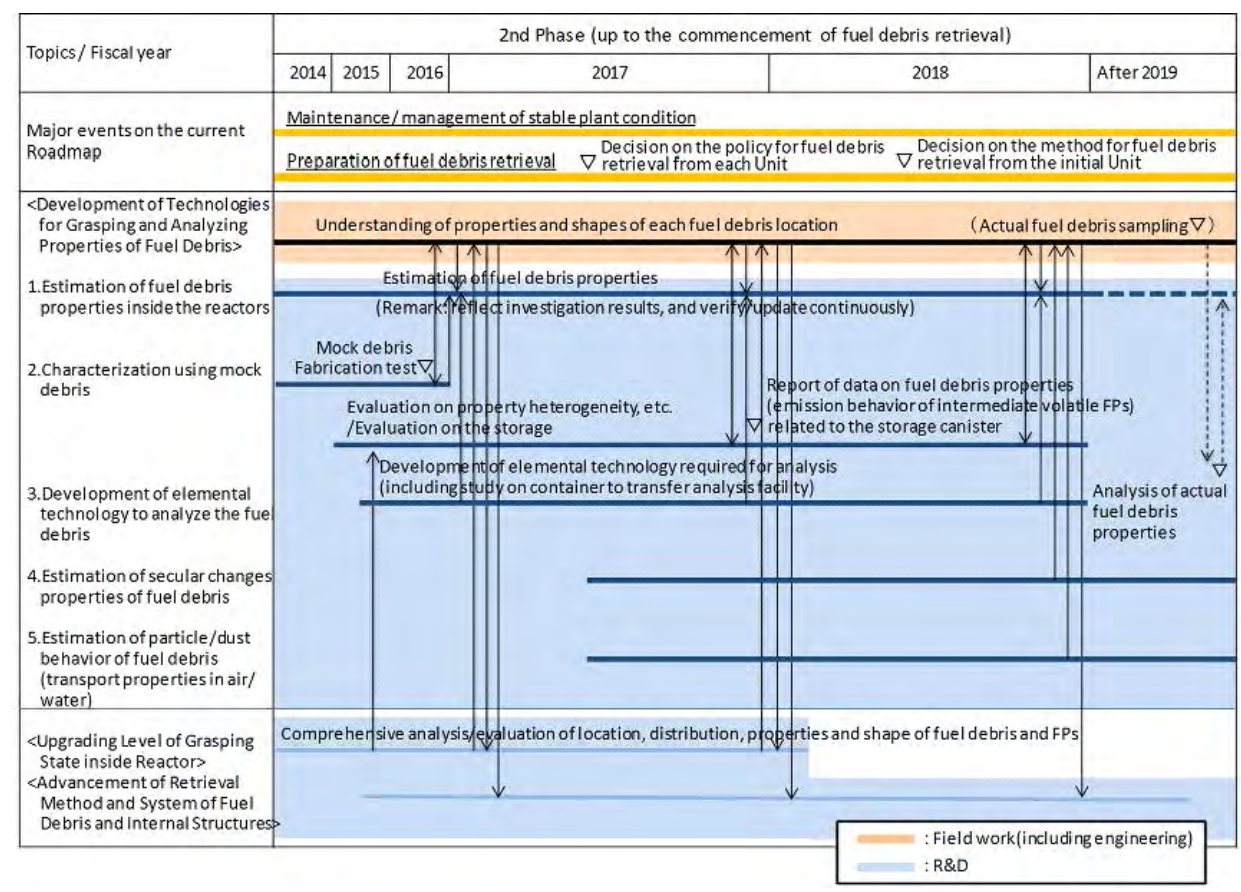

Figure D-3. Processes for debris retrieval and characterization technology development. (Courtesy of NDF [106]) 


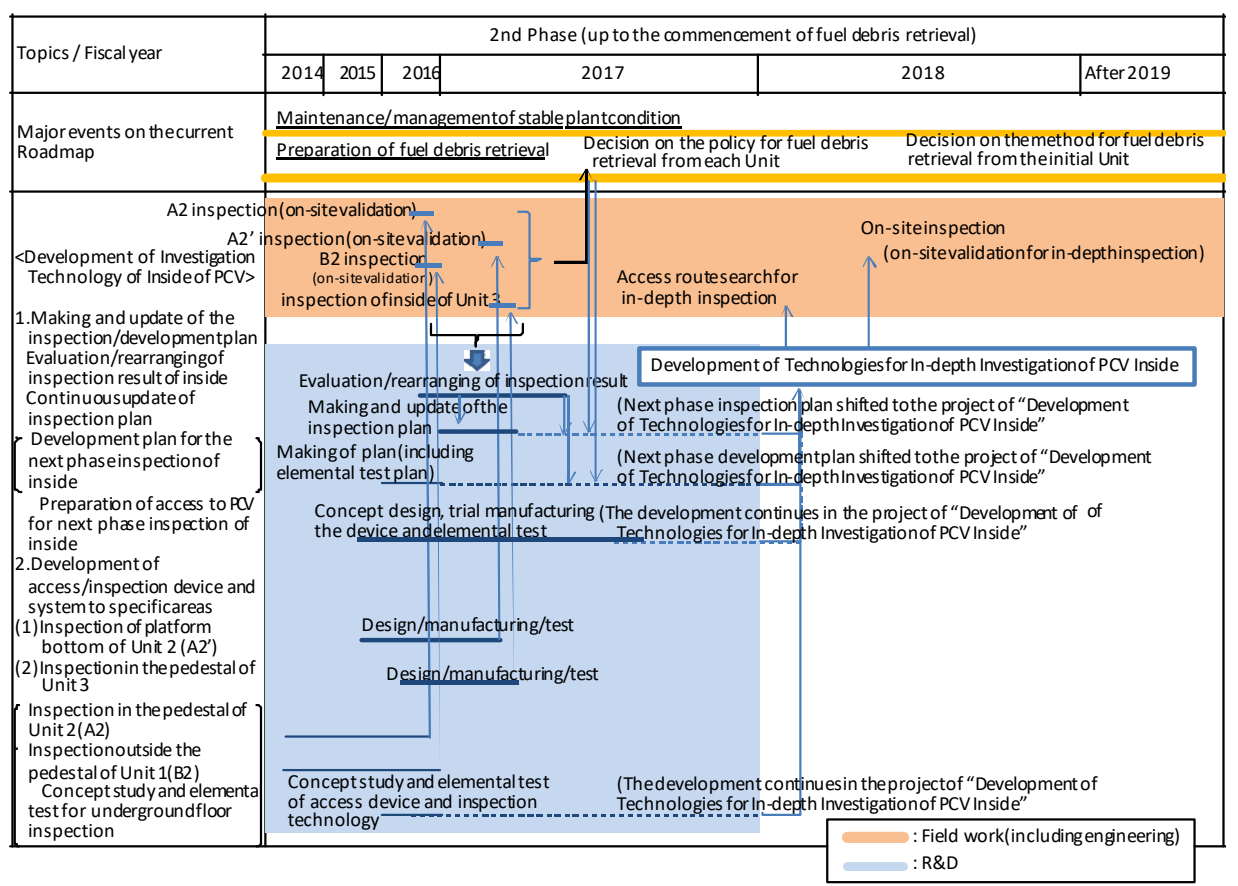

Figure D-4. Processes for developing technologies for investigation inside the PCV. (Courtesy of NDF [106])

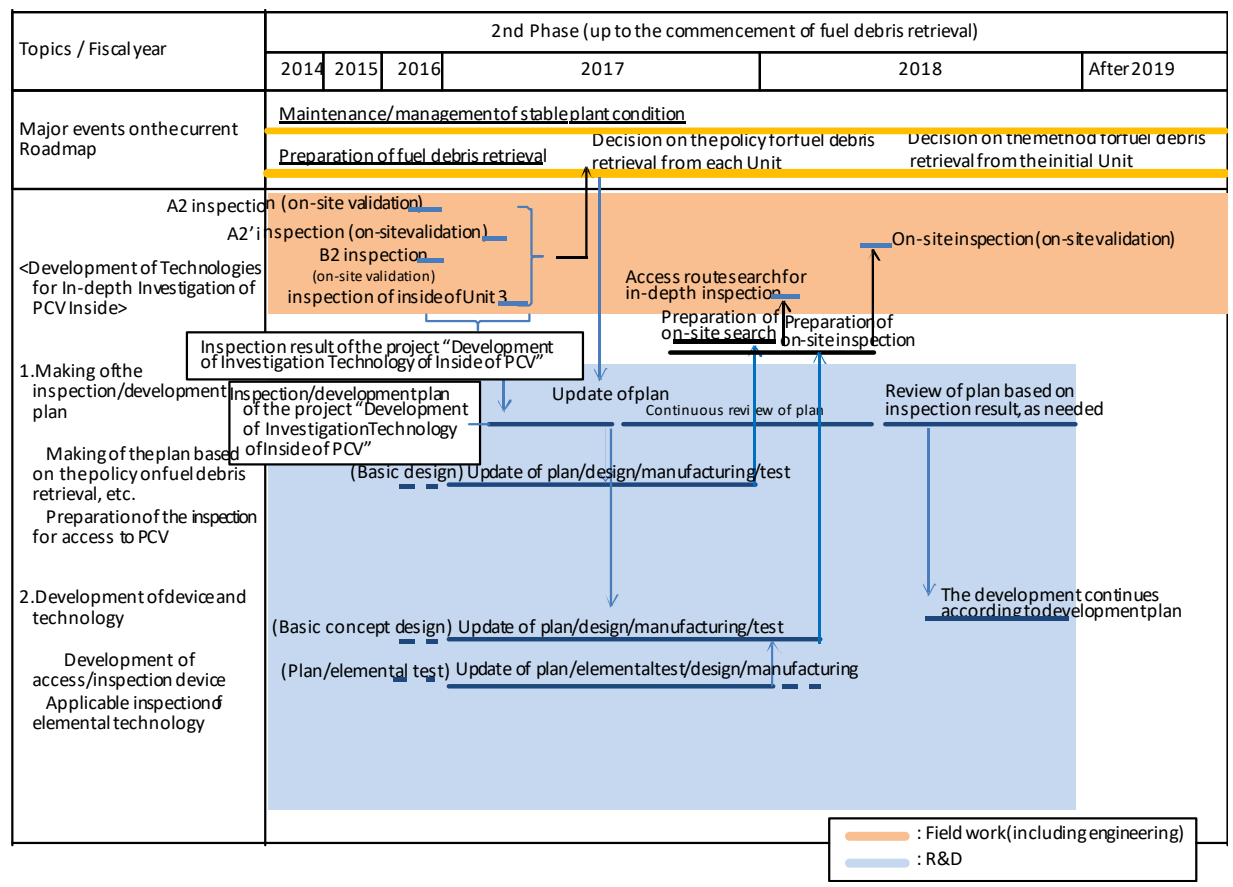

Figure D-5. Processes for developing technologies for in-depth investigation inside the PCV. (Courtesy of NDF [106]) 


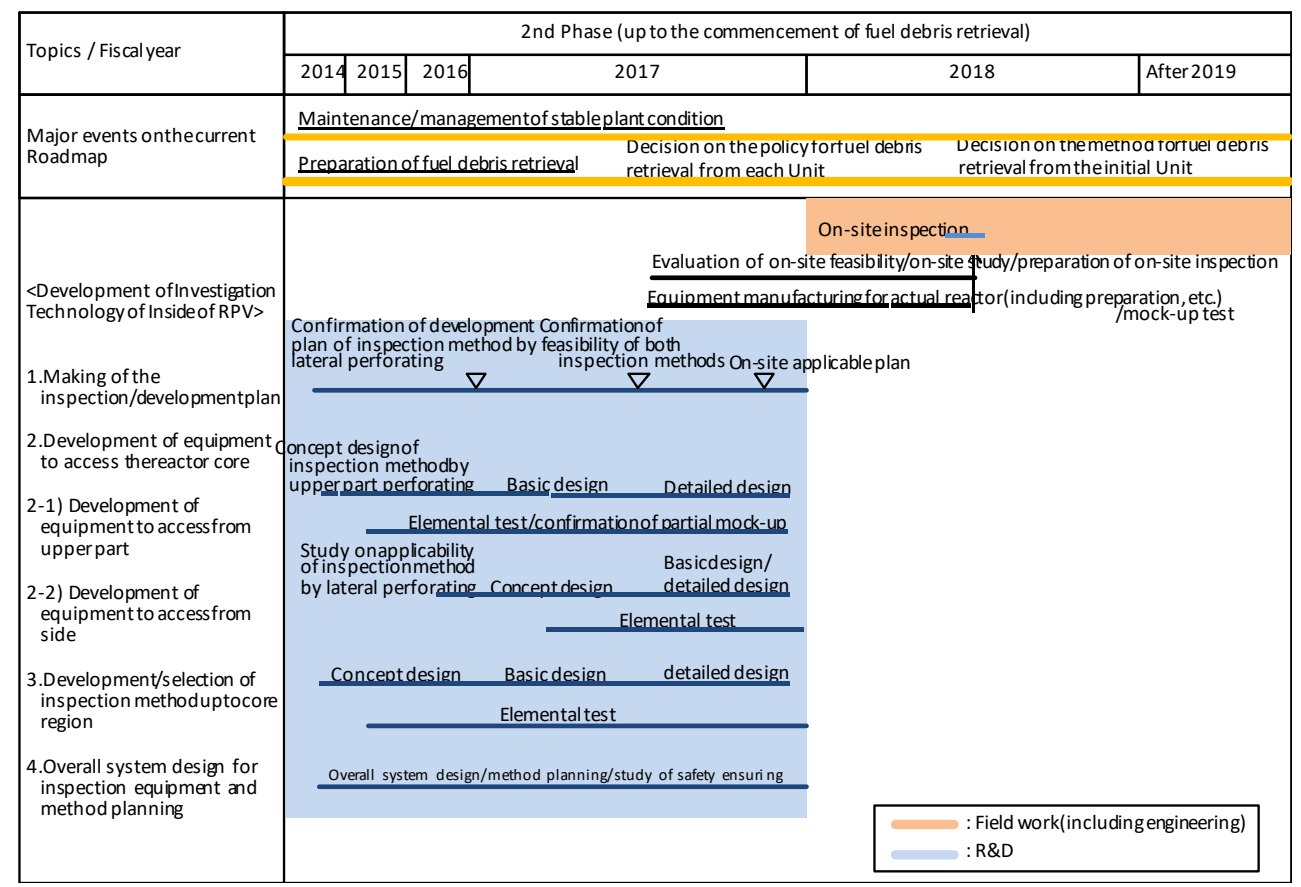

Figure D-6. Processes for developing technologies for investigation inside the RPV. (Courtesy of NDF [106])

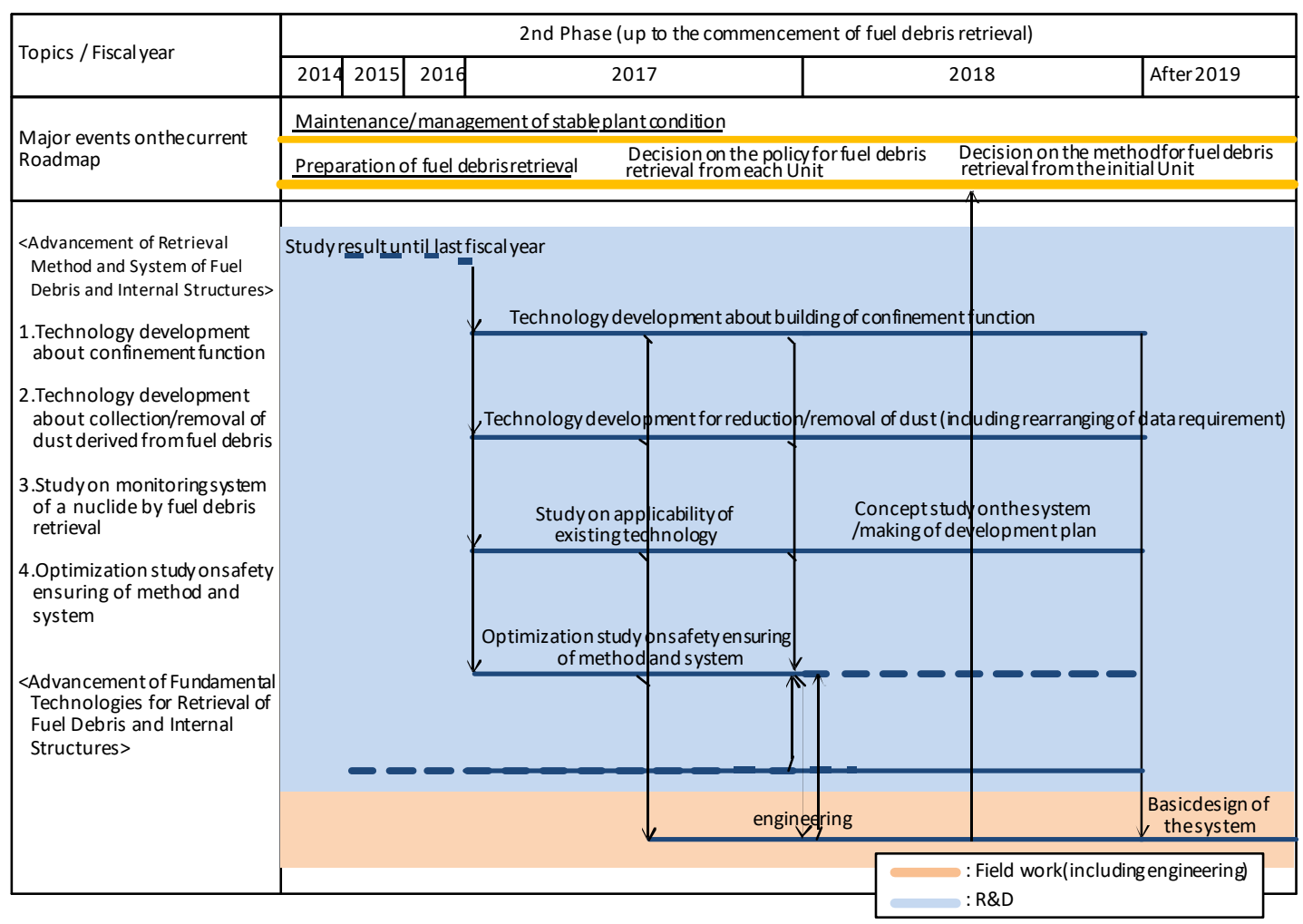

Figure D-7. Processes for advancing debris and internal structure retrieval technologies. (Courtesy of NDF [106]) 


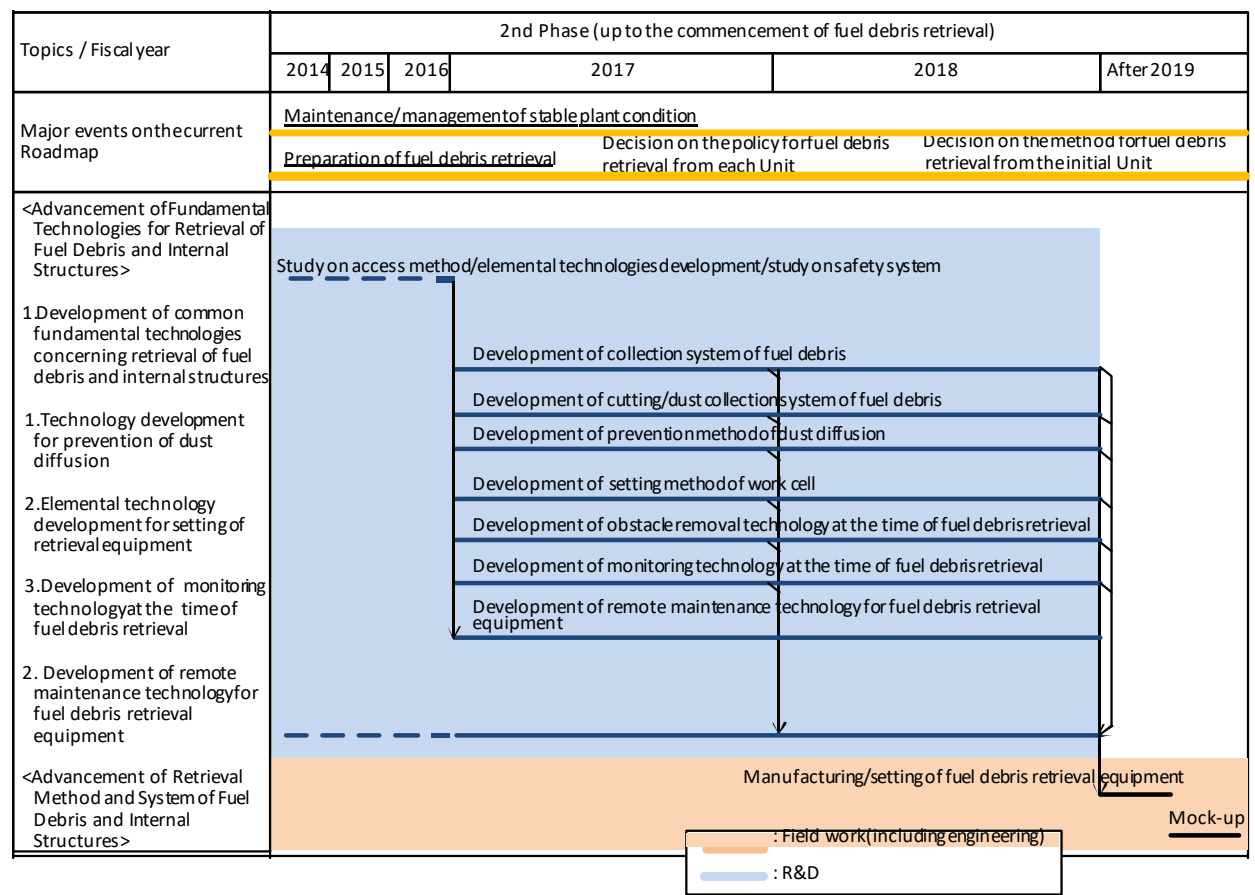

Figure D-8. Processes for advancing fundamental debris and internal structure retrieval technologies (Courtesy of NDF [106])

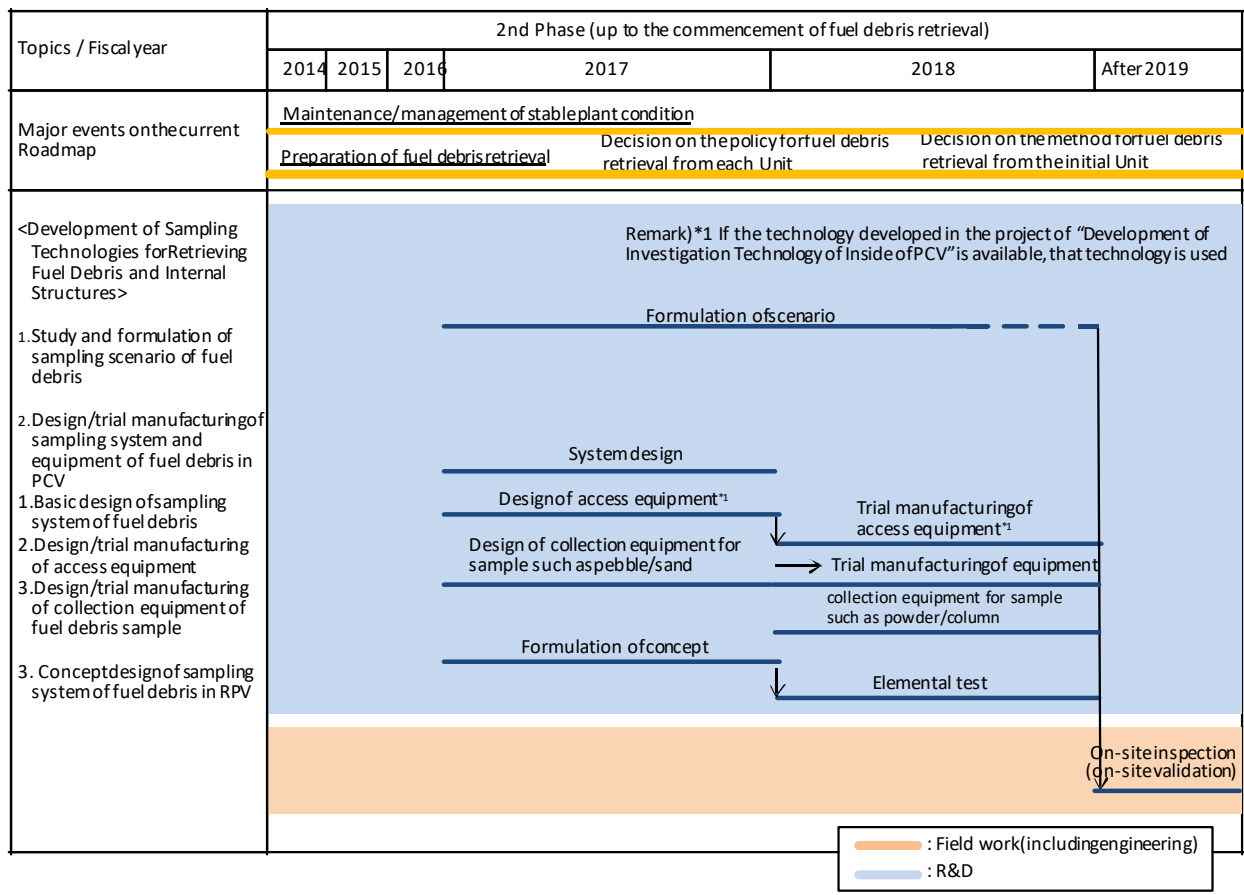

Figure D-9. Processes for developing sampling technologies for retrieving debris and internal structures (Courtesy of NDF [106]) 


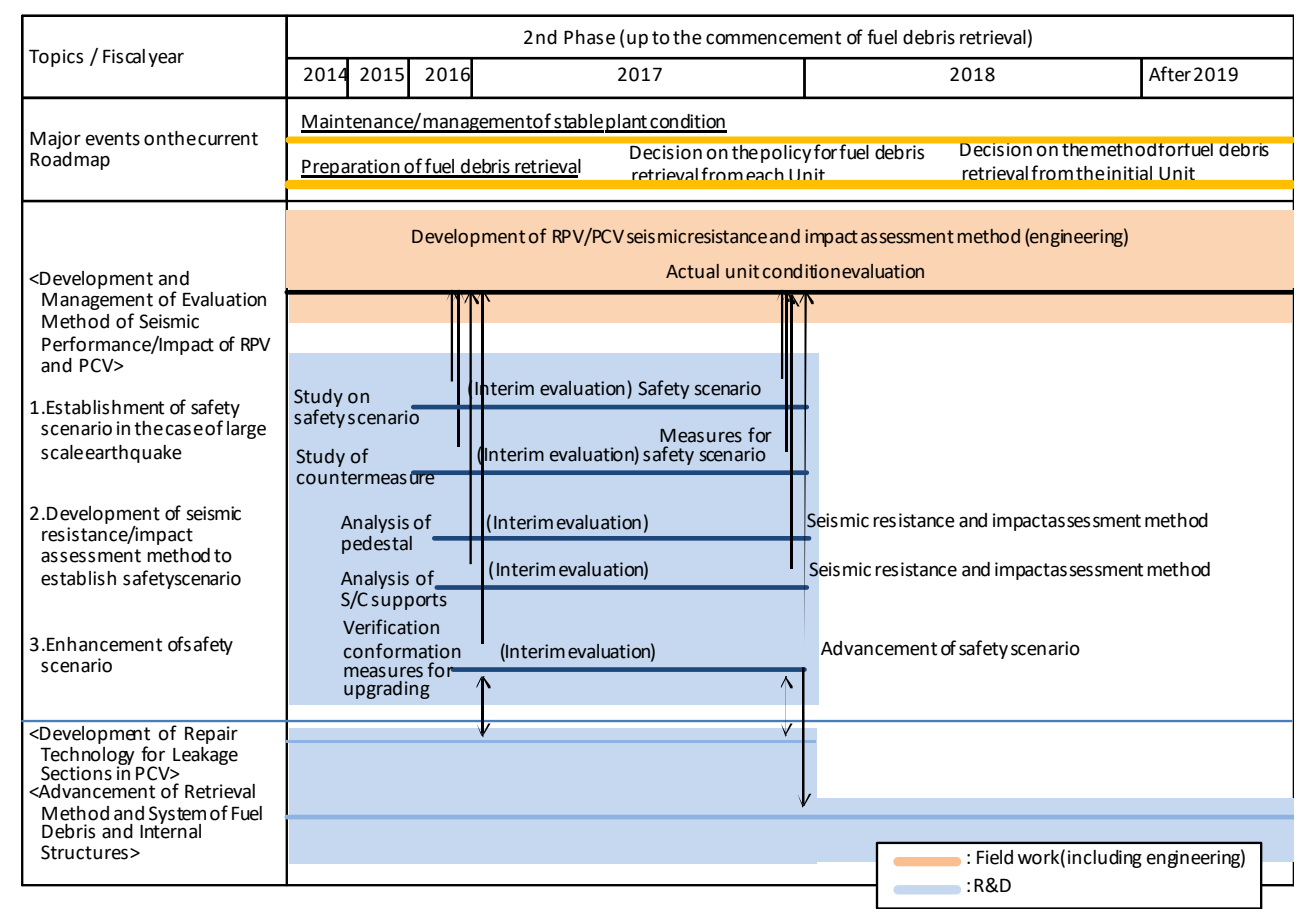

Figure D-10. Processes for developing methods for evaluating RPV and PCV seismic performance. (Courtesy of NDF [106])

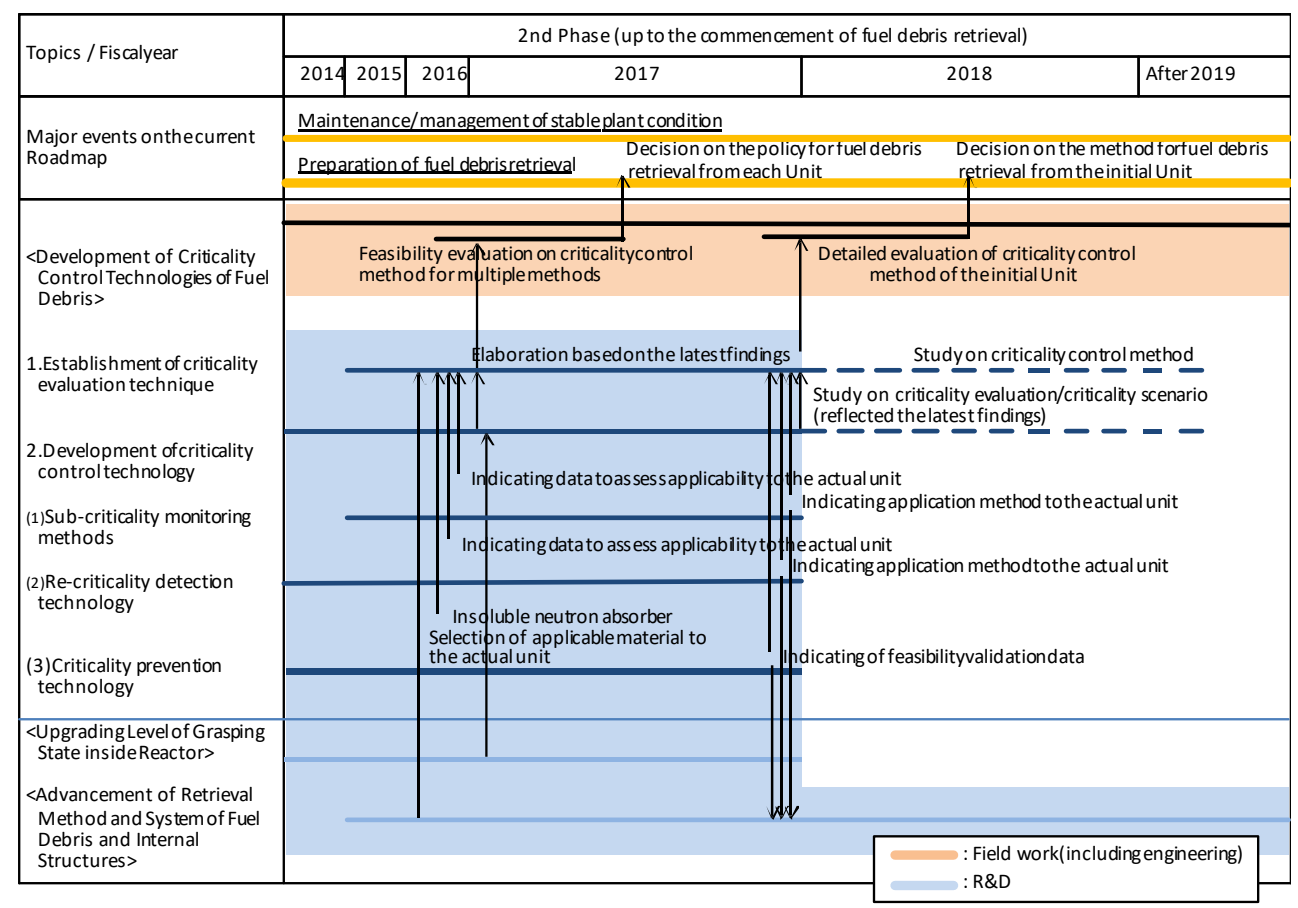

Figure D-11. Processes for developing criticality control technologies. (Courtesy of NDF [106]) 


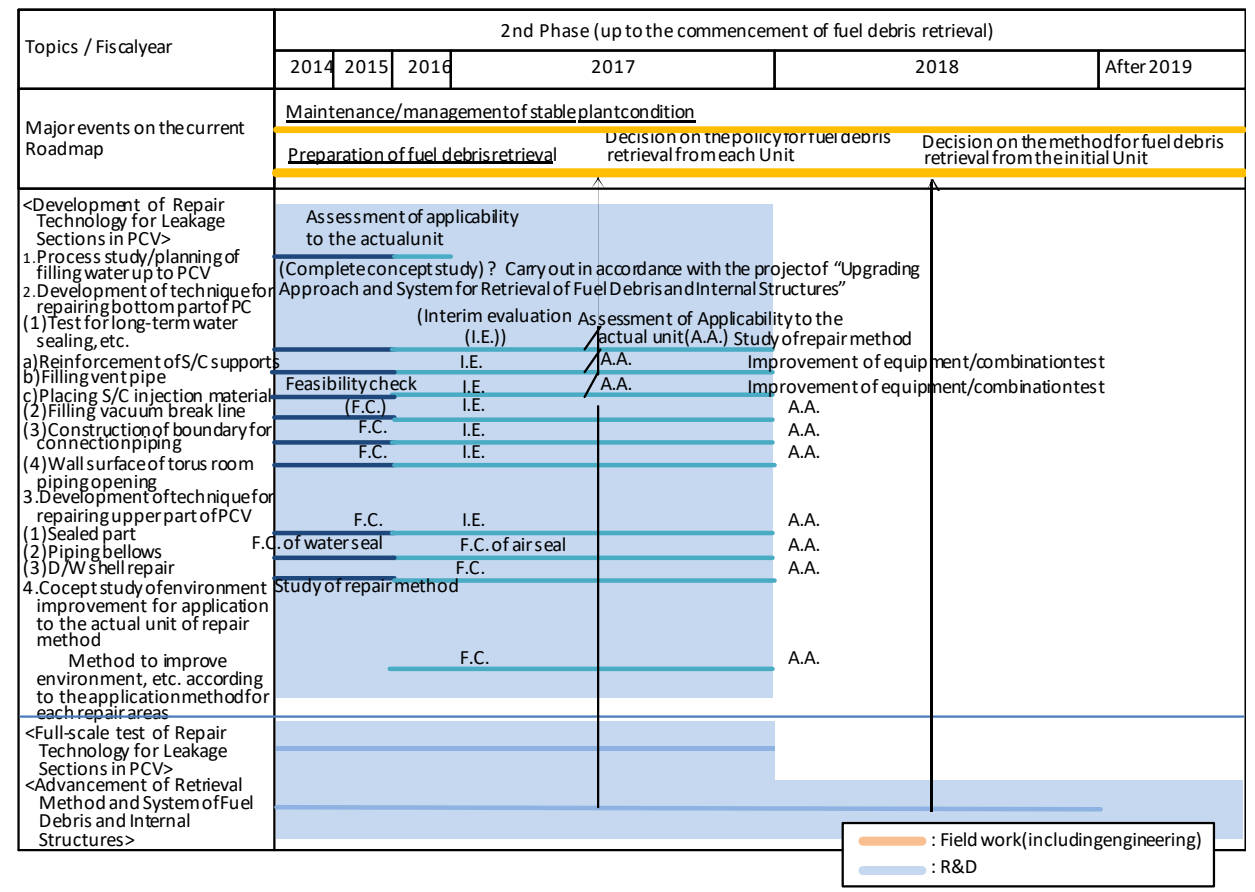

Figure D-12. Processes for developing technologies to repair leakage sections in PCV. (Courtesy of NDF [106])

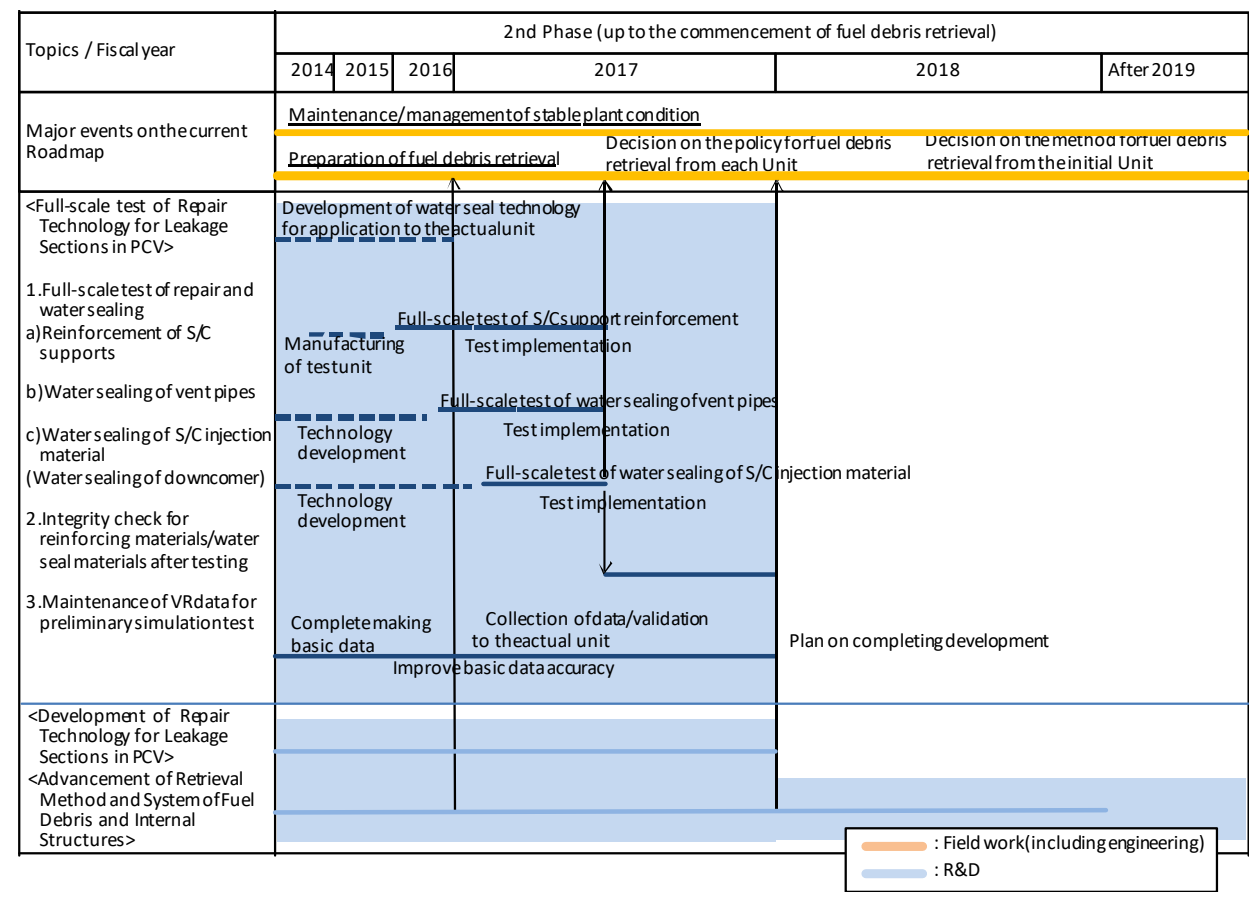

Figure D-13. Processes for full-scale test of PCV leakage repair technologies. (Courtesy of NDF [106]) 


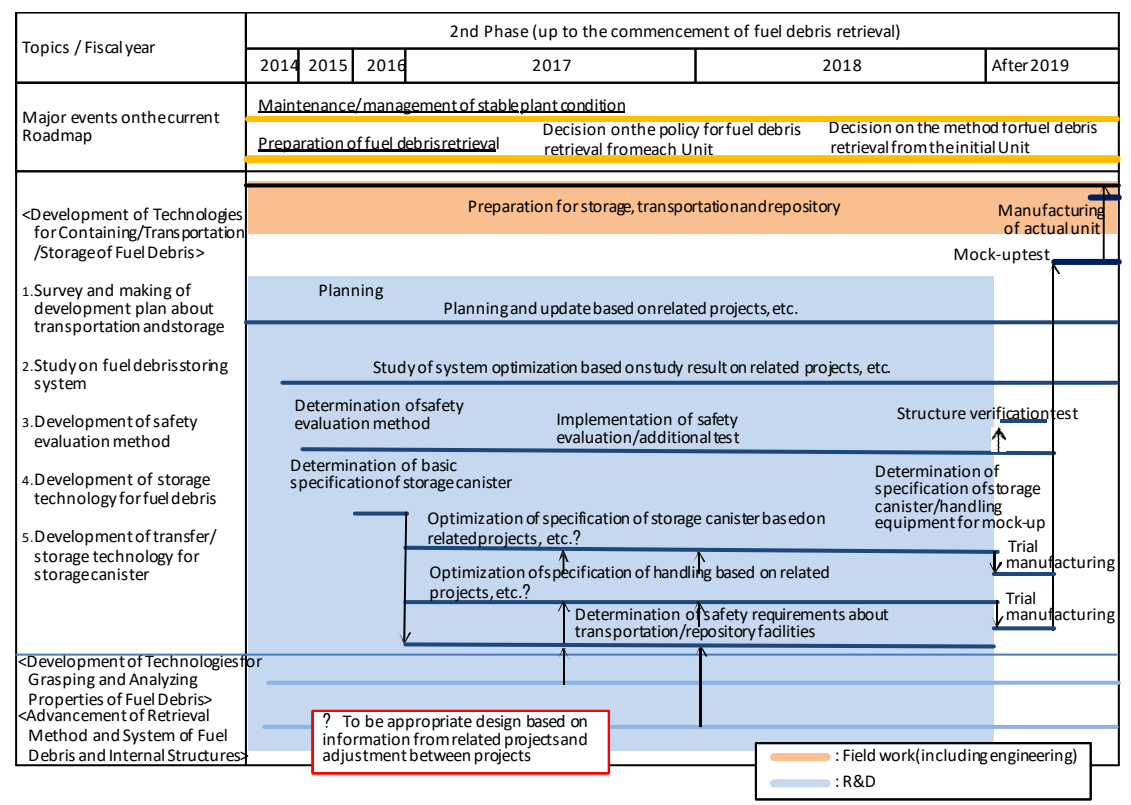

Figure D-14. Processes for developing technologies for containing, transporting, and storing fuel debris. (Courtesy of NDF [106])

\begin{tabular}{|c|c|c|c|c|c|c|}
\hline \multirow{2}{*}{ Topics / Fiscal year } & \multicolumn{6}{|c|}{ 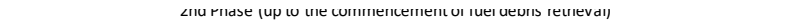 } \\
\hline & 2014 & 2015 & 2016 & 2017 & 2018 & After 2019 \\
\hline $\begin{array}{l}\text { Major events on the current } \\
\text { Roadmap }\end{array}$ & \multicolumn{5}{|c|}{$\begin{array}{l}\text { Establishment of basic concept of } \\
\text { processing/disposal for solid radioactive wastes }\end{array}$} & $\begin{array}{l}\text { for processing } \\
\text { and the safety }\end{array}$ \\
\hline $\begin{array}{l}\text { Roadmap } \\
\text { <Research and Development of } \\
\text { Processing and Disposal of Solid } \\
\text { Waste> } \\
? \text { ?.Characterization }\end{array}$ & \multicolumn{3}{|c|}{$\begin{array}{l}\text { Preparation of sampling } \\
\text { of rubble, ALPS, soil, } \\
\text { incineration ash and } \\
\text { high dose sample, and } \\
\text { exhibition of data }\end{array}$} & \multicolumn{2}{|c|}{$\begin{array}{l}\text { Efficiency of sampling/analysis method of rubble, ALPS, soil, } \\
\text { incineration ash, sample in R/B and high dose sample, and } \\
\text { establishment of database }\end{array}$} & $\begin{array}{l}\text { Response to } \\
\text { progress of } \\
\text { sampling/analysis }\end{array}$ \\
\hline $\begin{array}{l}\text { analysis data } \\
\text { 2.Accuracy improvement of } \\
\text { analytic evaluation method }\end{array}$ & \multicolumn{3}{|c|}{$\begin{array}{l}\text { Development of evaluation } \\
\text { method for secondary } \\
\text { water treatment waste, } \\
\text { rubble, trees and soil } \\
\end{array}$} & \multicolumn{2}{|c|}{$\begin{array}{l}\text { Accuracy improvement of analytic inventory evaluation } \\
\text { reflecting the variation of analysis result }\end{array}$} & $\begin{array}{l}\text { Upgrading of } \\
\text { evaluation method }\end{array}$ \\
\hline $\begin{array}{l}\text { 3.Comprehensive report of } \\
\text { inventory evaluation }\end{array}$ & \multicolumn{3}{|c|}{$\begin{array}{l}\text { Making/update of } \\
\text { analysis plan }\end{array}$} & \multicolumn{2}{|c|}{$\begin{array}{l}\text { Comprehensive evaluation of the estimate of analysis data and radioactivity } \\
\text { inventory/estimation of inventory/confirmation of updateflow }\end{array}$} & \multirow{2}{*}{$\begin{array}{l}\text { Preparation of } \\
\text { analysis evaluation } \\
\text { of influence }\end{array}$} \\
\hline $\begin{array}{l}\text { 4.Response to disposalinfluence } \\
\text { material, etc. }\end{array}$ & \multicolumn{5}{|c|}{$\begin{array}{l}\text { Rearranging of the concept about temporary acceptance density } \\
\text { concerning management before the disposal and disposal facilities }\end{array}$} & \\
\hline \multicolumn{7}{|l|}{$\begin{array}{l}\text { ?. Management before the } \\
\text { dispesal }\end{array}$} \\
\hline $\begin{array}{l}\text { 1.Applicability evaluation of } \\
\text { solidification technology suitable } \\
\text { for character of solid waste }\end{array}$ & \multicolumn{3}{|c|}{$\begin{array}{l}\text { Technology survey/test/makir } \\
\text { ff catalogue /presentation of } \\
\text { candidate technology }\end{array}$} & \multicolumn{2}{|c|}{$\begin{array}{l}\text { Survey and evaluation of applicability/performance test } \\
\text { /basic test about influence of radioactivity and heat }\end{array}$} & $\begin{array}{l}\text { performance test } \\
\text { and evaluation }\end{array}$ \\
\hline \multirow{3}{*}{$\begin{array}{l}\text { 2.Study/evaluation on storage } \\
\text { /management method suitable } \\
\text { for character of solid waste } \\
\text { (1)Studyon storage measures of } \\
\text { high dose waste } \\
\text { (2) Stabilizingtreatment } \\
\text { technology of secondary water } \\
\text { treatment waste }\end{array}$} & \multicolumn{3}{|c|}{$\begin{array}{l}\text { Soundness evaluation abou } \\
\text { storage of Cs adsorption } \\
\text { tower, etc./study and } \\
\text { presentation of measures }\end{array}$} & $\begin{array}{l}\text { out Study and presentation about reductio } \\
\text { outbreak and requirements of vent, } \\
\text { outbreak/study on storage method } \\
\text { the time of fuel debris retrieval }\end{array}$ & $\begin{array}{l}\text { measures of hydrogen } \\
\text { tc. at the time of hydrogen } \\
\text { f waste such as rubble at }\end{array}$ & $\begin{array}{l}\text { Study on the } \\
\text { evaluation/study } \\
\text { on measures } \\
\text { based onon-site }\end{array}$ \\
\hline & \multicolumn{3}{|c|}{$\begin{array}{l}\text { Study and selection of } \\
\text { stabilization technology of } \\
\text { ALPS pretreatment slurry }\end{array}$} & \multicolumn{2}{|c|}{$\begin{array}{l}\text { Applicability evaluation of stabilization technology of waste sludge, } \\
\text { etc. and performance test }\end{array}$} & $\begin{array}{l}\text { based on on-site } \\
\text { condition } \\
\end{array}$ \\
\hline & \multirow{2}{*}{\multicolumn{3}{|c|}{$\begin{array}{l}\text { Study ofdisposal concept } \\
\text { and safety evaluation } \\
\text { method in the country } \\
\text { existing }\end{array}$}} & \multicolumn{3}{|c|}{$\begin{array}{l}\text { Survey/study on pollution measurement } \\
\text { and evaluation method for reduction of Study of the } \\
\text { amounaluation tof waste. }\end{array}$} \\
\hline $\begin{array}{l}\text { ?. Studyon disposal concept and } \\
\begin{array}{l}\text { safety evaluation method } \\
\text { suitable for solid waste character }\end{array}\end{array}$ & & & & $\begin{array}{l}\text { Survey about disposal method at home } \\
\text { and abroad }\end{array}$ & $\begin{array}{l}\text { Study on disposal concept and } s \\
\text { safety evaluation scenario }\end{array}$ & $\begin{array}{l}\text { Study on disposal } \\
\text { concept and } \\
\text { safety evaluation } \\
\text { model, etc. }\end{array}$ \\
\hline \multirow[t]{2}{*}{$\begin{array}{l}\text { ?. Integrating of R\&D results } \\
\text { Study on waste stream }\end{array}$} & \multicolumn{3}{|c|}{$\begin{array}{l}\text { Making of draft plan } \\
\text { /reflection of result } \\
\text { /review }\end{array}$} & \multicolumn{2}{|c|}{ Comprehensive evaluation of progress/adjustment/problem of R\&D } & $\begin{array}{l}\text { Evaluation based } \\
\text { on progress of } \\
\text { R\&D }\end{array}$ \\
\hline & & & & & $\begin{array}{l}\text { : Field work(includinge } \\
\text { : R\&D }\end{array}$ & gengineering) \\
\hline
\end{tabular}

Figure D-15. Processes for R\&D of processing and storage of solid waste. (Courtesy of NDF [106]) 


\section{APPENDIX E. AREA 1 - COMPONENT/SYSTEM PERFORMANCE PREVIOUSLY REPORTED FINDINGS}

This appendix tabulates previous findings by TEPCO Holdings related to Area 1 (Component/System Performance) for the affected reactors at Fukushima Daiichi. Although the majority of this information was previously reported for Area 1 (Component/System Performance) in the U.S. Forensics Effort FY2017 report,[3] some minor updates and additional references are included in this appendix.

\section{E.1. Examinations Outside of the Primary Containment}

A wide range of equipment resides outside of containment that supports plant operation and accident response. In addition, the spent fuel pools and other key facilities (i.e., common spent fuel storage building) also reside onsite. Being outside of containment and generally accessible, several inspections have been performed.

An aerial inspection, intended for radiation inspections, of the shared vent stack ( 111 m tall) for 1F1 and 1F2 was conducted in 2016.[227] An object, posited to be a beam, was found located inside the stack approximately $10-20 \mathrm{~m}$ below the top of the stack. No other abnormalities were noted. A previous inspection of the outside of the stack in 2013 noted rust and fractures in some of the structures.[228] Subsequent inspections and analyses provided confidence in the structure's capability to withstand additional seismic activity.[229, 230, 231]

The main turbine of 1F4 was inspected.[232]. Examinations found evidence of cracking of the blades, which was attributed to normal operation, and contact traces between the moving and stationary blades and between the oil thrower bearing and the rotor, which was attributed to the earthquake. The damage was reported as minimal.

Inspections of the standby gas treatment systems (SGTS) have also been performed. Five valves on the 1F3 SGTS were inspected. All of the inspected valves were found to be in their expected positions for loss of valve power.[233] Based on the investigation of the radiation dose around the rupture disk of 1F2, the rupture disk is not thought to have opened.[234] The measured doses and locations of the 1F2 SGTS filters suggest there was backflow from 1F1 to 1F2 through the SGTSs and interconnected piping.[234] In addition, the measured dose and locations of the 1F4 SGTS filters suggest there was backflow from 1F3 to 1F4 through the SGTSs and interconnected piping.[235] Gravity dampers installed on the down stream side of the SGTS filters apparently did not prevent this backflow.

Of special interest in U.S. expert panel discussion was the endstate of the 1F1 drywell head shield plug, the reactor building closed cooling water system, the spent fuel pools and shared spent fuel storage building, and the 1F3 and 1F4 spent fuel pool gate.

\section{E.1.1. 1F1 Drywell Head Shield Plug Relocation}

Thermal images taken in October of 2011 of the top of the 1F1 shield plugs, located on the refueling floor above the PCV head, indicated elevated temperatures.[236] Inspection of the 1F1 shield plugs in 2016 and 2017 [237,192] found the top, middle, and bottom layers to be displaced as well as deformed 
[238]. In addition, higher dose rates were measured in the shield plug vicinity (see Section 4). Sections of the bottom layer are suspected to be resting on the PCV drywell head. The elevated temperatures and doses, as well as the observed shield plug displacement, support the possibility of drywell head leakage during the accident. This is generally consistent with simulations that predict drywell head flange leaked during the accident. $[55,56]$ The following is an extended analysis of the potential causes for the displacement of the 1F1 shield plugs.

In [237], TEPCO Holdings reported that the drywell head shield plugs in $1 \mathrm{~F} 1$ were lifted and physically displaced during the accident (see Figure E-1). For this to occur, a substantial pressure difference would have likely developed between the refueling floor and the space below the shield plugs. One important question to address is, "What is the pressure force required to lift the plugs?". From Figure E-1, the combined shield plug mass is evaluated as $\sim 520 \mathrm{MT}$ and the cross-sectional area is $\sim 110 \mathrm{~m}^{2}$. The required $\Delta \mathrm{P}$ to lift the plug is thus estimated as $\sim 47 \mathrm{kPa}(\sim 7 \mathrm{psi})$. Possible methods by which this pressure difference could have developed include (but are not necessarily limited to) the following:

- A high rate of gas production inside the PCV that caused the drywell head to lift and leak gas into the gap between the head and shield plugs, causing the gap to pressurize, or

- The hydrogen deflagration on the refueling floor that created a temporary sub-atmospheric condition above the shield plugs that is characteristic of an explosive event.

These two scenarios are examined for plausibility below.
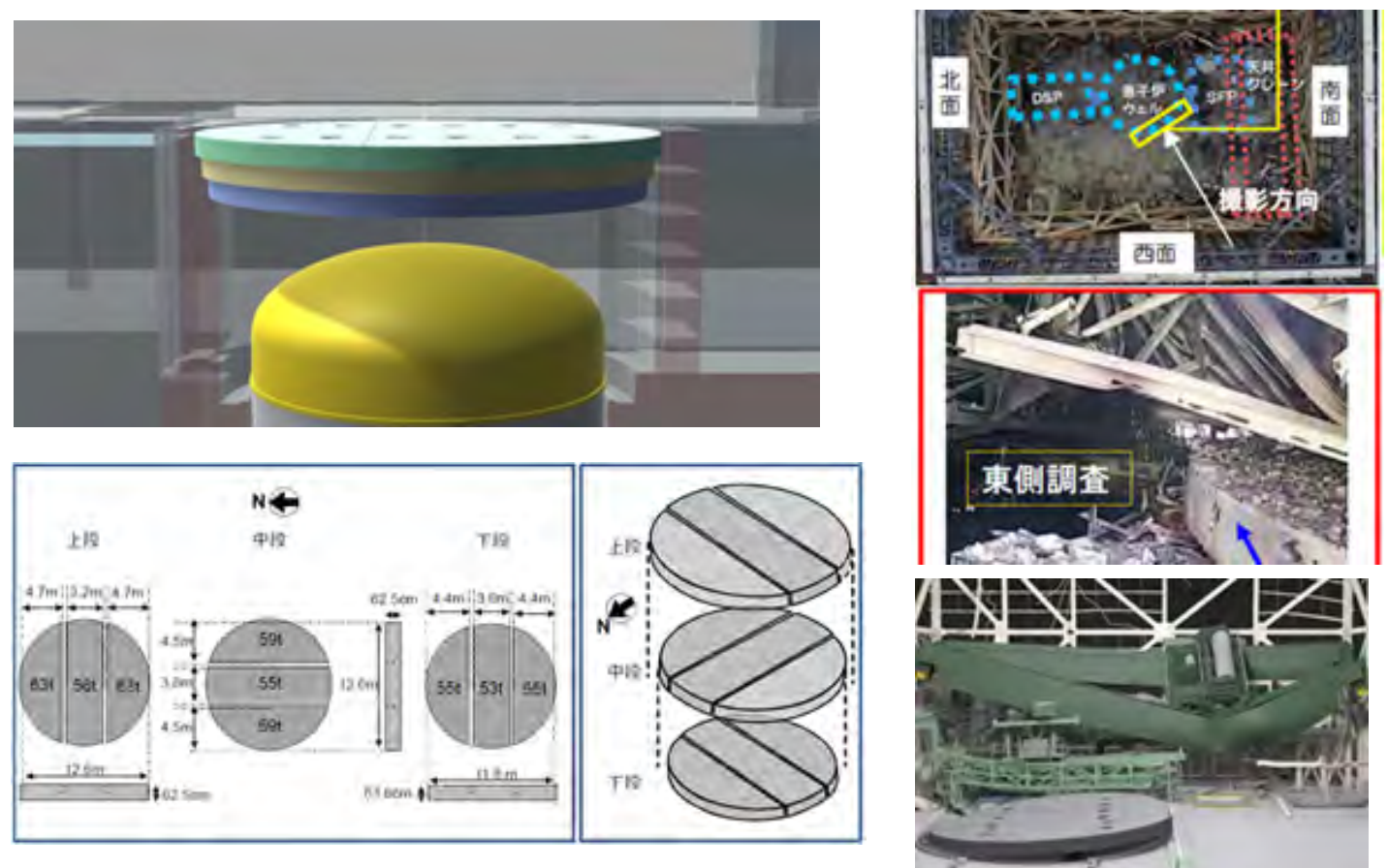

Figure E-1. Physical characteristics, photographs, and 3D images based on photographs showing the displacement of the 1F1 drywell head shield plugs. (Courtesy of TEPCO Holdings [237, 239])

\section{E.1.1.1. High Rate of Gas Production Inside PCV}

One possible source for rapid gas production is steam generated from rapid debris cooling. Aside from normal boiling heat transfer to debris spread over the pedestal and drywell floors, possible transient mech- 
anisms include: i) melt jet fragmentation during relocation through water on the drywell floor, and/or ii) rapid water ingress into the core debris in the sump coming from the sump drain line. Another possible source is non-condensible gas produced from MCCI, but calculations indicate that this source is not credible.*

As noted above, the pressure difference required to lift the shield plugs is estimated as $47 \mathrm{kPa}$ ( $7 \mathrm{psig}$ ). With a rough estimate of flow area, this $\Delta \mathrm{P}$ could be used to evaluate mass flowrates for comparison to other data. For instance, if a crack width of $\sim 6 \mathrm{~mm}(1 / 4 \mathrm{inch})$ is assumed around the $11.8 \mathrm{~m}$ diameter of the shield plug, the flow area would thus be $\sim 0.22 \mathrm{~m}^{2}$. Treating the opening as an orifice with a loss coefficient $(K)$ equal to 1 and assuming a pressure inside the gap between the drywell head and shield plugs of $100+47=147 \mathrm{kPa}$, then a steam flowrate of $\sim 63 \mathrm{~kg} / \mathrm{sec}\left(73 \mathrm{~m}^{3} / \mathrm{sec}\right)$ would be needed to produce the required lift force.

With respect to evaluating potential steam sources that could produce this type of flowrate, MAAP and MELCOR predict 10 and $55 \mathrm{~cm}$ water depths on the drywell floor, respectively, at the time of vessel failure.[240] This corresponds to 1.3 and $1.8 \mathrm{~m}$ water depths in the sumps, respectively, at the time of RPV breach since the sumps are $1.2 \mathrm{~m}$ deep. The estimated steam production rate needed to lift the plugs $(\sim 63 \mathrm{~kg} / \mathrm{sec})$ is similar to that estimated by MELTSPREAD3 [241] to be produced by melt jet fragmentation and quenching for MAAP and MELCOR pours into the sumps; see Figure E-2. However, the argument that jet fragmentation could have occurred in the sump(s) is not straightforward as the sumps are offcenter from the RPV in 1F1; see Figure E-3.
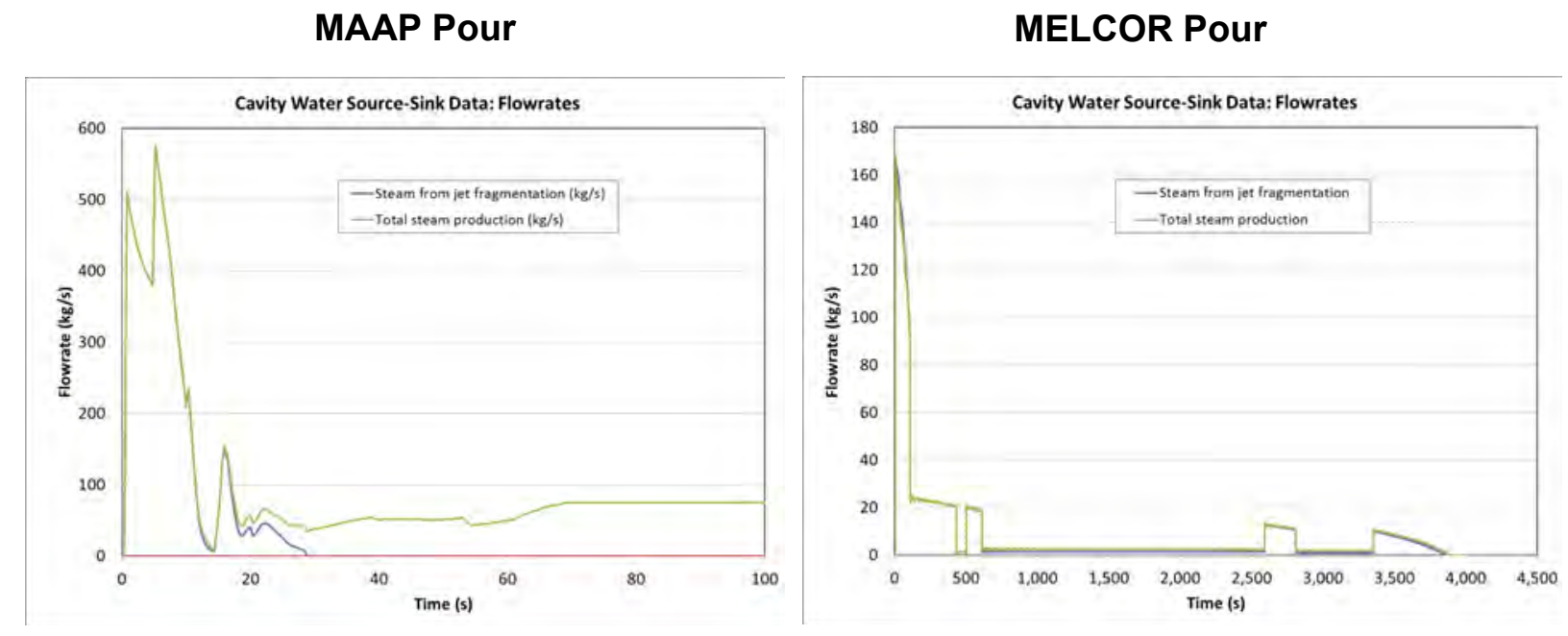

Figure E-2. Predicted steam production from melt jet fragmentation during relocation into the sumps for MAAP and MELCOR pour conditions. (Courtesy of ANL [241])

*. For example, at $5 \mathrm{MW}$ decay heat level and $50 \%$ up-down power split, then gas production from MCCI with siliceous concrete would be predominately $\mathrm{H}_{2}$ at a mass flowrate of $\sim 0.2 \mathrm{~kg} / \mathrm{s}$, or a volumetric flowrate of $\sim 0.3 \mathrm{~m}^{3} / \mathrm{s}$. This is far less than the required gas flowrate to lift the plug, as discussed. 


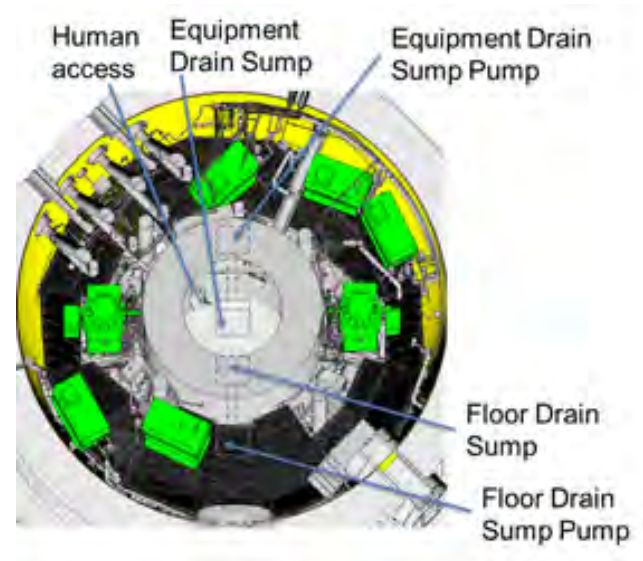

Figure E-3. Plan view of 1F1 showing sump locations in pedestal and drywell regions. (Courtesy of TEPCO Holdings [19])

Another possible steam source is rapid cooling of debris in the sump(s) by water ingress through the sump drain piping system. As noted later in this section, the Reactor Building Closed Cooling Water System (RBCCW or RCW) closed loop piping system that provides cooling to the sumps was found to be heavily contaminated, likely indicating breach by corium during the accident. The sump drains in the pedestal and drywell are plumbed together by interconnected piping. Thus, if water was present on the drywell floor at the time of vessel failure as MAAP and MELCOR predict, this water could have flowed back into the pedestal under gravity through the sump drain lines, leading to rapid steam formation by cooling of debris in the sumps. This overall concept has in fact been envisioned as a method to increase the coolability of core melt by providing a pathway to passively inject water from below.[242] In this concept, water injection nozzles are cast into concrete basemat at a recessed location, with the nozzles plumbed to a water source at an elevated location in the plant to provide a static water head. In the event of an accident, the tops of the nozzles are intended to fail by ablation as the melt front arrives, thereby opening a pathway for water to flow into the material under gravity and increase the cooling rate. This approach has been investigated through a series of reactor material tests [242] that focused on examining the effect of water head on the debris cooling rate. The results indicate that this cooling mechanism is very effective, even for very low water heads (e.g., $1 \mathrm{~m}$ or less). In fact, it was found that the injection nozzles $(2.5 \mathrm{~cm}$ or less in diameter or less in the tests) had to be orificed to limit the debris cooling rate to a level that would not disperse the melt due to the rapid steam generation from below. Thus, a second possible explanation for a steam source capable of lifting the drywell head and pressuring the gap between the head and the shielding plugs to the point that the plugs would be lifted is water ingress into relocated core debris through the sump drain lines. If this did occur, there could be some benefits for accident management depending upon melt pour conditions and the degree of spreading. Two examples include:

- Sump drains with access to a water source may provide a means for increasing the coolability of deep melt accumulations by bottom water injection that testing has shown to be very effective. Note that orificing is in fact beneficial to limit the debris cooling rate.

- For cases in which large debris accumulations form in the pedestal (as is predicted for MELCORtype pours, for instance), then sump drains may provide a way for injecting possibly unused water on the drywell floor into the debris via the sump drain lines. The same would be true for water injected via the drywell sprays, or water from core injection that flows over core debris and out the pedestal door onto the drywell floor. 


\section{E.1.1.2. Vacuum Condition Created by Hydrogen Deflagration}

As noted, a transient lift force would have been created on the shield plugs from the hydrogen deflagration on the 1F1 refueling floor due to the backdraft created by an event of this type. As concluded earlier, a net pressure difference of $\sim 47 \mathrm{kPa}$ (7 psig) would be able to lift the plugs given their geometry and weight. Thus, any pressure difference exceeding this value would be sufficient to cause the plugs to relocate. In fact, a detailed hydrogen deflagration analysis has been completed for 1F1.[186] Results indicate that the absolute pressure on the refueling floor would have fallen to $\sim 4 \mathrm{kPa}$ for $\sim 100 \mathrm{~ms}$. This information allows a rough estimate of the relocation behavior of the plugs to be developed by solving Newton's second law; the results are shown in Table E-1. The results indicate that the plugs likely 'jumped' because of the deflagration, but would not have been elevated to the point that the top plug $(63 \mathrm{~cm}$ thick) would have cleared the surface level of the refueling floor. This rough evaluation could be further refined if the actual pressure profile during the transient was known.

Table E-1. Rough estimate of the relocation behavior of the shield plugs induced by the hydrogen deflagration in $1 \mathrm{~F} 1$.

\begin{tabular}{|c|l|}
\hline Time (ms) & \multicolumn{1}{c|}{ Condition } \\
\hline 0 & $\begin{array}{l}\text { Upper surface of shield plugs suddenly subjected to a vacuum condition on refueling floor. The } \\
\text { pressure below the plugs is assumed to be atmospheric during the brief vacuum phase, resulting in } \\
\text { an upwards pressure difference of } \sim 100 \mathrm{kPa} .\end{array}$ \\
\hline 100 & $\begin{array}{l}\text { Vacuum condition ends and the pressure surrounding the plugs returns to atmospheric. Plugs have } \\
\text { risen } 6 \mathrm{~cm} \text { at this point and are moving upwards at velocity of } 1.2 \mathrm{~m} / \mathrm{sec} .\end{array}$ \\
\hline 220 & $\begin{array}{l}\text { Deaccelerating under the influence of gravity, the plugs reach a maximum displacement height of } \\
13 \mathrm{~cm} .\end{array}$ \\
\hline 380 & Falling under the force of gravity, the plugs reseat. \\
\hline
\end{tabular}

\section{E.1.2. Reactor Building Closed Cooling Water System}

The RCW system supplies cooling water to a range of equipment in the reactor building, containment, and other locations. In containment, it supplies water to cool the sumps, drywell coolers, and other equipment. A surge tank is located on the $4^{\text {th }}$ floor of the reactor building and has a vent to the reactor building airspace. A shaft for moving equipment is located next to the surge tank and spans multiple floors.

As noted in [41] and discussed in Section 4.3.1, elevated doses were measured in the 1F1 reactor building around the systems fed by the RCW. In particular, high dose rates were observed around the RCW heat exchangers. The possibility for failure of RCW piping in the drywell sumps and the flow of contaminated water into the RCW system was explored by TEPCO Holdings.[41] To summarize, a check valve would prevent backflow into the supply side of the sump coolers. However, if piping failure occurred, contaminated water could possibly flow into the downstream side of the coolers, through the RCW piping, and towards the vented surge tank. Upon lower containment pressures, the contaminated water could flow back towards the drywell following two paths. One path allows the water to flow through the RCW heat exchangers. This was presented as a possible cause for the high doses observed around the RCW heat exchangers and the RCW in general.

Additional observations are as follows. Based on illustrations of the system[41], the static head of water between the drywell sumps and the surge tank on the $4^{\text {th }}$ floor is approximately $0.26 \mathrm{MPa}$ (differen- 
tial). Comparing this pressure to the available drywell and wetwell data [243] for $1 \mathrm{~F} 1$, the containment pressure was sufficiently high for an extended period of time that was sufficient to push water into the RCW system (if failure of the sump cooler piping occurred and water was available), see Figure E-3. The pressure was also sufficiently high to possibly push water out of the surge tank. Based on images (see Figure E-5) from [244, 245], the surge tank appears intact; however, inspection of the tank and nearby piping has not been reported.

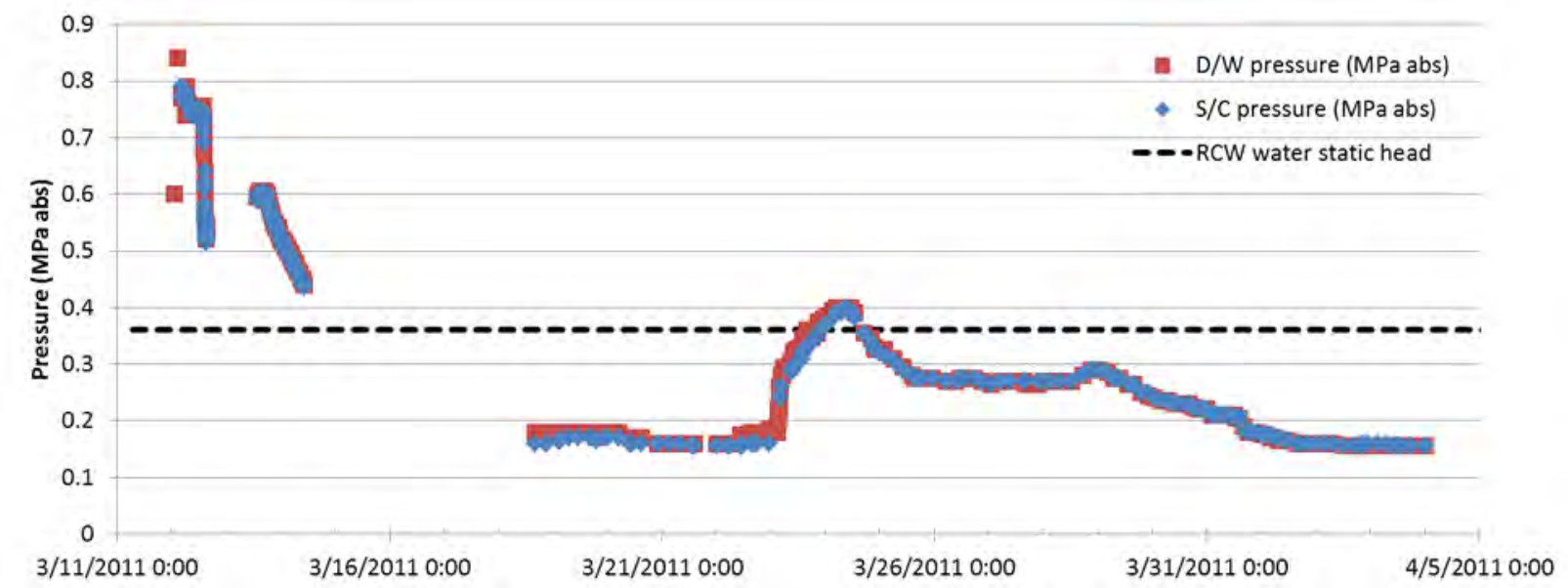

Figure E-4. 1F1 containment pressure versus time. (Courtesy of TEPCO Holdings [243])

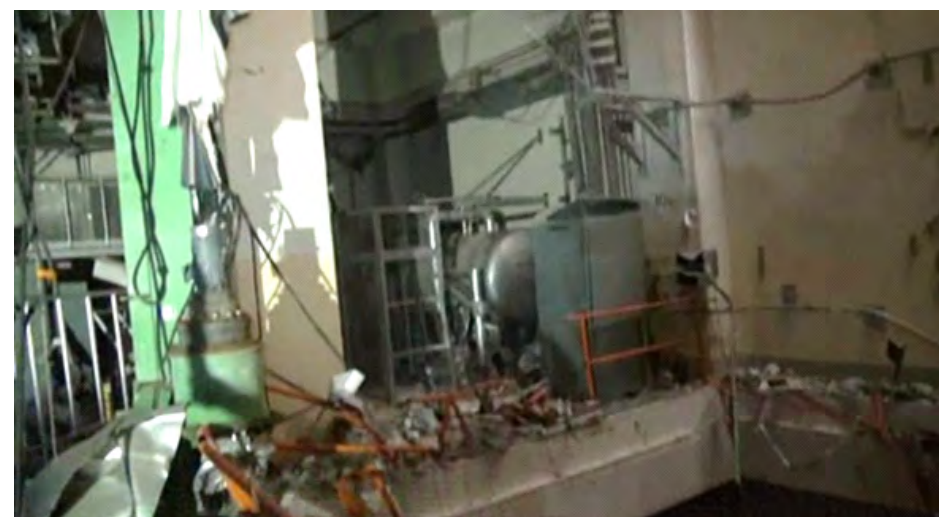

Figure E-5. 1F1 RCW surge tank. (Courtesy of TEPCO Holdings [245])

Design details of the RCW at $1 \mathrm{~F} 1$ are not readily available. In reviewing the design for a similar BWR4 in a Mark I containment at the Browns Ferry Nuclear Power Plant (BFN) [246], the pipe size for the drywell equipment drain sump heat exchanger is $3.81 \mathrm{~cm}(1.5 \mathrm{inch})$. The rest of the RCW piping of relevance is much larger, in the $5-30.5 \mathrm{~cm}$ range (4-12 inch). The volume of water in the system (relevant to RCW piping, surge tank, and heat exchangers of interest) is not readily known; however, it is estimated to be on the order of several cubic meters (i.e., on the order of 1000 gallons). The RCW piping is designed for 1.14 MPa-gauge (150 psig) at BFN which exceeds available values recorded for the 1F1 drywell pressure.

Available 1F1 drywell pressure data from 1:00 on March 12 until 10:00 on March 14 are greater than the RCW water static head (Figure E-4). To reproduce the 1F1 drywell pressure during the March 12, 7:0014:00 timeframe, previous simulations modeled a drywell head flange leak.[55, 56] The models require 
leakage areas (that vary with time) of approximately $4.4 \mathrm{~cm}^{2}$ [55] and $5 \mathrm{~cm}^{2}$ [56], which have an equivalent diameter of approximately $2.5 \mathrm{~cm}$ ( $1 \mathrm{inch})$. Interestingly, this corresponds to the approximate size of the RCW piping for the drywell drain sump heat exchangers at BFN. Thus, a possible alternative to the 1F1 drywell head seal leakage path is through the RCW system during periods of high drywell pressure (i.e., greater than 0.36 MPa-abs.). However, as noted in Appendix E.1.1, there is evidence the drywell head likely leaked. Substantially higher doses have not been measured near the surge tank or on the refueling floor above the surge tank. Thus, to date, the inspection evidence supports the possibility for drywell venting through the drywell head flange. While one explanation for the high doses observed by the RCW heat exchangers is due to contaminated water being pushed up into the system, there is a lack of evidence to support the possibility of 'venting' the drywell through the RCW piping and surge tank.

Besides a potential leakage path for the drywell, the RCW is a potential source of water. With variations in drywell pressure, water could either flow from the drywell to the RCW or in the opposite direction (assuming there is a failure in the RCW drywell sump heat exchanger piping). As discussed in Appendix E.1.1, water from RCW has the potential to quench ex-vessel debris in and around the drywell sumps. The efficacy of this cooling method (water injection into the debris from below) is supported by previous testing as discussed in Appendix E.1.1. It should be noted that previous simulations predict the relocation of approximately 140 tons of debris from the RPV.[240]

In summary, elevated doses are observed around portions of the RCW system in 1F1. Based on available pressure data and analyses, there is a potential that the RCW drywell sump cooler heat exchanger piping failed. Failure of the piping represents a potential leakage path from drywell and a source of cooling water for ex-vessel debris in the drywell. Additional inspections may provide insight as to the role of the $\mathrm{RCW}$ during the $1 \mathrm{~F} 1$ accident progression.

\section{E.1.3. Spent Fuel Pools and Shared Spent Fuel Storage Building}

The removal of the spent fuel in the $1 \mathrm{~F} 1,1 \mathrm{~F} 2,1 \mathrm{~F} 3$, and $1 \mathrm{~F} 4$ spent fuel pools (SFP) is a key activity within the D\&D roadmap, and efforts have been underway for several years. In addition to the SFPs of these units, defueling logistics also involve the large common SFP, the dry cask storage building, and the newly constructed dry cask temporary storage facility. Insights about the integrity of the spent fuel and supporting structures and facilities during and after the accident are of interest to both TEPCO Holdings and the U.S. nuclear industry.

Six SFPs, the common SFP, and the dry cask storage building were all subjected to severe ground motions due to the earthquake. Early after the accident, no indication of leakage from the SFPs was reported, other than from possible sloshing.[247] To date, no leakage (other than from sloshing) has been reported. There were repeated inspections and analyses of the integrity of the 1F4 SFP and reactor building.[247, 248] The findings indicated the building and SFP had sufficient margin to withstand another large earthquake [247] and confirmed there was no long-term change in structural integrity.[248] The nine spent fuel casks, stored within the dry cask storage building, were found to have remained bolted in their original position after the earthquake(s).[246]

Underwater video inspections of the 1F4 SFP was undertaken in April and May of 2011, March 2012, as well as during defueling. There has been no indication of leakage from the SFP noted. Starting November 2013, the spent fuel was removed from 1F4 spent fuel and transferred to the common spent fuel pool. As noted by TEPCO Holdings, one assembly in the SFP was previously (i.e., before 2011) deformed, and 
two assemblies were known 'leakers'.[249] As of December 2014, all spent and new fuel have been removed from the 1F4 spent fuel pool. Inspection of a new assembly, from the fuel pool, was conducted in August 2012. Some rubble and 'rust' were noted.[250,251] Visual inspections of spent fuel assemblies were reported in April 2014. The inspection found there were no problems (i.e., corrosion, deformation, tie rods/plates, etc.) with respect to the soundness of the spent fuel for fuel removal operations $[251,252]$. Measured oxide layer thicknesses, multiple measurements for each assembly inspected, were within normal ranges for five assemblies with burnup ranging from 37.3-50.5 GWd/t.[253]

Numerous underwater video inspections of the 1F3 spent fuel pool have been undertaken (e.g., April 2012, September 2012, October 2012, February 2013, August 2015, and October 2015). There has been no indication of leakage from the SFP noted. In general, rubble was found on the top of the spent fuel racks. No large-scale deformation of the racks was noted. White deposits were observed on the racks.[253] A deformed control rod blade and a fallen control rod (from the storage hangers on the pool periphery) were found.[253] The handles of 4 fuel assemblies were noted to be bent, attributed to the fuel handling machine which was resting in this location [254]. The handles were bent on a couple of additional assemblies that were located under a 2.6-ton concrete hatch that had relocated into the pool. [253]

Underwater video inspections of fuel in the 1F1 and 1F2 pools have not been reported.

The dry cask storage building contained 9 loaded horizontally oriented casks, holding 408 total assemblies, at the time of the events in 2011.[247] This building was partially damaged and flooded during the tsunami.[255] One cask was transferred from the storage facility to the common spent fuel pool facility for inspections. Inspections in 2013 did not note any abnormalities with respect to the cask and structure appearance, fuel assemblies, seal integrity, gas leakage, etc.[256] The fuel from the 9 casks were transferred to the common SFP in 2013. Starting in 2013, fuel from the common spent fuel pool is being transferred to a newly constructed dry cask temporary storage facility onsite.[257]

In general, the observations to date provide confidence in the integrity of the spent fuel, SFPs, storage racks, and storage casks that experienced off-normal conditions (e.g., seismic, water purity, debris) during and after the accident. The responses of the buildings and SFPs provide points of comparison for domestic SFP seismic response assessments.[258,259]

\section{E.1.4. Spent Fuel Pool Gate}

At 1F3, one of two gates between the SFP and the reactor well was observed to be displaced (i.e., the displaced gate closest to the reactor well). Observations indicated the other gate is maintaining the seal between the spent fuel pool and reactor well.[260]

Visual observation of 1F4 gate did not identify any abnormalities.[261] TEPCO Holdings has postulated that leakage from the reactor well to the spent fuel pool occurred in the days following the accident as the water level in the SFP dropped.[233] 


\section{E.2. Containment Examinations}

PCV examinations are of interest to TEPCO Holdings with respect to D\&D. In addition, this information is of interest to U.S. experts with respect to validating revised severe accident management guidance and verifying the adequacy of code models.

\section{E.2.1. Leakage Locations}

Examinations have informed D\&D planning by understanding the ability to flood-up containment. Currently, the water level within the DW of each of the units differs, with 1F3 being filled the highest, followed by $1 \mathrm{~F} 1$, and finally $1 \mathrm{~F} 2$. This indicates differences in containment failure locations and/or areas. Damage or indication of leakage has been found in at least one location in the containment boundary in each unit (1F1: leakage on expansion joint of one DW-WW vacuum breaker line [123], DW sand cushion drain pipe leakage [125]; 1F2: melted material at X-6 PCV penetration [114, 115]; 1F3: main steam line (MSL) D leakage near MSIV [261]; and all three units: possible DW head flange leakage). Although no damage has been detected for many penetrations/lines, there are several penetrations and locations for which survey information is not available.

The information to date highlights diverse leakage point locations and the possibility for multiple leakage points. Identifying leakage locations, the timing of, and the conditions causing this leakage was of special interest to the expert panel because of industry efforts related to severe accident water addition (SAWA). The expert panel focused on available information that could provide insights related to peak temperatures and pressures within the PCV that would cause such leakage. Expert evaluations of examination information identified relevant, but different, information for each unit.

For $1 \mathrm{~F} 1$, pressure data [9] indicate that peak PCV pressures were as high as $0.84 \mathrm{MPa} / 122$ psia on March 12, 2011. Temperature data were not available until March 21, 2011. Calculated saturation temperatures for this measured peak pressure, assuming a pure steam environment and neglecting localized hot spots, indicate values as high as $172^{\circ} \mathrm{C} / 342^{\circ} \mathrm{F}$. However, as shown in Figure E-6, examinations within $1 \mathrm{~F} 1$ revealed that a lead shield plate was missing. It is currently unknown whether the plate relocated due to melting or creep. For this lead plate to have melted, gas temperatures inside the drywell exceeded $328{ }^{\circ} \mathrm{C} /$ $622^{\circ} \mathrm{F}$, the melting point for lead.

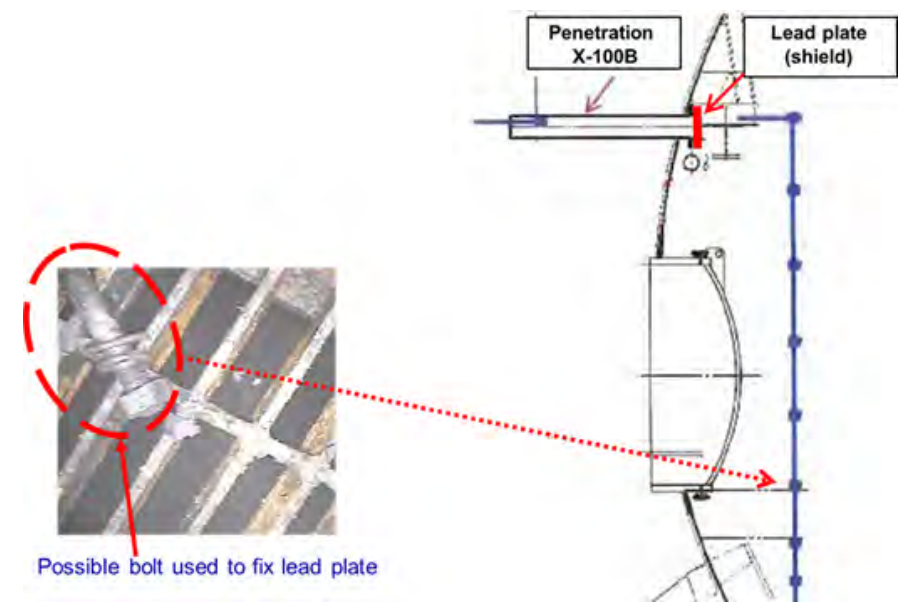

Figure E-6. Visual examinations within 1F1 X-100B penetration. (Courtesy of TEPCO Holdings [11]) 
As discussed in Section 3, insights related to peak temperatures within the 1F2 PCV are available from visual examinations, radiation survey information, and temperature and pressure data. As shown in Figure 3-1, visual examinations of material from the X-6 penetration suggest that either the chloroprene cable cover or silicon flange seal material melted and dribbled out of this penetration. In their review, U.S. experts concluded this evidence indicates peak temperatures at this location exceeded $300{ }^{\circ} \mathrm{C} / 572^{\circ} \mathrm{F}$ and the dribbling pattern suggests that relocation occurred at low pressure (rather than a high-pressure ejection of material). Plant data [9] indicate that $1 \mathrm{~F} 2$ peak pressures were as high as $0.75 \mathrm{MPa} / 109$ psia on March 15, 2011. Temperature data were not available until March 21, 2011. Calculated saturation temperatures for the measured peak pressure, assuming a pure steam environment and neglecting localized hot spots, indicate values as high as $168^{\circ} \mathrm{C} / 334^{\circ} \mathrm{F}$.

For 1F3, insights about leakage come from photos and data obtained in March 2011 and dose rates obtained in November 2013. As shown in Figure E-7, steam appears to be escaping at locations near the drywell head, and higher dose rates were measured near this location. Both observations are consistent with a failure of the drywell head, perhaps due to drywell bolt expansion, strain, or seal degradation from high temperatures and pressures within the PCV. Plant data [9] indicate that 1F3 pressures were as high as $0.75 \mathrm{MPa} / 109 \mathrm{psia}$ on March 13, 2011. Temperature data were not available until March 20, 2011. Calculated saturation temperatures for the measured peak pressure, assuming a pure steam environment and neglecting localized hot spots, indicate values as high as $168^{\circ} \mathrm{C} / 334^{\circ} \mathrm{F}$. The combined pressure and temperature challenges are postulated to have stretched the drywell head bolts and allowed leakage through that pathway. However, the degree of damage to the head gasket is not known at this time. Photos showing leakage from MSIV expansion joints and radiological surveys from the equipment hatch penetration indicate that $1 \mathrm{~F} 3$ experienced multiple leakage locations.

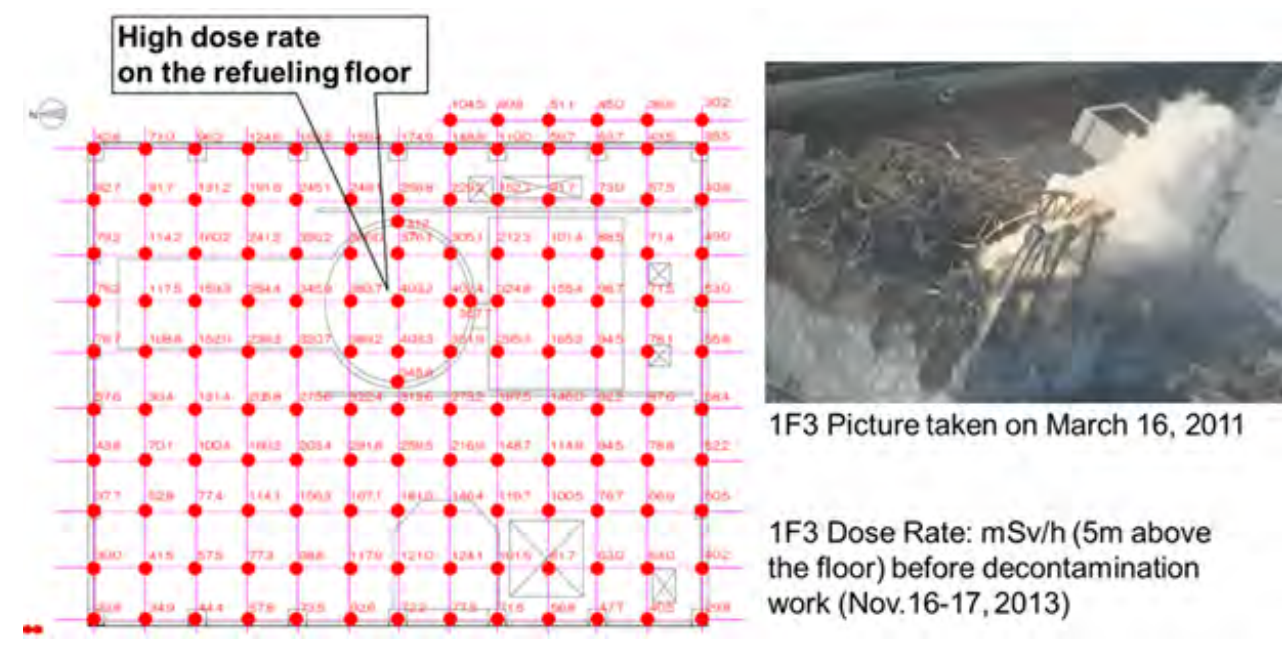

Figure E-7. 1F3 radiation survey (value in $\mathrm{mSv} / \mathrm{hr}$ measured on November 16-17, 2013 at $5 \mathrm{~m}$ above the floor at points shown on red grid) and photograph taken on March 16, 2011. (Courtesy of TEPCO Holdings $[11,13])$

Many of the leakage points identified for $1 \mathrm{~F} 1,1 \mathrm{~F} 2$, and $1 \mathrm{~F} 3$ are not routinely modeled by systems level severe accident codes (e.g., MELCOR, MAAP, etc.). Both MAAP and MELCOR simulations predict DW head failure for the three units. It is evident that re-consideration of other penetrations/piping failures may be warranted for investigation in these systems analyses codes, including the impact of failure locations and sizes. 
The potential for multiple penetrations to fail due to seal degradation is considered by industry in their proposed SAWA strategy. In the U.S., the new BWROG and PWROG severe accident management guidance places a high priority on venting the primary containment when the pressures and temperatures reach prescribed limits. For BWRs, these primary containment conditions can be very close to the primary containment design basis pressure and temperature, but guidance documented in the Nuclear Energy Institute (NEI) report, NEI-13-02, [84] also considers water addition and water management strategies to enhance the effectiveness of fission product release mitigation during primary containment venting. Although there is variability in information from the units at Fukushima, the available information nonetheless confirms that maintaining containment conditions below the design basis, as well as reducing containment conditions, are appropriate strategies.

Figure E-8 shows typical peak temperature and pressure information for BWR Mark I and II PCVs on a figure developed from information in the NEI 13-02 industry guidance for venting. The DW is assumed to begin penetration degradation at a temperature of $285^{\circ} \mathrm{C} / 545^{\circ} \mathrm{F}$, based on engineering evaluations and testing information available in the literature. Black dotted lines in Figure E-8 correspond to peak temperature information available from examinations at $1 \mathrm{~F} 1$ and $1 \mathrm{~F} 2$. These values are consistent with the range of values assumed to cause degradation in NEI 13-02; thus, available information from Daiichi support NEI 13-02 guidance recommending that operators maintain containments at low pressure.

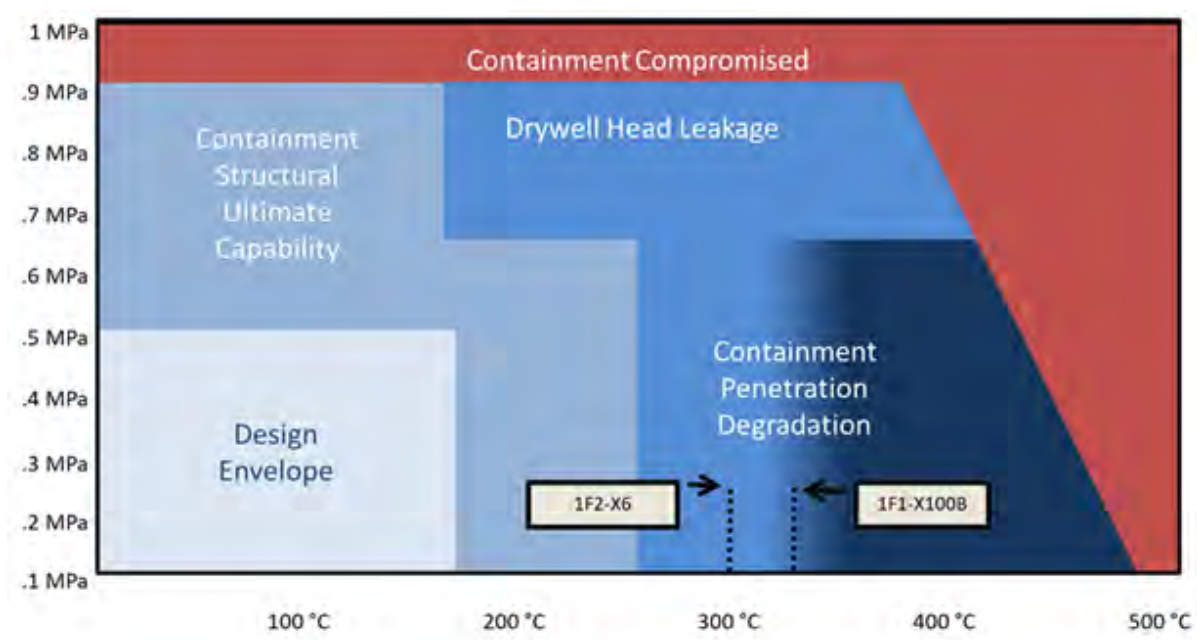

Figure E-8. Containment pressure/temperature curve with available 1F1 and 1F2 information. (Graphic courtesy of Nuclear Energy Institute [84] as modified by Jensen Hughes)

\section{E.2.2. Code Modeling Enhancements}

In developing severe accident guidance for water addition (and confirming that the integrity of the drywell head and seals was preserved), there was a desire to confirm the adequacy of the MAAP code to predict temperatures in the drywell. Comparisons between available Daiichi temperature information and analyses results have led to refinements in MAAP containment nodalization. Specifically, the MAAP code has been refined to include three containment volumes and a separate volume for the refueling cavity (see Figure E-9). Comparisons of predictions from the MAAP code with available data confirm the adequacy of the revised model to predict the measured gr within the drywell.[262] 

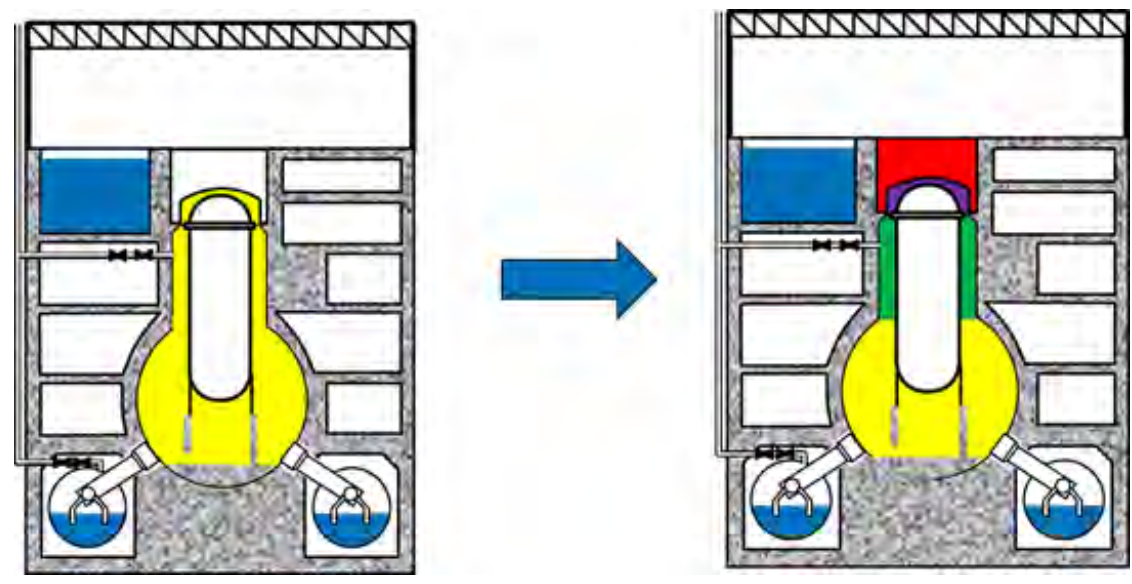

Figure E-9. Improved MAAP nodalization. (Courtesy of Jensen Hughes, [26])

In $1 F 3$, the PCV pressure increased more rapidly in the first 20 hours than systems level codes would generally predict.[55,56] Since 2012, there has been discussion and modeling of possible thermal stratification in the SC of 1F3.[17,41,263] This has led to the development and adoption of refined modeling approaches and is an area of continued investigation. Note, this pressurization possibly caused the trip of the 1F3 RCIC, see Section 3.3.2.

Additional efforts are underway to assess the effects of SRV and RCIC operation on stratification within the containment.[264] Evaluations with the enhanced MAAP models are being applied to predict instrumentation readings available to operators during severe accidents (and identify potential false instrumentation readings). Hence, reduced uncertainties in systems analysis code predictions provide additional confidence in severe accident management guidance in the U.S. Evaluations with these codes are also useful to Japan as input for D\&D Phase II assessments.e

\section{E.3. Primary System Integrity and Water Injection}

To date, there is limited direct information related to the integrity of the primary system. Direct observation of the tailpipes for the SRV, RCIC, HPCI, or the SRVs, MSLs, recirculation piping and pumps, lower head penetrations, etc., have not been made.

\section{E.3.1. Leakage}

A leak was observed in line D of the 1F3 MSL near the MSIV.[135] However, no leakage was observed in the MSIV room of 1F2. This motivates two open questions: What caused line D to leak but not lines A-C in 1F3? Was there a difference in the accident progression between 1F2 and 1F3 that resulted in a leak in 1F3 and not 1F2? Subsequent correspondence with TEPCO Holdings [265] indicate that these differences were not attributed to differences in the SRV setpoints. Rather, available information suggests that differences may be due to differences in the accident progression and water levels within the PCV of these units (e.g., water levels prevent observations of leakage). 


\section{E.3.2. Fire Engine Injection}

During the accident, there were attempts to inject water via fire engines. However, it is unclear how much of the injected water was successfully injected into the RPVs during and after the accident. TEPCO Holdings has reviewed the piping networks at the three units used to inject the water to identify possible bypass routes.[41] Ten bypass flow lines were identified for 1F1 and four lines were identified in both 1F2 and 1F3. This information has led to revised estimates of water injection into the RPV for 1F1 and could be used to revise estimates for $1 \mathrm{~F} 2$ and $1 \mathrm{~F} 3$. In addition, a similar review of bypass lines and check valve locations was performed for the Kashiwazaki-Kariwa Nuclear Power Plant and led to the installation of an addition motor operated valve. 
ANL-18/24

E-14 


\section{APPENDIX F. AREA 2 - DOSE SURVEYS AND ISOTOPIC SAMPLING PREVIOUSLY REPORTED FINDINGS}

This appendix tabulates previous findings by TEPCO Holdings related to Area 2 (Dose Surveys and Isotopic Sampling) for the affected reactors at Fukushima Daiichi. Key findings obtained since the U.S. Forensics Effort FY2017 report[3] was issued are summarized in the main body of the report.

\section{F.1. Post-accident Evaluations of Reactor Building Contamination}

Post-accident examinations of the reactor buildings provide important information related to likely points of containment impairment. Key results from TEPCO Holdings post-accident reactor building inspections are summarized in this section.

\section{F.1.1. 1F1 Reactor Building Contamination}

Access to the 1F1 reactor building is challenging because of damage to the upper floors that occurred because of flammable gas combustion at 24.8 hours after the earthquake. The following areas in the 1F1 reactor building have been identified with elevated radiation dose rates:

- First floor area around the penetration between the basement and the first floor providing passage for the WW vent line. This has been linked to impairment of the expansion joint on the WW vacuum breaker line, as shown in Figure F-1.

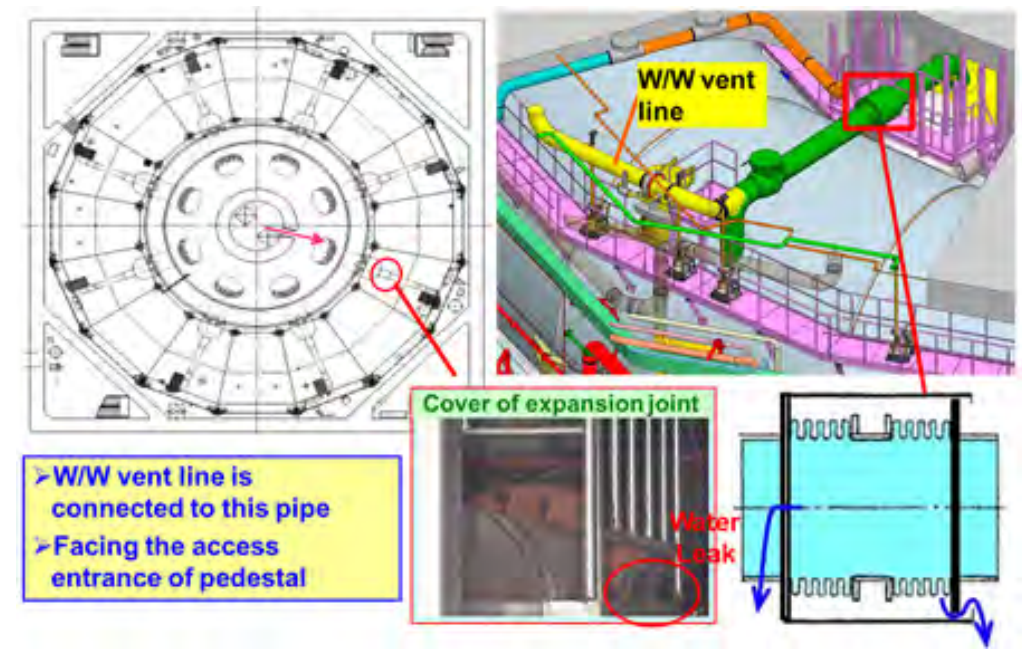

Figure F-1. Impairment of 1F1 vacuum breaker line expansion joint. (Courtesy of TEPCO Holdings [155])

- Reactor Building Closed Cooling Water System (RCW) heat exchangers ( $\sim 1 \mathrm{~Sv} / \mathrm{h})$ and associated piping found in the contaminated waste treatment areas (see, for example, Figure F-2). RCW equipment provides an important signature of the possible extent of core damage because ex-vessel core debris could potentially attack the RCW piping present in the drywell sumps.

Contaminated water running into the $1 \mathrm{~F} 1$ torus room from the drywell sand pit (suggesting the 1F1 drywell liner is impaired). Entry into the torus room of 1F1 showed that the sand cushion drain 
pipes in 1F1 are leaking water (see Figure F-3). A potential explanation for this is that the liner of the containment drywell was breached because of melt ablation. Then, as water is injected into the containment it makes its way through the pedestal region out of the hole in the DW liner and into the sand cushion, eventually leaking out of this area into the torus room.

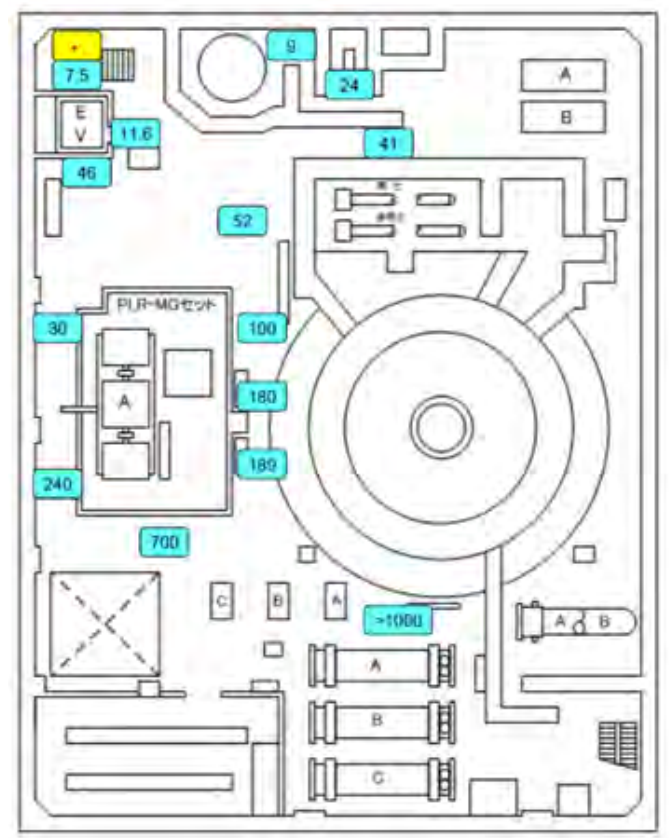

Figure F-2. 1F1 reactor building first floor dose rate measurements (in $\mathrm{mSv} / \mathrm{hr}$; taken above floor elevation measured on February 14, 2013) illustrating elevated radiological contamination of RCW (circled area). (Courtesy of TEPCO Holdings [156])

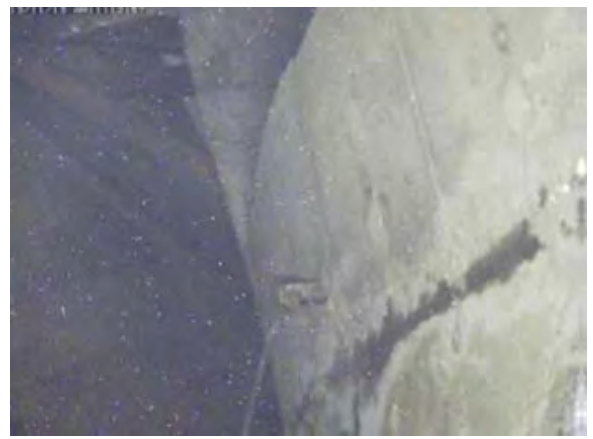

Figure F-3. Leakage out of the sand cushion drain pipes at 1F1. (Courtesy of TEPCO Holdings [157])

The elevated dose in the torus room of $1 \mathrm{~F} 1$, compared to $1 \mathrm{~F} 2$ and $1 \mathrm{~F} 3$, is a consequence of gasphase leakage into the torus room occurring at $1 \mathrm{~F} 1$. Measured doses within the torus room of $1 \mathrm{~F} 1$ (see Figure F-4) are significantly higher than those in 1F2 and 1F3 (see Sections 4.2.1.2 and 4.2.1.3). 


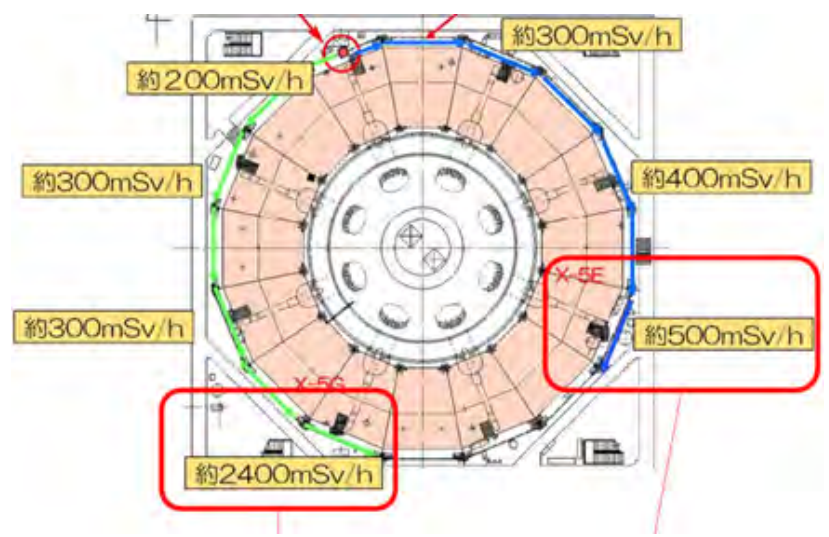

Figure F-4. Torus room radiation level readings from entry into 1F1 reactor building measured on May 30, 2014 (in $\mathrm{mSv} / \mathrm{hr}$; taken above floor elevation). (Courtesy of TEPCO Holdings [158])

- Although no elevated dose rates were measured in the backside of the 1F1 Traversing In-core Probe (TIP) room, significant dose rates have been measured near the penetrations, see Figures F5 and F-6. Gamma camera measurements also indicated relatively high dose rates around the X$31, \mathrm{X}-32$, and X-33 instrumentation piping from the primary system, but not the X-35 penetration for the TIP tubes. Thus, failures of in-core instrument tubes during core damage progression did not impair the containment, contaminating the entire room.

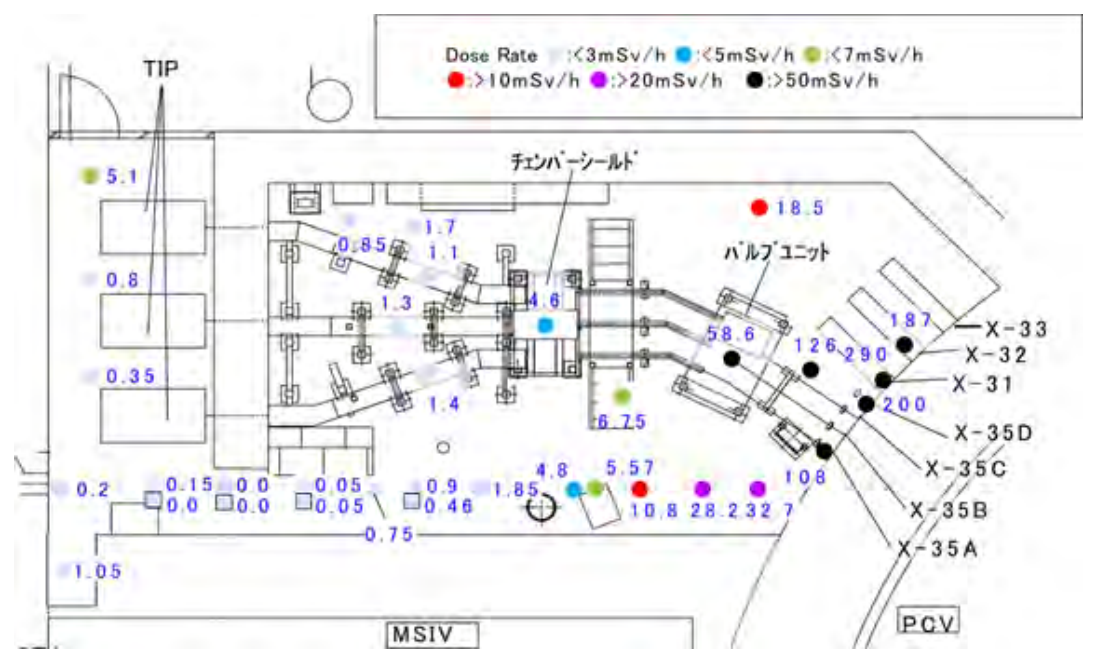

Figure F-5. 1F1 reactor building TIP room dose rate measurements (in $\mathrm{mSv} / \mathrm{hr}$; taken above floor elevation between September 24 through October 2, 2015). (Courtesy of TEPCO [159])

\section{F.1.2. 1F2 Reactor Building Contamination}

Currently, personnel access to the $1 \mathrm{~F} 2$ reactor building is less restricted than at $1 \mathrm{~F} 1$; combustion of any flammable gas leakage from containment impairments did not occur at $1 \mathrm{~F} 2$. This is likely due to the open- 


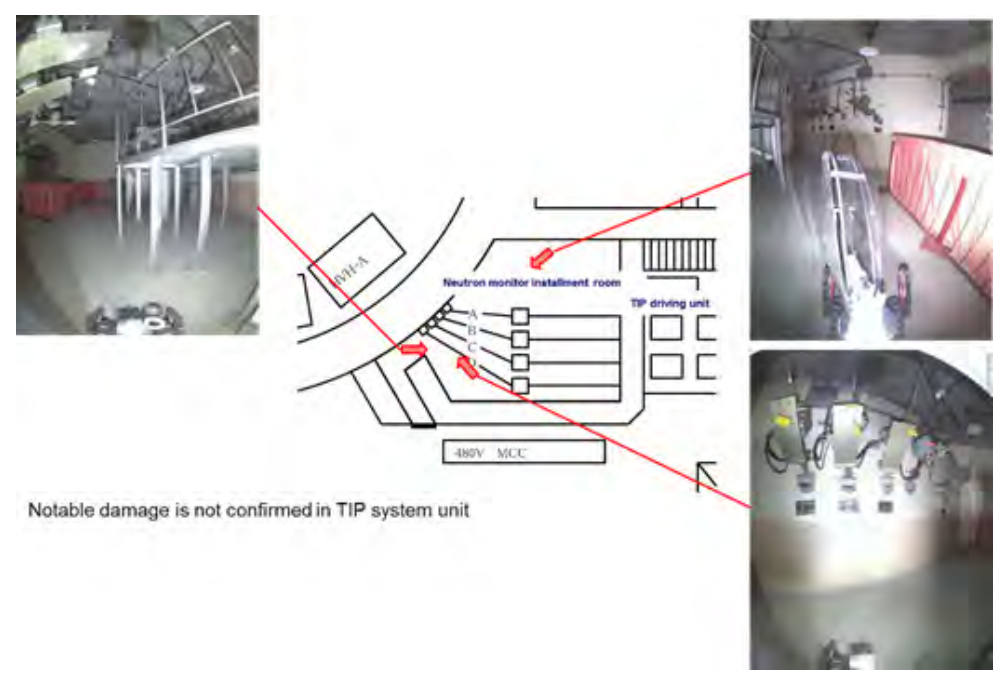

Figure F-6. Typical TIP room illustration. (Courtesy of TEPCO Holdings [160])

ing of the reactor building blowout panel on the refueling floor, which occurred due to gas rarefaction following the pressure waves propagating away from the $1 \mathrm{~F} 1$ reactor building flammable gas explosion (see Figure 4-6).

Torus room radiation dose rates measured in 1F2 (see Figure F-7) are lower than values measured in 1F1. Examinations have identified the following areas within the 1F2 reactor building with notably elevated radiation doses:

- In front of the X-6 penetration pipe flange. As discussed in Section 3.2.1, high dose rates were measured at this location (see Figure 3-1). In addition, the rubber material [likely the chloroprene rubber cable sheath material stored inside the penetration for use with the Control Rod Drive (CRD) replacement machine] has apparently melted and led to the formation of organic debris outside the penetration. The presence of this material suggests that high temperature conditions likely occurred inside the penetration leading to ultimate impairment of the silicone rubber O-ring seal and melting of chloroprene rubber cable sheath.

- Shield plugs above the drywell head, covering the refueling cavity. Evaluations have measured dose rates of $\sim 800 \mathrm{mSv} / \mathrm{h}$ (Figure F-8).

Unlike $1 \mathrm{~F} 1$, the RCW equipment is not contaminated. The cause for this difference is still unknown. It is speculated that the closure system (an explosive closure system) may have been initiated with the return of battery control.

No elevated doses inside the 1F2 TIP room have been identified, neither in the room nor near the penetrations, see Figure F-9. Relatively small dose rates were measured near the penetrations. Any failures of in-core instrument tubes during core damage progression did not impair the containment. During panel meetings, U.S. experts questioned if the explosive closure system could have activated and sealed the guide tubes. The "explosive closure valve" is for emergency closure when the isolation valve (motor operated ball valve) cannot be closed during TIP operation (usually this ball valve is closed). However, U.S. experts learned that the TIP was not in operation at the time of the earthquake. Hence, the TIP line was closed and activation of the explosive closure system would not be triggered. Furthermore, it was directly confirmed in December 2012 that the 1F2 TIP ball valves were actually closed, and explosive closure 


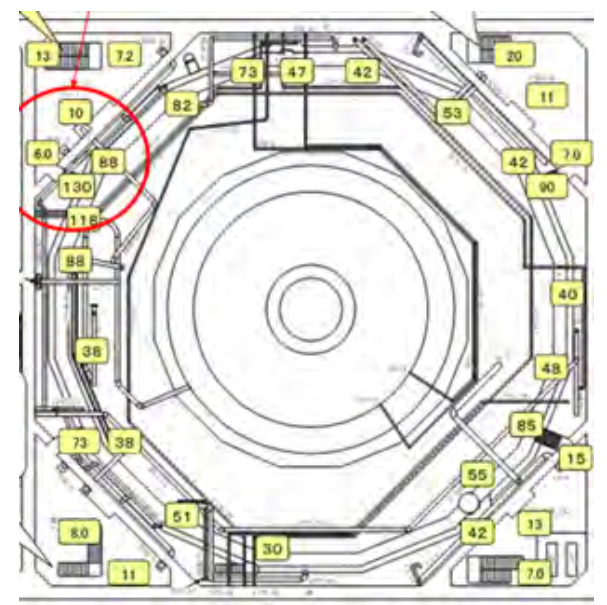

Figure F-7. Torus room radiation level readings from entry into $1 \mathrm{~F} 2$ reactor building (in $\mathrm{mSv} / \mathrm{hr}$; taken above floor elevation in April 2011). (Courtesy of TEPCO Holdings [137])

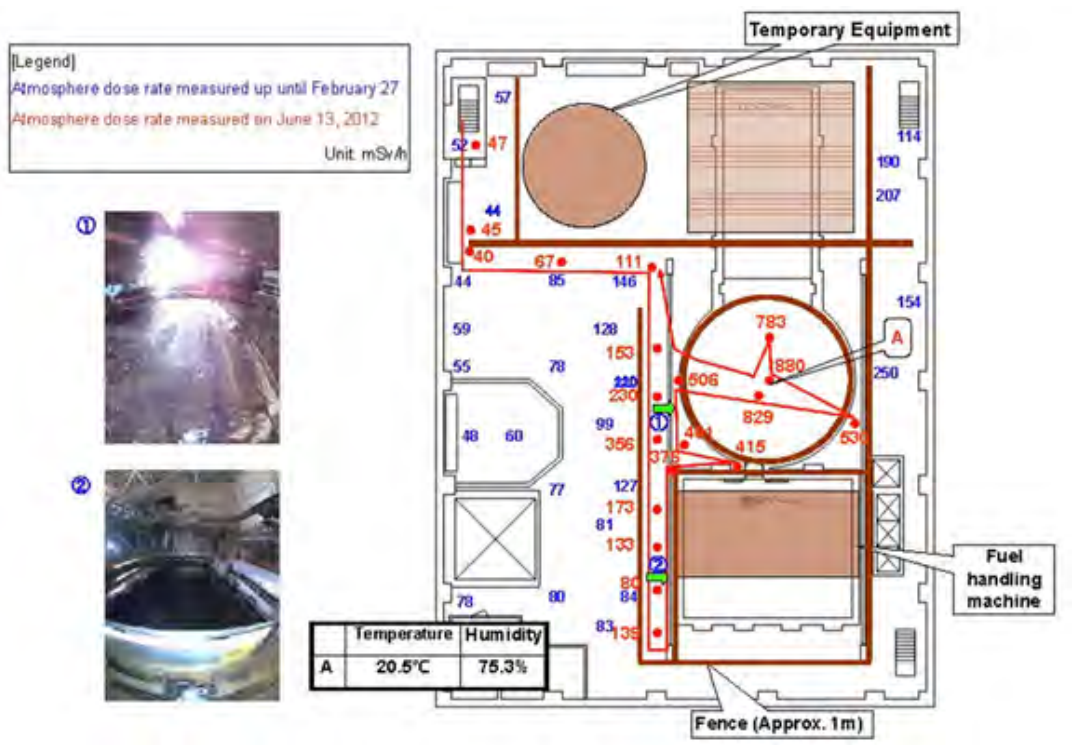

Figure F-8. 1F2 reactor building refueling floor visual and dose rate information (in $\mathrm{mSv} / \mathrm{hr}$; taken above floor elevation on February 27, 2012 and June 13, 2012). (Courtesy of TEPCO Holdings [161])

valves were kept open [162]. Dummy TIP cables were inserted into the guide tubes (see [163]). On July $9^{\text {th }}$ of 2013, after the dummy TIP cable was pulled out, attached substances were found on the head with a $\gamma$-ray dose rate of $14.0 \mathrm{mSv} / \mathrm{h}$. A similar action was performed on July $19^{\text {th }}$ of the same year, the attached substances yielded a dose rate of $95.0 \mathrm{mSv} / \mathrm{h}$. 


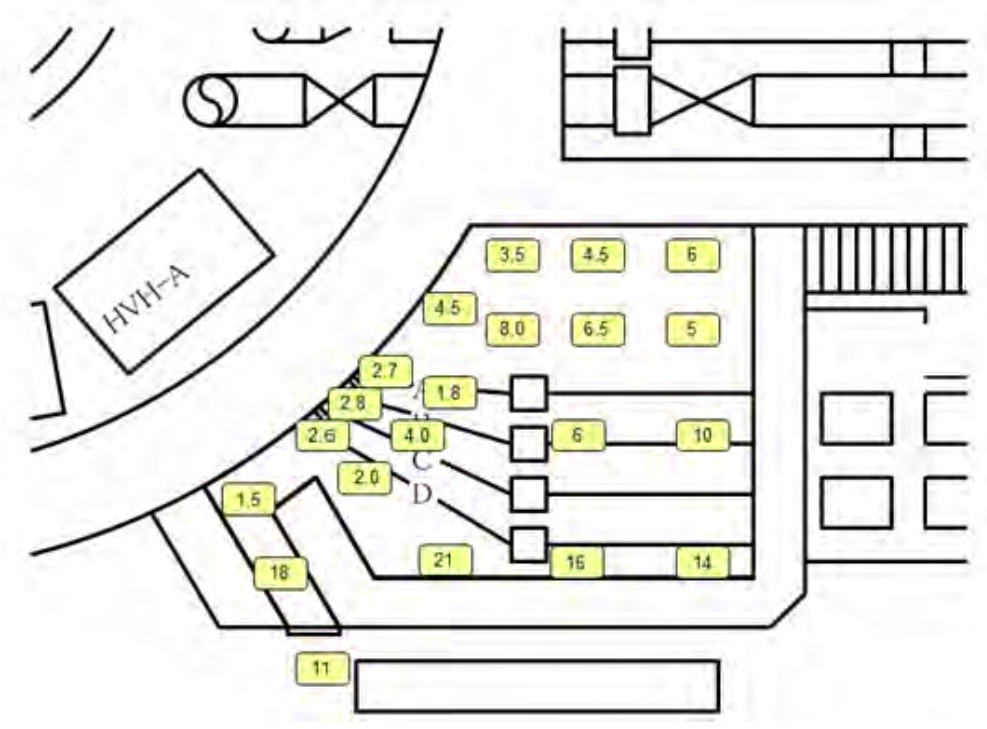

Figure F-9. Air dose rates in 1F2 TIP room (in mSv/hr; taken above floor elevation on March 22, 2013). (Courtesy of TEPCO Holdings [137])

\section{F.1.3. 1F3 Reactor Building Contamination}

As with the 1F1 reactor building, access to the $1 \mathrm{~F} 3$ reactor building is difficult because of damage that occurred when flammable gases combusted at 68.7 hours after the earthquake. Unlike the 1F1 reactor building, more extensive damage occurred to lower elevations of the $1 \mathrm{~F} 3$ reactor building.

Elevated radiation dose rates have been observed in the $1 \mathrm{~F} 3$ reactor building at the following areas:

- Equipment hatch on the first floor of the reactor building (see Figures F-10 and F-11):

High dose rates are restricted to water pools that formed on the floor immediately outside of this hatch;

There does not appear to be sufficient evidence to suggest that gas-phase leakage occurred from this location.

- Elevated dose rates inside the MSIV room:

Contamination in this region has developed due to leakage of water from containment through an impairment of this penetration;

The 1F3 drywell water level does not exceed the elevation of the MSIV penetrations.

- Elevated dose rates above the drywell head have been confirmed at 1F3 (Figure E-7).

Unlike 1F1, the RCW piping is not contaminated. The cause for this difference is still unknown.

The door leading to the 1F3 TIP room was blown off its hinges (see Figure F-12). 


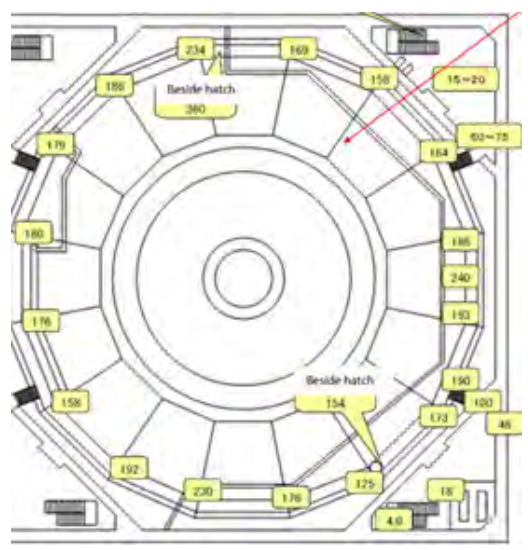

Figure F-10. Torus room radiation level readings from entry into $1 \mathrm{~F} 3$ reactor building (in $\mathrm{mSv} / \mathrm{hr}$; taken above floor elevation on April 25, 2011). (Courtesy of TEPCO Holdings [137])

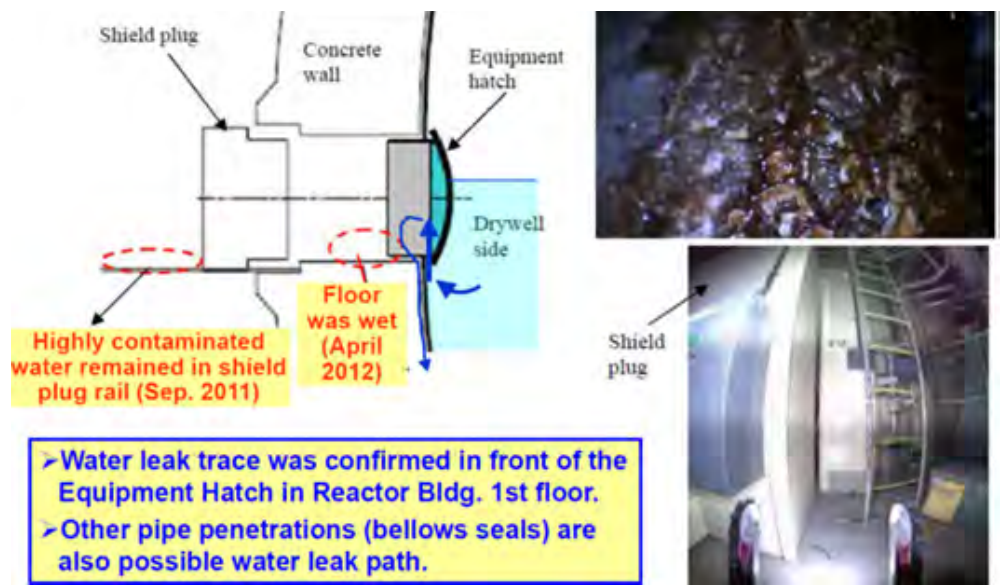

Figure F-11. Liquid-phase leakage from 1F3 equipment hatch. (Courtesy of TEPCO Holdings [155])

The damage to the door indicates an overpressure in the room either from blowdown of the vessel or a hydrogen combustion event, suggesting that a thimble tube failed in the core region while the RCS was slightly pressurized. However, the dose rates leading to the labyrinth were small (on the order of 10 to 40 $\mathrm{mSv} / \mathrm{hr})$. Inside the TIP room, the dose rates were lower $(\sim 2 \mathrm{mSv} / \mathrm{hr})$. Near the penetrations, the dose rates were found to be in the range of 30 to $50 \mathrm{mSv} / \mathrm{hr}$.[165] This implies that some leakage back through the guide tubes may have occurred; however, if a tube had failed, substantial higher dose rates would have been expected.

Thus, it can be concluded that any failures of in-core instrument tubes during core damage progression did not result in containment impairment. 


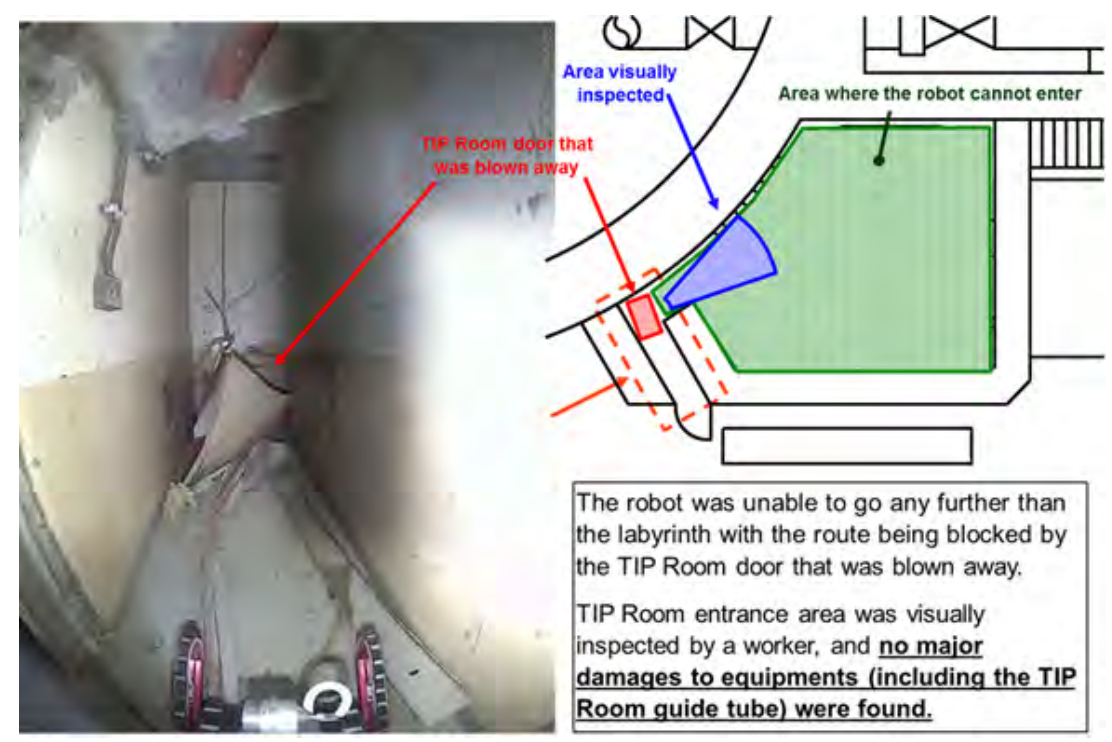

Figure F-12. Robot image leading to 1F3 TIP room. (Courtesy of TEPCO Holdings [165])

\section{F.2. Containment Radiation Data Obtained during Event Progression}

Radiological data acquired during the event also provide some insight into core damage progression and fission product release to the environment.

\section{F.2.1. Overview of Available Radiation Measurements}

The periods of most significant core degradation were not fully captured by the drywell and wetwell radiation measurements (see Figure F-13). Power was not available to the CAM systems at these units to support gathering of this information during the periods when most active core degradation occurred.

For 1F1, DW and WW CAM system measurements were not available prior to March 14, 2011; much of the significant core damage progression, including RPV lower head breach, likely occurred prior to March 13, 2011. Thus, distinct signatures showing a change in conditions (i.e., a notable increase in radiation readings) are generally not discernible from the available CAM system data for $1 \mathrm{~F} 1$. The one exception is that DW radiation readings increased near the end of the day on March 14, 2011). Although CAM data were fluctuating,[166] the elevated radiation level in the 1F1 drywell persisted for about one day. This coincides with a restoration of water injection to the unit. It also supports the hypothesis that fission products were released from 1F1 early on March 15, 2011, coincident with a shift of winds to the southwest of the Daiichi site. Elevated radiation levels to the southwest of the site, at locations such as Oono, were identified over this period.

There are sparser radiation measurements available from 1F3 during notable periods of core damage progression from March 13, 2011 to March 16, 2011. There are some radiation readings available from the suppression chamber CAMS on March 14, 2011; however, these readings exhibit a relatively constant 


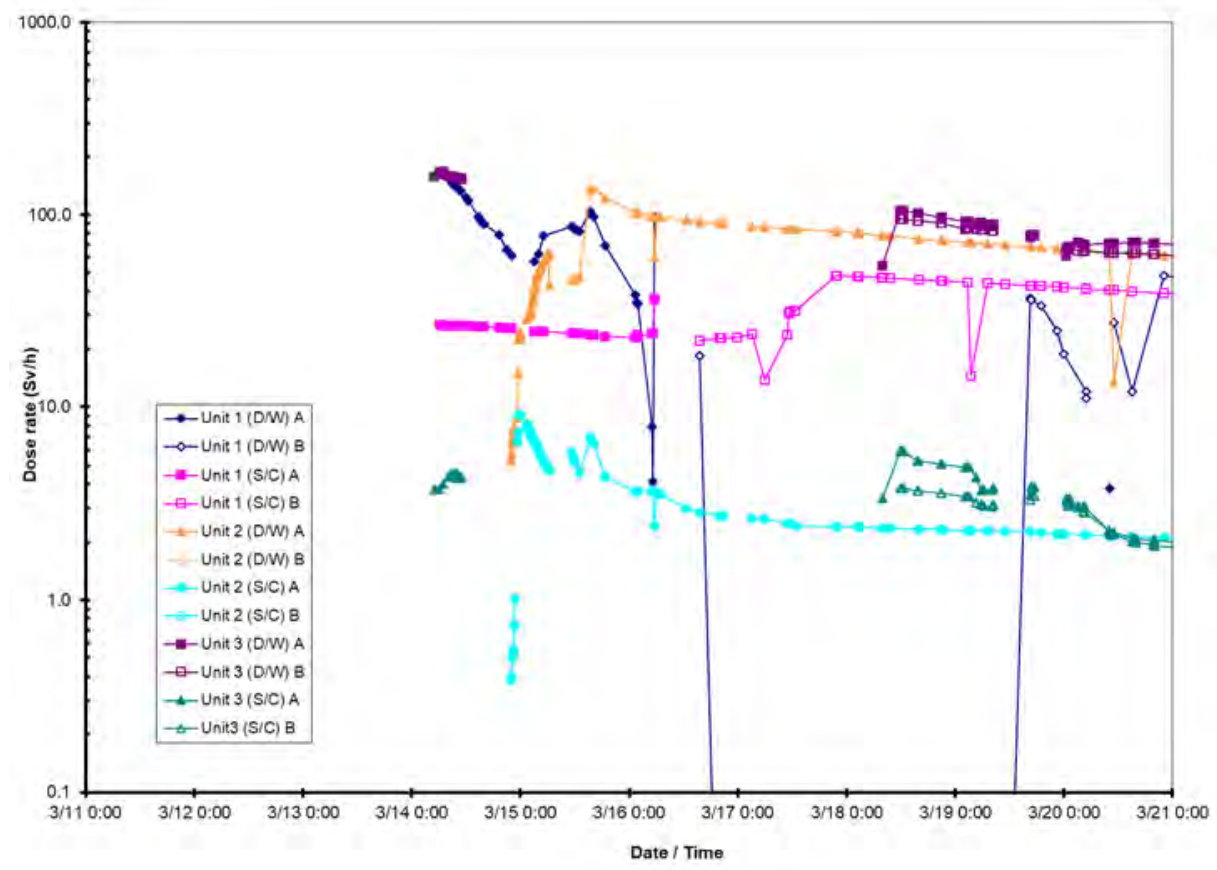

Figure F-13. 1F CAM data. (Data courtesy of TEPCO Holdings [9])

radiation level. Thus, there is no clear signature suggesting when core damage progression events led to an increase of fission product release to containment.

In contrast, DW and WW radiation readings at $1 \mathrm{~F} 2$ were restored during a time of active core damage progression (i.e., from late March 14, 2011). The measurements of DW and WW radiation levels obtained during active event progression at 1F2 provide insights into evolving core damage and potential failure of the reactor pressure boundary. Figure F-14 shows radiation measurements obtained from the DW and WW during a period of significant core damage progression at $1 \mathrm{~F} 2$.

As shown in Figure F-14, DW radiation readings increased just prior to 80 hours into the event (e.g., DW radiation measurements increased significantly over a few hours around this time). This increase in radiation readings also corresponds to the measured rapid increase in DW pressure at around 80 hours into the event.

Beyond 80 hours, WW radiation readings began to decrease. Wetwell radiation readings initially provided the leading indicator for release of fission products from damaged fuel around the time of core damage onset ( $\sim 75$ hours). After about 80 hours, drywell radiation readings provide the leading indicator of enhanced fission product release from damaged fuel. Definitive evidence is currently not present, but the shift to the drywell radiation readings as the leading indicator of core damage progression tends to indicate a failure of the RPV pressure boundary directly into the drywell. Note that this does not mean lower head breach; RPV depressurization could be due, for example, to failure of either:

- In-core instrument tubes due to core degradation and relocation, or

- Steam line/tail pipe assembly (including the SRV gasket) impairment due to occurrence of very high temperatures following the onset of core damage. 


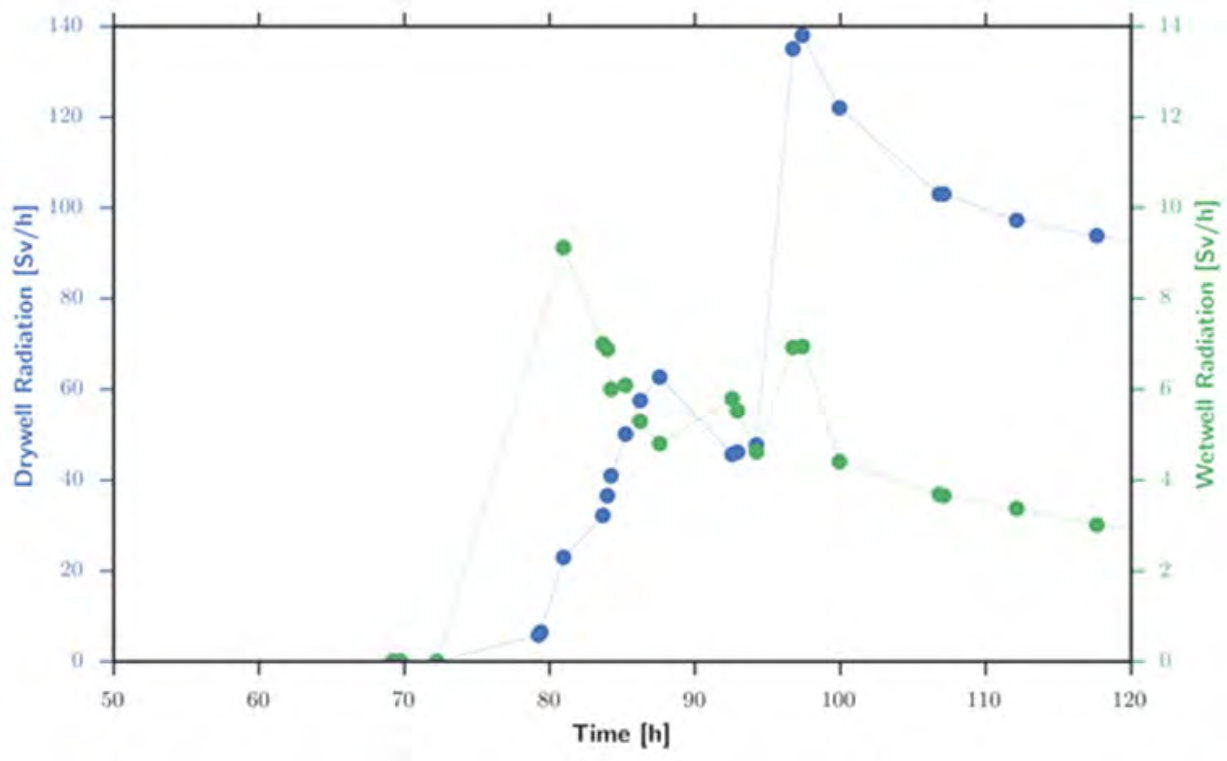

Figure F-14. 1F2 DW and WW CAMS readings starting from 14:46 on March 11, 2011. (Courtesy of Jensen Hughes based on information in [97])

Between approximately 87 hours and 92 hours, 1F2 containment depressurization occurred, stabilizing drywell containment radiation levels. As discussed above, this is postulated to be due to impairment of the drywell head flange. Beyond 94 hours into the event, the 1F2 containment radiation readings provide an indication of renewed core damage progression. At $\sim 94$ hours into the event, a rapid increase in the drywell radiation level occurred with similarly rapid increases in containment and RPV pressures. The surge in containment pressure quickly abated. One possible explanation for the containment radiation readings and pressure measurements around this time is an interaction between molten core debris and water. Such an event could be due to slumping of molten core debris into lower plenum water or relocation of core debris out of a breached lower head. Around this time, there was also a shift in winds to the northwest of the plant coincident with precipitation (i.e., rain and snow). Any releases that occurred from 1F2 during this period would have been transported over a region of Japan that has exhibited the most significant land contamination (as indicated by the long-lived radionuclide, ${ }^{137} \mathrm{Cs}$ ).

The implicit assumption that $1 \mathrm{~F} 2$ was the only contributor to this measured land contamination merits further study; the $1 \mathrm{~F} 1$ and $1 \mathrm{~F} 3$ containments were already impaired by this time. However, international code comparison efforts (see Section 2.2.2.2) indicate that some 1F1 and 1F3 accident progression results do not predict significant radionuclide release to the respective containments and the environment at this time.[98] In this effort, comparisons are made to measured values.[167]

\section{F.2.2. Insights and Limitations}

The impairment of the RPV pressure boundary prior to breach of the RPV lower head (early RPV pressure boundary impairment) is an important insight captured in the containment radiation measurements. Available data do not provide sufficient means to discriminate between alternative scenarios for the source

of the RPV pressure boundary impairment. The specific source of impairment is not ultimately germane to 
reactor safety considerations; direct discharge from the RPV into the DW promotes a rapid evolution of gases that present an overpressure challenge to containment integrity.

That said, the rate associated with an overpressure challenge may be slower in the case of in-core instrument tube failures because there is a smaller area available for discharge from the RPV into the DW. In addition, it is unknown if the guide tube explosive sealing systems were activated when power was restored. Gross failure of piping in the steam line and tail pipe assembly could result in a more rapid release of energy directly into the DW and thus a more sudden escalation of containment pressure toward or beyond its design value.

Resolving the likelihood of different early RPV pressure boundary impairments (i.e., prior to RPV lower head breach) is an important limitation associated with available information from the affected units at Daiichi. There is much uncertainty in predicting RPV impairment. Much of this uncertainty stems from the lack of information to uniquely extrapolate smaller scale experiments to reactor scale. Thus, computer codes can exhibit significantly different predictions for the tendency of high temperature conditions to develop above the core following the onset of a severe accident. Previous studies have noted that severe accident models exhibit significantly different predictions of the gas temperature above the core once core damage commences (see, for example, the MAAP-MELCOR crosswalk [57]).

Thus, the containment radiation readings at $1 \mathrm{~F} 2$ provide an indication that further inspections of its RPV pressure boundary impairment locations will provide information of relevance to assessing fundamental differences in core damage progression models. Furthermore, the DW pressure measurements obtained from $1 \mathrm{~F} 1$, though sparse during the first 10 hours of the event, provide additional indication of rapid pressurization of the DW due to a possible early impairment of the RPV pressure boundary. MELCOR simulations tend to highlight creep failure of a main steam line as the source of early RPV pressure boundary impairment at $1 \mathrm{~F} 1$. MELCOR modeling of the $1 \mathrm{~F} 3$ event scenario highlights the potential for conditions to have developed in the 1F3 RPV that would have challenged the integrity of the MSLs.

Given the strong indications of early RPV pressure boundary impairment, visual data from each of the damaged units relevant to RPV pressure boundary integrity would be of significant value for enhancing the severe accident knowledge base at reactor scale. RPV upper internals and steam line/tail pipe assembly visual data would also be of considerable value.

\section{F.3. Post-Accident Examinations within the Containment}

Insights can also be obtained from dose measurements obtained within the containment during examinations conducted with robots.

\section{F.3.1. 1F1 Examinations}

During the March 2017 entry with the self-propelled, shape-changing, "Scorpion" robot through the 1F1 X-100B penetration (see Section 5.2.3 and Appendix G.2.1), it was found that the dose rates were very similar to those obtained in April 2015. Because the dose is likely driven by long-lived isotopes, this is expected. The dose rates at the grating surface were between $3.8 \mathrm{~Sv} / \mathrm{h}$ and $12 \mathrm{~Sv} / \mathrm{h}$ in March 2017 and between 4.7 Sv/h and 9.7 Sv/h in April 2015. In the most recent analysis, a radiation detector was gradually lowered from the grating surface and the dose was found to drop as the detector approached the water's 
surface and then drop even further until the floor of the PCV was approached. Here, there is a significant amount of accumulated sediment that is likely contributing to the increase in dose. Dose rate measurements for March 2017 can be seen in Figure F-15, while similar values for April 2015 can be seen in Figure F-16.[168]

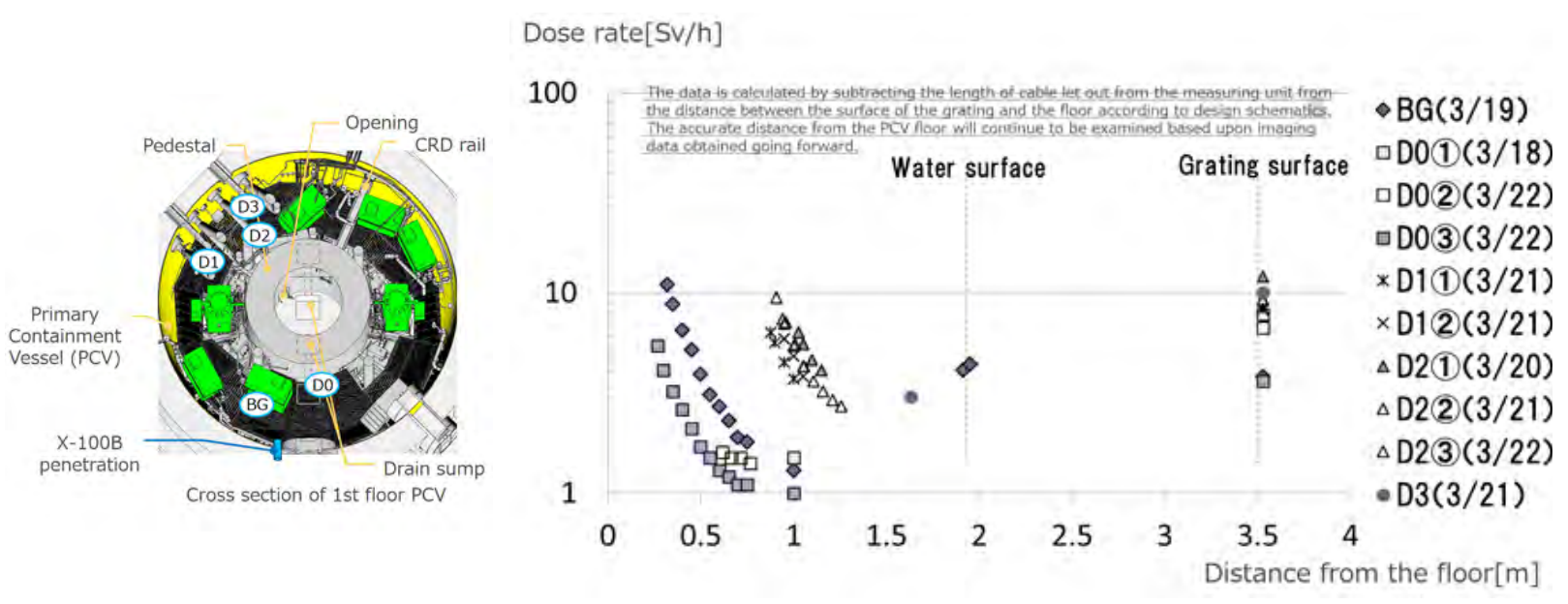

Figure F-15. PCV dose measurements on and below the grated floor outside the pedestal region of 1F1, taken in March 2017. (Courtesy of TEPCO Holdings [168])

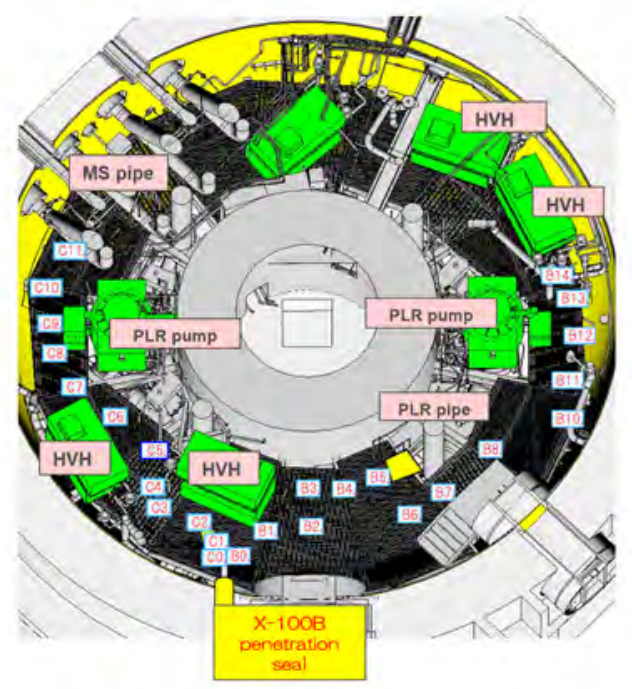

\begin{tabular}{|l|c|}
\hline & $\begin{array}{c}\text { Dose rate } \\
(\text { Sv/h) }\end{array}$ \\
\hline B3 & 7.4 \\
\hline B4 & 7.5 \\
\hline B5 & 8.7 \\
\hline B7 & 7.4 \\
\hline B11 & 9.7 \\
\hline B14 & 7.0 \\
\hline C2 & 6.7 \\
\hline C5 & 8.3 \\
\hline C6 & 7.7 \\
\hline C9 & 4.7 \\
\hline C10 & 5.3 \\
\hline C11 & 6.2 \\
\hline
\end{tabular}

B3 B14 (Measurement date: April 10, 2015)

C2 C6 (Measurement date: April 15, 2015)

C9 C11 (Measurement date: Anril 16. 2015)

Figure F-16. PCV dose measurements on the grated floor outside the pedestal region of $1 \mathrm{~F} 1$, taken in April 2015. (Courtesy of TEPCO Holdings [168]) 


\section{F.3.2. 1F2 Examinations}

During the January and February 2017 entries, dose measurements were also obtained with a self-propelled, shape-changing "Scorpion" robot through the 1F2 X6 penetration (see Section 5.2.3.1). As discussed in Section 4.3.2, the dose rates, which had to be corrected due to some initial calibration errors, are slightly higher, but similar to values measured for $1 \mathrm{~F} 1$. It is speculated that variations in dose rate measurements are due to the distribution of debris within the PCV.

\section{F.3.3. 1F3 Examinations}

Dose rates were also obtained during the July 2017 entry with the submersible 'Little Sunfish' robot through the 1F3 X53 penetration (see Section 5.2.3.2). Although measurements were limited to the control system location for this robot, the cumulative dose values were 2 Gy (July 19), 2 Gy (July 21), and 13 Gy (July 22). It is speculated that observed variations are associated with the distribution of debris within the PCV.[166,169]

\section{F.4. Other Radiological Measurements}

Evaluations of radiological samples from outside the containment buildings provide insights on two important questions:

- Did late-phase fission product releases (i.e., around the 94 hour mark in the event) originate primarily from $1 \mathrm{~F} 2$, which was still undergoing active core damage progression?

- Did the notable land contamination to the northwest of the Fukushima Daiichi plant primarily arise due to a coincidence of rapid core degradation, impairment of containment, and meteorological conditions?

Both questions pertain to increased understanding that can be gained from these reactor-scale events, whether protection of containment during the most active periods of core damage progression can significantly ameliorate the potential for notable off-site consequences. Another issue of interest is whether a core degradation event ultimately progresses to a point where the geometry of the degraded core does not have sufficient surface area to support strong fission product release to the containment and ultimately the environment. Evidence to this effect tends to remove from consideration late-phase impairment of containment due to harsh environments (e.g., temperature and radiation fields) as a meaningful contributor to offsite risk. Issues of late-phase containment impairment would thus be more relevant from the perspective of accident remediation.

Other radiological information from Fukushima Daiichi primarily consists of concrete samples taken from the reactor buildings of the affected units and evaluations of contaminated soil samples from outside the affected units.

\section{F.4.1. Insights from Examinations of Concrete Samples}

To date, the information available from examinations of concrete samples is insufficient to support a broad-spectrum evaluation of fission product chemistry. However, some trends in the available data are worth noting.[170] 
- The overall volatile fission product releases appear to be consistent across all three units. The ${ }^{137} \mathrm{Cs}$ concentration (in units of $\mathrm{Bq} / \mathrm{g}$ ) is high in the concrete samples obtained from all three units.

- The release of fission products having lower volatility appears to be relatively higher at 1F2 compared with $1 \mathrm{~F} 1$ and $1 \mathrm{~F} 3$. The concentrations of, for example, Eu, Tc and Sr are generally higher in the concrete samples from $1 \mathrm{~F} 2$.

Despite these trends, the different locations from which concrete samples were taken prevent any accident progression insights to be developed at this time. The 1F2 information was acquired from a highlycontaminated region, the floor concrete in the shield plug area (i.e., above the DW head).

\section{F.4.2. Insights from Examinations of Soil Samples}

TEPCO Holdings has been collecting and analyzing samples from the $1 \mathrm{~F}$ site for the past several years; and in this collection, the total activity of Cs is of large interest because of its contribution to human dose. In determining the activity of Cs, their sample collection and examination have also yielded the Cs134/137 ratios in several key areas around the site. These ratios, which are summarized in Table F-1 for $1 F 1$ and $1 F 2$, range from 0.82 to 1.12 . These values are consistent with previous samples collected onsite and the average plant-average Cs ratio. These values are also in good agreement from the sample collected within the $1 \mathrm{~F} 1$ containment and the combined $1 \mathrm{~F} 1 / 1 \mathrm{~F} 2$ vent stack drain water. This indicates that a significant amount of contamination in this sump is likely from 1F1.[19]

Table F-1. Back-calculated cesium activity ratios found in 1F1 and 1F2 samples.[19]

\begin{tabular}{|l|c|}
\hline \multicolumn{1}{|c|}{ Measurement Location } & Cs 134/Cs 137 Ratio \\
\hline 1F2 TIP Tube B-Line & 1.01 \\
\hline Sediment from PCV Entry 1F1 & 0.92 \\
\hline Refueling Floor 1F2 Concrete - Strippable Paint & 1.12 \\
\hline Refueling Floor 1F2 Concrete - Waste Cloths & $0.82-0.83$ \\
\hline 1F1/1F2 Vent Stack Drain Water & 0.89 \\
\hline
\end{tabular}

Interestingly, two separate peaks of Cs-ratio were found on paint-covered concrete from the 1F2 refueling floor. The first peak centers on $0.82-0.83$ and was found in Cs that was easily wipe-able from the surface. The higher Cs-ratio peaks were found when the paint itself was stripped off the concrete and examined. Two potential explanations for this are: (1) the influence of 1F1 PCV vent gas flowing backward through SGTS of 1F2 and (2) differing Cs-ratios resulting from the degradation of fuel assemblies with different burn-ups. These two separate peaks can be seen in Figure F-17.[19]

Examination of the ratio of ${ }^{134} \mathrm{Cs}$ to ${ }^{137} \mathrm{Cs}$ in the off-site contaminated soil samples indicates that there may also be a statistically relevant contribution from 1F3.[171] This evidence should provide a cautionary warning to avoid excluding $1 \mathrm{~F} 1$ and $1 \mathrm{~F} 3$ core damage progression scenarios exhibiting enhanced fission product release from containment to the environment beyond the 90 hour mark. As discussed above, both the $1 \mathrm{~F} 1$ and $1 \mathrm{~F} 3$ containments were impaired well before this time. Additional information on this topic may be obtained by isotopic evaluations of concrete samples taken from the 1F1 and 1F3 refueling floor shield plugs. Evaluation results could be used to assess the off-site ${ }^{134} \mathrm{Cs}$ to ${ }^{137} \mathrm{Cs}$ isotopic ratios. 


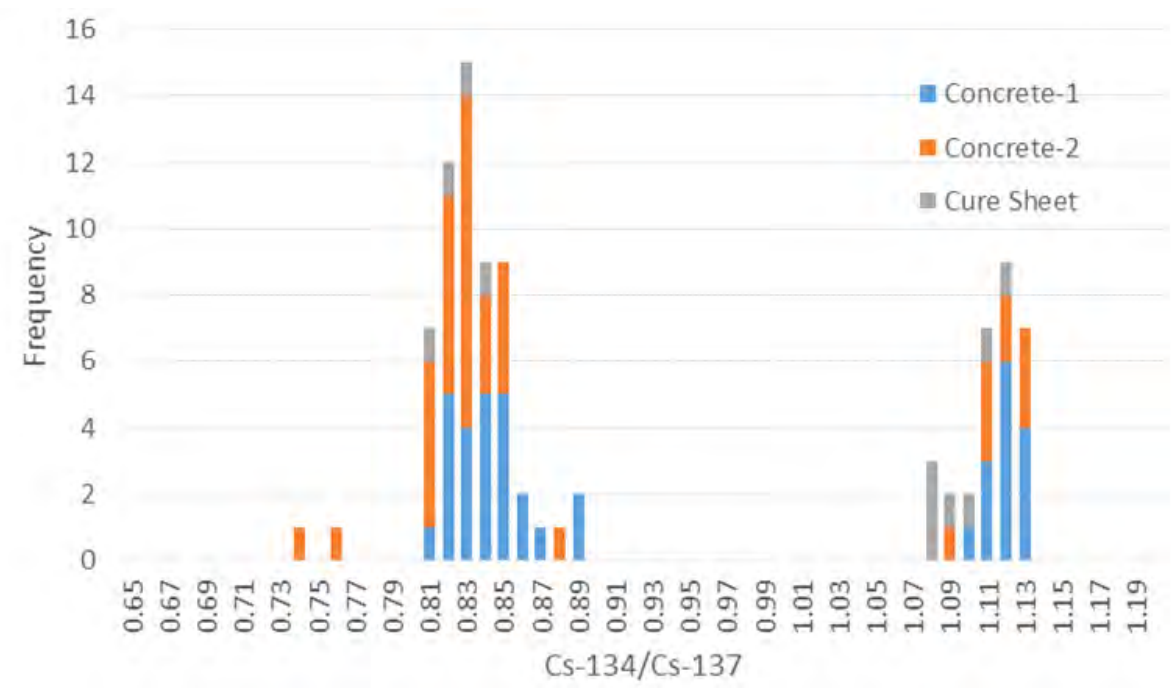

Figure F-17. Cs-134/Cs-137 ratios of paint-covered 1F2 concrete. (Courtesy of TEPCO Holdings [19])

\section{F.4.3. Insights based on Initial Burnup}

Multiple organizations have explored initial radionuclide inventories at the time of the accident, including the JAEA, TEPCO Holdings, GRS and SNL.[172] These calculations require a 3D representation of the reactor core and subsequent full-core neutronic modeling. Generalized power distributions and burnup distributions for a characteristic BWR can be seen in Figure F-18.[172] It can clearly be seen that there is a wide variety in the individual power of any given assembly, as well as the local burnup. The difference in these two values drives both decay heat and the overall radionuclide release. When examining key radionuclides and radionuclide ratios for each unit, it becomes apparent that these values are highly dependent on local conditions within the reactor. The Cs-134 to Cs-137 activity ratio for $1 \mathrm{~F} 3$, averaged on an assembly by assembly basis, is given in Figure F-19. [172] This ratio varies from 0.2 to 1.4 , based primarily on assembly burnup. This introduces additional uncertainty in efforts to attribute key events to releases and deposition patterns to specific units at Daiichi.

\section{F.4.4. Potential for Recriticality}

The possibility for a recriticality has been discussed and analyzed by multiple organizations, including Gesellschaft für Anlagen- und Reaktorsicherheit (GRS) [266] and EPRI.[267] Discussion of this possibility arose as a possible explanation for radiation measurements near the 1F site main gate. As shown in Figure F-20, measurements indicate several times when gamma dose rates increased and neutrons were detected.[40] It has been postulated that these observations could be explained by one or more BWR control rod blades melting prior to the reflooding of the reactor core by firewater injection.

\section{F.4.5. Limitations}

As discussed above, evaluations of sources from outside the containment provide a very gross assessment of fission product transport from the degraded fuel and ultimately through an impaired containment 

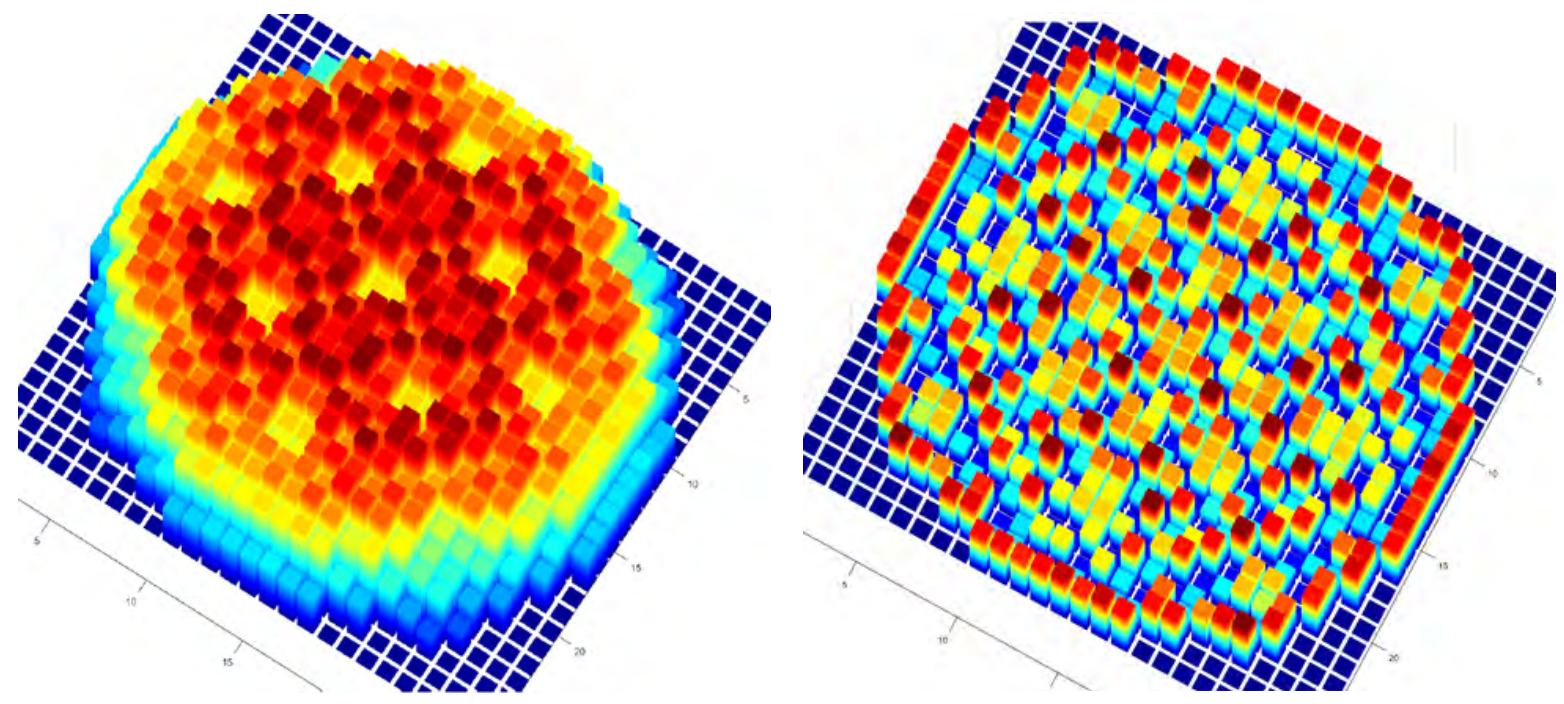

Figure F-18. Generalized BWR power distribution (left) and burnup distribution (right) on an assembly by assembly basis, red represents higher power and higher burnup. (Courtesy of SNL [172])

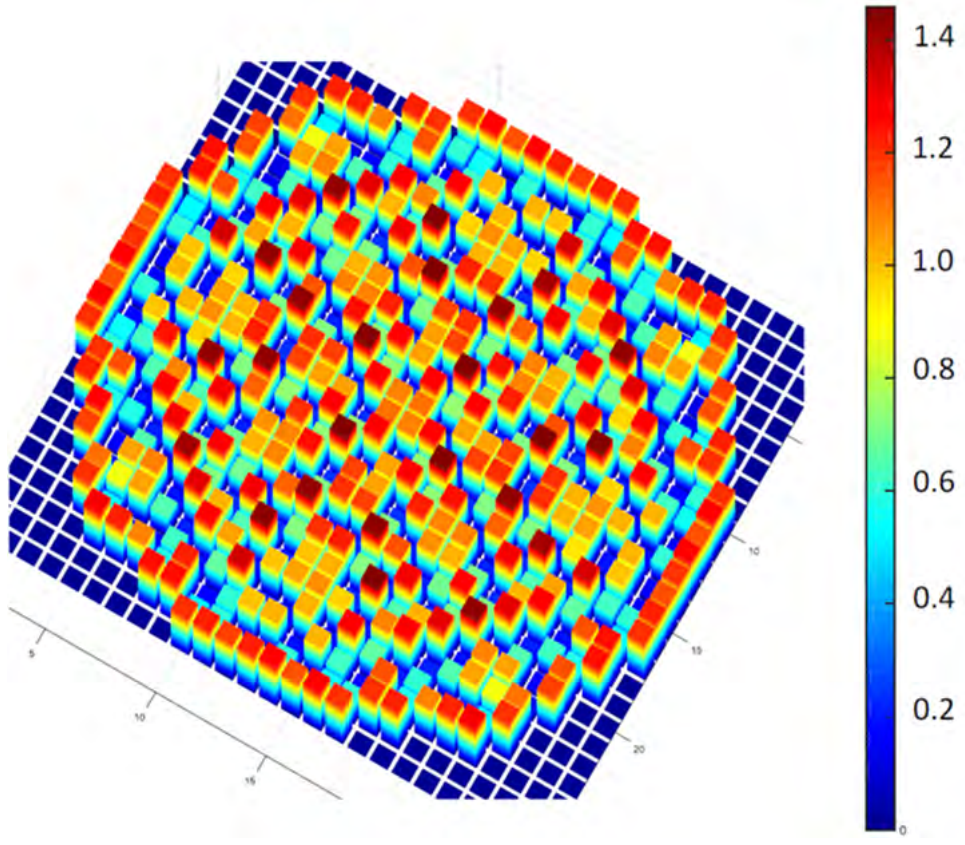

Figure F-19. 2D spatial distribution of the Cs-134 to Cs-137 activity ratios in 1F3. (Courtesy of SNL [172])

to the environment. It is of limited utility in identifying the release and transport of the range of radionuclide species expected to evolve during a severe accident. 


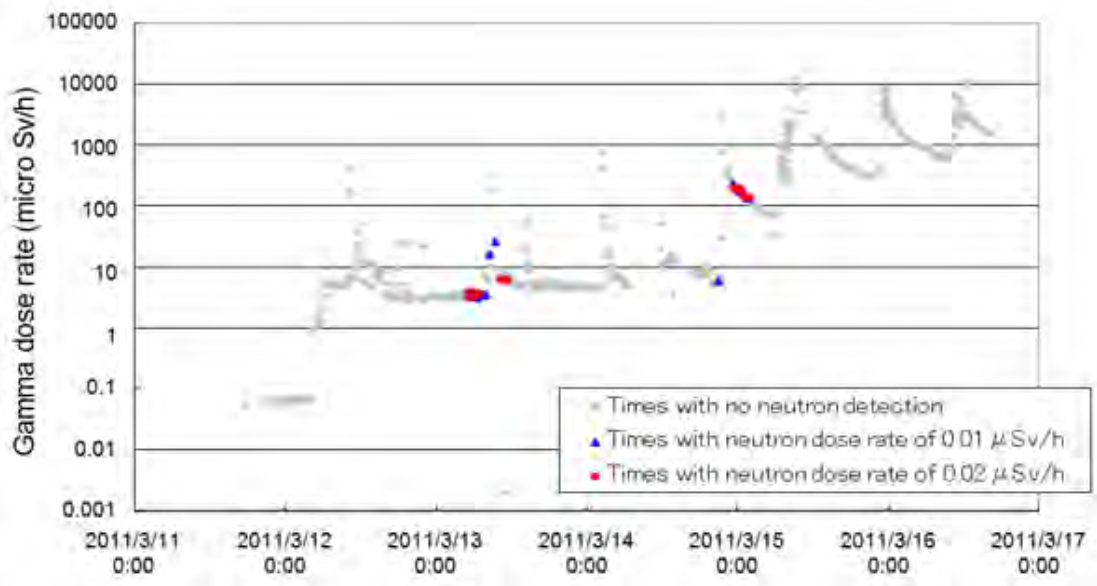

Figure F-20. Gamma dose rate measurements at the main gain, indicating timings of coincident neutron dose rate. (Courtesy of TEPCO Holdings [40])

The different locations from which concrete samples were taken prevent any accident progression insights to be developed at this time. The 1F2 information was acquired from a highly-contaminated region, and the concrete shield plugs were obtained from above the DW head. Any further information that could be acquired regarding isotopic composition from the shield plugs above the DW heads at 1F1 and 1F3 would be useful for evaluating fission product release and transport. These results highlight the insights that could be gained with respect to the release and transport of lower volatility fission products. Likewise, the range of burnup and power within each fuel assembly of each unit introduces additional uncertainties in efforts to attribute key events, releases and deposition patterns to specific units at Daiichi.

A significant amount of interest has developed in the European severe accident community related to the transport of Ru during a severe accident. It would be especially helpful if it is possible to use insights from the reactor scale events at Fukushima Daiichi to resolve fission product transport issues derived from smaller scale integral tests. 
ANL-18/24 


\section{APPENDIX G. AREA 3 - DEBRIS END-STATE PREVIOUSLY REPORTED FINDINGS}

This appendix tabulates previous findings by TEPCO Holdings related to Area 3 (Debris Endstate) for the affected reactors at Fukushima Daiichi. Key findings obtained since the U.S. Forensics Effort FY2017 report[3] was issued are summarized in the main body of the report.

\section{G.1. Thermocouple Measurements}

Figures G-1 through G-3 provide thermocouple measurements [11] obtained from 1F1, 1F2, and 1F3, respectively, for a time period spanning several months following the accident. These measurements provided the first indication of where core debris likely resides, and equally important, where it is not. Water injection was shifted from the fire protection (FP) to feedwater (FDW) injection systems for the three units in the April-May 2011 timeframe. However, RPV thermocouple (TC) measurements indicated temperatures well above the coolant saturation temperature after this switch was made, particularly for 1F2 and 1F3. This provided an early indication that all core debris may not have been cooled using the FDW injection pathway. As a reminder, the feedwater for a BWR is introduced near the top of the RPV (see Figures G-1 through G-3) and then flows down along the exterior surface of the core barrel to the core inlet. This led TEPCO Holdings and the technical support community to conclude that there may be significant leakage path(s) in the bottom region of the reactor vessel for all three units (e.g., BWR recirculation pumps are known to leak under severe accident conditions [268]). In such cases, some fraction of the coolant could bypass the core debris, and the material was not fully cooled.

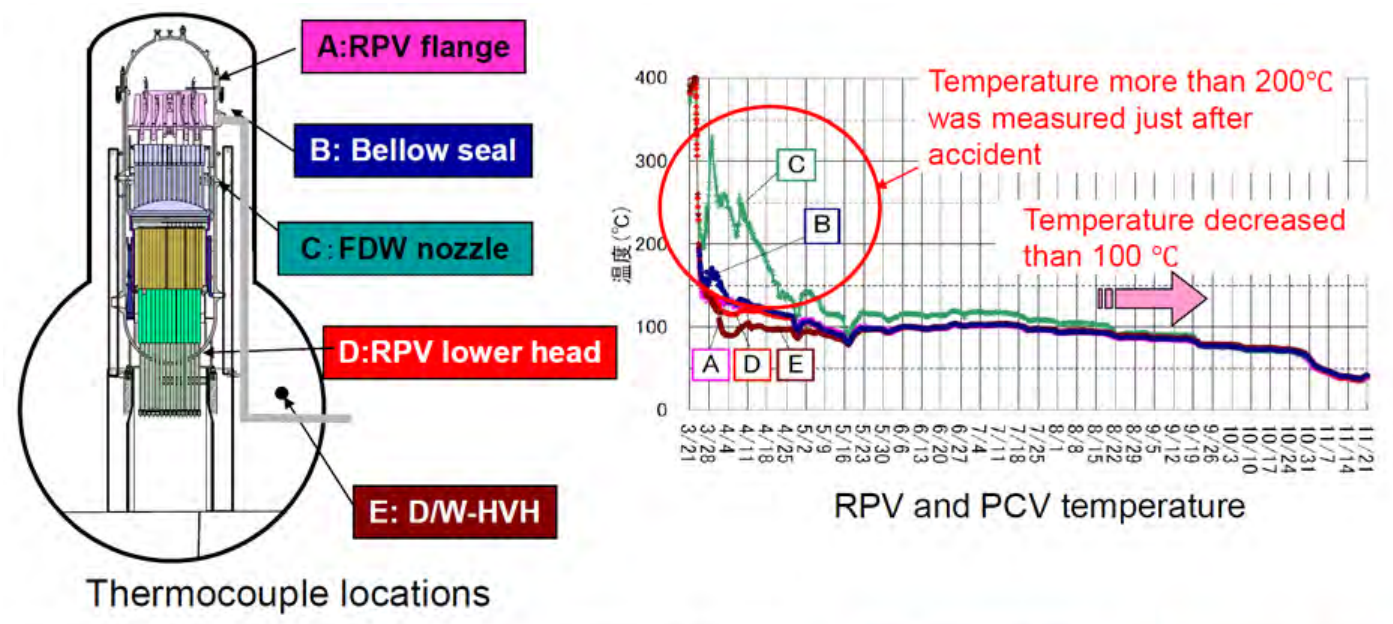

\begin{tabular}{|c|c|c|c|}
\hline End of March or April & End of June & Begin. of Aug. & End of Dec. \\
\hline \multirow{2}{*}{$\begin{array}{l}\text {-Switch from fire trucks to motor pump } \\
\text {-Switch from FP system to FDW system } \\
\text {-Minimize water injection to restrain } \\
\text { contaminated water generation }\end{array}$} & $\begin{array}{l}\text {-Start of water } \\
\text { treatment system }\end{array}$ & $\begin{array}{l}\text { - Temperature reached } \\
\text { to subcooling condition }\end{array}$ & $\begin{array}{l}\text {-Start of water } \\
\text { injection from CS }\end{array}$ \\
\hline & & \multicolumn{2}{|c|}{ Suggested no large debris in RPV } \\
\hline
\end{tabular}

Figure G-1. RPV temperature measurements for 1F1 following the accident. (Courtesy of TEPCO Holdings [11] 

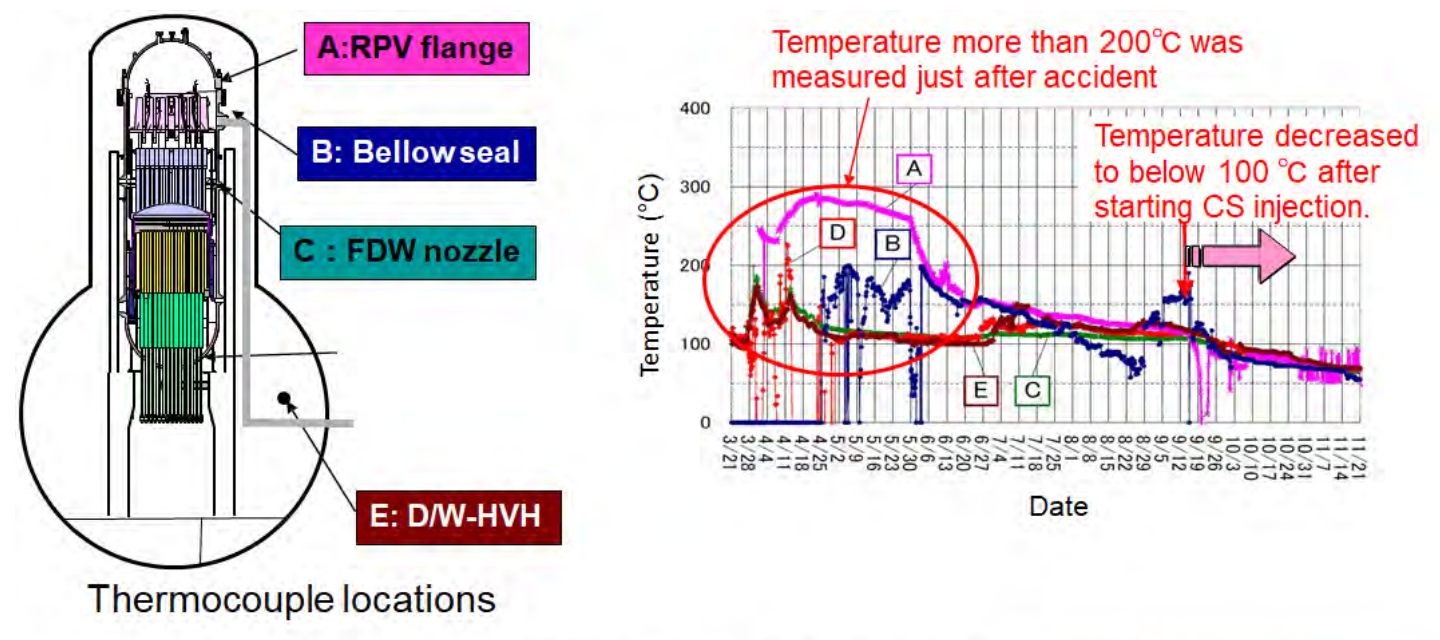

\begin{tabular}{l}
\hline End of March \\
-Switch from fire trucks to \\
motor pump \\
-Minimize water injection to \\
restrain contaminated water \\
generation
\end{tabular}

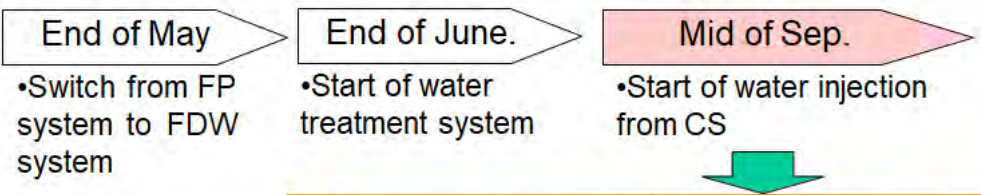

Suggested some debris in core region

Figure G-2. RPV temperature measurements for 1F2 following the accident. (Courtesy of TEPCO Holdings [11])
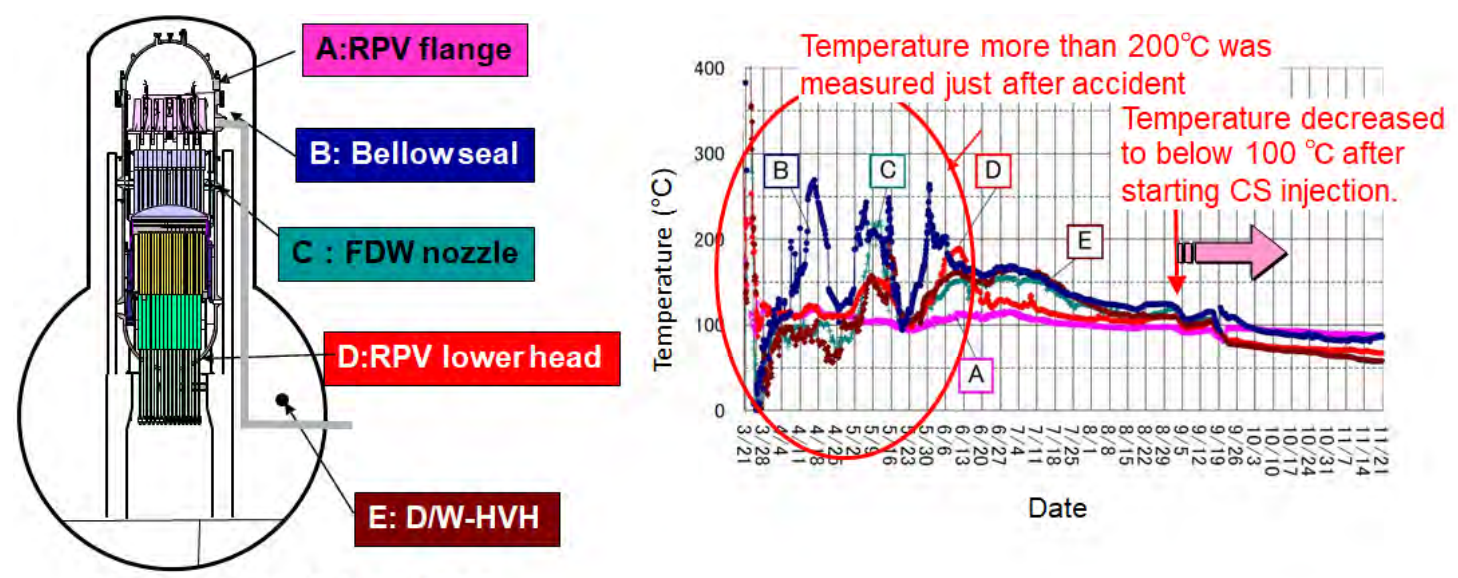

Thermocouple locations

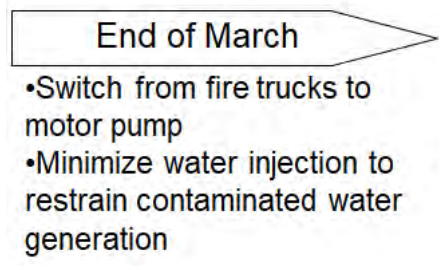

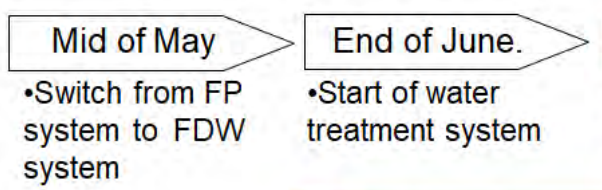

Suggested some debris in core region

Figure G-3. RPV temperature measurements for 1F3 following the accident. (Courtesy of TEPCO Holdings [11]) 
On this basis, TEPCO Holdings changed the water injection from the FDW system to the core spray (CS) system in the September 2011 timeframe for $1 \mathrm{~F} 2$ and 1F3, while this change was made in late December 2011 for $1 F 1$. This injection method introduces a water spray from directly above the core. As shown in Figures G-2 and G-3, this changed injection point caused the RPV temperatures for 1F2 and 1F3 to be reduced to coolant saturation temperature, which is the expected condition when core debris is covered with water. However, this change had little if any impact for $1 \mathrm{~F} 1$, for which the RPV temperatures had already fallen below saturation. This, along with indications from water level instrumentation not increasing, led TEPCO Holdings and many in the technical support community to conclude that some fraction of fuel remained in the RPV for 1F2 and 1F3, but most of the core debris was likely ex-vessel for 1F1. Note that this information does not rule out the possibility of ex-vessel core debris for 1F2 and 1F3; however, there is likely some fraction of core debris in-vessel that caused elevated temperatures to occur when water was introduced via the FDW system.

This information is consistent with early U.S. [55,56] as well as international [269] code predictions of likely debris locations for the three units based on modeling conducted relatively soon after the accident. Since that time, further refinements of these analyses have not changed these same basic conclusions. The picture is clearest for $1 \mathrm{~F} 1$, which was essentially an unmitigated station blackout until $\sim 15$ hours into the accident sequence [e.g., an event in which all onsite and offsite alternating current power is lost and in which no successful mitigating actions are taken]. At this point, operators could reflood the core with seawater. However, the predictions are less consistent for 1F2 and 1F3 where operators could maintain some degree of core cooling by various means for the first several days of the accident. The uncertainties arise as to the effectiveness of water injection (due to elevated PCV pressure), and the effectiveness and extent of backup cooling system operation under severe accident conditions; this situation was compounded by a general lack of functioning instrumentation (as well as the fact that surviving instrumentation had in many cases been pushed well outside the normal operating envelope; this statement is true for the TC measurements shown in Figures G-1 through G-3) that would allow the actual plant conditions to be ascertained.

Aside from these general observations, it is noteworthy that the TC data in Figures G-1 through G-3 may provide valuable information that could be used to further evaluate likely core debris end-state locations using system-level codes. In particular, these codes have the ability to calculate heatup of the RPV, and through appropriate nodalization, it may be possible to calculate temperatures on structures that correspond to locations where the measurements were obtained in Figures G-1 through G-3. The core debris distribution calculated by the codes would influence the temperature responses at these locations, and the extent that the codes are able to reproduce the signatures shown in Figures G-1 through G-3 may provide further insights on likely debris distributions. This type of analysis is relevant to the MAAP-MELCOR cross-walk activity; [57,270] i.e., these two codes predict quite different in-vessel core melt behavior and, thus, RCS failure modes. These modeling differences may be reflected in long-term RPV temperature predictions that could, by comparison with the data, provide an indication of likely relocation mode(s), which is one of the key questions being addressed as part of the crosswalk activity.

More recently, HVH temperature measurements made by TEPCO Holdings since the accident indicate that there is likely some core debris around the CRDs in the peripheral region below the RPV;[18] see Figure G-4. However, based on these measurements it is difficult to tell if the debris is inside or outside the CRD housing. This is based on the observation that the HVH temperatures surrounding the CRDs are higher than the average PCV atmospheric temperature, and this tendency becomes stronger when the FDW injection flowrate decreases. These inferences are consistent with newly developing information being generated by TEPCO Holdings using robot examinations. As discussed in Section 5.2.2, photographs 
obtained inside the PCVs for $1 \mathrm{~F} 2$ and $1 \mathrm{~F} 3$ indicate extensive damage to CRD structures and adhering material that could be core debris, but at this point chemical analysis has not been completed to verify that the material contains fuel and/or cladding.

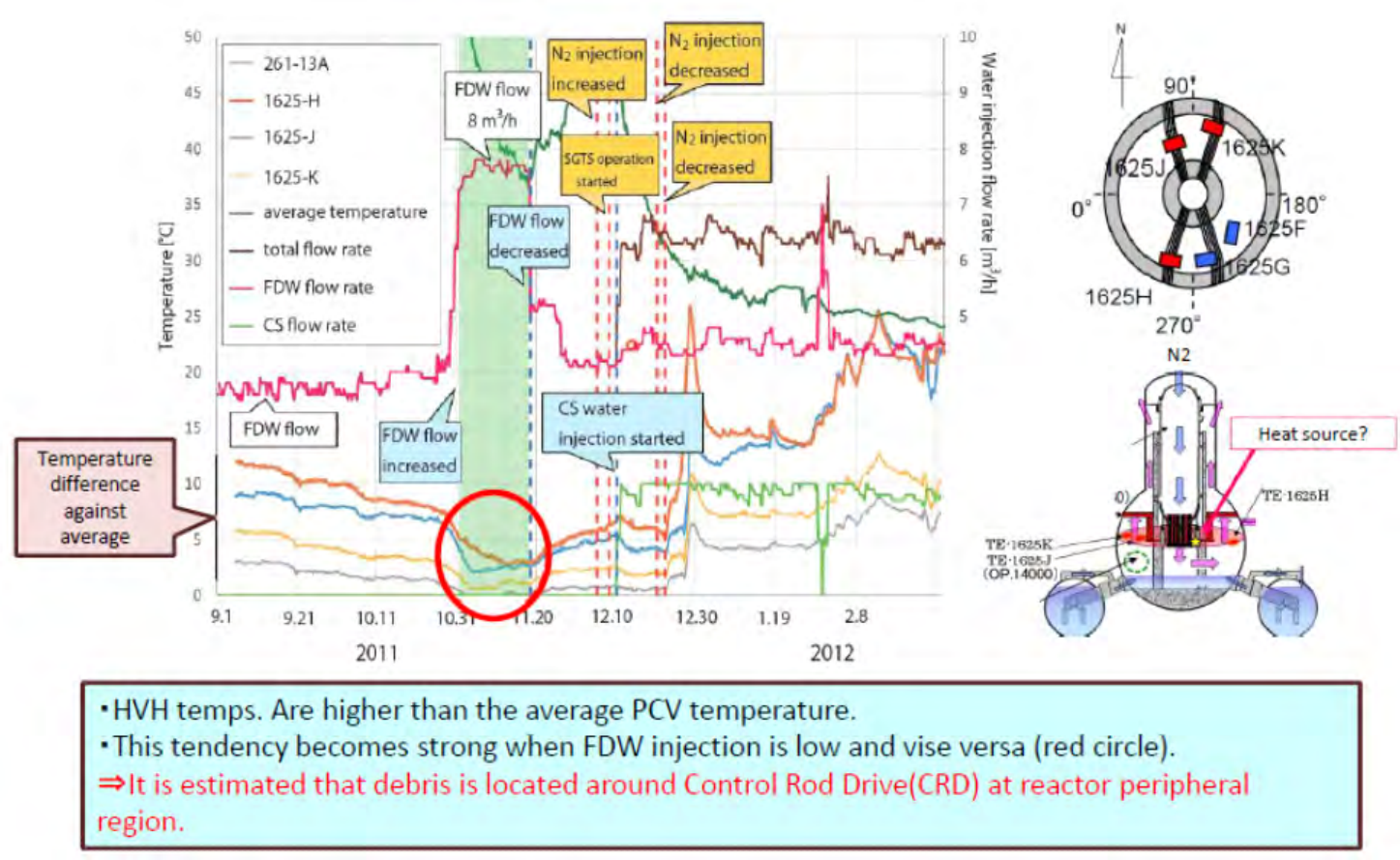

Figure G-4. Relationship between HVH temperature and water injection from the feedwater system. (Courtesy of TEPCO Holdings [18])

The results of this collection of temperature measurements, as well as the supporting code analyses and observations obtained by robots in all three units (see Section 5.2.2), help to inform D\&D activities. The results indicate that TEPCO Holdings will likely be faced with the need to remove core debris not only from the RPVs for at least two units, but also from the PCV for all three units. Finally, these measurements have also been very useful in terms of informing post-Fukushima enhancements to severe accident guidance (SAG). In particular, the data illustrate the benefit of injecting though core sprays for BWRs; this method optimizes the probability that core debris will be contacted by and cooled with the injected water, even if there are leaks in the pressure vessel.

In closing, TEPCO Holdings has effectively used TC measurements on the RPV coupled with variations in water injection flowrate and location to make inferences on debris location. One limitation with this last technique is the fact that many of the TCs on the RPV were pushed well outside their qualification envelop during the accident, which raises questions about calibration as well as potential failures that are difficult to diagnose; e.g., formation of false junctions within the TCs that can provide erroneous indications of temperature at a given location. 


\section{G.2. Images from Inspections within the PCV}

\section{G.2.1. 1F1 Examinations}

For $1 \mathrm{~F} 1$, visual information has been obtained by gaining access through the ' $\mathrm{X}-100 \mathrm{~B}$ ' penetration (see Figure G-5).[271] Prior to the accident, this penetration was shielded on the interior of the PCV to reduce the radiation level in the reactor building. The first piece of information gathered when this penetration was opened was that the lead shielding appears to have melted during the accident (see Section 3.3). Lead melts at $328^{\circ} \mathrm{C}$; temperatures this high in the PCV are hard to rationalize unless one postulates vessel failure and core debris discharge into the PCV.

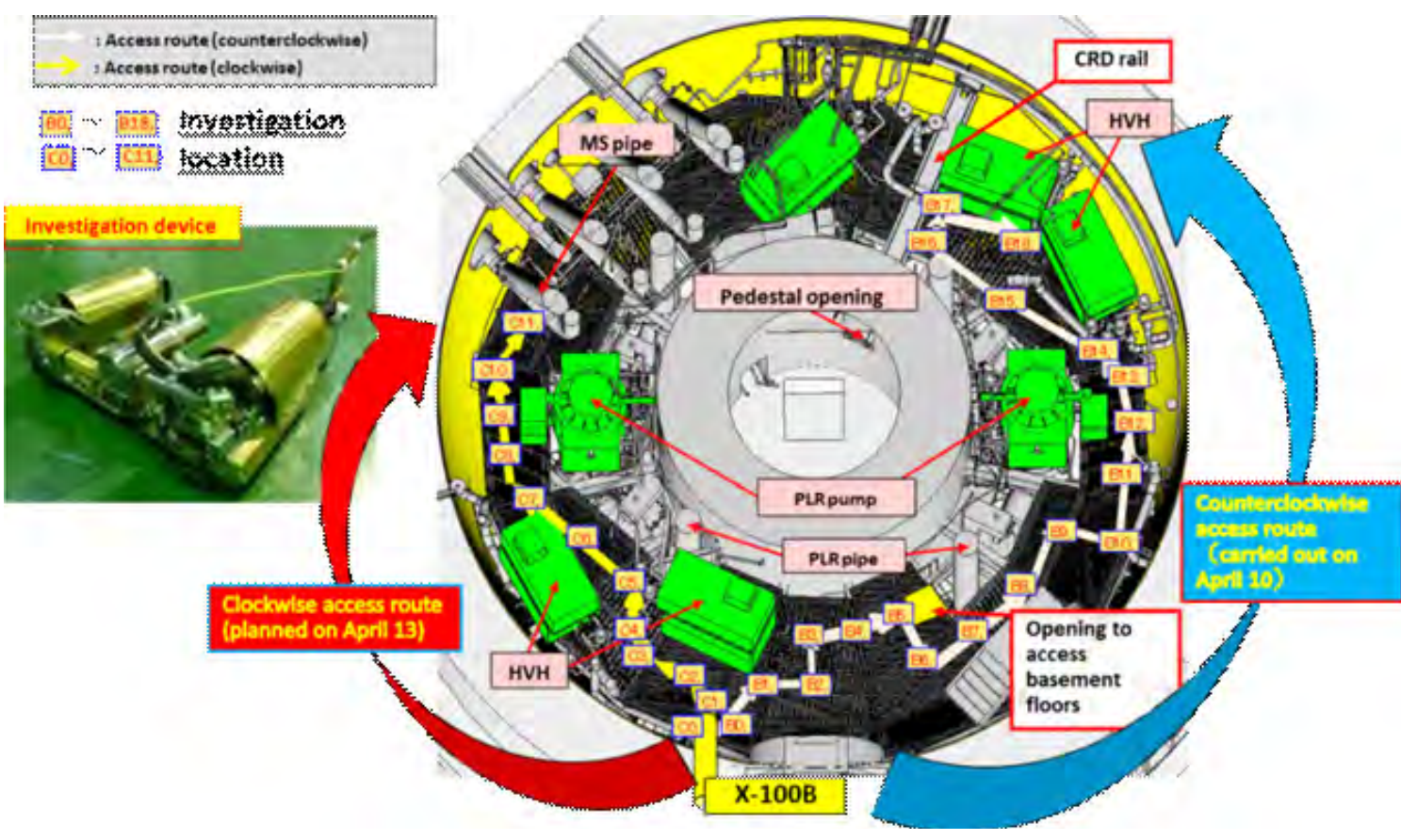

Figure G-5. Location of X-100B in 1F1 PCV and pathways of robotic examinations completed on April 10, 2015. (Courtesy of TEPCO Holdings [271])

Upon gaining access through this penetration, TEPCO Holdings initially lowered a video camera through the catwalk to the drywell floor to measure water level, temperatures, and radiation levels inside the PCV (see Figure G-6). The camera views revealed the presence of a fairly deep (i.e., $\sim 30 \mathrm{~cm}$ ) layer of sediment covering the drywell floor at the penetration location (see Figure G-7). The sediment layer deformed when touched by the camera. The blue material on top of the sediment shown in Figure G-7 was thought to be lead, which is consistent with the fact that the penetrations shielding was found to be melted upon gaining access through the penetration (see Section 3.3). It was not possible to determine if this $30 \mathrm{~cm}$ deep accumulation of material was all sediment, or if the sediment layer was shallower and covered other material which could include core debris that spread from the pedestal doorway opening. 

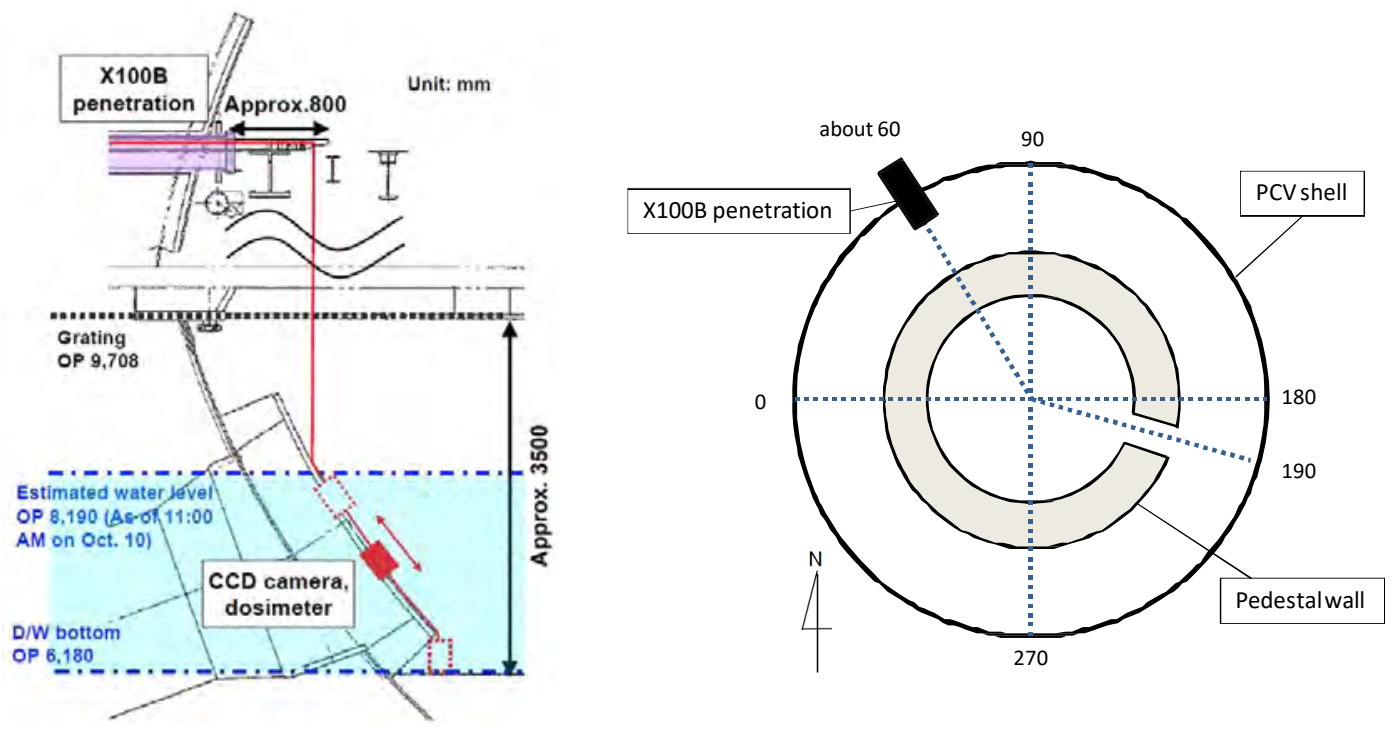

Figure G-6. Illustration of CCD camera access through X-100B penetration. (Courtesy of TEPCO Holdings [18])
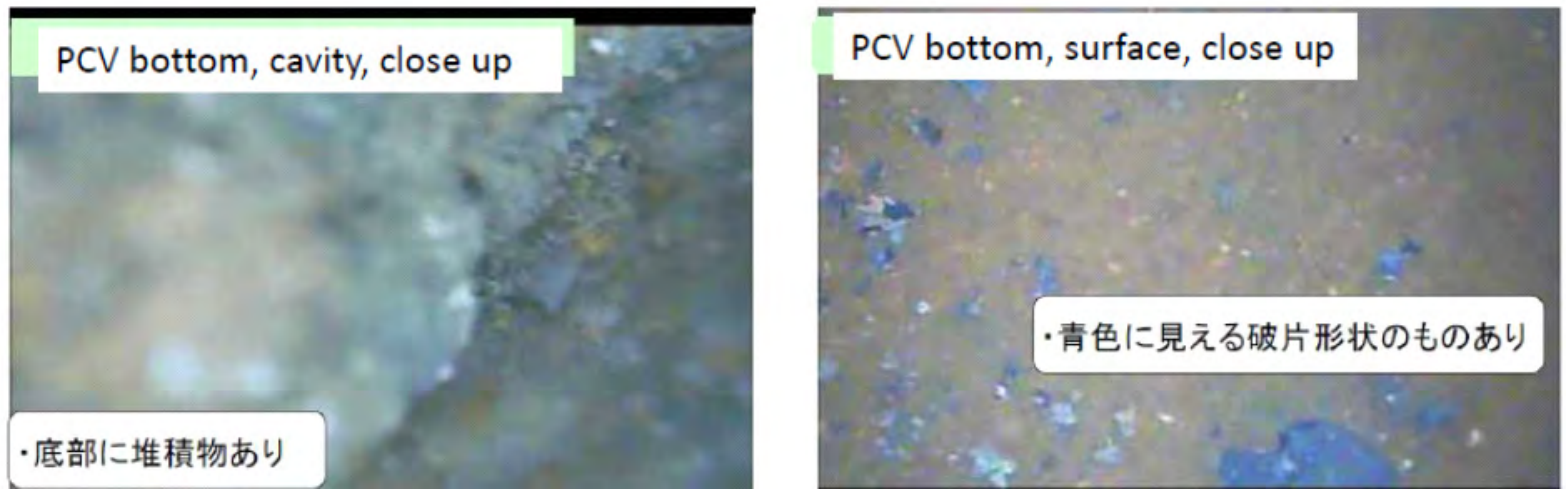

Figure G-7. Views of sediment surface covering the drywell floor at the X-100B location. (Courtesy of TEPCO Holdings [18])

Possible materials that could be included in the sediment are paint and rust from the PCV structure, RPV insulation (typically containing silica, calcia, and/or alumina), sand from injected seawater, or concrete aerosols from MCCI.[272] Thus, analysis of this sentiment could provide valuable data on the event sequence (e.g., if core/concrete interaction occurred). Concrete aerosol would be expected to be dominated by $\mathrm{SiO}_{2}$ since the reactors at Fukushima employee siliceous concrete. To determine if the silica was from insulation versus MCCI, it would be important to compare the silica/calcia and silica/alumina ratios in the sediment to that expected from insulation versus that expected from MCCI. Furthermore, it would be desirable to probe below the sediment surface to determine if hard structure exists, as would be expected if core debris had spread to the X-100B location. 
As noted, due to the presence of the sediment layer, it is not possible to determine if core debris is on the drywell floor at the X-100B penetration, which is $\sim 130$ degrees from the pedestal doorway (Figure G5). Determining if debris lies below the penetration would provide a data point for assessing predictions of ex-vessel core melt spreading based on MAAP and MELCOR pour scenarios as calculated with MELTSPREAD.[58] As is evident from Figure G-8, the measurement indicates that if core debris is at the penetration location, then MELTSPREAD prediction of spreading distance based on MAAP pour conditions would be consistent with that finding. However, this single data point is insufficient to gauge the accuracy of the MELTSPREAD-MELCOR prediction as the spreading prediction for that case is limited to the vicinity of the pedestal doorway. For this scenario to be correct, the material at the X-100B location would need to consist entirely of sediment. Determining the actual material composition at this location would be useful in reducing the range of possibilities regarding the extent of melt spreading in $1 \mathrm{~F} 1$.

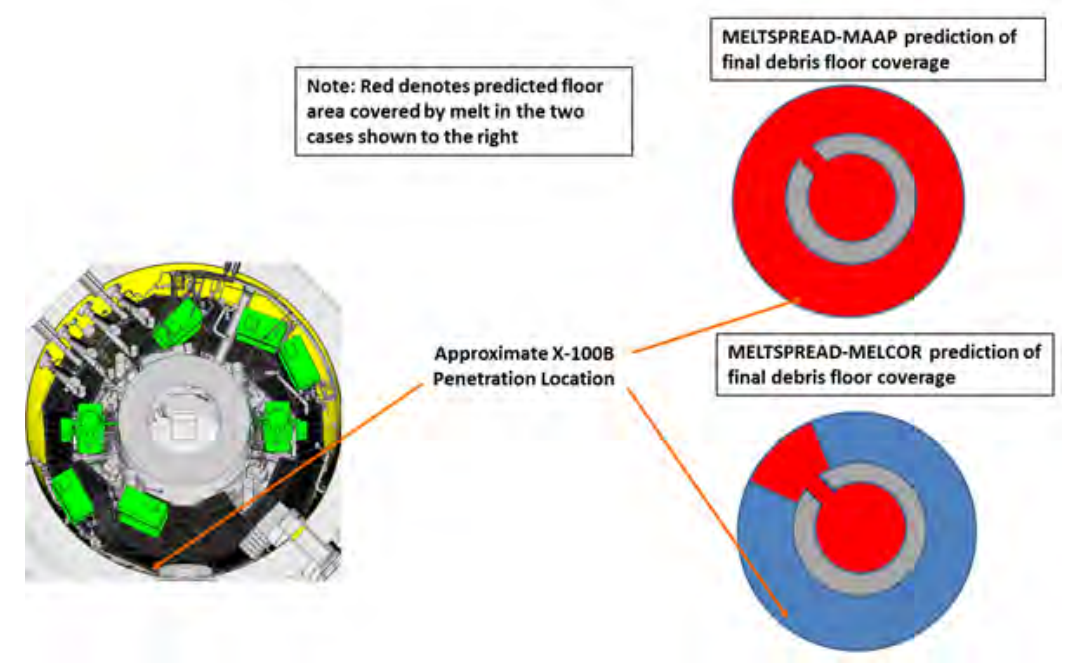

Figure G-8. Approximate location of X-100B penetration relative to predictions of core debris spreading in 1F1. (Courtesy of TEPCO Holdings and ORNL [58,271])

Additional examinations in $1 \mathrm{~F} 1$ near the pedestal doorway and sumps have indicated the presence of foreign material on the drywell floor and walls; see Figure G-9.[168] The presence of sediment on horizontal surfaces makes it difficult to determine if this is core debris on the floor in most photos. However, one image (i.e. 'D3' in Figure G-9) from outside of the pedestal doorway from a vertical structure suggests the presence splattered core-like debris. If this is splattered core material, two possible deposition methods are: i) melt relocation from the RPV, or ii) splattered from melt eruptions due to MCCI near the structure; see Figure G-10 for a comparison with splattered material formed by melt eruptions from previous MCCI tests [273]. Elemental analysis of a splatter sample would be able to distinguish between these two cases based on whether concrete oxides (e.g. $\mathrm{SiO}_{2}, \mathrm{CaO}, \mathrm{Al}_{2} \mathrm{O}_{3}, \mathrm{MgO}$ ) are present in the material, which are indicative of MCCI. This analysis has been highlighted as part of the PC-3 recommended examinations; see Table 5-2. 


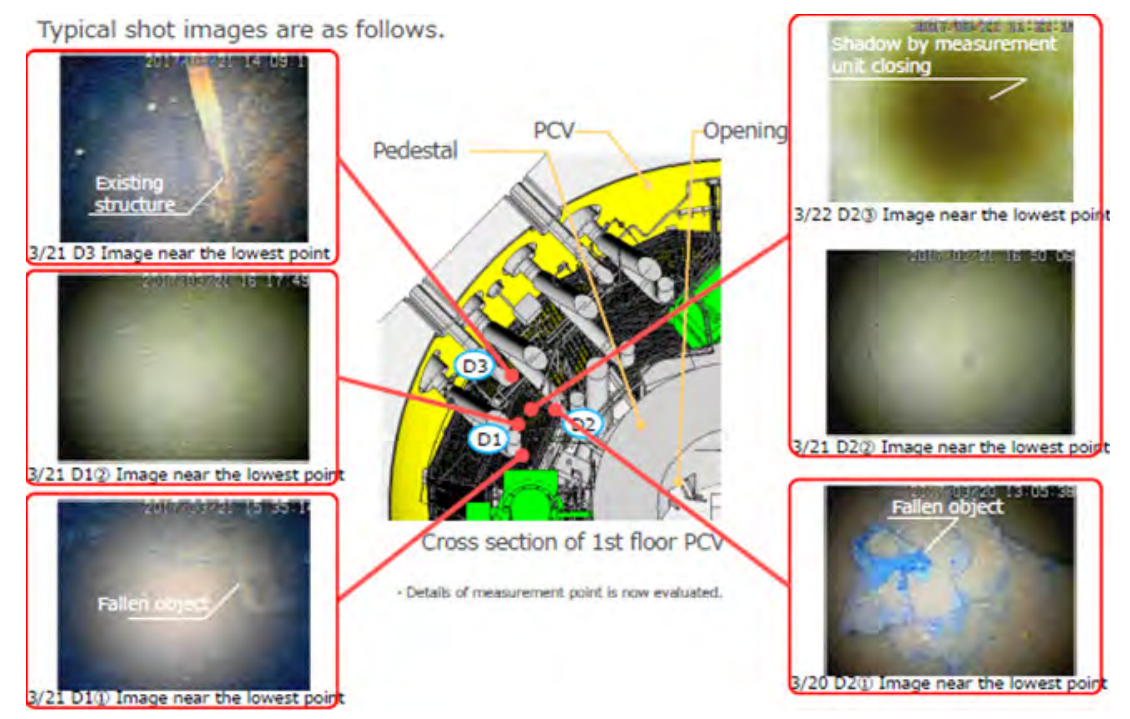

Figure G-9. Photographs of structures outside the pedestal doorway in 1F1. (Courtesy of TEPCO Holdings [168])

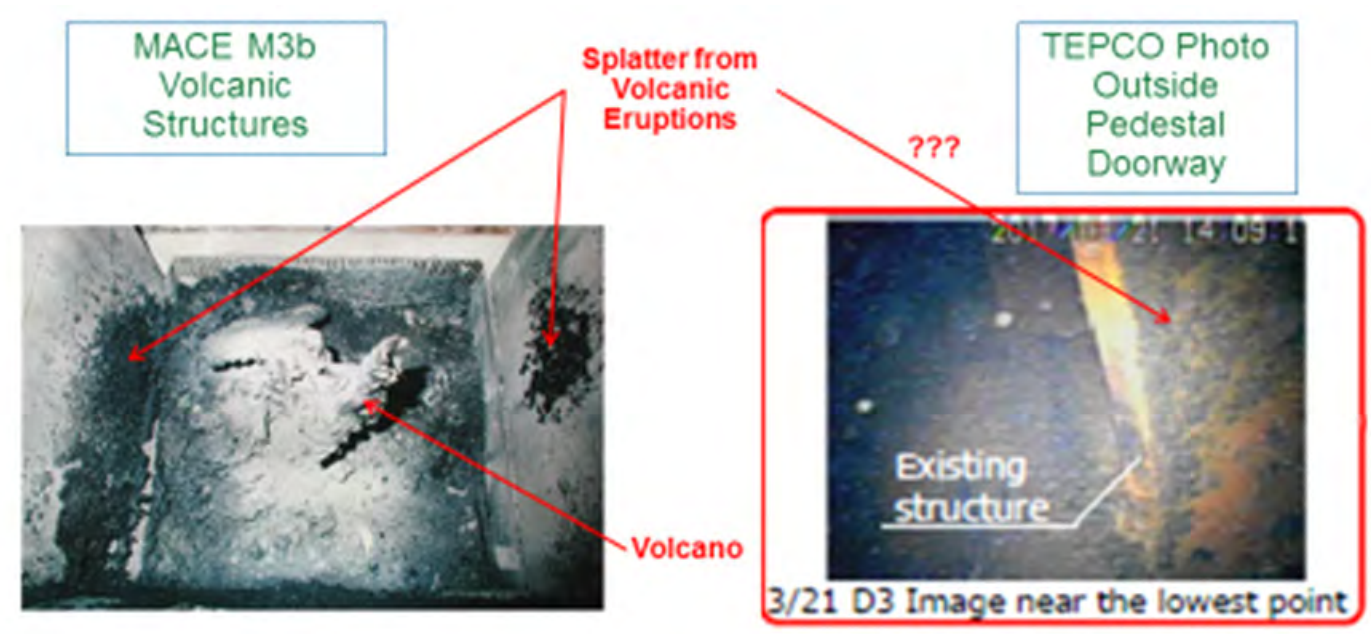

Figure G-10. Comparison of photographs of wall splatter material observed in MCCI tests with prototypic reactor material and material observed in 1F1. (Courtesy of ANL[273] and TEPCO Holdings[168])

\section{G.3. Images within the Reactor Building}

One important finding regarding ex-vessel behavior is the discovery by TEPCO Holdings that the sand cushion drain line is leaking in 1F1.[125] This indicates that there is a leak through the PCV liner. Examinations did not detect water leakage from the bellows on the downcomer, but observations were limited. The MELTSPREAD analyses of liner heatup (Figure G-11) indicate that the liner would not have been ablated through based on either the MAAP low pressure (LP) or MELCOR pour scenarios [55,56,58]; however, the liner would have been heated significantly, resulting in a vulnerability to failure by creep rup- 
ture due to the elevated containment pressures ( $\sim$ twice the design pressure) at the time of the accidents. Hence, liner failure is consistent with code predictions and measured radiation levels in the $1 \mathrm{~F} 1$ reactor building.
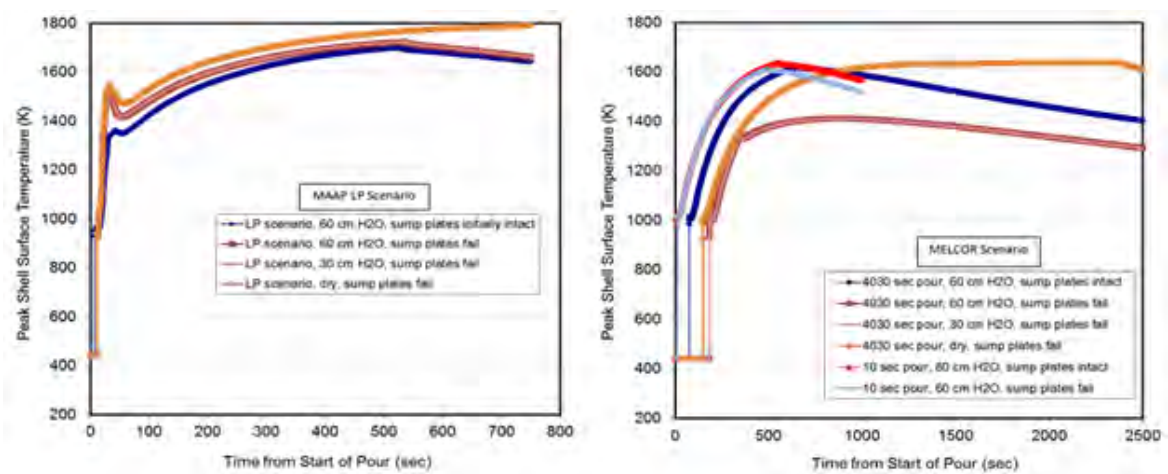

Figure G-11. MELTSPREAD predictions of liner heatup due to heat transfer from impinging melt for 1F1 based on a MAAP low pressure (LP) scenario [56] (left) and MELCOR[55] (right) melt pour conditions. (Courtesy of ORNL [58])

\section{G.4. Muon Tomography Examinations}

Evaluations have been completed using muon tomography techniques in each of the three affected units.

\section{G.4.1. 1F1 Examinations}

Muon tomography measurements using scintillation detectors are another information source that has been extremely valuable for evaluating debris end-state conditions for 1F1 (see Figure G-12).[15] Using this approach, high density fuel should show up as dark regions in captured images due to muon attenuation. As shown in Figure G-12, the core region appears to be essentially devoid of core material. The findings for $1 \mathrm{~F} 1$ are consistent with previously described system-level code analyses.[55,56]

\section{G.4.2. 1F2 Examinations}

In addition, muon tomography measurements have been obtained from 1F2 [18]; see Figure G-13. These measurements indicate the possible presence of core debris located at the bottom of the lower head (due to the dark nature of the material in that region). To a first order, the data can be used to estimate the amount of core material remaining in the RPV. For an assumed core mass of 240 metric tons, the debris volume would be $\sim 34 \mathrm{~m}^{3}$. Based on the dimensions provided in Figure G-13, the volume of the spherical lower head is calculated to be $\sim 33 \mathrm{~m}^{3}$ (which neglects CRD structures in the lower head volume). The dark area to the right suggests that approximately one third to one half of the lower head is filled with dense core debris. Thus, this difference suggests that one half to two thirds of the core material is ex-vessel. 


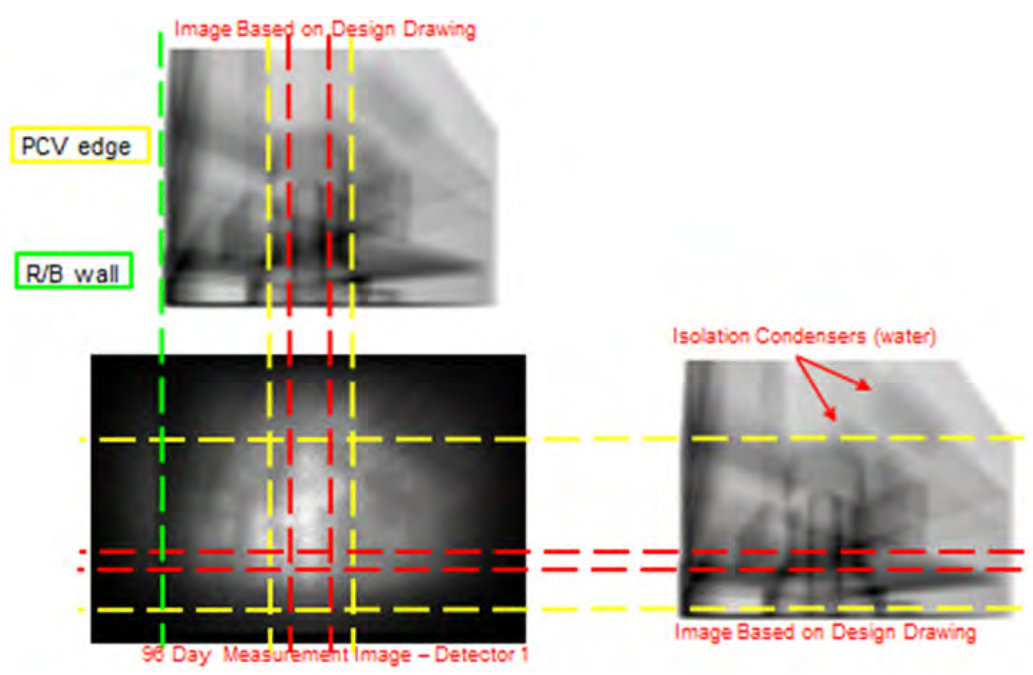

Figure G-12. Images of 1F1 obtained using muon tomography with scintillation detectors (The lower left image is measured; the other two images were calculated. Dashed lines show location of identified geometrical features). (Courtesy of TEPCO Holdings [15])
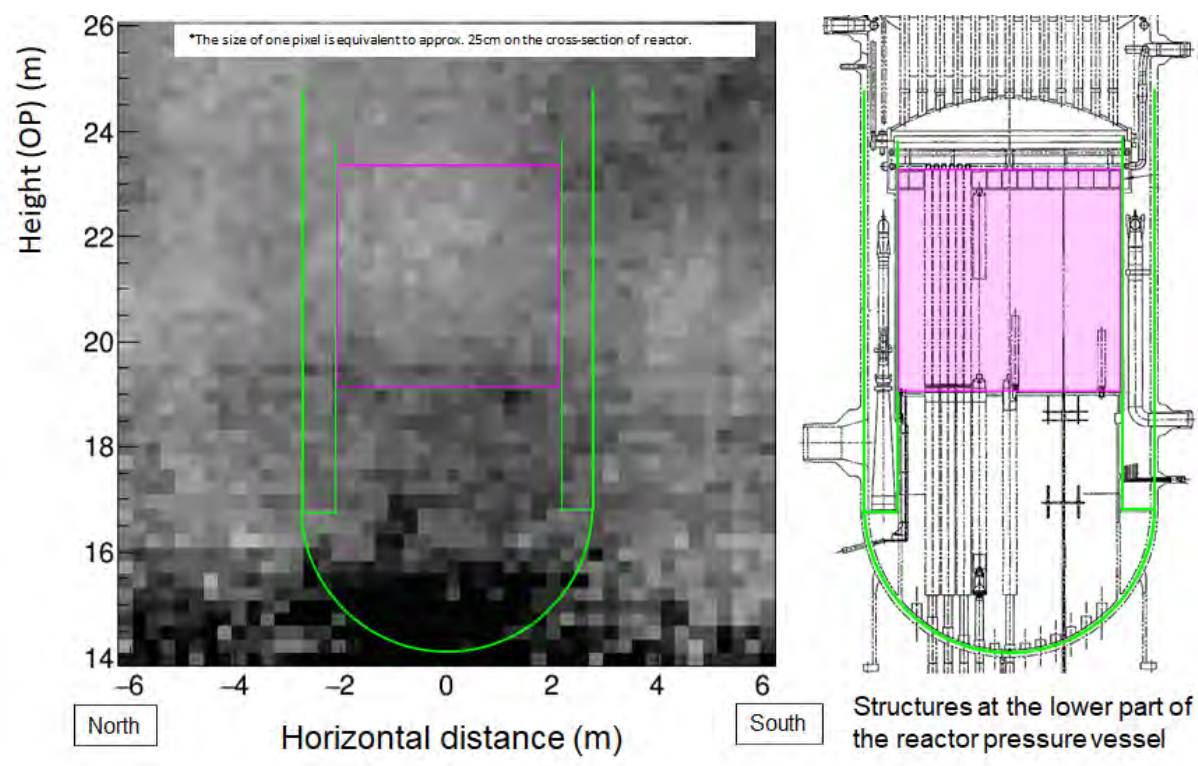

Structures at the lower part of the reactor pressure vessel

Figure G-13. Images of 1F2 obtained using muon tomography with scintillation detectors. (Courtesy of TEPCO Holdings [18])

The muon tomography readings of the bottom of the RPV, in conjunction with qualitative information obtained from the most recent entry into the $1 \mathrm{~F} 2$ containment indicates that there is most likely a significant amount of corium both within the bottom of the RPV and in the pedestal region of the containment. The results of the muon tomography scan of the bottom of the 1F2 RPV can be seen in Figure G-14 indicating the likely presence of debris.[179] 


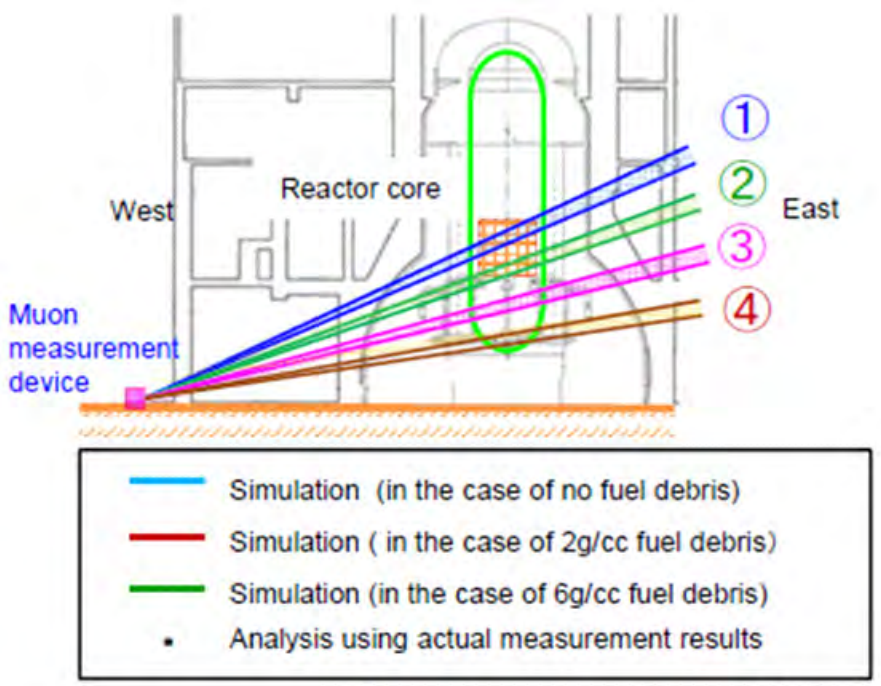

(Measurement results as of July 22, 2016)

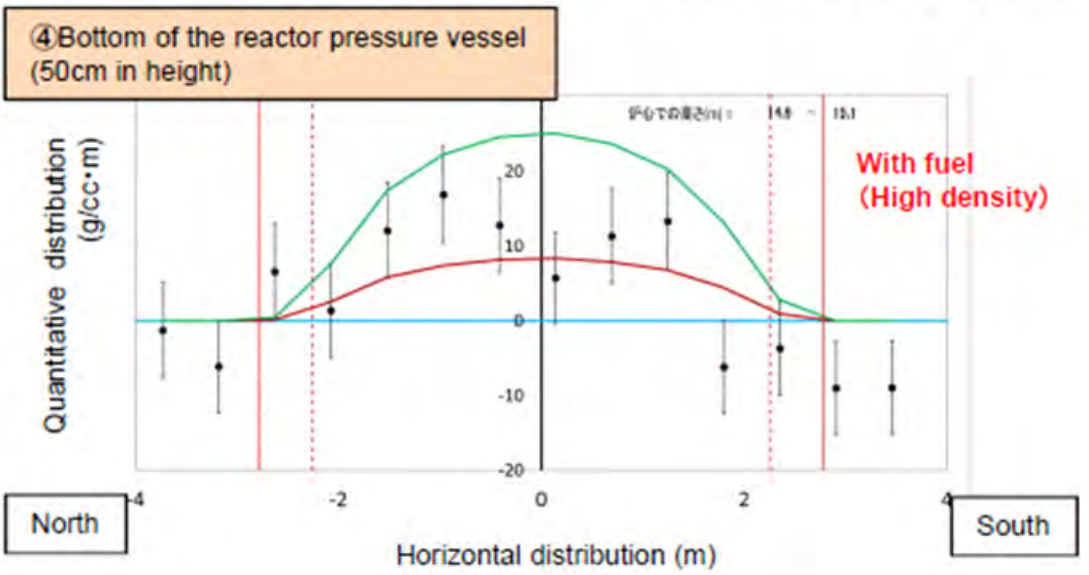

Figure G-14. Muon tomography scan of the lower head of the 1F2 RPV (Scan 4). Data points near the upper (green) line indicate the presence of high density debris (between 2.0 and $6.0 \mathrm{~g} / \mathrm{cc}$ ). The presence of high density debris was only found in the muon tomography ray that passed through the lower head. (Courtesy of TEPCO Holdings [179])

The photos taken within the pedestal region of 1F2 during entry to the pedestal region suggest RPV failures at penetration locations. However, available photos do not preclude RPV failure near the top of the hemispherical bottom head. For example, if the MELCOR debris configuration is assumed (see Figure G15), failing along the side of the RPV would lead to more "molten" (non-particulate) metallic debris to relocate ex-vessel. The metallic debris could form a molten pool when debris agglomerates in the lower plenum, situating itself on top of ceramic debris. The metallic layer has a higher heat flux to the RPV vessel wall, leading to potential failure earlier than areas within the lower plenum that are adjacent to ceramic debris. If this metallic layer were to fail the side of the lower head, then metallic debris and a portion of built-up ceramic debris would relocate ex-vessel, while a significant amount of particulate debris would remain in the bottom of the lower head. 


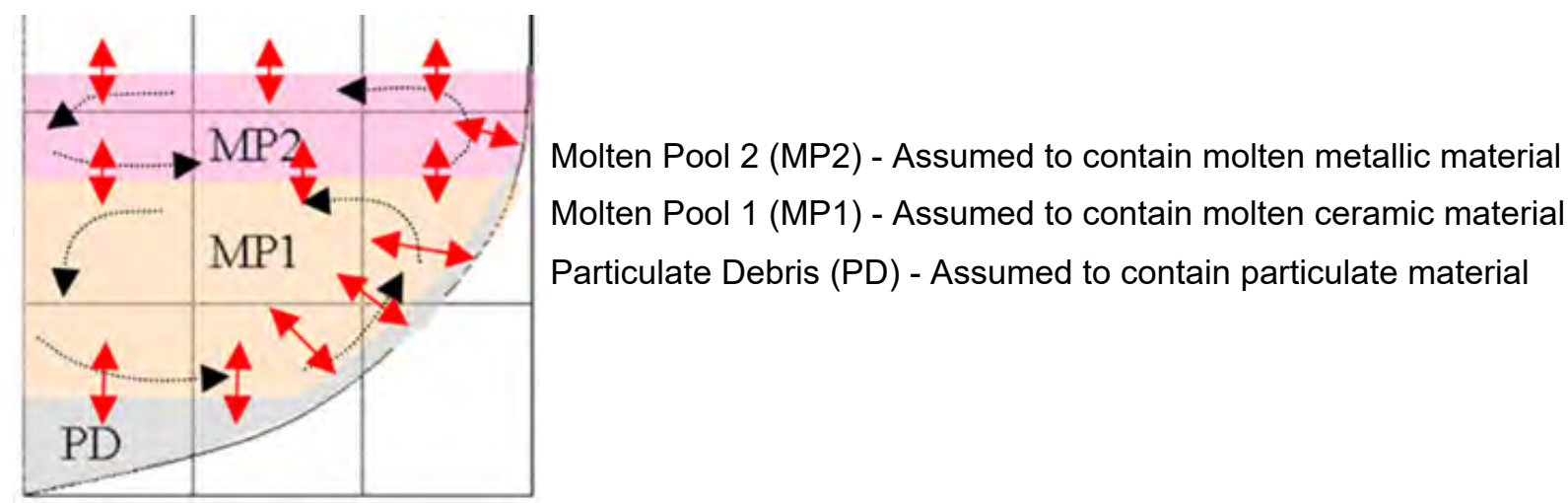

Figure G-15. MELCOR modeling of molten pools and particulate debris within the lower plenum, particulate and molten debris mases are dependent on the accident transient. (Courtesy SNL [8])

\section{G.4.3. 1F3 Examinations}

Starting in May 2017, muon tomography data were collected from 1F3. An interim report [185], issued on July 27, 2017, suggests the possibility that the amount of fuel debris remaining in the core and lower area of the RPV is less than what was observed in 1F2 (see Figure G-16).
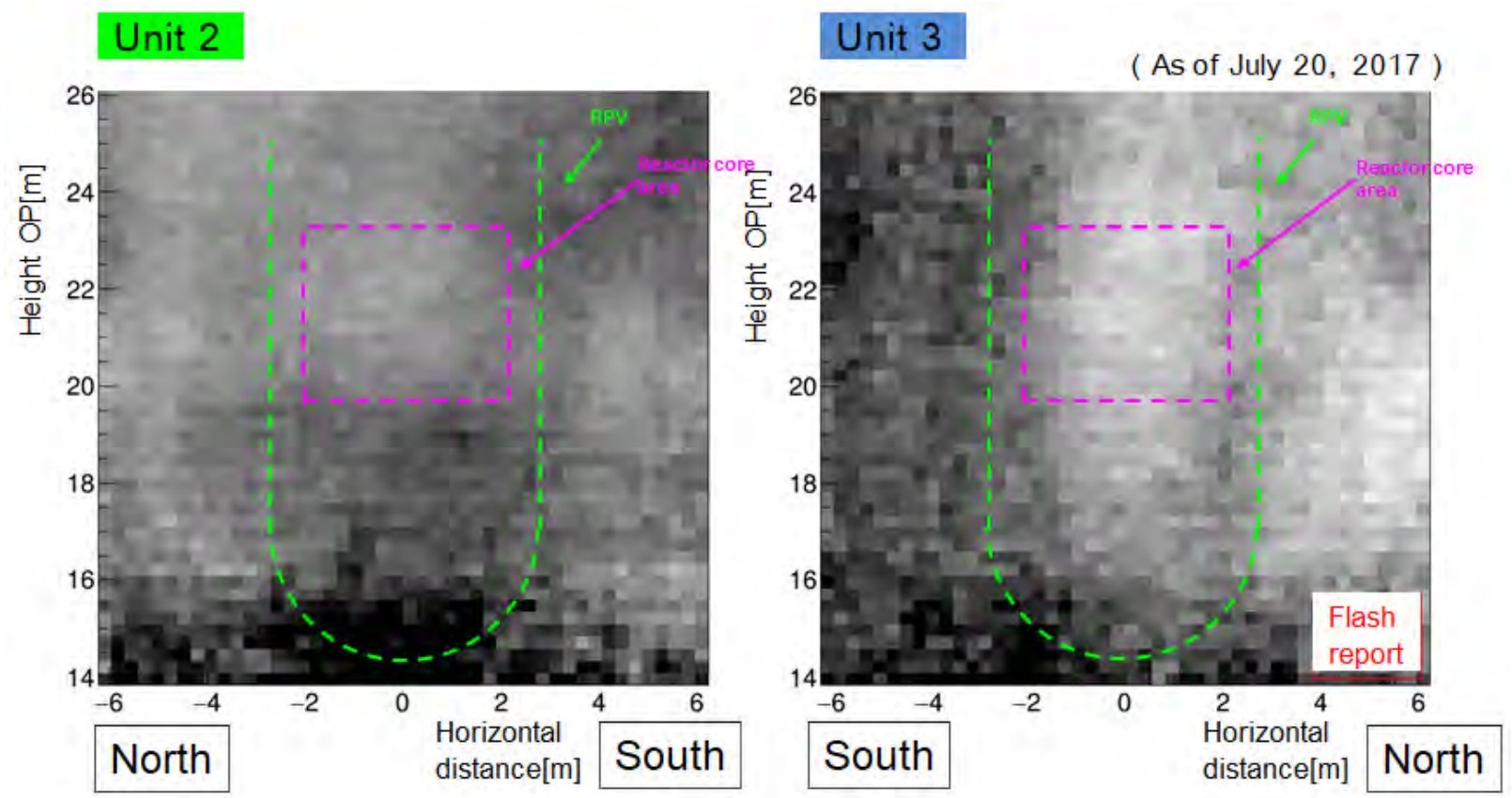

Figure G-16. Comparison of muon tomography images obtained for $1 \mathrm{~F} 2$ and $1 \mathrm{~F} 3$ using scintillation detectors. (Courtesy of TEPCO Holdings [185]) 


\section{G.5. Gas Cleanup System Measurements}

Aside from the three main data sources discussed above, additional data gathered by TEPCO Holdings that has been extremely useful for reactor safety evaluations are the PCV atmospheric composition measurements obtained from 1F1 and 1F2 a few months after the accidents occurred [274] (see Table G-1). As discussed earlier, system-level code analyses $[55,56]$ of these accidents indicate that RPV failure with follow-on MCCI was likely, particularly for 1F1. These analyses further indicate that combustible gas production due to MCCI contributed significantly to hydrogen accumulation and eventual combustion on the refueling floor of $1 \mathrm{~F} 1$. TEPCO Holdings used these measurements to determine if $\mathrm{H}_{2}, \mathrm{CO}$, and $\mathrm{CO}_{2}$ gases produced through MCCI were still present in the containment atmospheres.[271] Based on the low levels of these gases (see Table G-1), it was concluded that the core debris was likely quenched and stabilized, thereby terminating MCCI. Note that trace levels of $\mathrm{H}_{2}$ and $\mathrm{CO}_{2}$ were still present at the time these samples were taken, but parasitic $\mathrm{H}_{2}$ production would be expected by dissociation of water caused by radiolysis, whereas $\mathrm{CO}_{2}$ would be introduced (in dissolved form) from water that is continuously injected to cool the core/core debris.

Table G-1. Concentrations ( Vol\%) of $\mathrm{H}_{2}, \mathrm{CO}$, and $\mathrm{CO}_{2}$ in the PCV atmospheres of $1 \mathrm{~F} 1$ and $1 \mathrm{~F} 2$ measured several months after the accidents [274]

\begin{tabular}{|c|c|c|c|}
\hline Sample Location & $\mathbf{H}_{\mathbf{2}}$ & $\mathbf{C O}$ & $\mathbf{C O}_{\mathbf{2}}$ \\
\hline 1F1 (September) & 0.154 & $<0.01$ & 0.118 \\
\hline 1F1 (September) & 0.101 & $<0.01$ & 0.201 \\
\hline 1F1 (September) & 0.079 & $<0.01$ & 0.129 \\
\hline 1F2 (August) & 0.558 & 0.014 & 0.152 \\
\hline 1F2 (August) & 1.062 & 0.016 & 0.150 \\
\hline 1F2 (August) & $<00.01$ & $<0.01$ & 0.152 \\
\hline
\end{tabular}

The question arises as to what level of MCCI gases would be expected within the containment atmospheres of the affected units if the core debris had not been quenched. In order to evaluate this potential scenario, a CORQUENCH MCCI calculation was performed [35] with debris coolability mechanisms (i.e., melt eruptions and water ingression) disabled to estimate likely gas concentrations at the time the samples were taken (August-September 2011 timeframe). The calculation was run out to 150 days, which corresponds to mid-August. The MAAP prediction of the melt composition at the time of vessel failure was utilized [56] as input into the CORQUENCH simulation. The analysis was limited to the sump volume because this would be the likely location for deep accumulations if the debris was not cooled. Limiting the analysis to the sumps thus represents $26 \%$ of the total core mass available for core-concrete interaction.[35]

The results (Figure G-17) indicate that if the MCCI had not been stabilized, then $\sim 1.8 \mathrm{Sm}^{3} / \mathrm{hr}$ of noncondensable-combustible gases would still be generated through parasitic, long-term core-concrete interaction at the time the gas samples were drawn. Although cladding and core structural steel initially present in the melt would be oxidized in the first few hours of the accident, long-term production of combustible gases $\mathrm{H}_{2}$ and $\mathrm{CO}$ could occur due to oxidation of iron that is present as rebar in the concrete; reinforcement was assumed to be present at a level of $6 \mathrm{wt} \%$. 


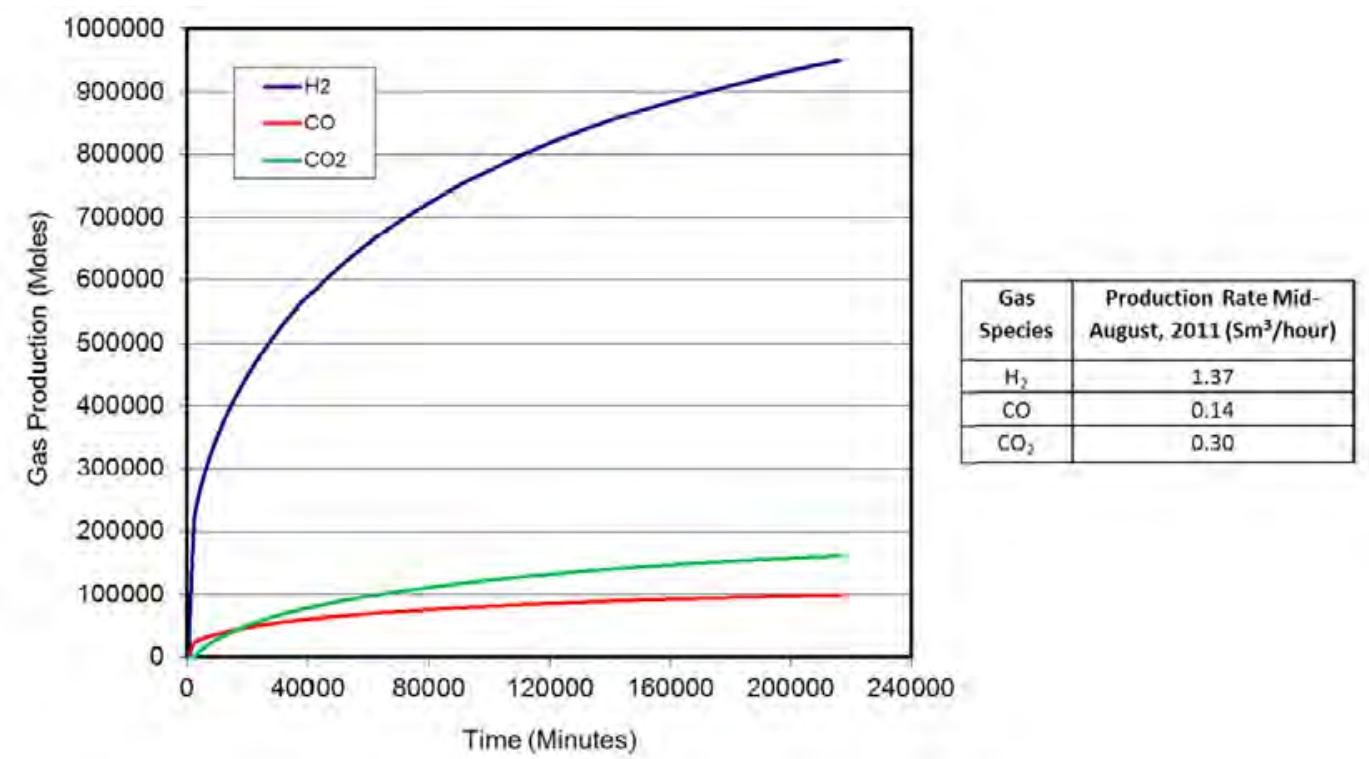

Figure G-17. Expected long-term noncondensable-combustible gas production from ablation within the 1F1 sump if debris had not been quenched and stabilized. (Courtesy of ANL [36])

Given the data in Figure G-17, the expected levels of noncondensable-combustible gases from MCCI in the containment atmosphere for 1F1 at the time the samples were taken are summarized in Table G-2. These levels reflect the fact that a $\mathrm{N}_{2}$ purge into containment has been maintained at a rate of 10-30 $\mathrm{Sm}^{3} / \mathrm{hr}$. The results indicate that if the core debris had not been quenched and stabilized, then the expected gas production would have been easily detectable by gas mass spectroscopy. In addition, by comparing Tables G-1 and G-2, it is noted that the expected $\mathrm{H}_{2}$ levels would be at least an order of magnitude greater than the measured values if the core debris had not been quenched. Thus, if the vessel did fail in $1 F 1$ and MCCI occurred, then the indications are that the ex-vessel core debris was quenched and stabilized. This is an important observation for reactor safety. Ex-vessel debris coolability is one of the key technical issues raised in the wake of the TMI-2 accident. The fact that the debris was stabilized was one of the factors that allowed TEPCO Holdings to declare that cold shutdown conditions had been achieved and the accident effectively terminated.

Table G-2. Expected atmospheric concentration of MCCI gases in the $1 \mathrm{~F} 1$ containment atmosphere if MCCI was not terminated.[36]

\begin{tabular}{|c|c|c|c|}
\hline \multirow{2}{*}{ Gas } & \multirow{2}{*}{ Source } & \multicolumn{2}{|c|}{ Expected atmospheric concentration (Vol.\%) at N2 PCV purge rate of: } \\
\cline { 3 - 4 } & & $\mathbf{1 0 ~} \mathbf{S m}^{\mathbf{3}} \mathbf{h r}$ & $\mathbf{3 0 ~ \mathbf { ~ m }} \mathbf{3} \mathbf{h r}$ \\
\hline $\mathrm{N}_{2}$ & PCV purge & 84.7 & 94.4 \\
\hline $\mathrm{H}_{2}$ & MCCI & 11.6 & 4.3 \\
\hline $\mathrm{CO}_{2}$ & MCCI & 2.5 & 0.9 \\
\hline $\mathrm{CO}$ & MCCI & 1.2 & 0.4 \\
\hline
\end{tabular}

Aside from providing general insights related to phenomenology and reactor safety evaluations, the preliminary findings from TEPCO Holdings regarding ex-vessel coolability in 1F1 motivated the developers of the MAAP and MELCOR codes to integrate advanced debris coolability models (e.g., see [58]) into their modules for calculating ex-vessel MCCI behavior. These updates improve the ability of these codes 
to realistically reproduce actual severe accident behavior and, thereby, support severe accident mitigation planning for BWRs and PWRs.

\section{G.6. Deposits from Leaking Penetrations}

As a part of characterizing high dose rate locations within the 1F1 reactor building,[16] TEPCO Holdings has discovered a high dose rate deposit that could provide additional insight regarding the accident progression, particularly as it relates to debris location. Namely, TEPCO Holdings found white sediment that was deposited by leakage within the HPCI PCV wall penetration; see Figures G-18 and G-19.

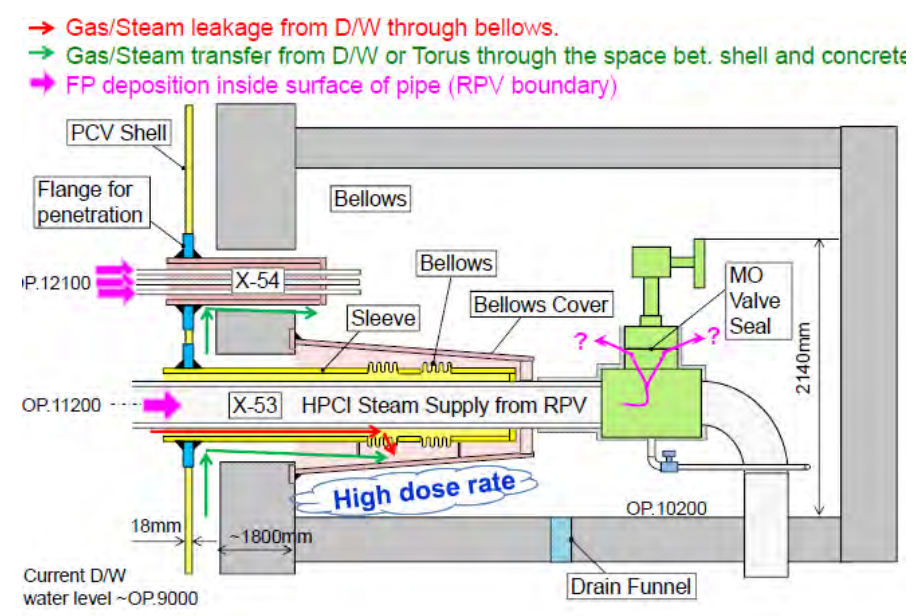

Figure G-18. Depiction of HPCI pump steam supply penetration showing location of deposit with high dose rate. (Courtesy of TEPCO Holdings [16])

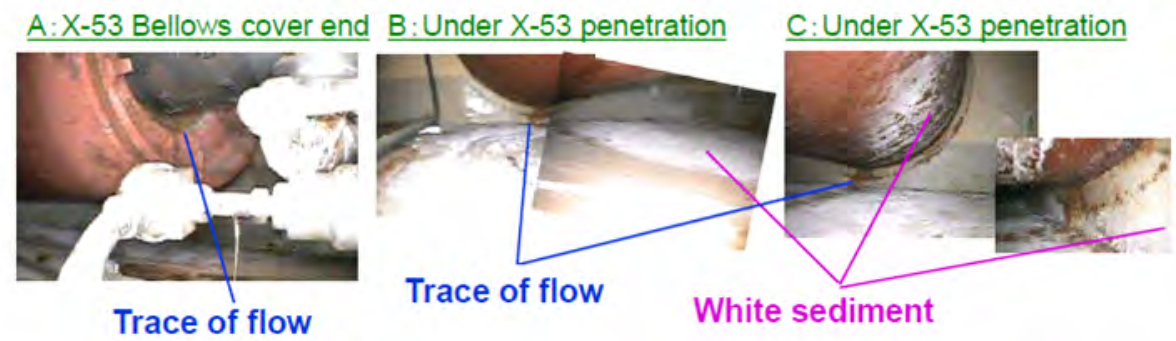

Figure G-19. Photographs of leakage location and sediment. (Courtesy of TEPCO Holdings [16])

TEPCO Holdings indicates that the likely leakage point within this penetration is the bellows seal.[16] One pathway by which fission products could migrate from the PCV to the bellows location is by leakage through the drywell liner (see Figure F-1). As noted in Appendix F, there is other evidence indicating probable liner penetration; i.e., sand cushion drain line leakage (see Figure F-3). Although the chemical composition of this deposit has not yet been determined, one possible candidate is $\mathrm{NaCl}$ (i.e., salt). It is well known that extensive seawater injection occurred at $1 \mathrm{~F} 1$ as operators struggled to cool the damaged core. Salt increases coolant corrosivity which could have been a contributing factor to the development of the 
leak. However, this is believed to be unlikely because corrosion is a longer-term issue, and sea water injection was only maintained for the first few days of the accident progression.

A second possibility regarding the composition of the sediment is amorphous $\mathrm{SiO}_{2}$ which is also white. As noted previously, this material dominates aerosol produced during core-concrete interaction, [272] particularly for the siliceous concrete type used in Fukushima plant construction. Aside from insulation, the only significant source of $\mathrm{Si}$ within the $\mathrm{PCV}$ is in the form of $\mathrm{SiO}_{2}$ within the concrete. Furthermore, the only credible method by which $\mathrm{SiO}_{2}$ could be aerosolized is by core-concrete interaction. Thus, if the sediment is found to contain $\mathrm{Si}$, this would be a very strong indication that the RPV failed and that core-concrete interaction ensued as part of the $1 \mathrm{~F} 1$ accident progression.

\section{G.7. Contamination of the RCW System}

Another important finding by TEPCO Holdings that provides valuable clues regarding likely debris locations is the fact that the Reactor Coolant Water (RCW) system is contaminated. As shown in Figure G-20, the RCW is a closed-loop system that is intended to cool the water in the $1 \mathrm{~F} 1$ sumps. The fact that coolant water within this loop is highly contaminated indicates that the piping boundary was likely breached. The presence of core debris within the sumps, coupled with the high PCV pressures experienced during the accident, would likely cause this type of breach and infiltration of fission products into the RCW system. Thus, this finding provides additional information that is consistent with RPV failure and core debris relocation into the sumps, as predicted by various system level code analyses [34,35] for this unit.

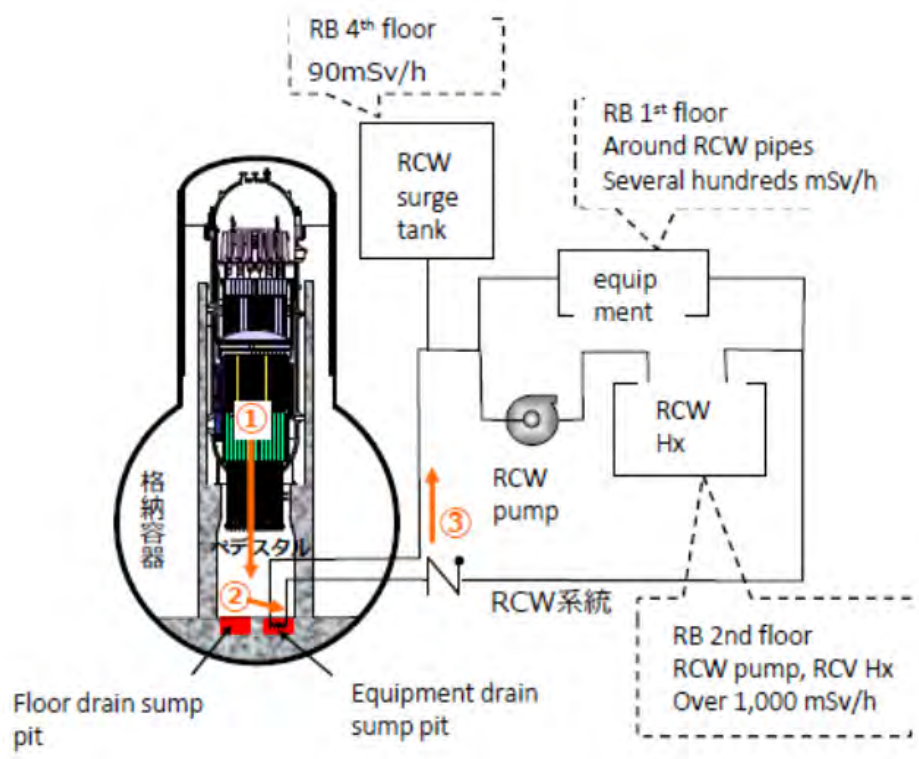

Figure G-20. Illustration of 1F1 RCW system showing contamination levels within the system. (Courtesy of TEPCO Holdings [176]) 


\section{APPENDIX H. AREA 5 - EVALUATIONS OF REGARDING INSTRUMENTATION PERFORMANCE AT 1F1, 1F2, AND1F3}

This appendix, which was developed by Bill Williamson and Phil Ellison, provides additional information to support Section 7. It focuses on addressing several questions:

How accurate were instrument readings which were taken during the early days of the accident at Fukushima Daiichi Nuclear Plant Units 1 through 3 (1F1, 1F2, and 1F3)?

Could the indications be validated while going through the events?

Can the data be used to extend calibration intervals or extend the Environmental Qualification of like instruments?

The purpose of this evaluation is to look at the data from TEPCO for 1F1, 1F2, and 1F3 to see which information was true and which was in error and identify when it went into error if possible. This evaluation considers the following instrument readings:

- RPV Water Level

- RPV Pressure

- DW Pressure

- SC Pressure

- DW Radiation

- Suppression Pool Temperature

- $\quad$ RPV Metal and DW and SRV Temperatures

Evaluations are performed using English units because that is of most interest to operators within the US operating fleet.

The following principles were found to be helpful in validating instrumentation readings:

- Confirm each fact with two or three witnesses

- For each action, there should be a reaction (look for feedback)

- Trends and changes in trends may be true even when absolute values are not

- Look for physical explanations

- Keep in mind the sequence of events

Based on these evaluations, the following conclusions can be drawn:

- $1 \mathrm{~F} 1$ instrumentation was still providing indication 85 days into the event; evidence the transmitters were still working.

- $1 F 2$ instrumentation was still providing indication 17 days into the event; evidence the transmitters were still working.

*. Information developed in this appendix was based on data released by TEPCO [9] up through January 19, 2012. Although the data do not include minor corrections issued by TEPCO after this date, we believe that insights obtained from the data are still valid. 
- $1 \mathrm{~F} 3$ instrumentation was still providing indication 11 days into the event; evidence the transmitters were still working.

- Various RPV metal, drywell, and SRV tailpipe temperature sensors were maintained for 1F1, 1F2, and 1F3 for six months into the event and longer to monitor going to cold shutdown conditions.

\section{H.1. 1F1 Instrumentation Data}

Up until power was lost, there was no question about data provided by instrumentation. As shown in Figure $\mathrm{H}-1,{ }^{*}$ the RPV pressure (blue squares) remained between 1030 psig and, except for the first low pressure reading of $671 \mathrm{psig}, 875 \mathrm{psig}$. Between 1030 and 875 psig there would have been no impact on the wide range (WR) RPV water level readings. Because RPV pressure remained high, relative to containment conditions, there was no possibility of flashing of the RPV water level reference leg.

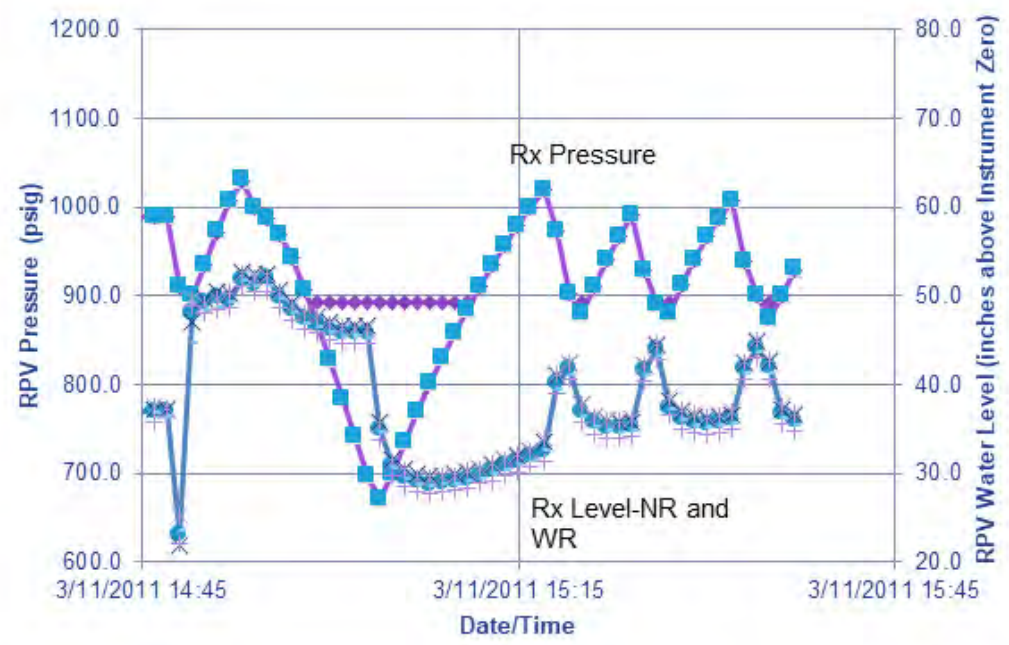

Figure H-1. 1F1 RPV pressure and wide range (WR) and narrow range (NR) water levels. (Data courtesy of TEPCO Holdings [9])

When the tsunami struck, AC and DC power was lost. The last RPV water level reading was +35.5 " at 15:36 on March 11, 2011. By estimating the conditions when RPV pressure would reach the lowest SRV lift pressure, using the trend of pressure, the water level would be +34.8 " at 15:41 with RPV pressure at 1056 psig.

At 16:45, 17:00 and 17:07 on March 11, 2011, readings of the wide range RPV water level were obtained when some power returned before fading permanently. Figure H-2 plots those readings relative to TAF (-135" relative to instrument zero for the WR (emergency range) RPV water level instruments).

*. Plots are based on data released by TEPCO [9] up through January 19, 2012. The data do not include corrections issued by TEPCO after this date. However, we believe that insights obtained from the data are still valid. 


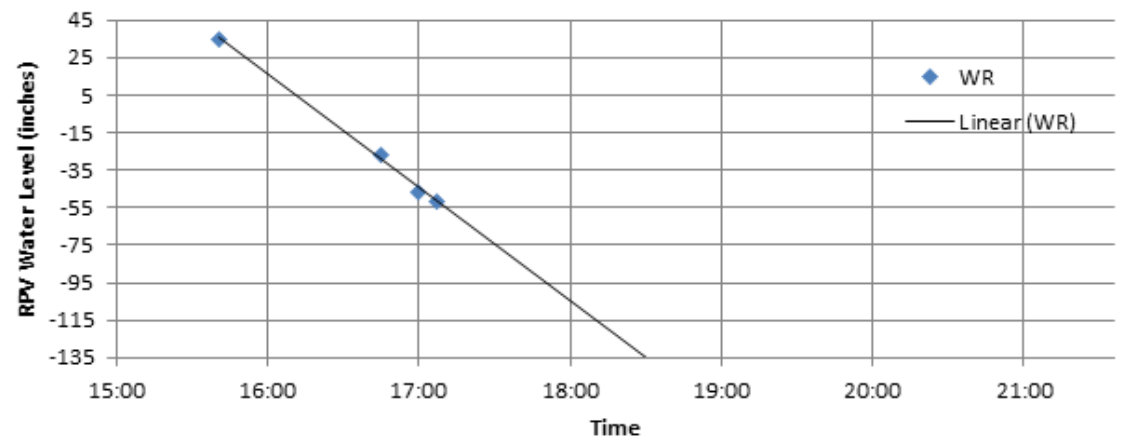

Figure H-2. 1F1 WR trend on March 11, 2011. (Data courtesy of TEPCO Holdings [9])

The scale on the $\mathrm{x}$-axis is inches relative to instrument zero. The scale on the horizontal axis is time in hours. The first point is at 15:41. The subsequent points are at 16:45, 17:00 and 17:07. By plotting these points an estimate of time that top of active fuel (TAF) will be reached can be seen (between 18:00 and 19:00, slightly before 18:30. This information is used to validate later RPV water level readings obtained.

Figure H-3 shows the first readings obtained by restoring power to the instruments. At 20:07 a value of $1000.5 \mathrm{psig}$ (red triangle) is obtained for RPV pressure. If accurate this would rule out the possibility of flashing of reference legs for RPV water level instruments to this point. (20:07).

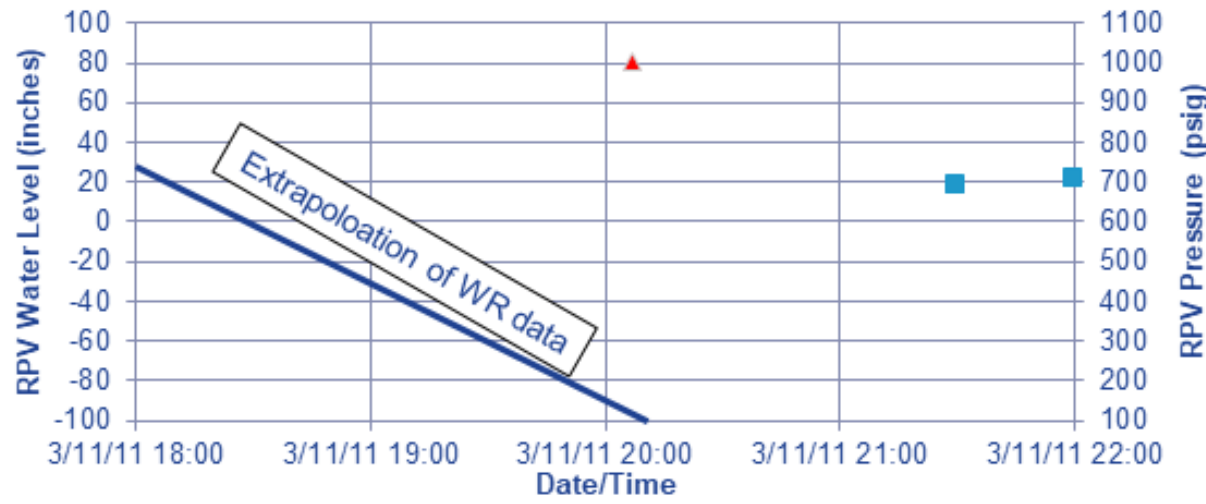

Figure H-3. 1F1 pressure and water level (March 11, 2011). (Data courtesy of TEPCO Holdings [9])

The first values for the post accident RPV water level instruments, also known as Fuel Zone (FZ) level instruments, are obtained (blue squares) at 21:30 and 22:00. The first values are +17.7 " and 21.7" above TAF. Here the zero for the post accident RPV water level instruments is the top of active fuel (TAF). These readings (which should be corrected for RPV pressure and drywell temperature) indicate a level above TAF. For an RPV pressure of 1000.5 psig, an indication of 17.7" corrected for RPV pressure would be -14.4 " if DW temperature was $135^{\circ} \mathrm{F}$. Corrected level if DW temperature was higher, say $350{ }^{\circ} \mathrm{F}$, would be -24 " or 24 inches below TAF. This is still higher than the extrapolation of wide range data would indicate. 
These readings cannot be correct three hours after the trends indicated TAF would have been reached. Also, at 21:50 operators logged that access to the Reactor Building (RB) was restricted due to high dose rates. This indicates that true RPV water level is below TAF and that the peak clad temperature had reached $\sim 1800^{\circ} \mathrm{F}\left(\sim 1000^{\circ} \mathrm{C}\right)$ causing oxidation of the fuel. With RPV pressure accurate and high, RPV water level is not. It must be reading higher than actual here. The corrected fuel zone level was -24" at the time dose rates in the RB were rising. Oxidation should not occur until after water level is more than $\sim 40$ inches below TAF or further. This indicates that in addition to the high drywell temperature some flashing of the reference legs must have occurred.

The point to recognize here is that the transmitter and wires and such were still providing an indication. The RB, where the transmitters are located $\left(1^{\text {st }}\right.$ and $2^{\text {nd }}$ floors in the Reactor Building of a similar BWR with a Mark I containment in the U.S.), was subjected to, as a minimum, higher dose rates. Other data are necessary to determine what the RPV water level instruments indicate. The reason for the error is the offcalibration conditions existing at that time and some flashing of the reference legs.

Figure H-4 shows the Fuel Zone A (blue squares) and B (purple diamonds) RPV water level instruments, RPV pressure (red triangle) and drywell (PCV) pressure (purple 6 legged cross) and suppression chamber pressure (blue circles) as functions of time. The left $Y$-axis if for RPV water level is in inches and $\mathrm{DW}$ and $\mathrm{SC}$ pressure is in psig. The right $\mathrm{Y}$-axis is RPV pressure, psig.

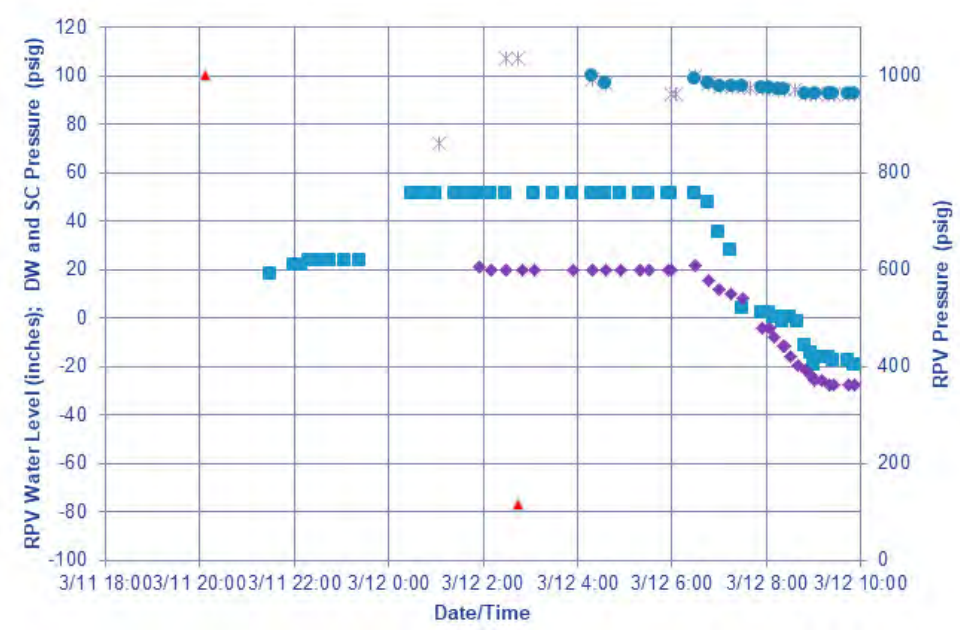

Figure H-4. 1F1 pressure and water level during the first 19 hours (March 11-12, 2011). (Data courtesy of TEPCO Holdings [9])

This graph covers the first 19 hours of the $1 \mathrm{~F} 1$ event. The following changes can be observed on this graph:

- RPV pressure lowers from SRV setpoint to 116 psig by 02:45

- RPV water level A rises +30" between 23:24 and 00:30

- RPV water level begins lowering at 06:30

- DW pressure small bump at 06:30 (92.6 to 98.4 psig)

- At 04:19 SC pressure 1.4 psig above DW

- At 06:30 DW pressure 1.45 psig above SC pressure 
The ability to obtain such data indicates that the RPV water level, RPV pressure and drywell and suppression chamber pressure transmitters are working after power is restored. The second fuel zone level indication (B) is obtained at 01:55. It reads $\sim 21 ", \sim 30$ " below the A RPV water level fuel zone reading (51"). This difference indicates some difference in conditions for the two fuel zone instruments. It seems probable that different amounts of water in the reference leg have flashed.

The transmitters of RPV water level are working even though they are giving false information (both indicating above TAF). DW pressure could indicate the DW temperature could be as high as the saturation temperature of $342.4^{\circ} \mathrm{F}$.

RPV pressure indicates the lowering of pressure probably between 23:24 and 00:30 based upon what the RPV water level fuel zone As indicated at those times. RPV pressure has equalized with DW (PCV) pressure by $02: 45$, within the limits of the instrumentation.

SC pressure chamber pressure is obtained at 04:19 (99.9 psig) and DW pressure at that time is 98.5 psig. These values tend to confirm the other as being valid and indicating rightly. At this time, the relation of DW to SC pressure, with drywell pressure below SC pressure, indicates that the energy is first being deposited in the suppression chamber (SC). At 06:30 The relationship switches and the DW pressure is above the SC pressure (99.85 versus 98.4 psig). This occurring in conjunction with the drop in RPV water level readings indicates something may be affecting both DW and SC and RPV Level A and B at the same time.

This appears to be the case. The DW pressure transient would be impacting the DW first under those conditions (DW pressure higher than SC pressure). The containment was venting itself at that time so the rise in pressure would have been less than under other conditions. Still DW pressure and SC pressure did rise indicating possible breach of the RPV.

This is 12 hours and 86.9 MW-hrs (based on decay heat) after RPV water level reached TAF (18:30). The transient at 06:30 indicates the possible breach of RPV. Lowering of RPV levels could indicate draining/flashing of RPV variable legs until empty.

No useful information is obtained from the RPV water level transmitters after this point in time (it is likely that both the reference and variable legs evaporated) although the transmitters continued to work.

Figure H-5 shows the data out to 105 hours. The graph shows that RPV pressure B is recovered (blue x's) and the estimated (at that time) injection (purple squares) into the RPV. Previously, the RPV pressure and drywell (PCV) pressure equalized within the limits of the instrumentation. In this plot, MDRIR is the Minimum Debris Retention Injection Rate, which is sometimes referred to the Decay Heat Removal Injection rate. This is the minimum injection rate required to remove decay energy from the debris.

Operators logged that at 03:45 March 12 (T+12 hours), workers attempted to enter the RB. As soon as the door was open, steam was observed and the door was closed. So, at 12 hours the transmitters were still working even though there was a steam and radiation environment $\left(1^{\text {st }}\right.$ and $2^{\text {nd }}$ floors of the RB). These transmitters were working 105 hours into the event, even with the steam and high dose environment.

*. Credit should go to Doug Osborn of Sandia at the TSG workshops. He suggested this could be breach signature for $1 \mathrm{~F} 1$. 


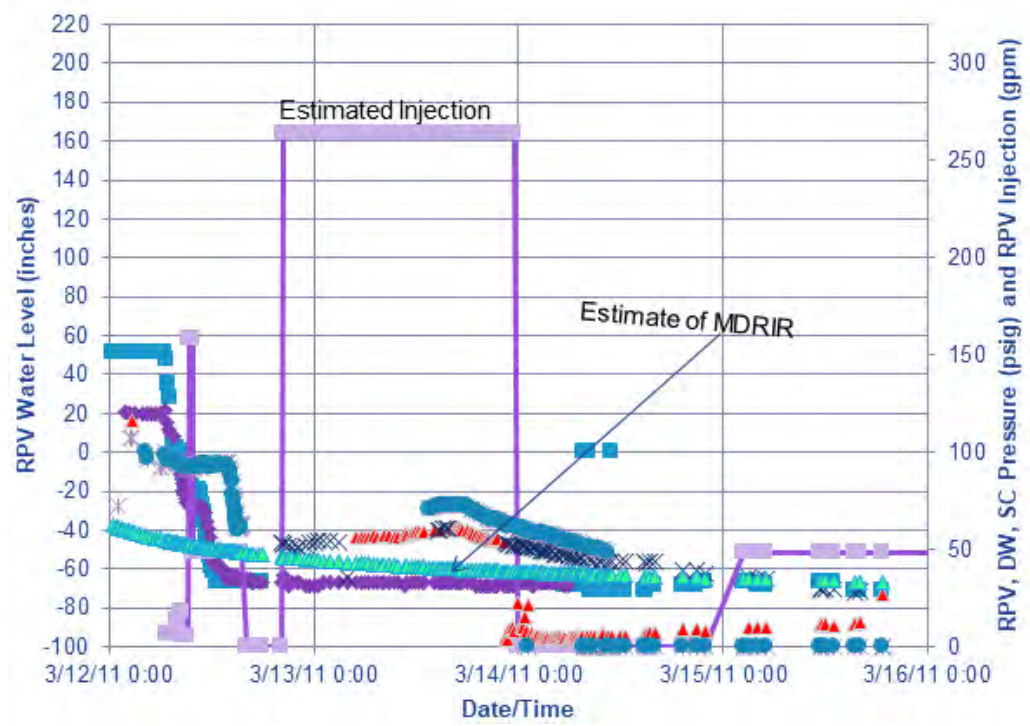

Figure H-5. 1F1 pressure, water level, and injection from 19 to 105 hours. (Data courtesy of TEPCO Holdings [9])

This graph simply shows that the monitored parameters were not responding to the RPV injection. After the deflagration, injection is stopped; note the RPV water level instruments do not respond but continue to straight-line. This is likely because both reference legs and variable legs are drained at this point. Note the transmitters are still working. In addition, the following should be noted:

- At $\mathrm{T}+12$ hours the RB environment is filled with steam, so temperature and humidity around the transmitters is high. Transmitters are still working and continued to work 105 hours

- In general, the narrower range instruments will be more accurate when the indication is in their range. Also, most instrument in nuclear power are calibrated to be most accurate in the normal operating range. The $0-1500$ psig RPV pressure instruments probably aren't as accurate as the DW pressure instruments which address perhaps a 0 to 100 or 0 to 300 psig range.

- The RPV pressure instruments are also indicating low by at least the height of the reference leg inside the DW. RPV pressure instruments are normally calibrated to account for the DP corresponding to the height of the reference leg from which their indication is obtained.

Figure H-6 follows the data out to two weeks. This graph shows the data between 273 hours and 345 hours into the event.

On 3/23/11 at 03:23 the injection location was changed from the core spray sparger to the feedwater sparger. Feedback was obtained: both RPV pressure indicators A and B responded, and both DW and SC pressure indicators responded. The changes are following the rate of RPV injection. This occurred 277 hours into the event.

Figure H-7 shows the initial RPV metal and SRV tailpipe temperatures during this timeframe.

As shown in this graph, 79 gpm of water was injected into the system for 5.5 hours before the temperatures dropped on-scale. An estimate of true temperature could be made assuming all the mass in the drywell and the steam at one temperature and the energy capacity of the water ( 79 gallons per minute and its heat capacity) but was not done as part of this evaluation. 


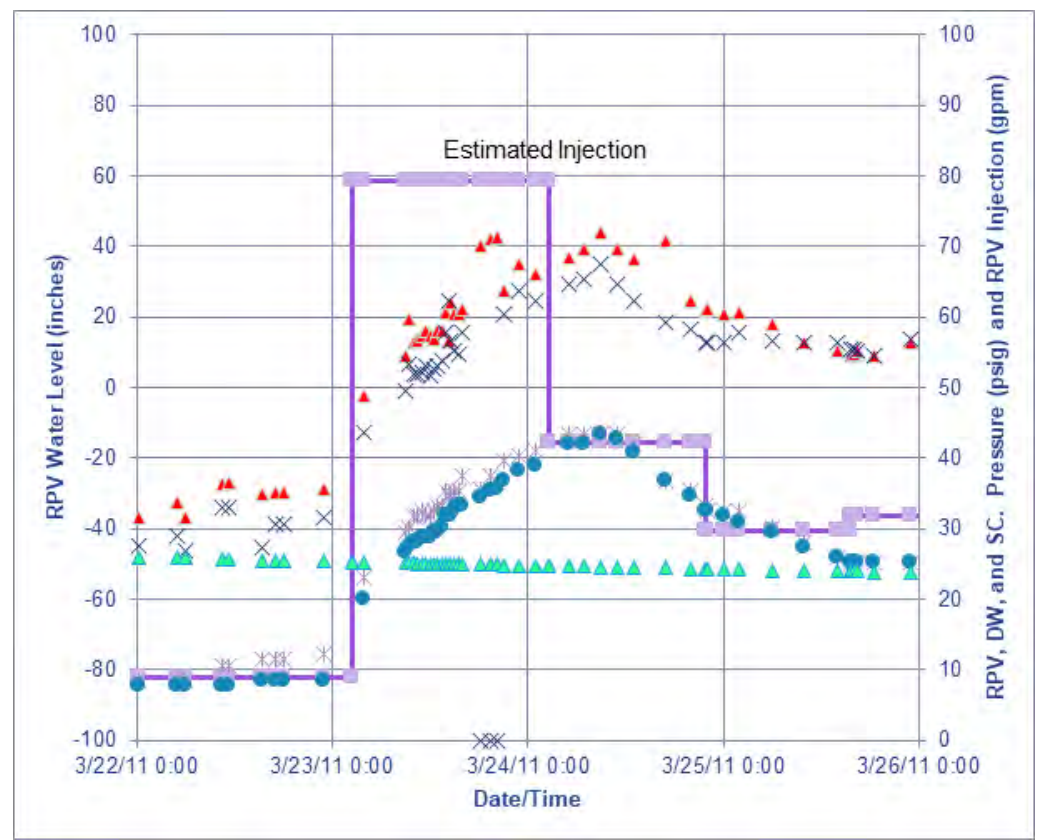

Figure H-6. $1 F 1$ pressure, water level, and injection from 273 to 345 hours. (Data courtesy of TEPCO Holdings [9])

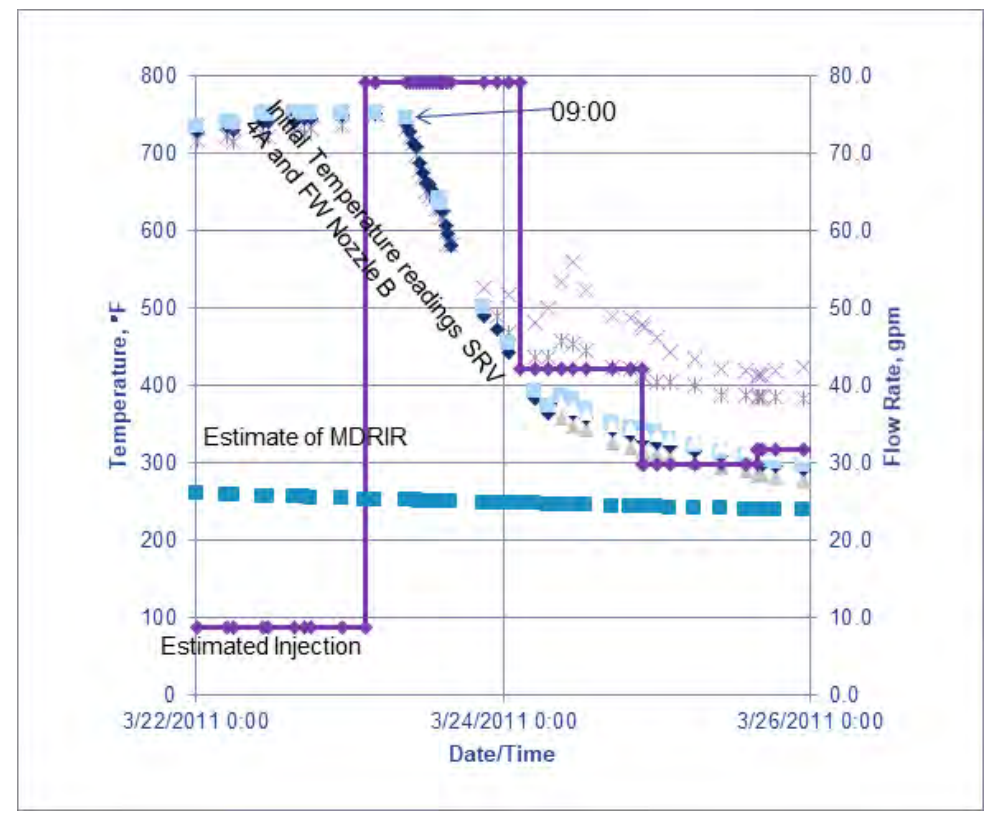

Figure H-7. 1F1 pressure, water level, and injection with SRV and FW temperatures from 273 to 345 hours. (Data courtesy of TEPCO Holdings [9])

The initial water is cooling very hot material and generating superheated steam. As the temperature of the steam and the hot material get lower, the temperatures come on scale at $400^{\circ} \mathrm{C}\left(752^{\circ} \mathrm{F}\right)$. The system now should cool towards the saturation temperature for the system pressure. If the system pressure is indi- 
cated by the RPV pressure, temperatures should lower to $304.4^{\circ} \mathrm{F}$ for 71.54 psia. If the $\mathrm{DW} / \mathrm{SC}$ pressure represents the true system pressure, then the temperature indications should lower to $264.9^{\circ} \mathrm{F}$ for 38.5 psia. The temperatures lower below $300^{\circ} \mathrm{F}$ and indicate the DW/SC pressures are more accurate measurement of the system pressure than the RPV pressure indicators by this time.

The temperatures tend to confirm the accuracy of DW/SC pressures as true, or closer than RPV pressures; and the DW/SC pressures tend to confirm the temperatures are reading accurately. What they also show is how close operators came to stabilizing the ex-vessel core debris.

Figure H-8 shows the data out to 439 hours. $^{\dagger}$ This graph shows that RPV pressure B (dark blue x's) began drifting compared to RPV pressure A (red triangles with gray edge) and DW (purple X's)/SC pressures blue circles) on March 26 at about 11:30. This is 356.7 hours or 15 days in a humid, hot, radiation field. RPV B lasted this long. The trending of the DW and SC pressure and the injection rate confirm that RPV pressure A is more accurate than $\mathrm{B}$ during this time.

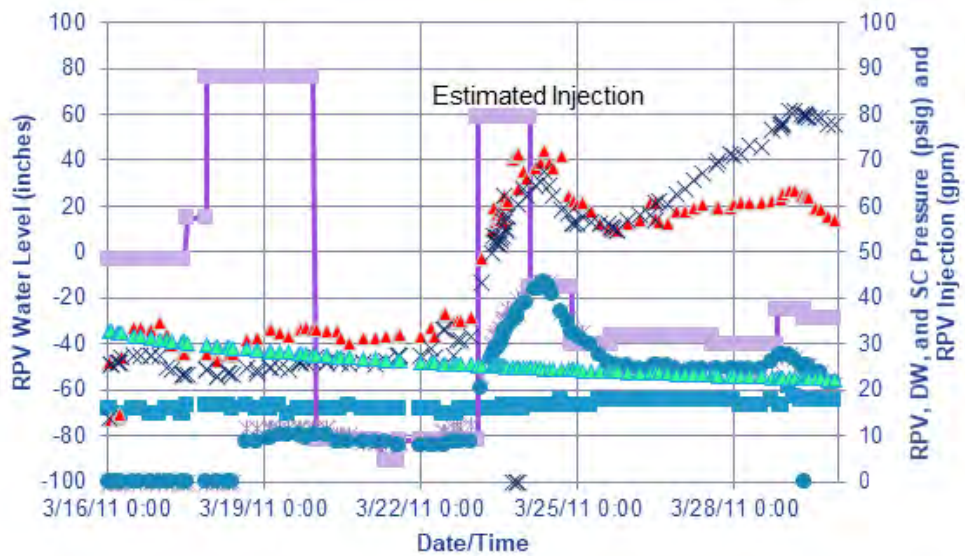

Figure H-8. 1F1 pressure, water level, and injection out to 439 hours. (Data courtesy of TEPCO Holdings [9])

All other parameters are trending with injection flow (purple blocks), indicating some core debris is still not cooled. Note the drifting parameter still sees the change in trend caused by the change in injection rate on 3/29/11. This illustrates the principle that trends may be true even when absolute values are not.

The other transmitters continue to work, and DW and SC pressure trend together, confirming the system pressure by two independent (diverse and redundant) indications. The temperatures also provide confidence that DW and SC are still accurate. DW and SC pressure are 22 psig. T-sat ( $22 \mathrm{psig}$ ) is $262^{\circ} \mathrm{F}$. The lowest metal temperature is $274^{\circ} \mathrm{F}$. It is still trending towards saturation but not there at that time.

Figure H-9 presents data out to 126 days. $^{\dagger}$ This shows that ultimately the A (B?) RPV pressure indication drifted and failed high. 6/4/11 08:00 (85 days). Although DW and SC pressure respond to injection on

*. Thanks to Mitch Farmer of Argonne National Laboratory for his insights into this condition.

$\dagger$. Corrections issued by TEPCO have led to differences in values for RPV A and RPV B. However, the insights reported here remain valid. 
March 23 and 24, 2011, their data show that system pressure is being lowered to near atmospheric pressure.

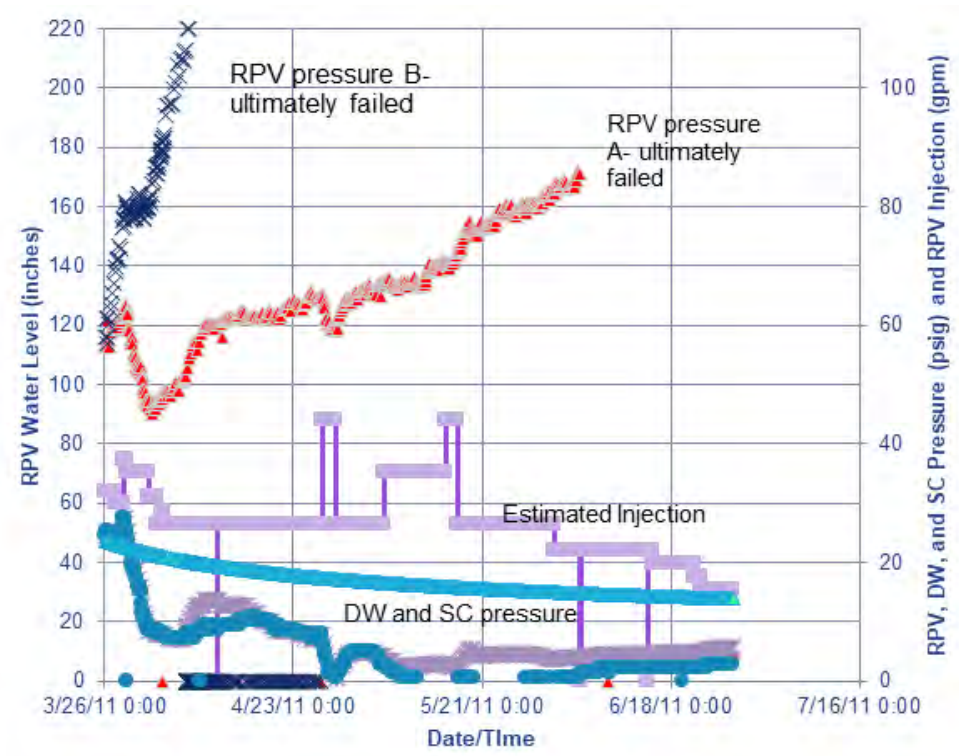

Figure H-9. 1F1 pressure, water level, and injection out to 126 days. (Data courtesy of TEPCO Holdings [9])

Several important questions arise from evaluating the data:

Can it be determined why the RPV pressure indicators failed before other transmitters. All should be in the RB.

Is there some environmental factor that affected the RPV pressure transmitters more than the other transmitters (drywell, suppression chamber)?

As discussed in Sections 7, additional images and evaluations of these pressure transmitters would be of interest to U.S. experts. In addition, as indicated in Section 7, calculations estimating the environmental conditions to which these sensors provide additional insights.

Data in Figure H-10 shows that temperatures for the RPV, for the DW, and the SRVs follow the saturation temperature for the system pressure: $\mathrm{T}_{\text {sat }}(\mathrm{Pdw})$ and $\mathrm{T}_{\text {sat }}(\mathrm{Pww})$ [see Figures 7-6 and 7-7]. All the temperature parameters trend with the saturation temperature, and many indicate similar values. The temperatures trending above the saturation temperature are the SRV exhaust (203-4A) and the Feedwater Nozzle (N4B). 


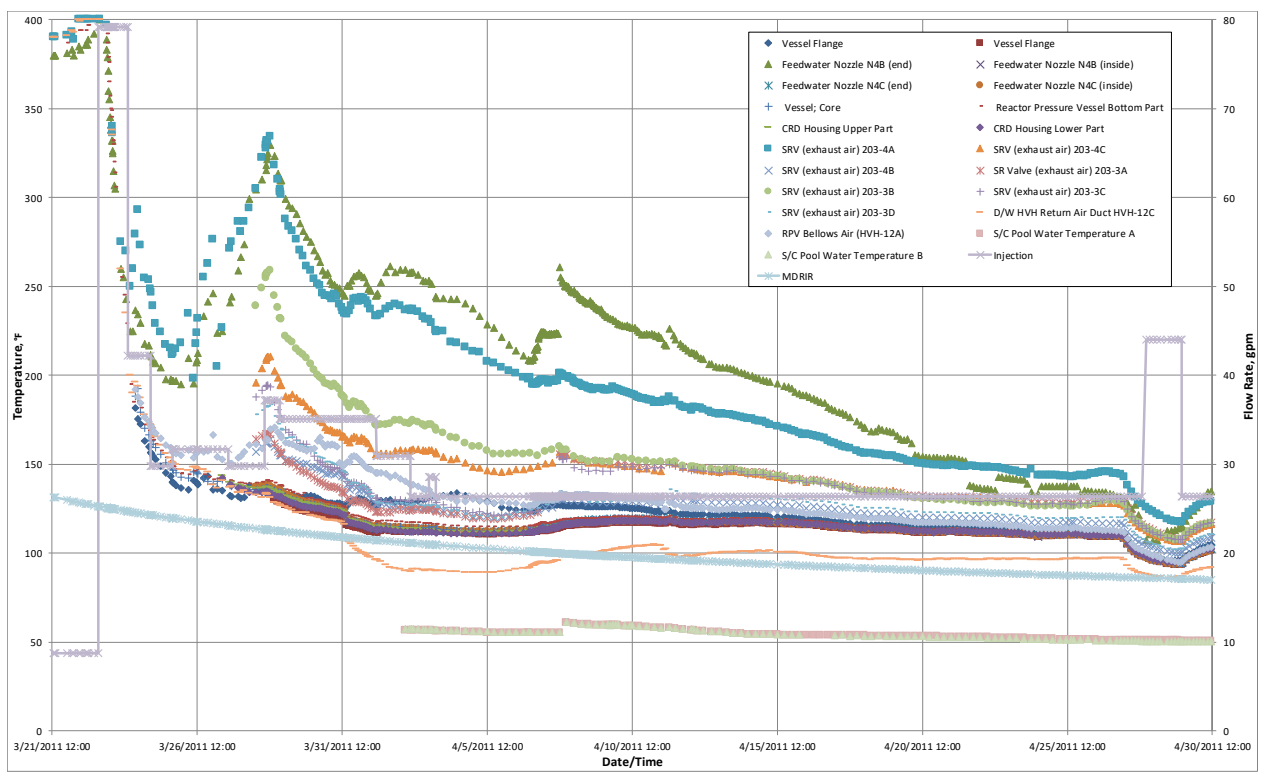

Figure $\mathbf{H - 1 0 .}$ 1F1 temperature data. (Data courtesy of TEPCO Holdings [9])

Data in Figure H-11 indicate that all temperatures are below saturation by August 19, 2011. As discussed in Appendix G (Section G.1), injection continued through FW sparger and was not switched to core spray until December 2011. Hence, temperature data, along with information from muon tomography examinations, are consistent. Both sources of information suggest that no large amount of fuel debris remains in the RPV and that injection did not have to be switched in $1 \mathrm{~F} 1$ to obtain the cooling observed in $1 \mathrm{~F} 2$ and $1 \mathrm{~F} 3$.

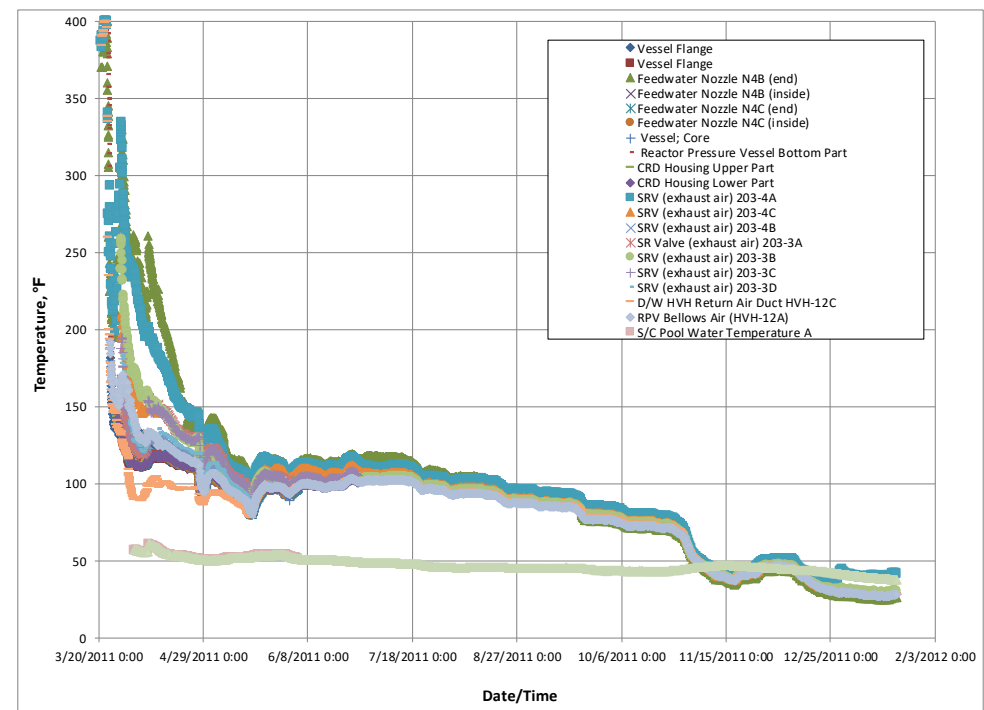

Figure H-11. 1F1 temperature data out through early 2012. (Data courtesy of TEPCO Holdings [9]) 


\section{H.2. 1F2 Instrumentation Data}

Figure $\mathrm{H}-12$ shows $1 \mathrm{~F} 2 \mathrm{RPV}, \mathrm{DW}$, and SC data out to 75 hours. In this section, data are evaluated to assess whether they may be trusted.

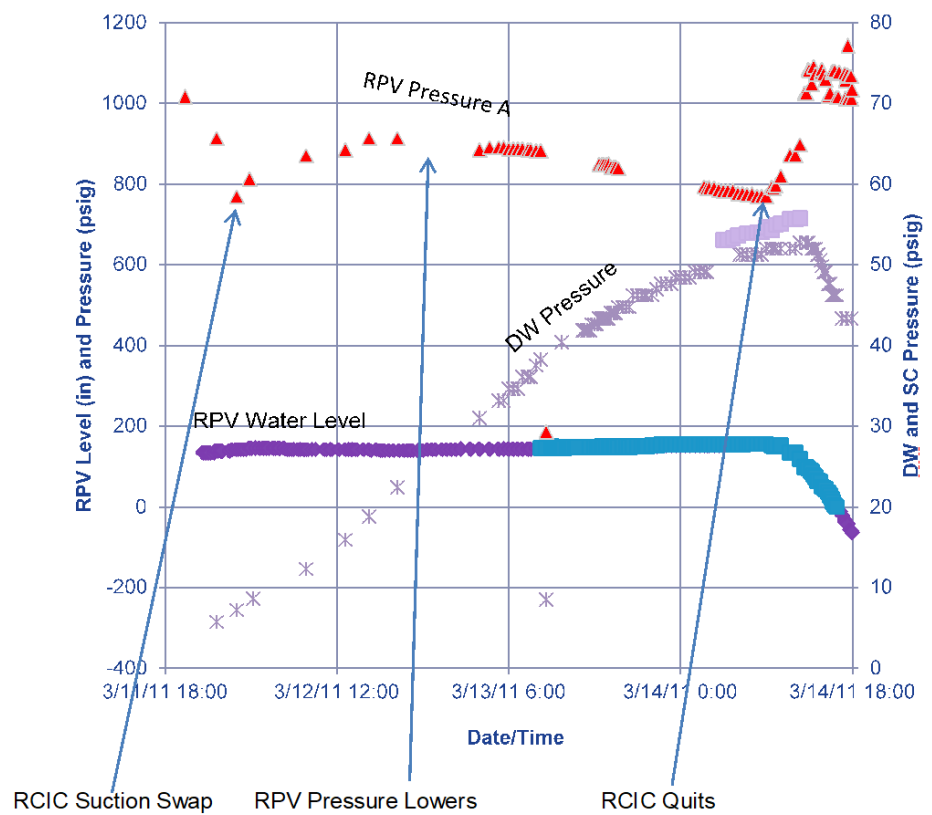

Figure H-12. 1F2 RPV, DW, and SC data from March 11 through14, 2011 (annotated for RPV pressure evaluation). (Data courtesy of TEPCO Holdings [9])

Figure H-12 shows the changing trend of RPV pressure when RCIC suction is changed from the Condensate Storage Tank (CST) to the suppression pool at 01:30 on 3/12/11. The rising pressure should be because suppression pool water is hotter than CST water. This is because RCIC is controlling RPV pressure during this time frame. Later, RPV pressure begins lowering again, possibly due to the change in decay energy. The RPV pressure trend then shows the increase in pressure when RCIC either quits performing, or its performance deteriorates significantly.

During this period, the RCIC was controlling pressure, indicating that it was removing all the decay energy generated by the fuel.

The initial indications of RPV water level A, when corrected for the off-calibration conditions indicate that RPV water level is somewhere above the reference leg tap located at +233 " above TAF. The initial lowering by RPV water level (at 10:00 on 3/14/2011) is due to the rise in RPV pressure. Only at 1200 and after do the RPV water level indications, after correction, indicate that corrected RPV water level, is below the reference leg tap at +233 " above TAF. RPV water level A and B (both fuel zone (purple and blue) are trending together. Using the RPV pressure and the temperature corresponding to drywell pressure, actual water level is calculated to be above reference leg tap at +233 " above TAF. All this can tell one is that actual level is above the reference leg tap and probably at or below the bottom of the MSLs. When RPV pressure rises to the SRV spring lift setpoint and begins cycling, the RPV pressure can be checked for accuracy. 
The SC pressure (purple squares) confirms the DW pressure readings (different purple x's). It indicates slightly higher than DW pressure. This relationship confirms the heat was going to the suppression pool first and then the vacuum breaker equalized with the drywell within limits of vacuum breaker opening and closing. The vacuum breaker operation should keep the drywell within the opening pressure of the vacuum breakers $(0.5$ psig). The SC pressure is about 3 psig above DW pressure. This could indicate the readings are accurate within about 2.5 psig.

\section{H.2.1. RPV Pressure}

Another important question that can be answered is whether the RPV pressure indications can be trusted more than three days ( 76 hours) into the event. After RCIC quit working, RPV pressure rose to the SRV spring lift setpoint and cycled (the blue line in Figure H-13, based on data shown in Table H-1).

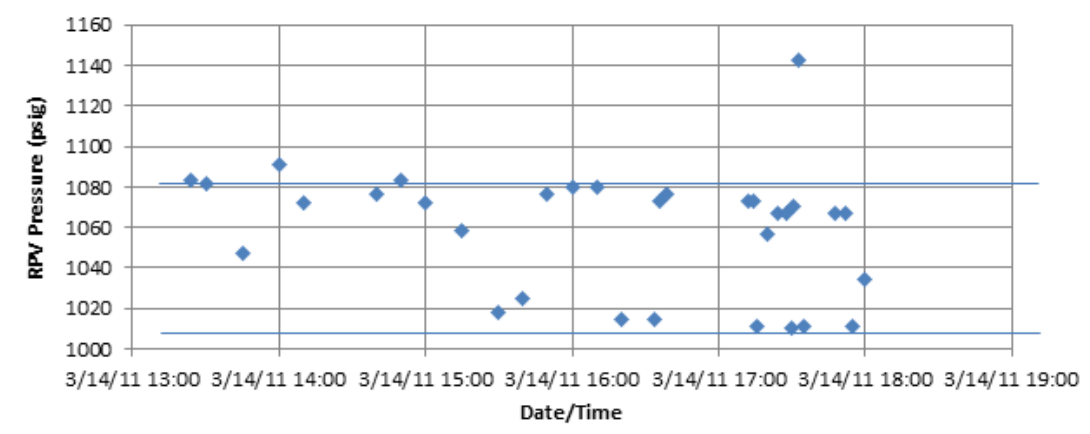

Figure H-13. 1F2 RPV pressure on March 14, 2011. (Data courtesy of TEPCO Holdings [9])

Table H-1. Typical SRV setpoint pressures.[275]

\begin{tabular}{|c|c|c|c|c|c|c|c|}
\hline \multirow{10}{*}{$\begin{array}{c}\text { Main Steam } \\
\text { Safety Relief } \\
\text { Valves }\end{array}$} & Number of Valves & \multicolumn{2}{|c|}{4} & \multicolumn{2}{|c|}{8} & \multicolumn{2}{|c|}{8} \\
\hline & Total Capacity & \multicolumn{2}{|c|}{1201} & \multicolumn{2}{|c|}{3197} & \multicolumn{2}{|c|}{3197} \\
\hline & & Pressure & Valves & Pressure & Valves & Pressure & Valves \\
\hline & \multirow{3}{*}{$\begin{array}{c}\text { Relief valve } \\
\text { function (psig) }\end{array}$} & 1056.1 & 1 & 1080.3 & 1 & 1080.3 & 1 \\
\hline & & 1066.1 & 2 & 1090.2 & 3 & 1090.2 & 3 \\
\hline & & 1076.0 & 1 & 1100.2 & 4 & 1100.2 & 4 \\
\hline & \multirow{3}{*}{$\begin{array}{c}\text { Safety valve } \\
\text { function (psig) }\end{array}$} & 1110.2 & 2 & 1110.2 & 2 & & \\
\hline & & 1120.1 & 2 & 1120.1 & 3 & & \\
\hline & & & & 1130.1 & 3 & & \\
\hline & Blow-off area & \multicolumn{2}{|c|}{ Suppression Chamber } & \multicolumn{2}{|c|}{ Suppression Chamber } & \multicolumn{2}{|c|}{ Suppression Chamber } \\
\hline
\end{tabular}

Are the RPV pressure indications in truth or error?

Look for the physical explanation. The SRV lift pressure is given for the lowest pressure 1080.3 psig. Most of the RPV pressure recordings are at or below 1080.3 psig. Data indicate that the reseat pressure is about 1010 psig. The one reading at 17:30 indicates 1142 psig which is above the safety valves lift pressure. This appears to be a bad reading. The remaining readings appear to be indicating truly or very nearly: no more than 10 psig high (based on the 14:00 reading). 
RPV pressure remained high until 18:06. The high pressure was enough to keep the reference leg for the RPV water level instruments from flashing due to high temperature. Hence, the RPV water level readings are considered reliable, even three days into the event.

\section{H.2.2. RPV Water level}

Figure H-14 shows RPV water level and DW radiation data on March 14, 2011. Water level trend readings are for Fuel Zone A (purple diamonds) and Fuel Zone B (blue squares). Using the indicated readings and the RPV pressure and drywell pressure saturation temperature, corrected RPV water level readings (purple x's) are compared with TEPCO data. The actual level is reading higher than the indicated level due to the RPV pressure and drywell temperature.

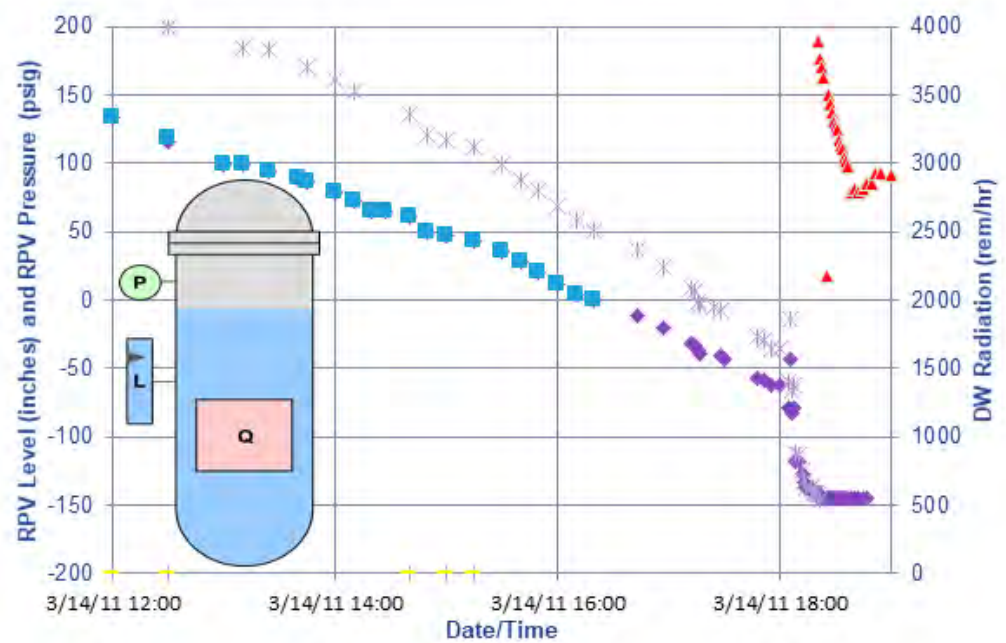

Figure H-14. 1F2 water level and DW radiation data on March 14, 2011. (Data courtesy of TEPCO Holdings [9])

RPV pressure (red triangles) for most of this graph is cycling at the SRV lift setpoint until an SRV is manually opened between 18:00 and 18:06. Drywell radiation data (yellow plus signs) are trended on this graph also and still reading $0 \mathrm{Rem} / \mathrm{hr}$.

Can the RPV water level instrument be trusted 75-76 hours into this event?

Look for physical explanation. RPV pressure remained high until 18:06. The high pressure was enough to keep the reference leg from flashing due to high temperature even though DW temperature could have been as high at $302^{\circ} \mathrm{F}$ (saturation temperature for the SC pressure reading).

The bottom of scale for this unit's fuel zone level is -145 " relative to TAF. Bottom of the active fuel is -145 ". This physical check (relation to scale and to physical location) indicates these RPV fuel zone level instruments (after correction) were indicating true up until 18:22. Also note that for lower values in the scale, both the corrected value and indicated value converged. This is expected for such instrumentation.

Look for action/reaction. RPV pressure begins lowering between 18:00 and 18:06 in response to the opening of an SRV. This is the expected response. 
Drywell radiation is being recorded on this graph (see the yellow/red markers reading " 0 Rem/hr" on this graph). Recall there was no injection but SRVs were operational during this time. Together, this information suggests that steam flow was sufficient to maintain cladding below temperatures where oxidation would occur. For time periods up to 18:22 or so, when BAF was reached, there was still no core damage taking place.

With RPV water level below 50\% of core and lowering to BAF, shouldn't DW radiation monitors show an increase?

Barring any other indications the fact that drywell radiation monitors did not increase indicates the steam flow past the core through the SRV was enough to maintain cooling all the way to BAF. Only when the RPV pressure reached a low value did the core begin heating up.

This is the strategy known as steam cooling in the BWROG Emergency Procedures.

\section{H.2.3. Drywell Pressure}

Can drywell pressure be trusted 75 hours into the event?

Figure H-15 compares RPV and containment data from March 11 through 14, 2011. The suppression chamber pressure confirms the DW pressure, and their relationship indicates the SC to DW vacuum breakers were working.

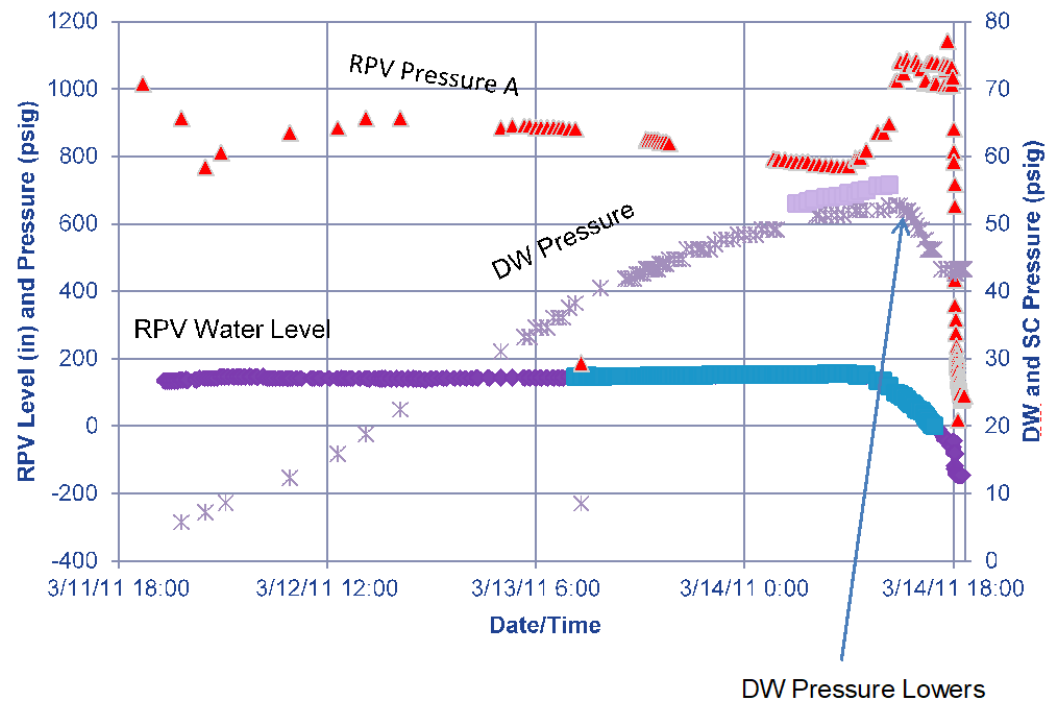

Figure H-15. 1F2 RPV and containment data March 11 through 14, 2011 annotated for DW pressure evaluation. (Data courtesy of TEPCO Holdings [9])

Why does DW pressure begin lowering (at 14:20 on March 14, 2011)?

The SC pressure is temporarily not recorded after 12:30. It may be because personnel became very busy. DW pressure begins lowering at the same time the RPV pressure reaches the SRV lift spring setpoint pressure. When SRVs begin cycling, the DW pressure begins lowering. 
From the sequence of events, it was known the containment vent was not open. A sudden leak with DW pressure below design pressure seems unlikely although possible.

Could the RCIC exhaust steam cause the suppression pool water to stratify because of insufficient mixing in the suppression pool?

Yes. Based on the configuration at BFN, the RCIC injects into a sparger that is sized for HPCI, but the RCIC steam flow is much lower. Prior BFN evaluations suggest that stratification will occur. This condition was changed when the SRV(s) begin lifting. This is further confirmed when DW pressure quits lowering at 18:09 at a pressure of $43.3 \mathrm{psig}$. The saturation temperature for $43.3 \mathrm{psig}$ is $290^{\circ} \mathrm{F}$. The SC pressure and the DW pressure and the SP temperatures all tend to confirm the accuracy of these instrument readings over 72 hours into the event.

\section{H.2.4. Suppression Pool Temperature}

Figure H-16 shows RPV, SC, and DW data out to 76 hours. After restoring power to the recorders and transmitters, operators logged that suppression pool temperature was $295^{\circ} \mathrm{F}$ at 07:00 on March 14, 2011. At 12:30, they logged that the suppression pool was reading $301^{\circ} \mathrm{F}$. Comparing the suppression pool temperatures to the saturation temperature for the DW and SC pressures: at 07:00 when SP temperature is $295^{\circ} \mathrm{F}$, the DW pressure was $51.3 \mathrm{psig}$ and the $\mathrm{SC}$ pressure was 53.9. The saturation temperatures for these pressures are $299.0^{\circ} \mathrm{F}$ and $301.6^{\circ} \mathrm{F}$, respectively.

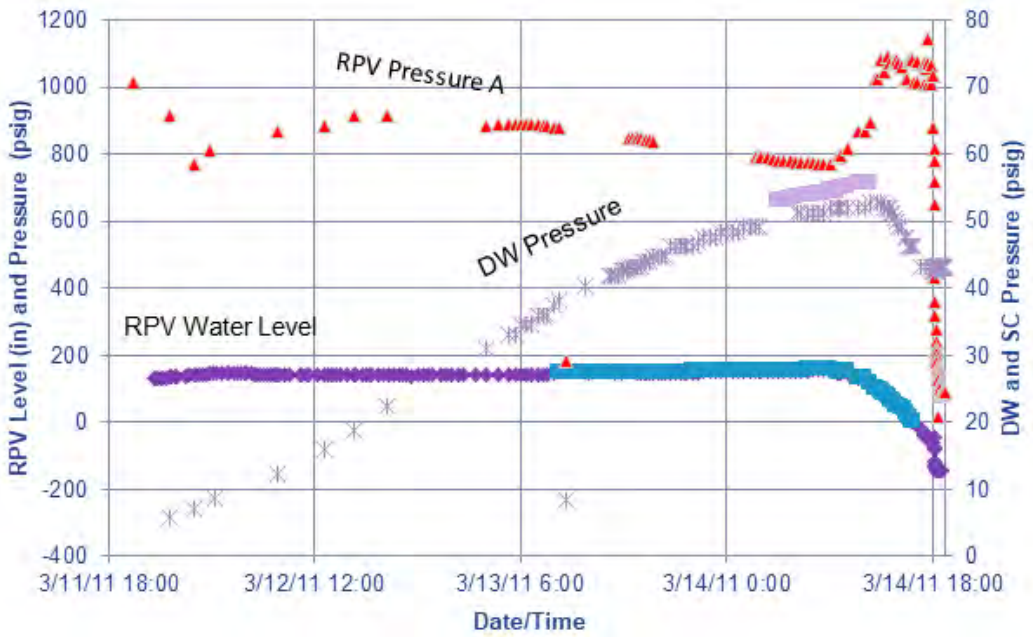

Figure H-16. 1F2 RPV and containment data March 11 through 14, 2011. (Data courtesy of TEPCO Holdings [9])

At 12:30 the suppression pool was recorded at $301^{\circ} \mathrm{F}$. DW pressure was 52.7 psig with a saturation temperature of $300.4^{\circ} \mathrm{F}$. Suppression chamber pressure was 55.7 psig with a saturation temperature of $303.4^{\circ} \mathrm{F}$. Agreement between these indications was within two degrees above and one degree below. This tends to confirm the accuracy of all three instruments at that time.

*. Dave Luxat of Jensen-Hughes was first to notice the connection of DW pressure lowering when SRVs began cycling. 
This approach would be the method to use when returning any instrumentation to service, e.g., testing/comparing its output against other diverse and redundant indications.

Of course, under normal conditions the saturation temperatures of the DW and SC are nowhere near the suppression pool temperature. It is only true because the pool temperature had risen, and pool temperature stratified and had quit condensing RCIC discharge steam. Steam had made its way into the DW so that the entire containment was at saturated conditions.

The principles demonstrated here is to keep in mind the sequence of events, look for physical explanations, and confirm each fact with two or three witnesses.

Figure H-17 shows DW pressure readings out to three days and 7 hours. The sequence of events reports the fire truck trying to inject into RPV, beginning at 19:54. A second truck augments the first truck at 19:57. At 19:54 DW pressure rises from 42.6 psig to 46.2 psig at 20:07, this indicates injection is reaching the overheated core.

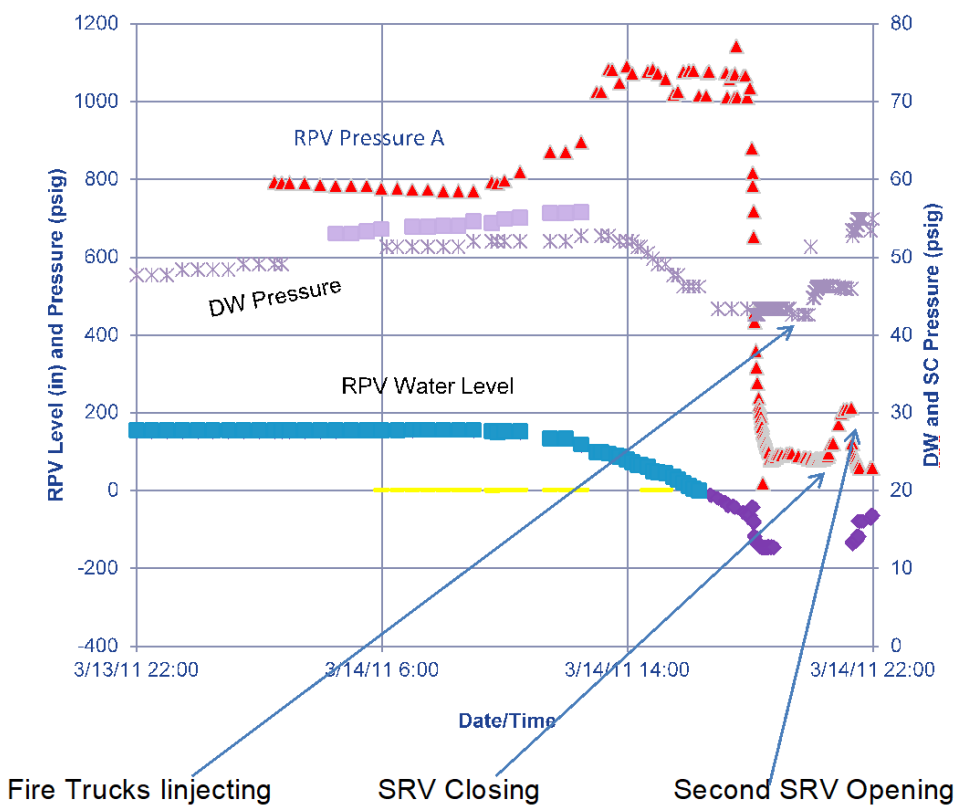

Figure H-17. 1F2 RPV and containment data March 13 through 14, 2011. (Data courtesy of TEPCO Holdings [9])

DW pressure is $42.6 \mathrm{psig}$, and RPV pressure ranges from 78 to $81 \mathrm{psig}$. The fire engines must overcome $42.6+81 \mathrm{psig}$ (123.6 psig) to inject. The height of the jet pump is 76.3 feet, and the site level is 32.8 feet above sea level. The elevation head is 43.6 feet or 18.9 psi.

When the DW pressure rises to 46.2 psig, the injection appears to stop because DW pressure quits rising. It requires only a little pressure rise to stop the injection. There were 13 minutes (19:54 to 20:07) of injection causing some steam and hydrogen generation. The steam and hydrogen generation quits when the injection stopped when the pressure head the fire trucks had to overcome rose to $127.2 \mathrm{psig}$. 
At 20:23, the RPV pressure began rising from 78 psig to 212 psig at 21:18. Since injection is not taking place, this can only be the SRV closing. A second SRV is opened at 21:18 - 21:20,[275] and RPV pressure begins lowering. RPV water level begins rising. Closer examination of the data can provide insights what is very likely happening.

Figure H-18 examines the first two peaks in drywell pressure. "Combined" represents the combined pressure head: DW pressure; the RPV pressure; plus 18.9 psi corresponding to the elevation difference between plant elevation and elevation of jet pump injection. If the first bump in DW pressure (from 42.6 psig to $46.2 \mathrm{psig}$ ) is from the fire engines beginning injection, then the head to be overcome to inject is 143 psig (DW + RPV pressure + Elevation head). The second DW peak from 46.2 to 53.4 psig at 21:20 is due to the opening of the second SRV. It cannot be from injection because the combined head is 193 psig at 21:20. The SRV opening generates some flashing steam which passes through the core and causes some steam and hydrogen production. Injection from fire engines does not appear to begin until after 21:31 when the combined head drops to 139 psig, which is below 143 psig.

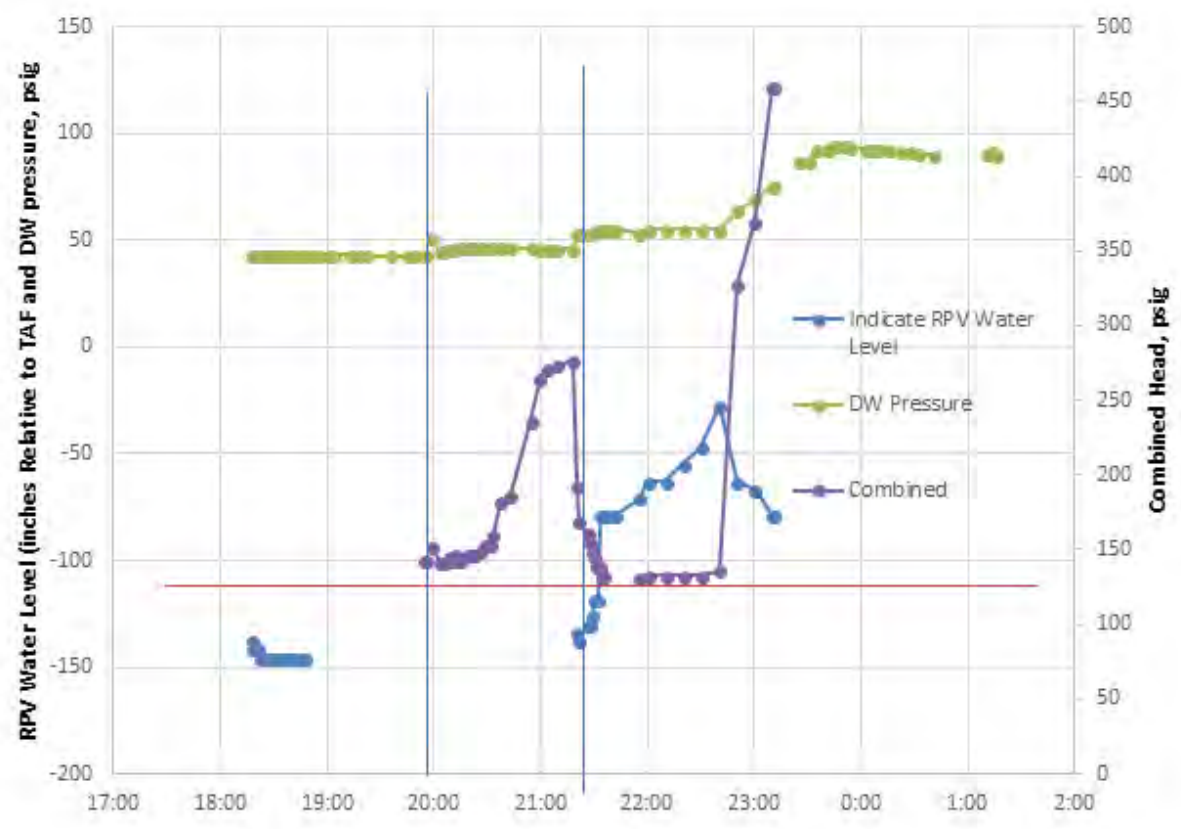

Figure H-18. Closer look at the first two peaks in 1F2 DW pressure (March 14 through 15, 2011). (Data courtesy of TEPCO Holdings [9])

The RPV water level readings when the SRV is opened are most likely bottom of active fuel (BAF) with some loss of reference leg already occurring. When the SRV is opened, the rapid rise of RPV water level from -118" to -78.7 " is due to the flashing of the reference leg. It is possible, perhaps probable, that -78.7 " is BAF. The fact that RPV water level B is not recorded when it again lowers to -78.7" appears to confirm that it is indicating BAF. The injection rate would have had to be approximately $810 \mathrm{gpm}$, raising level from -118 to -78.7 " in 6 minutes. This is much higher than other reported injection rates from fire engines at Fukushima. The rate of rise from $21: 38$ to $22: 40$ is 81 gpm if one uses the indicated readings: (78.7 to -27.6 "). Using corrected readings, as discussed below, the injection rate is $42.8 \mathrm{gpm}$. 
With $5.5 \mathrm{ft}$ of the reference leg boiled off, at $65 \mathrm{psig}$ and $300^{\circ} \mathrm{F}$ in the drywell, an indication of $-78.7^{\prime \prime}$ would correspond to BAF (-145"). If this is the case, then the highest RPV water level indicated, -27.6 ", was no more than -91.3 ", or slightly less than $40 \%$ of the core is the highest level reached before RPV water level begins lowering back to BAF, indicated by -78.7 '”

\section{H.2.5. Indication of Hydrogen without Using Monitors}

Figure $\mathrm{H}-19$ shows data that can be used to detect that hydrogen has been generated. Indication of $\mathrm{H}_{2}$ without monitors is given by the trends of lowering level and increasing DW pressure concurrently.

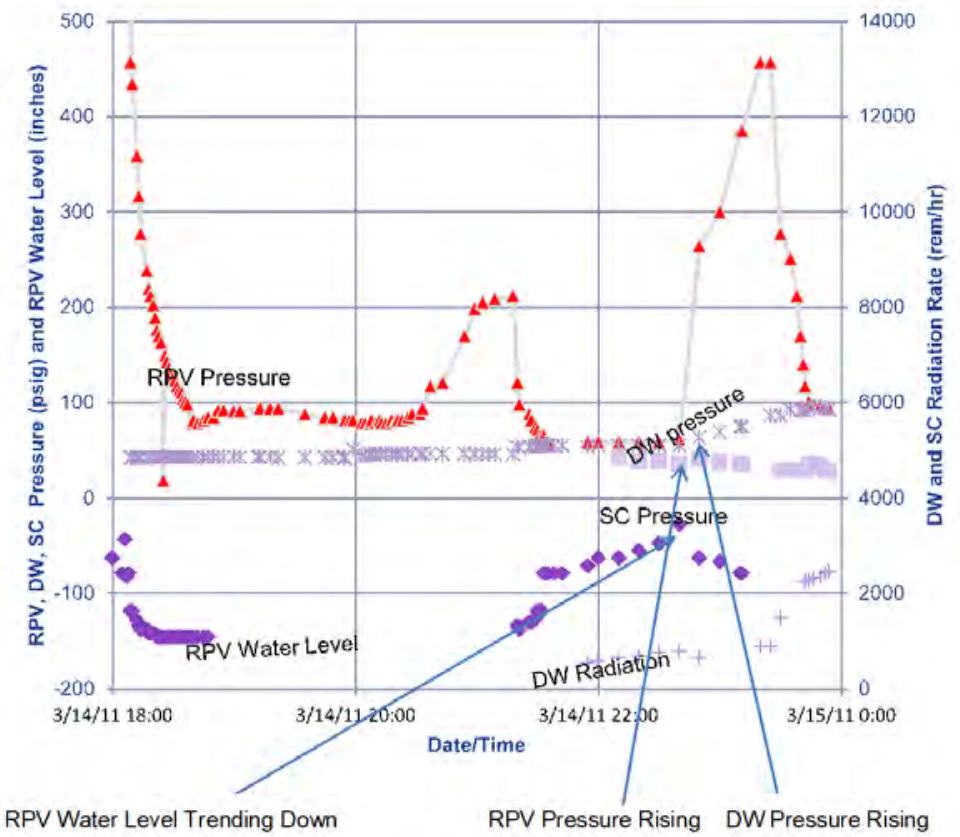

Figure H-19. 1F2 RPV, DW, and SC data from March 14 through 15, 2011. (Data courtesy of TEPCO Holdings [9])

Together, RPV water level begins trending down at the same time RPV pressure rises, and DW pressure begins to rise. The DW radiation begins changing slightly later. This indicates that the injection reaching $\sim 40 \%$ of core and then boils down, causing significant hydrogen generation and increasing DW and RPV pressures until BAF is reached. At that point, DW pressure quits rising.

The following sequence occurs. Injection causes RPV water level to rise, and steam and hydrogen are generated. RPV pressure rises due to hydrogen generation. DW pressure rises due to hydrogen generation. The combined head rises above shutoff head of the fire trucks, and injection stops. RPV water level begins lowering. More steam and hydrogen are generated until level lowers to BAF. RPV pressure lowers to the DW pressure, which stopped rising. At this time, the combined head was above the shutoff head, and no further injection into the core occurs. The DW radiation is responding due to the fission products released into the RPV moderator with the oxidation of the cladding. 
Can the absolute value of RPV water level be trusted here?

The answer is no. Some amount of the reference leg has flashed.

Can the level trend be trusted?

The answer is yes because the variable leg has stayed filled with RPV water level at or near BAF. As seen previously, we can estimate the water level; but after the RPV has depressurized again, more of the reference leg must have flashed.

It is important to recognize that after 81 hours into this event, RPV water level, RPV pressure, and DW and SC pressure transmitters are still working.

In Figure H-20, the DW pressure rises from 55.2 to 92.6 psig while $\mathrm{SC}$ air pressure lowers from 43.3 to 33.2 psig.

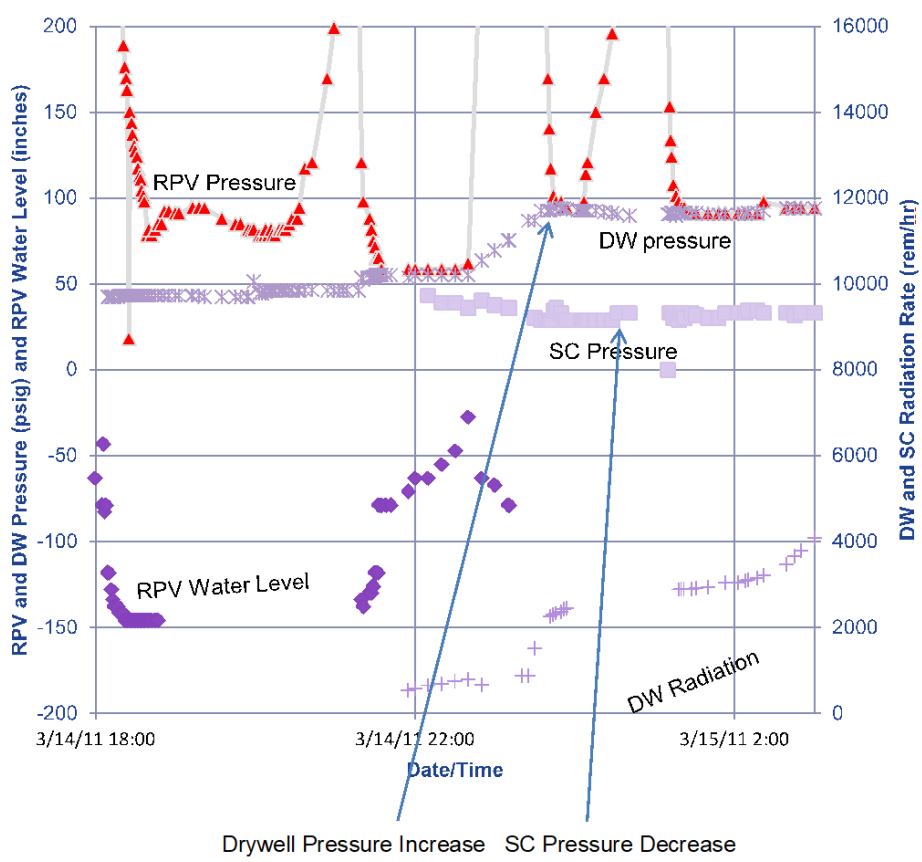

Figure H-20. 1F2 RPV, DW, and SC data on March 14 through 15, 2011 annotated for DW and SC pressure evaluations. (Data courtesy of TEPCO Holdings [9])

How do you validate indications which should confirm one another?

Which do you trust? The DW pressure or the SC pressure?

Here is when one must depend on two or more witnesses. The witnesses for the suppression chamber pressure being accurate are (1) containment vent hasn't opened. The rupture disc should open above 62 psig. 
The witnesses for DW pressure: (1) These SRVs can lower RPV pressure down to 0 differential pressure with discharge location but cannot physically lower pressure below the pressure of its discharge location; (2) RPV pressure agrees with DW pressure.

That RPV pressure quit lowering at the DW pressure indicates that DW pressure is correct and SC pressure is drifting low.

Other facts which confirm DW pressure are the maximum true pressure difference between the DW and Suppression chamber when the DW is higher is the head of water between the downcomer openings and the suppression pool level. This is about 8-9 psig. This would tell one that either the DW pressure or $\mathrm{SC}$ was drifting.

Also, the dropping water level and the rising pressures in RPV and drywell explain the sequence of events previously examined.

\section{H.2.6. Indication of Vessel Breach}

Figure H-21 extends the time out to 101 hours. Note the RPV water level transmitter were still working even though the indications may not have made any sense. When the breach occurs, it seems that both reference and variable legs inside the drywell must be filled with steam.

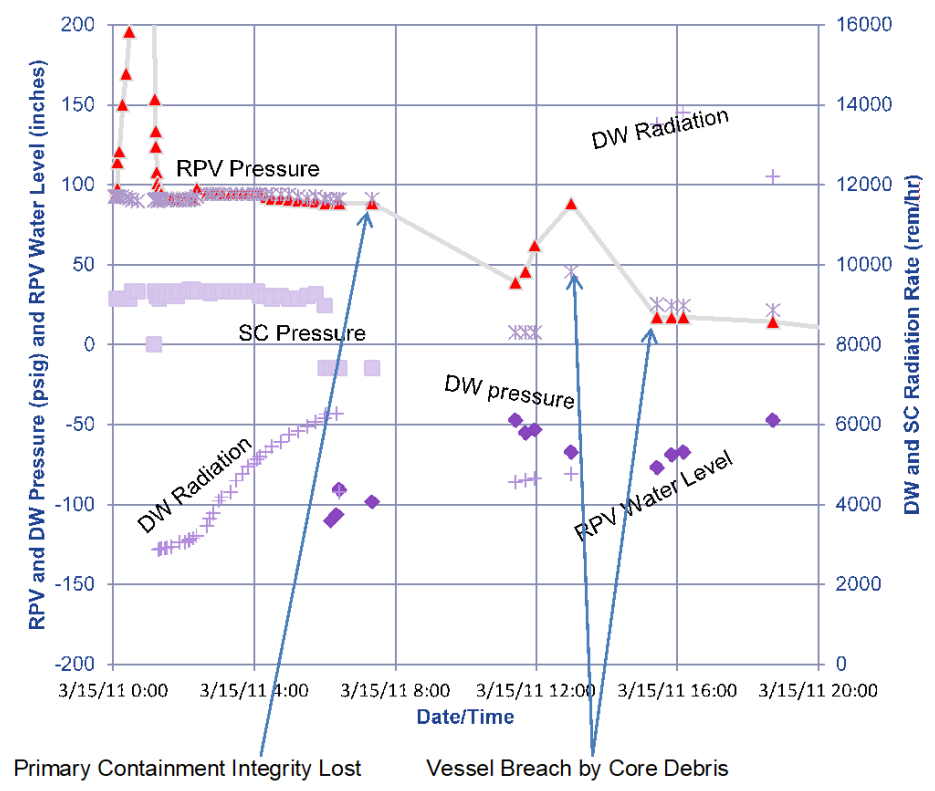

Figure H-21. 1F2 RPV, DW, and SC data on March 15, 2011 indicating loss of primary system and vessel breach. (Data courtesy of TEPCO Holdings [9])

Note the RPV water level transmitter were still working even though the indications may not have made any sense. When the breach occurs, it seems that both reference and variable legs inside the drywell must be filled with steam. 
The loss of primary containment integrity was indicated by the lowering of drywell pressure (between 07:20 and 11:25) after the SC instrument went hard downscale. The RPV pressure and DW pressure separated slightly after this, and the DW radiation lowers indicating that some of the radioactive gases and particles have moved outside the primary containment.

The RPV breach occurred here between 13:00 and 15:25. This is indicated by the trends of rising RPV pressure and rising DW pressure and by the major increase in DW radiation, followed by the decreasing difference between the RPV and DW pressures. The breach occurs 22 hours and 104.9 MW-hrs after TAF was reached.

\section{H.2.7. DW Radiation}

Figure H-22 presents pressure and radiation data from March 16 through 30, 2011.

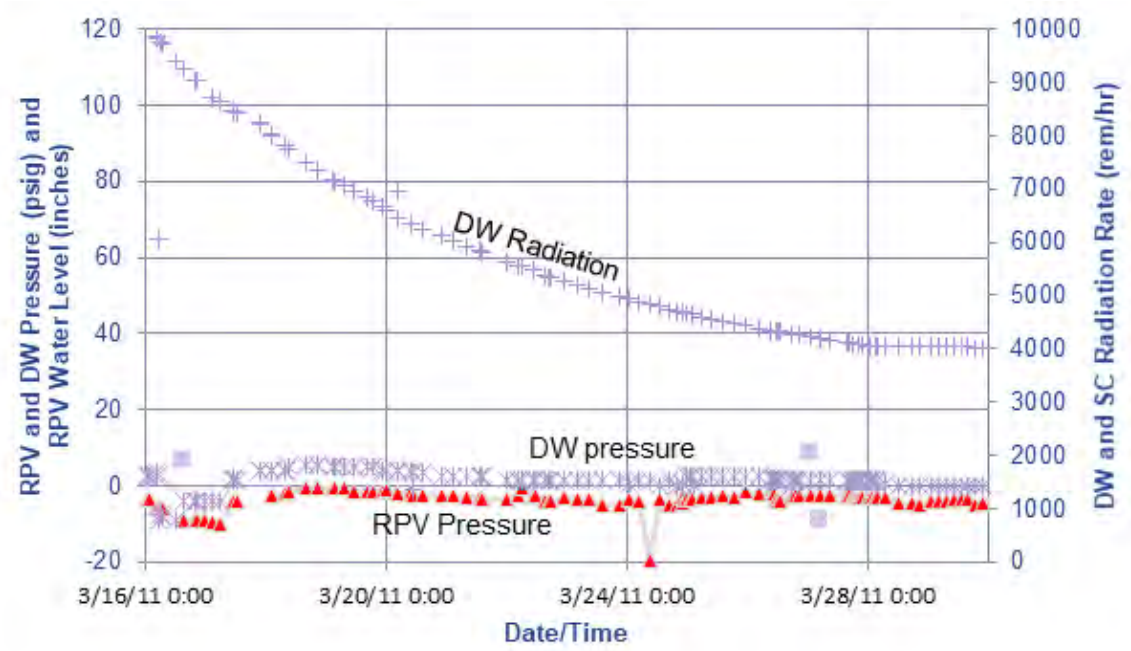

Figure H-22. 1F2 pressure and radiation data from March 16 through 30, 2011. (Data courtesy of TEPCO Holdings [9])

How would one confirm the DW radiation rate?

There may not be any diverse and redundant measures for comparisons with DW radiation data. The only way to validate them, then, was to compare them to pre-calculated curves. Comparisons of DW radiation data with BFN curves indicate that the decay trend appears reasonable (see Figure H-23).

\section{H.2.8. RPV Metal Temperatures}

Figure H-24 presents RPV metal temperatures through October 2011. Most of the initial temperatures appear reasonable, ranging from 221 to $302^{\circ} \mathrm{F}$ As discussed in Appendix G (Section G.1), temperatures dropped below $212^{\circ} \mathrm{F}$ when injection went into core spray header (September 2011). Results from muon tomography examinations (Appendix G; Section G.4.2) confirm that temperatures are valid (e.g., that is there was still some core debris in the RPV). Therefore, injection had to go into the core spray header to cool the last of the core debris. 


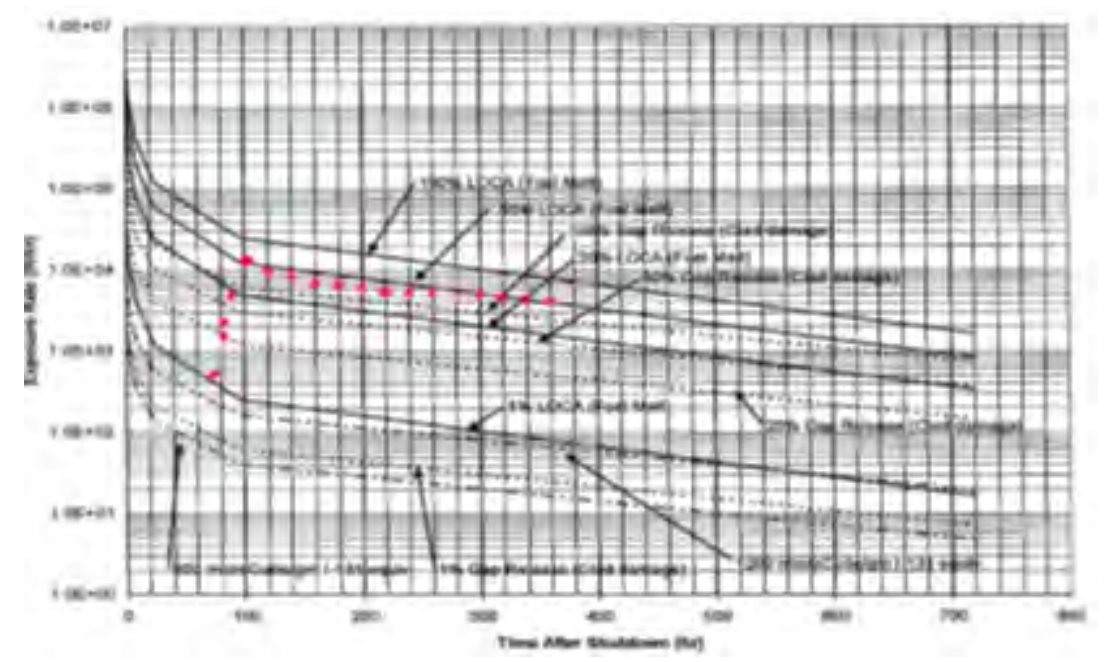

Figure H-23. 1F2 radiation data (red) plotted on Browns Ferry Nuclear plant decay curve (Decay plot courtesy of TVA [276]; Data courtesy of TEPCO Holdings [9])

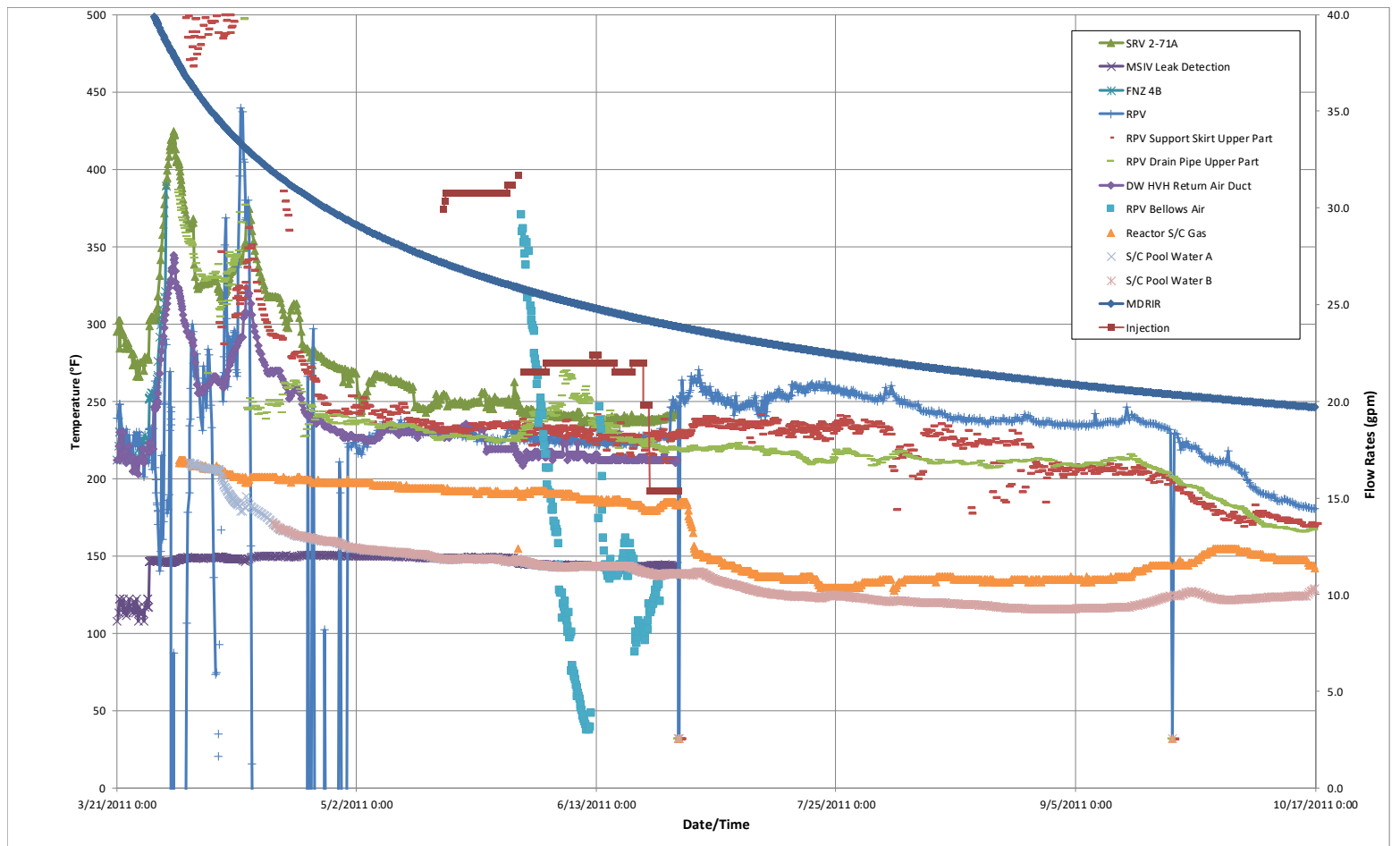

Figure H-24. 1F2 RPV metal temperatures. (Data courtesy of TEPCO Holdings [9]) 


\section{H.3. 1F3 Instrumentation Data}

\section{H.3.1. RPV Water Level}

Figure H-25 shows 1F3 RPV water level and pressure data out to 26 hours. The RCIC turbine tripped at 11:36 on March 12, 2011. After this time, the RPV water level drops from +172 " to +116 " above TAF. A value of +116 " is -48 " relative to instrument zero that the wide range instruments used. HPCI started automatically at 12:35 when level lowered to its low-low level setpoint (-48"). A purple star is shown on Figure H-25 at this time to designate this water level (although the value was not indicated by instrumentation). HPCI restored RPV water level to indicated normal ranges.

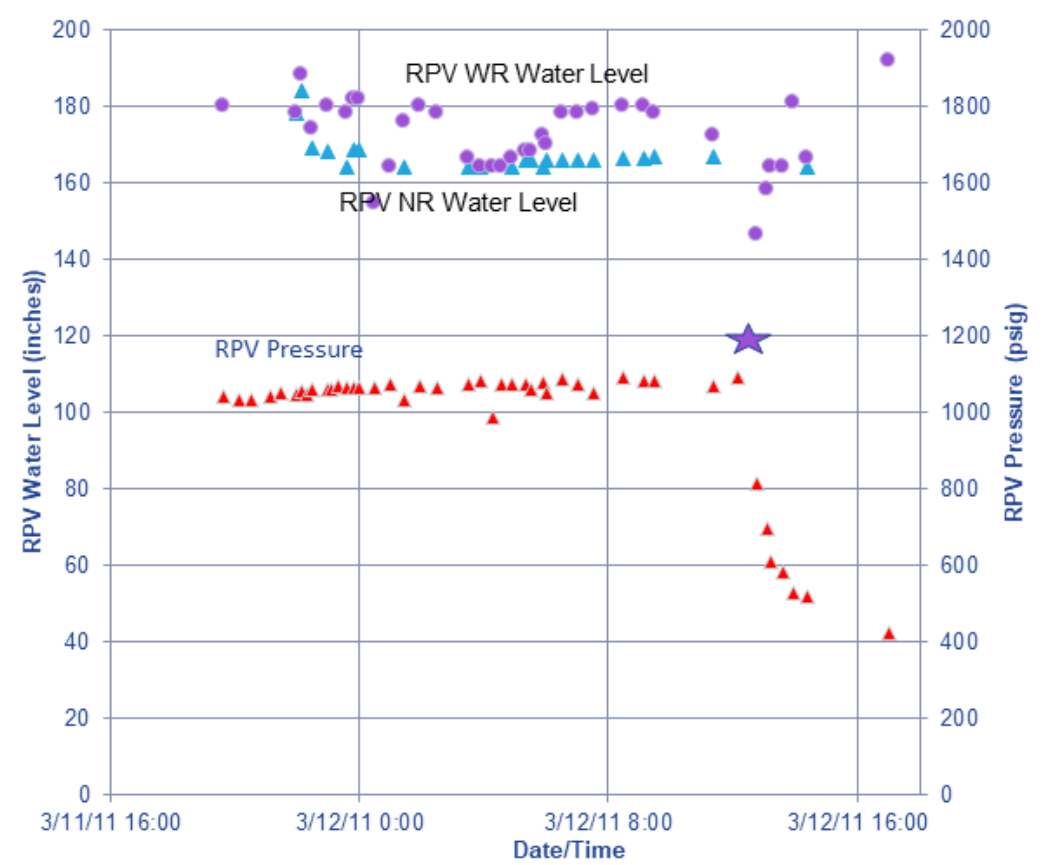

Figure H-25. 1F RPV pressure and water level (March 11 through 12, 2011). (Data courtesy of TEPCO Holdings [9])

The TSG-2 calculation that was developed to look at level changes indicated that the time to lower from +172 to +116 " was extremely reasonable for decay energy using El-Wakil with a finite correction.[277] This provided some confirmation the wide range instruments were indicating correctly up to $12: 35$ on $3 / 12 / 11$.

HPCI also began depressurizing the RPV through the injection of cold water and through the steam demand for the HPCI turbine. This should be expected this long after shutdown (as decay heat decreased).

Can RPV water level be trusted here?

Once HPCI begins lowering RPV pressure, the WR water level rises only because of RPV pressure lowering. WR water level must be corrected to give an accurate value once RPV pressure drops below about 700-800 psig. The NR instrument is probably corrected for pressure, but true level appears to be below the narrow range variable leg (164" above TAF or 517" above vessel zero). This is seen by the nar- 
row range not changing much. Comparisons between the different RPV water level instruments provides some confidence.

With RPV pressure lowering there is a possibility of flashing of the reference leg. Still WR must be corrected simply because of the changing density in the variable leg due to RPV pressure lowering.

Figure H-26 shows RPV water level readings with RPV, DW, and SC pressure data for the first 41 hours. On this figure, the purple star designates the location for the HPCI low level injection setpoint, and the red star designates when the RPV pressure returned to the SRV lift setpoint value based upon the heatup rate (although neither value was indicated by instrumentation). The last WR reading was obtained at 20:30 on March 12, 2011; notice WR level rose until pressure was maintained at 119 psig. When corrected for off-normal conditions (see Figure H-27), the indications show level was below the narrow variable leg at first and by 20:30 had only increased to about 7.5 inches (172" above top of active fuel). This is only true if none of the reference leg has flashed. Based upon the time RPV pressure was lowered, the data after 20:00 may be impacted by flashing of the reference legs.

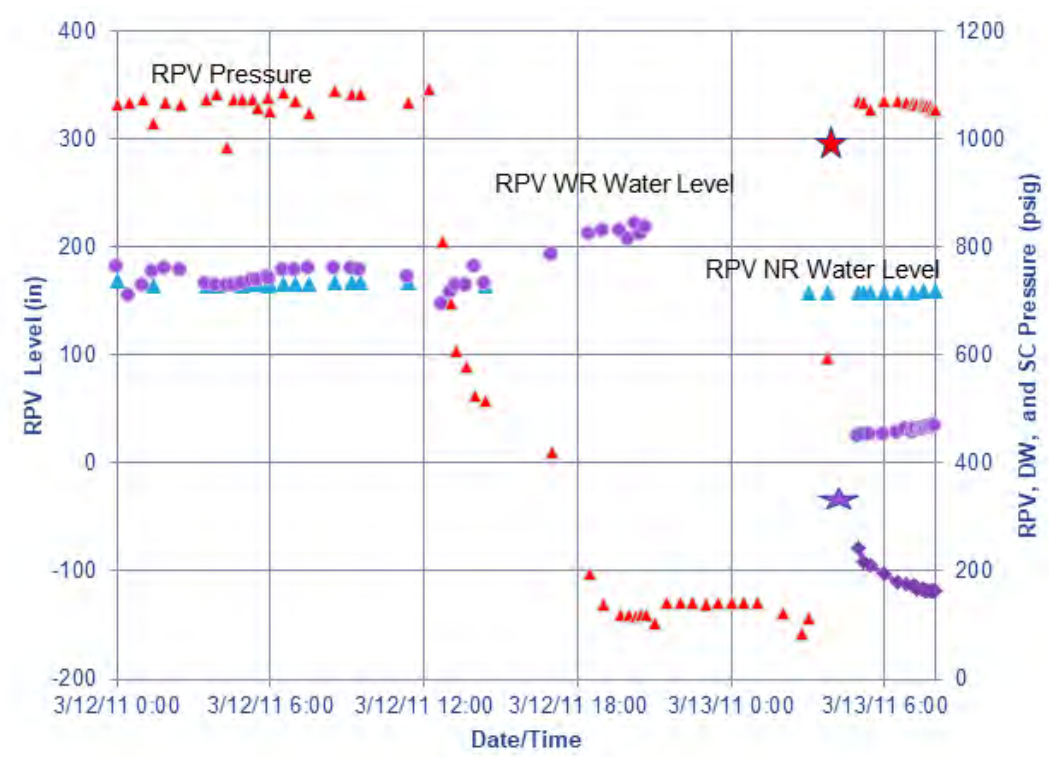

Figure H-26. 1F3 RPV pressure and water level and DW and SC pressure (March 12 through 13, 2011). (Data courtesy of TEPCO Holdings [9])

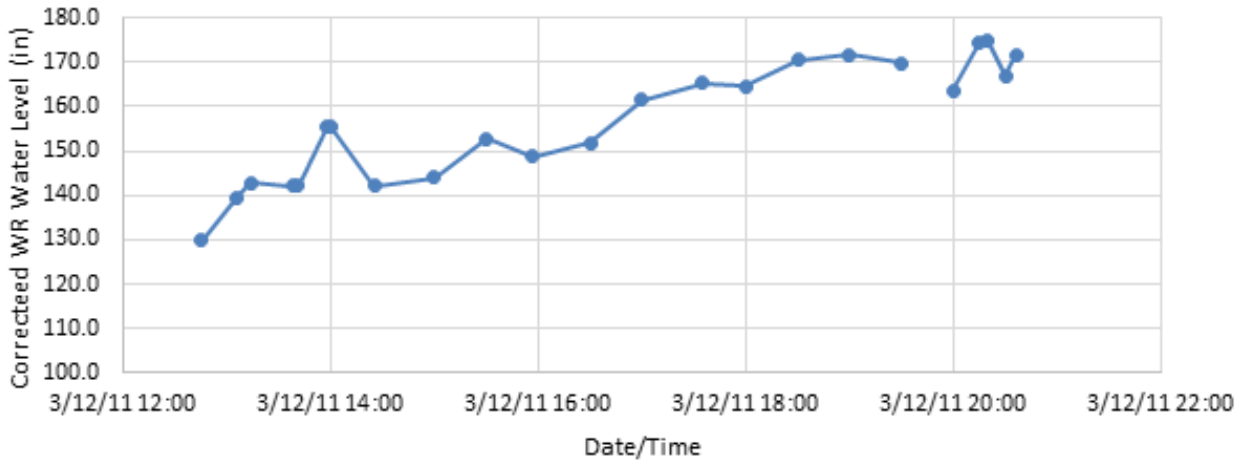

Figure H-27. Corrected 1F3 WR readings. (Data courtesy of TEPCO Holdings [9, 201]) 
At 03:00 on March 13, 2011, the narrow range is back at the bottom of scale or at the variable leg elevation. This was the first level instruments returned to service. At 03:51 batteries exhausted. At 04:15, operators reported TAF was reached. At 05:00, WR is back at bottom of scale (or variable leg which is at or near TAF). However, data indicate that water level is already below TAF. The Fuel Zone (FZ) RPV water level instrument stopped lowering at 08:00 at -116". The rise in DW pressure between 05:00 and 08:00 indicate that oxidation was occurring and stopped when RPV water level stopped lowering (see Section H.3.3). This implies that BAF was reached but oxidation was starved when RPV water level stopped lowering.

Could these RPV water level instruments be trusted after 12:35 on March 12, 2011 ?

The answer is no. Once the RPV pressure began lowering, conditions required correction of the wide range for off-calibration. After RPV pressure lowered to $\sim 200 \mathrm{psig}$, really once it started lowering, the possibility of flashing of the reference legs existed for all the RPV water level instruments.

HPCI injection is not guaranteed below $150 \mathrm{psig}$. The RPV pressure just about guaranteed reference leg flashing. Had the WR been around during this time, this might have been observed. The FZ instrument stopped lowering at -118 ". If it is assumed that RPV level only stopped lowering when BAF was reached, an estimate of the impact on reference level can be made. The indication of TAF at 04:15 was likely -33" below TAF, and oxidation started shortly thereafter.

\section{H.3.2. RPV Pressure}

Can the RPV pressure indication be trusted?

If one examines the RPV pressure data during the time SRVs are cycling (from 0:00 until 12:00 on March 12, 2011 in Figure H-26), an estimate of their accuracy can be made. For 1F3, the lowest pressure that a relief valve will open is 1080.3 psig (see Table H-1).

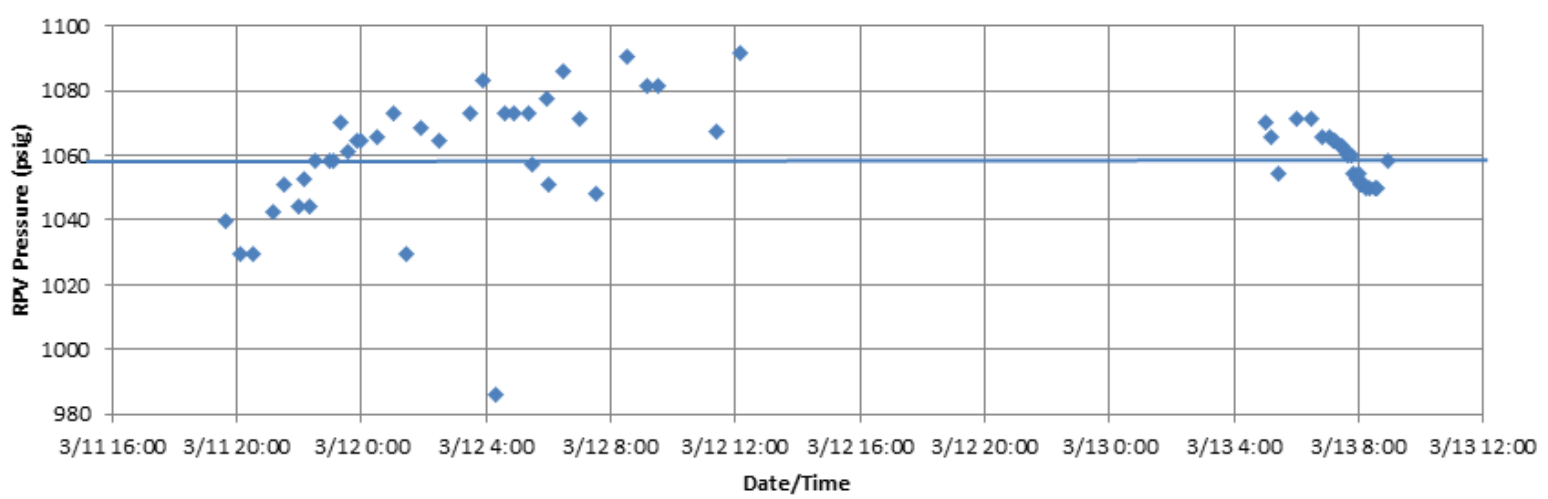

Figure H-28. 1F3 RPV pressure on March 11-12, 2011. (Data courtesy of TEPCO Holdings [9])

The data during the time RCIC operated indicates that relief through a second SRV at 1090 psig may have been necessary. This seems unlikely. Some RPV pressure values are high; some are low. All the pressure values after HPCI appear to be about 10 psig lower than the actual RPV pressure. The first group of data appears to be somewhat high, perhaps 10 psig.

With regards to data obtained after HPCI operated being low, the flashing of the reference legs would impact these instruments. The RPV pressure instruments are calibrated assuming the head of water from 
the tap to the transmitter. With some of the reference leg flashed, steam would occupy the reference leg, and a lower pressure would be transmitted to the transmitter. For pressure in the dome at the SRV pressure, the indications would be somewhat lower.

For a reference leg of 20 feet inside the drywell, the difference could be about $8.6 \mathrm{psig}$ ( $20 \mathrm{ft} \times 0.4333$ ). The second grouping of data appears to be about 8-9 psig low. Therefore the indications appear to be accurate (taking into account the impact of losing the reference leg).

\section{H.3.3. DW and SC Pressure}

Figure H-29 shows 1F3 data from water level and pressure sensors out to 42 hours.

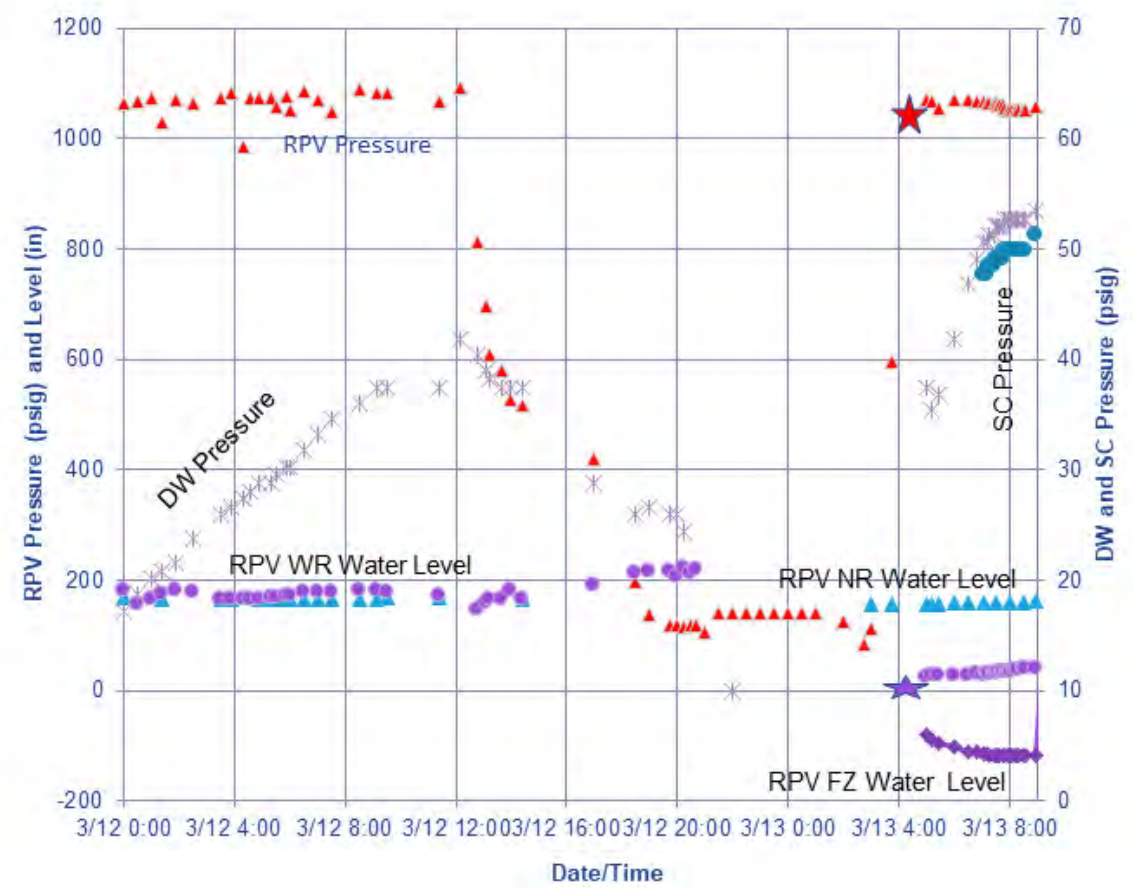

Figure H-29. 1F3 RPV pressure and water level and DW and SC pressure (March 12 through 13, 2011). (Data courtesy of TEPCO Holdings [9])

The SC pressure (blue circles) and DW pressure (purple x's) confirm each other. The relationship between DW and SC pressure shows that the DW pressure is being raised and the SC pressure is following. At 08:41 on March 12, 2011, the plant staff had the containment vent ready except for the rupture disc. Even with a peak DW pressure of 53.45 psig, the SC vent didn't open, so the pressure seen by the rupture disc is still below 62 psig disc opening pressure. This would make the DW pressure indication accurate to within 9 psig or less.

DW pressure is also confirmed by SC air pressure. The relationship shows that energy is pressurizing the drywell first. This is another confirmation that the rise in pressure is due to noncondensable gases because operators were using diesel driven fire pump into DW spray header while DW pressure was rising. Note that DW pressure quits rising when RPV water level quits lowering. All the data indicate that RPV water level reached top of active fuel some time before 04:15 and continued to lower to BAF (as indicated 
by fuel zone of -118"). When RPV water level quit lowering, the oxidation lowered or ceased and the drywell pressure quit rising. Less data are available, but enough is available to conclude what is happening.

\section{H.3.4. Indication of Vessel Breach}

Figure H-30, which shows data out to 46 hours, can provide insights regarding vessel breach. The first peak $(\sim 10: 00$ on March 13, 2011) is apparently relocation of core debris into the lower plenum, because RPV pressure and FZ water level respond, but DW and SC pressure do not respond. The second peak is the breach of the RPV by core debris as indicated by the response of DW/SC and RPV pressure. Although more confirmatory data would be helpful, it is likely that vessel breach occurred at 12:40 on March 13, 2011. If breach occurred at this time, this is 14 hours after TAF is uncovered and $101 \mathrm{MW}$-hrs (based only on decay heat).

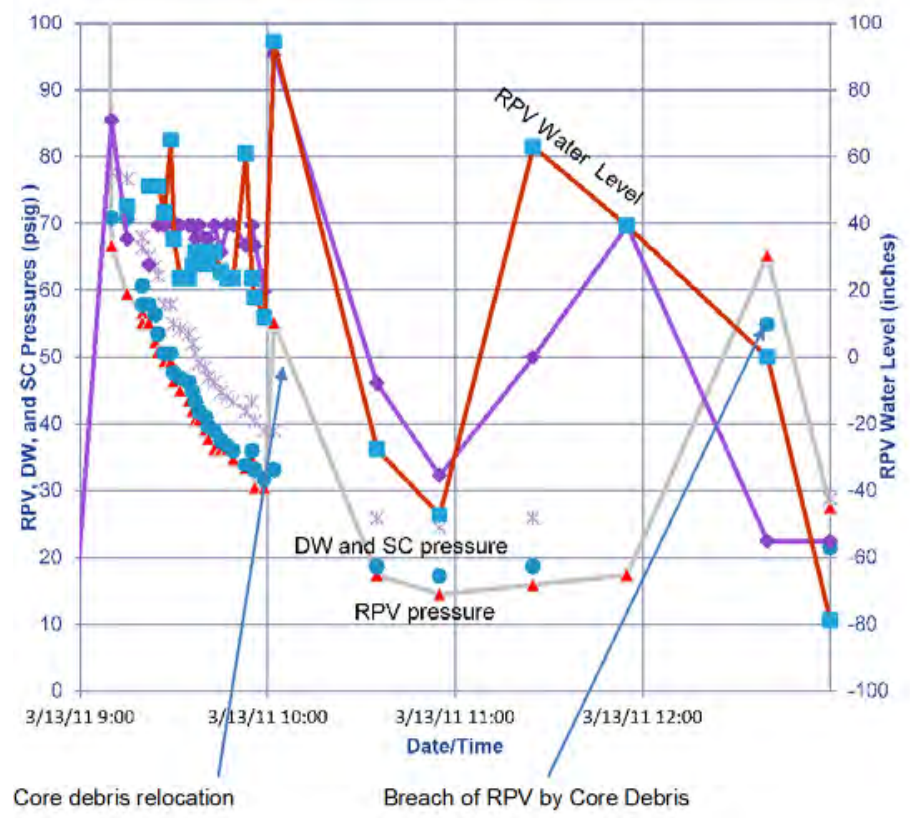

Figure H-30. 1F3 data from 9:00 to 13:00 on March 13, 2011. (Data courtesy of TEPCO Holdings [9])

Figure H-31 shows plant data out to 71 hours. DW and SC pressure respond to containment venting at 20:30 on March 13, 2011. RPV pressure A is lost from 20:00 until 23:00 when the RPV A and RPV B pressure indications are recovered. They trend with DW and SC pressures although lower (7 psig compared to 20-22 psig). If the reference leg is evaporated within the drywell, the RPV pressure would be $\sim 20$ feet $\mathrm{x} 0.433$ or $\sim 8.6$ psig. This may be part of the difference between the drywell and RPV pressure readings. 


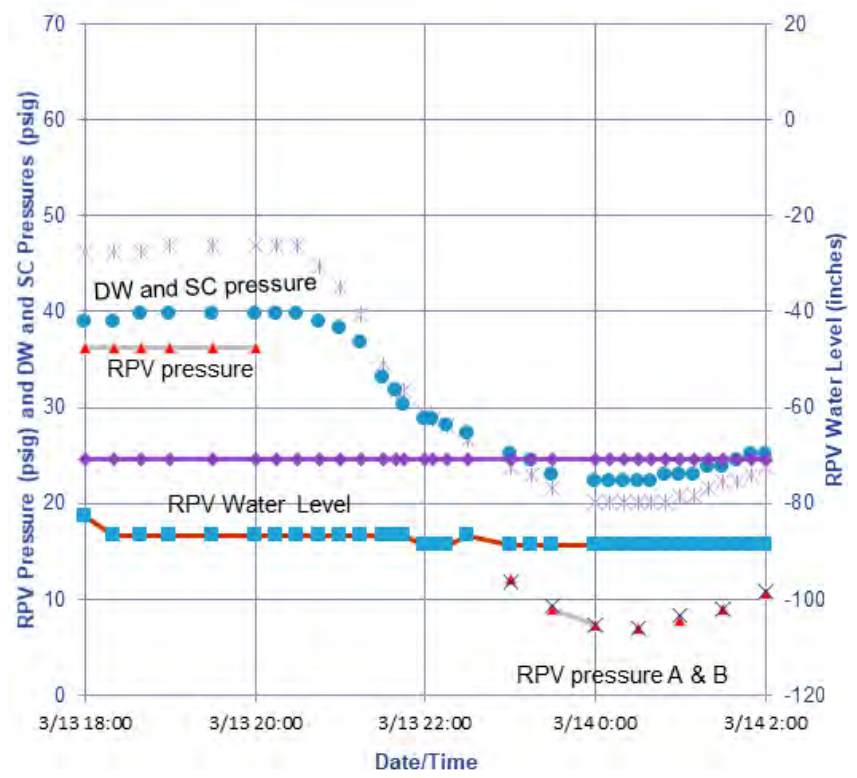

Figure H-31. 1F3 data from 18:00 on March 13, 2011 through 02:00 on March 14, 2011. (Data courtesy of TEPCO Holdings [9])

\section{H.3.5. DW Radiation}

Figure $\mathrm{H}-32$ shows $1 \mathrm{~F} 3$ pressure and radiation data out to 67 hours. DW radiation trends with DW and SC pressure and with RPV pressure. RPV pressure is not accurate because it physically can't be less than DW and SC pressure. Part of this inaccuracy is due to the flashing of the reference leg and part of it is due to the RPV pressure instrument having a much larger range than the drywell pressure instrument.

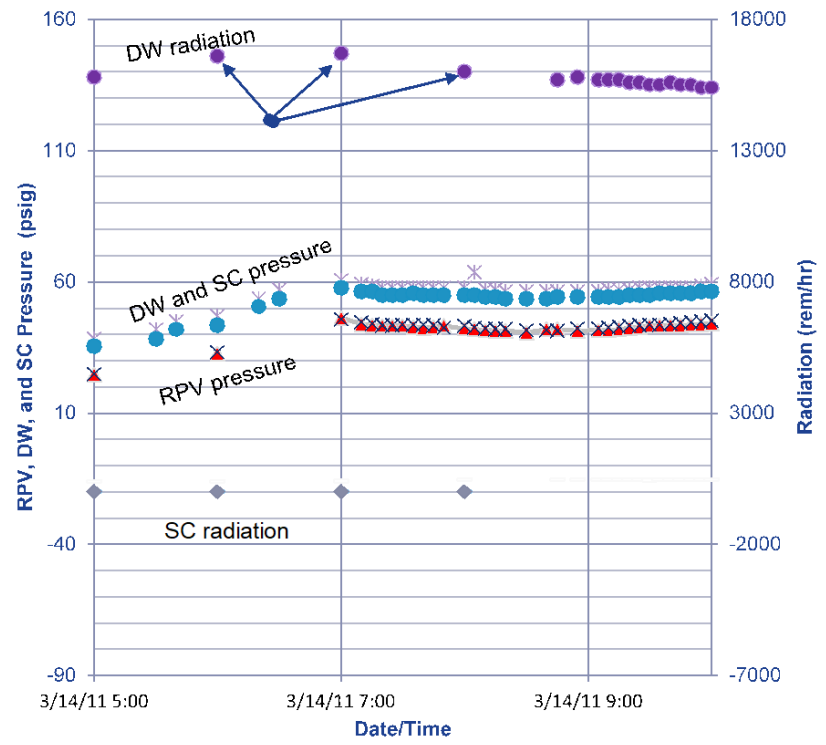

Figure H-32. 1F3 pressure and radiation data (March 14, 2011). (Data courtesy of TEPCO Holdings [9]) 
All the parameters indicate leakage from the drywell begins at 07:00. DW radiation peaks and begins lowering. DW and SC pressures quit rising and start to lower slightly. RPV pressures A and B indicate the same pattern; they are 'percolating' similar to the DW pressure.

Figure H-33 shows 1F3 pressure, water level, and radiation data out to 74 hours. The DW and SC pressure trend together even after the 1F3 RB explosion. Level transmitters are still working, but it is likely that both reference legs and variable legs are empty, which would impact both RPV water level and RPV pressure indications.

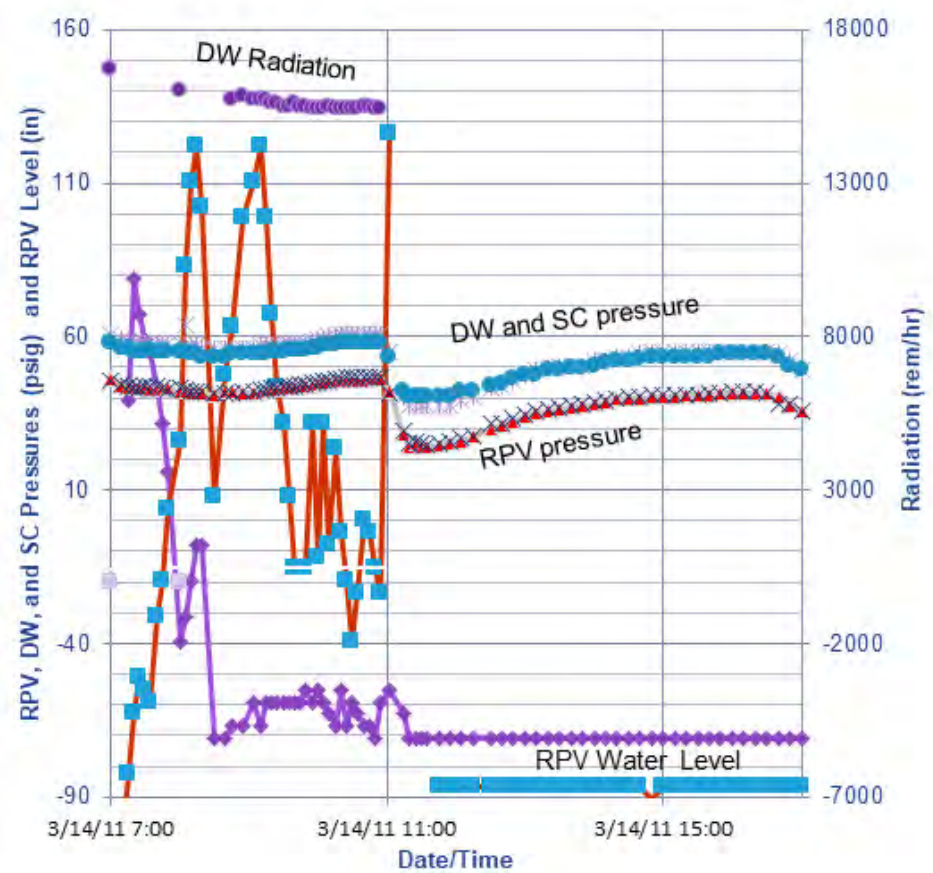

Figure H-33. 1F3 pressure, water level, and radiation data (March 14, 2011). (Data courtesy of TEPCO Holdings [9])

Figure H-34 shows 1F3 pressure, water level, and radiation data between March 19 and 22, 2011. Due to containment venting, DW pressure data are below $10 \mathrm{psig}$ (near atmospheric conditions). RPV pressure remains slightly higher, but follows a similar trend. In reviewing the data, it is important to consider the range of these instruments.

During this time, the DW radiation B confirms DW radiation A data. MCR dose rate data on this chart indicates that levels range between 30-40 Rem $/ \mathrm{hr}$. As suggested in Section H.2.7, insights regarding the validity of DW radiation data may also be gained by comparisons with pre-calculated curves to see if the decay trend was reasonable. As shown in Figure H-35, 1F3 DW radiation data plotted on BFN decay curves suggest that the data trends are reasonable.

\section{H.3.6. RPV Metal Temperatures}

Figure H-36 presents RPV metal temperatures through September 2011. The initial temperatures appear reasonable, ranging from 220 to $260{ }^{\circ} \mathrm{F}$. Temperatures respond to core spray and lower below $212^{\circ} \mathrm{F}$ when injection is switched to the CS header. After injection was switched, the heat removal rate 


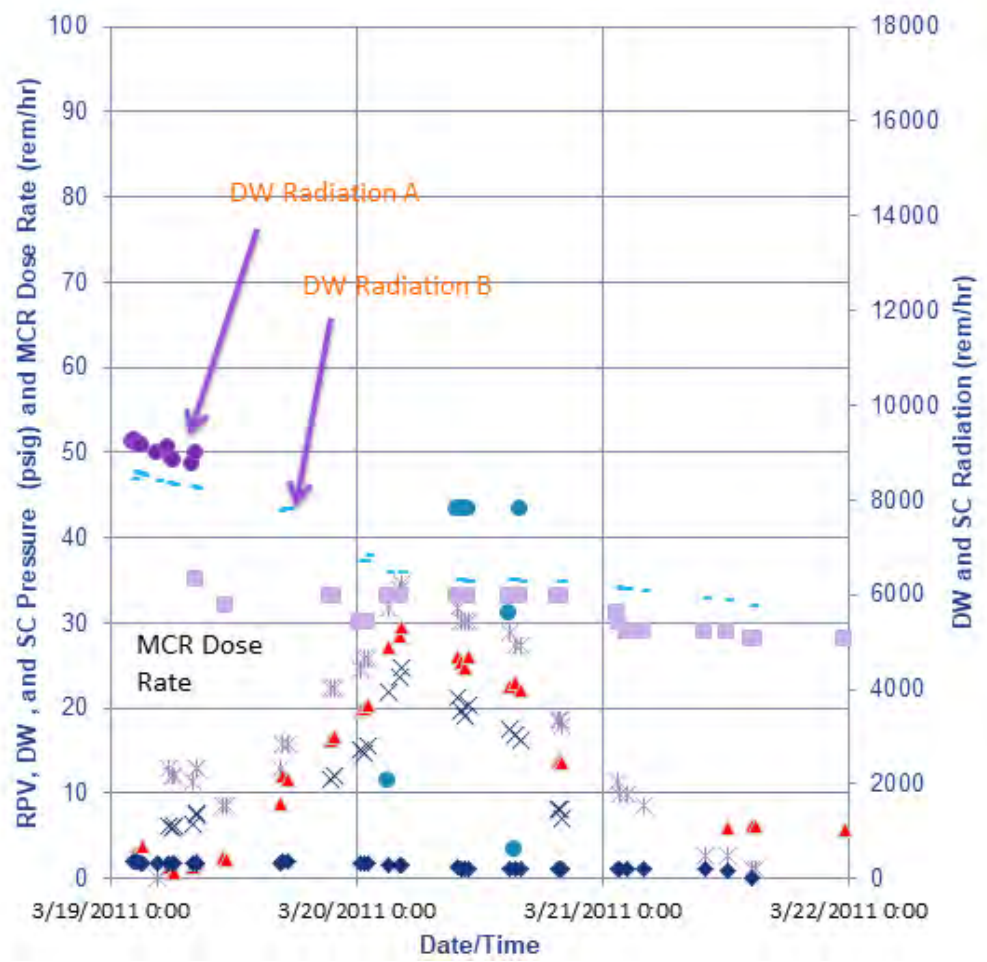

Figure H-34. 1F3 pressure and radiation data (March 19 through 22, 2011). (Data courtesy of TEPCO Holdings [9])

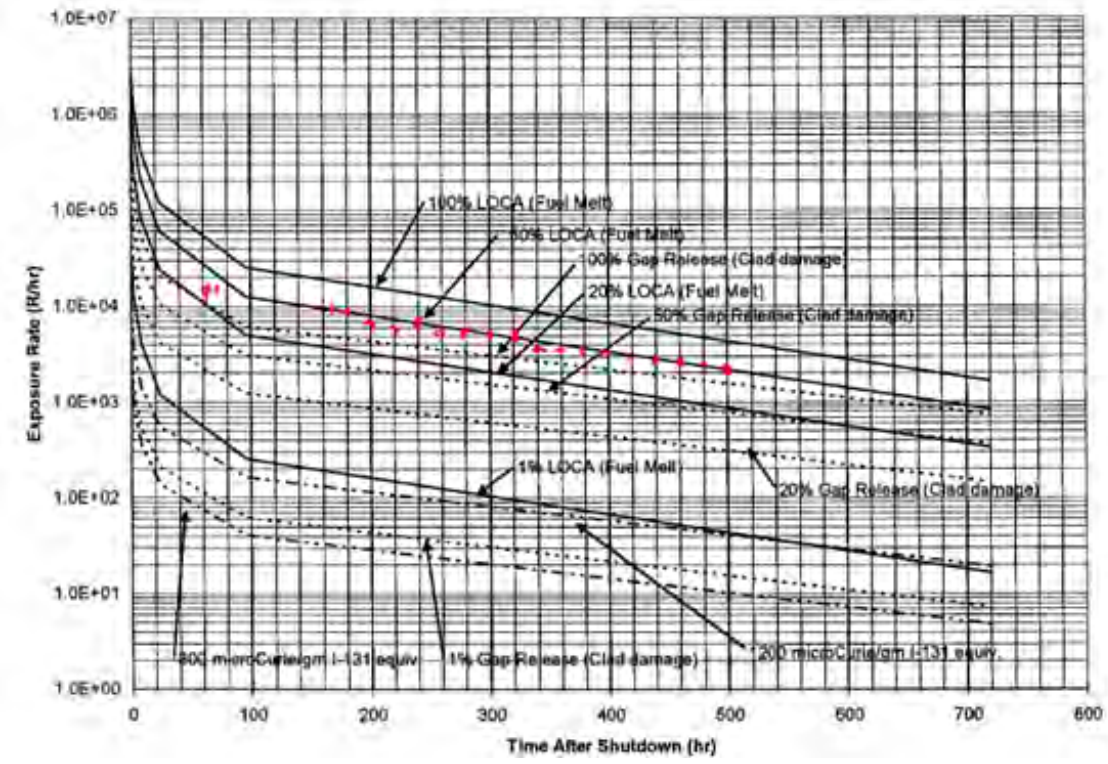

Figure H-35. 1F3 radiation data (red) plotted on Browns Ferry Nuclear plant decay curve (Decay curve courtesy of TVA [276]; Data courtesy of TEPCO Holdings [9]) 
exceeded the amount of decay heat and temperatures decreased below $212{ }^{\circ} \mathrm{F}$. This indicates some fuel was still in the RPV at that time. As discussed in Appendix G; Section G.4.3, this result is consistent with results from muon tomography examinations.

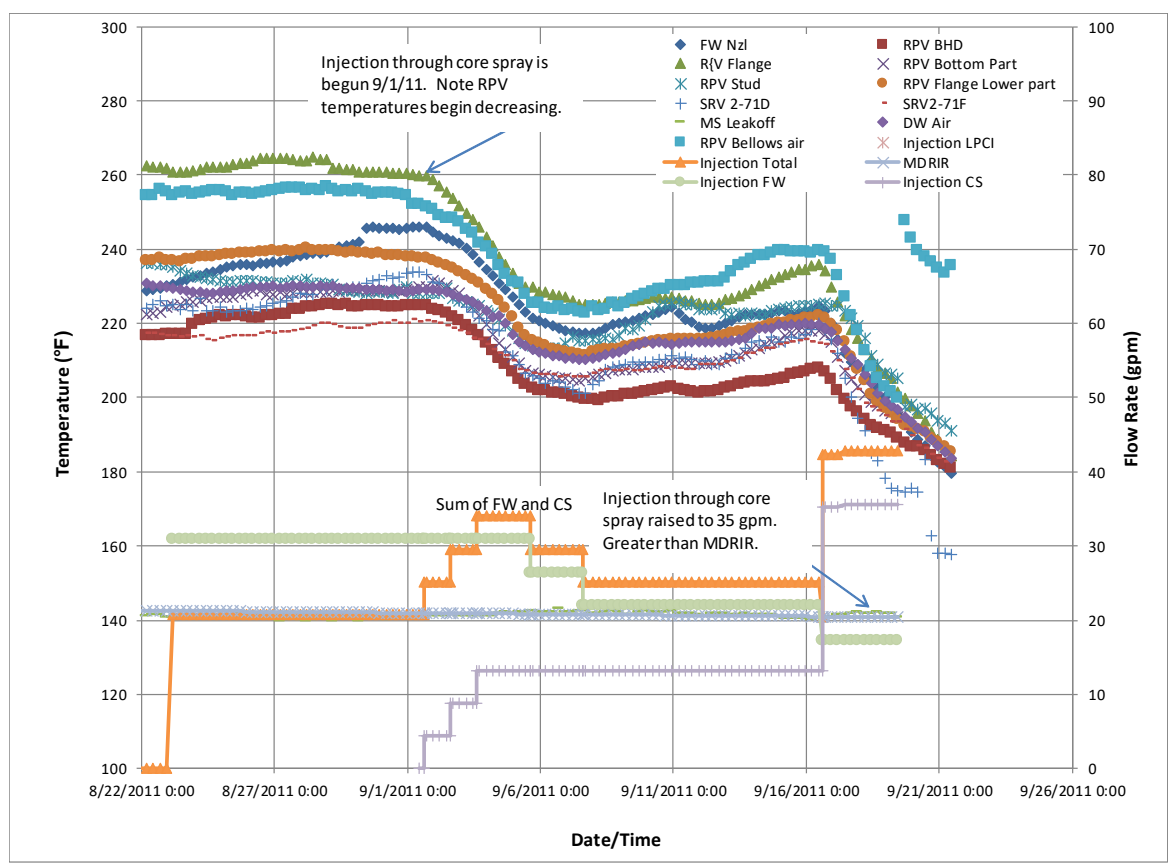

Figure H-36. 1F3 RPV temperature and injection data (August 22 through September 26, 2011). (Data courtesy of TEPCO Holdings [9]) 
ANL-18/24

H-32 